UNIVERSIDAD DE SALAMANCA - USAL DOCTORADO CIENCIAS AMBIENTALES

\title{
EVOLUCIÓN CLIMÁTICO-HIDROLÓGICA RECIENTE Y CAMBIOS EN LOS USOS DEL SUELO EN DIVERSAS CUENCAS DE CABECERA DE LOS RÍOS DUERO Y TAJO
}

Doctoranda: Luciana Aparecida Magalhães

Director: José Martínez Fernández

Departamento: Geografía 

VNiVERSiDAD

DSALAMANCA

\section{EVOLUCIÓN CLIMÁTICO-HIDROLÓGICA RECIENTE Y CAMBIOS EN LOS USOS DEL SUELO EN DIVERSAS CUENCAS DE CABECERA DE LOS RÍOS DUERO Y TAJO}

Memoria presentada por la Licenciada en Ciencias Biológicas Luciana Aparecida Magalhães para optar al Título de Doctor. 



\section{VNiVERSIDAD \\ DSALAMANCA}

\section{DEPARTAMENTO DE GEOGRAFÍA}

D. José Martínez Fernández, Profesor Titular del Área de Geografía Física en la Universidad de Salamanca

\section{CERTIFICA}

Que la memoria titulada "EVOLUCIÓN CLIMÁTICO-HIDROLÓGICA RECIENTE Y CAMBIOS EN LOS USOS DEL SUELO EN DIVERSAS CUENCAS DE CABECERA DE LOS RÍOS DUERO Y TAJO" ha sido realizada por la Licenciada en Ciencias Biológicas Dña. LUCIANA APARECIDA MAGALHÃES bajo mi dirección y constituye su Tesis Doctoral.

Para que así conste, firmo el presente certificado en Salamanca, a 20 de octubre de 2009.

D. José Martínez Fernández 

Âo meu pai, à minha mãe $e$ às minhas irmãs Valéria, Andréia y Fernanda dedico este trabalho e todo o meu amor. Sem o apoio de vocês, eu simplesmente, não seria capaz... Obrigada, por tudo, sempre... 

"Minha terra tem palmeiras, Onde canta o sabiá; As aves, que aqui gorjeiam, $\mathcal{N a ̃ o ~ g o r j e i a m ~ c o m o ~ l a ́ . ~}$

Nosso céu tem mais estrelas, Nossas várzeas têm mais flores, Nossos bosques têm mais vida,

$\mathcal{N}$ ossa vida mais amores.

$\mathcal{N}$ ão permita Deus que eu morra,

Sem que eu volte para lá; Sem que desfrute os primores

Que não encontro por cá; Sem qu'inda aviste as palmeiras, Onde canta o sabiá."

(Canção do Exílio - Gonçalves Dias) 



\section{AGRADECIMIENTOS}

Quiero expresar mis más sinceros agradecimientos a todas aquellas personas que de una forma u otra han colaborado en la elaboración de este trabajo.

Al Dr. José Martínez Fernández, director de esta tesis doctoral, por haber creído en mí y en mis ganas de trabajar y por estar presente en todo momento con sus ideas y oportunos consejos, participando de manera continua en la revisión de esta memoria. Gracias también a todos los compañeros del Grupo de Investigación en Recursos Hídricos de la Universidad de Salamanca, por el apoyo en mi proceso de aprendizaje e investigación. No puedo dejar de agradecer de forma muy especial a la Dra. Nilda Sánchez por su ayuda, por dividir su conocimiento conmigo y principalmente por muchas veces haber creído más que yo en mi capacidad de trabajo.

Al Banco Santander y a la Universidad de Salamanca que son las instituciones que han hecho posible esta investigación con su programa de becas para estudiantes iberoamericanos.

A la Agencia Estatal de Meteorología (AEMET) y a las Confederaciones Hidrográficas del Tajo y del Duero por la facilitación de los datos utilizados en este estudio.

A Dios por haberme dado todas las oportunidades y principalmente fuerzas en los momentos más difíciles.

A todos los amigos que yo hice en Salamanca, gracias por el apoyo, cariño y amistad. Muchos probablemente no volveré a ver, pero que sepáis que cada sonrisa, cada palabra de apoyo, cada momento juntos fue fundamental para hacer de mi estancia en Salamanca algo inolvidable y liviano. Lo siento pero no voy a nombrarlos para no incurrir en el error de olvidarme alguno. En mi corazón y en mi cabeza tengo cada uno... Gracias también a mis amigos de Brasil que siempre creyeron en mí y siempre me apoyaron desde el otro lado del charco.

Para agradecer a mi familia yo necesitaría de otras cuantas páginas y no sabría decir todo lo que me gustaría. Aunque en la distancia siempre estuvieron presentes en cada esfuerzo realizado en esta investigación. A vosotros sólo me resta dedicar esta tesis doctoral y todos sus frutos... Eu amo vocês!!! Obrigada por serem minha estrutura!!! Obrigada por me apoiarem em todos os momentos!!! Esta vitória é nossa... 



\section{ÍNDICE GERAL}

Item

Pág.

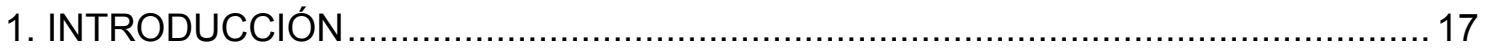

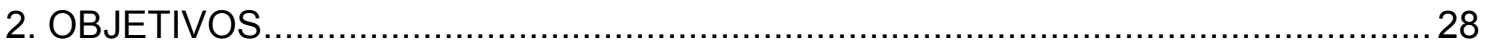

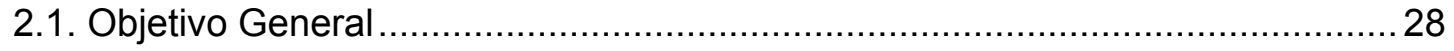

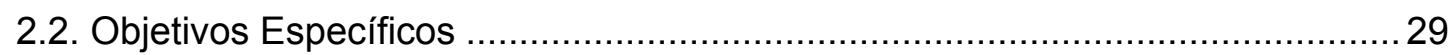

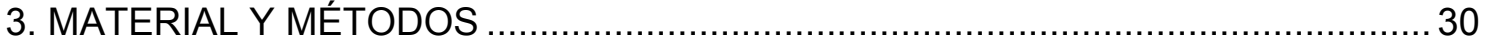

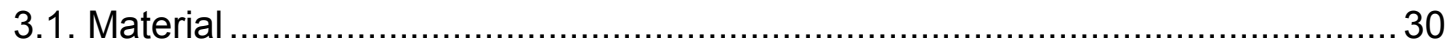

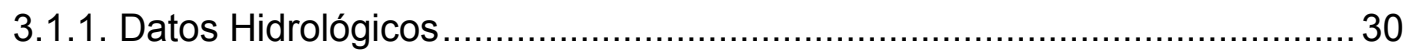

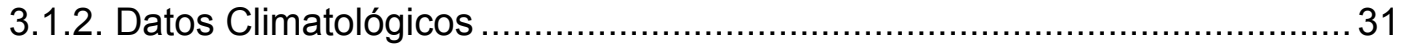

3.1.3. Datos de usos y cobertura del suelo................................................... 31

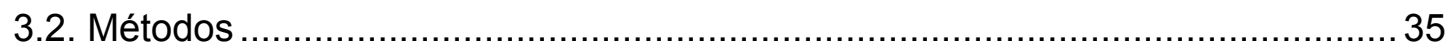

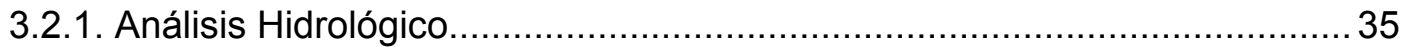

3.2.3. Análisis de los cambios en los usos y en la cobertura del suelo ................50

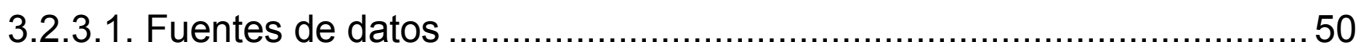

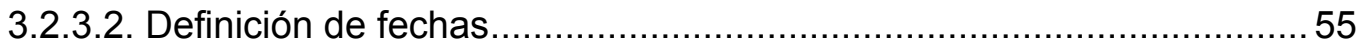

3.2.3.3. Definición de las categorías de clasificación ....................................56

3.2.3.4. Tratamiento de las fotografías aéreas .............................................59

3.2.3.5. Tratamiento de las imágenes de satélite .......................................... 64

4. ASPECTOS GENERALES DEL ÁREA DE ESTUDIO ......................................... 70

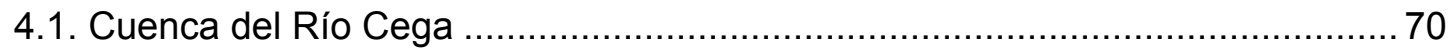

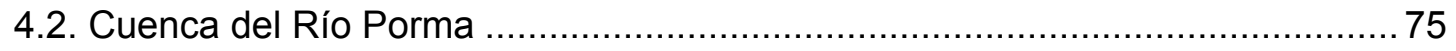

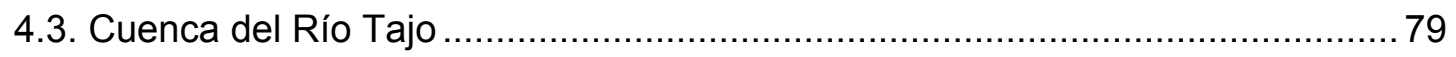

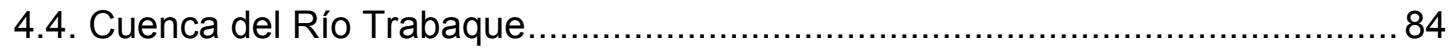

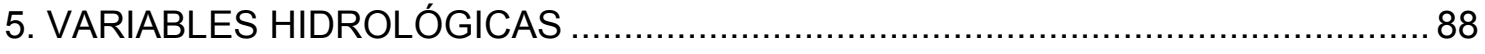

5.1. Evolución del Caudal en la Cuenca Del Río Cega .......................................... 89

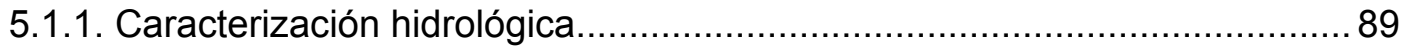

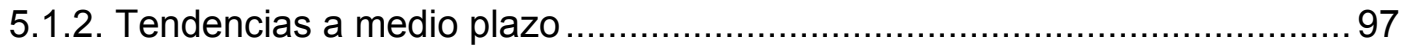


5.2. Evolución del Caudal en la Cuenca Del Río Porma ...................................... 100

5.2.1. Caracterización hidrológica.......................................................... 100

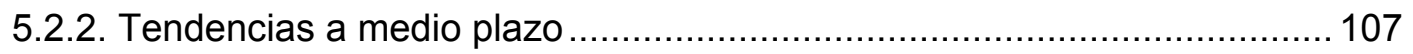

5.3. Evolución del Caudal en la Cuenca Del Río Tajo ......................................... 111

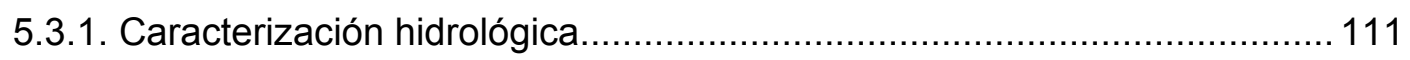

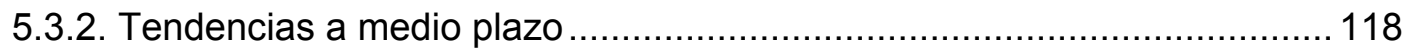

5.4. Evolución del Caudal en la Cuenca Del Río Trabaque ................................. 122

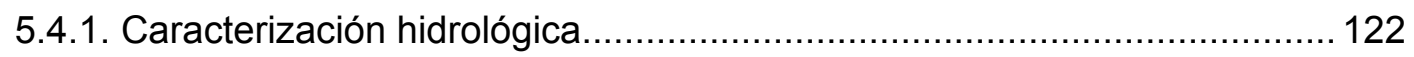

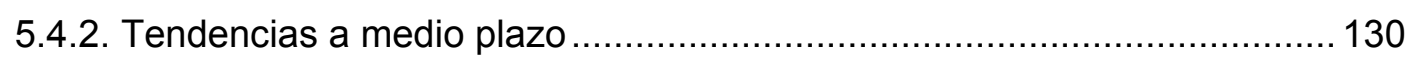

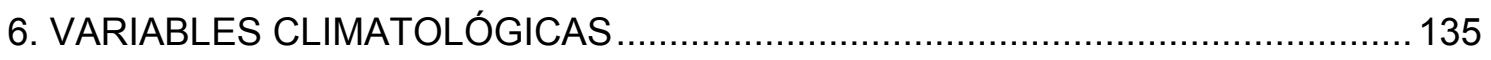

6.1. Evolución de la Precipitación en la Cuenca Del Río Cega ............................. 137

6.1.1. Caracterización de la precipitación .............................................. 137

6.1.2. Caracterización de cada estación................................................... 139

6.1.2.1. Estación La Granja de San Ildefonso ........................................ 139

6.1.2.2. Estación Matabuena ................................................................. 141

6.1.2.3. Estación Rascafria ............................................................... 143

6.1.2.4. Estación Torreiglesias.......................................................... 145

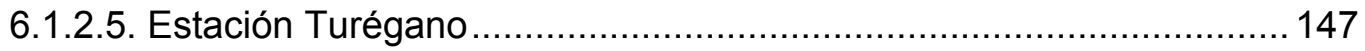

6.2. Evolución de la Precipitación en la Cuenca Del Río Porma ........................... 149

6.2.1. Caracterización de la precipitación .................................................. 150

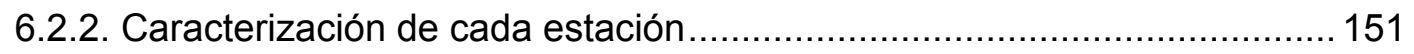

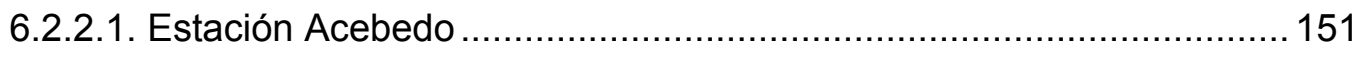

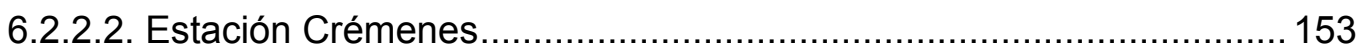

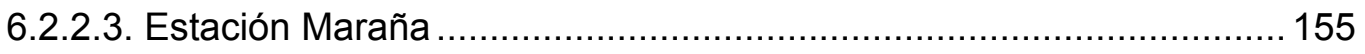

6.2.2.4. Estación Pantano del Porma .................................................... 157

6.2.2.5. Estación Puebla de Lillo............................................................... 158

6.3. Evolución de la Precipitación en la Cuenca Alta Del Tajo ............................... 161

6.3.1. Caracterización de la precipitación ................................................. 161

6.3.2. Caracterización de cada estación........................................................ 163 


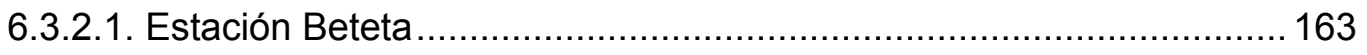

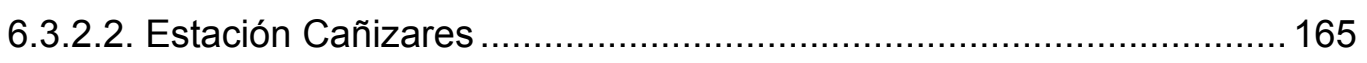

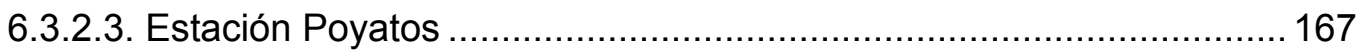

6.3.2.4. Estación Santa María del Val......................................................... 169

6.3.2.5. Estación Vega del Codorno ……………………............................ 170

6.4. Evolución de la Precipitación en la Cuenca Del Río Trabaque ........................ 173

6.4.1. Caracterización de la precipitación ..................................................... 173

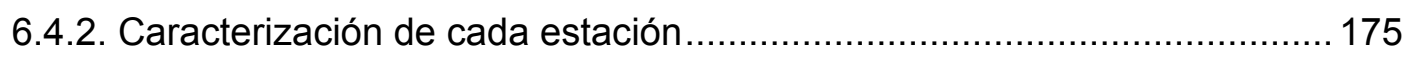

6.4.2.1. Estación Albalate de las Nogueras ................................................. 175

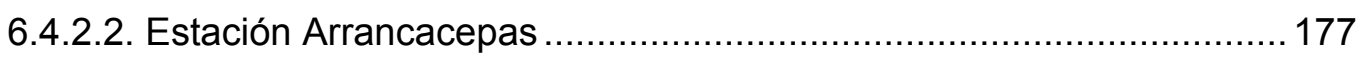

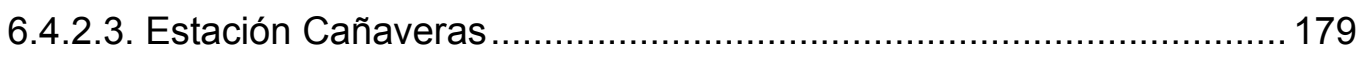

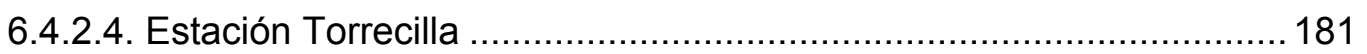

6.4.2.5. Estación Villar de Domingo García ................................................... 182

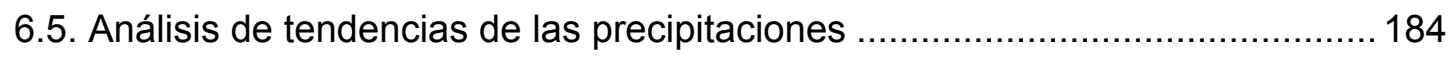

6.5.1. Cuenca del río Cega ........................................................................... 184

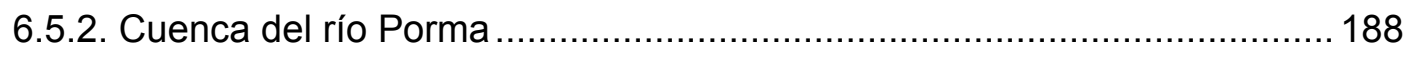

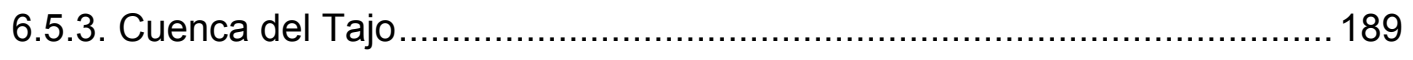

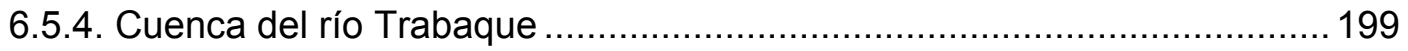

6.6. Evolución de la Temperatura en las Cuencas de los Ríos Cega, Porma, Tajo y

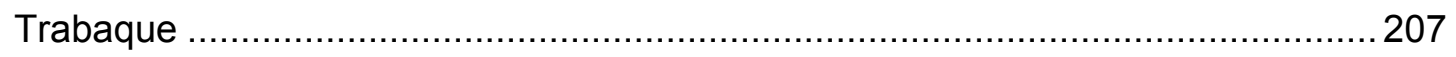

6.6.1. Evolución de la Temperatura en la Cuenca Del Río Cega ........................ 207

6.6.1.1. Caracterización de la temperatura ...................................................... 207

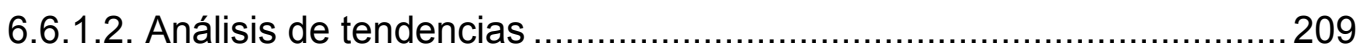

6.6.2. Evolución de la Temperatura en la Cuenca Del Río Porma ...................... 213

6.6.2.1. Caracterización de la temperatura ..................................................... 213

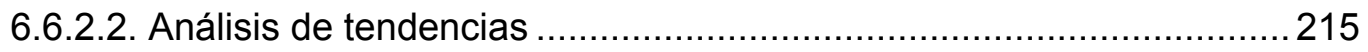

6.6.3. Evolución de la Temperatura en la Cuenca Del Tajo ............................... 216

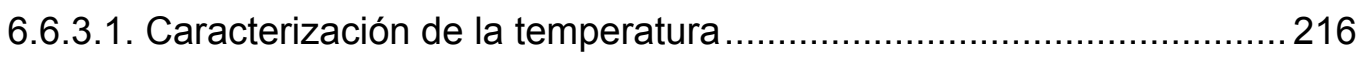

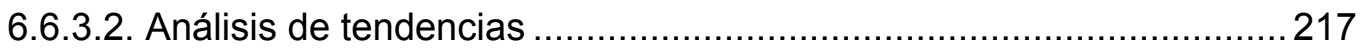


6.6.4. Evolución de la Temperatura en la Cuenca Del Río Trabaque 223

6.6.4.1. Caracterización de la temperatura

6.6.4.2. Análisis de tendencias 224

7. ANÁLISIS DE LA EVOLUCIÓN DE LOS USOS Y DE LA COBERTURA DEL SUELO 230

7.1. Los cambios de población 230

7.2. Aumento de masas forestales 232

7.3. Evolución reciente de los usos y cobertura del suelo 234

7.3.1. Cuenca del río Cega 235

7.3.2. Cuenca del río Porma 241

7.3.3. Cuenca del río Tajo 246

7.3.4. Cuenca del río Trabaque 252

7.4. Discusión de los resultados encontrados 258

8. ANÁLISIS GLOBAL DE LAS VARIABLES ESTUDIADAS 261

8.1. Evolución de la Escorrentía 261

8.2. Evolución de la Precipitación. 264

8.3. Evolución de la Temperatura. 267

8.4. Evolución de los Cambios en los Usos y en la Cobertura Del Suelo 270

8.5. Relación entre Aportación y Precipitación 271

8.6. Análisis de las Relaciones entre las Variables Estudiadas 274

9. CONCLUSIONES 277

10. REFERENCIAS BIBLIOGRÁFICAS 281

Lista de páginas web consultadas 309

Lista de Figuras 310

Lista de Tablas 321

Lista de Fotos 331

Acrónimos 332 


\section{INTRODUCCIÓN}

En la actualidad, la preocupación por el medio ambiente viene siendo el foco de discusiones en todo el mundo, y uno de los grandes problemas que se plantea es la incertidumbre del agua disponible. La gran aportación de todas esas discusiones es que cada vez se busca más la mejora de todos los procesos productivos, tanto agrarios como industriales procurando la reducción del consumo de agua, y la recuperación y mantenimiento de la vegetación natural.

El agua es fundamental para el mantenimiento de la biodiversidad y de todos los ciclos naturales así como el mantenimiento de la producción de alimentos y la preservación de la propia vida. Así, el agua se ha convertido en un gran recurso estratégico para la humanidad. La gestión de los recursos hídricos es, posiblemente, el tema ambiental con mayor poder de integración, afectando todos los segmentos de la sociedad y pasando por los diversos usos del suelo y del agua, tales como la explotación de los bosques, la agricultura, la industria, entre otros.

Aunque el agua es el elemento más abundante en la Tierra, únicamente el 2,53\% es agua dulce. Aproximadamente las dos terceras partes del agua dulce se encuentran inmovilizadas en glaciares y al abrigo de nieves perpetuas. A la cantidad natural de agua dulce existente en lagos, ríos y acuíferos se agregan los $8.000 \mathrm{~km}^{3}$ almacenados en embalses. Los recursos hídricos son renovables (excepto ciertas aguas subterráneas), con enormes diferencias de disponibilidad y amplias variaciones de precipitación estacional y anual en las diferentes partes del mundo (UNESCO, 2003).

El agua es utilizada en todo el mundo para diversas finalidades, como el abastecimiento de ciudades y usos domésticos, la generación de energía, la irrigación, la navegación y la pesca (Tabla 01). Con el crecimiento de los países, crecen también las industrias y la agricultura, que son las actividades que más consumen agua, comparadas con los otros usos. El escenario de escasez provocado por la degradación y por la distribución irregular del agua, sumado al aumento de la demanda en varias actividades que dependen de ella, genera conflictos, sea dentro de los propios países (como discusiones para decidir cual será el principal uso de las aguas de un determinado río) o entre naciones (por ejemplo, en el caso de las cuencas que se localizan en territorio de más de un país). 
Tabla 01. Países con más y menos agua per cápita en el mundo.

\begin{tabular}{|l|l|l|l|}
\hline \multicolumn{2}{c|}{$\begin{array}{c}\text { Países con más agua } \\
\text { per capita }\left(\mathbf{m}^{\mathbf{3}}\right)\end{array}$} & \multicolumn{2}{c|}{$\begin{array}{c}\text { Países con menos agua } \\
\text { per capita }\left(\mathbf{m}^{\mathbf{3}}\right)\end{array}$} \\
\hline Guyana Francesa & 812.121 & Kuwait & 10 \\
\hline Islandia & 609.319 & Emiratos Árabes Unidos & 58 \\
\hline Guyana & 316.689 & Bahamas & 66 \\
\hline Surinam & 292.566 & Qatar & 94 \\
\hline Congo & 275.679 & Maldivas & 103 \\
\hline Papua Nueva Guiñé & 166.563 & Libia & 113 \\
\hline Gabán & 133.333 & Arabia Saudi & 118 \\
\hline Islas Salomón & 100.000 & Malta & 129 \\
\hline Canadá & 94.353 & Singapur & 149 \\
\hline Nueva Zelanda & 86.554 & Jordania & 179 \\
\hline
\end{tabular}

Fuente: UNESCO/WWAP (2003).

Según los datos del World Bank (2001) el uso industrial del agua aumenta según el nivel de ingresos del país, variando desde el $10 \%$ en países de ingresos medios y bajos, hasta el $59 \%$ en países con ingresos elevados. El uso agrícola del agua disminuye según aumenta el nivel de ingresos del país, presentando así más protagonismo en los países con ingresos medios y bajos con $82 \%$, y $59 \%$ en los países con ingresos elevados. En el mundo en general, el uso agrícola es el gran responsable por el consumo del agua con el $70 \%$, mientras que el uso industrial consume $22 \%$ y el uso doméstico $8 \%$.

El mantenimiento de ese recurso natural tan importante para la humanidad y sus procesos en general, acumulado en la superficie de la tierra y en el interior del suelo ocurre a través del ciclo hidrológico. El agua potencialmente utilizable por el hombre es la diferencia entre la precipitación y la evaporación real, diferencia que tiene un origen exclusivamente atmosférico. Este recurso natural se conoce como lluvia útil, o precipitación eficaz, y no es otra cosa que el agua disponible para escorrentía tanto superficial como subterránea. Al tener la precipitación útil un origen atmosférico, ésta es consecuencia del propio clima de la región o de la zona geográfica donde se modeliza el ciclo hídrico, por lo que la variabilidad interanual e intra-anual del recurso hídrico es función de la variabilidad del propio clima (Chazarra Bernabé et al. 2002). Todo el agua del planeta está en continuo movimiento cíclico entre las fases líquida, sólida y gaseosa y el ciclo hidrológico representa la interdependencia entre sus distintas fases. El ciclo hidrológico (Fig. 01) es fundamental tanto para la comprensión del clima como para el uso de las fuentes de agua dulce y el manejo sostenible de los medios naturales, sobre todo, en el contexto de cambio climático que el mundo vive. 


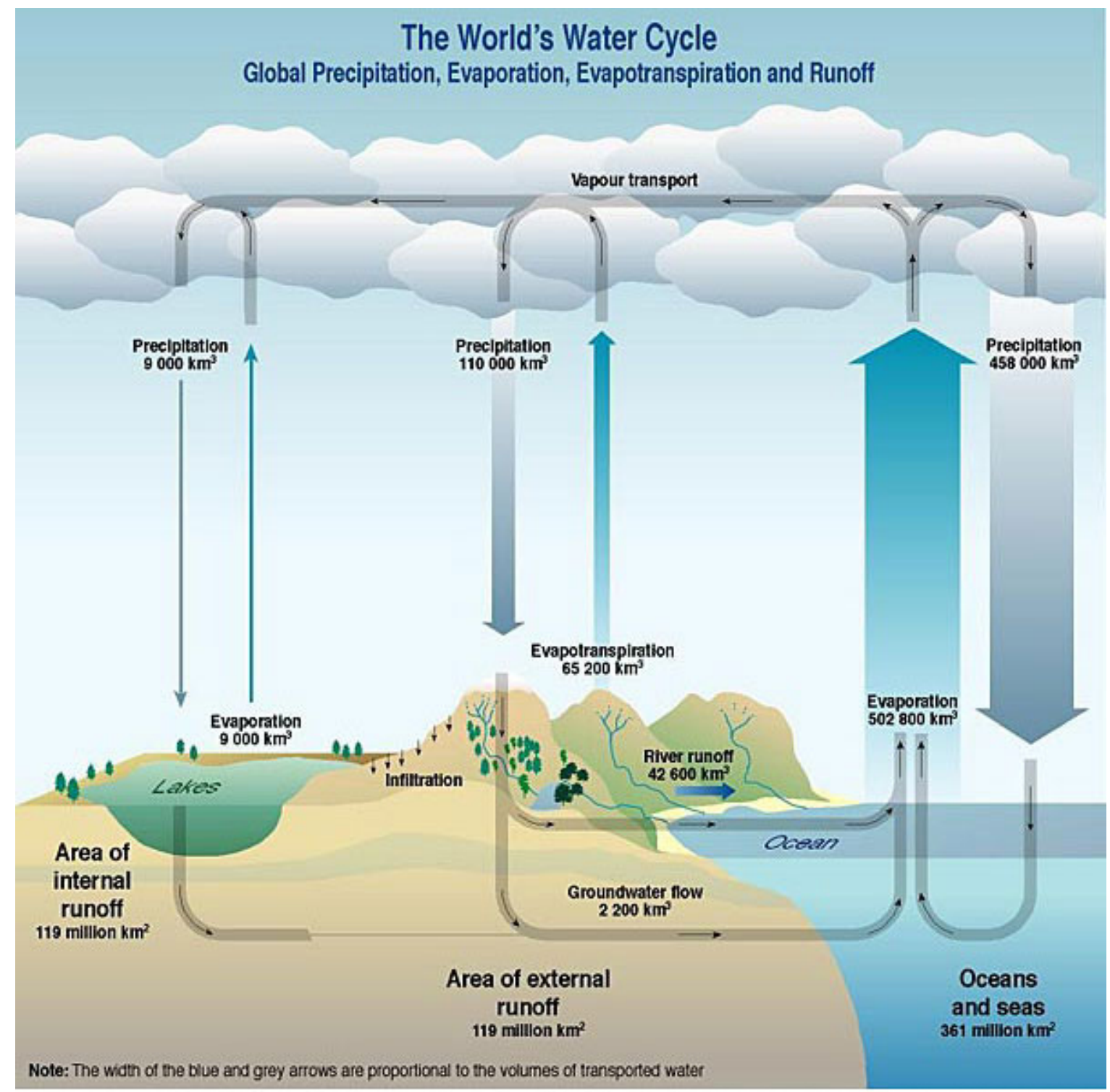

Figura 01 - El Ciclo Hidrológico con el balance hídrico general. Fuente: Unep (2002)

El cambio climático ya es un hecho y se trata de un fenómeno climático de larga extensión que viene reflejado por un aumento en la temperatura media de la superficie global en los últimos 150 años. Sin embargo, el significado real del aumento de las temperaturas y las consecuencias del cambio climático es objeto constante en las mesas de debate de los grandes investigadores mundiales. Según el IPCC (2001) el cambio climático se refiere a importantes variaciones que persisten durante un período prolongado, normalmente de decenios o incluso más. Incluye desplazamientos en la frecuencia y magnitud de fenómenos meteorológicos esporádicos, además del aumento continuo y lento en la temperatura media de la superficie de la Tierra, mostrado en las variaciones climáticas y meteorológicas en todas las escalas temporales y espaciales, lo que abarca las fuertes tormentas breves y repentinas, los fenómenos estaciónales como los producidos por El Niño, hasta las sequías que duran 
decenios, y los cambios de temperaturas y la variación de las capas de hielo que se han producido a lo largo de siglos.

De acuerdo con los datos del IPCC (2001), la principal evidencia del calentamiento global proviene de las medidas de las temperaturas de estaciones meteorológicas en todo el globo desde 1860 que presentan un aumento de la temperatura de $0,6 \pm 2^{\circ} \mathrm{C}$ durante el siglo XX (Tabla 02). Los aumentos más considerables han sido en dos periodos: 1910 a 1945 y 1976 a 2000.

Tabla 02. Indicadores meteorológicos y probables cambios.

\begin{tabular}{|l|l|}
\hline \multicolumn{1}{|c|}{ Indicadores Meteorológicos } & \multicolumn{1}{c|}{ Cambios } \\
\hline $\begin{array}{l}\text { Temperatura media mundial de la } \\
\text { superficie }\end{array}$ & $\begin{array}{l}\text { Aumento en el } 0,6 \pm 0,2^{\circ} \text { C en el siglo XX; la superficie } \\
\text { de la Tierra se ha calentado más que los océanos } \\
\text { (muy probable). }\end{array}$ \\
\hline $\begin{array}{l}\text { Temperatura en la superficie del } \\
\text { Hemisferio Norte }\end{array}$ & $\begin{array}{l}\text { Aumento durante el siglo XX más que en otro siglo de } \\
\text { los últimos } 1.000 \text { años; el decenio de 1990 ha sido el } \\
\text { más cálido del milenio (probable). }\end{array}$ \\
\hline Temperatura diurna de la superficie & $\begin{array}{l}\text { Disminución en el período 1950-2000 en las zonas } \\
\text { terrestres; las temperaturas mínimas nocturnas han } \\
\text { aumentado el doble de las temperaturas máximas } \\
\text { diurnas (probable). }\end{array}$ \\
\hline Días calurosos/índice de calor & Aumento (probable). \\
\hline Días de frío/heladas & $\begin{array}{l}\text { Disminución en casi todos las zonas terrestres durante } \\
\text { el siglo XX (muy probable). }\end{array}$ \\
\hline Precipitaciones continentales & $\begin{array}{l}\text { Aumento en un 5-10 por ciento en el siglo XX en el } \\
\text { Hemisferio Norte (muy probable), } \\
\text { aunque han disminuido en algunas regiones (como en } \\
\text { África del Norte y occidental y } \\
\text { partes del Mediterráneo). }\end{array}$ \\
\hline Precipitaciones fuertes & $\begin{array}{l}\text { Aumento en latitudes medias y altas en el Norte } \\
\text { (probable). }\end{array}$ \\
\hline $\begin{array}{l}\text { Frecuencia e intensidad de las } \\
\text { sequías }\end{array}$ & $\begin{array}{l}\text { Aumento del clima seco estival y las consiguientes } \\
\text { sequías en algunas zonas (probable). En } \\
\text { algunas regiones, como en partes de Asia y África, } \\
\text { parecen haberse acentuado la frecuencia } \\
\text { e intensidad de las sequías en los últimos decenios. }\end{array}$ \\
\hline
\end{tabular}

Fuente: IPCC (2001).

El estudio de las temperaturas es el campo en el que se están dedicando mayores esfuerzos por parte de la comunidad científica experta en los estudios observacíonales del clima, al ser considerada ésta como el principal indicador del estado del sistema climático. No obstante, el estudio de la precipitación es otra variable clave de este sistema (Saladié et al. 2002). La preocupación existente por la evolución futura de los recursos hídricos en el contexto de la problemática del cambio climático ha suscitado un gran interés por el estudio de las tendencias de las series de precipitaciones (Guijarro, 2004). La precipitación es sin duda, el factor meteorológico más importante 
en el mantenimiento y en la disponibilidad del agua en la superficie de la tierra. La distribución de la precipitación en el tiempo y en el espacio es esencial para la generación de los recursos hídricos en cada región, y conocer sus mecanismos de funcionamiento y sus posibles tendencias es crucial para entender el equilibrio hidrológico de una determinada región.

En lo estrictamente climático, el balance de precipitaciones ha determinado históricamente dos Españas diferentes: la seca y la húmeda. A grandes rasgos se puede dividir la Península en dos partes, la más lluviosa al norte y la más seca en el centro y sur. Partiendo de la premisa general de que las precipitaciones disminuyen de norte a sur, los sectores con mayores índices pluviométricos los encontramos en el tercio norte peninsular, mientras que la más seca abarca una amplia zona próxima al litoral mediterráneo en el entorno del cabo de Gata, en la que anualmente no se supera los 150-200 mm. Además de que las vertientes atlántica y cantábrica de la Península son mucho más lluviosas que el área mediterránea y la vertiente sur, en aquellas dos zonas se da la circunstancia añadida de que el clima es mucho más regular a lo largo del año, mientras que en las otras dos, así como en numerosas zonas del interior, la variabilidad es una característica fundamental de la personalidad climática. A este respecto debe subrayarse que además de los menores aportes pluviométricos, en buena parte de la España seca el aprovechamiento del agua se ve perjudicado por el hecho de que una parte del balance anual de lluvia se produce en episodios de chubascos intensos pero de corta duración, tal como reflejan los datos históricos de máximos de precipitación en 24 horas (Aupí et al. 2004).

Además del estudio del contexto climático y sus posibles cambios a lo largo del tiempo es necesario analizar también los regímenes fluviales y las características generales que componen sus cuencas y sus posibles alteraciones, para que se pueda hacer una gestión efectiva de los recursos hídricos. Un factor muy importante a considerar es que la mayoría de las características de una cuenca son comúnmente estables a lo largo del tiempo. Sin embargo, los usos del suelo y la cubierta vegetal pueden cambiar rápidamente en respuesta a la actividad humana. Esto es muy importante, ya que la cubierta vegetal es uno de los factores que efectivamente controlan la escorrentía y la producción de sedimentos (Beguería et al. 2006). Como la temperatura y la precipitación, los diversos cambios en los usos y en la cobertura del suelo son también motivo de gran interés y preocupación por parte de los científicos, sobre todo, en relación con la aceleración de esos procesos alcanzada en las últimas décadas y los posibles impactos, tanto ambientales cuanto socio-económicos, que puedan generar. 
Desde el punto de vista de la generación y del mantenimiento de los recursos hídricos, sobre todo en ambientes mediterráneos, los espacios forestales, son los grandes responsables del equilibrio hidrológico. Según Beguería et al. (2003), las montañas contienen la llave de los recursos hídricos, especialmente en áreas mediterráneas donde la precipitación es escasa, la evapotranspiración es intensa y hay un fuerte contraste entre estaciones húmedas y secas.

En este marco de cambio global, cobra especial interés medioambiental el estudio de los regímenes fluviales en cuencas de montaña representativas, que albergan una gran biodiversidad y en las que la sostenibilidad de sus ecosistemas puede verse seriamente afectada. Dado el horizonte de incertidumbre de los recursos hídricos, su planificación y gestión sostenible requiere, como tarea fundamental, una primera fase de evaluación de los mismos y de su evolución temporal que permita confirmar o descartar posibles tendencias (Machin et al. 2005). Las áreas de montaña, especialmente las localizadas en ambientes Mediterráneos, se caracterizan por una alta variabilidad de la precipitación y una extrema heterogeneidad espacial del relieve, cubierta vegetal y propiedades del suelo (García Ruiz et al. 2004). Estos ambientes de clima mediterráneo son los que más riesgos presentan de sufrir las consecuencias del cambio climático por sus características muy peculiares que hacen que sean muy vulnerables a dichos cambios. Son ambientes que presentan relativamente pocos recursos frente a una demanda creciente y que está relacionada, sobre todo, con el incremento del turismo y de la agricultura, que obliga a un aumento de los sistemas de regadíos; así los recursos disponibles son escasos frente a la gran demanda ofertada. Otro problema que se presenta es que las montañas son las grandes responsables de regeneración de los recursos hídricos, y los cambios en los usos y en la cobertura del suelo que las mismas vienen sufriendo en las últimas décadas han traído grandes transformaciones en el proceso de generación y mantenimiento de estos recursos. Las precipitaciones presentan una gran variabilidad estacional e interanual, lo que dificulta las recargas de los acuíferos y la formación de la escorrentía. Como consecuencia principalmente de esa variabilidad de las precipitaciones, los caudales también presentan una gran irregularidad y suelen registrar valores prácticamente nulos o incluso nulos en algunas regiones en determinados meses. En los ecosistemas mediterráneos hay una marcada coincidencia entre las épocas de máxima temperatura con la ausencia de lluvias, produciendo una intensa sequía estival, lo que asociado a todos los factores ya mencionados, dificulta todavía más la generación y el mantenimiento de los recursos hídricos. De acuerdo con Machin et al. (2005), en Europa, los países del área mediterránea son los que más riesgo presentan de sufrir 
cambios ambientales que afectarán a los recursos de agua y suelo y que podrían conducir, incluso, a la desertificación.

En este contexto, las cabeceras de cuencas forestales, en zonas de montaña mediaalta, pueden ser indicadores de respuesta más rápida a los procesos de cambio global. Las condiciones de menor transformación que generalmente se suelen encontrar en ellas, las menores afecciones antrópicas en zonas de menor densidad de población y por consiguiente la relativamente menor explotación de los recursos hídricos, hacen que estas cuencas de cabecera puedan servir como sectores de control de cambios ambientales y antrópicos, para poder así analizar su impacto en ambientes de menor confluencia de factores (Machin et al. 2005). Las cabeceras son un segmento del paisaje de extrema importancia para los ambientes fluviales, pues constituyen el entorno de las áreas de nacientes del agua. Los problemas causados en las cabeceras pueden influir en todo el funcionamiento hidrológico de la cuenca incluso comprometiendo la vida del río. Los procesos de cambio global y el impacto antrópico van a afectar a los regímenes fluviales y modificar los recursos hídricos. Por lo tanto, es de fundamental importancia el mantenimiento sostenible de esas áreas y, por consiguiente, de los ambientes forestales naturales. En virtud de todos los problemas relacionados con los recursos hídricos, hay una creciente necesidad de profundizar en el conocimiento del funcionamiento eco-hidrológico de cada parte de los sistemas fluviales, especialmente lo concerniente a las cabeceras.

El funcionamiento hidrológico y geomorfológico de los ríos se halla relacionado con las características de las cuencas que drenan, incluyendo especialmente la topografía, la litología, la cubierta vegetal y los usos del suelo (García Ruiz et al. 2001). Entre las variables que controlan la producción de agua en la cuenca están el tipo del suelo, la pendiente, la precipitación, la interceptación y la evapotranspiración. La generación de escorrentía está fuertemente relacionada con los cambios en el clima y en los usos del suelo, sobretodo con relación al tipo de la cobertura vegetal. La problemática del cambio climático ha renovado el interés por el estudio de las tendencias de diferentes variables climatológicas, y especialmente de la temperatura y la precipitación (Guijarro, 2004). Estos estudios se realizan a diferentes escalas espaciales y temporales, una vez que las fluctuaciones en los recursos hídricos que se atribuyen a los factores mencionados presentan una gran irregularidad y variabilidad, tanto espacial como temporal. Según Mossmann et al. (2004), en las últimas décadas, el incremento de las observacíones y el desarrollo de la tecnología de la instrumentación meteorológica, el análisis de los elementos climáticos y la caracterización del sistema climático han 
permitido establecer niveles de referencia y detectar posibles cambios más o menos recientes. El estudio de las tendencias en las precipitaciones y en las temperaturas tiene como objetivo principal relacionar los resultados de estas posibles tendencias con posibles variaciones en los caudales. López Moreno et al. (2002) han mencionado que cada vez más estudios detectan anomalías en ese paralelismo. Gallart y Llorens (2004), concluyen que la disminución de caudal en la mayor parte de los ríos españoles durante los últimos 50 años no puede explicarse sólo por la tendencia de las precipitaciones. Así, el funcionamiento hidrológico de una cuenca presenta todavía una gama de incertidumbres que necesitan de estudios que puedan explicarlas y proporcionar así medios para que la gestión de los recursos hídricos sea efectiva y de carácter preventivo y conservacíonista.

Muchos son los estudios que están siendo llevados a cabo en todo el mundo por la comunidad científica sobre la evolución de las temperaturas (Alexandersson y Moberg, 1997; Hanssen-Bauer et al. 2000; Brunetti et al. 2004; Hanssen-Bauer et al. 2005), de la precipitación (Piervitali et al. 1998; Hanssen-Bauer et al. 2000; Brunetti et al. 2004; Hanssen-Bauer et al. 2005; Serrano Muela et al. 2005; Ezzat Elshamy et al. 2006; Norrant et al. 2006; Picarreta et al. 2006), de la escorrentía de diversos ríos (Putty y Prasad, 2000; Arora, 2002; Cosandey et al. 2005) y también del cambio en los usos y en la cobertura del suelo (Andréassian, 2004; Cosandey et al. 2005) con el objetivo de analizar posibles tendencias y verificar el cambio global. En España, como en todo el mundo, hay cada vez más investigadores que se dedican a evaluar posibles tendencias en la temperatura (Brunet et al. 2005; Del Río et al. 2005; Andreo et al. 2006), en la precipitación (Esteban-Parra et al. 1998; Labajo y Piorno, 2001; Abaurrea et al. 2002; Chazarra Bernabé et al. 2002; Saladié et al. 2002; Guijarro, 2004; Mossmann et al, 2004; Del Río et al. 2005; Andreo et al. 2006), en la escorrentía (García Ruiz et al. 2001; López Moreno et al. 2002; Dunjó et al. 2004; García Ruiz et al. 2004; Machin et al. 2005; Martínez Fernández et al. 2005; Serrano Muela et al. 2005; López Moreno, 2006) y en los cambios en los usos del suelo (González González et al. 1987; Beguería et al. 2003; Dunjó et al. 2004; Gallart y Llorens, 2004; Beguería et al. 2006; Martínez Fernández, 2006) y sus consecuencias.

En Europa los estudios que analizan las variaciones climáticas y su relación con los procesos hidrológicos están siendo llevados a cabo desde hace algunos años. Piervitali et al. (1998) estudiaron las tendencias de la precipitación en el período de 1951 a 1995, evaluando estaciones en los países del centro-oeste mediterráneo y detectaron tendencias negativas significativas. Cosandey et al. (2005) evaluaron los 
impactos hidrológicos de tres áreas de bosques en Francia con distintos tratamientos y concluyeron que es muy grande la influencia de los usos del suelo en la complejidad del estudio entre la precipitación y la escorrentía. Norrant et al. (2006) analizaron las tendencias mensuales y diarias de la precipitación en los ambientes mediterráneos en general y no pudieron encontrar tendencias significativas. Piccarreta et al. (2006) analizaron las variaciones en la precipitación y los usos del suelo, en Basilicata en Italia, y sus consecuencias en la erosión de los suelos utilizando el período de 1955 a 2002, y concluyeron que hubo una tendencia negativa significativa en las precipitaciones. Brunetti et al. (2004) estudiaron las temperaturas, la precipitación y los eventos extremos en el último siglo también en Italia y detectaron un aumento de las temperaturas y un aumento considerable en la intensidad de las precipitaciones. Hanssen-Bauer et al. (2000) y Hanssen-Bauer (2005) Ilevaron a cabo el estudio de las variaciones en las temperaturas y en las precipitaciones en Noruega en 2000 y después en 2005. En el estudio de 2000 concluyeron que había variaciones climáticas considerables que podrían ser explicadas por las variaciones en la presión atmosférica. En 2005 ha podido detectar un aumento de la temperatura media anual de 0,5 a $1,5^{\circ} \mathrm{C}$ y la precipitación presentó un aumento significativo en nueve de las trece regiones estudiadas. Muy variados son los resultados de los análisis y se observan variaciones todavía más grandes entre áreas con contextos bioclimáticos y geográficos distintos.

En España, tanto como en Europa, los cambios que están experimentando los usos del suelo en ámbitos geográficos muy diversos, están suscitando un gran número de investigaciones que tienen por objeto analizar las consecuencias de dichos cambios en medios tan sensibles como los forestales (Martínez Fernández et al. 2005). Dunjó et al. (2004) hicieron su estudio sobre el papel de los usos del suelo y de las coberturas vegetales en la generación de escorrentía y en la producción de sedimento en una pequeña cuenca mediterránea. Martínez Fernández (2006), analizó los cambios en la cubierta vegetal y los recursos hídricos en la Cuenca del Duero, desde el punto de vista de la interceptación. En todas estas investigaciones se puede percibir la gran influencia de los usos del suelo en la generación de la escorrentía, así como en los procesos hidrológicos en general. Beguería et al. (2003) evaluaron el efecto de las oscilaciones climáticas y de los cambios en los usos del suelo en la escorrentía en los Pirineos Centrales españoles y demostraron que las variaciones anuales entre la precipitación y la escorrentía son relativamente más bajas en la segunda mitad del período estudiado, coincidiendo con el período de mayores cambios en los usos del suelo. Gallart y Llorens (2004) estudiaron los cambios en la cubierta vegetal y los 
recursos hídricos en las cabeceras del río Ebro y también concluyeron que coincide una disminución en la escorrentía con un incremento en la cobertura de los bosques. Todas estas investigaciones fueron hechas teniendo como principal objetivo analizar las tendencias en los procesos hidrológicos, en general, y el papel de los cambios en los usos del suelo, en particular.

La variabilidad climática también viene siendo estudiada exhaustivamente en España, sobre todo, con el objetivo de verificar el impacto real del cambio climático sobre la precipitación y la temperatura en la Península Ibérica. Labajo y Piorno (2001), hicieron un análisis del comportamiento de la precipitación en Castilla y León en el período de 1931 a 1996. Chazarra Bernabé et al. (2002) hicieron la reconstrucción de la precipitación útil de las Cuencas del Sureste y Levante desde 1864 hasta 2000. Saladié et al. (2002) estudiaron la evolución de la precipitación en el sector suroriental de la Depresión del Ebro durante la segunda mitad del siglo XX. Abaurrea et al. (2002) hicieron una caracterización de la evolución de la precipitación en la Cuenca del Ebro utilizando el período de 1916 a 2000. Andreo et al. (2006) llevaron a cabo una investigación sobre las variaciones climáticas e hidrológicas durante los últimos 117 166 años en el sur de la Península. Todos estos estudios llegaron a la conclusión que no hubo tendencias significativas a lo largo del tiempo en la distribución de la precipitación y de la temperatura. No obstante hay otros trabajos con resultados distintos. Mossmann et al. (2004) llevaron a cabo un análisis regional para determinar las partes de España continental que muestran cambios, estadísticamente significativos, de la precipitación en los meses de febrero, marzo y abril, y evaluar el año en torno al cual comenzaron a detectarse estos comportamientos. Los resultados muestran una tendencia estadísticamente significativa que revela una disminución en la proporción de la precipitación en amplias zonas de la España continental. EstebanParra et al. (1998) estudiaron las variaciones en la precipitación en España en el período de 1880 a 1992 y demostraron que hubo una disminución significativa en las zonas mediterráneas y regiones interiores y un aumento significativo en la costa norte. Del Río et al. (2005) hicieron un estudio de las variaciones climáticas en Castilla y León en el período de 1961 a 1997 y concluyeron que hubo una disminución en la precipitación en la primavera, en el invierno y en el otoño, pero sólo encontraron una tendencia significativa en marzo. En ese trabajo la temperatura sufrió un aumento en la primavera y en el invierno, encontrando únicamente en esta última estación una tendencia significativa. Las variaciones en la temperatura también fueron analizadas por Brunet et al. (2005) en el período de 1850 a 2003 y detectaron un aumento significativo. 
Sobre la evolución de los ríos desde el punto de vista hidrológico y sus tendencias en España hay que señalar que García Ruiz et al. (2001) analizaron los recursos hídricos superficiales del Pirineo aragonés y su evolución reciente. López Moreno et al. (2002) evaluaron el régimen del río Ésera, en el Pirineo Aragonés, y su tendencia. Machin et al. (2005) hicieron la caracterización de la evolución reciente y las tendencias del río Arlanza en su cabecera. Estos estudios confirmaron la existencia de una tendencia general a la reducción de los aportes.

El análisis hidrológico, climatológico y de los cambios en los usos y en la cobertura de suelo de las cuencas de montaña está justificado una vez que en el contexto de cambio climático que estamos viviendo se hace de extrema necesidad saber cual es la cantidad y la calidad de los recursos hídricos que se deja a las generaciones futuras. Para esto se hace necesario saber cual es la respuesta hidrológica de los ríos frente a la gestión humana. Es imprescindible evaluar los recursos hídricos existentes y estudiar sus tendencias y los factores que influyen en su generación y en su conservación para que se pueda hacer una gestión integrada de tales recursos. La evaluación de los recursos hídricos superficiales y las previsiones sobre su posible evolución requieren como punto de partida el análisis de las series de caudales existentes con objeto de valorar su disponibilidad final para asegurar la sostenibilidad de los agroecosistemas (García Ruiz et al. 2001). El análisis de la distribución de caudales y de sus cambios a lo largo del año proporciona criterios científicos de base necesarios para la planificación de los recursos hídricos.

El conocimiento es el gran responsable del cambio de comportamiento y actitud que probablemente serán los protagonistas en la lucha contra el cambio climático y sus consecuencias. Así, para que las acciones de conservación, preservación y recuperación de los ambientes sean más efectivas es necesario demostrar la interactividad y la interdependencia de estos factores. 


\section{OBJETIVOS}

\subsection{Objetivo General}

El objetivo de esta tesis consiste en analizar las tendencias hidro-climáticas recientes en cuencas de cabecera, las verdaderas fábricas del agua que discurre por los ríos, en ambientes mediterráneos. A la vista de la evolución ambiental de las últimas décadas, bajo un escenario de cambio global, inferir los cambios que están acaeciendo en esas áreas hidrográficas tan sensibles $\mathrm{y}$, de esa manera, poder analizar las perspectivas de futuro en el ámbito de los recursos hídricos.

Se trata de hacer un análisis climático, hidrológico y de los cambios en los usos y en la cobertura del suelo, en diversas subcuencas de cabeceras pertenecientes a las cuencas del Duero y del Tajo, situadas en sectores montañosos y en los que el régimen natural no se ha visto modificado.

Las cuatro cuencas utilizadas en este trabajo se encuentran en ambientes con diferentes condiciones bioclimáticas. Esto ha permitido establecer una comparación entre cuatro territorios dentro de un mismo contexto geográfico mediterráneo. De la cuenca del Duero han sido seleccionadas las cabeceras de los ríos Cega y Porma y de la cuenca del Tajo las de los ríos Trabaque y del propio Tajo.

Se trata de un análisis de la evolución reciente en el caudal de los ríos, en el régimen de la precipitación y de la temperatura a diferentes escalas de tiempo y en los cambios en los usos y en la cobertura del suelo, para el estudio de posibles tendencias en estas variables. Por consiguiente, se pretende hacer una comparación de los resultados obtenidos con otros estudios sobre los impactos del cambio global en la Península lbérica, intentando explicar estas posibles tendencias.

El trabajo se basa en datos medios y en la ocurrencia de determinados caudales, que definen el régimen fluvial y trata de analizar las tendencias de los caudales anuales y mensuales, relacionándolos con la posible existencia de una deriva climática y con los cambios ocurridos en los usos y en la cobertura del suelo. 


\subsection{Objetivos Específicos}

Los objetivos específicos que plantean esta tesis doctoral son:

- Analizar las características hidro-climáticas que definen el comportamiento de los ríos Cega, Porma, Tajo y Trabaque en régimen natural;

- Analizar los caudales de dichos ríos en los últimos años con el objetivo de detectar posibles tendencias;

- Hacer un análisis desde el punto de visto de las precipitaciones para saber cómo ha sido el comportamiento de las mismas y definir si hubo algún tipo de tendencia;

- Hacer un análisis de las temperaturas de las zonas dónde se encuentran dichos ríos para verificar si hubo variaciones significativas en los últimos años;

- Analizar los cambios en los usos y en la cobertura del suelo en los últimos años $y$ intentar definir si hubo alguna tendencia;

- Relacionar las posibles tendencias de todas estas variables para verificar si están correlacionadas;

- Comparar los resultados obtenidos en ese trabajo con otros estudios ya desarrollados en el contexto de la Península Ibérica. 


\section{MATERIAL Y MÉTODOS}

\subsection{Material}

\subsubsection{Datos Hidrológicos}

En esta investigación se analizaron las cuencas hidrográficas de los ríos Cega, Porma, Tajo y Trabaque. Los datos hidrológicos utilizados en este estudio proceden de las redes de estaciones de aforos de las Confederaciones Hidrográficas del Duero y del Tajo (Tabla 03).

Tabla 03. Estaciones de aforo utilizadas.

\begin{tabular}{|l|c|c|c|}
\hline \hline \multicolumn{1}{|c|}{ Río } & Estación & Localización & Fuente \\
\hline Cega & 016 & Pajares de Pedraza & Confederación Hidrográfica del Duero \\
\hline Porma & 078 & Camposolillo & Confederación Hidrográfica del Duero \\
\hline Tajo & 001 & Peralejos de las Truchas & Confederación Hidrográfica del Tajo \\
\hline Trabaque & 186 & Priego & Confederación Hidrográfica del Tajo \\
\hline \hline
\end{tabular}

Los mapas del Ministerio de Fomento y del Servicio Geográfico del Ejército, fueron utilizados para hacer la delimitación de las cuencas así como su georreferenciación. Todos los mapas utilizados son topográficos con una escala de 1:50.000 (Tabla 04).

Tabla 04. Mapas topográficos utilizados para delimitación de las cuencas.

\begin{tabular}{|c|c|c|}
\hline Cuenca & Fuente & Hojas \\
\hline$\overline{\bar{C} \text { Cega }}$ & $\begin{array}{l}\text { Servicio Geográfico del Ejército } \\
\text { (Cartografía Militar de España) }\end{array}$ & $\begin{array}{l}18-18(457) \text { - Turégano } \\
18-19 \text { (483) - Segovia } \\
19-17(431) \text { - Sepúlveda } \\
19-18(458) \text { - Prádena } \\
19-19(484) \text { - Buitrago de Lozoya }\end{array}$ \\
\hline Porma & $\begin{array}{l}\text { Ministerio de Fomento (Instituto } \\
\text { Geográfico Nacional) }\end{array}$ & $\begin{array}{l}586 \text { - Gascueña } \\
587 \text { - Las Majadas } \\
563 \text { - Priego } \\
564 \text { - Fuertescusa }\end{array}$ \\
\hline Tajo & $\begin{array}{l}\text { Servicio Geográfico del Ejército } \\
\text { (Cartografía Militar de España) } \\
\text { Ministerio de Fomento (Instituto } \\
\text { Geográfico Nacional) }\end{array}$ & $\begin{array}{l}24-21 \text { (539) Peralejos de las Truchas } \\
25-21 \text { (540) - Checa } \\
25-22 \text { (565) - Tragacete } \\
24-22 \text { (564) - Fuertescusa }\end{array}$ \\
\hline Trabaque & $\begin{array}{l}\text { Servicio Geográfico del Ejército } \\
\text { (Cartografía Militar de España) }\end{array}$ & $\begin{array}{l}\text { 14-6 (79) - Puebla de Lillo } \\
\text { 14-7 (104) - Boñar } \\
\text { 15-6 (80) - Burón }\end{array}$ \\
\hline
\end{tabular}




\subsubsection{Datos Climatológicos}

Para el estudio de las variables climatológicas fueron utilizados para cada cuenca una estación termométrica y cinco estaciones pluviométricas (Tabla 05). Los datos climáticos (precipitación y temperatura) fueron obtenidos de la Agencia Estatal de Meteorología (Aemet).

Tabla 05. Estaciones pluviométricas y termométricas utilizadas en este estudio.

\begin{tabular}{|l|l|c|}
\hline \multicolumn{1}{|c|}{ Cuenca } & \multicolumn{1}{|c|}{ Estaciones } & \multicolumn{1}{c|}{ Tipo } \\
\hline \hline \multirow{5}{*}{ Cega } & La Granja de San Ildefonso & Pluviométrica \\
\cline { 2 - 3 } & Matabuena & Pluviométrica \\
\cline { 2 - 3 } & Rascafria (El Paular) & Pluviométrica y Termométrica \\
\cline { 2 - 3 } & Torreiglesias & Pluviométrica \\
\cline { 2 - 3 } & Turégano & Pluviométrica \\
\hline \multirow{5}{*}{ Porma } & Acebedo & Pluviométrica \\
\cline { 2 - 3 } & Crémenes & Pluviométrica \\
\cline { 2 - 3 } & Maraña & Pluviométrica \\
\cline { 2 - 3 } & Pantano del Porma & Pluviométrica y Termométrica \\
\cline { 2 - 3 } & Puebla de Lillo & Pluviométrica \\
\hline \multirow{5}{*}{ Trabaque } & Beteta & Pluviométrica \\
\cline { 2 - 3 } & Cañizares (Central Vadillo) & Pluviométrica y Termométrica \\
\cline { 2 - 3 } & Poyatos (Tejadillos) C. F. & Pluviométrica \\
\cline { 2 - 3 } & Santa María del Val & Pluviométrica \\
\cline { 2 - 3 } & Vega del Codorno & Pluviométrica \\
\hline \hline & Albalate de las Nogueras & Pluviométrica \\
\cline { 2 - 3 } & Arrancacepas & Pluviométrica \\
\cline { 2 - 3 } & Cañaveras & Pluviométrica \\
\cline { 2 - 3 } & Torrecilla & \\
\cline { 2 - 3 } & Villar de Domingo García & \\
\hline
\end{tabular}

\subsubsection{Datos de usos y cobertura del suelo}

Los datos utilizados para el análisis de los cambios en los usos y en la cobertura del suelo fueron obtenidos de diferentes fuentes de información (Fig. 02) y por consiguiente fueron utilizadas diferentes metodologías. 
a)

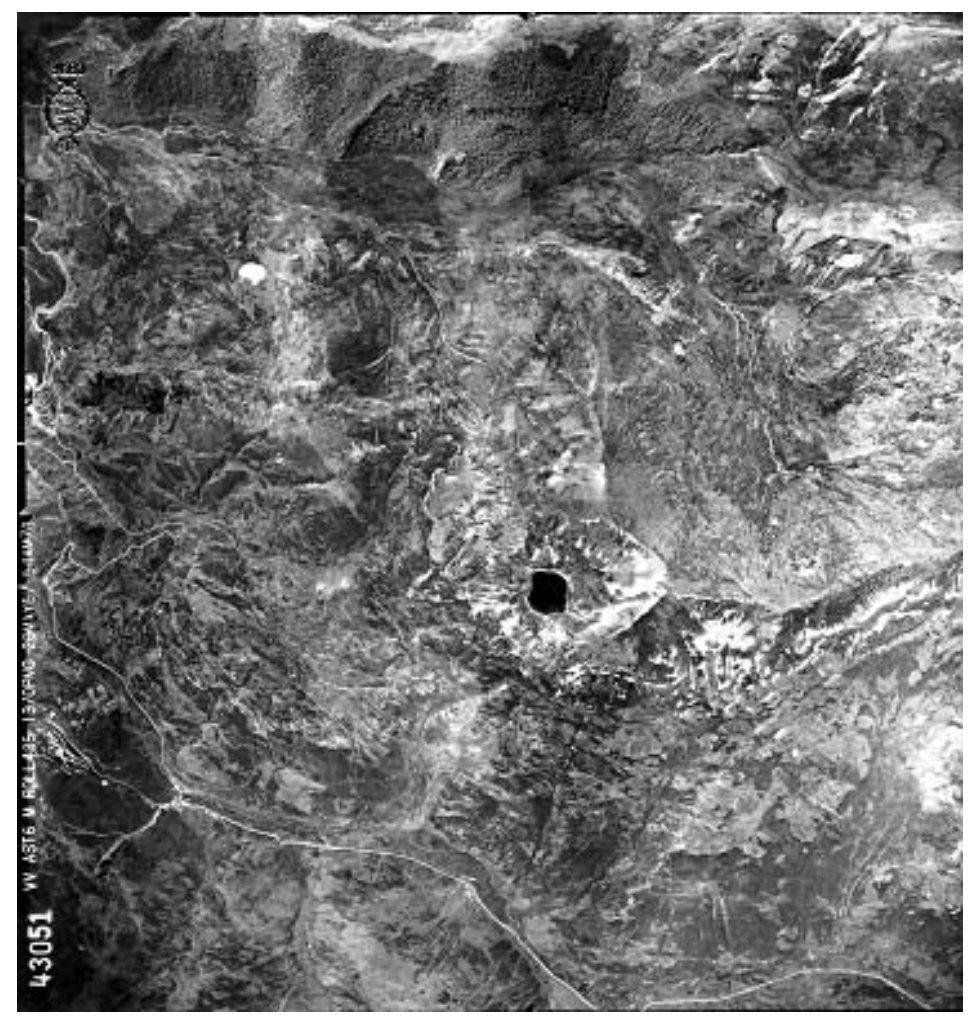

b)

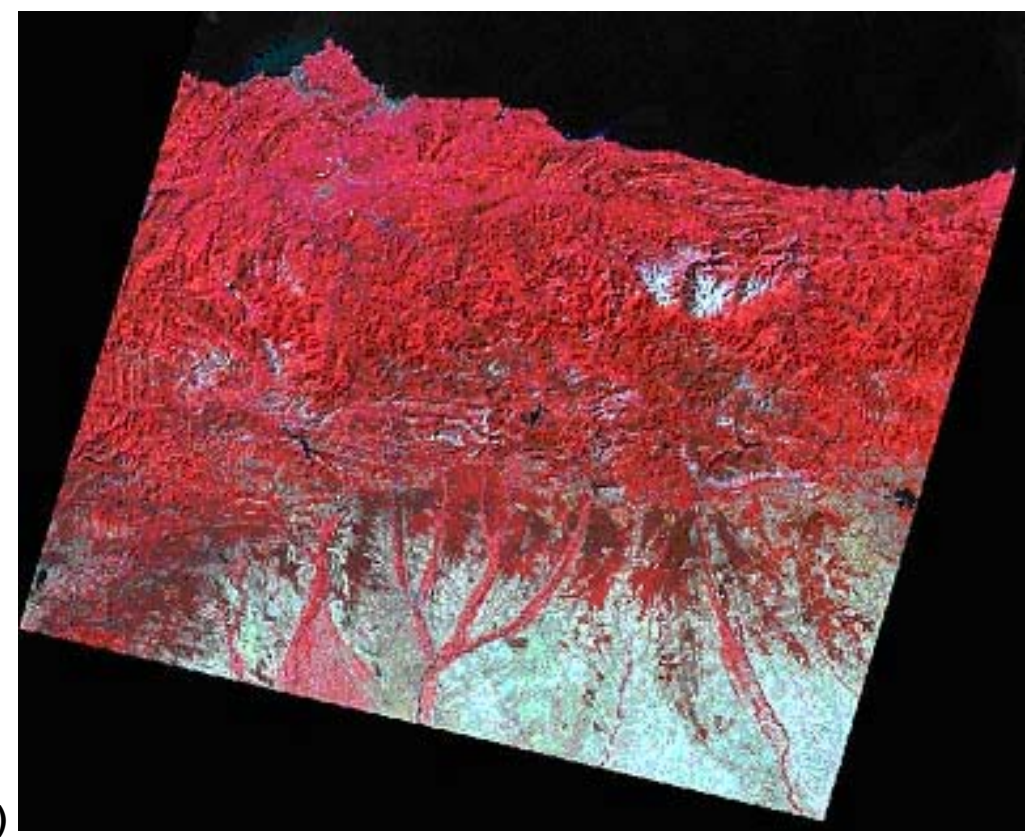

Figura 02 - (a) Foto aérea $n^{\circ} 43051$ del vuelo americano de 1956-57 y (b) Escena de satélite Landsat $n^{\circ}$ 218-030.

Las fotografías aéreas (Tabla 06) empleadas en este estudio proceden del Centro Cartográfico y Fotográfico (CECAF) del Ministerio de Defensa. El material es resultante del vuelo fotográfico de la "serie B", realizado entre 1956 y 1957 que fue un trabajo de cooperación entre el Ejército del Aire de España y la Fuerza Aérea de los Estados Unidos. Coloquialmente es conocido como "vuelo americano". El Servicio Geográfico del Ejército y el Instituto Geográfico y Catastral efectuaron la observación 
de los puntos de apoyo del vuelo. Se realizó un plan de vuelos destinado a componer un conjunto de fotografías aéreas de todo el territorio nacional español, con pasadas parciales para nuevas tomas en años sucesivos, una altura de 5.000 metros (equiparable a una escala de 1:33.000) y utilizándose los recursos más avanzados para su época, con cámaras y materiales de gran calidad. En términos globales, el vuelo consta de más de 60.000 fotogramas. Las primeras imágenes se tomaron el 3 de marzo de 1956 al sur de las provincias de Madrid y Guadalajara y el norte de Cuenca y las últimas el 15 de septiembre de 1957 al norte de la provincia de Huesca (Fajardo de la Fuente 2008).

Tabla 06. Fotografías aéreas utilizadas para análisis de las cuencas de los ríos Cega, Porma, Tajo y Trabaque y su correspondencia en el Mapa Topográfico Nacional (MTN).

\begin{tabular}{|c|c|c|c|c|}
\hline Cuenca & Hojas MTN & Año & Escala & $\mathrm{N}^{\circ}$ Fotos \\
\hline Cega & $430,431,457,458,483,484$ & 1956 & \begin{tabular}{|l|}
$1 / 31.000$ \\
$1 / 32.500$ \\
$1 / 33.000$
\end{tabular} & 52 \\
\hline Porma & $79,80,104,105$ & 1957 & \begin{tabular}{|l|}
$1 / 32.500$ \\
$1 / 30.500$ \\
$1 / 32.000$ \\
\end{tabular} & 31 \\
\hline Tajo & $539,540,564,565,587,588$ & $\begin{array}{l}1956 \\
1957\end{array}$ & \begin{tabular}{|l|}
$1 / 32.500$ \\
$1 / 31.000$ \\
$1 / 33.000$ \\
$1 / 32.000$ \\
$1 / 34.000$ \\
\end{tabular} & 92 \\
\hline Trabaque & $563,564,586,587$ & $\begin{array}{l}1956 \\
1957\end{array}$ & \begin{tabular}{|l|}
$1 / 35.000$ \\
$1 / 31.000$ \\
$1 / 33.500$ \\
$1 / 32.500$ \\
$1 / 32.000$ \\
\end{tabular} & 74 \\
\hline
\end{tabular}

Este no fue el primer vuelo fotográfico nacional ya que anteriormente fue llevado a cabo otro entre febrero de 1945 y septiembre de 1946, también por parte de personal estadounidense. Este vuelo, identificado como "serie A", quedó prácticamente sin uso sobre todo debido al nuevo vuelo (1956-57) que disponía de más calidad y más tecnología (Quirós Linares et al. 1997). A partir de la serie B y con la asistencia técnica y medios materiales del Departamento de Defensa estadounidense se procedió a la elaboración del primer mapa fotogramétrico de España, conocido también como AMS (Army Map Service). Además fue también punto de partida de otro cambio importante, la sustitución del antiguo sistema de referencia geodésico español, basado en el Elipsoide de Struve, y con Punto Astronómico Fundamental y origen de longitudes en el Observatorio Astronómico de Madrid, por el Datum Europeo de 1950, utilizado en la 
actualidad como base de la cartografía oficial española (Instituto Geográfico Nacional y Servicio Geográfico del Ejército).

Por otro lado, se emplearon las escenas Landsat MSS, TM y ETM+ (Tabla 07) que fueron obtenidas gratuitamente en Internet a través de la Global Land Cover Facility (GLCF) de la Universidad de Maryland (Estados Unidos) a través de la página web http:/glcf.umiacs.umd.edu.

Tabla 07. Imágenes de satélite utilizadas para análisis de las cuencas de los ríos Cega, Porma, Tajo y Trabaque.

\begin{tabular}{|c|c|c|c|c|}
\hline Cuenca & Escena & Satélite - Sensor & Fecha & $\begin{array}{c}\text { Resolución } \\
\text { Espacial }\end{array}$ \\
\hline \multirow[t]{3}{*}{ Cega } & 217-031 & Landsat MSS & $03 / 05 / 1976$ & $60 \mathrm{~m}$ \\
\hline & 201-032 & Landsat 5 TM & $25 / 03 / 1989$ & $30 \mathrm{~m}$ \\
\hline & 201-032 & Landsat 7 ETM+ & $22 / 04 / 2002$ & $30 \mathrm{~m}$ \\
\hline \multirow{3}{*}{ Porma } & $218-030$ & Landsat MSS & $24 / 08 / 1977$ & $60 \mathrm{~m}$ \\
\hline & \begin{tabular}{|l|}
$202-030$ \\
\end{tabular} & Landsat $5 \mathrm{TM}$ & $13 / 08 / 1991$ & $30 \mathrm{~m}$ \\
\hline & $202-030$ & Landsat 7 ETM+ & $29 / 06 / 2001$ & $30 \mathrm{~m}$ \\
\hline \multirow[t]{3}{*}{ Tajo } & $215-032$ & Landsat MSS & $06 / 06 / 1976$ & $60 \mathrm{~m}$ \\
\hline & $200-032$ & Landsat $5 \mathrm{TM}$ & $14 / 04 / 1987$ & $30 \mathrm{~m}$ \\
\hline & $200-032$ & Landsat 7 ETM+ & $30 / 05 / 2001$ & $30 \mathrm{~m}$ \\
\hline \multirow{3}{*}{ Trabaque } & $215-032$ & Landsat MSS & $06 / 06 / 1976$ & $60 \mathrm{~m}$ \\
\hline & $200-032$ & Landsat $5 \mathrm{TM}$ & 14/04/1987 & $30 \mathrm{~m}$ \\
\hline & $200-032$ & Landsat 7 ETM+ & $30 / 05 / 2001$ & $30 \mathrm{~m}$ \\
\hline
\end{tabular}

El programa GLCF es un convenio entre esa universidad y la NASA (National Aeronautics and Space Administration) que distribuye gratuitamente escenas Landsat de cualquier parte de la tierra, lo que facilita el trabajo de los investigadores ya que el alto coste de esta fuente de datos siempre ha sido un problema a la hora de plantear cualquier estudio. En España ha sido implantado recientemente el Plan Nacional de Teledetección que pone a la disposición el acceso a imágenes de satélite de todo el país, dentro de la suscripción que se ha firmado con Eurimage. El Instituto Geográfico Nacional a través de la Comisión Especializada de Observación del Territorio es el responsable de coordinar las actividades del Plan Nacional de Teledetección. El proyecto está en fase de implantación y conlleva la adquisición de un gran volumen de información procedente de diversos sensores, con diversa frecuencia, formatos, resolución, etc. Desde el año de 2005 hasta 2008 se ha estado elaborando el proyecto, incluyendo la redacción y firma de los convenios. A partir de entonces empieza la adquisición de las escenas y tratamiento de las mismas para ponerlas a la 
disposición de la comunidad científica. Especialmente para la baja resolución, pueden obtenerse datos con frecuencia diaria, semanal, quincenal y con distintos niveles de proceso. Al inicio de esta investigación todavía no estaban disponibles en España estas imágenes y con la intención de no elevar demasiado el coste del trabajo se ha optado por las escenas disponibles a través del programa GLCF. Estas se basan en una colección de ficheros para cada una que contiene los archivos para cada banda en el formato GeoTiff, los archivos de cabecera para cada escena con los metadatos relacionados, fundamentales a la hora de analizarlas, los archivos con los valores de calibración radiométrica para cada banda y otros archivos suplementarios.

El nivel de procesamiento de las escenas es el denominado Nivel 1, System Corrected, o L1G. Esto implica la corrección de las distorsiones radiométricas (ruido) derivadas del escaneo y el alineamiento de los píxeles y una corrección sistemática geométrica. En este nivel no se realizan correcciones atmosféricas. Se remuestrea y orienta la imagen conforme a una proyección cartográfica mediante algoritmos de corrección generados a bordo del propio satélite, simultáneamente a la captura de las imágenes. La información del sensor, el plano focal y la alineación de los detectores que proporciona el archivo de calibración del sistema mejora la fidelidad geométrica del resultado. El producto resultante está libre, por tanto, de distorsiones debidas al sensor (ángulo de vista, por ejemplo), satélite (desviación del eje de la toma) y tierra (rotación, curvatura). El modelo geodésico utilizado es el WGS84 (World Geodetic System 1984) y la proyección cartográfica la UTM (Universal Transversal Mercator) pero no utiliza puntos de control terreno ni modelos de elevación. El error espacial residual se estima en aproximadamente 250 m (ESA/ESRIN-GAEL, 2003). Además según las informaciones obtenidas a través de la GLCF las escenas poseen una cobertura nubosa de menos de un $20 \%$. Para lograr los objetivos de este estudio, en que se desea hacer la clasificación de los usos y coberturas del suelo a grandes rasgos, este nivel de corrección fue considerado suficiente.

\subsection{Métodos}

\subsubsection{Análisis Hidrológico}

Para análisis de los aportes en las cuencas estudiadas fue utilizado un mismo período con el objetivo de poder hacer comparaciones entre ellas. El período utilizado fue de 31 años, de 1974 hasta 2004. Para la elección del período se hizo un análisis previo 
de los datos, verificando la mayor calidad posible y series con pocas o ninguna laguna. Además, en todos los análisis se utiliza el año hidrológico, con inicio en el 1 de octubre de un año y final el 30 de septiembre del año siguiente. Este criterio es aceptado convencionalmente y utilizado por organismos como las Confederaciones Hidrográficas de España y por investigadores de todo el mundo. Según García Ruiz et al. (2001), este período se adapta al ciclo normal del recurso hídrico, que a finales de verano conoce su mínimo para iniciar un nuevo período. El paso inicial en el proceso de análisis fue la elección de las cuencas hidrográficas (Fig. 03).

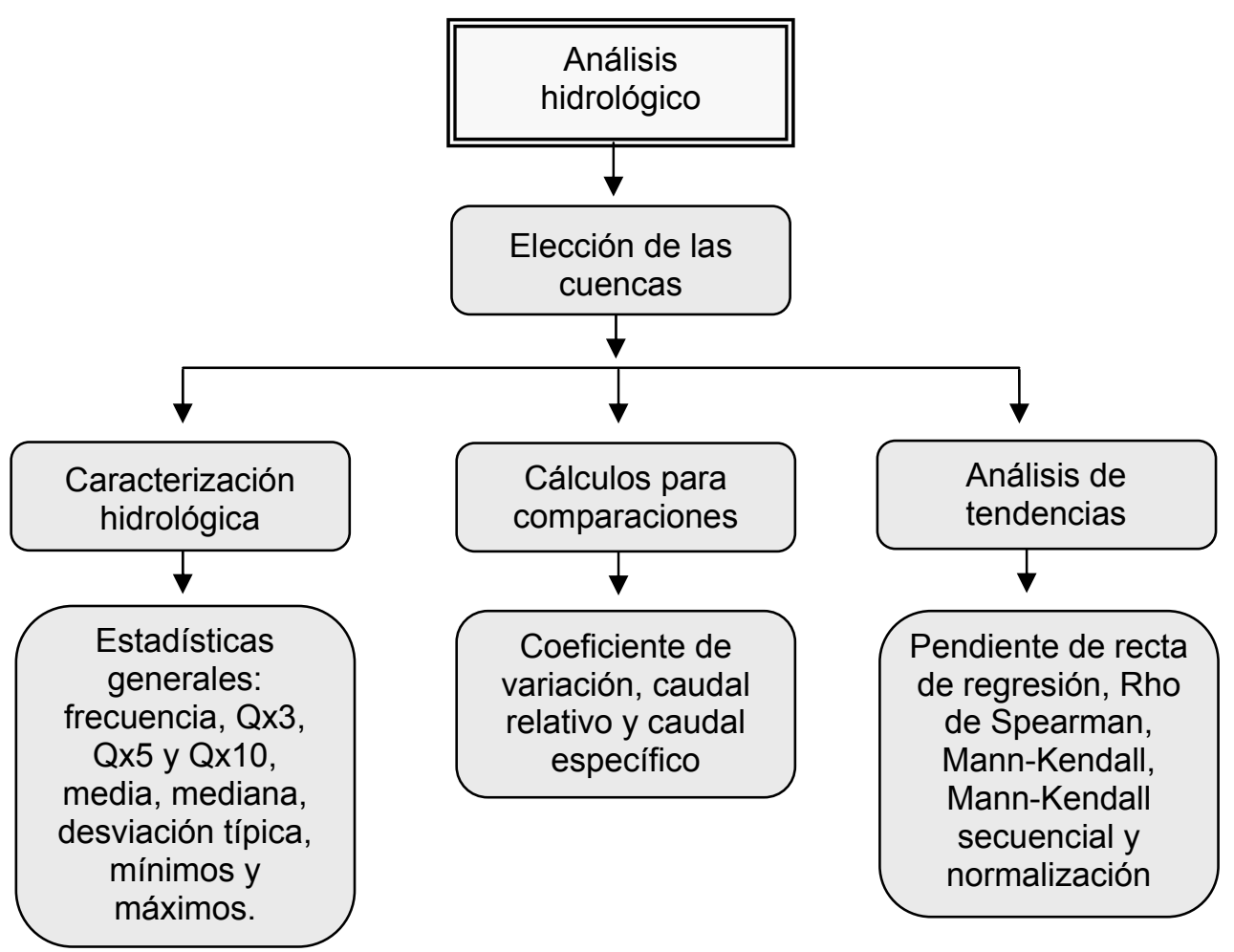

Figura 03 - Secuencia del trabajo desarrollado en el análisis hidrológico.

Las cuencas fueron elegidas siguiendo una serie de criterios. El primer paso fue la selección de todas las cuencas de cabeceras, tributarias de los ríos Duero y Tajo, que poseen estaciones de aforo, de acuerdo con los mapas de la red hidrográfica de ambas cuencas obtenidos en las confederaciones responsables de la gestión de éstas. Fueron encontradas inicialmente 31 para el río Duero y 27 para el río Tajo. Las estaciones que estaban localizadas aguas abajo de cualquier embalse fueron descartadas (16 del Duero y 13 del Tajo), buscando así cuencas con un régimen lo más natural posible. El siguiente paso fue analizar el tamaño de las series históricas. Todas las series con menos de 30 años fueron descartadas, siendo 4 en el caso del Duero y 5 en el caso del Tajo. Al mismo tiempo fue observada también la calidad de 
los datos existentes. Las estaciones que contenían muchas lagunas o series históricas muy irregulares fueron también retiradas, restando en este punto 8 estaciones de la cuenca del río Duero y 5 de la cuenca del Tajo. A partir de entonces se hizo un análisis previo de todos los datos para comprobar la calidad de los registros con la posterior verificación de la localización de cada una de estas cuencas restantes con el objetivo de buscar ambientes que estuviesen en contextos bioclimáticos distintos. Al final, las cuatro estaciones elegidas son las que mejor atendieron a todos estos requisitos.

Los registros de caudales son diarios y fueron utilizados solamente para el cálculo de frecuencias y para el análisis de las veces en que el caudal sobrepasó en 3, 5 o 10 $\left(Q_{3}, Q_{5}\right.$ y $\left.Q_{10}\right)$ veces el caudal medio. Para los demás cálculos fueron hechas agregaciones en meses y años. Fueron rechazados los meses en que faltaban más de cinco días de datos (García Ruiz et al. 2001). Las lagunas fueron rellenadas a partir de la estimación de una media los registros más cercanos y más correlacionados (Abaurrea et al. 2002; Saladié et al. 2002). Para la agregación de meses a años fue utilizado el mismo procedimiento rechazando los años en que definitivamente faltaran más de 3 meses (García Ruiz et al. 2001). Así se obtuvo una serie histórica con bastante calidad y homogeneidad en los datos.

El primer paso para el análisis de los registros fue hacer una caracterización hidrológica de las zonas utilizando para esto la estadística básica de los caudales y de los aportes (López Moreno et al. 2002; Machin et al. 2005), con indicación de la media, mediana, desviación típica, valores mínimos y máximos, caudal medio $\left(\mathrm{m}^{3} \mathrm{~s}^{-1}\right)$, aportación media $\left(\mathrm{hm}^{3}\right)$, distribución de frecuencias, coeficientes de variación, caudales relativos y específicos $\left(\mathrm{Is}^{-1} \mathrm{~km}^{2}\right.$ ) (García Ruiz et al. 2001; López Moreno et al. 2002; Machin et al. 2005; López Moreno, 2006;). Estos tres últimos métodos de análisis fueron utilizados con el objetivo de hacer comparaciones entre las cuatro cuencas.

El coeficiente de variación (CV) es un indicador de la dispersión de los datos respecto a su promedio. Generalmente se expresa en porcentaje. Cuanto menor sea el coeficiente de variación menor será la diferencia entre los datos observados y mejor representados estarán por su promedio (Rius Díaz et al. 1999). Se calcula:

$\mathbf{C V}=\boldsymbol{\sigma} / \boldsymbol{x} \quad$ o bien $\mathbf{C V}=\boldsymbol{\sigma} / \boldsymbol{x} \cdot \mathbf{1 0 0}$ (si se expresa en porcentaje)

Donde $\boldsymbol{\sigma}$ es la desviación típica y $\mathbf{x}$ la media. 
El CV sólo se debe calcular para variables con todos los valores positivos. Todo índice de variabilidad es esencialmente no negativo. Las observacíones pueden ser positivas o nulas, pero su variabilidad debe ser siempre positiva. Como la media y la desviación típica se expresan en la misma unidad que la variable $X$, se trata de una cantidad sin dimensión, independiente de las unidades elegidas, es decir, invariante ante un cambio de escalas. Este hecho permite que pueda utilizarse este coeficiente para comparar distribuciones diferentes (Moreno Soto et al. 2006). El coeficiente de variación puede ser bajo si es menor que $0,15(15 \%)$, medio se está entre 0,15 y 0,5 (15 y $50 \%$ ) o alto si es mayor que 0,5 (50\%) (Warrick, 1998).

El caudal relativo $\left(Q_{r}\right)$ se obtiene de la división del caudal medio mensual por el caudal medio anual (o módulo). Con este cálculo se establece una categoría de valores que oscilan de 0 a 3 y que permiten comparar espacial y temporalmente los caudales (Machin et al. 2005). El caudal relativo fue utilizado sobre todo para las comparaciones entre los regímenes de los ríos.

El caudal específico $\left(Q_{\text {esp }}\right)$ es un valor por unidad de superficie, lo que permite hacer comparaciones entre cuencas con áreas de drenaje distintas (Molinier et al. 1995; Tucci, 2000; García Ruiz et al. 2001; López Moreno et al. 2002; Machin et al. 2005; López Moreno, 2006;). Por lo tanto, se trata de la relación existente entre el módulo absoluto y la superficie de la cuenca. Genera un valor dependiente del área y se expresa en $\mathrm{m}^{3} / \mathrm{s}^{-1} / \mathrm{km}^{-2}$ o l/s $\mathrm{s}^{-1} / \mathrm{km}^{-2}$ (Molinier et al. 1995; Tucci 2000).

Para el análisis de la evolución de los caudales se hizo inicialmente un análisis de la pendiente de la recta de regresión con el objetivo de intentar observar la evolución de los caudales en el tiempo. La regresión lineal simple comprende el intento de desarrollar una línea recta o ecuación matemática lineal que describe la reacción entre dos variables. La finalidad de una ecuación de regresión es estimar los valores de una variable con base en los valores conocidos de la otra. Una ecuación lineal tiene la forma:

\section{$y=a+b x$}

En la que a y b son valores que se determinan a partir de los datos de la muestra; $a$ indica la altura de la recta en $x=0, y b$ señala su pendiente. La variable $y$ es la que se habrá de predecir. $X$ es la variable predictora (Draper et al. 1998). 
Para intentar localizar posibles tendencias, su magnitud, así como el inicio de las mismas fueron utilizados los estadísticos Rho de Spearman (García Ruiz et al. 2001; Yue et al. 2001; López Moreno et al. 2002; López Moreno et al. 2004; Machin et al. 2005; López Moreno et al. 2008), Mann-Kendall (Groppo et al. 2001; Yue et al. 2001; Bouza Deaño et al. 2006; Pasquini et al. 2006; Hamed, 2008; McBean et al. 2008; Rose, 2009) y Mann-Kendall en su versión secuencial (Moraes et al. 1998; Li et al. 2007).

El estadístico Rho de Spearman, es una prueba no paramétrica que mide el coeficiente de correlación entre el rango de la variable y el tiempo. La correlación de Spearman, o por rangos, se basa en reemplazar los valores originales, de ambas variables, por números enteros positivos, comenzando del 1 en adelante, que correspondan a su ordenamiento de menor a mayor magnitud (rangos). Para ello, los valores reales de cada una de las variables son ordenados de menor a mayor, por separado y reemplazados por los rangos (Guilford et al. 1984). Este estadístico no es influenciado por valores extremos de $\mathrm{X}$ o de $\mathrm{Y}$, al revés de lo que ocurre con la correlación lineal o de Pearson. Por eso es muy adecuado usar Rho cuando $\mathrm{X}$ e $\mathrm{Y}$ son cuantitativas, pero no normales. El cálculo del coeficiente viene dado por:

$$
\rho=1-\frac{6 \sum d^{2}}{d d^{2} 1}
$$

donde $n=$ número de rangos y $d=$ es la diferencia entre los rangos. El estadístico varía de -1 a 1 , indicando el 0 la ausencia de correlación. Al mismo tiempo cuanto más cerca de los extremos (-1 ó 1) más significativa es la correlación, sea negativa o positiva (Mauricio Salinas, 2007). Este estadístico fue utilizado para análisis mensuales y anuales de los datos hidrológicos. En adelante se hará referencia al test Rho de Spearman usando como abreviatura la letra $\mathbf{R}$.

El estadístico Mann-Kendall también es un test no paramétrico y fue utilizado para evidenciar la existencia de posibles tendencias en las series de caudal. Según Mossmann et al. (2004), la potencia de este test es muy elevada, ya que indica que la probabilidad de rechazar la hipótesis nula cuando existe una tendencia es tan alta como la que daría un test paramétrico. Si bien al tratarse de un test no paramétrico no es preciso conocer a priori la distribución a la que obedecen los datos de la serie 
analizada. El test de Mann-Kendall, considera que, en la hipótesis de estabilidad de una serie temporal, la sucesión de valores ocurre de forma independiente y la distribución de probabilidad debe permanecer siempre la misma (Back, 2001).

La aplicación del test de Mann-Kendall para una serie de $n$ datos $\left(x_{1}, x_{2}, \ldots, x_{n}\right)$ independientes e idénticamente distribuidos supone la aceptación previa de la hipótesis nula $\mathrm{H}_{0}$, que supone la no existencia de tendencia (Bouza Deaño et al. 2006). Este test se define según la siguiente expresión (Sneyers, 1975; Libiseller, 2002; Salmi et al. 2002):

$S=\sum_{i<k} \operatorname{sgn}\left(y_{k j}-y_{i j}\right)$

donde:

$\operatorname{sgn}\left(y_{k j}-y_{i j}\right)=\left\{\begin{array}{c}1 \rightarrow\left(y_{k j}-y_{i j}\right)>0 \\ 0 \rightarrow\left(y_{k j}-y_{i j}\right)=0 \\ -1 \rightarrow\left(y_{k j}-y_{i j}\right)<0\end{array}\right.$

El test Mann-Kendall está basado en la diferencia entre sucesivos datos para el período estudiado. El estadístico $S$ es calculado con base en la suma de los signos (que puede ser $-1,0$ o 1 ). Un valor $Z$ es entonces calculado para $S$ para evaluar el nivel de significación de la tendencia. Un valor positivo o negativo de $Z$ indica una tendencia ascendente o descendente. Si la hipótesis nula $\mathrm{H}_{0}$ es cierta, la estadística $Z$ tendrá una distribución normal y permitirá la utilización de las tablas facilitadas por Gilbert (1987) para rechazar o confirmar esta hipótesis $H_{0}$ con un nivel de confianza $\alpha$. Esta será rechazada a favor de una tendencia ascendente o descendente si:

$|Z|>Z_{1-\frac{\alpha}{2}}$

Mann-Kendall nos proporciona un valor de significancia, pvalue. Si este es inferior a $0,05-0,1$ nos garantiza que la hipótesis adoptada tiene unas altas garantías de veracidad; a medida que este valor se hace más grande, las probabilidades van disminuyendo; hasta que llegando a un valor de 1, en que la probabilidad es nula (Bouza Deaño et al. 2006). El estadístico Mann-Kandall fue utilizado para análisis 
mensuales y anuales de los datos hidrológicos. En adelante, se utilizará la abreviatura M-K para hablar de este test.

El test Mann-Kendall en su versión secuencial, propuesto inicialmente por Sneyers (1975), es también un test no paramétrico, que puede demostrar el punto aproximado del inicio de las tendencias detectadas así como cambios abruptos en los datos (Ezber et al. 2007).

Considerando una serie temporal dada $Y_{i}$ de $N$ términos $(1 \geq i \geq N)$ a ser analizada, este test consiste en la sumatoria descrita en la ecuación:

(1) $\quad t_{n}=\sum_{i=1}^{N} m_{i}$

donde:

$t_{n}$ es la sumatoria, $m_{i}$ es el número de términos de la serie, relativo al valor $Y_{i}$, cuyos términos precedentes $(\mathrm{j}<\mathrm{i})$ son inferiores al mismo tiempo $\left(\mathrm{Y}_{\mathrm{j}}<\mathrm{Y}_{\mathrm{i}}\right)$ y $\mathrm{N}$ es el número de términos de la serie.

Para $\mathrm{N}$, bajo hipótesis nula $\mathrm{H}_{0}$ de ausencia de tendencia, $\mathrm{t}_{\mathrm{n}}$ presentará una distribución normal con media $E\left(t_{n}\right)$ y varianza $\operatorname{Var}\left(t_{n}\right)$, de acuerdo a lo expuesto en las ecuaciones siguientes:

$$
\begin{aligned}
& E\left(t_{n}\right)=N(N-1) / N \\
& \operatorname{Var}\left(t_{n}\right)=N(N-1)(2 N+5) / 72
\end{aligned}
$$

Testando la significación estadística de $t_{n}$ para la hipótesis nula utilizando un test bilateral, ella puede ser rechazada para grandes valores del estadístico $u\left(t_{n}\right)$ a través de:

$$
u\left(t_{n}\right)=\left(t_{n}-E\left(t_{n}\right)\right) /\left(\operatorname{var}\left(t_{n}\right)\right)^{1 / 2}
$$

El valor de la probabilidad $\alpha_{1}$ es calculada por medio de una tabla de la normal reducida, tal que $\alpha_{1}=\operatorname{prob}\left(|\mathrm{u}|>\left|\mathrm{u}\left(\mathrm{t}_{\mathrm{n}}\right)\right|\right)$. Siendo $\alpha_{0}$ el nivel de significación del test $\left(\alpha_{0}=0,05\right.$ e 0,1 para significante y ligeramente significante, respectivamente), la hipótesis nula es aceptada si $\alpha_{1}>\alpha_{0}$. Si la hipótesis nula es rechazada, significa la existencia de tendencia significativa, siendo el signo de la estadística $u\left(t_{n}\right)$ el que 
indica si la tendencia es positiva $\left(u\left(t_{n}\right)>0\right)$ o negativa $\left.u\left(t_{n}\right)<0\right)$. La última ecuación es calculada en el sentido directo de la serie, partiendo de $\mathrm{i}=1$ hasta $\mathrm{i}=\mathrm{N}$, generando la estadística $u\left(t_{n}\right)$, y en el sentido inverso de la serie, partiendo de $i=N$ hasta $i=1$, generando la estadística $u^{*}\left(t_{n}\right)$. La intersección de las dos curvas generadas representa el punto aproximado de un cambio abrupto en la media. Una tendencia es confirmada cuando la curva $u\left(t_{n}\right)$, que es el test aplicado en el sentido directo de la serie temporal, cruza los límites de confianza. Este intervalo viene dado por $-1,96<$ $\mathrm{u}\left(\mathrm{t}_{\mathrm{n}}\right)<1,96\left(1,96\right.$ correspondiendo a $\left.\alpha_{0}=0,05\right)$ (Back, 2001; Groppo et al. 2001; Piccinini Silveira et al. 2006). Este estadístico también fue empleado para análisis mensuales y anuales de los datos hidrológicos. En adelante, se utilizará la abreviatura M-Ks para hablar del test Mann-Kendall en su versión secuencial.

Fue hecha también la normalización de los datos del caudal obtenida a partir del promedio y la desviación típica (García Ruiz et al. 2001; López Moreno, 2006). Los valores normalizados son también una herramienta importante a la hora de hacer comparaciones sobre el comportamiento hidrológico de las cuatro cuencas.

Los valores normalizados se obtienen por:

$x_{i}^{\prime}=\left(x_{i}-z\right) / \sigma$

donde, $x_{i}^{\prime}$ es el valor normalizado del año $\mathrm{i} ; x_{i}$ es el valor original del año $\mathrm{i} ; z$ es el promedio de la serie; y $s$ la desviación estándar de la serie. Este cálculo fue empleado para análisis anuales de los datos hidrológicos.

\subsubsection{Análisis Climatológico}

Los análisis aplicados para la temperatura y para la precipitación son prácticamente los mismos (Fig. 04) y lo fundamental es la seguridad de una buena calidad de los datos. 


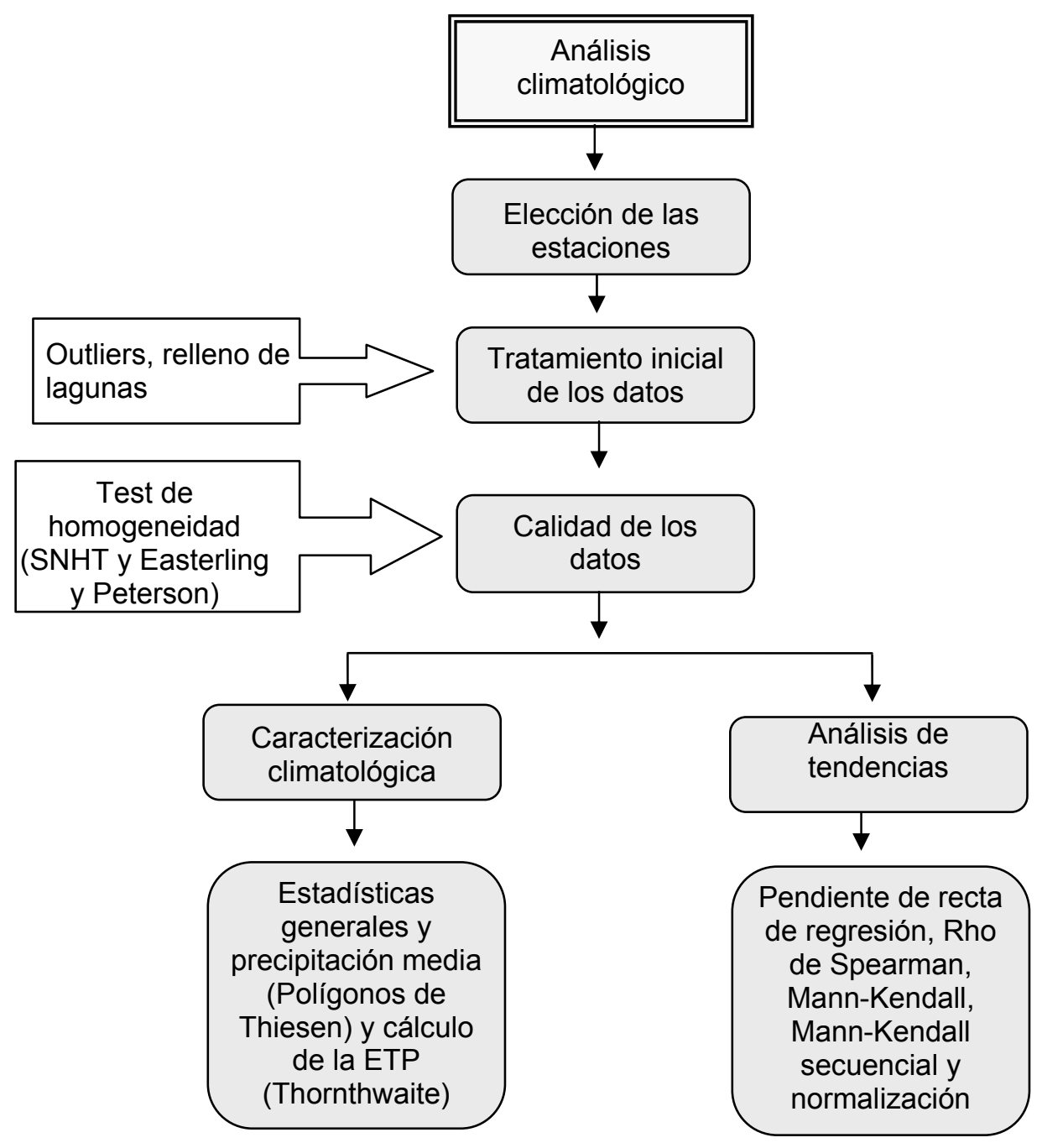

Figura 04 - Secuencia del trabajo desarrollado en el análisis climatológico.

Para la elección de las estaciones climatológicas lo primero a considerar fue la localización de las mismas. Se obtuvo de la Aemet una lista con informaciones generales (serie histórica, fecha de alta y de baja, coordenadas geográficas, etc) de todas las estaciones climatológicas de Castilla y León y de Castilla-la-Macha, donde están localizadas las cuencas de los ríos Cega, Porma, Tajo y Trabaque. A partir de esta lista fue hecha inicialmente la elección de las estaciones localizadas más cerca de las cuencas. Para la localización fueron utilizados también los mapas del Ministerio de Fomento (Dirección General del Instituto Geográfico Nacional) y del Servicio Geográfico del Ejército. El siguiente paso fue un análisis de los datos, buscando series con poca o ninguna laguna y con un mínimo de 30 años de datos. Este criterio de tiempo a ser analizado está de acuerdo con las orientaciones de la Organización Meteorológica Mundial (OMM), según la cual, para el estudio de la evolución de la precipitación y de la temperatura hay que tener en cuenta como mínimo las últimas tres décadas del siglo XX (1971-2000). Al final de este proceso inicial de selección, las 
estaciones elegidas son las que mejor atendieron a todos estos requisitos. Lamentablemente, en estas zonas, no hay disponibilidad de muchas estaciones lo que ha sido un factor limitante para la elección del número de estaciones.

Para los estudios climáticos se hicieron también las agregaciones de días a meses y meses a años y fueron utilizados los mismos criterios anteriormente descritos para los datos de caudal. De acuerdo con lo mencionado anteriormente fueron utilizadas 5 estaciones pluviométricas para el análisis de la evolución de la precipitación en cada una de las cuencas. Las series históricas eran muy variadas y para hacer la selección de los años utilizados se realizó un análisis previo con el objetivo de elegir los períodos con pocas o ninguna lagunas y con la máxima calidad posible de datos.

Una información que debería ser siempre utilizada al analizar datos meteorológicos son los llamados metadatos. Estos son informaciones históricas de la estación y de los procesos de medición, tales como, cambios en la localización de la estación, en los instrumentos utilizados, problemas con estos instrumentos, nuevas formulas utilizadas para los cálculos, cambios en el ambiente del entorno, etc. (Peterson et al. 1998; Colotti et al. 2001). Aunque sepamos su importancia, en este estudio, los metadatos no fueron utilizados pues no fueron suministrados por la Aemet.

El control de calidad de los datos ha empezado con la identificación de outliers que son valores extremos en el conjunto de los datos y la detección de falsos ceros (Saladié et al. 2002).

El siguiente paso fue hacer el relleno de alguna posible laguna, que fue hecha a partir de una estimación de valores mediante regresión lineal con las estaciones mejor correlacionadas, con una correlación mínima de $r=0,8$ (García-Barrón et al. 2001; González Hidalgo et al. 2002; López Moreno, 2006; Mirón Pérez et al. 2006; Luo et al. In press). En los casos en que la correlaciones no superaron el umbral establecido bien como en el caso de los datos de temperatura que provienen de una única estación, se ha efectuado el relleno con el promedio de la serie (Peterson et al. 1998; Rodríguez et al. 1999).

La siguiente fase en el proceso de evaluación de la calidad de los datos es el análisis de su homogeneidad. De acuerdo con González Hidalgo et al. (2002) en climatología se entiende que una serie de datos temporales es homogénea cuando sus variaciones provienen exclusivamente de la dinámica natural y no han sido originadas por la 
intervención humana. Una serie de datos climáticos no homogénea presupone que cualquier resultado que obtengamos de su análisis no será fiable, por ello el primer paso necesario para analizar las bases de datos reconstruidas debe consistir en estimar su calidad, su homogeneidad y su estabilidad. La comprobación de la homogeneidad de las series se ha realizado por medio de la prueba SNHT de Alexanderson (Alexandersson y Moberg, 1997) que es exhaustivamente utilizada por la comunidad científica (García-Barrón et al. 2001; González Rouco et al. 2001; González Hidalgo et al. 2002; Saladié et al. 2002; Guijarro, 2004; López Moreno, 2006; Pasquini et al. 2006; López Moreno et al. 2007; Staudt et al. 2007). Como contraste fue empleada la prueba de Easterling \& Peterson (Easterling y Peterson, 1995) también utilizada en muchos estudios de climatología (Easterling y Peterson, 1995; Alexanderson y Moberg, 1997; Peterson et al. 1998), sin considerar serie de referencia. La determinación de no emplear serie de referencia surgió del hecho de la falta de criterios objetivos para asegurar que dicha serie de referencia fuese a su vez homogénea (Alexanderson y Moberg, 1997; Peterson et al. 1998; González Hidalgo et al. 2002; Pasquini et al. 2006). Los test fueron aplicados utilizando el software Anclim (Stepanek, 2003). Esta plataforma permite la aplicación de dichas metodologías y posibles correcciones que se decidan hacer y viene siendo ampliamente utilizado (González Hidalgo et al. 2002; Stepanek, 2003, 2004; López Moreno, 2006; MartinVide et al. 2006; López Moreno et al. 2007; Vicente Serrano et al. 2007).

El software Anclim comprueba la homogeneidad e informa las discrepancias encontradas. A partir de este momento es importante proceder a un análisis de tales discrepancias con el objetivo de establecer hasta que punto constituyen inhomogeneidades o no (García-Barrón et al. 2001). Solamente se acepta la ruptura cuando ambas pruebas coinciden en señalarla en el mismo año. Evaluada la existencia de una ruptura significativa, la corrección de la serie se realiza según el valor de la diferencia de medias entre los dos períodos definidos por el año donde se produce la ruptura, aplicada al conjunto de años anteriores a ésta. La asunción fundamental es que los años finales de la serie se prolongarán eventualmente al futuro y en principio se debe aceptar la bondad de sus registros (González Hidalgo et al. 2002).

Con las series históricas bien estructuradas se realizaron las estadísticas básicas con obtención de media, mediana, desviación típica, mínimos, máximos y coeficientes de variación para todas las estaciones. Para el estudio de la precipitación fueron utilizados períodos distintos al analizar cada estación individualmente, teniendo en 
cuenta la mejor calidad de los datos. Al hacer los análisis de cada estación fueron utilizados el máximo posible de datos y con la máxima calidad. No obstante, al analizar toda la cuenca fue utilizado un período común de 30 años (1977-2006). Por otro lado en el caso de la temperatura fue utilizado un mismo período para todas las cuencas de 38 años de datos (1969-2006).

Para la evaluación de la precipitación media en las cuencas se ha utilizado el método de los polígonos de Thiessen también conocidos como Polígonos de Voronoi o Teselación de Dirichlet (Salas Guillermo et al. 1985; Pizarro et al. 2003; Cuadrat Prats et al. 2004; Best et al. 2005; Gomig et al. 2007; Machado et al. 2007; Reis de Andrade et al. 2008). Este es un método de interpolación bastante sencillo pero eficaz, basado en la distancia euclidiana y es indicado cuando no hay una distribución uniforme de las estaciones. Además de la información pluviométrica, requiere para su ejecución sólo de la ubicación espacial de las estaciones. A cada una se le asigna una superficie, la cual es obtenida representando las estaciones en un plano y uniéndolas a través de rectas. A estas rectas posteriormente se les trazan sus mediatrices hasta que se intersectan entre sí (Fig. 05).

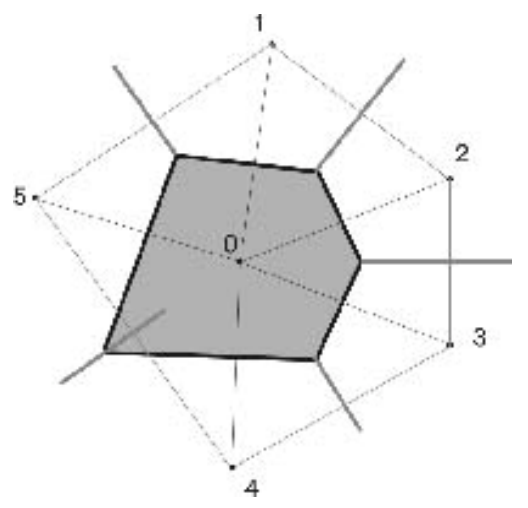

Figura 05 - Esquema clásico de los Polígonos de Thiessen.

Con los límites del área en estudio y los que definen las mediatrices se obtiene la superficie de influencia para cada estación (Fig. 06, 07, 08 y 09). A cada una es atribuido un peso proporcional al área de influencia que es dado por la división de esta por el área total de la cuenca. Con estos pesos se determina la precipitación media utilizando, por tanto, la media ponderada. Son consideradas las estaciones incluidas 
en la cuenca así como las localizadas en el entorno y que ejercen influencia en el área de la misma (Pizarro et al. 2003; Gomig et al. 2007).

a)

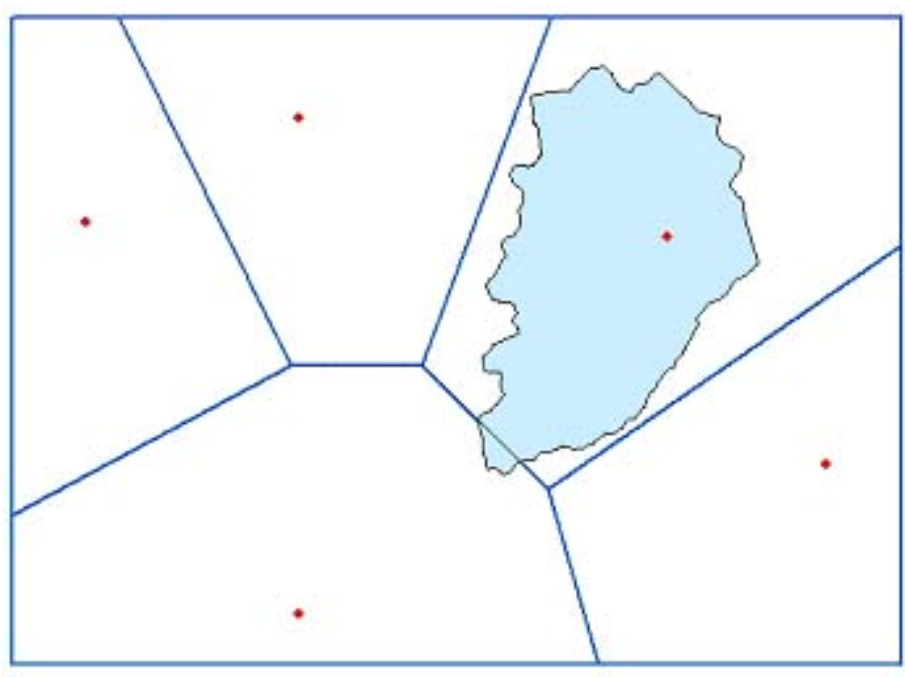

Figura 06 - Polígonos de Thiessen - Cuenca del río Cega.

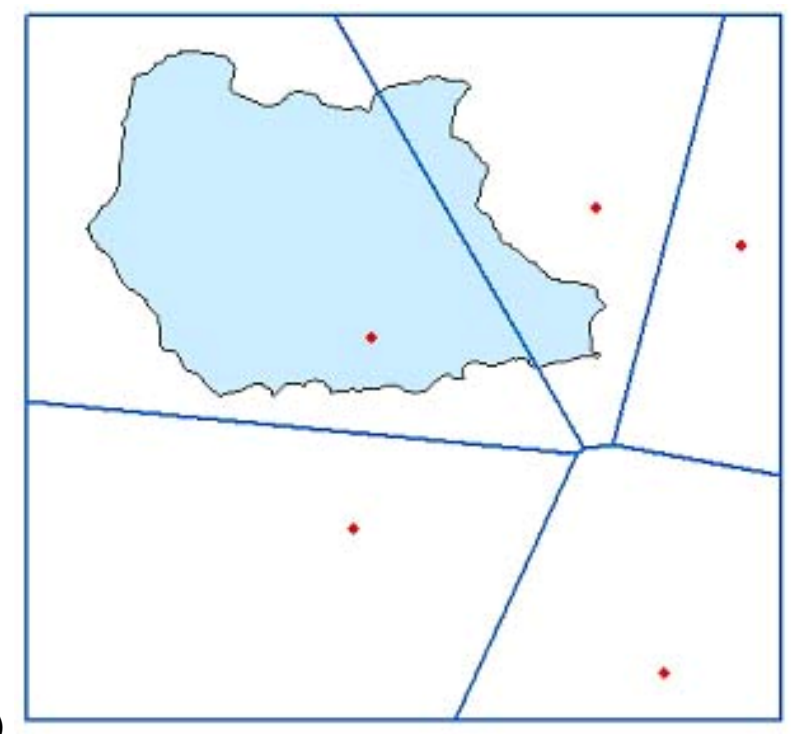

Figura 07 - Polígonos de Thiessen - Cuenca del río Porma.

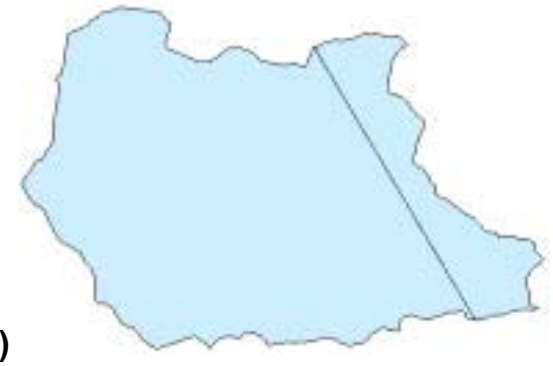

b)

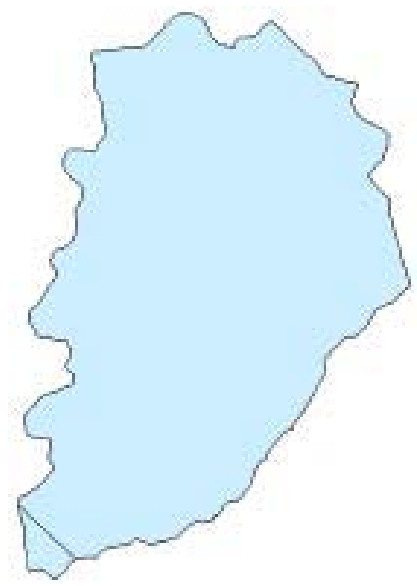

b) 

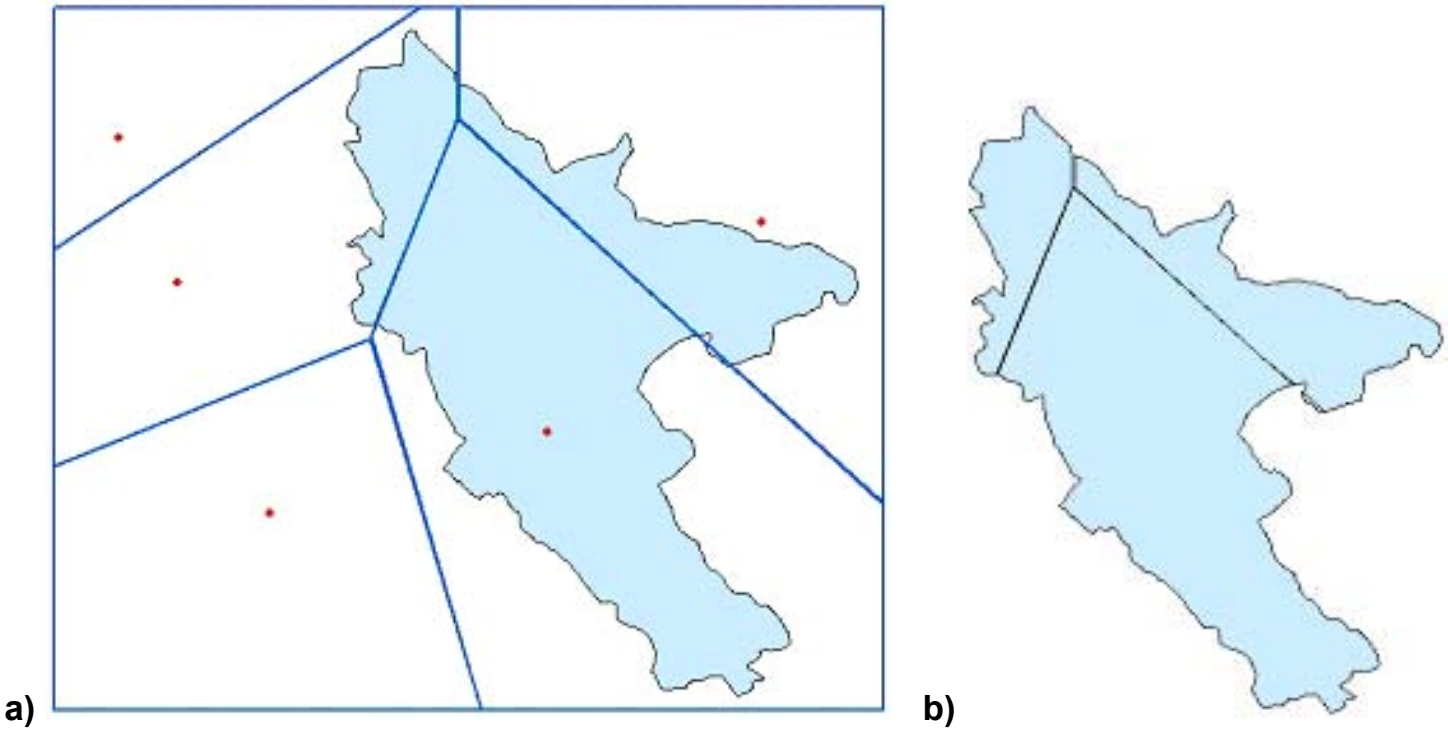

Figura 08 - Polígonos de Thiessen - Cuenca del río Tajo.

a)
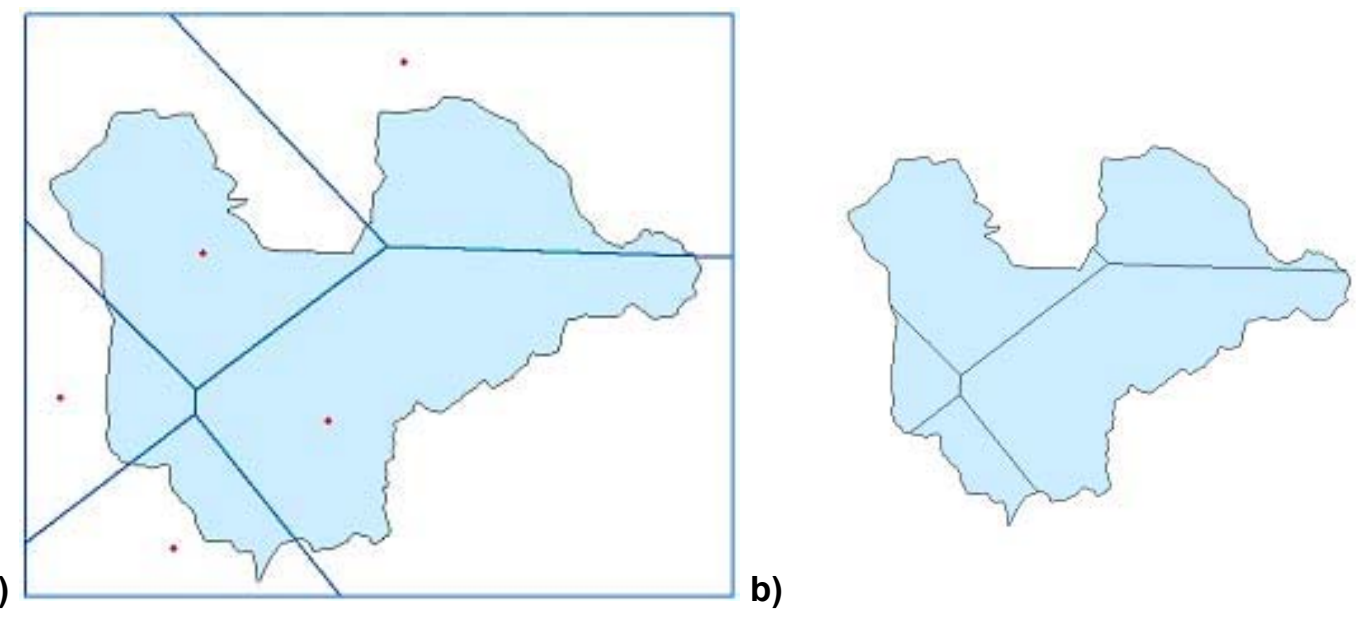

Figura 09 - Polígonos de Thiessen - Cuenca del río Trabaque.

Para apoyar la caracterización climática general de la cuenca fue realizado el cálculo de la evapotranspiración potencial (ETP). La ETP es un parámetro hidrológico que depende de muchos y complejos factores que influencian la evaporación y la transpiración. En la ETP, se considera tanto la evaporación y transpiración que se produce desde las plantas, como la evaporación que se manifiesta desde el suelo. Para su cálculo muchos son los métodos que utilizan la temperatura del aire como variable de entrada. Entre estos métodos se puede destacar los de Thornthwaite, Blaney-Criddle, Camargo, Linacre e Hargreaves \& Samani (Stone \& Silveira, 1995; Pereira et al. 1997; Samani, 2000). En esta investigación se ha optado por el método de Thornthwaite que es utilizado frecuentemente en todo el mundo científico (Palmer et al. 1958; Paes de Camargo et al. 2000; Fonseca Conceição, 2003; Ngatcha 
Benjamin et al. 2007). Este método fue desarrollado con base en datos de evapotranspiración medidos y datos de temperatura media mensual, para días con 12 horas de luz solar y mes con 30 días (Thornthwaite, 1948). Se calcula de la siguiente manera:

$$
\mathrm{ETP}=F_{c} \cdot 16 \cdot\left(10 \cdot \frac{T}{\mathrm{I}}\right)^{a}
$$

Donde,

ETP es evapotranspitación potencial $(\mathrm{mm} / \mathrm{mes}), F_{c}$ es el factor de corrección en función de la latitud y del mes del año, T es la temperatura media mensual $\left({ }^{\circ} \mathrm{C}\right)$, a es la función del índice de calor anual (I), que simplificado equivale aproximadamente a $0,016^{0,5}=6,75 \cdot 10-7 \cdot \mathrm{I} 3-7,71 \cdot 10-5 \cdot 12+0,01791 \cdot \mathrm{I}+0,492(\mathrm{~mm} / \mathrm{mês})$ e I es el índice anual de calor, correspondente a la suma de doce índices mensuales:

$I=\sum_{i=1}^{12}\left(\frac{T_{i}}{5}\right)^{1,514}$

Debido a la complejidad de esta variable en el balance hídrico de una cuenca, y teniendo en cuenta que no se tienen datos suficientes para cálculos más exhaustivos, se ha utilizado la misma solamente en la caracterización climática general de las zonas de estudio.

Para el análisis de la evolución de la precipitación y de le temperatura se hizo inicialmente un análisis de la pendiente de la recta de regresión para todas las estaciones (Colotti et al. 2001; Mossmann et al. 2004; Dario Maldonado et al. 2005). Además fue utilizado también el coeficiente de correlación Rho de Spearman (Mccabe Jr et al. 1997; Labajo y Piorno, 2001; Del Río et al. 2005; De Juana et al. 2005; López Moreno et al. 2007) y el estadístico Mann-Kendall (Esteban-Parra et al. 1998; Hanssen-Bauer et al. 2000; Chazarra Bernabé et al. 2002; Brunetti et al. 2004; Del Río et al. 2005; Hanssen-Bauer, 2005; Partal et al. 2006; Staudt et al. 2007; McBean et al. 2008; Rose, 2009; Luo et al. In press) para comprobar la significación estadística de las tendencias. Por último fue empleado el test Mann-Kendall en su versión secuencial (Back, 2001; Groppo et al. 2001; Bednorz et al. 2004; Partal et al. 2006; Piccinini Silveira et al. 2006; Smadi et al. 2006; Ezber et al. 2007; Li et al. 2007; Luo et al. In press) para intentar localizar los años en que empezaron las tendencias. 
Finalmente, para la evolución conjunta de las variables climatológicas en las cuatro cuencas se ha utilizado la normalización de los datos a través del promedio y de la desviación típica (Dai et al. 1997; Piervitali et al. 1998; Labajo y Piorno, 2001; Saladié et al. 2002; Brunetti et al. 2004).

\subsubsection{Análisis de los cambios en los usos y en la cobertura del suelo}

\subsubsection{Fuentes de datos}

Para desarrollar el estudio de los cambios en los usos y en la cobertura del suelo se ha utilizado como metodología el análisis multitemporal (Pizarro et al. 2005), es decir, esta investigación cuenta con más de una fecha de observación, permitiendo de esta manera un estudio de la evolución de la variable. Según Pascual Aguilar (2002), los cambios de usos del suelo en el tiempo y en el espacio marcan paulatinas transformaciones del paisaje. La naturaleza continua del proceso de cambio exige, a la hora de abordar un estudio evolutivo de las transformaciones de la cubierta superficial, el suficiente número de observacíones que describan de manera eficiente los cambios, tanto en su dimensión temporal como en su expresión superficial. Sin embargo, debido al escaso registro histórico de datos, este tipo de estudios se centran en algunas pocas décadas.

La gran mayoría de los estudios multitemporales de los cambios en los usos y en la cobertura del suelo a nivel mundial y nacional utilizan solamente dos fechas (Briceño, 2003; González Gonzáles, 2004; Angnes Teresa, 2005; Silva Brito et al. 2005; Dupuy Rada et al. 2006; Henríquez et al. 2006; Lasanta y Vicente-Serrano, 2007; Muschong, 2007; Sousa Silva et al. 2007; Arnáez et al. 2008; Márquez González, 2008). No obstante es posible encontrar también muchas investigaciones que utilizan tres (Ruescas Orient, 2001; François Mas et al. 2003; Almeida Matos et al. 2005; Pizarro et al. 2005; Boletta et al. 2006), cuatro (Lasanta et al. 2000; Kleinpaul et al. 2005) o incluso cinco fechas (Pascual Aguilar, 2002).

Inicialmente se evaluó la potencialidad de las fuentes de datos del estudio multitemporal. Es tradicional el uso de las fotografías aéreas para análisis 
medioambiental. Durante las décadas de 1940 y 50 se trazaron mapas de gran escala de países completos, por ejemplo de muchas de las colonias, especialmente de África, con ayuda de la aerofotografía con película pancromática en blanco y negro. La fotografía aérea permite obtener una visión aérea del lugar y dependiendo de su escala, puede revelar mayores o menores detalles de la superficie terrestre que cubre. Desde el punto de vista técnico, un fotograma es un registro de percepción remota pasivo, es decir, que detecta la energía natural, ya sea emitida o reflejada. Esta radiación es recogida en la película con diferentes intensidades de gris. La utilización de esta fuente de datos resulta de gran efectividad en los estudios ambientales, por permitir la posibilidad de observar los rasgos de la superficie terrestre y los impactos que en ella deja la actividad del hombre en diferentes épocas. Desde el inicio de la investigación esta fuente de datos ha sido considerada como una opción idónea.

Desde finales de los años cincuenta se ha registrado una enorme actividad en el campo de la teledetección, a partir del lanzamiento del Sputnik 1 en 1957. En 1959, el Explorer 6 transmitió las primeras imágenes de la tierra, y en 1960 se lanzó el primer satélite meteorológico, el TIROS-1. El siguiente avance importante para la teledetección ocurrió en 1972, con el lanzamiento del satélite de tecnología de los recursos terrestres (ERTS-1, rebautizado más tarde como Landsat 1). Fue el primer satélite diseñado para obtener una cobertura global uniforme a largo plazo, y tenía la capacidad de transmitir los datos captados para el levantamiento de mapas. A partir del Landsat 1 ha habido una serie de lanzamientos de satélites de observación de la tierra, primero por los Estados Unidos y la extinta URSS, y más recientemente por otros países. Algunos de estos programas aún están funcionando, mientras que otros se han suspendido.

Las imágenes que mejor podrían responder a los objetivos del presente trabajo son las de los programas Landsat, Spot (Satellite Probatoire pour l'Observation de la Terre) y NOAA - AVHRR (Tabla 08). En esta investigación se ha optado por las escenas del programa Landsat como fuentes de datos, entre otras razones, porque inicia sus observacíones en el año de 1972 siendo por tanto el que tiene imágenes más antiguas. 
Tabla 08. Características generales de los programas Landsat, SPOT y NOAA-AVHRR.

\begin{tabular}{|c|c|c|c|}
\hline Programa & Inicio & $\begin{array}{l}\text { Institución } \\
\text { responsable }\end{array}$ & Principales características \\
\hline $\begin{array}{l}\text { LANDSAT (Land } \\
\text { Remote Sensing } \\
\text { Satellite ) }\end{array}$ & $23 / 7 / 1972$ & NASA & $\begin{array}{l}\text { Iniciado en finales de la década de } \\
60, \text { a partir de un proyecto } \\
\text { desarrollado por la Agencia Espacial } \\
\text { Americana dedicado exclusivamente } \\
\text { a la observación de los recursos } \\
\text { naturales terrestres. Actualmente } \\
\text { están operativos LANDSAT-5 y } 7 . \\
\text { Posee alta resolución espectral. } \\
\text { (http://landsat.gsfc.nasa.gov) }\end{array}$ \\
\hline $\begin{array}{l}\text { SPOT (Système } \\
\text { Probatoire } \\
\text { d'Observation } \\
\text { de la Terre) }\end{array}$ & $22 / 02 / 1986$ & $\begin{array}{c}\text { Centre National } \\
\text { d'Etudes Spatiales - } \\
\text { CNES }\end{array}$ & $\begin{array}{l}\text { La plataforma del SPOT está en } \\
\text { órbita con tres satélites }(2,4 \text { y } 5) \text {, lo } \\
\text { que posibilita acceso a cualquier } \\
\text { punto de la tierra en menos de } 24 \\
\text { horas. Las revisitas son en } \\
\text { intervalos de } 3 \text { a } 5 \text { días. La misión } \\
\text { inauguró la posibilidad de } \\
\text { adquisición de imágenes orbítales } \\
\text { tridimensionales gracias a su } \\
\text { capacidad de visión lateral de }+/- \\
27^{\circ} \text { off-nadir (http://www.spot.com) }\end{array}$ \\
\hline $\begin{array}{l}\text { NOAA (National } \\
\text { Oceanic and } \\
\text { Atmospheric } \\
\text { Administration) }\end{array}$ & $14 / 05 / 1991$ & $\begin{array}{c}\text { National } \\
\text { Environmental } \\
\text { Satellite Data and } \\
\text { Information Service } \\
\text { (NESDIS) y (NASA) }\end{array}$ & $\begin{array}{l}\text { La escena NOAA recubre áreas de } \\
\text { dimensiones continentales. El } \\
\text { satélite NOAA posee varios } \\
\text { sensores: AMSU-A, AMSU-B, } \\
\text { AVHRR/3, HIRS/3, SBUV/2, OCI y } \\
\text { adquiere datos de todo el planeta. } \\
\text { (www.noaa.gov) }\end{array}$ \\
\hline
\end{tabular}

Las fotografías aéreas y las imágenes Landsat son bastante utilizadas en diversas áreas de investigación y sobre todo en aquéllas que centran la investigación sobre el territorio. Algunos estudios utilizan únicamente imágenes de satélite (Bocco et al. 2001; Briceño, 2003; Berlanga Robles et al. 2007), otros solamente las fotografías aéreas (López González et al. 2002; Peña Llopis et al. 2005; Henke de Oliveira, 2009) y muchos utilizan ambos orígenes de datos (Borges et al. 1993; Harris et al. 1995; Pozo Ríos et al. 1998).

Como en cualquier tipo de trabajo, ambas fuentes presentan una serie de ventajas y limitaciones (Tabla 09) que deben ser tenidas en cuenta a la hora de su elección. 
Tabla 09. Fuentes de información utilizadas. Ventajas y limitaciones.

\begin{tabular}{|c|c|c|c|}
\hline \multicolumn{2}{|c|}{ Fotografías Aéreas } & \multicolumn{2}{|c|}{ Imágenes de satélite } \\
\hline Ventajas & Limitaciones & Ventajas & Limitaciones \\
\hline $\begin{array}{l}\text { - Carácter } \\
\text { "histórico" (fotos } \\
\text { de los años 1956- } \\
\text { 1957); } \\
\text { - Resolución } \\
\text { espacial alta; } \\
\text { Cobertura espacial } \\
\text { continua de toda } \\
\text { España; } \\
\text { - Permite análisis } \\
\text { más detallados y } \\
\text { más facilidad a la } \\
\text { hora de } \\
\text { identificación de } \\
\text { las categorías de } \\
\text { clasificación. }\end{array}$ & $\begin{array}{l}\text { - Proceso costoso } \\
\text { en tiempo; } \\
\text { - Subjetividad en la } \\
\text { fotointerpretación; } \\
\text { Formato papel } \\
\text { (calidad final } \\
\text { dependiente del } \\
\text { escaneo); } \\
\text { - Pobre resolución } \\
\text { espectral; } \\
\text { - Dificultad para } \\
\text { componer una } \\
\text { zona amplia; } \\
\text { - Falta de } \\
\text { repetición } \\
\text { periódica. }\end{array}$ & $\begin{array}{l}\text { - Cobertura de amplias } \\
\text { áreas; } \\
\text { - Resolución temporal más } \\
\text { elevada (dependiente de la } \\
\text { del satélite); } \\
\text { - Posibilidad de tratamiento } \\
\text { digital automático para la } \\
\text { extracción de parámetros } \\
\text { físicos de la cubierta } \\
\text { vegetal; } \\
\text { - Extracción automática de } \\
\text { estadísticas; } \\
\text { - Mayor resolución } \\
\text { espectral (bandas en } \\
\text { diferentes longitudes de } \\
\text { onda) lo que permite la } \\
\text { combinación entre ellas. }\end{array}$ & $\begin{array}{l}\text { - Resolución espacial } \\
\text { baja dependiente de la } \\
\text { del satélite; } \\
\text { - Elevado coste; } \\
\text { - Necesidad de } \\
\text { entrenamiento previo } \\
\text { en técnicas de } \\
\text { teledetección; } \\
\text { - Menos nivel de detalle } \\
\text { en la detección de las } \\
\text { categorías de } \\
\text { clasificación; } \\
\text { - Calidad muy } \\
\text { dependiente de la } \\
\text { cobertura nubosa. }\end{array}$ \\
\hline
\end{tabular}

Son evidentes también las diferencias entre ambas fuentes de datos (Tabla 10), lo que exige un análisis individual y riguroso previo de cada fecha y comparar al final los resultados generales.

Tabla 10. Comparación de las fotografías aéreas y escenas Landsat utilizadas en este estudio.

\begin{tabular}{|l|l|l|}
\hline \multicolumn{1}{|c|}{ Características } & \multicolumn{1}{|c|}{ Fotografías Aéreas } & \multicolumn{1}{c|}{ Escenas Landsat } \\
\hline Superficie comprendida & $\begin{array}{l}\text { Cada foto mide } \\
\text { aproximadamente } 7 \mathrm{~km}\end{array}$ & $\begin{array}{l}\text { Cada escena mide } \\
\text { aproximadamente } 180 \mathrm{~km}\end{array}$ \\
\hline Resolución & Píxel mide $2,7 \mathrm{~m}$ & Píxel mide $30 \mathrm{~m}$ \\
\hline $\mathbf{N}^{\circ}$ de datos por cuenca & $\begin{array}{l}\text { Cega: } 52 \\
\text { Porma: } 31 \\
\text { Tajo: } 92 \\
\text { Trabaque: } 74\end{array}$ & 1 escena para cada cuenca \\
\hline Tratamiento & $\begin{array}{l}\text { Analógico inicialmente, } \\
\text { seguido de fotointerpretación } \\
\text { y digitalización }\end{array}$ & Digital \\
\hline \hline
\end{tabular}

De la comparación de ambas fuentes de datos (Fig. 10) es posible identificar la diferencia con relación a la resolución de las imágenes y de las fotografías aéreas. En la 1(a) se ve una fotografía aérea de un pequeño tramo del río Cega y en 1(b) se ve la misma zona recortada de una escena Landsat. 


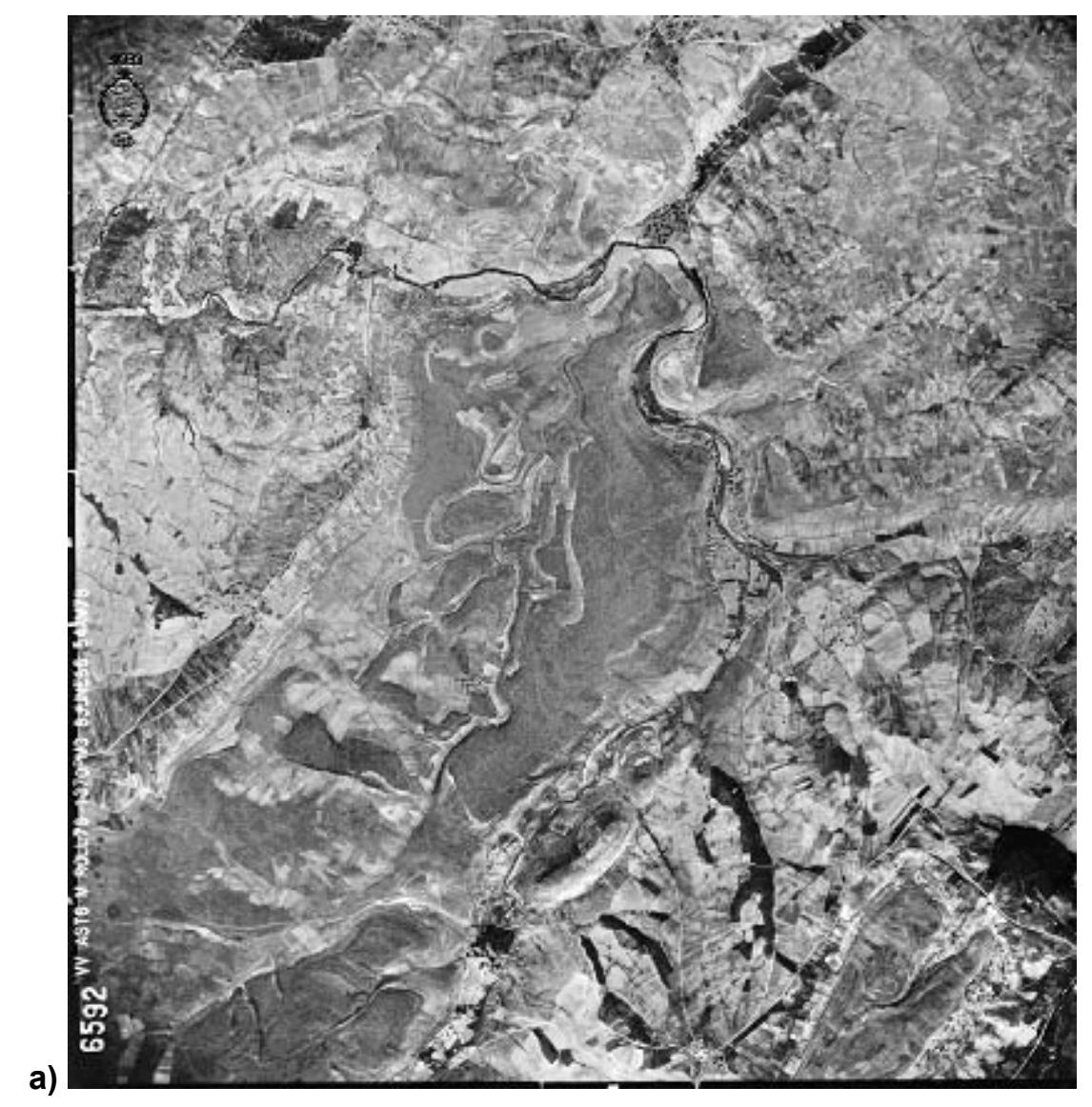

a)

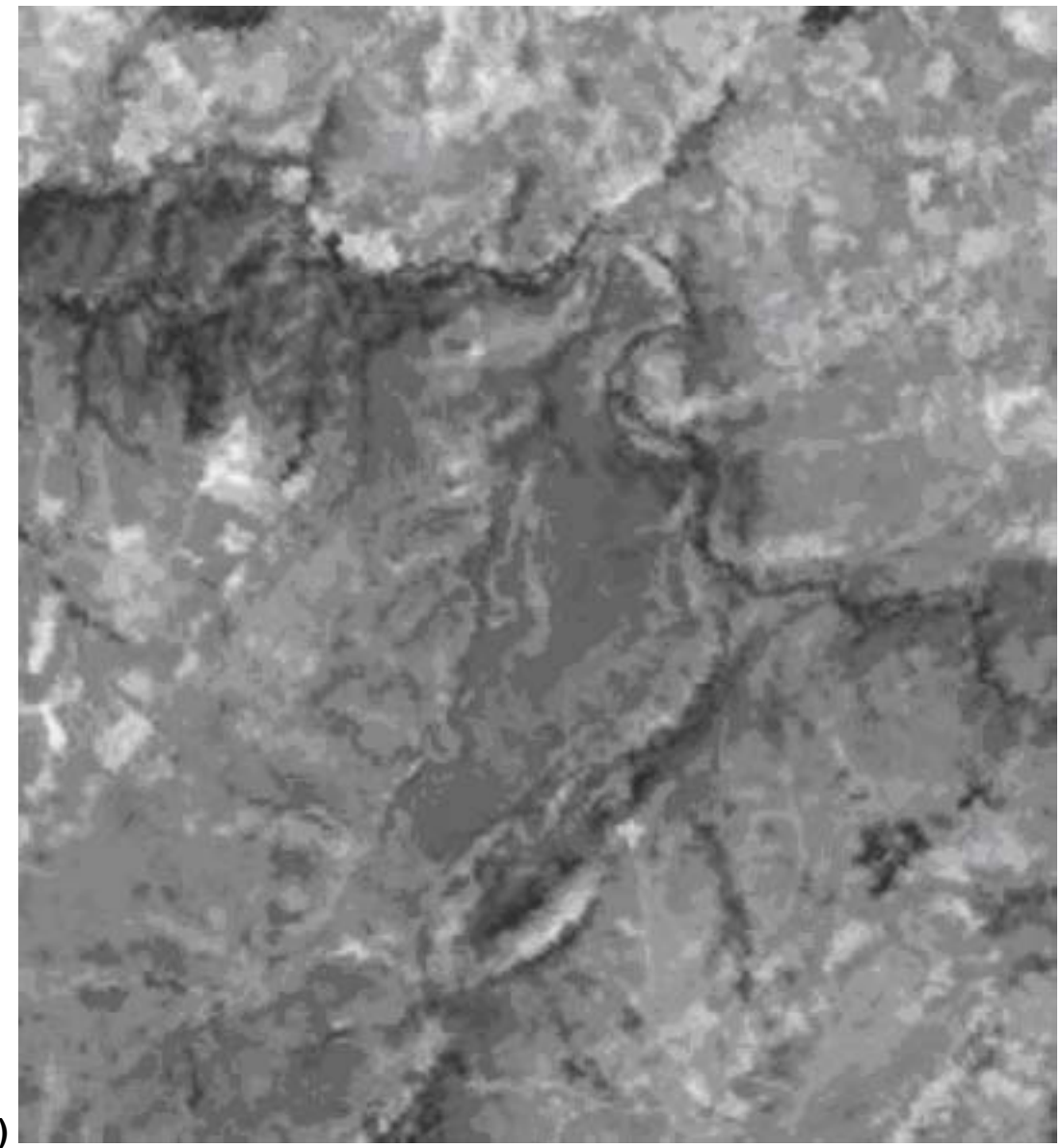

Figura 10 - Fotografía aérea $n^{\circ} 6592$ de 1956 (a) e imagen de la misma zona recortada de la escena Landsat 201/031 de 15/07/89 (b). 


\subsubsection{Definición de fechas}

Kleinpaul et al. (2005) afirman que la elección de las fechas de estudio es un problema frecuente y asociado con los datos históricos (multitemporales) de imágenes remotas para la detección de cambios ya que casi nunca son de la misma fecha (día/mes). Como el objetivo principal del apartado es estudiar la evolución de la variable usos y coberturas del suelo en el tiempo, se ha decidido fijar la fecha de inicio lo más antigua posible. Partiendo de esta premisa ha sido elegido el vuelo aéreo americano de 1956-57 como el marco inicial de esta investigación. Esta elección se justifica sobre todo debido a su carácter histórico, a la calidad de sus imágenes y por coincidir con el momento en que empezaron las grandes transformaciones relacionadas con el abandono del medio rural y el aumento de la concentración de las poblaciones en las grandes ciudades.

A partir de esa primera fecha se busca una distribución temporal lo más continua posible, es decir, fechas distribuidas en períodos más o menos parecidos hasta llegar al momento actual. De esta manera sería posible tener una base comparativa para analizar su evolución. Con respecto a la fotografía aérea, en España existen solamente cuatro vuelos generales, dos en convenio con el Ejército Americano y denominados Serie A (años 1946-1947) y Serie B (años 1956-1957) y otros correspondientes a los años 1967-1968 (Serie C) y 1981-1984, estos últimos del Instituto Geográfico Nacional (IGN). Esta falta de repetición periódica ha llevado a la elección de imágenes de satélite como otra fuente de información ya que éstas tienen más resolución temporal.

No hay duda de que el gran problema encontrado, sobre todo por tratarse de cuatro áreas en zonas diferentes, fue fijar una fecha exacta para el estudio. En este estudio se ha seleccionado la utilización del vuelo americano de 1956-57 como primera fecha y en las demás se ha utilizado las escenas Landsat disponibles (Tabla 11). 
Tabla 11. Fuentes de datos utilizadas para análisis de las cuencas de los ríos Cega, Porma, Tajo y Trabaque.

\begin{tabular}{|l|l|c|}
\hline \hline \multicolumn{1}{|c|}{ Cuenca } & \multicolumn{1}{|c|}{ Fuente de datos } & Fecha \\
\hline \hline \multirow{4}{*}{ Cega } & Vuelo americano & $1956-1957$ \\
\cline { 2 - 3 } & Landsat MSS & $03 / 05 / 1976$ \\
\cline { 2 - 3 } & Landsat 5 TM & $25 / 03 / 1989$ \\
\cline { 2 - 3 } & Landsat 7 ETM+ & $22 / 04 / 2002$ \\
\hline \multirow{4}{*}{ Porma } & Vuelo americano & $1956-1957$ \\
\cline { 2 - 3 } & Landsat MSS & $24 / 08 / 1977$ \\
\cline { 2 - 3 } & Landsat 5 TM & $13 / 08 / 1991$ \\
\cline { 2 - 3 } & Landsat 7 ETM+ & $29 / 06 / 2001$ \\
\hline \multirow{4}{*}{ Trabaque } & Vuelo americano & $1956-1957$ \\
\cline { 2 - 3 } & Landsat MSS & $06 / 06 / 1976$ \\
\cline { 2 - 3 } & Landsat 5 TM & $14 / 04 / 1987$ \\
\cline { 2 - 3 } & Landsat 7 ETM+ & $30 / 05 / 2001$ \\
\cline { 2 - 3 } & Vuelo americano & $1956-1957$ \\
\cline { 2 - 3 } & Landsat MSS & $06 / 06 / 1976$ \\
\cline { 2 - 3 } & Landsat 5 TM & $14 / 04 / 1987$ \\
\cline { 2 - 3 } & Landsat 7 ETM+ & $30 / 05 / 2001$ \\
\hline \hline
\end{tabular}

\subsubsection{Definición de las categorías de clasificación}

Determinadas las fuentes de información fue necesario definir las clases que serían analizadas en este estudio. El primer criterio para esta definición y para elegir la metodología más adecuada fue analizar claramente los objetivos que se persiguen. Se busca un análisis de los cambios en los usos y en la cobertura del suelo a grandes rasgos y no con alto nivel de detalle. Cabe resaltar también que por tratarse de fuentes de datos que tienen escalas espaciales muy diferentes se hace necesaria la elección de categorías de clasificación que puedan al mismo tiempo responder a la resolución de las fotografías aéreas y de las imágenes de satélite y simultáneamente puedan satisfacer el estudio de la evolución de los usos y coberturas.

Las categorías establecidas en este estudio se definieron siguiendo la metodología sugerida por Anderson et al. (1976), que desarrollaron un sistema de clasificación para el U. S. Geological Survey y que es ampliamente utilizado por investigadores de todo el mundo desde su concepción (M.O.P.T., 1992; Whistler et al. 1995; Fritsch et al. 1998; Johnson et al. 2002; Briceño, 2003; O’Hara et al. 2003; Goetz et al. 2004; Bektas et al. 2005; Di Gregorio, 2005; Güler et al. 2006; Mennis, 2006; Aaviksoo et al. 2008; Lang et al. 2008). 
El trabajo de Anderson et al. (1976) ha servido también de base para la leyenda diseñada para el programa CORINE Land Cover, que tiene como objetivo fundamental la creación de una base de datos cartográfica europea a escala 1:100.000 sobre la cobertura y/o uso del territorio.

El sistema de Anderson et al. (1976), propone cuatros niveles de clasificación que deben ser utilizados para diferentes orígenes de datos (Tabla 12):

Tabla 12. Niveles de clasificación propuesto por Anderson et al., 1976.

\begin{tabular}{|c|l|}
\hline \hline Nivel & Características típicas de los datos \\
\hline \hline I & Tipo de datos Landsat \\
\hline II & $\begin{array}{l}\text { Datos de elevada altitud } 40.000 \text { pies }(12.400 \mathrm{~m}) \text { o por encima (escala menor de } \\
1: 80.000)\end{array}$ \\
\hline III & $\begin{array}{l}\text { Datos de media altitud, tomados entre } 10.000 \text { y } 40.000 \text { pies }(3.100 \text { y } 12.400 \mathrm{~m}) \\
\text { (escala de 1:20.000 hasta } 1: 80.000)\end{array}$ \\
\hline IV & $\begin{array}{l}\text { Datos de baja altitud, tomados por debajo de } 10.000 \text { pies }(3.100 \mathrm{~m}) \text { (escala mayor de } \\
1: 20.000)\end{array}$ \\
\hline \hline
\end{tabular}

Según la tabla 12, el nivel I es el indicado para utilizar con datos de imágenes Landsat. Este nivel de categorización puede también ser utilizado en una amplia gama de escalas. Sin embargo, niveles más detallados pueden ser utilizados con sensores remotos de más alta resolución, como los de alta y muy alta resolución espacial como IKONOS o QuickBird. Las clases propuestas por Anderson et al. (1976), para el nivel I son: áreas urbanas o edificadas, áreas de agricultura, pastizales, áreas forestales, agua, humedales, suelo desnudo / estéril, tundra, hielo o nieve perpetuos.

Basado en la metodología citada, en el proyecto europeo CORINE - Land Cover y en la nomenclatura utilizada por el Ministerio de Medio Ambiente y Medio Rural y Marino de España (Aguilo Alonso et al. 2007), se ha decidido utilizar cuatro categorías de clasificación de usos y coberturas del suelo:

a) Forestal arbolado: Incluye áreas que tienen una densidad de cubierta arbórea por encima de $5 \%$. Generalmente son fácilmente identificables por imágenes de altas altitudes, aunque sus límites con otras categorías de usos del suelo pueden ser difíciles de delinear de forma precisa. La división en los distintos tipos de bosques (Nivel II) necesita de informaciones complementarias, sobre todo trabajo de campo.

b) Forestal no arbolado: Áreas dónde la vegetación potencial natural son predominantemente herbáceas, matorrales, arbustos y pastizales con cubierta arbórea 
inferior al 5\%. La división entre herbáceas, arbustos o matorral debe ser postergada al nivel II y con datos de sensores remotos que tengan una resolución más alta. Es una clase que representa la tradicional transición del uso forestal al cultivo o bien del cultivo al forestal, que viene ocurriendo secularmente en España, muy relacionada con la ganadería y posteriormente con su abandono.

c) Cultivo: Zonas de uso exclusivamente agrícola, tanto de secano como de regadío (de herbáceas o leñosas) y con fuerte intervención humana. Estas áreas son fácilmente identificables en las imágenes Landsat y en las fotografías aéreas, sobre todo por su conformación geométrica y por sus marcados ciclos fenológicos.

d) Improductivo: Áreas de limitada capacidad productiva, generalmente suelos desnudos, afloramientos rocosos, escarpes o arenas. Se incluye en esta categoría también el terreno cubierto por estructuras edificadas y construcciones como son los núcleos urbanos, carreteras, autopistas y otras edificaciones que puedan estar aisladas de áreas urbanas.

No hay un sistema de clasificación ideal de uso y cobertura del suelo, y es improbable que uno pueda ser desarrollado. Hay diferentes perspectivas en los procesos de clasificación y el propio proceso tiende a ser subjetivo, sobre todo cuando se trabaja con fuentes de datos distintas. Cada clasificación trata de adaptarse a las necesidades de los usuarios y pocos se adaptan a un inventario que no fue hecho para sus necesidades. Según Angnes Teresa (2005), el uso de bases de datos obtenidas con criterios, leyendas y escalas distintas, genera categorías de cambios que podrían no ajustarse a la realidad. Este tipo de dificultades tienden a minimizarse cuando se opta por niveles de generalización medios y altos, se utilizan escalas de análisis y representación medianas y pequeñas, y se utilizan pocas categorías en las leyendas de los mapas. En este estudio, además de intentar adecuar una metodología ampliamente utilizada en el medio científico, se ha buscado la mayor precisión posible en la interpretación de las fotos aéreas y de las imágenes de satélite. Además, se han buscado clases capaces de homogeneizar las características comunes encontradas en todas las cuencas, ya que las mismas poseen características bioclimáticas diferentes. Al aplicar niveles de clasificación más generalizados es más eficiente este proceso de homogeneización por ser más clara la definición de las características comunes a cada zona en lo que se refiere a usos y coberturas del suelo. 


\subsubsection{Tratamiento de las fotografías aéreas}

El flujo de trabajo realizado con las fotografías aéreas se indica en la figura 11.

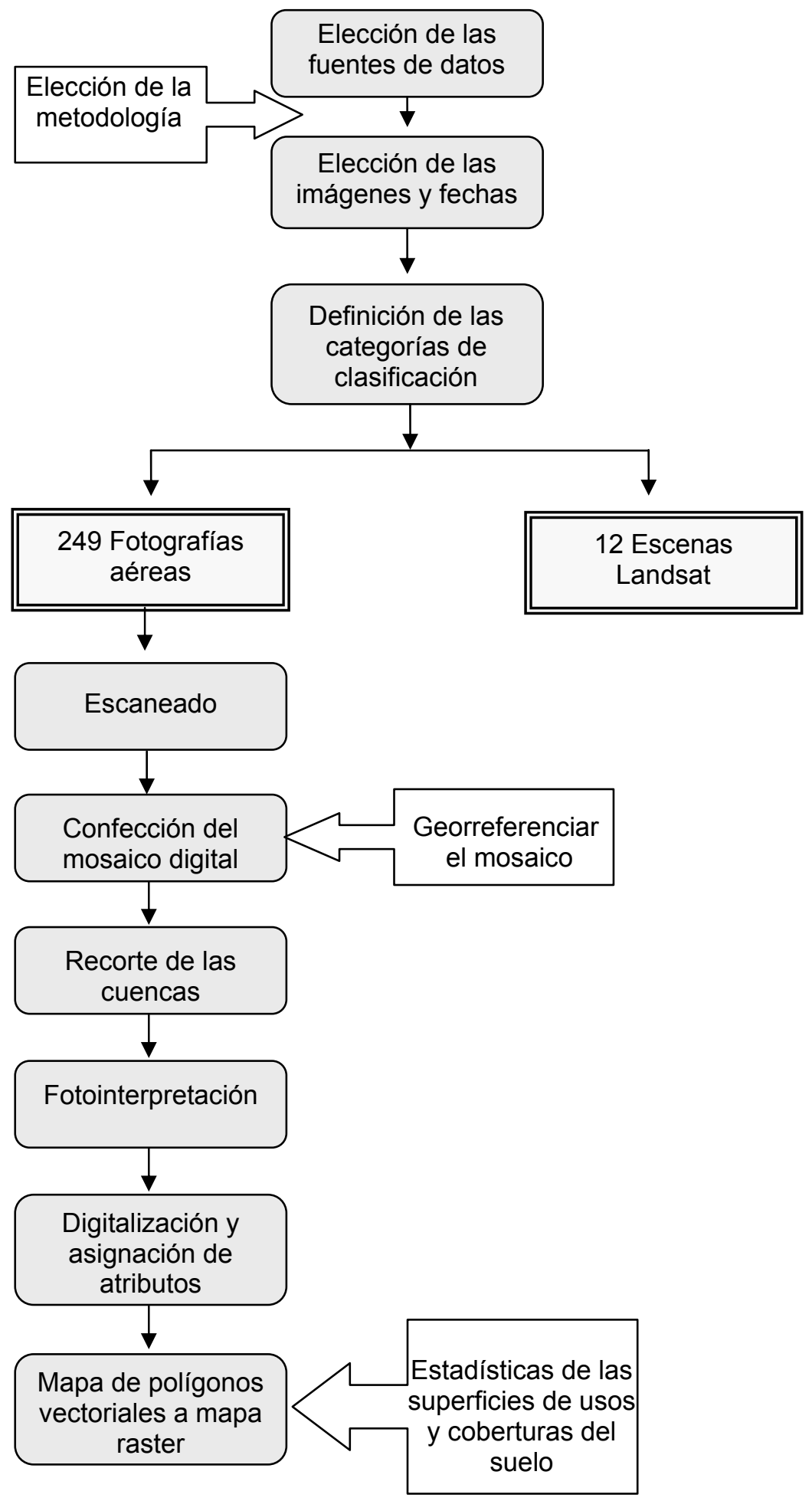

Figura 11 - Secuencia del trabajo desarrollado con las fotografías aéreas. 
Para cada zona fue realizado inicialmente el escaneado de las fotografías aéreas (52 para la cuenca del río Cega, 31 para la del Porma, 92 para la del Tajo y 74 para la del río Trabaque). La resolución aplicada en el escáner fue de 300 dpi, lo que traducido al tamaño del fotograma resulta en una resolución espacial de píxel de 2,70 m. Esta es una importante diferencia con relación a las imágenes de satélite, en las que la resolución es de $30 \mathrm{~m}$ por píxel. No obstante hay que insistir en que las metodologías aplicadas en ambas fuentes de datos tratan de adecuarse a las diferencias existentes entre ellas.

Con las fotos escaneadas se ha hecho un mosaico digital (Fig. 12).

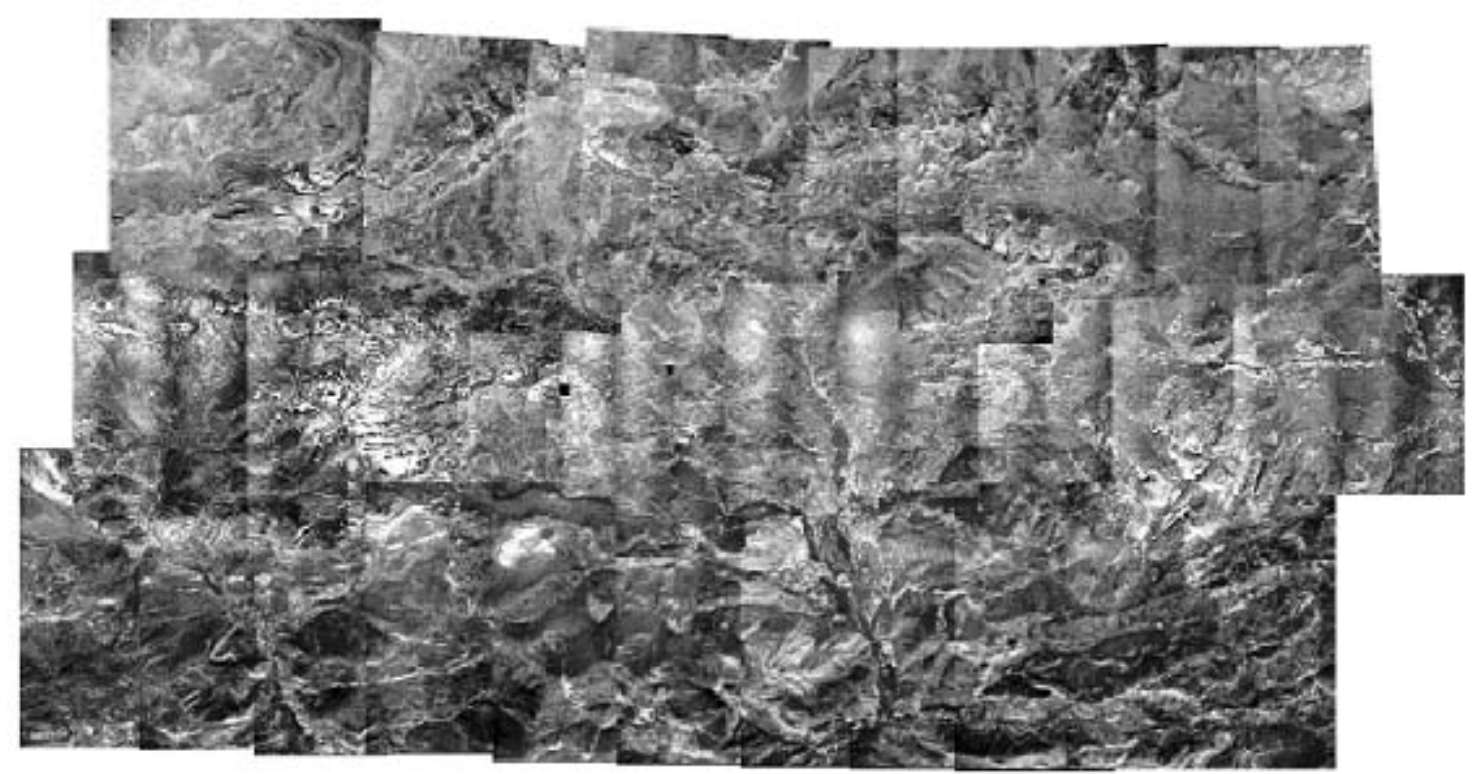

Figura 12 - Mosaico digital de la cuenca del río Porma.

Hay que tener en cuenta que una fotografía aérea es una imagen fotográfica obtenida desde el espacio aéreo a través de una cámara montada usualmente en un avión. Estas fotos son tomadas en forma continua, con intervalos de disparo de pocos segundos, conformando lo que se llama la pasada fotogramétrica, la cual se repite en forma paralela hasta cubrir el área requerida. La escala de la foto es la relación matemática entre la dimensión real de los objetos situados en la superficie terrestre y la de su imagen captada, y se define por la altura del vuelo y la distancia focal de la cámara empleada. La geometría de cada fotografía refleja es una proyección en perspectiva cónica donde las distorsiones geométricas aumentan conforme nos alejamos del centro del fotograma, por lo que la razón de escala varía en función de la distancia al centro de la imagen y de la altitud que refleje el relieve. Además, las 
variaciones ocurridas en la altitud, velocidad y posición del avión pueden causar distorsiones en las imágenes obtenidas (Wolf, 1983). Por lo tanto para hacer el mosaico hay que considerar estas distorsiones, ya que este proceso consiste en componer las imágenes adyacentes, para obtener un recubrimiento mayor de un área (Gómez et al. 2000; Ruescas Orient, 2001; Sousa Silva et al. 2007). La solución consiste en unir la parte de cada fotograma en que hay menos distorsiones debido a su proyección (zona de recubrimiento). Según Ruescas Orient (2001), la realización de un mosaico con las fotos del vuelo americano 1956-1957 (1:33.000) es una tarea casi imposible. Sin embargo es la metodología más utilizada y es la única manera posible de visualizar toda la zona de estudio (Oliveira Pinto et al. 2002; Aparecido Gonçalves et al. 2005; Cunha et al. 2006; Felix et al. 2006).

El mosaico digital fue georreferenciado en el sistema geodésico ED50 y proyección cartográfica UTM (huso 30 , zona T). Este proceso fue realizado sobre el mosaico global de cada cuenca, y no individualmente en cada fotograma, debido al volumen de fotografías aéreas empleadas. La georreferenciación o corrección geométrica consiste en una transformación empírica a partir de puntos de control con el objetivo de cambiar las coordenadas fila y columna de los píxeles de la imagen a un sistema de referencia geográfico en la proyección UTM (Ruescas Orient, 1999). Los puntos de control deben estar bien distribuidos en el mosaico. Se utiliza una transformación polinómica de dos dimensiones. Las coordenadas proyectadas en el sistema cartográfico se obtienen del SIGPAC - Sistema de Información Geográfica de Parcelas Agrícolas, que permite identificar geográficamente las parcelas declaradas por los agricultores y ganaderos. Concebido inicialmente con el propósito de facilitar a los agricultores la presentación de solicitudes de ayudas europeas a la agricultura, así como para facilitar los controles administrativos el SIGPAC se ha convertido en una herramienta de enorme utilidad que trasciende los objetivos iniciales y tiene aplicación en campos como la geología, infraestructuras, y urbanismo. Este sistema está disponible en la página web del Ministerio de Medio Ambiente y Medio Rural y Marino y fue posible utilizarlo como base para la georreferenciación de los mosaicos digitales. La precisión de los puntos obedece a la escala de esta base de datos, 1:10.000, y se considera suficiente para los objetivos del trabajo. Tras la aplicación del modelo matemático a los puntos de control, es necesaria la transformación del mosaico completo. Este procedimiento es llamado remuestreo y en este trabajo ha sido ejecutado según el método de vecino más próximo, en el que el valor de gris del píxel transformado se asigna tomando el valor del más cercano en la geometría original de 
la imagen previa (Pinilla, 1995; Ruescas Orient, 1999; Gómez et al. 2000; Ruescas Orient, 2001; Kleinpaul et al. 2005; Dupuy Rada et al. 2006).

Posteriormente se recortó el mosaico de cada cuenca utilizando como base los límites de las mismas (Fig. 13).

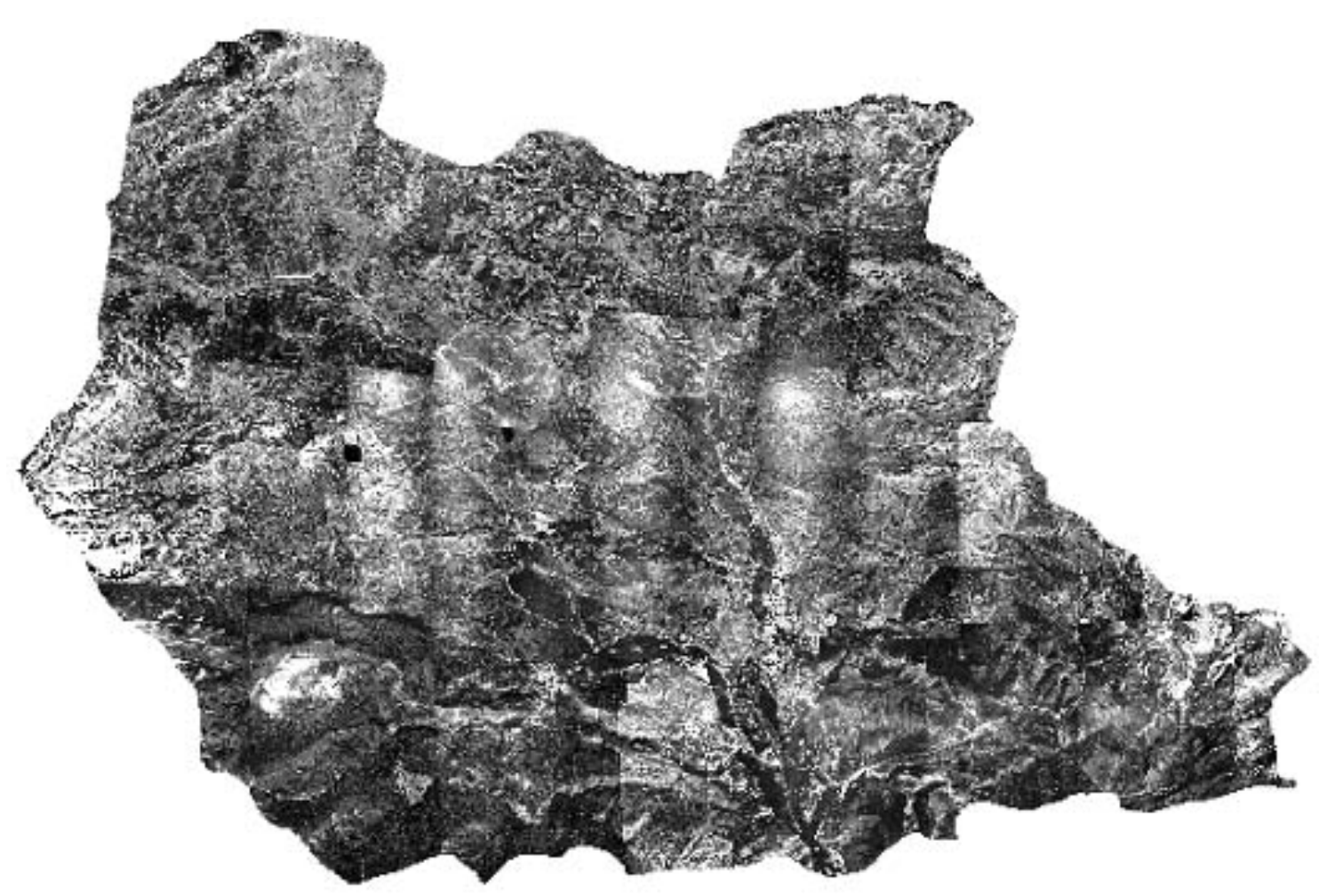

Figura 13 - Recorte del mosaico - Cuenca del río Porma.

A continuación se pasa a la fase de fotointerpretación, una metodología clásica y ampliamente utilizada que se basa en la interpretación visual de las fotografías aéreas (Teng, 1997; Lozano Rivera et al. 2005). Hay que reconocer y delinear todos los usos y coberturas establecidos en la leyenda (Pemán García, 1996; Pizarro et al. 2005; Fernández García, 2000).

Algunos de los elementos de la fotografía aérea más relevantes de uso común para lograr los propósitos de la fotointerpretación son tamaño, forma, sombra, tono y color y textura (Graham, 1993). El primer paso para la interpretación es la diferenciación de elementos basados en estos criterios y en la combinación de ellos tales como ríos, manchas vegetales, urbanizaciones, etc. El tamaño es uno de los factores más útiles para la identificación de objetos y se puede inferir realizando comparaciones del tamaño relativo de un objeto con respecto a otro conocido presente en la imagen. La 
forma es el elemento que mejor explica la clasificación de objetos debido a que las formas observadas en la fotografía aérea se pueden relacionar directamente con las formas conocidas. El problema es que en ciertas situaciones es altamente difícil interpretar objetos vistos de forma vertical; esto es debido a la variación que presenta la forma comparada con el habitual punto de vista. La sombra, como elemento de la fotointerpretación, permite el reconocimiento de objetos que no son fácilmente reconocibles en un plano vertical, dando referencias de la forma en un plano horizontal. Las sombras son particularmente útiles en zonas de bajo contraste tonal, permitiendo diferenciar objetos. Tono y color son elementos de juicio muy importantes dentro de la fotointerpretación, ya que con la tonalidad se pueden conocer características de la superficie interpretada. La textura en la fotografía está constituida por repeticiones tonales de grupos de objetos, los cuales son muy pequeños para ser reconocidos como objetos individuales.

La identificación, reconocimiento y análisis del medio a partir de fotografías aéreas están sujetos a un factor humano muy importante, ya que quedan supeditados únicamente a la capacidad y experiencia del fotointérprete que desarrolla el proyecto. Se puede decir que la fotointerpretación no es una ciencia exacta sino un arte, que conjuga la experiencia, conocimiento y capacidad del fotointérprete (Araneda Milla et. al. 1999). Por lo tanto, este es un método en gran parte subjetivo y sus posibles errores son muy difíciles de cuantificar. Se puede citar también que algunas fotografías no presentan la misma calidad con relación a los niveles de gris, lo que lleva a alguna confusión. Además, debido a las distorsiones propias de las fotografías ya citadas, algunos límites de zonas no quedan perfectamente unidos al hacerse el mosaico.

El siguiente paso fue la digitalización y la asignación de atributos a cada uno de los polígonos de acuerdo con la leyenda escogida. En esta etapa se vectorizan los polígonos manualmente sobre el mosaico digital mediante un software de sistema de información geográfica (SIG), concretamente el ArcGis 9.2 y se asignan las etiquetas con el uso que contiene (Pizarro et al. 2005; Henríquez et al. 2006).

Posteriormente se ha convertido este mapa de polígonos vectoriales en un mapa raster con el objetivo de hacer comparaciones con los mapas resultantes de las demás fuentes (Ruescas Orient, 2001).

Finalmente se han hecho cálculos de la superficie total y de las distintas clases de usos y coberturas seleccionadas. Los resultados fueron convertidos en porcentaje de 
ocupación de cada una de las clases. Los mapas y los gráficos resultantes han servido de base para el análisis comparativo de los usos y de la cobertura del suelo (Gómez et al. 2000; Sousa Silva et al. 2007).

\subsubsection{Tratamiento de las imágenes de satélite}

Para el análisis de las imágenes de satélite se aplican metodologías diferentes aunque con el mismo objetivo final que es identificar los cambios sufridos por las zonas con relación a los usos y las coberturas del suelo (Fig. 14).

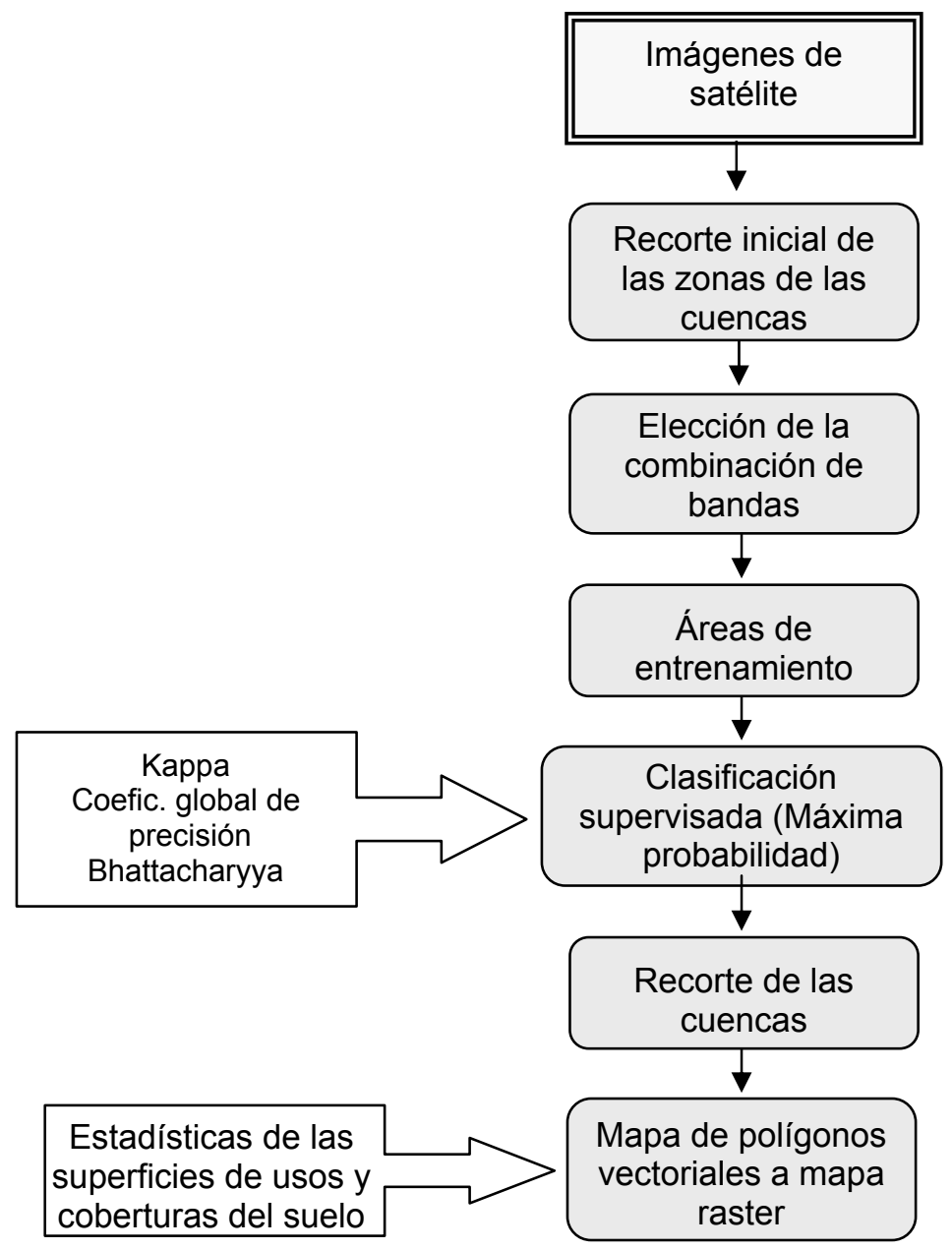

Figura 14 - Secuencia del trabajo desarrollado con las escenas Landsat.

Para el análisis de las escenas Landsat se hizo inicialmente un recorte preliminar (Fig. 15) en las escenas originales para que se adecuara a las zonas de estudio y para trabajar con imágenes más pequeñas evitando de esta forma ralentizar el procesado digital. 

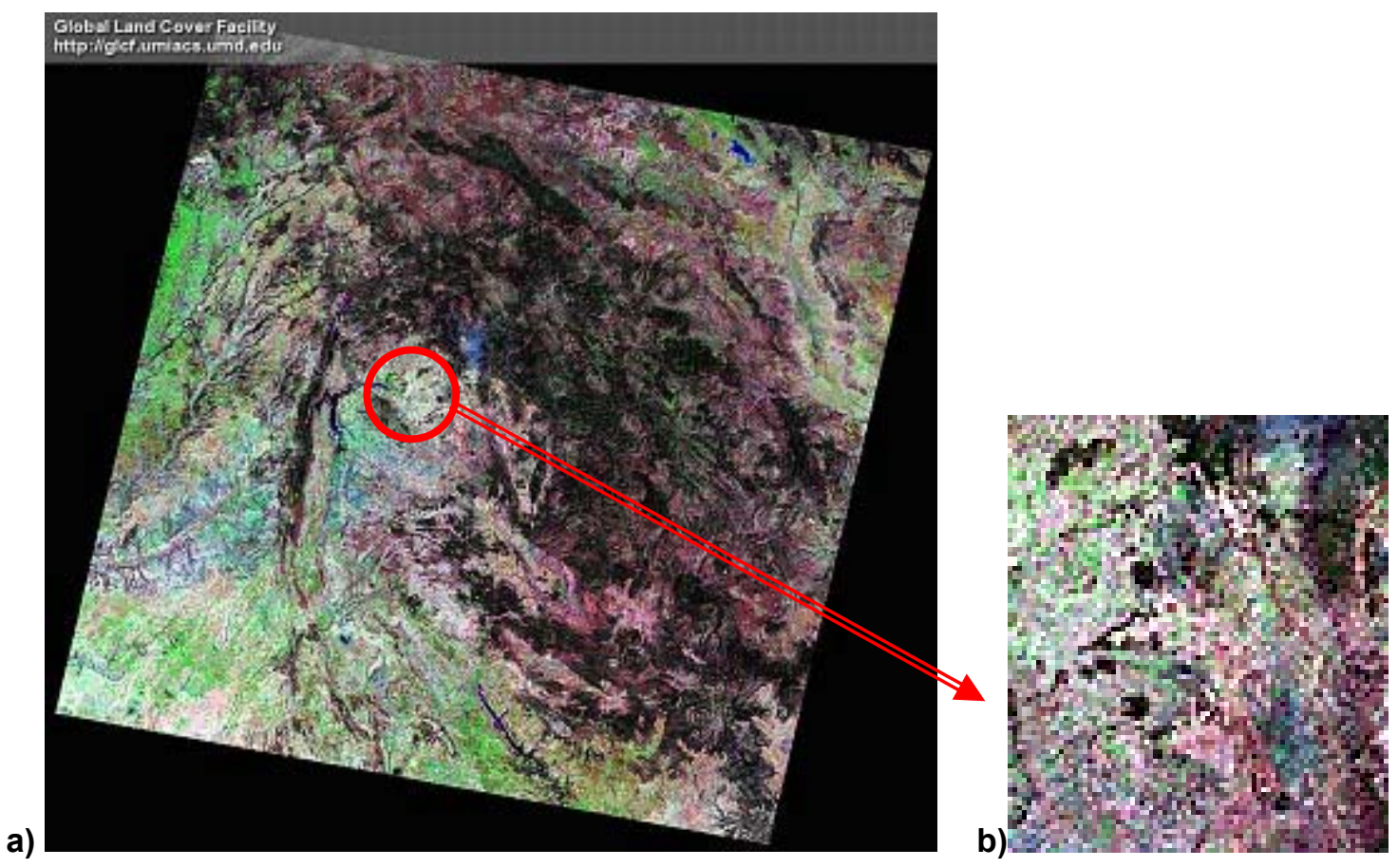

Figura 15 - a) Escena Landsat 200032 y b) Recorte preliminar de la escena Landsat Cuenca del río Tajo.

El siguiente paso fue la elección de las bandas que serían utilizadas en este análisis. La descarga de las escenas se realiza por bandas, cuya combinación genera las imágenes en color. Gracias a las combinaciones de bandas (Tabla 13) se pueden resaltar variaciones de color, textura, tonalidad y diferenciar los distintos tipos de cobertura que existen en la superficie (Nakajima et al. 1996).

Tabla 13. Combinaciones de bandas de imágenes Landsat más utilizadas.

\begin{tabular}{|l|l|}
\hline \hline Combinaciones & \multicolumn{1}{|c|}{ Resultado } \\
\hline Bandas 3, 2, 1 (RGB) & $\begin{array}{l}\text { Es una imagen de color natural. Refleja el área tal como la observaría } \\
\text { el ojo humano en una fotografía aérea a color. }\end{array}$ \\
\hline Bandas 4, 3, 2 (RGB) & $\begin{array}{l}\text { Tiene buena sensibilidad a la vegetación verde, que aparece de color } \\
\text { rojo, los glaciares se ven de color blanco y el agua se ve de color } \\
\text { oscuro debido a sus características de absorción. }\end{array}$ \\
\hline Bandas 7, 4, 1 (RGB) & $\begin{array}{l}\text { Ampliamente utilizada en geología. En la banda 7, en rojo, se } \\
\text { identifican los minerales arcillosos; la banda 4, en verde, cubre el } \\
\text { segmento en el que la vegetación refleja fuertemente; y la banda 1, en } \\
\text { azul, abarca el segmento en el cual los minerales con óxidos de hierro } \\
\text { absorben energía. }\end{array}$ \\
\hline Bandas 7, 4, 2 (RGB) & Permite discriminar los tipos de rocas. \\
\hline Bandas 5, 4, 3 (RGB) & $\begin{array}{l}\text { En esta combinación la vegetación aparece en distintos tonos de color } \\
\text { verde. }\end{array}$ \\
\hline Bandas 7, 3, 1 (RGB) & $\begin{array}{l}\text { Ayuda a diferenciar tipos de rocas. La vegetación aparece con color de } \\
\text { verde oscuro a negro, los ríos son negros y con algunas coloraciones } \\
\text { acules a celestes, los glaciares se ven celestes. }\end{array}$ \\
\hline \hline
\end{tabular}

Elaboración propia según Reginaldo Tenorio et al. (1993); Grández et al. (2006). 
Se ha decido utilizar en este trabajo la combinación de las bandas 3, 2, 1 (RGB en color verdadero) por ser suficiente en el caso de análisis multitemporales para evaluación de los cambios en los usos y en la cobertura de los suelos (Sousa Silva et al. 2007), sobre todo por tratarse de una combinación en la que el resultado se aproxima mucho a los colores naturales de la escena (Sabins, 1996).

Para realizar el proceso de clasificación es necesario recurrir previamente a otras fuentes de información auxiliar. Es la llamada fase de entrenamiento, que trata de definir cada una de las categorías que pretenden discriminarse teniendo en cuenta su propia variabilidad en la zona de estudio (Chuvieco, 1996). Este objetivo se logra haciendo polígonos que delimiten píxeles de la imagen que representen adecuadamente a las categorías de interés (áreas verdad-terreno). La obtención de áreas de entrenamiento es un proceso lento y clave para una buena y correcta clasificación (Chuvieco, 1996; Arquero et al. 1998; Ruescas Orient, 1999; Ferreira et al. 2005; Kleinpaul et al. 2005; Silva Brito et al. 2005; Criscuolo et al. 2006; Angueira et al. 2008). Los principales criterios al elegir las áreas de entrenamiento son una buena distribución por toda la imagen, la representación de cada clase temática existente mediante al menos un área de entrenamiento, la minimización del solapamiento entre clases y la consideración de que el conjunto de las áreas de entrenamiento debe superar el $1,5 \%$ de la superficie total (Ormeño, 1993). En este estudio, como ya se ha dicho, se han definido cuatro categorías de clasificación: forestal arbolado, forestal no arbolado, cultivo e improductivo. Las áreas de entrenamiento conocidas a priori sirven para generar una signatura espectral característica de cada una de las clases. A partir de esas áreas de entrenamiento se realiza la clasificación propiamente dicha.

El algoritmo de clasificación elegido ha sido el de máxima probabilidad (Duda y Hart, 1973), que es ampliamente utilizado entre la comunidad científica en trabajos semejantes a éste (Ruescas Orient, 1999; Gómez et al. 2000; Ruescas Orient, 2001; Ferreira et al. 2005; Boletta et al. 2006; Criscuolo et al. 2006; Sousa Silva et al. 2007). Esta técnica asume que los niveles digitales de cada clase se ajustan a una distribución normal, lo que permite describir cada categoría por una función de probabilidad. La clase a la que se asigne un píxel dado será aquella para la que alcance mayor valor dicha función de probabilidad (Ferrer et al. 1998; Criscuolo et al. 2006). 
Los estadísticos Kappa y la clasificación global de precisión (Tabla 14) fueron utilizados para evaluar la calidad de las áreas de entrenamiento definidas en todo este proceso.

Tabla 14. Coeficientes Kappa y clasificación global de precisión para todas las imágenes utilizadas en este estudio.

\begin{tabular}{|c|c|c|c|}
\hline \multicolumn{5}{|c|}{ Cuenca del río Cega } \\
\hline \hline Imagen & Fecha & Precisión global & Coeficiente Kappa \\
\hline 217031 & $03 / 05 / 1976$ & 99,74 & 0,99645 \\
\hline 201031 & $15 / 07 / 1989$ & 100,00 & 1,00 \\
\hline 201031 & $19 / 06 / 2000$ & 99,85 & 0,99768 \\
\hline 201032 & $25 / 03 / 1989$ & 99,94 & 0,99806 \\
\hline 201032 & $22 / 02 / 2002$ & 99,58 & 0,99305 \\
\hline \multicolumn{5}{|c|}{ Cuenca del río Porma } \\
\hline \hline \multicolumn{5}{|c|}{ Imagen } & Fecha & Precisión global & Coeficiente Kappa \\
\hline 218030 & $24 / 08 / 1977$ & 98,21 & 0,97065 \\
\hline 202030 & $13 / 08 / 1991$ & 98,57 & 0,97536 \\
\hline 202030 & $29 / 06 / 2001$ & 98,82 & 0,97563 \\
\hline \hline \multicolumn{5}{|c|}{ Cuenca del río Tajo } \\
\hline \hline Imagen & Fecha & Precisión global & Coeficiente Kappa \\
\hline 215032 & $06 / 06 / 1976$ & 99,13 & 0,98572 \\
\hline 200032 & $14 / 04 / 1987$ & 99,10 & 0,98483 \\
\hline 200032 & $30 / 05 / 2001$ & 98,88 & 0,97177 \\
\hline \hline \multicolumn{5}{|c|}{ Cuenca del río Trabaque } \\
\hline Imagen & Fecha & Precisión global & Coeficiente Kappa \\
\hline 215032 & $06 / 06 / 1976$ & 99,93 & 0,99832 \\
\hline 200032 & $14 / 04 / 1987$ & 98,84 & 0,97781 \\
\hline 200032 & $30 / 05 / 2001$ & 98,26 & 0,96786 \\
\hline \hline
\end{tabular}

El coeficiente kappa (Lillesand y Kiefer, 1999) expresa el error generado por el proceso de clasificación respecto a una clasificación de referencia o a unos valores reales. Por otro lado la estimación global de precisión proviene de dividir el total de píxeles correctamente clasificados sobre el total de píxeles correspondientes a las áreas verdad terreno (Marini et al. 2007). Ambos test, en todas las imágenes, alcanzan un resultado mínimo superior al $85 \%$, límite recomendado por Foody (2002). Los coeficientes Kappa y la precisión global más altos fueron encontrados en las escenas de la cuenca del río Cega, llegando a su valor máximo en la escena 201/031 de 15/07/1989. Por otro lado los valores más bajos de ambos test fueron encontrados en la escena 200/032 (Cuenca del río Trabaque) de 30/05/2001. Los altos valores encontrados se justifican por el extremo cuidado a la hora de determinar las áreas de 
entrenamiento y por ser un proceso de ensayo-error hasta llegar a una clasificación satisfactoria. La repetición del proceso de clasificación es un procedimiento normal realizado para mejorar los resultados finales.

Como criterio de separabilidad entre las clases se ha utilizado la distancia de Bhattacharyya (Bhattacharyya, 1943), que es frecuentemente utilizada en diversas investigaciones (François Mas et al. 2003; Graciani et al. 2003; Oliveira Moraes, 2005; Boletta et al. 2006; Oliveira Moraes et al. 2006; Batista et al. 2007; Opazo Saldivia et al. 2007).

La separabilidad mide la distancia media entre las distribuciones de probabilidad de las clases espectrales consideradas (Graciani et al. 2003) evaluando en su conjunto todas las bandas de cada imagen (Opazo Saldivia et al. 2007). En este caso se ha evaluado la separabilidad de las áreas de entrenamiento en las bandas 1, 2 y 3 . En general los valores encontrados fueron bastante satisfactorios $(1,86$ a 2,0$)$ ya que 2,0 es el valor optimo de este estadístico. Los valores más bajos indican la confusión entre clases más similares, como es el caso de forestal arbolado y forestal no arbolado. Al contrario, entre las clases forestal arbolado e improductivo es donde se encuentran los valores más altos de separabilidad. Esto se debe sobre todo a la mayor semejanza o bien discrepancia entre una clase y otra. Parece lógico que entre forestal arbolado y no arbolado se produzca la mayor confusión ya que son los que más se parecen en cuanto a tonos, colores, texturas, etc. La división entre usos forestales atendiendo a porcentajes de superficie produce confusión debido al ambiguo porte arbóreo, a la mezcla con especies de matorral y a las diferentes morfologías de las especies forestales. Son categorías difíciles de discriminar a través del proceso de clasificación, pese a lo cual la separabilidad obtenida es buena. Otras clases como forestal arbolado e improductivo son fácilmente identificables, como indica el alto valor de separabilidad.

Como en el caso de las fotografías fue hecho el recorte de las zonas de estudio (Fig. 16) utilizando los límites de las cuencas analizadas en este estudio. 


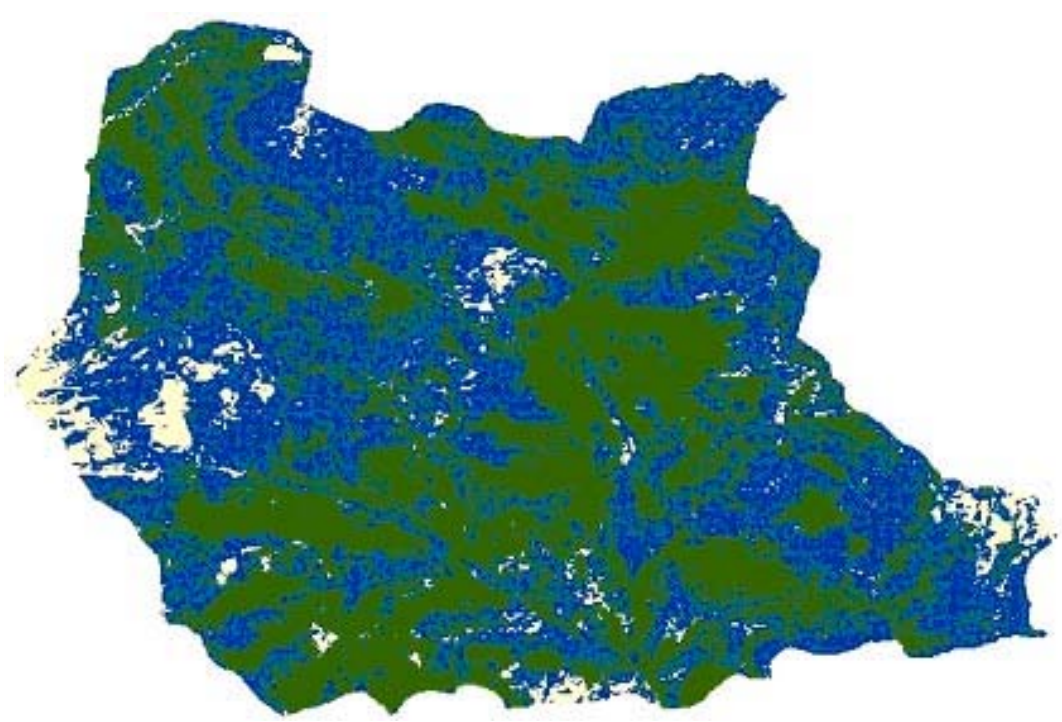

Figura 16 - Recorte de la cuenca del río Porma a partir de la imagen Landsat.

El siguiente paso fue transformar la imagen raster en polígonos y asignar a cada uno atributos de acuerdo con la clasificación de usos y coberturas del suelo (Pemán García, 1996; Fernández García, 2000; Henríquez et al. 2006).

Finalmente, como en las fotografías aéreas, se han hecho cálculos de la superficie total y de las distintas clases de usos y coberturas seleccionadas y los resultados convertidos en porcentaje de ocupación de cada una de las clases (Muschong, 2007; Santana et al. 2007).

Para desarrollo de todos los pasos descritos anteriormente fueron utilizados los paquetes informáticos PCI Geomatica V 9.1., Corel Draw 12.0 y ArcGis 9.2. 


\section{ASPECTOS GENERALES DEL ÁREA DE ESTUDIO}

Las cuatro cuencas analizadas en este trabajo presentan algunas características comunes que han servido de base para la elección de las mismas. Todas son de cabecera, en zonas de media montaña, y han sufrido poca intervención humana, lo que las hace especialmente idóneas para estudiar su comportamiento natural.

Otra característica común a ellas, y de fundamental importancia para que se haga un análisis hidrológico y climatológico riguroso, es que no hay embalses, ni ningún tipo de derivación, es decir, sus aguas siguen su régimen natural, lo que reafirma la poca intervención humana en esas cuencas.

Además, todas las cuencas se encuentran en un contexto geográfico mediterráneo pero con condiciones bioclimáticas diferentes. Sin embargo hay otras cuencas en estas mismas condiciones dichas anteriormente, pero, después de un análisis exhaustivo en los datos de los aforos, de este trabajo, se optó por las cuencas del río Cega, Porma, Trabaque y Tajo en función también de la calidad de los datos de aforos disponibles.

Las cuatro cuencas poseen una serie larga de datos, con un mínimo de 30 años, lo que permite evaluar con mayor precisión el comportamiento hidrológico de los ríos y sobre todo hacer un análisis de tendencias. Son también series de datos con poca o ninguna laguna.

\subsection{Cuenca del Río Cega}

La cuenca del río Cega se localiza en la Comunidad Autónoma de Castilla y León, en la Provincia de Segovia (Fig. 17), con una superficie total de $280 \mathrm{~km}^{2}$, hasta la estación de aforo 016 en el pueblo de Pajares de Pedraza. Es tributario del río Duero en su margen izquierda y la cuenca alcanza su cota máxima a los 2209 m y la mínima a los $937 \mathrm{~m}$. 


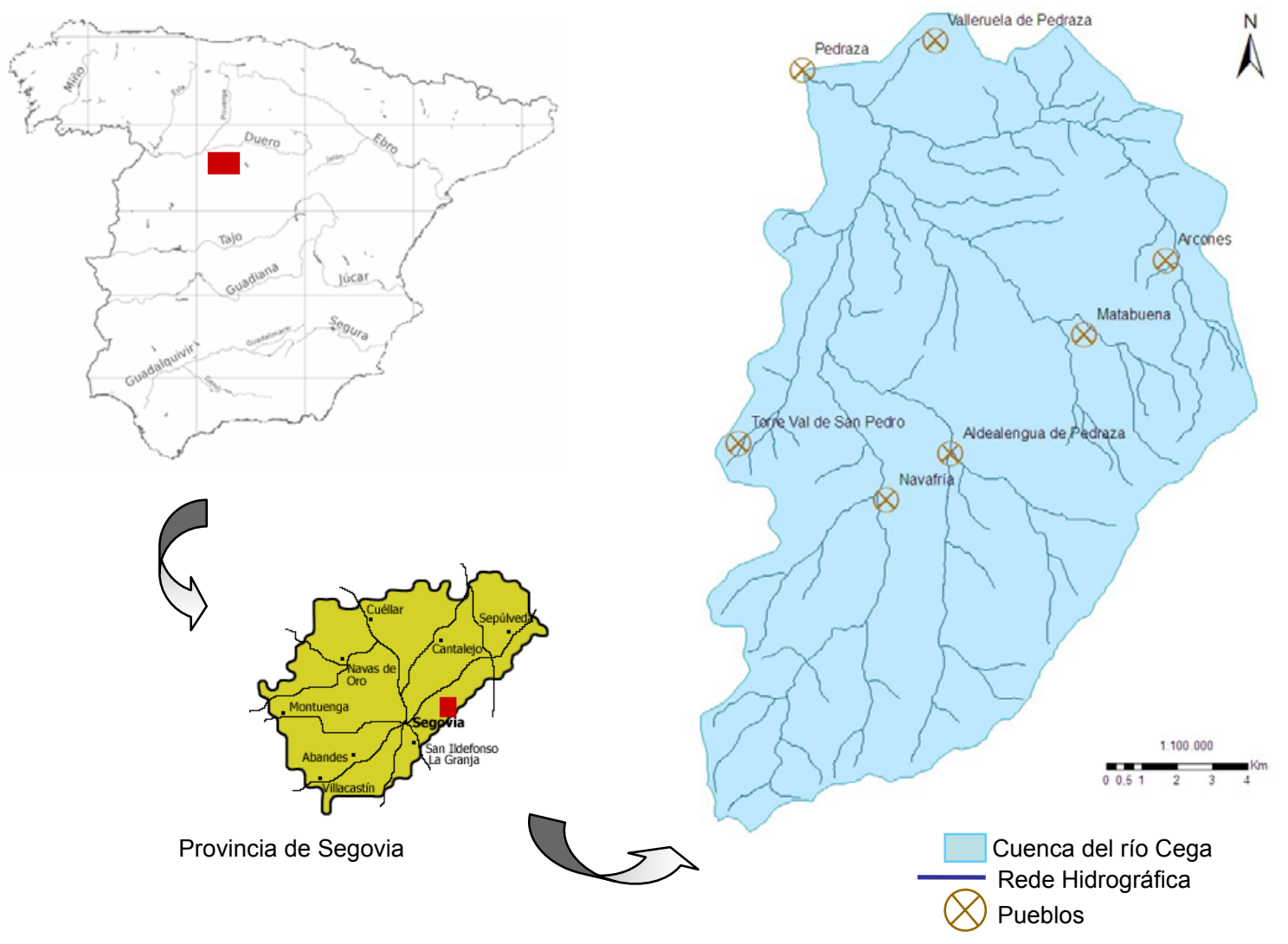

Figura 17 - Localización de la cuenca del río Cega.

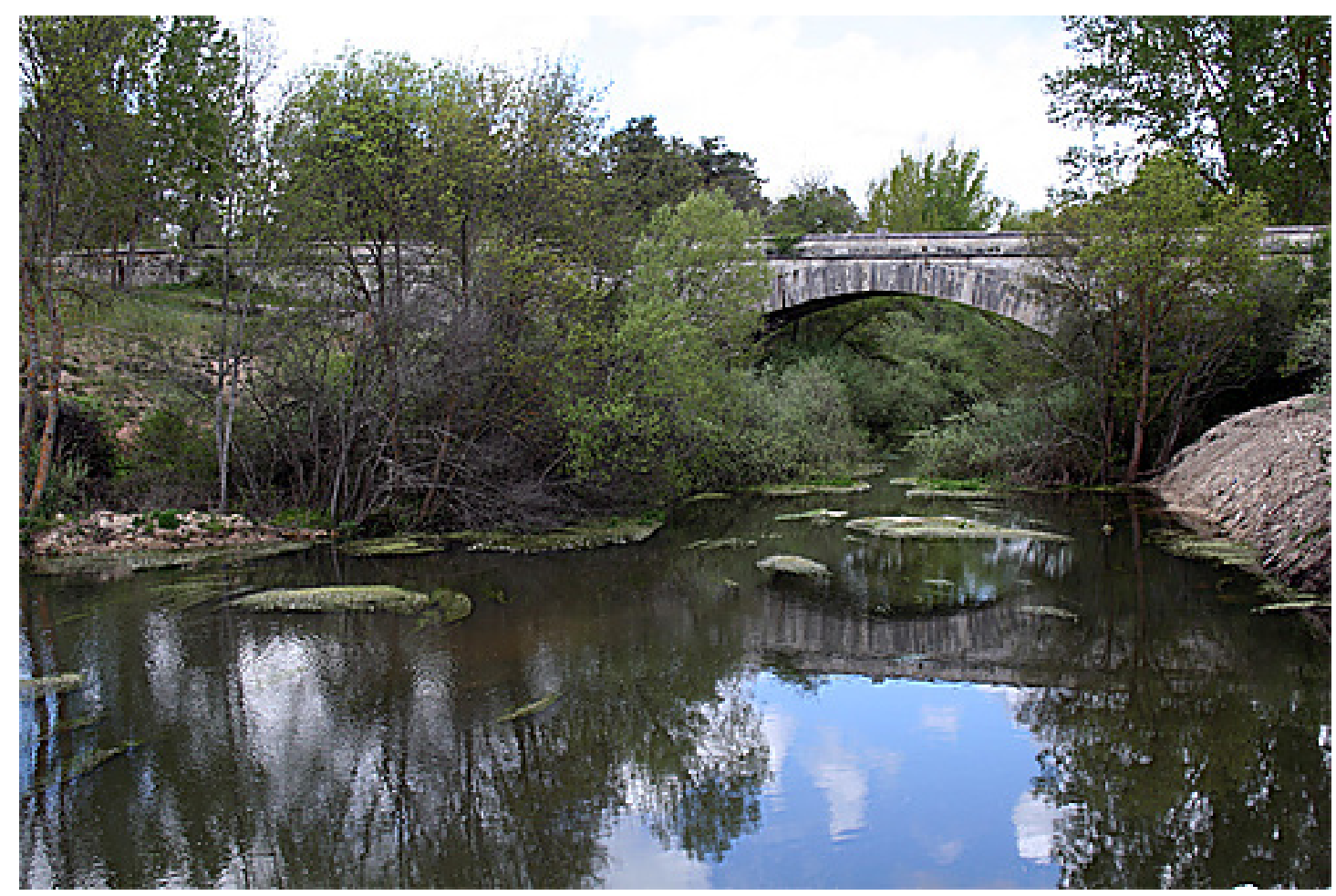

Foto 01 - Río Cega. 


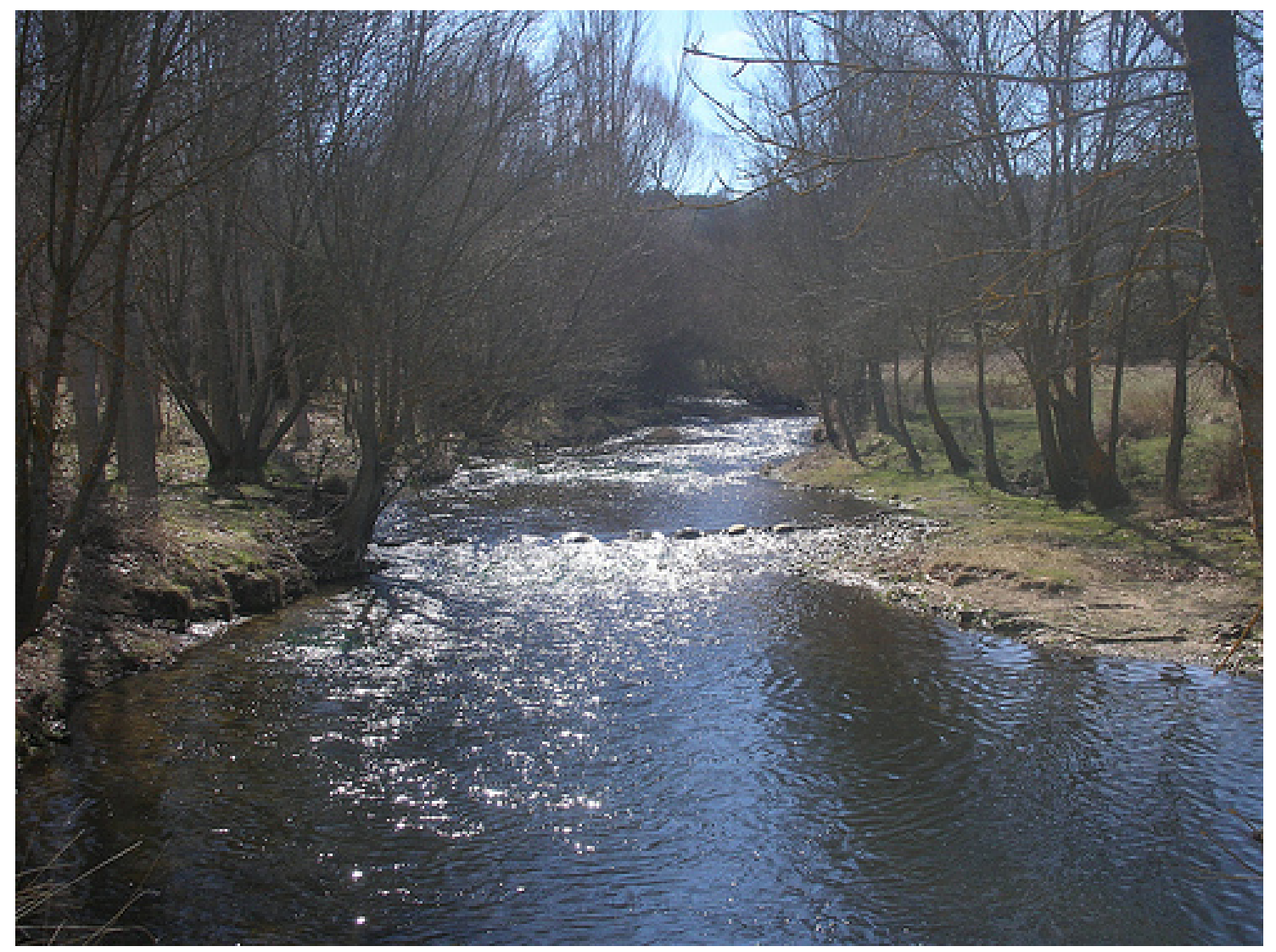

Foto 02 - Río Cega.

Está localizada en el Sistema Central, verdadero "regulador" climático y ecológico e incluso social entre las dos mesetas; sobre todo, en los tramos de contacto entre montaña y llanura. Concretamente, la zona de estudio se sitúa en el borde del piedemonte norte de la Sierra de Guadarrama en que el modelado reciente ha sido elaborado por procesos fluviales, glaciares, periglaciares, gravitacionales y mixtos. Su incidencia es heterogénea y dominada por los procesos fluviales y asociados (Del Olmo et al. 1994). Esta zona esta constituida por un basamento de rocas ígneas y metamórficas del Proterozoico y Paleozoico. Dicho basamento está en contacto, mediante una serie de cabalgamientos, con una cobertera de sedimentos del Mesozoico, concretamente del Cretácico Superior (Lucía et al. 2008). En el entorno del valle del río Cega se encuentran arenas síliceas, arcillas, margas y yesos de edad Cretácico Superior (Vicente Rodado et al. 2008). Es posible encontrar una asociación de suelos de cambisoles cálcicos, leptosoles rendzicos y arenosotes cámbicos (Forteza et al. 1987), que aparecen sobre los coluviones carbonáticos, y los arenosoles cámbicos cuando el suelo se desarrolla directamente sobre los sedimentos en facies utrillas (Lucía et al. 2008). El carácter marcadamente inicial de la red, por encontrarnos en un borde montañoso, así como las características del sustrato de las áreas fuentes, queda reflejado en cursos altos donde arroyos, manantiales, fuentes y 
torrentes juegan un papel fundamental en la dinámica hidrológica. La transición desde las superficies peniplanizadas y laderas, hasta el piedemonte y, posteriormente, a las superficies tipo glacis o depresiones interiores, está convenientemente reflejada en el perfil de los cursos fluviales: desniveles acusados en el curso alto que bruscamente se nivelan a partir de la rotura de pendiente en su camino hacia la desembocadura en colectores de primer y segundo orden (Cabero Diéguez et al. 2008).

La zona de estudio presenta un clima mediterráneo templado fresco de montaña, con inviernos largos y fríos, y veranos cortos, secos y no demasiado calurosos. Sin embargo, las condiciones termopluviométricas presentan abundantes matices que están escalonadas y estrechamente vinculadas a la sucesión altitudinal. Dependen además del carácter más o menos abierto o abrigado de los lugares. Las temperaturas medias anuales descienden por debajo de los $10^{\circ} \mathrm{C}$. Asimismo, los meses más cálidos rondan los $18{ }^{\circ} \mathrm{C}$, con máximas absolutas en torno a los $33^{\circ} \mathrm{C}$. El periodo estival, pues, se convierte en fresco y corto, mientras las estaciones intermedias de otoño $(8,7$ $\left.{ }^{\circ} \mathrm{C}\right)$ y primavera $\left(7,3^{\circ} \mathrm{C}\right)$ pueden calificarse de frías, prolongándose los efectos invernales a casi nueve meses. El periodo de heladas tiene más de 142 días anuales y se prolonga aproximadamente de septiembre a junio. La oscilación térmica se amortigua, en torno a $17^{\circ} \mathrm{C}$. Por tratarse de una zona con fuerte influencia altitudinal las precipitaciones oscilan entre 400 y $1000 \mathrm{~mm}$ y los menores valores anuales corresponden al área de contacto con la llanura. La disposición general del relieve influye decisivamente en los efectos derivados de la dinámica atmosférica, al convertirse en un obstáculo orográfico de envergadura y pantalla condensadora de humedad y al reactivar situaciones de inestabilidad atmosférica (Capel Molina, 1981; Gil Olcina et al. 2001; Franco-Múgica et al. 2005; Cabero Diéguez et al. 2008).

El río Cega y sus inmediaciones conforman un complejo ecológico de altísimo valor ambiental para toda la región (Díez et al. 2006). Las formaciones vegetales de gran porte están representadas por algunas especies de pinos, como el silvestre o de Valsaín (Pinus sylvestris) y el pino pudio o laricio (Pinus nigra). También se puede encontrar ejemplares de encinas (Quercus ilex) y algunos de roble melojo (Quercus pyrenaica). Los bosques de pinos se encuentran principalmente a lo largo del curso del río (Franco-Múgica et al. 2005; Cabero Diéguez et al. 2008). El sotobosque está representado por cantueso (Lavandula stoechas), tomillo (Tymus vulgaris L.), retama (Spartium junceum), jara (Cistus ladanifer), siempreviva (Sempervivum tectorum), escaramujo (Rosa sp.), majuelo (Crataegus monogyna), mundillo o bola de nieve (Viburnum opulus), cornejo (Cornus sanguinea) y aligustre (Ligustrum vulgare). En las 
riberas de los ríos y arroyos se ven alisos (Alnus glutinosa), acompañados en menor medida por chopos (Populus deltoides Marshall), avellanos (Corylus máxima L.), sauces (Salix alba L., Salix purpurea L. y Salix atrocinerea Brot.) y fresnos (Fraxinus angustifolia Vahl) (Guerra Velasco et al. 2006; Cabero Diéguez et al. 2008).

En cuanto a fauna destacan sin duda las aves forestales tales como águila imperial (Aquila adalberti), buitre negro (Aegypius monachus) y leonado (Gyps fulvus), cigüeña negra (Ciconia nigra), águila real (Aquila chrisaetos), acompañadas en los tramos de ribera por cucos (Cuculus canorus), ruiseñores (Luscinia megarhynchos) y petirrojos (Erithacus rubecula), entre otras. En el área de estudio también se pueden encontrar mamíferos tales como corzo (Capreolus capreolus), jabalí (Sus scrofa), nutria (Lutra lutra), gato montés (Felis sylvestris), zorro (Vulpes vulpes), tejón (Meles meles), ardilla (Sciurus Vulgaris) y jineta (Genetta genetta). Menos llamativos y menos conocidos pero también con un importante papel en el funcionamiento de los ecosistemas y sobre todo como bioindicadores, dada la relación entre su presencia y el grado de conservación de los hábitats se encuentran los anfibios tales como gallipato (Pleurodeles waltl M.), tritón jaspeado (Triturus marmoratus L.), sapillo pintojo meridional (Discoglossus jeanneae B.), sapo de espuelas (Pelobates cultripes), sapo común o escuerzo (Bufo bufo), sapo corredor (Bufo calamita), ranita de San Antón o de San Antonio (Hyla arborea L.), rana verde común (Rana perezi) y los reptiles lagarto ocelado (Lacerta lepida), lagarto verdinegro (Lacerta schreiberi B.), lagartija ibérica (Podarcis hispanica), lagartija roquera (Podarcis murales) y la lagartija colilarga (Psammodromus algirus). En el río Cega y en los otros ríos y arroyos de la región los peces más comunes son trucha común (Salmo truta), barbo común o de bocage (Barbus bocagei S.), bermejuela (Chondrostoma arcasii S.), gobio (Gobio lozanoi), bordallo (Squalius carolitertii), lamprehuela (Cobitis calderoni B.) (Cabero Diéguez et al. 2008).

El uso que el hombre ha hecho del suelo en esta región ha sido muy intensivo desde hace al menos 2000 años, dando lugar a una notable modificación de los ecosistemas y del paisaje. Esos usos van desde la utilización más antigua de los recursos del monte y del bosque, hasta aprovechamientos mineros para extraer arenas silíceas (areneras) y arcillas de las laderas (antiguas tejeras). Así mismo, el carboneo, pastoreo y los cultivos han sido importantes, dando lugar a una progresiva deforestación (Moreno, 1989). En la actualidad estos usos del suelo han perdido importancia y las laderas se encuentran ahora cubiertas por una masa forestal en claro proceso de recuperación (Vicente Rodado et al. 2008). Por otro lado aun se dan en la 
zona de estudio las parcelas de cultivos agrícolas leñosos, como frutales y viñedos, que ocupan extensiones muy reducidas en el entorno de algunos asentamientos urbanos (Cabero Diéguez et al. 2008).

\subsection{Cuenca del Río Porma}

La cuenca del río Porma se localiza en la Comunidad Autónoma de Castilla y León, en la Provincia de León, con una superficie total de $154 \mathrm{~km}^{2}$, hasta la estación de aforos 078 en Camposolillo (Fig. 18). El río Porma desemboca en el río Esla, uno de los principales afluentes del Duero por su margen derecha. Las cotas altitudinales en esta cuenca van desde 1092 hasta $2157 \mathrm{~m}$.

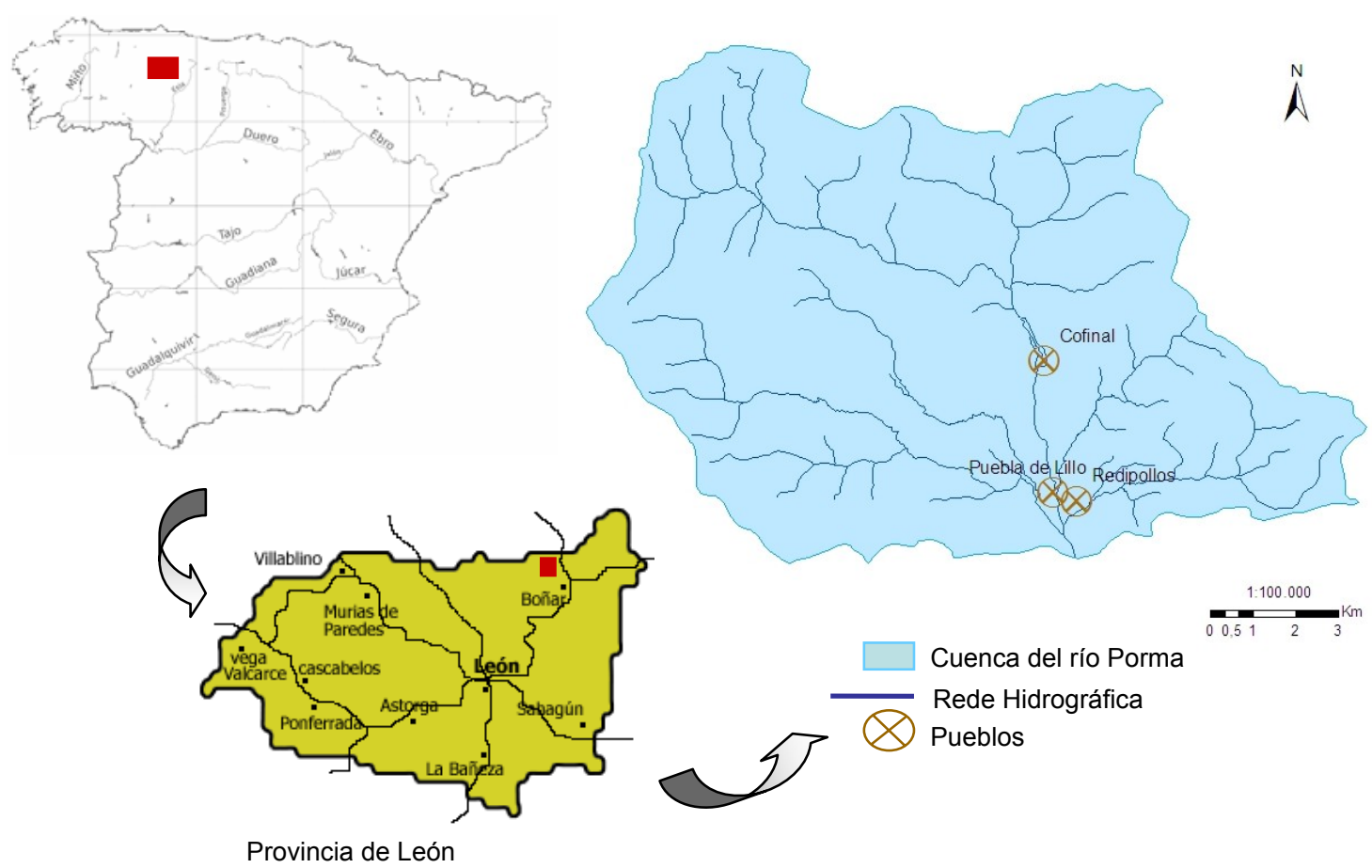

Figura 18 - Localización de la cuenca del río Porma. 


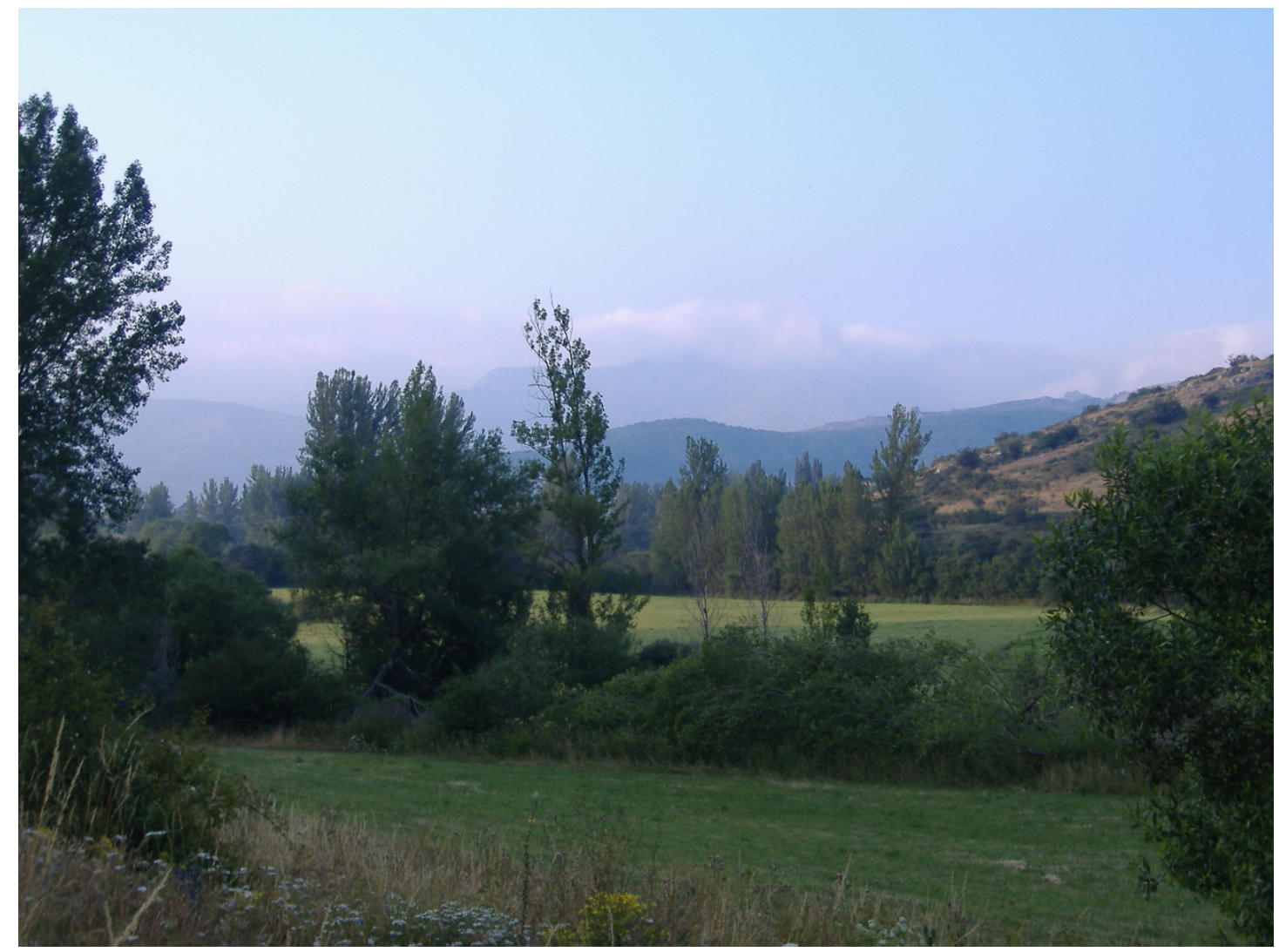

Foto 03 - Vista parcial de la cuenca del Río Porma (Puebla de Lillo).

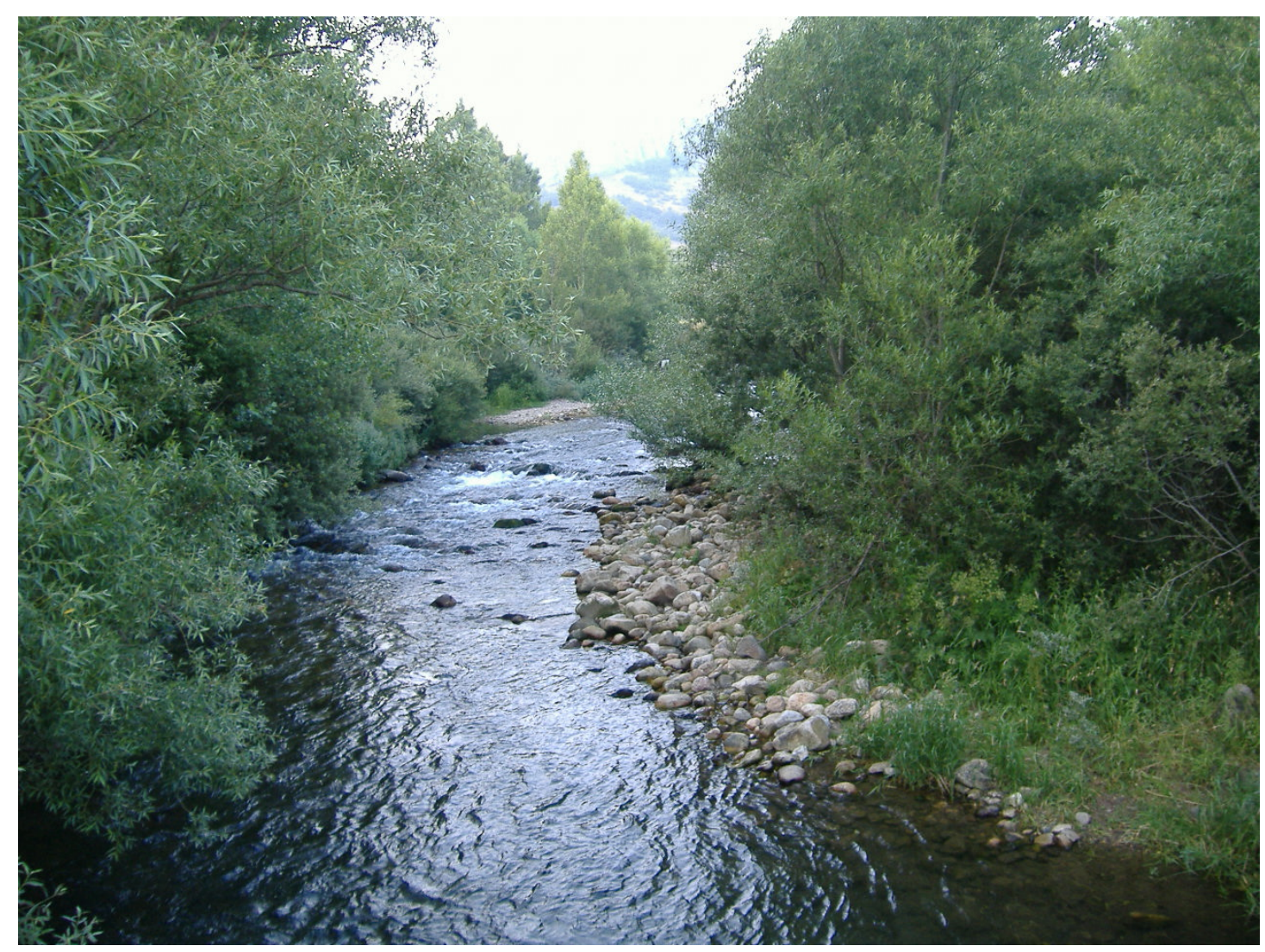

Foto 04 - Río Porma. 
Orográficamente, la cuenca alta del río Porma se halla ubicada en su totalidad en la Cordillera Cantábrica, concretamente en la vertiente sur de la misma (Hernández Hernández, 1987; Robredo et al. 1994). Se caracteriza por la alternancia de rocas duras (cuarcitas y calizas) y blandas (pizarras). Los fuertes contrates topográficos producto de la orogenia hercínico-alpina, se han visto acentuados por el encajamiento de la red fluvial que ha cortado las estructuras perpendicularmente. Los fenómenos de glaciarismo en las cumbres más elevadas, los importantes complejos kársticos, las encajadas gargantas y hoces de paredes casi verticales y la peculiar distribución de pequeñas cuencas intramontañas, son los elementos más significativos de esta región (García de Celis et al. 1988). Se trata de una zona montañosa aunque con valles amplios (García Fernández et al. 2000).

La formación actual del relieve está sobre todo vinculada a las variaciones climáticas ocurridas durante el Cuaternario y a las morfologías que se han originado. Éstas introducen matices y retoques en los sectores superficiales, resaltando unas veces los rasgos del armazón morfoestructural, u ocultándolo, con recubrimientos parciales. En estas fuertes variaciones climáticas han pasado diversas fases frías. De todas las fases frías, es de la última, al final del Pleistoceno superior, de la que se conservan los testimonios más claros. El enfriamiento climático permitió el desarrollo de unas condiciones periglaciares, generalizadas a la mayoría del espacio estudiado, y glaciares, restringidas a los sectores de cabecera más elevados. La importancia morfogenética de esta glaciación se plasma en la presencia de formas erosivas y acumulativas, aunque con diferente desarrollo de unos valles a otros. En el valle del Porma, numerosas cabeceras glaciares configuran crestas y paredes verticales (Redondo Vega et al. 2002). Estos hielos cuaternarios han dejado en las cotas más elevadas del relieve, huellas en forma de circos, morrenas y lagos glaciares (González González et al. 1987).

La zona de estudio pertenece a la región Eurosiberiana (García Fernández et al. 2000). El clima de la zona pertenece al tipo mediterráneo de influencia continental o de invierno frío, con una amplitud térmica fuerte (oscilación media anual de $18{ }^{\circ} \mathrm{C}$ ), temperaturas medias de enero inferiores a $4{ }^{\circ} \mathrm{C}$ y estivales altas (medias alrededor de los $20^{\circ} \mathrm{C}$ ), matizado en algunos sectores por la influencia atlántica (Del Olmo et al. 1994). Los inviernos muy fríos y largos se intensifican con un casi permanente riesgo de heladas durante todo el año. Se caracteriza por el efímero significado de la primavera y otoño y las temperaturas moderadas de los cortos veranos. Así, presenta un clima que, por un lado es frío y húmedo en los meses invernales y aledaños, y por 
el otro, presenta unos veranos cortos y secos (García de Celis et al. 1988). En definitiva, nieve en las cumbres y heladas generalizadas durante el invierno, y el calor estival, seco en la Meseta y húmedo en las sierras, representan los umbrales climáticos de la provincia de León (Luengo Ugidos, 2002) y no solamente de la zona estudiada. Las montañas son los sectores de precipitación más abundante y se registran valores por encima de $1.500 \mathrm{~mm}$ anuales, a menudo en forma de nieve, frente a los apenas $500 \mathrm{~mm}$ de las zonas llanas. Estas precipitaciones se concentran en los meses invernales y otoñales, por lo que a pesar de que se puede hablar de una cierta riqueza hídrica, la aridez estival ocurre a menudo y durante los meses más cálidos, siendo especialmente intensa en la llanura en julio y agosto (García de Celis et al. 1988).

En función de las condiciones termopluviométricas y la disposición orográfica, la cobertura vegetal se caracteriza por la diversidad y complejidad (García de Celis et al. 1988). La existencia de numerosos valles de orientación este-oeste crea unas condiciones climáticas locales, sobre todo de tipo térmico, muy diferentes según la orientación de las laderas. Si a todo ello se une los frecuentes cambios en la naturaleza del roquedo que sustenta el suelo, el resultado es la presencia de una cubierta vegetal que se caracteriza, sobre todo, por su diversidad, así como por la convivencia de especies vegetales que soportan elevados niveles de aridez con otras de marcado carácter atlántico (González González et al. 1987). Según datos bioclimáticos, geológicos, florísticos y de vegetación, el territorio pertenece fitogeográficamente al subsector Ubiñense (Sector Ubiñense-Picoeuropeano, Provincia Orocantábrica, Región Eurosiberiana). En el territorio existen dos pisos bioclimáticos: montano (de ombro-climas subhúmedo, húmedo e hiperhúmedo) y subalpino (de ombroclima hiperhúmedo) (Hernández Hernández, 1987). Entre las especies de matorrales se encuentran enebro rastrero (Juniperus nana), Arándano negro (Vaccinium uliginosum L.), mirtilo (Vaccinium myrtillus L.), brezo (Calluna vulgaris L.) entre otras. Entre las especies de mayor porte se encuentran hayas (Fagus sylvatica), roble peciolado (Quercus petrae) y también abedules (Betuna pubescens Ehrh. subsp. Celtiberica). Los encinares relictos (Cephalanthero longifoliae-Quercetum rotundifoliae) se sitúan en las áreas y biotopos más xerófilos de la zona de estudio (Hernández Hernández, 1987). La riqueza forestal se complementa con la vegetación de ribera (chopos, sauces, alisos, fresnos) que se pueden encontrar a lo largo de los cursos fluviales (García de Celis et al. 1988). Entre la fauna local se encuentran aves tales como urogallo (Tetrao urogallus), carbonero garrapinos (Parus ater), águila imperial, alimoche (Neophron percnopterus). Entre las especies de mamíferos están 
lobo (Canis lupus), lirón careto (Eliomys quercinus), corzos (Capreolus capreolus), jabalíes (Sus scrofa), zorros (Vulpes vulpes) y gato montés. En los ríos el ejemplar más importante es la trucha común, pero también se puede encontrar salmón atlántico (Salmo salar) y cangrejo de río (Austropotamobius pallipes), entre otros (Gil Olcina et al. 2001).

En cuanto a los usos del suelo, en la zona de estudio todavía hay la permanencia de rasgos socioeconómicos de autosubsistencia que guarda una estrecha relación con las dificultades de comunicación que se derivan de los obstáculos orográficos de la Cordillera Cantábrica y de las Montañas del Oeste, y de la escasa atención pública en materia de infraestructura y equipamiento. El aislamiento e incomunicación, la lejanía, la difícil accesibilidad y los graves problemas de transporte e intercambio explican en gran medida la organización tradicional del terrazgo y del espacio en estas comarcas, con un policultivo intensivo en torno a los pueblos y un labradío discontinuo y marginal destinado a la producción cerealística, hoy en gran medida convertido en terreno inculto. El abandono de las tierras afecta a los sectores agrícolas más liminares. El abandono no se refiere exclusivamente a las tierras labradas, sino también a las áreas de pastoreo y a los espacios forestales sobre los que la presión antrópica es ahora sensiblemente menor. Las razones de este abandono, aunque complejas, pueden resumirse en causas fundamentalmente socioeconómicas: escasa rentabilidad de los espacios marginales y envejecimiento de la población agraria a partir del violento éxodo rural, lo que conlleva una recuperación de los antiguos dominios del monte en el caso de abandono de aprovechamientos tradicionales de subsistencia, con frecuencia sobre tierras de carácter público (bienes de propios y comunales) (García de Celis et al. 1988).

\subsection{Cuenca del Río Tajo}

El Tajo es el río más largo de la península y el tercero tanto en superficie total como en aportaciones, después del Ebro y del Duero. Es también la cuenca que tiene mayor peso poblacional de España y de la península y la más solidaria de acuerdo con el volumen de agua que cede a otras cuencas. La cuenca tiene un total de $80.600 \mathrm{~km}^{2}$ hasta la desembocadura en Lisboa y $55.800 \mathrm{~km}^{2}$ en territorio español. El río Tajo discurre desde la Sierra de Albarracín, donde tiene su nacimiento, hasta el estuario del mar de la Paja junto a Lisboa en Portugal, por el centro del Macizo Hespérico en una longitud de $910 \mathrm{~km}$, recogiendo las aguas drenadas por su cuenca vertiente. La 
cuenca del río Tajo muestra marcadas disimetrías hidrográficas, pluviométricas e hidrogeológicas entre la depresión propiamente dicha y sus cordilleras vertientes (Gil Olcina et al. 2001).
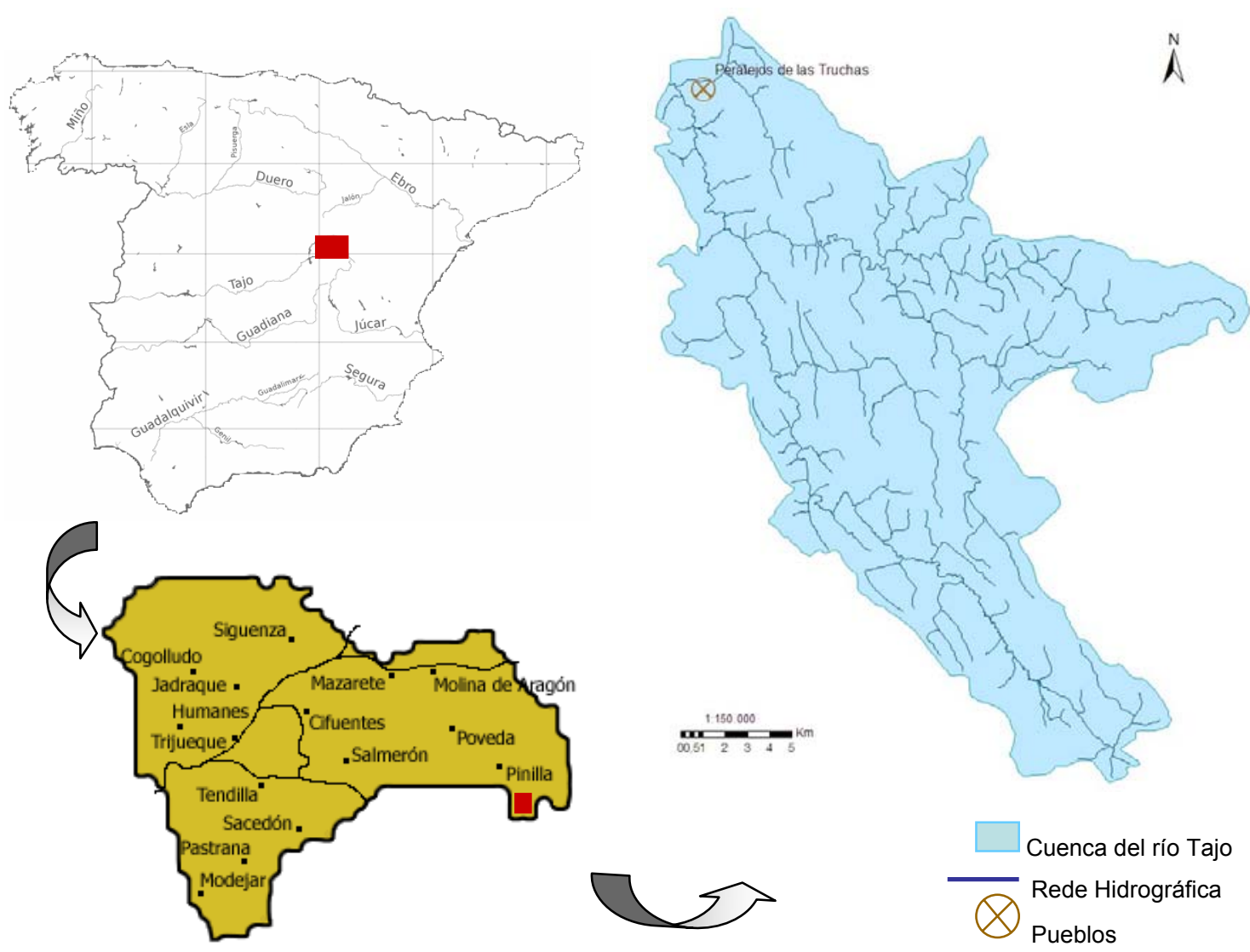

Provincia de Guadalajara

Figura 19 - Localización de la cuenca del río Tajo.

Es importante resaltar que en este estudio sólo será analizada la parte más alta de la cuenca del Río Tajo, localizada en la Provincia de Guadalajara, al norte de la Comunidad Autónoma de Castilla-La-Mancha (Fig. 19). Desde su nacimiento en Fuente García, en la Sierra de Albarracín, en la Cordillera Ibérica, hasta la estación de aforos $n^{\circ} 001$ en Peralejos de las Truchas, con una superficie total de $410 \mathrm{~km}^{2}$. No obstante, en toda la investigación trataremos este tramo de "Cuenca del río Tajo". 


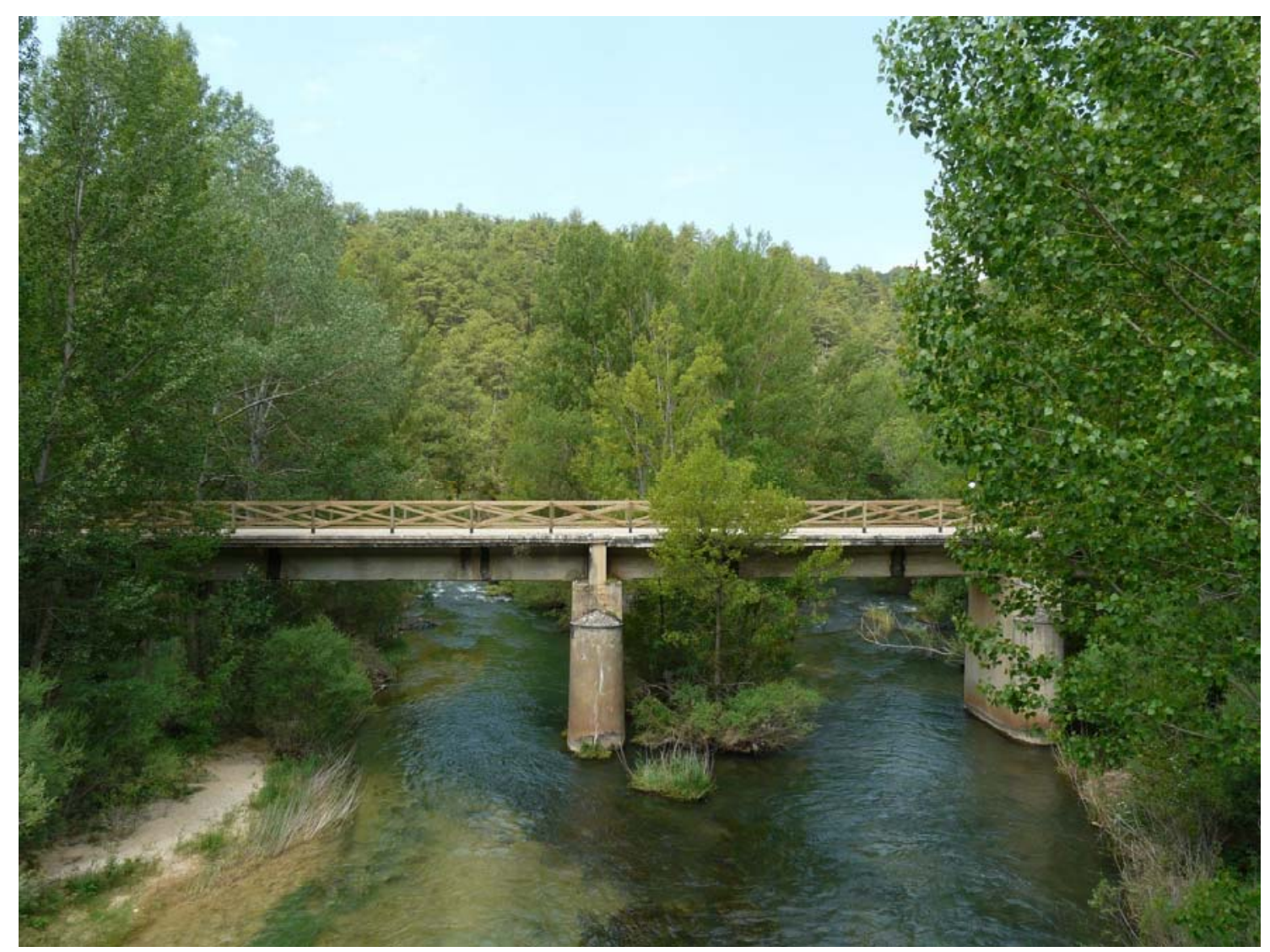

Foto 05 - Río Tajo.

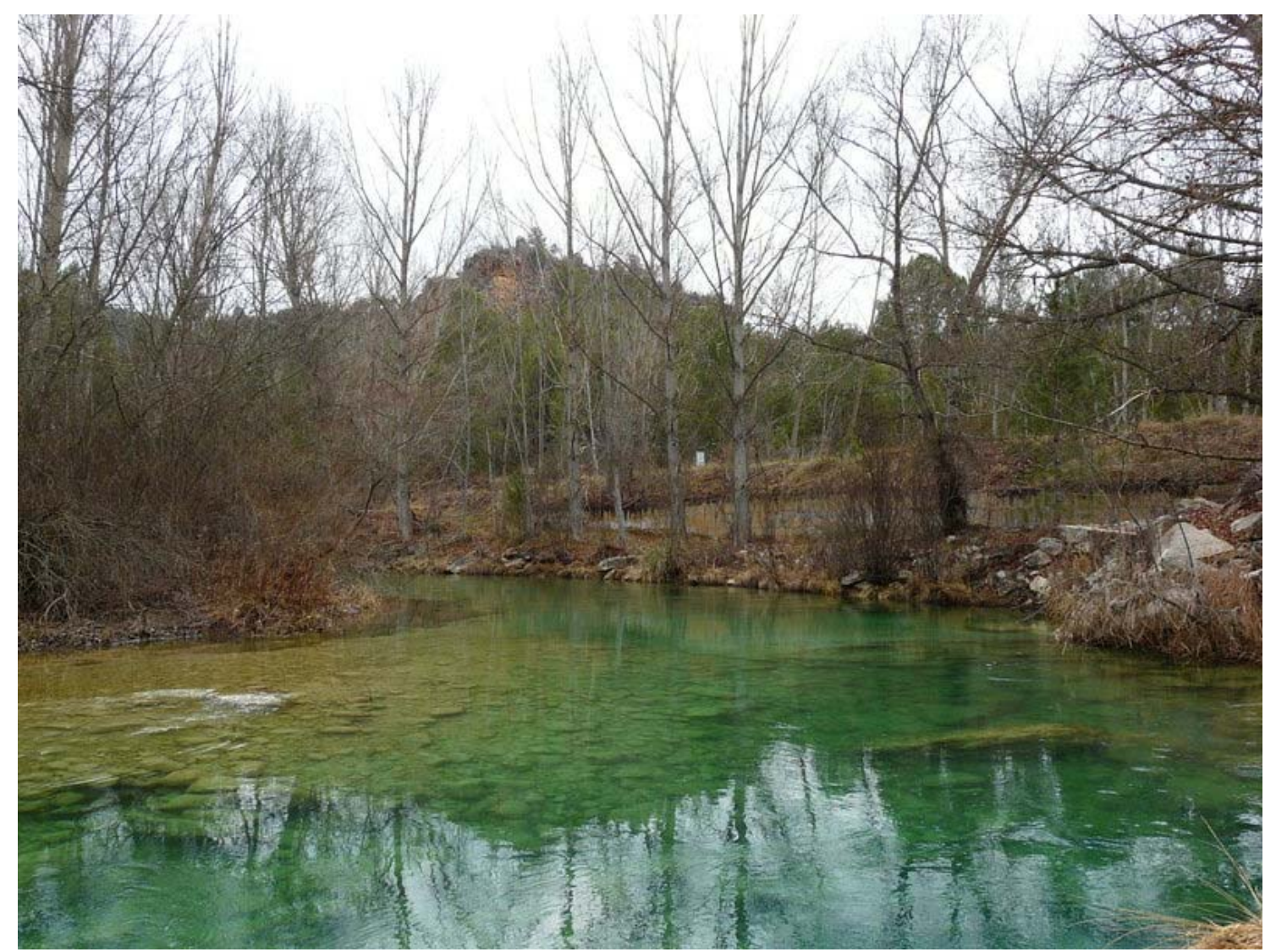

Foto 06 - Río Tajo. 
En este tramo, el río tiene que vencer fuertes pendientes y forma profundos e intrincados cañones sobre calizas y areniscas. El suelo se compone de materiales formados entre el Ordovícico y el Cuaternario, predominando calizas, dolomías y margas, aunque areniscas, conglomerados, arcillas, yesos y sales están bien representados. Por el contrario, son muy reducidos los afloramientos de pizarras y cuarcitas. También son relativamente abundantes los fósiles, encontrándose en la mayoría de las formaciones geológicas. En cuanto a los minerales, hay explotaciones de caolín, cuarzo y arenas feldespáticas, pero lo más típicos son los aragonitos, los yesos rojos y los jacintos de compostela. Los cañones y hoces destacan por su abundancia, longitud, altura y formas singulares, como cuchillos, agujas y monolitos. Calizas y dolomías mesozoicas, de edad jurásica fundamentalmente, y también del Cretácico superior afloran en el Alto Tajo, conformando entre otras la Sierra de Albarracín donde se sitúa el nacimiento de este río. Todo ello sin perder de vista que las llanuras, sobre terrenos carbonatados, presentan abundantes simas, dolinas, lapiaces, torcas y tornos (Flores Montoya et al. 2002, 2004).

La altitud y situación de la zona influyen decisivamente en su clima, caracterizado por temperaturas frescas y moderadas precipitaciones. Inviernos rigurosos y fríos y veranos cortos y suavizados por los cursos de agua, con una pluviometría relativamente escasa. Las precipitaciones se mueven normalmente entre 400 y 1000 $\mathrm{mm}$. Con relación a la temperatura se ven al menos 120 dias en que la mínima baja de $0{ }^{\circ} \mathrm{C}$ y más de 180 de $3^{\circ} \mathrm{C}$. Las medias de enero apenas suben de $0^{\circ} \mathrm{C}$. En los meses de julio y agosto las temperaturas media oscilan entre los 16 y $20{ }^{\circ} \mathrm{C}$. Esporádicamente, las advecciones de aire sahariano sitúan las temperaturas por encima de $30^{\circ} \mathrm{C}$, e incluso de $40^{\circ} \mathrm{C}$. Como contrapunto, pueden registrarse mínimas estivales inferiores a $5{ }^{\circ} \mathrm{C}$ con advecciones de aire ártico marítimo o circulaciones retrógradas (Capel Molina, 1981; Gil Olcina et al. 2001; Flores Montoya et al. 2004).

La región estudiada se caracteriza por la gran diversidad florística ya que alberga importantes especies de la flora ibérica. Entre las plantas más interesantes se puede incluir boca de dragón (Antiurrhinum pulverulentum), bálsamo (Saxifraga corbariensis), crisantemo pálido (Tanacetum pallidum) y zapatitos de la virgen (Sarcocapnos enneaphylla). Son relevantes los extensos pinares de diferentes especies. Se puede observar masas de pino silvestre, laricio y resinero (Pinus pinaster), además de superficies más reducidas pero no menos valiosas de pino carrasco (Pinus halepensis). Estas masas de pinares ocupan principalmente las cuestas de los valles fluviales y las zonas de mayor altitud. Bajo la cubierta de los pinares o formando 
masas puras se encuentran quejigos (Quercus faginea), encinas y melojos. La vegetación asociada a las riberas se caracteriza principalmente por álamo negro (Populus nigra), chopo, fresno, sauce y olmo (Ulmus minor) (Grunfeld, 1988; Flores Montoya et al. 2004).

La gran riqueza de hábitat asociada a las bajas densidades poblacionales, han permitido la existencia de poblaciones animales en buen estado de conservación en la región. Las paredes rocosas que coronan los cañones fluviales albergan poblaciones de rapaces rupícolas como el águila real (Aquila chrisaetos), halcón peregrino (Falco peregrinus), buitre leonado y búho real (Bubo bubo). En las masas arboladas de pinos y frondosas se puede encontrar especies como ratonero (Buteo buteo), arrendajo (Garrulus glandarius), pájaros carpinteros como el pito real (Picus viridis) y pico picapinos (Dendrocopos major). Entre los mamíferos se encuentran gatos monteses, tejones, garduñas (Martes foina), corzos, ciervos (Cervus elaphus), nutria (Lutra lutra) y jabalíes. En los tramos altos de los cursos fluviales de la cuenca del Tajo los salmónidos, como es el caso de la trucha, son las especies de peces mejor adaptadas a sus aguas rápidas, frías y oxigenadas. También se puede encontrar el barbo común (Barbus bocagei graellsii) (De la Peña, 1995; Flores Montoya et al. 2004).

Es importante resaltar que en la zona fue creado en el año 2000 por la ley $1 / 2000$, de 6 de abril el Parque Natural del Alto Tajo, que ocupa un total de 176.265 ha y abarca los municipios Cifuentes, Sacecorbo, Esplegares, Saelices de la Sal, Riba de Saelices, Arbeteta, Valtablado, Ocentejo, Armallones, Huertahernando, Ablanque, Anguita, Cobeta, Olmeda de Cobeta, Selas, Torremocha del Pinar, Corduente, Valhermoso, Tierzo, Terzaga, Pinilla de Molina, Megina, Traid, Alcoroches, Alustante, Orea, Checa, Chequilla, Peralejos de las Truchas, Taravilla, Baños de Tajo, Fuenbellida, Poveda de la Sierra, Peñalén, Zaorejas, Villanueva de Alcorán, Cuenca y Beteta. Toda la superficie está incluida en la propuesta de lugares que integran la Red NATURA 2000 como Lugar de Interés Comunitario (LIC) y Zona de Especial Protección para las Aves (ZEPA), lo que significa un gran paso a la conservación de la naturaleza en la zona de estudio.

Con relación a los usos del suelo y al desarrollo de la población en el área de estudio, el panorama es muy parecido con los descritos anteriormente para las cuencas de los ríos Cega y Porma. Durante la década de 1960-70, todo el Alto Tajo tiene una clara reducción en la población que migra principalmente a Madrid que en esta misma década tiene un aumento poblacional de 45,5\% (Flores Montoya et al. 2002). 
Evidentemente esta realidad afectó la gran mayoría de los pequeños municipios de España que sufrieron una fuerte despoblación debido a la emigración a los grandes centros urbanos. Debido a este fuerte éxodo rural y al consecuente envejecimiento demográfico en la zona de estudio la economía, únicamente de subsistencia, se ha basado tradicionalmente en la ganadería trashumante y en la explotación de los recursos madereros (Flores Montoya et al. 2004; Herrera Casado, 2005; Merino Poyo et al. 2008).

\subsection{Cuenca del Río Trabaque}

La cuenca del Río Trabaque se localiza en la Comunidad Autónoma de Castilla-La Mancha, en la Provincia de Cuenca, con una superficie total de $361 \mathrm{~km}^{2}$, hasta la estación de aforo 186 en Priego (Fig. 20). El Trabaque desemboca en el río Guadiela que es un importante tributario de la cabecera del río Tajo.

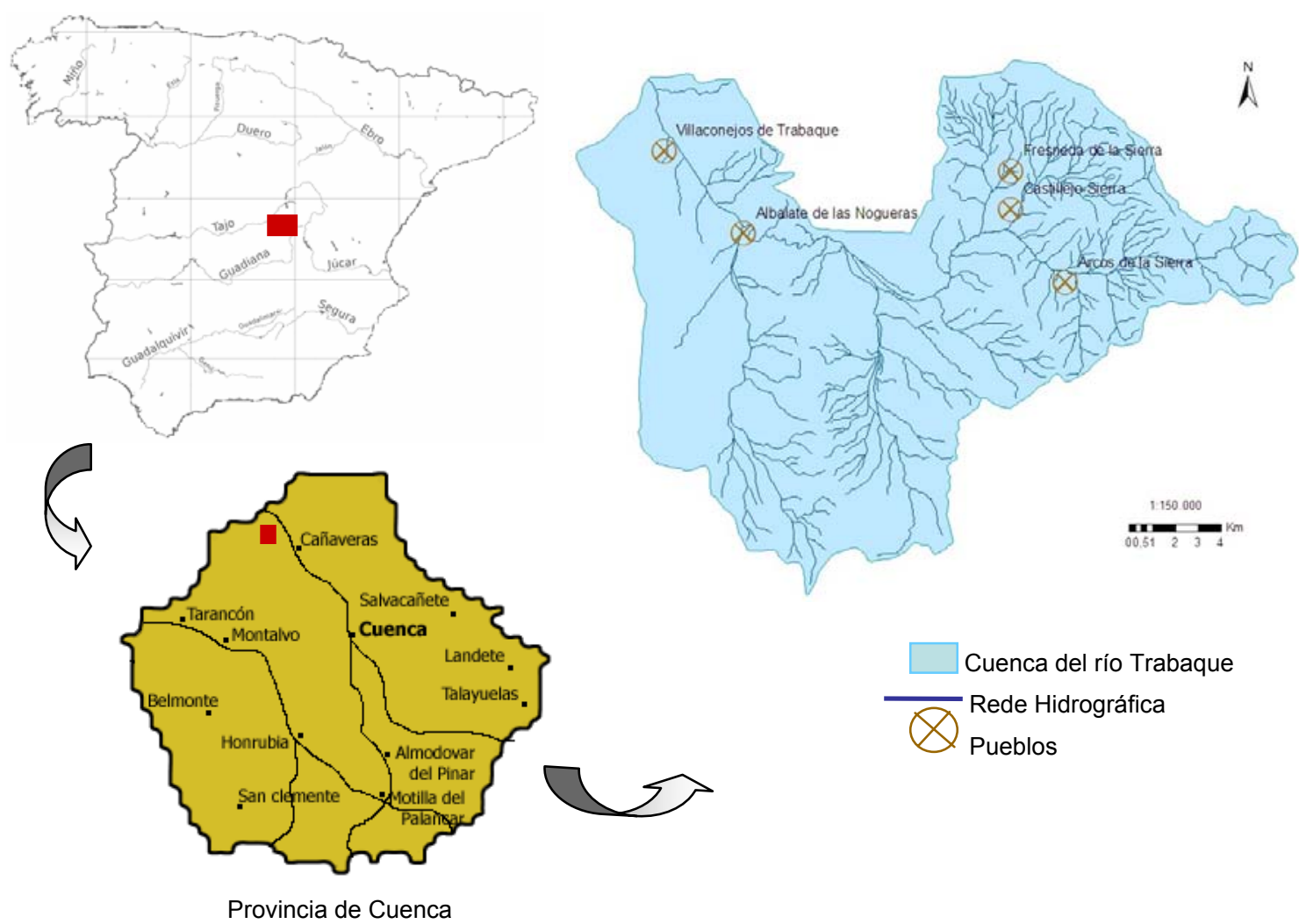

Figura 20 - Localización de la cuenca del río Trabaque. 


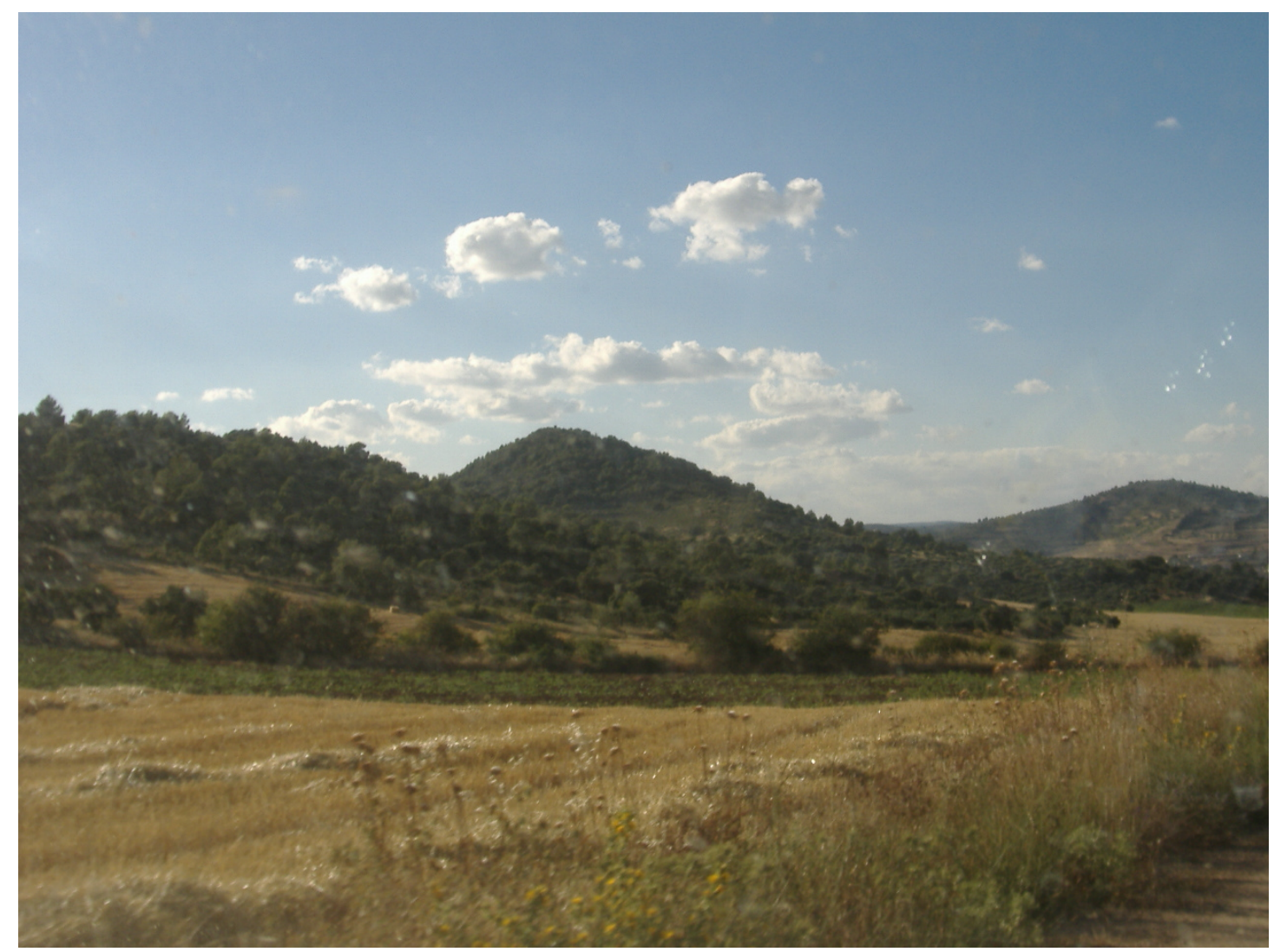

Foto 07 - Vista parcial de la cuenca del río Trabaque.

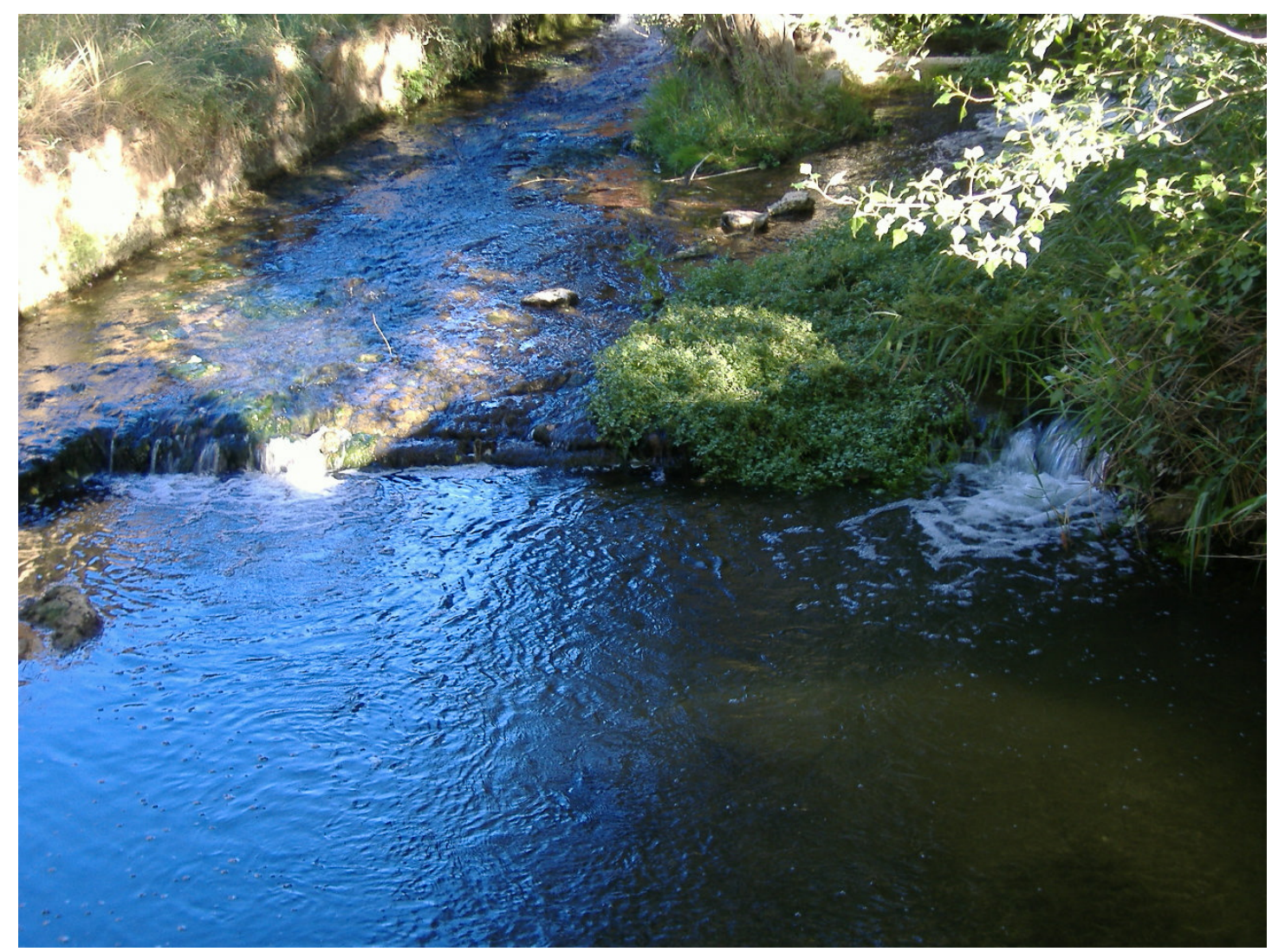

Foto 08 - Río Trabaque. 
El río Trabaque se localiza en la Depresión Intermedia, cuenca terciaria de relleno fundamentalmente lutítico-arenoso, que se extiende entre los afloramientos carbonatados mesozoicos de la alienación de la Sierra de Altamira, al oeste, y de las estribaciones de la Serranía de Cuenca (perteneciente al sector meridional de la Rama Castellana de la Cordillera Ibérica), al este.

El inicio de su historia geológica podemos situarlo en el Paleozoico, tiempo geológico durante el cual esos territorios estaban formando grandes cordilleras producto de la Orogenia Herciniana (Flores Montoya et al. 2004). En el Pleistoceno una relativamente larga red fluvial fue formada, relacionando los ríos Guadiela, Escabas y Trabaque. Hay un escenario paleogeográfico común en la historia de los tres ríos:

- Predominio de rocas carbonatadas fuertemente karstificadas formando el área de drenaje de los tres ríos produciendo aguas ricas en calcio y bicarbonato;

- Las cabeceras de los tres ríos alcanzan la Depresión Intermedia a través de profundos cañones;

- Aguas superficiales y calientes con colonias de plantas acuáticas y florecimiento de algas (Torres et al. 2005).

La unidad dónde se encuentra el río Trabaque, muy antigua, de origen precámbrico, está básicamente constituida por elementos graníticos y rocas metamórficas profundas, en sus partes centrales, y por elementos metamórficos más superficiales, especialmente pizarras, que afloran en los extremos de dichas cadenas montañosas (Flores Montoya et al. 2004).

El clima de la región es mediterráneo continentalizado, con matices de montaña y áreas de influencia atlántica (Flores Montoya et al. 2004). Los inviernos son fríos y los veranos muy cálidos, con la mayor amplitud térmica de España $\left(18-20,5^{\circ} \mathrm{C}\right)$. El rigor de los inviernos tiene más de 60 días al año de registros iguales o inferiores a $0{ }^{\circ} \mathrm{C}$. Las medias de enero varían entre 4 y $6{ }^{\circ} \mathrm{C}$. La niebla es frecuente en el invierno. $\mathrm{El}$ verano es muy caluroso. Las medias de julio y agosto alcanzan o rebasan a los 22,5 ${ }^{\circ} \mathrm{C}$ (Gil Olcina et al. 2001). Las precipitaciones se caracterizan por la relativa pobreza de los valores que éstas alcanzan, por la enorme irregularidad estacional e interanual con que se producen y por su concentración en escasos días a lo largo del año, entre 65 y 80 días de precipitación, que ocasionan la existencia de 2 a 4 meses marcadamente secos. Los meses más secos son julio y agosto que, coincidentes con las temperaturas más elevadas, causan un déficit hídrico de enorme amplitud (Flores 
Montoya et al. 2004). Las lluvias quedan entre 325 y $550 \mathrm{~mm}$. Los valores máximos corresponden a invierno y primavera en que las precipitaciones se vinculan a advecciones de aire polar o ártico; en verano, con fenómenos convectivos, resueltos a veces en intensos aguaceros tormentosos que ocasionan inundaciones locales (Gil Olcina et al. 2001).

El río Trabaque tiene parte de su cuenca el piso bioclimático supramediterraneo donde se encuentran melojos, quejigos y algunos ejemplares de encinas, y parte en el mesomediterraneo donde se encuentran los alcornocales (Quercus suber) y algunas series de encinas (Baeza Sanz et al. 1999). Entre las especies vegetales de la zona se destaca al mimbre (Salix viminalis). Entre la vegetación de ribera local es posible encontrar especies arbóreas como sauce y álamo (Populus alba). En otoño abundan níscalos (Lactarius deliciosus) y setas de chopo (Pleurotus ostreatus). Distintas especies de fauna se adaptan a sus paisajes. Entre los mamíferos se destacan el ciervo, corzo, ardillas, zorros, nutria y jabalí. Como aves representativas se pueden citar alimoche, buitre, águila real y perdicera (Hieraaetus fasciatus), halcón, mirlos (Turdus merula) y petirrojos (Erithacus rubecula). En el medio acuático abundan los cangrejos de río y las truchas (López González, 2001).

Como ha ocurrido en toda España, también esta región perdió por razones migratorias más del $20 \%$ de su población en la década de 60 . El abandono de las prácticas y de las orientaciones productivas tradicionales corre paralelo al cambio de las distintas estructuras económicas regionales y de la demanda agroalimentaria del conjunto de España. Desde los años sesenta, la crisis de la agricultura tradicional y el proceso de industrialización y urbanización, introdujeron modificaciones a menudo notables del hábitat rural, entre cuyas expresiones más extremas se encuentra la despoblación y el consiguiente abandono de un número no pequeño de núcleos rurales (Gil Olcina et al. 2001). Como ocurre en la mayoría de las cuencas de cabeceras, en el Trabaque, la agricultura viene sufriendo una fuerte reducción y las poblaciones están abandonando las tierras de usos agrícolas, pastoreo y las áreas forestales. En toda la zona una actividad económica que todavía sobrevive son los trabajos artesanales utilizando el mimbre, que por este motivo es considerada una de las más importantes especies vegetales de la zona. La mayoría de los productos son vendidos en las propias casas de los artesanos o se vende el mimbre a empresas de otras regiones como materias primas para otros productos (Rodríguez Cohard, 2002). 


\section{VARIABLES HIDROLÓGICAS}

Tal y como fue anteriormente mencionado, para hacer los análisis de las variables hidrológicas se utilizaron los datos de las Confederaciones Hidrográficas del Duero y del Tajo. Cabe en este punto resaltar que son utilizadas en este estudio las cuencas de los ríos que vienen definidas por las estaciones de aforo citadas en la tabla 15. Por lo tanto, aunque no se trate de toda la extensión de la cuenca, para facilitar la comprensión del documento así como para crear un patrón, a estas sub-cuencas se les denominará en todo el estudio cuencas de los ríos Cega, Porma, Tajo y Trabaque.

La serie histórica empleada en esta investigación es de 31 años, siendo homogénea para las cuatro cuencas. El período estudiado va desde 1974 hasta 2004. Se ha utilizado un período igual para todas con el objeto de que las comparaciones acerca del comportamiento hidrológico de estas cuencas sean rigurosas. Además, se ha empleado el año hidrológico, con inicio en el 1 de octubre de un año y final el 30 de septiembre del siguiente.

Tabla 15. Datos de localización de las estaciones de aforo utilizadas.

\begin{tabular}{|l|c|c|c|c|c|c|c|c|}
\hline \multicolumn{1}{|c|}{ Río } & $\begin{array}{c}\text { Estac. } \\
\mathbf{N}^{\circ}\end{array}$ & Localización & UTM X & UTM Y & Provincia & $\begin{array}{c}\text { Cota } \\
\mathbf{m i n} .(\mathbf{m})\end{array}$ & $\begin{array}{c}\text { Cota } \\
\text { máx. }(\mathbf{m})\end{array}$ & $\begin{array}{c}\text { Sup. } \\
\mathbf{K m}^{\mathbf{2}}\end{array}$ \\
\hline Cega & 016 & $\begin{array}{c}\text { Pajares de } \\
\text { Pedraza }\end{array}$ & 428405 & 4557885 & Segovia & 937 & 2209 & 280 \\
\hline Porma & 078 & Camposolillo & 315893 & 4762264 & León & 1092 & 2157 & 154 \\
\hline Tajo & 001 & $\begin{array}{c}\text { Peralejos de } \\
\text { las Truchas }\end{array}$ & 590452 & 4494469 & Guadalajara & 1143 & 1920 & 410 \\
\hline Trabaque & 186 & \multicolumn{10}{|c|}{ Priego } & 557275 & 4475300 & Cuenca & 785 & 1618 & 361 \\
\hline
\end{tabular}




\subsection{Evolución del Caudal en la Cuenca Del Río Cega}

\subsubsection{Caracterización hidrológica}

La cuenca del río Cega fue analizada desde donde nace, en el término municipal de Navafría, hasta la estación de aforos $n^{\circ}$ 016, localizada en Pajares de Pedraza, en la provincia de Segovia (Foto 09, Fig. 21).

Esta estación de aforos recoge los caudales de la cabecera del río Cega con una superficie total de $280 \mathrm{~km}^{2}$. En todo este recorrido no hay ninguna derivación, siendo este uno de los criterios citados anteriormente en el apartado material y métodos para la elección de las cuencas utilizadas en este estudio. Se registra en el aforo un caudal medio anual de 3,02 $\mathrm{m}^{3} \mathrm{~s}^{-1}$, con una aportación media anual de $96,3 \mathrm{hm}^{3}$.

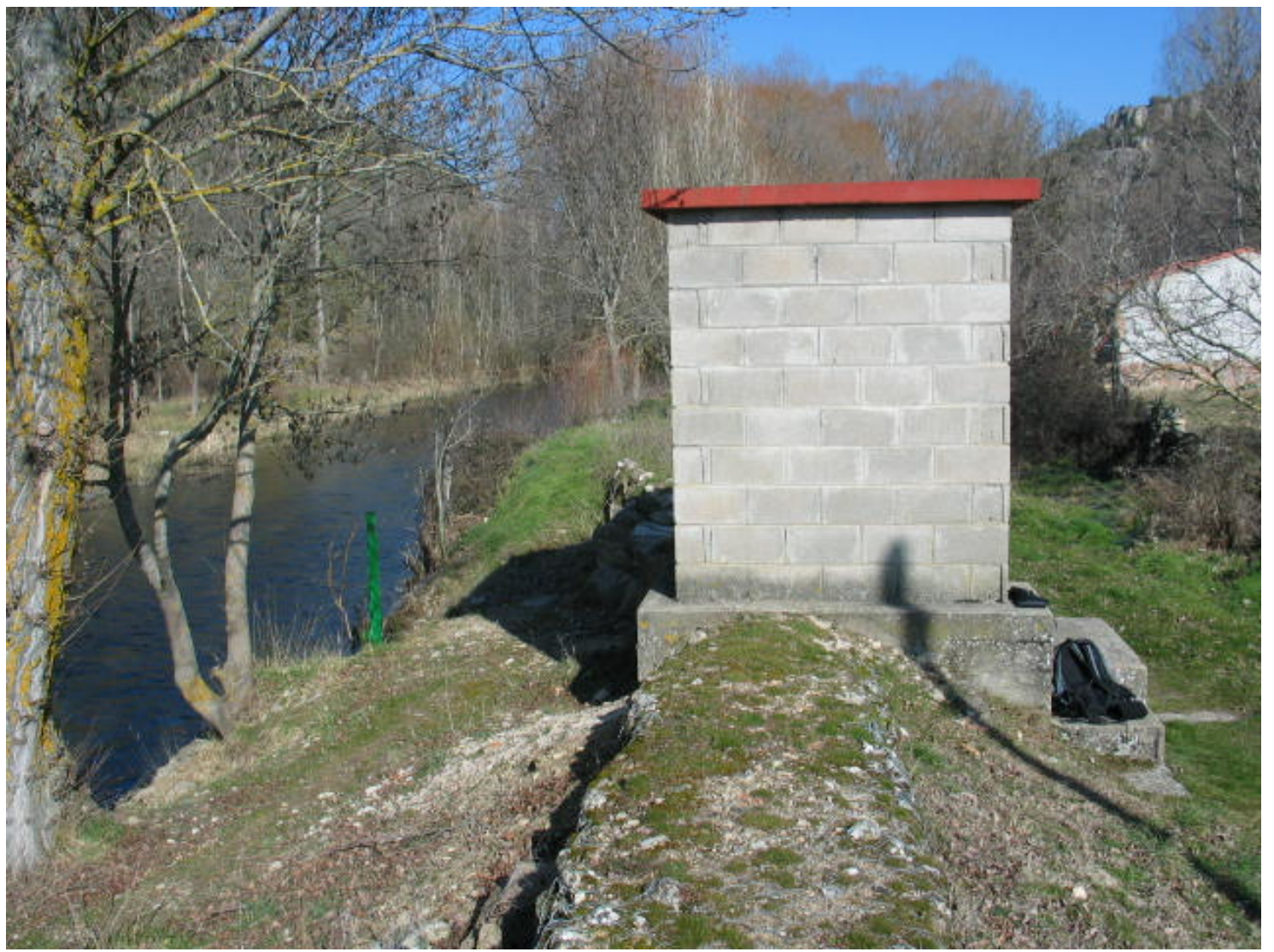

Foto 09 - Estación de aforo 016 en Pajares de Pedraza - Río Cega. 


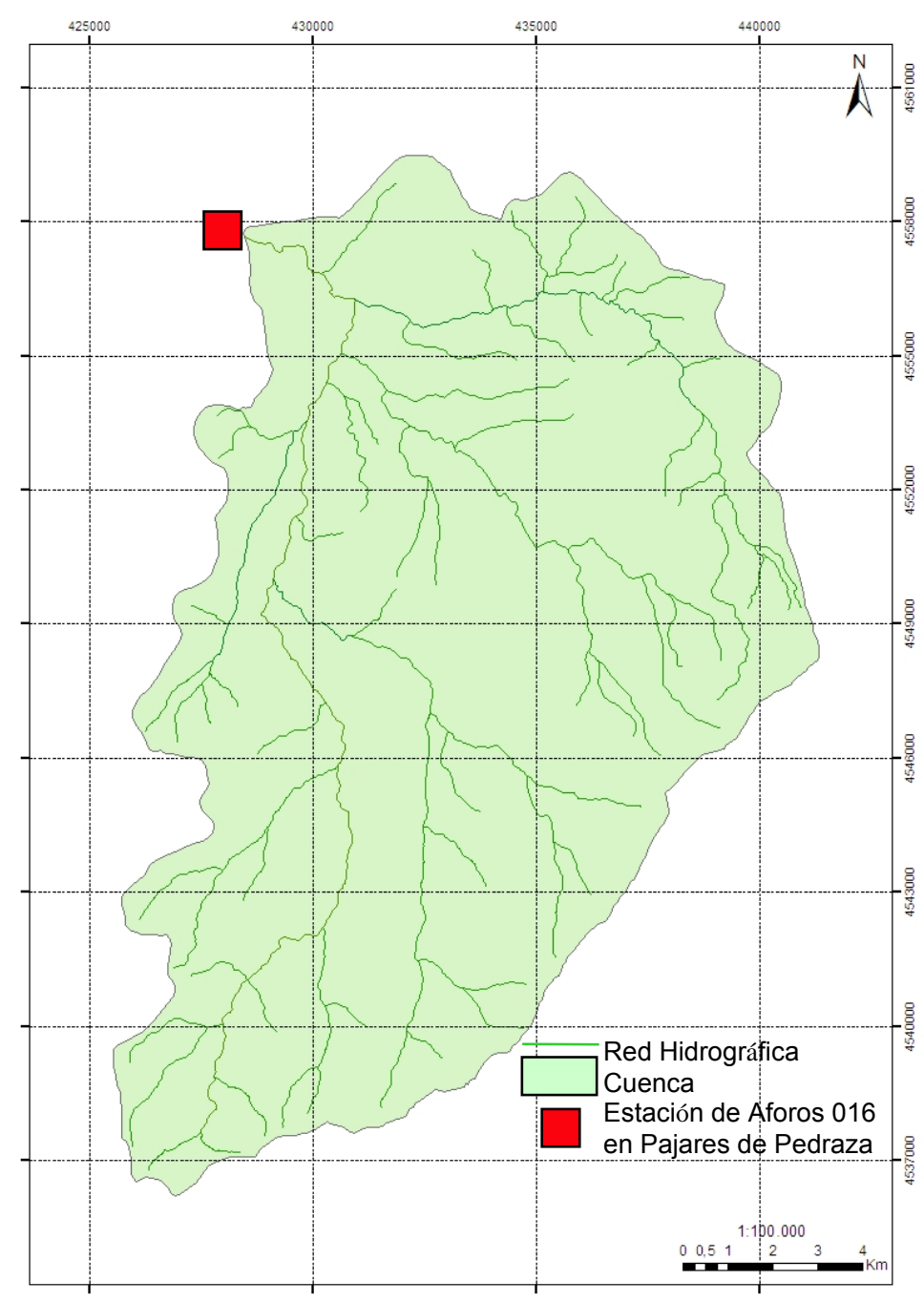

Figura 21 - Cabecera del río Cega y localización de la estación de aforo 016 en Pajares de Pedraza.

Para el análisis del régimen de los ríos se ha utilizado el caudal relativo. Este es una herramienta muy eficaz para la comparación espacial y temporal de los caudales de diferentes estaciones de aforo y de diferentes cuencas. El río Cega presenta un régimen de tipo pluvial, con un aumento más acusado en los meses de diciembre, enero y febrero y un aumento menos destacado en los meses primaverales de abril y mayo. En febrero se ha observado el caudal relativo más alto.

La figura 22 refleja fuertes contrastes estacionales en los valores de caudal relativo. Se puede observar también que este no supera el doble del caudal medio en ningún mes del año. El período llamado de aguas altas, en que los caudales están por encima de la media, se extiende desde el mes de diciembre hasta el mes de mayo. 


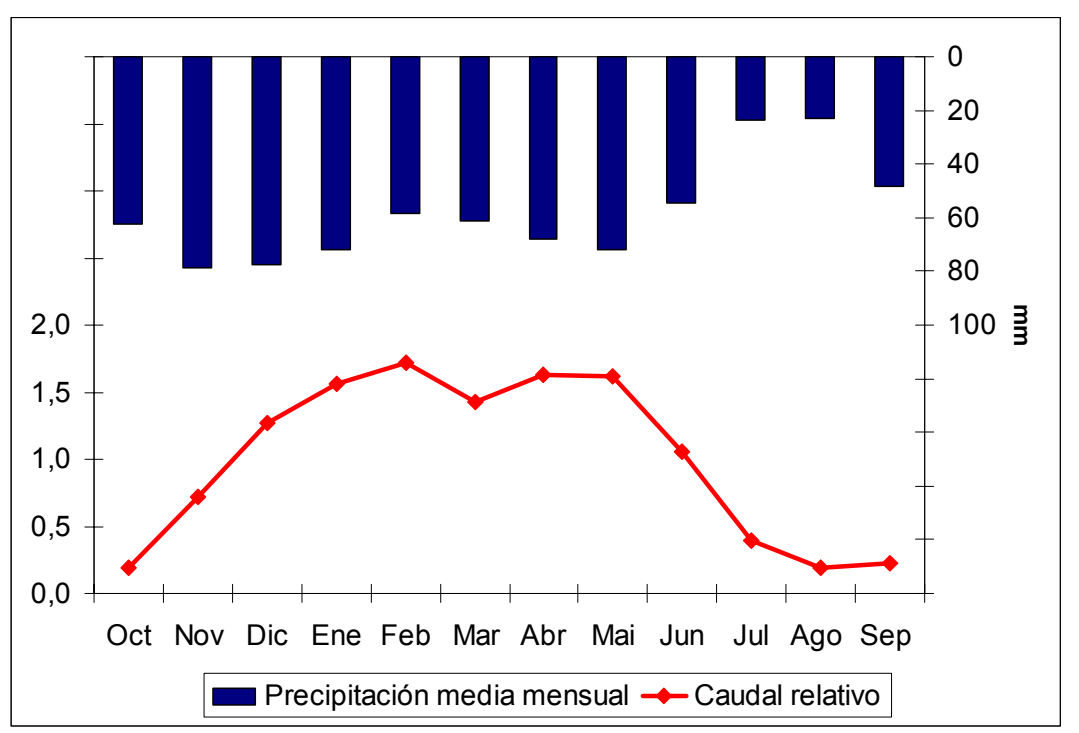

Figura 22 - Caudal relativo (adimensional) y precipitación media mensual en la cuenca del río Cega en la estación 016 en Pajares de Pedraza.

A partir de junio empieza a haber un descenso llegando a un fuerte período de aguas bajas en los meses de julio, agosto, septiembre y octubre. Este período también es llamado estiaje y no depende solamente de la escasez de precipitaciones, sino que también se debe a la mayor evapotranspiración y a la evaporación más intensa de los cursos de agua y los caudales son los mínimos (García Codrón et al. 2004). Los meses en que se registran los menores valores de caudal son agosto y octubre, llegando a valores próximos a cero en muchas fechas. Los resultados encontrados reflejan muy bien las características del verano mediterráneo con precipitaciones bastante escasas y elevadísima evapotranspiración. Solamente a partir de noviembre empieza a haber un aumento en los valores de caudal registrados.

Al analizar los caudales de cada año se concluye que, en la mayoría de ellos, el mes de octubre presenta valores absolutos más altos que los meses de agosto y septiembre (Tabla 16). Sin embargo, han sido encontrados valores atípicos en los años de 1993, 1996, 1997 y 1998, en que los meses de agosto y septiembre presentan valores más altos que octubre. Estos datos fueron corroborados por los de la estación Lastras de Cuellar ( $\left.N^{\circ} 714\right)$ que presentó una alta correlación $(r=0,83)$ con la estación 016, utilizada en esta investigación. Los resultados encontrados en estos años, por tratarse de valores atípicos, llevan a valores de caudal medio, relativo, específico y aportación ligeramente más bajos en octubre con relación a agosto y septiembre. No obstante estos datos pueden ser engañosos. Esto se comprueba al analizar la mediana que presenta valores de octubre superiores a agosto y septiembre, 
algo que parece más coherente. Esto ocurre pues la mediana está menos condicionada por los valores extremos que la media. De todas formas, el valor encontrado con la mediana tampoco difiere mucho, ya que siguen siendo los meses de agosto, septiembre y octubre en donde se encuentran los valores de caudales más bajos.

Tabla 16. Estadística básica de los caudales medios del Río Cega en Pajares de Pedraza para el período hidrológico de 1974 - 2004.

\begin{tabular}{|c|c|c|c|}
\hline \hline Período & $\begin{array}{c}\text { Caudal Medio } \\
\left(\mathbf{m}^{\mathbf{3}} \mathbf{s}^{-1}\right)\end{array}$ & $\begin{array}{c}\text { Mediana } \\
\left(\mathbf{m}^{\mathbf{3}} \mathbf{s}^{-1}\right)\end{array}$ & $\begin{array}{c}\text { Caudal } \\
\text { Relativo }\end{array}$ \\
\hline \hline ANUAL & 3,02 & 2,90 & 1,00 \\
\hline OCT & 0,57 & 0,38 & 0,19 \\
\hline NOV & 2,16 & 2,10 & 0,71 \\
\hline DIC & 3,85 & 3,02 & 1,27 \\
\hline ENE & 4,73 & 3,55 & 1,56 \\
\hline FEB & 5,18 & 3,33 & 1,71 \\
\hline MAR & 4,31 & 3,19 & 1,43 \\
\hline ABR & 4,94 & 3,83 & 1,63 \\
\hline MAY & 4,89 & 3,78 & 1,62 \\
\hline JUN & 3,19 & 1,25 & 1,06 \\
\hline JUL & 1,19 & 0,38 & 0,39 \\
\hline AGO & 0,58 & 0,07 & 0,19 \\
\hline SEP & 0,69 & 0,12 & 0,23 \\
\hline \hline
\end{tabular}

El caudal diario del río Cega presenta una variabilidad muy alta, con un coeficiente de variación del 143,4\%. En muchos días el caudal ha llegado a valores muy próximos a cero y el valor máximo diario registrado fue de $67,6 \mathrm{~m}^{3} \mathrm{~s}^{-1}$.

La figura 23 refleja los coeficientes $Q \times 3$, Qx5 y Qx10 para los datos diarios del caudal del río Cega. Dichos coeficientes expresan los valores alcanzados cuando el río registra tres, cinco o diez veces su caudal medio.

Del análisis de los datos se ha visto que en el río Cega en Pajares de Pedraza hubo, en el período estudiado, 835 días que registraron el triple del caudal medio, es decir, un $7,4 \%$ de aguas altas. Del total de días registrados en la estación de aforos 016 , solamente 2,6\% (289) superaron en cinco veces el caudal medio y tan sólo 0,23\% (26) superaron en diez veces este umbral. 


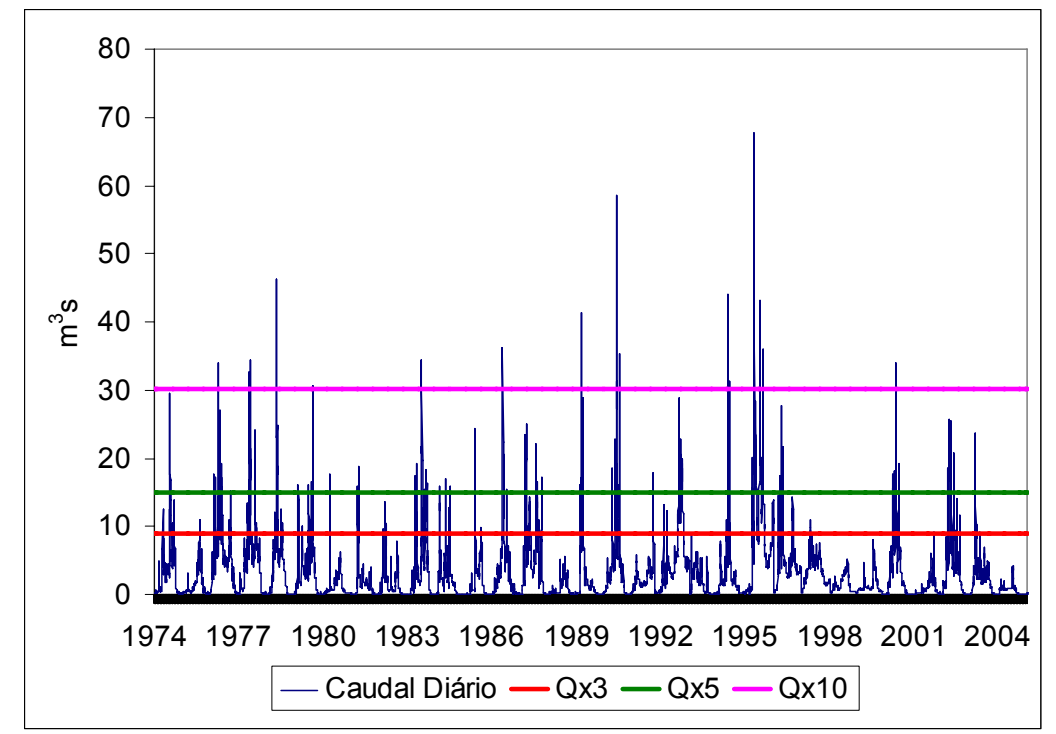

Figura 23 - Distribución de caudales diarios del río Cega en Pajares de Pedraza y los correspondientes a $3(Q \times 3), 5(Q \times 5)$ y $10(Q \times 10)$ veces el caudal medio en el período hidrológico 1974-2004.

Al analizar la frecuencia de los caudales diarios (Fig. 24) se ve que la mayoría están entre 0 y $10 \mathrm{~m}^{3} \mathrm{~s}^{-1}(93,9 \%)$. Por otro lado, se registran un total de $6,0 \%$ de caudales diarios entre 11 y $40 \mathrm{~m}^{3} \mathrm{~s}^{-1}$ y solamente $0,1 \%$ entre 41 y $50 \mathrm{~m}^{3} \mathrm{~s}^{-1}$. Las ligeras diferencias entre los valores medios demostrados en los gráficos de frecuencia y en las tablas de estadísticas básicas se dan debido a que en estas los cálculos fueron realizados con datos mensuales y en los gráficos con datos diarios.

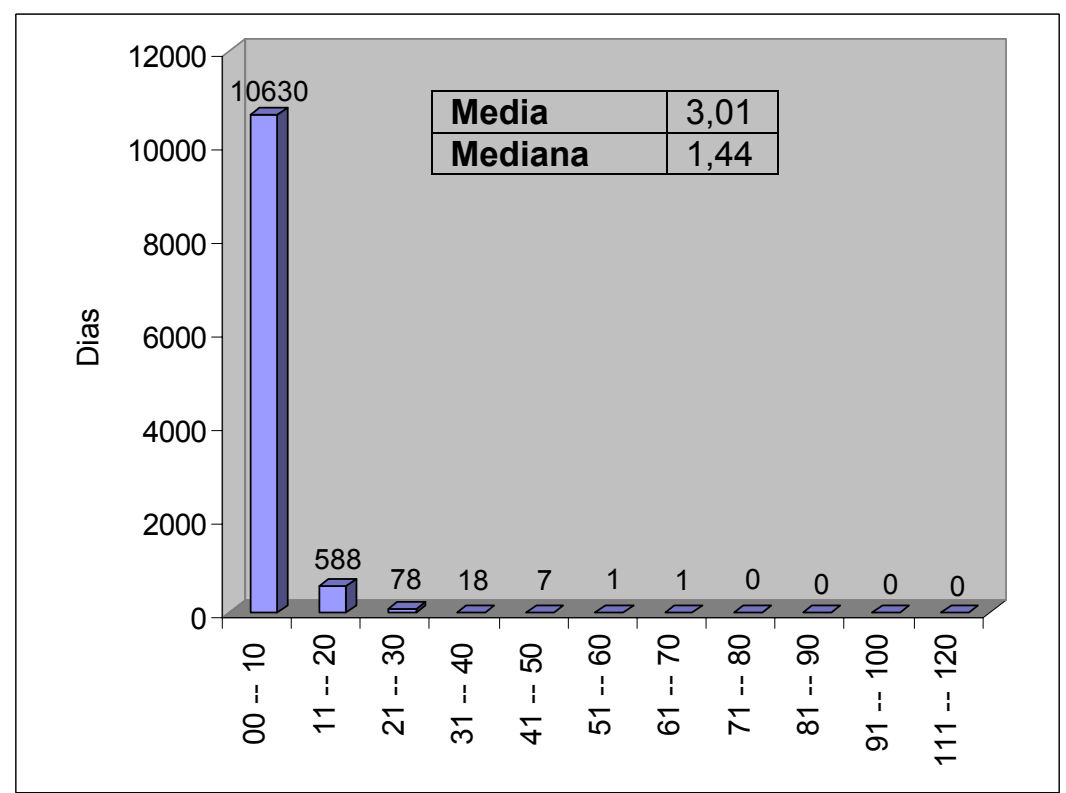

Figura 24 - Distribución de frecuencias de los caudales diarios del río Cega con indicación de la media y de la mediana. 
El coeficiente de variación del caudal medio anual es de $63,3 \%$ (Tabla 17). Estos resultados dejan clara la existencia de una variabilidad anual alta que es confirmada por los valores mensuales encontrados. Todos los meses presentan una variabilidad bastante alta (>50\%), lo que refleja muy bien las características mediterráneas del área de estudio. Los meses de junio, julio, agosto, septiembre y octubre son los meses que presentan valores más altos de coeficientes de variación, todos por encima de $100 \%$, llegando a $239 \%$ en agosto y $267,6 \%$ en el mes de septiembre. Estos dos valores son los más altos encontrados entre todas las cuencas analizadas. Por otro lado, los valores más bajos se dan en los meses primaverales, siendo en el mes de mayo el valor más bajo con $76,2 \%$.

Tabla 17. Coeficiente de variación de los caudales medios mensuales y anuales del Río Cega en Pajares de Pedraza para el período hidrológico de 1974 - 2004.

\begin{tabular}{|c|c|}
\hline Período & $\begin{array}{c}\text { Coeficiente de Variación } \\
\%\end{array}$ \\
\hline ANUAL & 63,3 \\
\hline OCT & 117,1 \\
\hline NOV & 87,0 \\
\hline DIC & 81,1 \\
\hline ENE & 87,1 \\
\hline FEB & 90,7 \\
\hline MAR & 77,2 \\
\hline ABR & 78,8 \\
\hline MAY & 76,2 \\
\hline JUN & 118,3 \\
\hline JUL & 182,2 \\
\hline AGO & 239,0 \\
\hline SEP & 267,6 \\
\hline \hline
\end{tabular}

A partir del análisis de la figura 25 se puede observar que los coeficientes de variación anual presentan una ligera disminución en el tiempo, lo que significa que la variabilidad interanual está sufriendo una pequeña reducción y una ligera tendencia negativa, aunque esta no puede ser considerada significativa.

La gran variabilidad encontrada en la cuenca del río Cega, sobre todo en los valores de los caudales medios mensuales, puede representar un problema en el momento de analizar las tendencias de los caudales. 


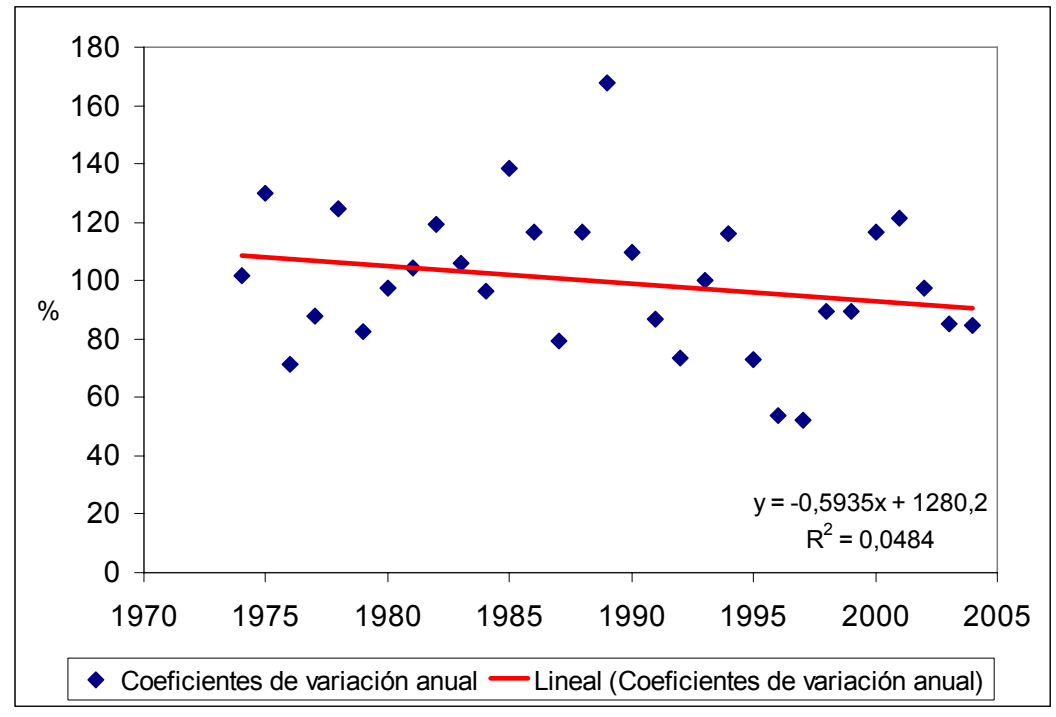

Figura 25 - Coeficientes de variación interanual del río Cega con indicación de su tendencia - Período 1974 - 2004.

Las figuras 26 y 27 presentan las variaciones interanuales en los valores de las aportaciones de septiembre y mayo, meses con mayor y menor coeficiente de variación, respectivamente. Es posible identificar que los valores más altos son en años (1992 y 1995) coincidentes en ambos meses.

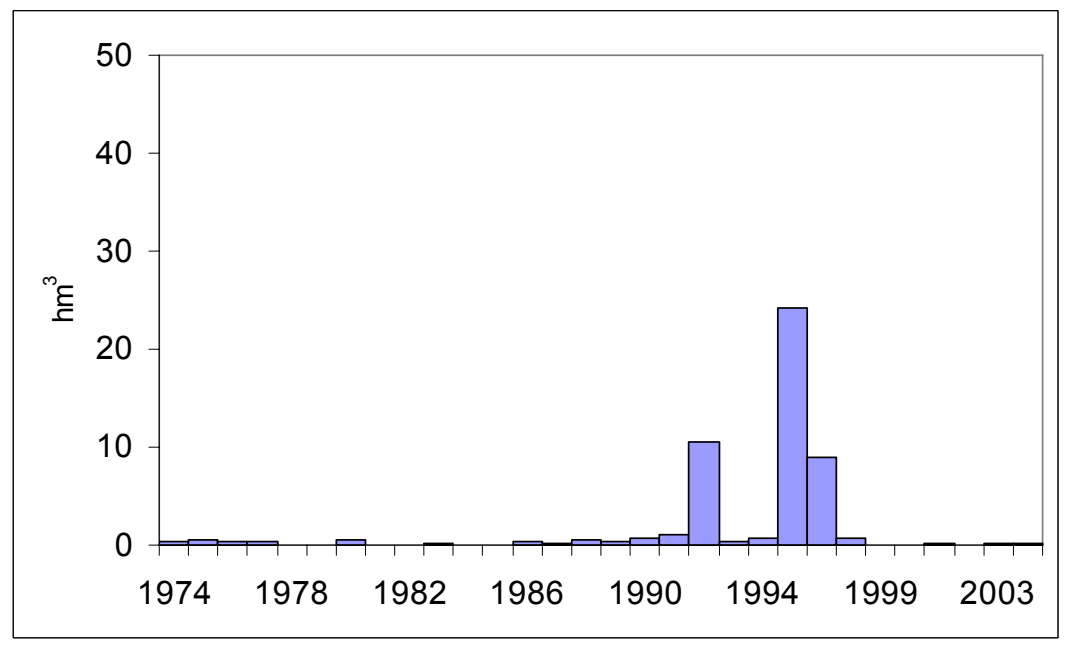

Figura 26 - Aportaciones del mes de septiembre en la estación de aforo 016, del río Cega en Pajares de Pedraza. 


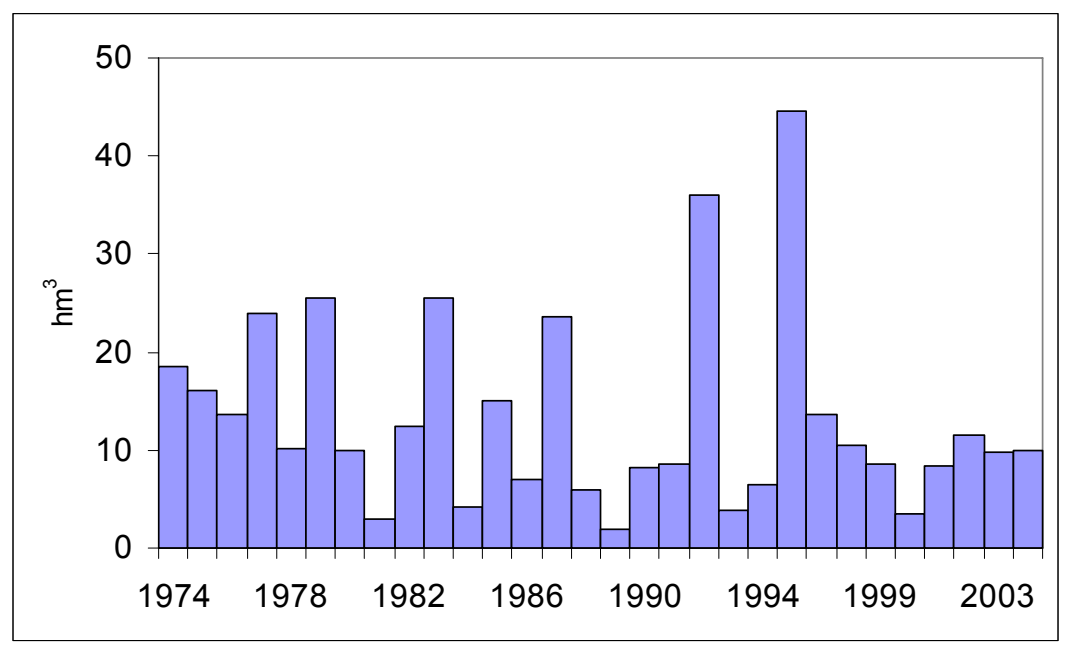

Figura 27 - Aportaciones del mes de mayo en la estación de aforo 016, del río Cega en Pajares de Pedraza.

Tabla 18. Caudal específico del Río Cega en Pajares de Pedraza para el período hidrológico de 1974 - 2004.

\begin{tabular}{|c|c|}
\hline \hline Período & $\begin{array}{c}\text { Caudal Específico } \\
\left(\mathbf{( I s}^{-1} \mathbf{k m}^{-\mathbf{2}}\right)\end{array}$ \\
\hline \hline ANUAL & 10,80 \\
\hline OCT & 2,05 \\
\hline NOV & 7,71 \\
\hline DIC & 13,74 \\
\hline ENE & 16,88 \\
\hline FEB & 18,51 \\
\hline MAR & 15,39 \\
\hline ABR & 17,64 \\
\hline MAY & 17,45 \\
\hline JUN & 11,40 \\
\hline JUL & 4,26 \\
\hline AGO & 2,09 \\
\hline SEP & 2,48 \\
\hline
\end{tabular}

El caudal específico anual encontrado (Tabla 18) fue de $10,80 \mathrm{ls}^{-1} \mathrm{~km}^{-2}$. Un valor muy similar al encontrado para el río Tajo en Peralejos de las Truchas que fue de 11,95 Is ${ }^{1} \mathrm{~km}^{-2}$. El mes que presenta el caudal específico más elevado es febrero con 18,51 ls' ${ }^{1} \mathrm{~km}^{-2}$. A su vez, octubre es el mes con menor caudal específico con $2,05 \mathrm{Is}^{-1} \mathrm{~km}^{-2}$, seguido de agosto con $2,09 \mathrm{Is}^{-1} \mathrm{~km}^{-2}$.

La aportación mínima registrada en el río Cega en Pajares de Pedraza fue de 27,2 $\mathrm{hm}^{3}$ en el año de 1988, mientras la máxima fue en 1995, con 293,7 hm (Tabla 19) y la aportación media anual fue de $96,3 \mathrm{hm}^{3}$ (Tabla 20). 
Tabla 19. Estadística básica de los aportes medios mensuales del río Cega en Pajares de Pedraza para el período hidrológico de 1974 - 2004.

\begin{tabular}{|c|c|c|c|c|c|c|}
\hline Período & $\begin{array}{l}\text { Media } \\
\left(\mathrm{hm}^{3}\right)\end{array}$ & $\begin{array}{c}\text { Mediana } \\
\left(\mathrm{hm}^{3}\right)\end{array}$ & $\begin{array}{c}\text { Desviación } \\
\text { Típica } \\
\left(\mathrm{hm}^{3}\right)\end{array}$ & $\begin{array}{c}\text { Mínimo } \\
\left(\mathrm{hm}^{3}\right)\end{array}$ & $\begin{array}{c}\text { Máximo } \\
\left(\mathrm{hm}^{3}\right)\end{array}$ & $\begin{array}{c}\text { Coeficiente } \\
\text { de variación } \\
(\%)\end{array}$ \\
\hline OCT & 1,49 & 0,98 & 1,83 & 0,001 & 8,53 & 122,25 \\
\hline NOV & 5,72 & 6,51 & 4,92 & 0,001 & 19,77 & 86,07 \\
\hline $\mathrm{DIC}$ & 10,64 & 9,48 & 8,37 & 0,56 & 35,36 & 78,61 \\
\hline ENE & 12,96 & 9,74 & 11,03 & 0,66 & 43,75 & 85,06 \\
\hline FEB & 12,82 & 7,99 & 11,54 & 1,28 & 40,58 & 90,03 \\
\hline MAR & 11,66 & 8,74 & 8,99 & 2,00 & 40,22 & 77,12 \\
\hline ABR & 12,99 & 9,54 & 10,13 & 1,64 & 53,55 & 77,92 \\
\hline MAY & 13,32 & 10,05 & 9,91 & 1,85 & 44,51 & 74,39 \\
\hline JUN & 8,35 & 3,26 & 9,86 & 0,39 & 44,53 & 118,11 \\
\hline JUL & 3,13 & 1,02 & 5,89 & 0,07 & 29,29 & 188,21 \\
\hline AGO & 1,49 & 0,18 & 3,78 & 0,001 & 15,76 & 253,85 \\
\hline SEP & 1,71 & 0,30 & 4,88 & 0,001 & 24,13 & 285,66 \\
\hline
\end{tabular}

Tabla 20. Estadística Básica de los aportes anuales del Río Cega en Pajares de Pedraza para el período hidrológico de 1974 - 2004.

\begin{tabular}{|l|c|}
\hline \multicolumn{2}{|c|}{ Río Cega - Estación de Aforos 016} \\
\hline \hline Media $\left(\mathrm{hm}^{3}\right)$ & 96,3 \\
\hline Mediana $\left(\mathrm{hm}^{3}\right)$ & 83,0 \\
\hline Desviación Típica $\left(\mathrm{hm}^{3}\right)$ & 59,7 \\
\hline Mínimo $\left(\mathrm{hm}^{3}\right)$ & 27,2 \\
\hline Máximo $\left(\mathrm{hm}^{3}\right)$ & 293,7 \\
\hline CV (\%) & 62,0 \\
\hline
\end{tabular}

\subsubsection{Tendencias a medio plazo}

En la figura 28 se observan las oscilaciones en las aportaciones, con años en los que el río circula con caudales muy bajos, frente a otros de aguas muy abundantes, demostrando las grandes fluctuaciones entre períodos secos y húmedos. La alta variabilidad mencionada anteriormente, con un coeficiente de variación de $62 \%$ está claramente reflejada en esta figura.

A partir del análisis de la pendiente de la recta de regresión no se puede definir ninguna tendencia y se observa, además, un claro paralelismo con la recta del análisis de regresión entre la precipitación y el tiempo. 


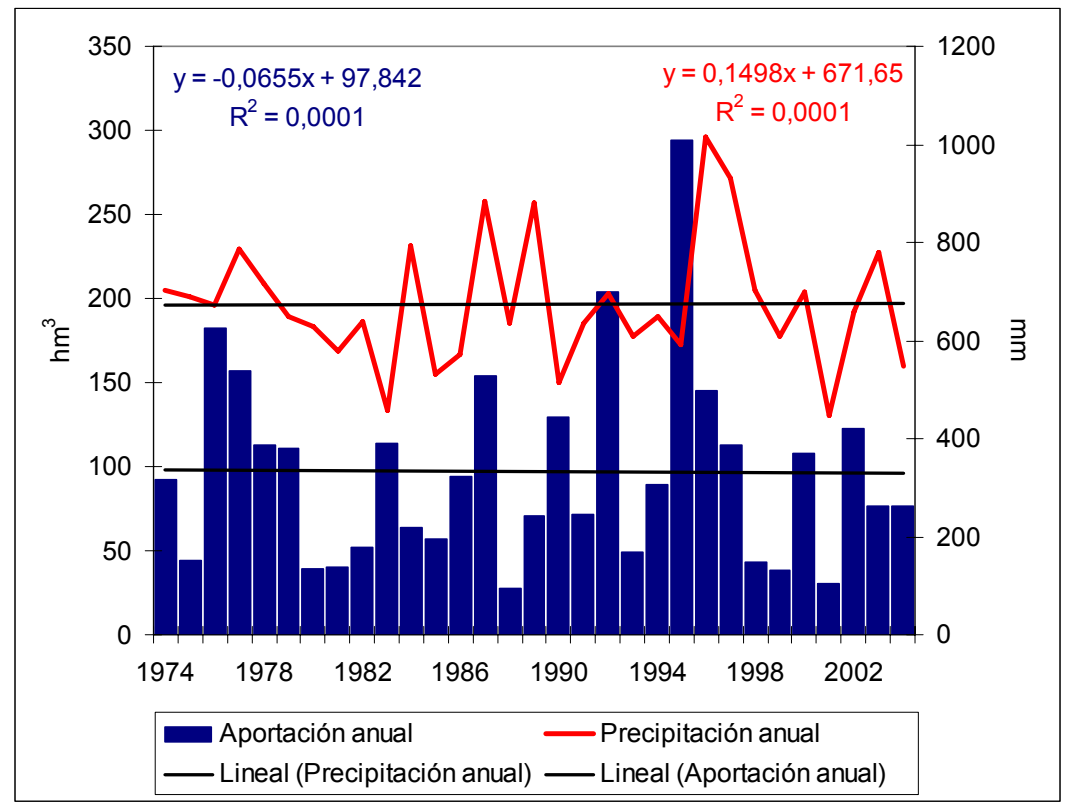

Figura 28 - Evolución de las aportaciones, línea de tendencia y precipitaciones anuales entre 1974 y 2004, con indicación de la tendencia del río Cega en Pajares de Pedraza.

La tabla 21 presenta el coeficiente de correlación entre la aportación anual y el tiempo del río Cega en Pajares de Pedraza y es posible ver que el valor de Rho de Spearman $(R)$, no permite detectar ningún tipo de tendencia.

Tabla 21. Coeficiente de correlación entre el aporte anual y el tiempo del río Cega en Pajares de Pedraza para el período 1974 - 2004.

\begin{tabular}{|l|c|c|c|}
\hline \hline Estación de Aforo & N & $\begin{array}{c}\text { Signif. } \\
\text { Estad. }\end{array}$ & R \\
\hline \hline Pajares de Pedraza & 31 & NS & $-0,069$ \\
\hline \hline
\end{tabular}

NS $=$ Valores no significativos

Se hizo también el análisis del coeficiente de correlación entre la aportación y el tiempo a escala mensual (Tabla 22). Ninguno de los meses muestra tendencia alguna. En agosto, septiembre, octubre, noviembre, diciembre y enero se puede ver que $R$ presenta valores positivos, sin embargo en ninguno de estos meses existe significación estadística. El valor de R positivo más alto fue encontrado en el mes de diciembre $(0,174)$. 
Tabla 22. Coeficientes de correlación entre el aporte mensual y el tiempo del río Cega en Pajares de Pedraza para el período de 1974 - 2004.

\begin{tabular}{|l|c|r|}
\hline \multicolumn{1}{|c|}{ Período } & $\begin{array}{r}\text { Signif. } \\
\text { Estad. }\end{array}$ & \multicolumn{1}{c|}{ R } \\
\hline \hline Octubre & NS & 0,135 \\
\hline Noviembre & NS & 0,140 \\
\hline Diciembre & NS & 0,174 \\
\hline Enero & NS & 0,148 \\
\hline Febrero & NS & $-0,079$ \\
\hline Marzo & NS & $-0,016$ \\
\hline Abril & NS & $-0,305$ \\
\hline Mayo & NS & $-0,304$ \\
\hline Junio & NS & $-0,184$ \\
\hline Julio & NS & $-0,022$ \\
\hline Agosto & NS & 0,027 \\
\hline Septiembre & NS & 0,027 \\
\hline \hline
\end{tabular}

NS = Valores no significativos

Por otro lado, los meses de febrero, marzo, abril, mayo, junio y julio presentan valores de $R$ negativos pero no pueden ser considerados estadísticamente significativos. Los meses en que se detectan valores más altos del descenso de la aportación son abril ($0,305)$, mayo $(-0,304)$ y junio $(-0,184)$, los dos primeros con valores muy cerca a la significación estadística.

El estadístico Mann-Kendall (M-K) fue utilizado para comprobar los resultados encontrados con R. M-K (Tabla 23) muestra una pequeña disminución en los valores de los aportes anuales, sin embargo no se puede rechazar la hipótesis nula de no tendencia $\left(Z_{s}>-1,96\right)$ ya que presenta un $S=-16$ y $Z=-1,44$. Al analizar los aportes mensuales individualmente no se puede rechazar la hipótesis nula de no tendencia en los meses de febrero, marzo, julio y agosto, apreciándose en este último mes un valor positivo aunque muy bajo. Como se puede ver en febrero, marzo y julio se registran valores negativos pero también muy pequeños. Los meses de abril, mayo y junio también presentan valores negativos de aportación en el tiempo y en todos ellos se puede rechazar la hipótesis nula de no tendencia. Los meses que presentan valores más altos de significación estadística son abril y mayo. Los resultados encontrados con los dos test estadísticos no dejan dudas de que en estos tres meses es donde se encuentra la evidencia más clara de disminución en los aportes. En los meses de septiembre, octubre, noviembre, diciembre y enero se encuentran valores de $S$ y $Z$ positivos, lo que sugiere un pequeño aumento en la aportación. En estos meses se 
puede rechazar la hipótesis nula de no tendencia y los valores más altos de $S$ y $Z$ se encuentran en los meses invernales de diciembre y enero.

Tabla 23. Test estadístico Mann-Kendall para los aportes mensuales y anuales del río Cega en Pajares de Pedraza.

\begin{tabular}{|l|c|c|c|c|}
\hline \multicolumn{1}{|c|}{ Período } & $\begin{array}{c}\text { S de } \\
\text { Kendall }\end{array}$ & $\mathbf{Z}_{\mathbf{s}}$ & $\begin{array}{c}\text { Rechazo de hipótesis } \\
\text { nula para } \mathbf{p}<\mathbf{0 , 0 5}\end{array}$ & Valor $\boldsymbol{p}$ \\
\hline Anual & -16 & $-1,44$ & $\mathrm{No}$ & 0,1499 \\
\hline Octubre & 36 & 3,09 & $\mathrm{Si}$ & 0,0020 \\
\hline Noviembre & 40 & 3,24 & $\mathrm{Si}$ & 0,0012 \\
\hline Diciembre & 45 & 4,36 & $\mathrm{Si}$ & 0,0001 \\
\hline Enero & 47 & 4,57 & $\mathrm{Si}$ & 0,0001 \\
\hline Febrero & -21 & $-1,77$ & $\mathrm{No}$ & 0,0767 \\
\hline Marzo & -5 & $-0,41$ & $\mathrm{No}$ & 0,6818 \\
\hline Abril & -88 & $-8,07$ & $\mathrm{Si}$ & 0,0001 \\
\hline Mayo & -77 & $-7,10$ & $\mathrm{Si}$ & 0,0001 \\
\hline Junio & -53 & $-5,04$ & $\mathrm{Si}$ & 0,0001 \\
\hline Julio & -4 & $-0,28$ & $\mathrm{No}$ & 0,7795 \\
\hline Agosto & 13 & 1,15 & $\mathrm{No}$ & 0,2501 \\
\hline Septiembre & 19 & 2,13 & $\mathrm{Si}$ & 0,0332 \\
\hline
\end{tabular}

Zs $>(+/-) 1,96$ se rechaza la hipótesis nula de no tendencia Valor $p<0,05$ se rechaza la hipótesis nula de no tendencia

Al analizar los datos de aportación en la cuenca del río Cega, se ha detectado una pérdida de solamente $0,07 \mathrm{hm}^{3}$ al año, que representa en los treinta años una pérdida de $2,7 \mathrm{hm}^{3}$. Esta cifra representa un $2,3 \%$ de la aportación media anual y refleja los resultados encontrados con los estadísticos $\mathrm{R}$ y $\mathrm{M}-\mathrm{K}$ que determinaron solamente una pequeña reducción en los aportes. Sin embargo, como se expuso anteriormente, no se puede hablar en tendencias estadísticamente significativas en sus valores.

\subsection{Evolución del Caudal en la Cuenca Del Río Porma}

\subsubsection{Caracterización hidrológica}

El río Porma se estudia desde donde nace en Cofiñal, hasta la estación de aforos localizada en Camposolillo, en la provincia de León (Foto 10, Fig. 29). Este tramo recoge los caudales de la cabecera de la cuenca, con una superficie total de $154 \mathrm{~km}^{2}$. En dicha estación de aforos se registra un caudal medio anual de $6,38 \mathrm{~m}^{3} \mathrm{~s}^{-1}$, con una aportación media anual de 205,4 $\mathrm{hm}^{3}$. 


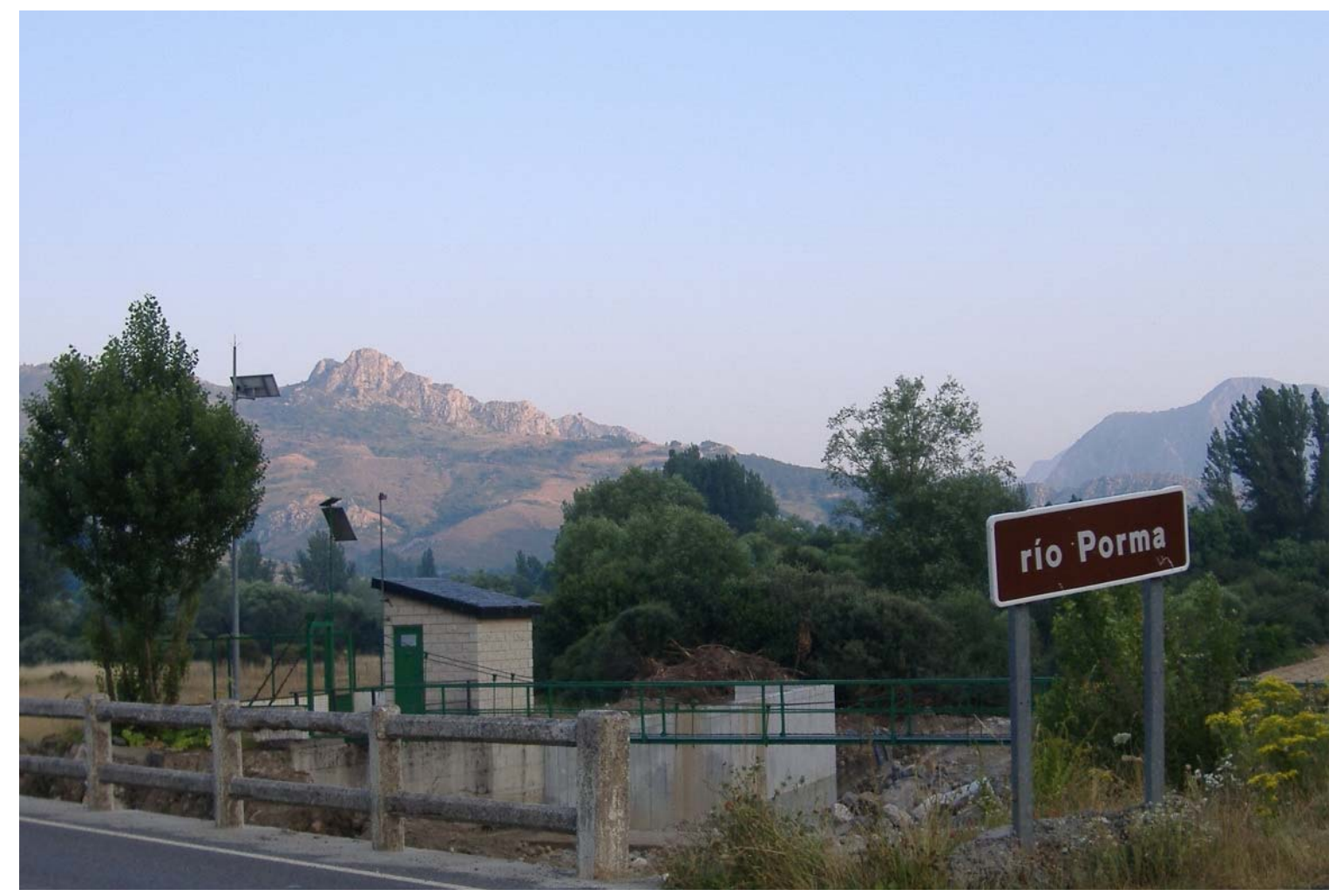

Foto 10 - Estación de aforo 078 en Camposolillo - Río Porma.

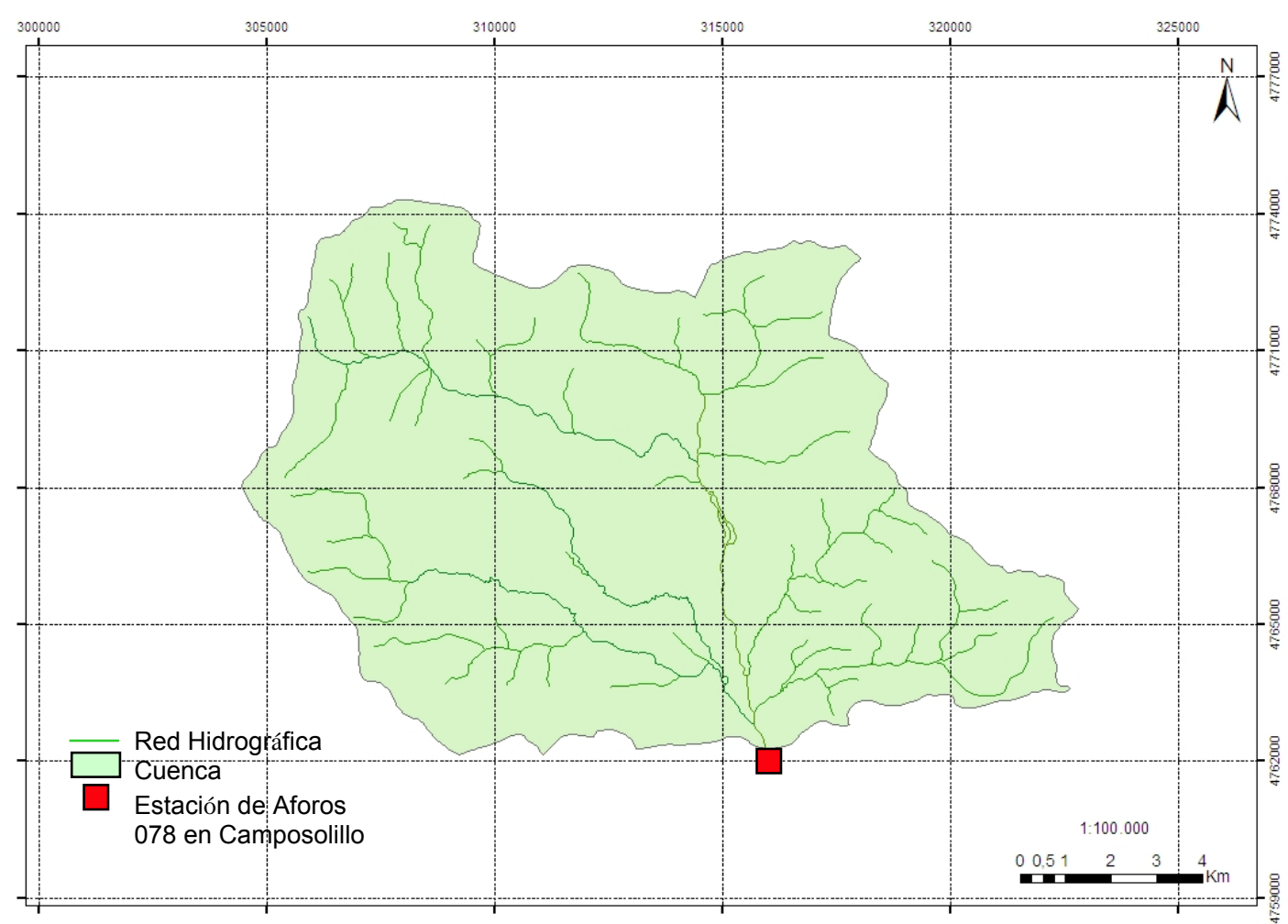

Figura 29 - Cabecera del río Porma y localización de la estación de aforo 078 en Camposolillo. 
El río Porma tiene un régimen pluvio-nival, presentando un aumento inicial de su caudal en los meses de octubre, noviembre y diciembre (máximo de precipitación), seguido de un aumento más acusado en los meses de marzo, abril y mayo.

La ausencia de coincidencia entre un pico de precipitación y otro de caudal en este máximo del año, se debe al protagonismo que tiene la fusión nival primaveral en esa zona de la vertiente sur de la Cordillera Cantábrica.

De acuerdo con la figura 30 , los registros de aforos no superan el doble del caudal medio en ninguna época del año. Desde el mes de diciembre hasta el mes de mayo se registra el período de aguas altas habiendo sido encontrado el pico máximo en el mes de abril. A partir de mayo empieza a descender y en junio se produce un descenso bien marcado para entrar en estiaje, que es muy evidente en todos los meses de verano y se prolonga hasta el mes de septiembre, el de menor aporte.

Los períodos de estiaje son muy fuertes, siendo esto muy evidente de julio hasta septiembre, lo que demuestra claramente la mediterraneidad del área de estudio. Los caudales en estos meses llegan a valores próximos a cero en algunas fechas (Tabla 24).

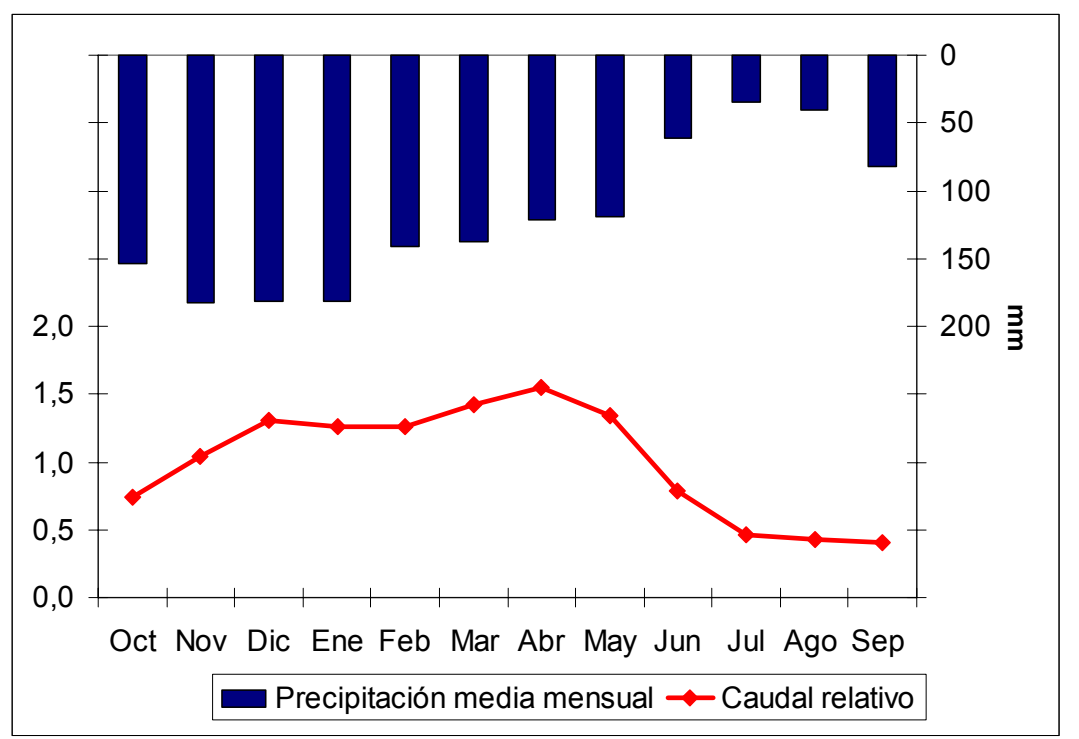

Figura 30 - Caudal relativo (adimensional) y precipitación media mensual en la cuenca del río Porma en la estación 078 en Camposolillo. 
Tabla 24. Estadística básica de los caudales medios del Río Porma en Camposolillo para el período hidrológico de 1974 - 2004.

\begin{tabular}{|c|c|c|c|}
\hline \hline Período & $\begin{array}{c}\text { Caudal Medio } \\
\left(\mathbf{m}^{\mathbf{3}} \mathbf{s}^{-1}\right)\end{array}$ & $\begin{array}{c}\text { Mediana } \\
\left(\mathbf{m}^{\mathbf{3}} \mathbf{s}^{-1}\right)\end{array}$ & $\begin{array}{c}\text { Caudal } \\
\text { Relativo }\end{array}$ \\
\hline \hline ANUAL & 6,38 & 5,66 & 1,00 \\
\hline OCT & 4,68 & 3,97 & 0,73 \\
\hline NOV & 6,60 & 6,20 & 1,03 \\
\hline DIC & 8,32 & 8,33 & 1,30 \\
\hline ENE & 8,07 & 6,97 & 1,27 \\
\hline FEB & 8,04 & 7,08 & 1,26 \\
\hline MAR & 9,09 & 8,56 & 1,42 \\
\hline ABR & 9,88 & 9,56 & 1,55 \\
\hline MAY & 8,55 & 7,46 & 1,34 \\
\hline JUN & 5,02 & 3,80 & 0,79 \\
\hline JUL & 2,94 & 2,41 & 0,46 \\
\hline AGO & 2,76 & 2,02 & 0,43 \\
\hline SEP & 2,60 & 2,35 & 0,41 \\
\hline
\end{tabular}

El río Porma presenta una variabilidad muy alta, con un coeficiente de variación del caudal diario de $97,3 \%$. El valor máximo diario registrado fue de $88,7 \mathrm{~m}^{3} \mathrm{~s}^{-1}$ en el día 22/08/1978. En el río Porma en Camposolillo aparecen 494 días que registran el triple del caudal medio (Fig. 31), es decir un $4,0 \%$ de aguas altas. Solamente un $0,01 \%$ alcanzan cinco veces el caudal medio y en tan sólo 5 días se supera en diez veces este umbral.

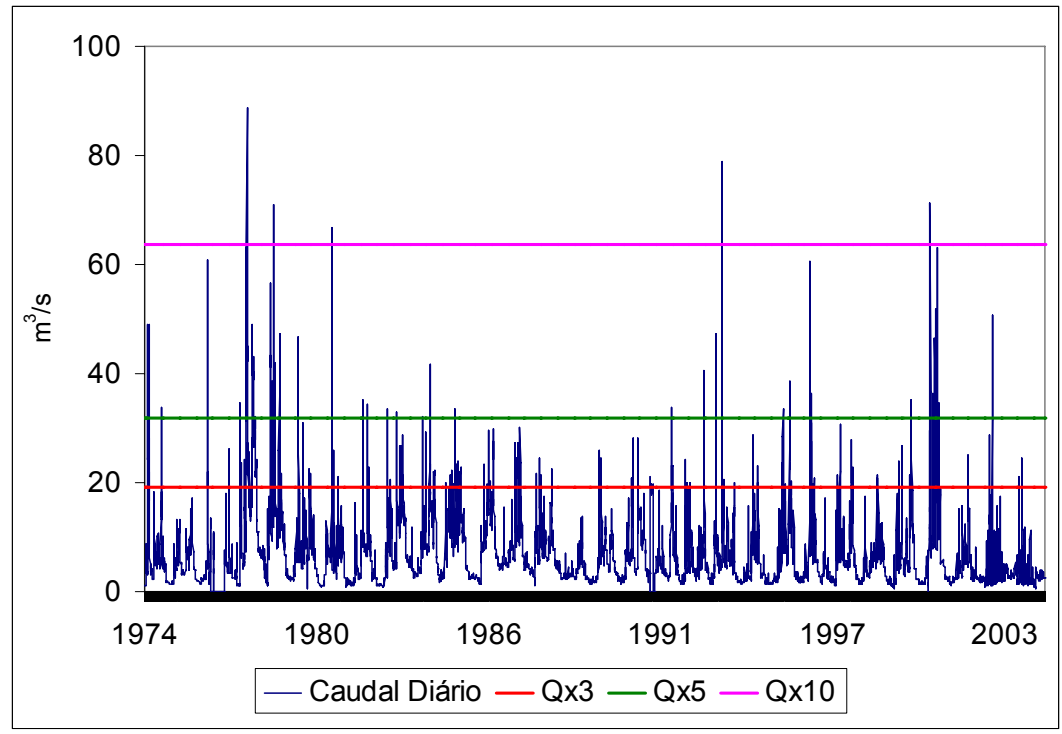

Figura 31 - Distribución de caudales diarios del río Porma en Camposolillo y los correspondientes a $3(Q \times 3), 5(Q \times 5)$ y $10(Q \times 10)$ veces el caudal medio en el período hidrológico 1974-2004. 
La figura 32 muestra la distribución de frecuencias de los caudales diarios y se observa que el $98,8 \%$ de estos están entre 0 y $30 \mathrm{~m}^{3} \mathrm{~s}^{-1}$, sin embargo, la gran mayoría de los valores registrados está entre 0 y $10 \mathrm{~m}^{3} \mathrm{~s}^{-1}$, con $81,81 \%$ del total.

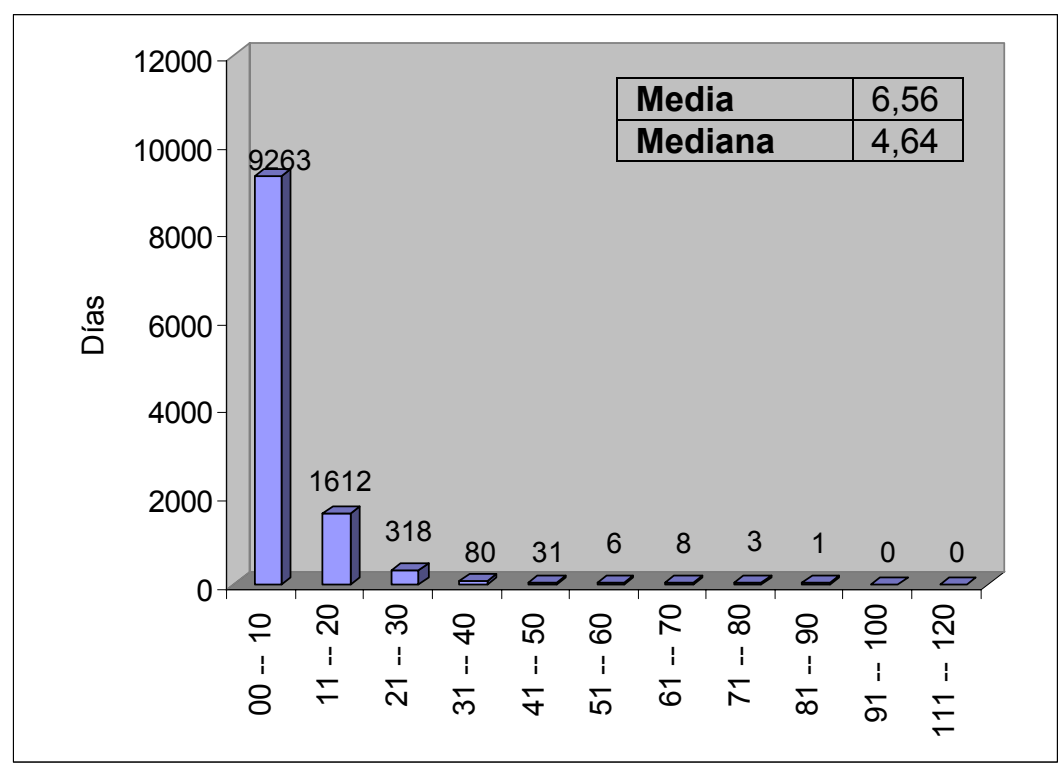

Figura 32 - Distribución de frecuencias de los caudales diarios del río Porma con indicación de la media y de la mediana.

Tabla 25. Coeficiente de variación de los caudales medios mensuales y anuales del Río Porma en Camposolillo para el período hidrológico de 1974 - 2004.

\begin{tabular}{|c|c|}
\hline \hline Período & $\begin{array}{c}\text { Coeficiente de Variación } \\
\%\end{array}$ \\
\hline ANUAL & 40,8 \\
\hline OCT & 54,0 \\
\hline NOV & 51,7 \\
\hline DIC & 54,9 \\
\hline ENE & 58,7 \\
\hline FEB & 72,7 \\
\hline MAR & 61,7 \\
\hline ABR & 53,8 \\
\hline MAY & 77,6 \\
\hline JUN & 81,1 \\
\hline JUL & 56,8 \\
\hline AGO & 91,3 \\
\hline SEP & 51,8 \\
\hline
\end{tabular}


Los caudales medios mensuales y anuales del río Porma presentan una variabilidad alta (Tabla 25), lo que representa un signo más de las características mediterráneas del área de estudio. Los otoñales son los meses con menor coeficiente de variación, dándose el mínimo en noviembre con un $51,7 \%$, y en verano, junio y agosto son los meses con mayor variabilidad en los caudales mensuales. Agosto es el mes con el valor más elevado, $91,3 \%$. Por otro lado, el coeficiente de variación anual es ligeramente más bajo $(40,8 \%)$.

A partir del análisis de la evolución de los coeficientes de variación (Fig. 33) no se observa ninguna tendencia significativa durante el periodo analizado en esta cuenca en esta variable.

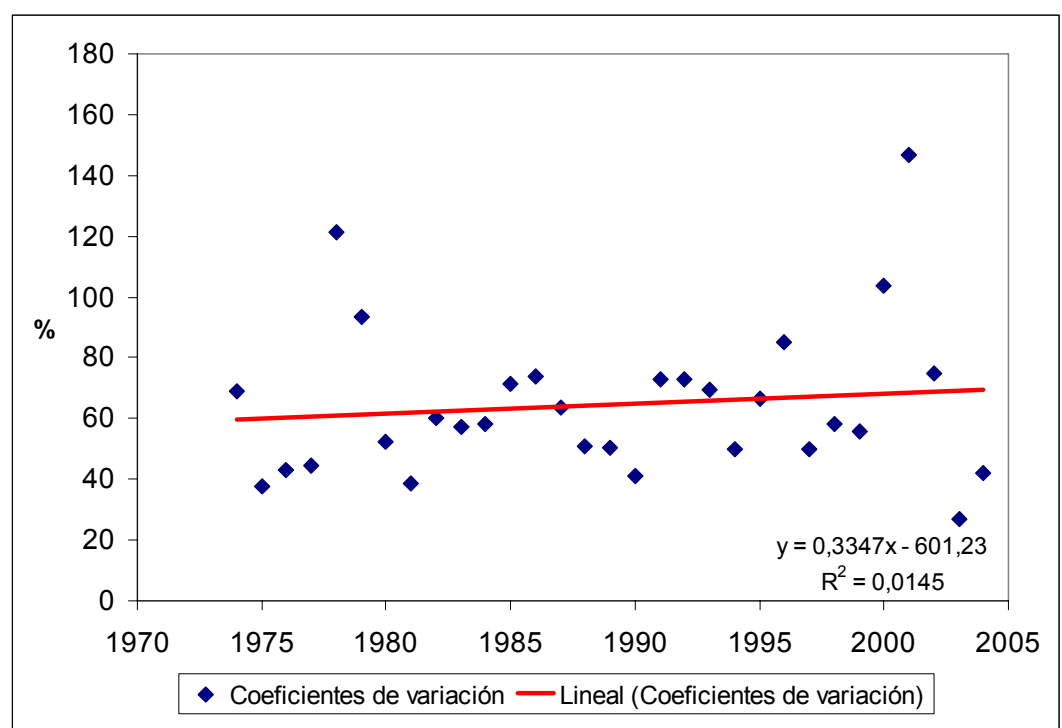

Figura 33 - Coeficientes de variación interanual del río Porma con indicación de su tendencia - Período 1974 - 2004.

El río Porma presenta un caudal específico anual (Tabla 26) de 41,42 $\mathrm{Is}^{-1} \mathrm{~km}^{-2}$, el valor más alto encontrado entre las cuencas analizadas en este estudio. Este dato está en consonancia con los observados por García Ruiz et al. (2001) en los ríos pirenaicos en los aforos de cabecera (superiores a $30 \mathrm{ls}^{-1} \mathrm{~km}^{-2}$ ). El mes que presenta el caudal específico más elevado es abril con $64,17 \mathrm{Is}^{-1} \mathrm{~km}^{-2}$ y septiembre el mes con menor caudal específico con $16,86 \mathrm{Is}^{-1} \mathrm{~km}^{-2}$. 
Tabla 26. Caudal específico del Río Porma en Camposolillo para el período hidrológico de $1974-2004$.

\begin{tabular}{|c|c|}
\hline Período & $\begin{array}{c}\text { Caudal Específico } \\
\text { (Is }^{-1} \mathbf{k m}^{-\mathbf{2}} \text { ) }\end{array}$ \\
\hline \hline ANUAL & 41,42 \\
\hline OCT & 30,41 \\
\hline NOV & 42,86 \\
\hline DIC & 54,01 \\
\hline ENE & 52,40 \\
\hline FEB & 52,18 \\
\hline MAR & 59,01 \\
\hline ABR & 64,17 \\
\hline MAY & 55,51 \\
\hline JUN & 32,58 \\
\hline JUL & 19,09 \\
\hline AGO & 17,95 \\
\hline SEP & 16,86 \\
\hline \hline
\end{tabular}

Tabla 27. Estadística Básica de los aportes medios mensuales del río Porma en Camposolillo para el período hidrológico de 1974 - 2004.

\begin{tabular}{|c|c|c|c|c|c|c|}
\hline Período & $\begin{array}{l}\text { Media } \\
\left(\mathrm{hm}^{3}\right)\end{array}$ & $\begin{array}{c}\text { Mediana } \\
\left(\mathrm{hm}^{3}\right)\end{array}$ & $\begin{array}{c}\text { Desviación } \\
\text { Típica } \\
\left(\mathrm{hm}^{3}\right)\end{array}$ & $\begin{array}{c}\text { Mínimo } \\
\left(\mathrm{hm}^{3}\right)\end{array}$ & $\begin{array}{c}\text { Máximo } \\
\left(\mathrm{hm}^{3}\right)\end{array}$ & $\begin{array}{c}\text { Coeficiente } \\
\text { de variación } \\
(\%)\end{array}$ \\
\hline OCT & 12,54 & 10,63 & 6,78 & 5,54 & 37,90 & 54,0 \\
\hline NOV & 17,11 & 16,09 & 8,84 & 3,80 & 37,92 & 51,7 \\
\hline DIC & 22,85 & 22,49 & 12,03 & 3,30 & 59,78 & 52,6 \\
\hline ENE & 22,13 & 18,82 & 12,53 & 2,00 & 62,20 & 56,6 \\
\hline FEB & 20,29 & 18,08 & 13,85 & 1,12 & 68,04 & 68,2 \\
\hline MAR & 26,20 & 24,82 & 13,80 & 6,01 & 65,01 & 52,7 \\
\hline$A B R$ & 27,03 & 26,98 & 12,32 & 5,02 & 46,68 & 45,6 \\
\hline MAY & 23,90 & 20,25 & 17,29 & 3,85 & 92,83 & 72,3 \\
\hline JUN & 13,16 & 9,63 & 10,44 & 4,59 & 60,36 & 79,3 \\
\hline JUL & 8,09 & 6,27 & 4,32 & 3,29 & 24,45 & 53,4 \\
\hline AGO & 6,57 & 5,44 & 3,56 & 3,12 & 18,33 & 54,2 \\
\hline SEP & 6,88 & 6,09 & 3,31 & 2,98 & 18,48 & 48,0 \\
\hline
\end{tabular}

En el año de 1977 se registró el valor más alto de aportación anual con 449,5 hm mientras que el valor más bajo de aportación anual fue encontrado en el año de 2003, con $98,2 \mathrm{hm}^{3}$ (Tablas 27 y 28) y la aportación media anual fue de $205,4 \mathrm{hm}^{3}$. 
Tabla 28. Estadística Básica de los aportes medios anuales del Río Porma en Camposolillo para el período hidrológico de 1974 - 2004.

\begin{tabular}{|l|c|}
\hline \multicolumn{2}{|c|}{ Río Porma - Estación de Aforos $\mathbf{0 7 8}$} \\
\hline \hline Media $\left(\mathrm{hm}^{3}\right)$ & 205,4 \\
\hline Mediana $\left(\mathrm{hm}^{3}\right)$ & 184,7 \\
\hline Desviación Típica $\left(\mathrm{hm}^{3}\right)$ & 75,1 \\
\hline Mínimo $\left(\mathrm{hm}^{3}\right)$ & 98,2 \\
\hline Máximo $\left(\mathrm{hm}^{3}\right)$ & 449,5 \\
\hline CV (\%) & 36,6 \\
\hline \hline
\end{tabular}

\subsubsection{Tendencias a medio plazo}

La evolución hidrológica reciente del río Porma (Fig. 34) se puede dividir en tres ciclos, que van aproximadamente de 1974 a 1981, de 1982 a 1989 y el último a partir de 1990.

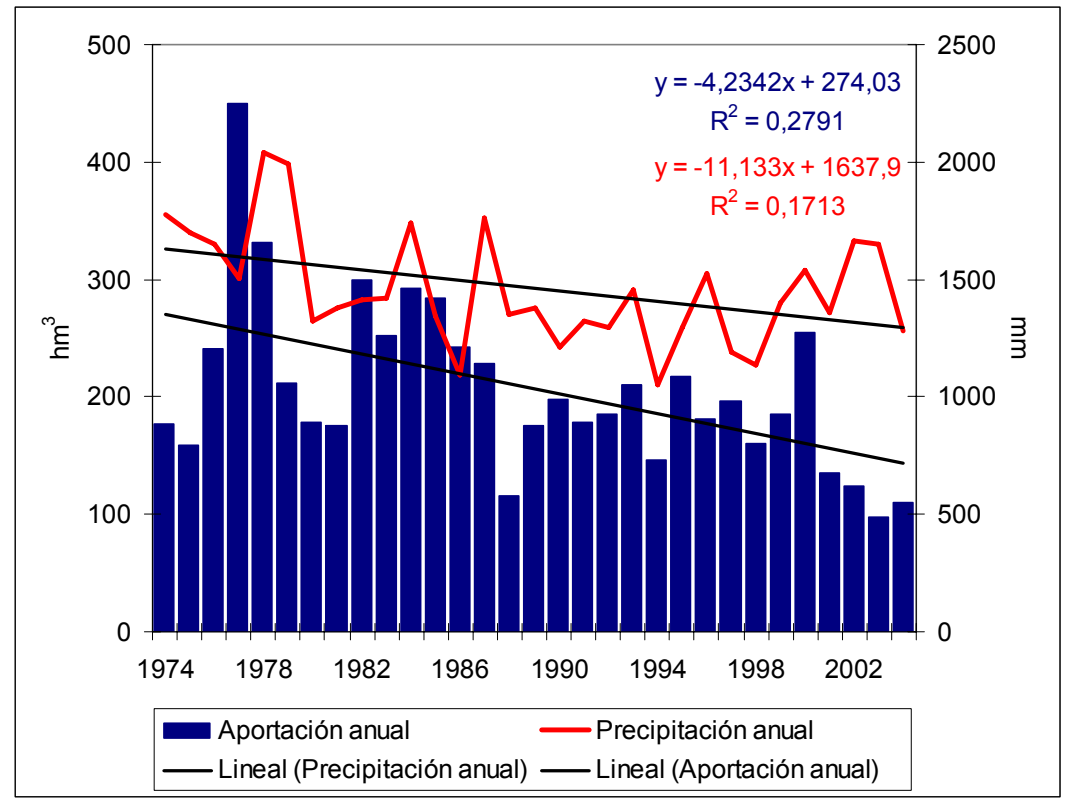

Figura 34 - Evolución de las aportaciones, línea de tendencia y precipitaciones anuales entre 1974 y 2004, con indicación de la tendencia del río Porma en Camposolillo.

En este último es donde se nota el mayor descenso en los valores de aportaciones y también una mayor estabilización. De hecho es el período donde se da el menor coeficiente de variación, con un $25,8 \%$. Este último ciclo coincide, incluso, con un periodo en el que la precipitación experimentó una evolución positiva, en términos generales. El primer ciclo es el que tiene mayor variabilidad, con un coeficiente de variación de $31,2 \%$ y en el segundo esta es un poco menor (26,8\%). El gráfico refleja perfectamente un descenso en los valores de aportación en el tiempo y se nota que en 
cada uno de los ciclos estos valores sufrieron una cierta reducción. La recta de regresión muestra el claro descenso en las aportaciones, pero es de destacar que la pendiente es ligeramente mayor que la de la regresión de la precipitación. Este comportamiento diferencial puede ser la evidencia de un desacople entre ambas variables producido por la intervención de otras con una influencia destacada en la generación de escorrentía.

El coeficiente de correlación ( $R$ ) entre el aporte anual y el tiempo (Tabla 29) para el período estudiado, muestra claramente una tendencia regresiva de los aportes con un valor de $\mathrm{R}$ de $-0,467$, significativo al nivel de $95 \%$. Este dato muestra una clara y considerable reducción de los aportes en el río Porma en las últimas tres décadas.

Tabla 29. Coeficiente de correlación entre el aporte anual y el tiempo del río Porma en Camposolillo para el período 1974 - 2004.

\begin{tabular}{|c|c|c|c|}
\hline \hline Estación de Aforo & N & $\begin{array}{c}\text { Signif. } \\
\text { Estad. }\end{array}$ & R \\
\hline Cuenca del río Porma & 31 & $*$ & $-0,467$ \\
\hline \hline
\end{tabular}

* = Significativo al 95\%

Se analizó también la correlación entre la aportación mensual y el tiempo para intentar identificar los meses en que dicha disminución se ve más claramente.

Tabla 30. Coeficientes de correlación entre el aporte mensual y el tiempo del río Porma en Camposolillo para el período de 1974 - 2004.

\begin{tabular}{|l|c|c|}
\hline \hline \multicolumn{1}{|c|}{ Período } & $\begin{array}{l}\text { Signif. } \\
\text { Estad. }\end{array}$ & R \\
\hline \hline Octubre & NS & $-0,063$ \\
\hline Noviembre & $*$ & $-0,377$ \\
\hline Diciembre & NS & $-0,189$ \\
\hline Enero & NS & $-0,193$ \\
\hline Febrero & $*$ & $-0,447$ \\
\hline Marzo & NS & $-0,323$ \\
\hline Abril & $* *$ & $-0,503$ \\
\hline Mayo & $* *$ & $-0,503$ \\
\hline Junio & NS & $-0,236$ \\
\hline Julio & NS & $-0,123$ \\
\hline Agosto & NS & $-0,027$ \\
\hline Septiembre & NS & $-0,228$ \\
\hline \hline
\end{tabular}

NS = Valores no significativos

* = Significativo al $95 \%$

** $=$ Significativo al $99 \%$ 
De acuerdo con los resultados expuestos en la tabla 30, la evolución temporal de las aportaciones mensuales también confirma la tendencia regresiva encontrada en el análisis anual. En todos los meses se obtienen coeficientes de correlación negativos, lo que representa una reducción en la aportación en todos ellos. Sin embargo, en su mayoría no se obtienen valores significativos. Los meses de noviembre y febrero presentan valores significativos al $95 \%$, y abril y mayo al $99 \%$. Los meses con valores de $\mathrm{R}$ más alto, en valor absoluto, coinciden también con los meses de caudales más elevados y, por tanto, con más peso en el total anual. Esto explicaría, probablemente, el que a escala anual se haya obtenido una tendencia regresiva muy evidente. No obstante, en los meses de estiaje también se comprueba una disminución de la aportación bastante considerable, sobre todo, en los meses de junio y septiembre, con $R$ igual a $-0,236$ y $-0,228$, respectivamente. Los dos meses en que fueron encontrados los menores coeficientes de correlación entre la aportación y el tiempo son agosto y octubre.

Para analizar si hay algún tipo de tendencia de la aportación, se utilizó también M-K. Todos los resultados obtenidos con este método (Tabla 31) corroboran los que fueron encontrados con R. Anualmente se observa una disminución bastante clara en los aportes durante el período analizado y es posible rechazar la hipótesis nula de no tendencia $(S=-150$ y $Z=-14,24)$.

Tabla 31. Test estadístico Mann-Kendall para los aportes mensuales y anuales del río Porma en Camposolillo.

\begin{tabular}{|l|c|c|c|c|}
\hline \hline \multicolumn{1}{|c|}{ Período } & $\begin{array}{c}\text { S de } \\
\text { Kendall }\end{array}$ & $\mathbf{Z}_{\mathbf{s}}$ & $\begin{array}{c}\text { Rechazo de hipótesis } \\
\text { nula para } \mathbf{p}<\mathbf{0 , 0 5}\end{array}$ & Valor $\boldsymbol{p}$ \\
\hline \hline Anual & -150 & $-14,24$ & $\mathrm{Si}$ & 0,0001 \\
\hline Octubre & -17 & $-1,69$ & $\mathrm{No}$ & 0,0910 \\
\hline Noviembre & -133 & $-9,94$ & $\mathrm{Si}$ & 0,0001 \\
\hline Diciembre & -29 & $-2,52$ & $\mathrm{Si}$ & 0,0117 \\
\hline Enero & -43 & $-3,70$ & $\mathrm{Si}$ & 0,0002 \\
\hline Febrero & -117 & $-9,67$ & $\mathrm{Si}$ & 0,0001 \\
\hline Marzo & -65 & $-6,02$ & $\mathrm{Si}$ & 0,0001 \\
\hline Abril & -141 & $-13,34$ & $\mathrm{Si}$ & 0,0001 \\
\hline Mayo & -133 & $-12,39$ & $\mathrm{Si}$ & 0,0001 \\
\hline Junio & -59 & $-4,35$ & $\mathrm{Si}$ & 0,0001 \\
\hline Julio & -53 & $-3,71$ & $\mathrm{Si}$ & 0,0002 \\
\hline Agosto & -24 & $-1,68$ & $\mathrm{No}$ & 0,0930 \\
\hline Septiembre & -73 & $-5,80$ & $\mathrm{Si}$ & 0,0001 \\
\hline
\end{tabular}

Zs $>(+/-) 1,96$ se rechaza la hipótesis nula de no tendencia Valor $p<0,05$ se rechaza la hipótesis nula de no tendencia 
El análisis mensual de los datos con $\mathrm{M}-\mathrm{K}$ demuestra que en todos los meses se ha encontrado valores negativos de $S$ y $Z$, lo que deja clara la existencia de una tendencia regresiva en el tiempo. Solamente en los meses de agosto ( $S=-24$ y $Z=-$ $1,68)$ y octubre $(S=-17$ y $Z=-1,69)$ no se puede rechazar la hipótesis nula. Los meses en que fueron localizados los valores más altos de $S$ y $Z$ son abril (-141 y 13,34) y mayo (-133 y -12,39), indicando que en estos meses se ha notado un descenso más acentuado de los aportes en el período analizado. También ha sido identificada una disminución muy considerable de la aportación en los meses de noviembre y febrero. En el caso de noviembre, aunque el valor de $S$ sea igual al encontrado para el mes de mayo, se obtuvo un valor menor de $Z$ debido a los valores de la desviación típica que han sido mayores en el mes de noviembre. El valor de $Z$ está directamente influenciado por los resultados de la desviación típica y, por tanto, por la variabilidad.

De acuerdo con los resultados encontrados utilizando los estadísticos $M-K$ y $R$, está bastante claro que hay una fuerte tendencia regresiva de los aportes en el río Porma en Camposolillo. Con el objetivo de localizar el momento de inicio de esta tendencia se ha utilizado el test estadístico M-Ks.

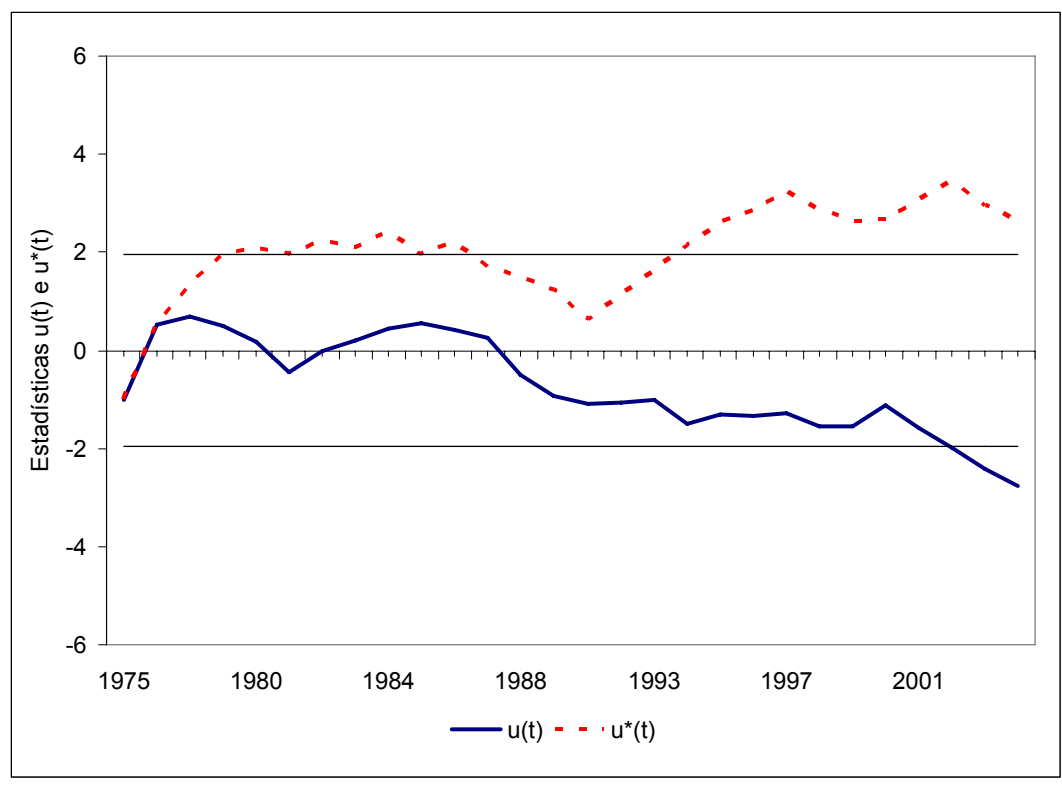

Figura 35 - Test Mann-Kendall secuencial para la aportación anual entre 1974 y 2004 del río Porma en Camposolillo.

A partir del análisis de M-Ks (Fig. 35), es posible ver con mucha claridad la tendencia regresiva ya identificada. Sin embargo, no se puede determinar a partir de que 
momento ha empezado esta tendencia, ya que en los primeros años de análisis hay valores coincidentes de las estadísticas $u(t)$ y $u^{*}(t)$ y no se han encontrado intersecciones de estos valores. Lo que sí se puede afirmar es que, a partir de 1977, las dos curvas se separan permanentemente, llegando a valores estadísticamente significativos a partir del año de 2002, cuándo se supera el intervalo de confianza $( \pm 1,96)$.

Por todos los resultados encontrados, se puede afirmar que en el río Porma en Camposolillo hay una tendencia regresiva en los caudales circulantes, que está muy bien confirmada por todos los test presentados anteriormente. Se ha podido detectar una pérdida media anual de aportación de $4,23 \mathrm{hm}^{3}(2,1 \%$ de la aportación media anual), lo que significa una pérdida de $131,13 \mathrm{hm}^{3}$ en el promedio en todo el período estudiado, un resultado muy alto si se considera que se trata de tan solo 30 años. La aportación media anual de la primera década analizada fue $247,5 \mathrm{hm}^{3}$, a su vez en la última década se ha observado un $33,5 \%$ menos $\left(164,5 \mathrm{hm}^{3}\right)$.

\subsection{Evolución del Caudal en la Cuenca Del Río Tajo}

\subsubsection{Caracterización hidrológica}

El área del río Tajo utilizada para el análisis en este estudio comprende desde Fuente García en la Sierra de Albarracín, donde se encuentra su nacimiento, hasta la estación de aforos $n^{\circ}$ 001, localizada en Peralejos de las Truchas (Foto 11, Fig. 36), en la provincia de Guadalajara. En esta estación se registran los caudales de la cabecera del río Tajo, con una superficie total de cuenca de $410 \mathrm{~km}^{2}$.

Como en los otros casos analizados anteriormente, en todo este tramo el río presenta su curso natural, sin apenas intervención humana. En esa estación se registra un caudal medio anual de 4,90 $\mathrm{m}^{3} \mathrm{~s}^{-1}$ y una aportación media anual de 149,7 hm $\mathrm{h}^{3}$. 


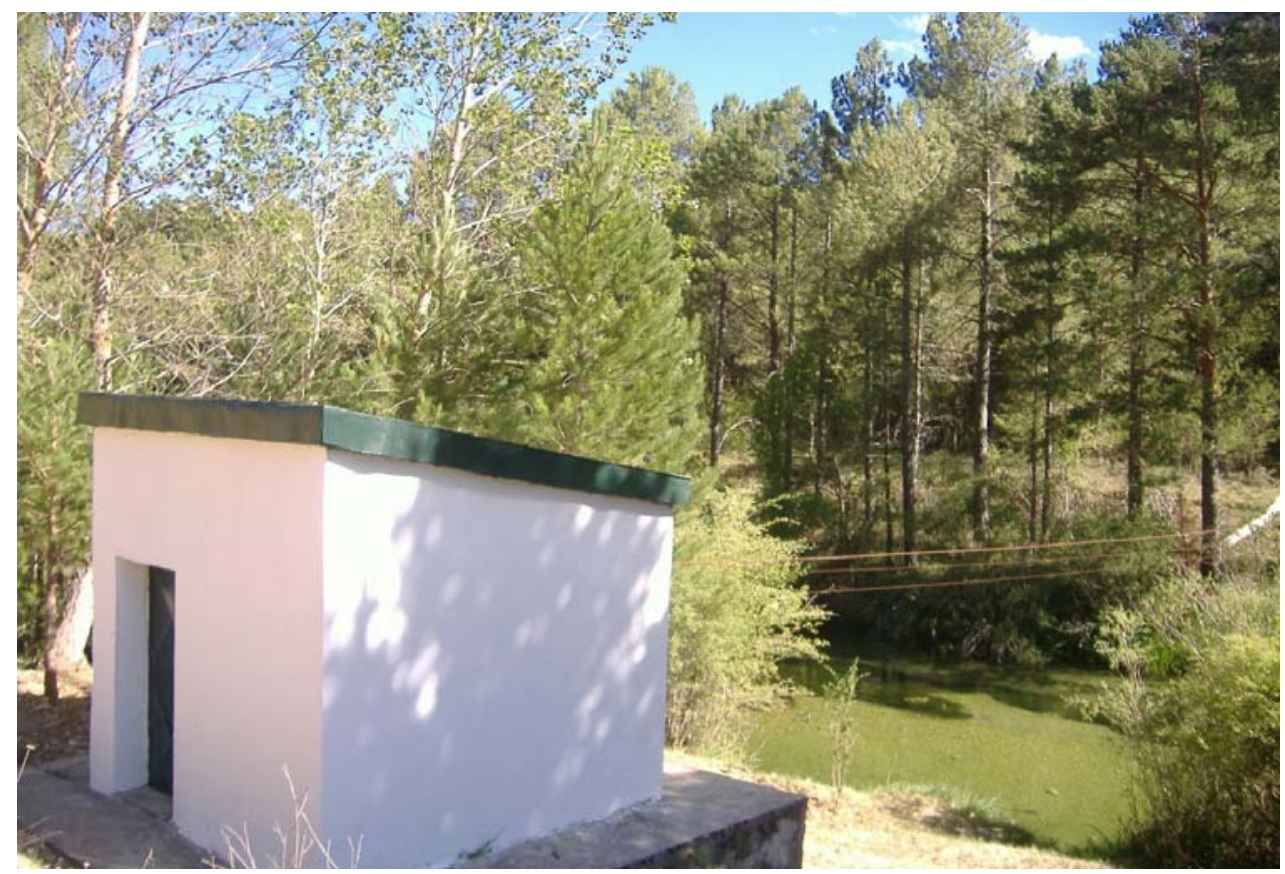

Foto 11 - Estación de aforo 001 en Peralejos de las Truchas - Río Tajo.

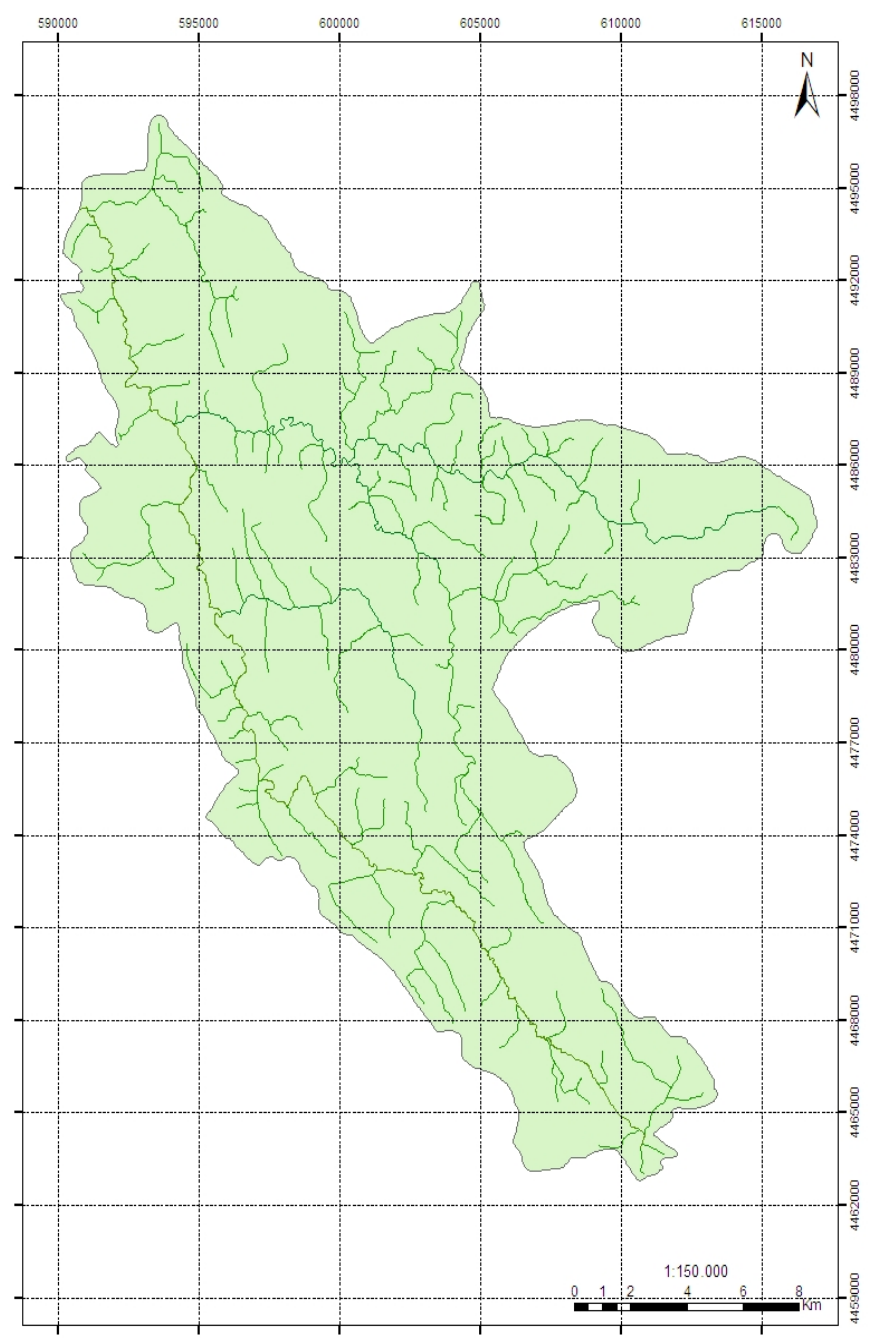

Figura 36 - Cabecera del río Tajo y localización de la estación de aforo 001 en Peralejos de las Truchas. 
El régimen de la cuenca alta del río Tajo en este tramo es pluvial (Fig. 37), donde la nieve tiene poca influencia y predominan las lluvias de finales de otoño y del invierno. En el mes de noviembre empieza a haber un aumento en las aportaciones del río Tajo en Peralejos de las Truchas, siendo febrero el mes con el pico más elevado, seguido del mes de enero. A partir de entonces empieza a haber un ligero descenso, aunque todavía se registran caudales elevados hasta el mes de junio. Por lo tanto, el período de aguas altas va desde noviembre hasta junio. El fuerte período de sequía se extiende desde julio hasta octubre, siendo los menores valores de caudal en los meses de agosto y septiembre, llegando a valores muy cerca de cero en algunas fechas. Como en las cuencas analizadas anteriormente, se observan fuertes contrastes estacionales y no se detecta en ningún mes del año caudales que superen el doble del caudal medio.

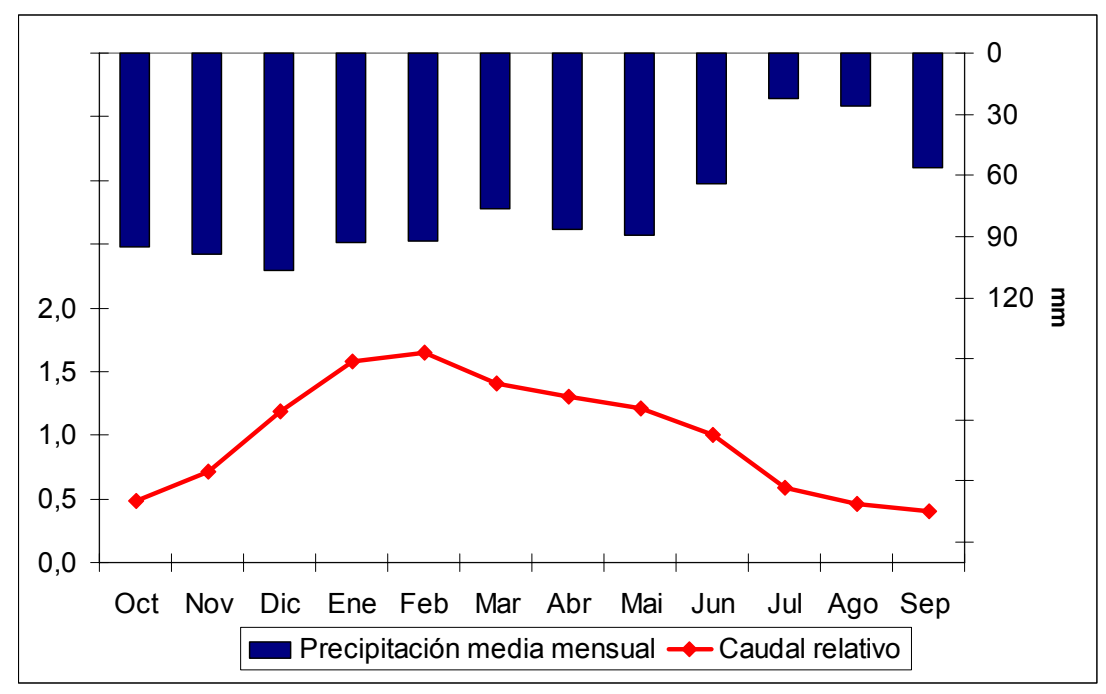

Figura 37 - Caudal relativo (adimensional) y precipitación media mensual de la cuenca alta del Tajo en la estación 001 en Peralejos de las Truchas.

El caudal medio anual es de $4,9 \mathrm{~m}^{3} \mathrm{~s}^{-1}$, por otro lado, en el período de estiaje se detecta un caudal medio de 2,38 $\mathrm{m}^{3} \mathrm{~s}^{-1}$. En los meses de diciembre, enero y febrero (Tabla 32) el caudal medio es de $7,21 \mathrm{~m}^{3} \mathrm{~s}^{-1}$, que es más que el triple del encontrado en los meses de estiaje. Desde el mes de marzo hasta el mes de junio el caudal medio es un poco menor, con $6,04 \mathrm{~m}^{3} \mathrm{~s}^{-1}$. En la cuenca del río Tajo está bastante demostrada que el período de estiaje se prolonga hasta octubre, que incluso presenta un valor de caudal medio menor que julio. Al analizar cada año, se observa que en un total de 20 años el mes de octubre presenta valores menores que julio. 
Tabla 32. Estadística básica de los caudales medios del Río Tajo en Peralejos de las Truchas para el período hidrológico de 1974 - 2004.

\begin{tabular}{|c|c|c|c|}
\hline \hline Período & $\begin{array}{c}\text { Caudal Medio } \\
\left(\mathbf{m}^{\mathbf{3}} \mathbf{s}^{-1}\right)\end{array}$ & $\begin{array}{c}\text { Mediana } \\
\left(\mathbf{m}^{3} \mathbf{s}^{-1}\right)\end{array}$ & $\begin{array}{c}\text { Caudal } \\
\text { Relativo }\end{array}$ \\
\hline \hline ANUAL & 4,90 & 4,97 & 1,00 \\
\hline OCT & 2,39 & 1,86 & 0,49 \\
\hline NOV & 3,48 & 2,88 & 0,71 \\
\hline DIC & 5,80 & 4,03 & 1,18 \\
\hline ENE & 7,74 & 4,18 & 1,58 \\
\hline FEB & 8,08 & 4,13 & 1,65 \\
\hline MAR & 6,91 & 5,01 & 1,41 \\
\hline ABR & 6,38 & 5,31 & 1,30 \\
\hline MAY & 5,95 & 4,96 & 1,21 \\
\hline JUN & 4,90 & 3,34 & 1,00 \\
\hline JUL & 2,89 & 2,56 & 0,59 \\
\hline AGO & 2,26 & 2,08 & 0,46 \\
\hline SEP & 1,99 & 1,72 & 0,41 \\
\hline \hline
\end{tabular}

La cuenca del río Tajo presenta una variabilidad muy alta del caudal diario, con un coeficiente de variación de 142,9\%. Se han registrado valores de caudal muy próximos a cero en muchas fechas. El valor máximo diario registrado fue de $159,93 \mathrm{~m}^{3} \mathrm{~s}^{-1}$, el día 18/12/1997.

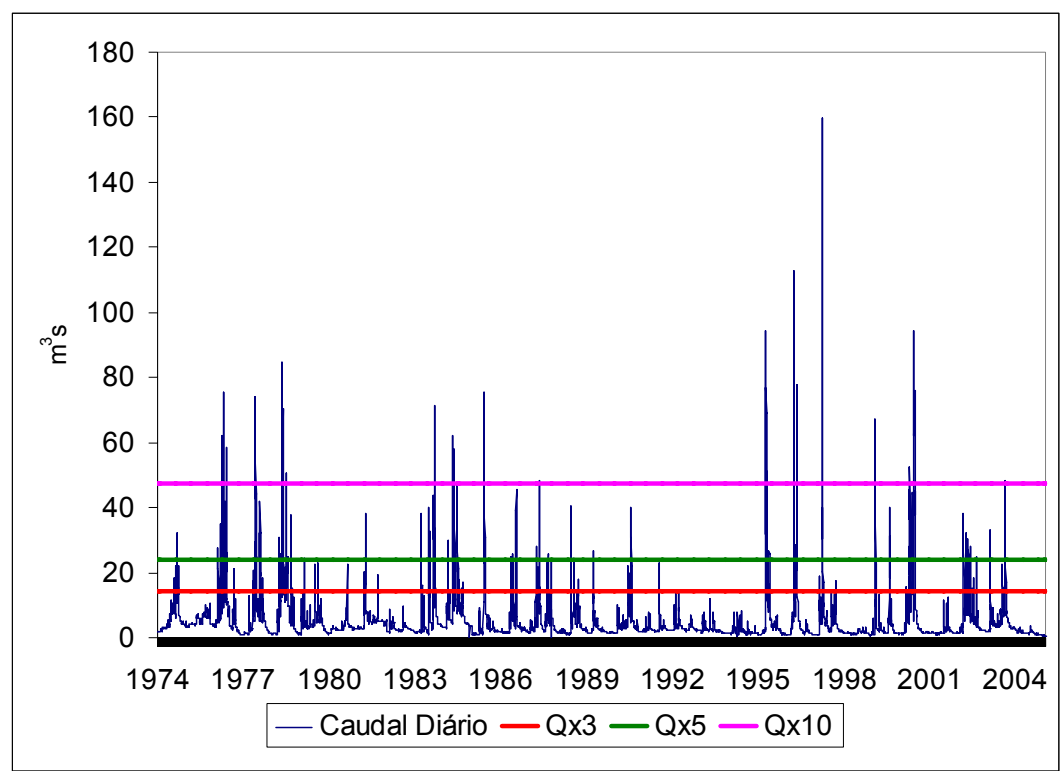

Figura 38 - Distribución de caudales diarios del río Tajo en Peralejos de las Truchas y los correspondientes a $3(Q \times 3), 5(Q \times 5)$ y $10(Q \times 10)$ veces el caudal medio en el período hidrológico 1974-2004.

Los coeficientes Qx3, Qx5 y Qx10 (Fig. 38) para los datos diarios del caudal del río Tajo revelan en el período estudiado 620 días que registraron el triple del caudal 
medio, correspondiendo a 5,5\% de aguas bastante altas. Fueron identificados también 258 días que superaron cinco veces el caudal medio, correspondiendo a 2,28\% del total y solamente en 49 se ha superado en diez veces el caudal medio.

Es posible ver en la figura 39 la distribución de frecuencias de los caudales diarios y se aprecia que la mayoría de los valores registrados están entre 0 y $10 \mathrm{~m}^{3} \mathrm{~s}^{-1}(90,7 \%)$. De todo el período estudiado, se registran un total de $8,6 \%$ de caudales diarios entre $11 \mathrm{y}$ $40 \mathrm{~m}^{3} \mathrm{~s}^{-1}$ y $0,6 \%$ entre 41 y $80 \mathrm{~m}^{3} \mathrm{~s}^{-1}$. De acuerdo con lo encontrado anteriormente en el análisis de frecuencias de los caudales diarios de las otras cuencas, en el río Tajo también ocurre un predominio de aguas bajas.

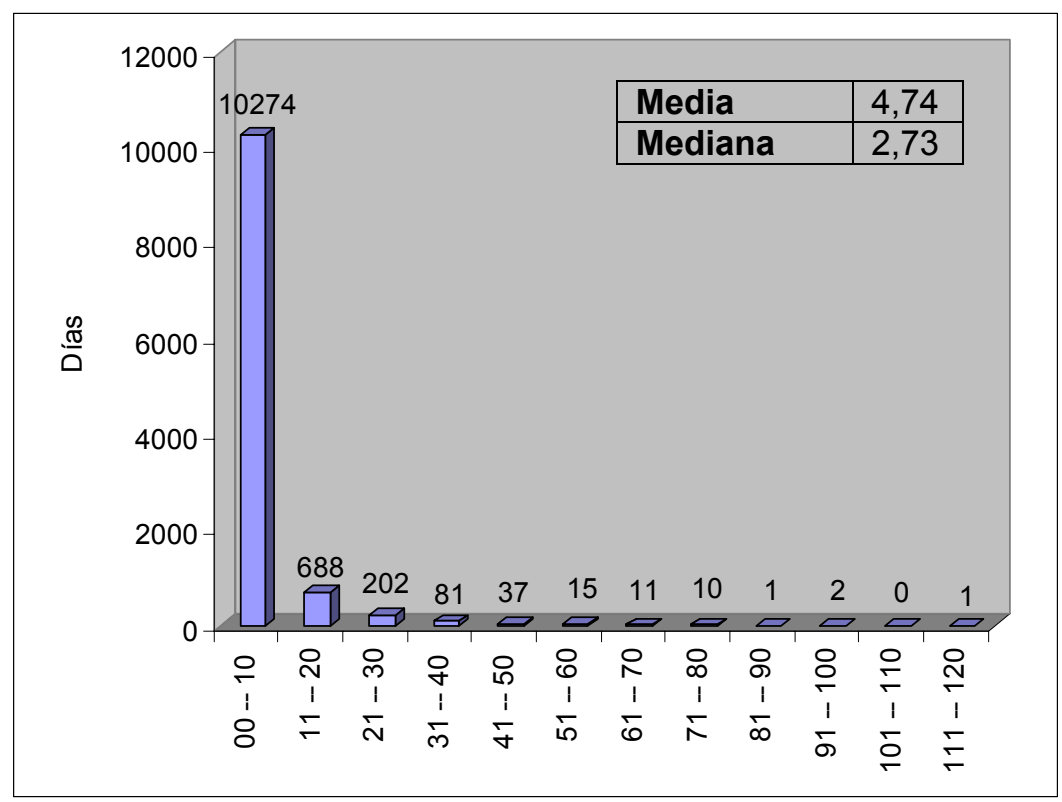

Figura 39 - Distribución de frecuencias de los caudales diarios del río Tajo con indicación de la media y de la mediana.

El río Tajo en Peralejos de las Truchas presenta una variabilidad media en los caudales anuales con un coeficiente de variación del 37,3\% (Tabla 33). Al hacer un análisis mensual, solamente en agosto y septiembre se identifican coeficientes de variación menores de $50 \%$, con $47,4 \%$ y $49,8 \%$, respectivamente. Los meses con más alta variabilidad coinciden con los de caudales más altos, siendo febrero con un coeficiente de variación de $97,1 \%$, enero con $95,2 \%$ y diciembre con $84,1 \%$.

Todos estos datos, con una alta variabilidad, reflejan una vez más la mediterraneidad de esta cuenca, como ya se ha observado en las anteriores. 
Tabla 33. Coeficiente de variación de los caudales medios mensuales y anuales del Río Tajo en Peralejos de las Truchas para el período hidrológico de 1974 - 2004.

\begin{tabular}{|c|c|}
\hline \hline Período & $\begin{array}{c}\text { Coeficiente de Variación } \\
\%\end{array}$ \\
\hline ANUAL & 37,3 \\
\hline OCT & 60,6 \\
\hline NOV & 67,2 \\
\hline DIC & 84,1 \\
\hline ENE & 95,2 \\
\hline FEB & 97,1 \\
\hline MAR & 85,5 \\
\hline ABR & 60,6 \\
\hline MAY & 62,7 \\
\hline JUN & 70,8 \\
\hline JUL & 51,4 \\
\hline AGO & 47,4 \\
\hline SEP & 49,8 \\
\hline
\end{tabular}

De acuerdo con los resultados obtenidos con los coeficientes de variación interanual del río Tajo (Fig. 40) se observa un ligero aumento, sobre todo en los últimos años, aunque no sea posible identificar ninguna tendencia significativa. La variabilidad encontrada puede representar problemas a la hora de evaluar las tendencias de los caudales en el tiempo.

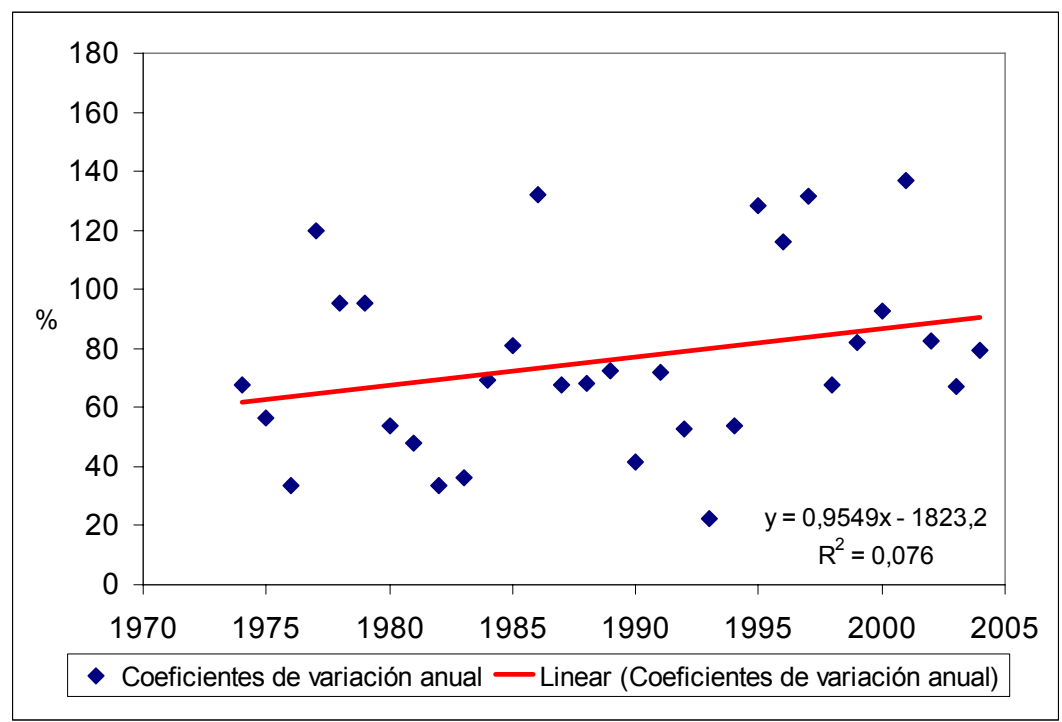

Figura 40 - Coeficientes de variación interanual del río Tajo con indicación de su tendencia - Período 1974 - 2004. 
Tabla 34. Caudal específico del Río Tajo en Peralejos de las Truchas para el período hidrológico de 1974 - 2004.

\begin{tabular}{|c|c|}
\hline Período & $\begin{array}{c}\text { Caudal Específico } \\
\left(\mathrm{Is}^{-1} \mathrm{~km}^{-2}\right)\end{array}$ \\
\hline ANUAL & 11,95 \\
\hline OCT & 5,83 \\
\hline NOV & 8,50 \\
\hline DIC & 14,15 \\
\hline ENE & 18,87 \\
\hline FEB & 19,71 \\
\hline MAR & 16,85 \\
\hline ABR & 15,56 \\
\hline MAY & 14,51 \\
\hline JUN & 11,96 \\
\hline JUL & 7,04 \\
\hline AGO & 5,50 \\
\hline SEP & 4,85 \\
\hline
\end{tabular}

Los datos de caudal específico de la cuenca del Tajo se muestran en la tabla 34 y es posible identificar que el valor anual, $11,95 \mathrm{Is}^{-1} \mathrm{~km}^{-2}$, se asemeja mucho al encontrado para el río Cega $\left(10,80 \mathrm{Is}^{-1} \mathrm{~km}^{-2}\right)$.

El valor más elevado fue encontrado en el mes de febrero con $19,71 \mathrm{Is}^{-1} \mathrm{~km}^{-2}$, seguido de enero. A su vez el valor más bajo de caudal específico fue encontrado en el mes de septiembre, con $4,85 \mathrm{Is}^{-1} \mathrm{~km}^{-2}$, seguido de agosto. La media del caudal especifico en el período de estiaje (julio, agosto, septiembre y octubre) es de $5,81 \mathrm{Is}^{-1} \mathrm{~km}^{-2}$, que está $51,4 \%$ por debajo de la media anual. Este dato confirma el predominio de un período de estiaje muy fuerte y con caudales bastante reducidos en este momento del año.

En el año de 2004 se registró la aportación mínima en toda la serie estudiada, con tan sólo $43,83 \mathrm{hm}^{3}$ (Tabla 35 ), que corresponde al $29,3 \%$ de la media anual de todo el período que fue de $149,7 \mathrm{hm}^{3}$ (Tabla 36), mientras la máxima fue encontrada en el año de 1978 , con $298,5 \mathrm{hm}^{3}$, que está $99,4 \%$ por encima de la media. 
Tabla 35. Estadística básica de los aportes medios mensuales del río Tajo en Peralejos de las Truchas para el período hidrológico de 1974 - 2004.

\begin{tabular}{|c|c|c|c|c|c|c|}
\hline Período & $\begin{array}{c}\text { Media } \\
\left(\mathrm{hm}^{3}\right)\end{array}$ & $\begin{array}{c}\text { Mediana } \\
\left(\mathrm{hm}^{3}\right)\end{array}$ & $\begin{array}{c}\text { Desviación } \\
\text { Típica } \\
\left(\mathrm{hm}^{3}\right)\end{array}$ & $\begin{array}{c}\text { Mínimo } \\
\left(\mathrm{hm}^{3}\right)\end{array}$ & $\begin{array}{c}\text { Máximo } \\
\left(\mathrm{hm}^{3}\right)\end{array}$ & $\begin{array}{c}\text { Coeficiente } \\
\text { de variación } \\
(\%)\end{array}$ \\
\hline OCT & 6,40 & 5,00 & 3,88 & 2,25 & 20,62 & 60,58 \\
\hline NOV & 9,03 & 7,46 & 6,07 & 3,00 & 25,70 & 67,17 \\
\hline $\mathrm{DIC}$ & 15,54 & 10,80 & 13,06 & 2,95 & 56,17 & 84,04 \\
\hline ENE & 19,93 & 10,40 & 19,89 & 3,00 & 65,30 & 99,82 \\
\hline FEB & 18,94 & 9,80 & 19,16 & 2,91 & 80,10 & 101,18 \\
\hline MAR & 17,65 & 12,90 & 15,82 & 3,67 & 64,80 & 89,60 \\
\hline ABR & 15,90 & 13,20 & 10,11 & 3,89 & 43,60 & 63,55 \\
\hline MAY & 15,56 & 12,71 & 10,24 & 3,52 & 46,20 & 65,81 \\
\hline JUN & 12,35 & 8,40 & 9,17 & 2,83 & 38,90 & 74,25 \\
\hline JUL & 7,49 & 6,70 & 4,07 & 2,37 & 17,90 & 54,27 \\
\hline AGO & 5,89 & 5,30 & 2,97 & 1,87 & 13,30 & 50,37 \\
\hline SEP & 5,04 & 4,20 & 2,65 & 1,67 & 12,40 & 52,51 \\
\hline
\end{tabular}

Tabla 36. Estadística Básica de los aportes anuales del Río Tajo en Peralejos de las Truchas para el período hidrológico de 1974 - 2004.

\begin{tabular}{|l|c|}
\hline \multicolumn{2}{|c|}{ Río Tajo - Estación de Aforos $\mathbf{0 0 1}$} \\
\hline Media $\left(\mathrm{hm}^{3}\right)$ & 149,7 \\
\hline Mediana $\left(\mathrm{hm}^{3}\right)$ & 154,1 \\
\hline Desviación Típica $\left(\mathrm{hm}^{3}\right)$ & 65,3 \\
\hline Mínimo $\left(\mathrm{hm}^{3}\right)$ & 43,8 \\
\hline Máximo $\left(\mathrm{hm}^{3}\right)$ & 298,5 \\
\hline CV (\%) & 43,6 \\
\hline \hline
\end{tabular}

\subsubsection{Tendencias a medio plazo}

A partir del análisis de los datos registrados de aportación anual (Fig. 41) se puede ver claramente la alta variabilidad mencionada anteriormente. Es posible, también, observar a partir de la pendiente de la recta de regresión de la figura una clara disminución en las aportaciones que discurre casi en paralelo a la de las precipitaciones. 


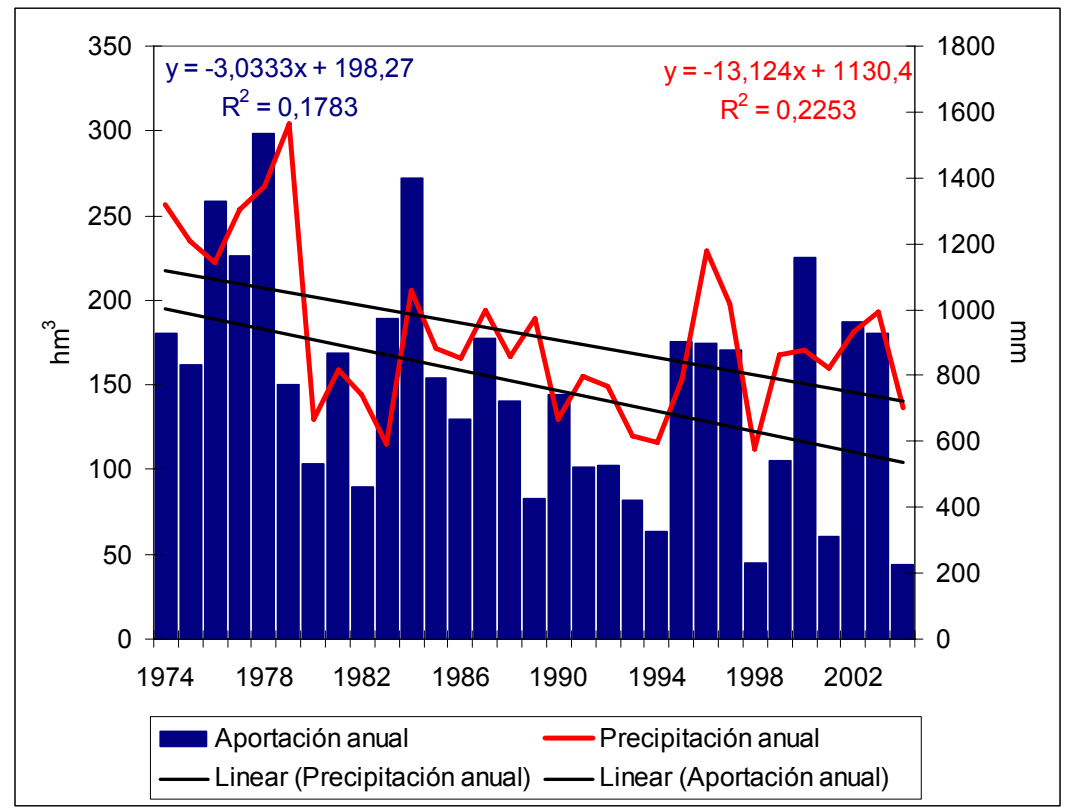

Figura 41 - Evolución de las aportaciones, línea de tendencia y precipitaciones anuales entre 1974 y 2004, con indicación de la tendencia del río Tajo en Peralejos de las Truchas.

Con el objetivo de verificar esta tendencia se calculó el estadístico R (Tabla 37). A partir del análisis de correlación entre el aporte anual y el tiempo se puede ver claramente la reducción de los caudales circulantes en el período estudiado. Un valor de $R=-0,355$, significativo al $95 \%$, evidencia una clara tendencia negativa.

Tabla 37. Coeficiente de correlación entre el aporte anual y el tiempo del río Tajo en Peralejos de las Truchas para el período 1974 - 2004.

\begin{tabular}{|c|c|c|c|}
\hline Estación de Aforo & $\mathbf{n}$ & $\begin{array}{c}\text { Signif. } \\
\text { Estad. }\end{array}$ & R \\
\hline \hline Peralejos de las Truchas & 31 & $*$ & $-0,355$ \\
\hline \hline
\end{tabular}

* = Significativo al $95 \%$

Con el objetivo de localizar los meses en que hubo mayor descenso en la aportación se hizo el análisis de correlación entre la aportación mensual y el tiempo (Tabla 38). Solamente en el mes de noviembre se ha obtenido un $\mathrm{R}$ positivo $(0,079)$, pero con un valor casi despreciable. En todos los demás meses se dan valores negativos de R. En diciembre estos son también despreciables $(-0,002)$. En los meses de octubre, enero, febrero y septiembre no se encontraron valores significativos, aunque se puede ver que en febrero y septiembre están muy cerca de la significación estadística (-0,351 y 0,315 , respectivamente). Los meses de marzo, abril y mayo presentan valores 
estadísticamente significativos al $95 \%$ y los meses de junio, julio y agosto al $99 \%$. El coeficiente de correlación negativo más alto fue encontrado en el mes de junio ($0,712)$, seguido de julio $(-0,672)$. Se aprecia en este momento una diferencia con relación a los valores encontrados para la cuenca del río Porma en que los valores de $R$ negativos más significativos fueron encontrados en abril y mayo, meses de mayor caudal relativo. Por otro lado, en la cuenca del Tajo los resultados de $\mathrm{R}$ negativos más significativos fueron observados en junio, julio y agosto, meses de menor caudal relativo.

Tabla 38. Coeficientes de correlación entre el aporte mensual y el tiempo del río Tajo en Peralejos de las Truchas para el período de 1974 - 2004.

\begin{tabular}{|l|c|r|}
\hline \hline \multicolumn{1}{|c|}{ Período } & $\begin{array}{r}\text { Signif. } \\
\text { Estad. }\end{array}$ & \multicolumn{1}{l|}{ R } \\
\hline \hline Octubre & NS & $-0,222$ \\
\hline Noviembre & NS & 0,079 \\
\hline Diciembre & NS & $-0,002$ \\
\hline Enero & NS & $-0,135$ \\
\hline Febrero & NS & $-0,351$ \\
\hline Marzo & $*$ & $-0,394$ \\
\hline Abril & $*$ & $-0,391$ \\
\hline Mayo & $*$ & $-0,408$ \\
\hline Junio & $* *$ & $-0,712$ \\
\hline Julio & $* *$ & $-0,672$ \\
\hline Agosto & $* *$ & $-0,465$ \\
\hline Septiembre & NS & $-0,315$ \\
\hline \hline
\end{tabular}

NS $=$ Valores no significativos

* = Significativo al $95 \%$

** $=$ Significativo al $99 \%$

En el análisis con M-K (Tabla 39) se puede ver claramente que en la mayoría de los meses se ha detectado una disminución en los aportes en el tiempo. Solamente en los meses de noviembre y diciembre se puede ver un ligero aumento en los valores de $\mathrm{M}$ $\mathrm{K}$, aunque de estos dos meses, noviembre es el único en que se puede rechazar la hipótesis nula de no tendencia. En diciembre los valores de $S$ y $Z$ son casi despreciables $(S=3$ y $Z=0,27$ ) y se diferencian del encontrado con $R$, que revelaba un valor negativo, aunque también casi despreciable. Por lo encontrado con los dos métodos no se puede afirmar ningún tipo de tendencias en los aportes en el río Tajo en Peralejos de las Truchas en el período estudiado en el mes de diciembre. En todos los demás meses se confirman las tendencias negativas encontradas con el análisis de correlación y en todos ellos se puede rechazar la hipótesis nula de no tendencia. Corroborando los valores encontrados con $\mathrm{R}$, los meses que presentan más alta 
significación estadística son junio $(S=-243$ y $Z=-23,99)$ y julio $(S=-232$ y $Z=-$ 23,38). Estos datos demuestran que estos dos meses son los mayores responsables del descenso en la aportación en la cuenca del Tajo.

Tabla 39. Test estadístico Mann-Kendall para los aportes mensuales y anuales del río Tajo en Peralejos de las Truchas.

\begin{tabular}{|l|c|c|c|c|}
\hline \hline \multicolumn{1}{|c|}{ Período } & $\begin{array}{c}\text { S de } \\
\text { Kendall }\end{array}$ & $\mathbf{Z}_{\mathbf{s}}$ & $\begin{array}{c}\text { Rechazo de hipótesis } \\
\text { nula para } \mathbf{p}<\mathbf{0 , 0 5}\end{array}$ & Valor $\boldsymbol{p}$ \\
\hline \hline Anual & -129 & $-13,62$ & $\mathrm{Si}$ & 0,0001 \\
\hline Octubre & -63 & $-6,27$ & $\mathrm{Si}$ & 0,0001 \\
\hline Noviembre & 26 & 2,18 & $\mathrm{Si}$ & 0,0293 \\
\hline Diciembre & 3 & 0,27 & $\mathrm{No}$ & 0,7872 \\
\hline Enero & -39 & $-4,15$ & $\mathrm{Si}$ & 0,0001 \\
\hline Febrero & -120 & $-11,52$ & $\mathrm{Si}$ & 0,0001 \\
\hline Marzo & -137 & $-14,91$ & $\mathrm{Si}$ & 0,0001 \\
\hline Abril & -121 & $-13,26$ & $\mathrm{Si}$ & 0,0001 \\
\hline Mayo & -132 & $-13,41$ & $\mathrm{Si}$ & 0,0001 \\
\hline Junio & -243 & $-23,99$ & $\mathrm{Si}$ & 0,0001 \\
\hline Julio & -232 & $-23,38$ & $\mathrm{Si}$ & 0,0001 \\
\hline Agosto & -159 & $-13,89$ & $\mathrm{Si}$ & 0,0001 \\
\hline Septiembre & -109 & $-8,29$ & $\mathrm{Si}$ & 0,0001 \\
\hline \hline
\end{tabular}

Zs $>$ (+/-) 1,96 se rechaza la hipótesis nula de no tendencia Valor $p<0,05$ se rechaza la hipótesis nula de no tendencia

Anualmente también es posible ver una tendencia regresiva bastante destacada y se puede rechazar la hipótesis nula de no tendencia $(S=-129$ y $Z=-13,62$. Estos resultados también corroboran los encontrados con $\mathrm{R}$ y la tendencia regresiva de los aportes en el tiempo en esta cuenca parece bastante evidente.

Por los resultados obtenidos al utilizar M-Ks para el análisis de la aportación en la cuenca del Tajo (Fig. 42), no se puede determinar con claridad el año de inicio de esta tendencia, pues la figura presenta coincidencia entre las estadísticas $u(t)$ y $u^{*}(t)$ en los años de 1977 y 1978, pero no se aprecia una intersección clara entre las curvas. Lo que sí se puede afirmar es que a partir de 1979 es bastante clara la disminución en los aportes, llegando a valores estadísticamente significativos a partir del año de 1991, cuando sus valores sobrepasan los límites de confianza $( \pm 1,96)$. 


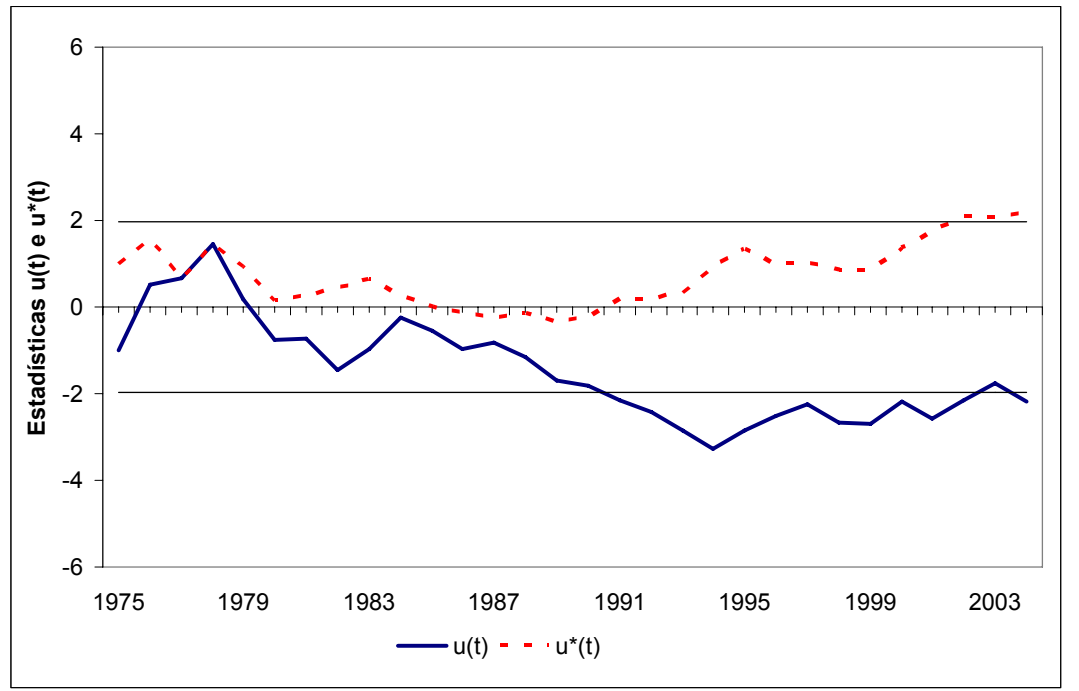

Figura 42 - Test Mann-Kendall secuencial para la aportación anual entre 1974 y 2004 del río Tajo en Peralejos de las Truchas.

Los resultados encontrados con $\mathrm{M}-\mathrm{Ks}$ corroboran los encontrados anteriormente con $\mathrm{R}$ y $M-K$, aunque no sea posible determinar con exactitud el año de inicio de esta tendencia.

Ha sido identificada en la aportación en la cuenca del río Tajo en Peralejos de las Truchas una pérdida anual media de $3,03 \mathrm{hm}^{3}$, representando un total de 93,93 $\mathrm{hm}^{3}$ en el período estudiado. La pérdida anual supone un $2,1 \%$ de la aportación media, valor que coincide exactamente con el obtenido en el río Porma. Como en ese caso, el resultado de la disminución es bastante alto al considerar que se trata de un período de 30 años de análisis. En la primera década la aportación media fue de $182,6 \mathrm{hm}^{3}$, ya en la última esta fue de $130 \mathrm{hm}^{3}$, lo que significa una reducción de un $30 \% \mathrm{si}$ comparados estos dos períodos.

\subsection{Evolución del Caudal en la Cuenca Del Río Trabaque}

\subsubsection{Caracterización hidrológica}

La cuenca del río Trabaque se estudia desde Arcos de la Sierra, donde éste nace, hasta la estación de aforos $n^{\circ} 186$ localizada en Priego (Foto 12, Fig. 43), en la provincia de Cuenca, donde recoge los caudales de la cabecera, con una superficie total de $361 \mathrm{~km}^{2}$. 


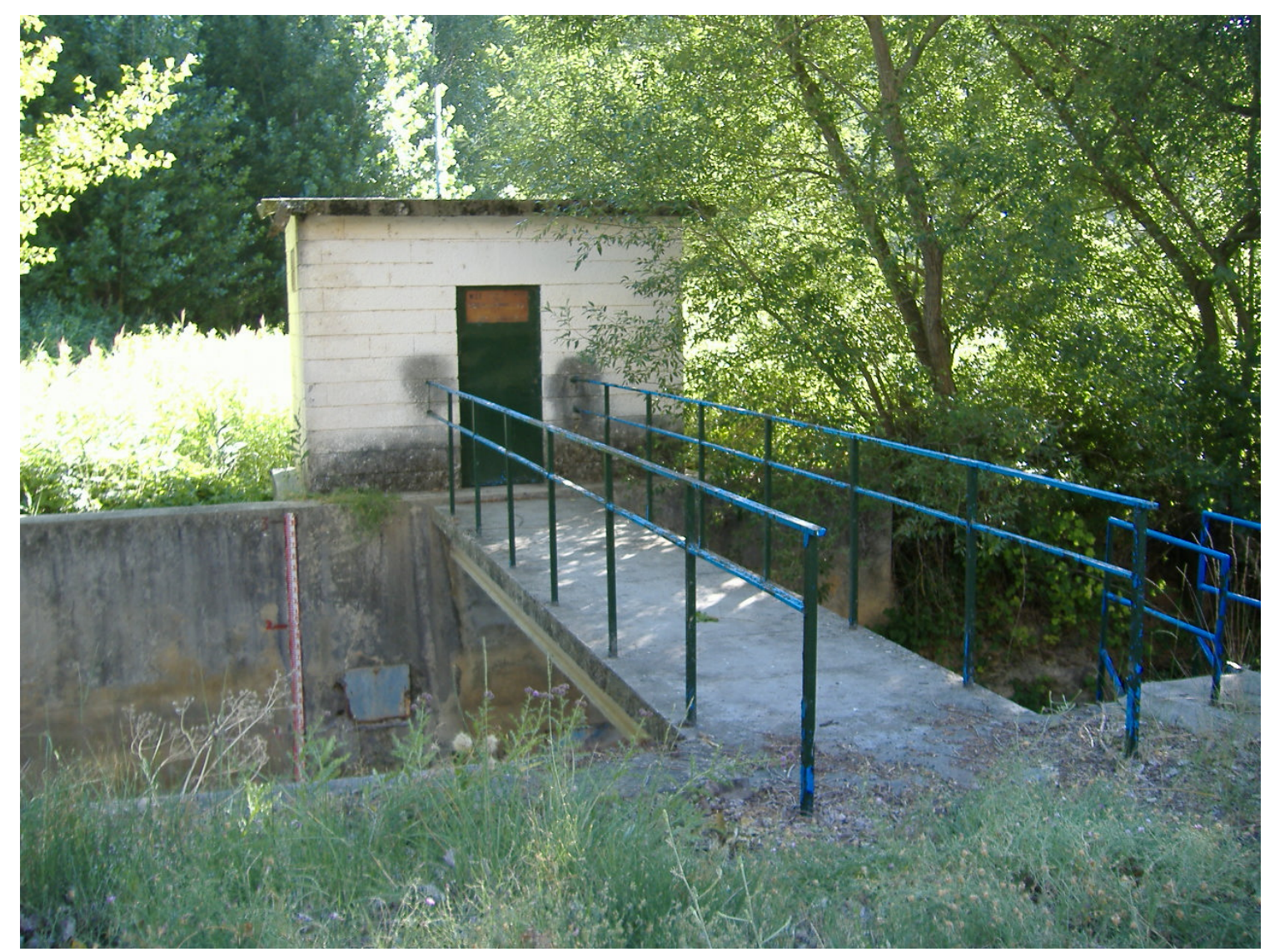

Foto 12 - Estación de aforo 186 en Priego - Río Trabaque.

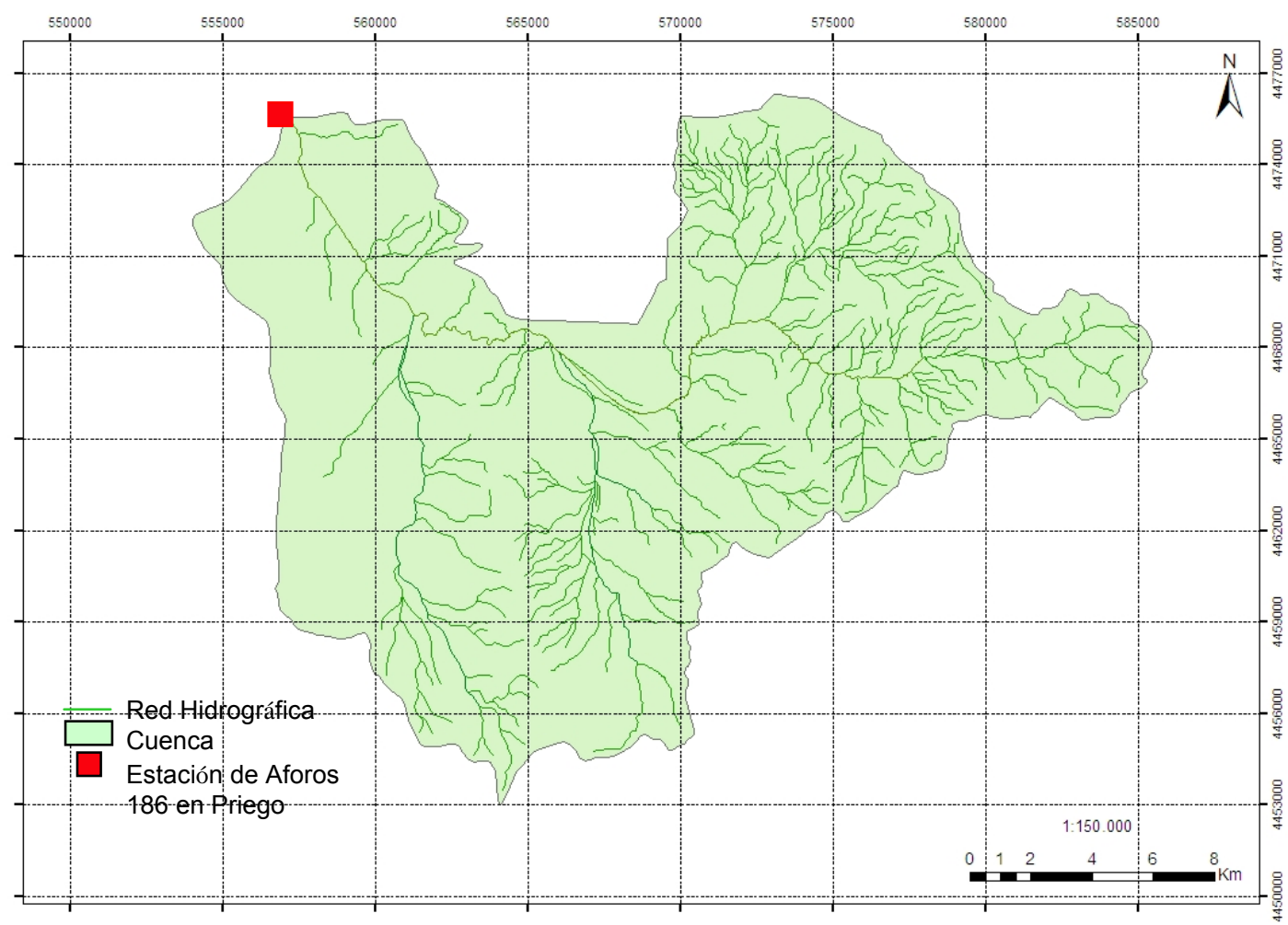

Figura 43 - Cabecera del río Trabaque y localización de la estación de aforo 186 en Priego. 
Como en todas las otras cuencas analizadas en este estudio, hasta esta estación el río mantiene su curso natural sin influencia de ninguna derivación ni embalse. La estación de aforos 186 registra un caudal medio anual de $0,59 \mathrm{~m}^{3} \mathrm{~s}^{-1}$, con una aportación media de $17,81 \mathrm{hm}^{3}$.

El río Trabaque tiene un régimen pluvial (Fig. 44) con algún matiz nival enmascarado por la coincidencia temporal entre la fusión de la nieve y las lluvias primaverales.

El río experimenta un aumento inicial de su caudal a partir del mes de noviembre llegando al punto máximo en febrero. Después se observa un pequeño descenso en marzo, pero sigue teniendo un nivel alto de aportación en los meses primaverales (marzo, abril y mayo). El período de aguas altas va desde diciembre hasta junio, donde empieza a descender. En julio hay un descenso muy acusado de la aportación llegando al período de estiaje. Éste es muy fuerte, teniendo el mínimo de aportación en agosto y septiembre, lo que está en consonancia con las características del verano mediterráneo. En octubre empieza a haber un cierto incremento en la aportación total hasta llegar de nuevo al invierno, donde este aumento es más marcado. Los registros de aforos no superan el doble del caudal medio en ninguna época del año.

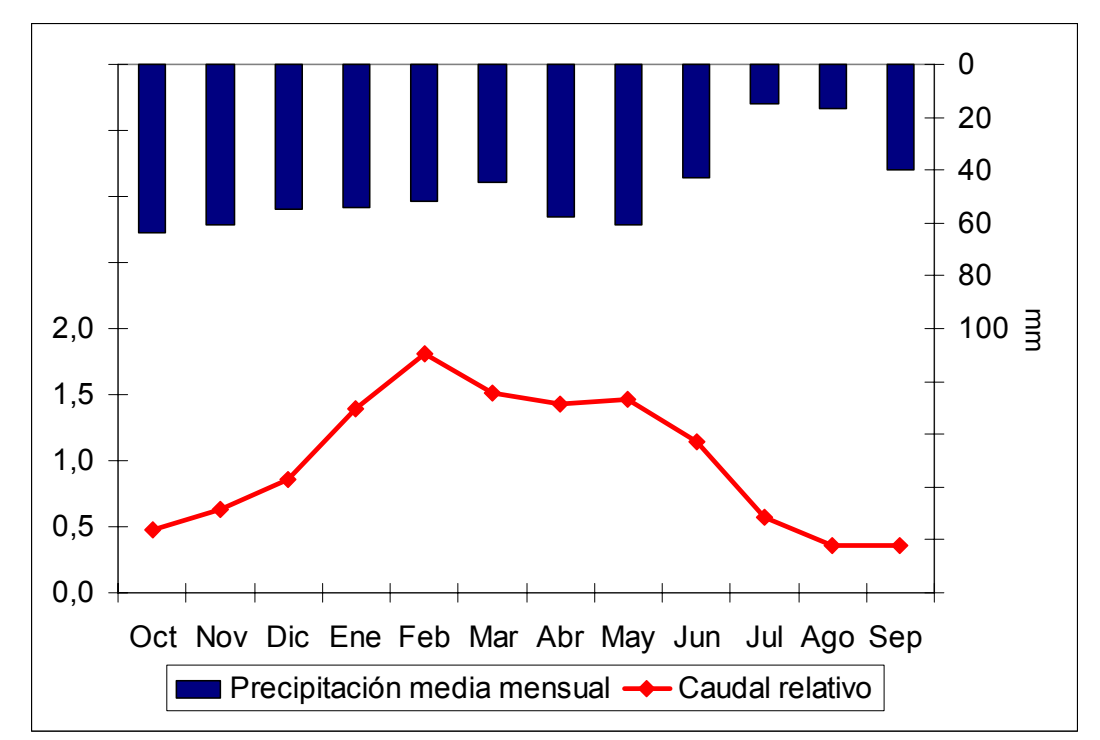

Figura 44 - Caudal relativo (adimensional) y precipitación media mensual de la cuenca del río Trabaque en la estación 186 en Priego. 
Los caudales más bajos se registran en el verano llegando a valores muy cercanos a cero en muchas fechas del año (Tabla 40). Como en el caso del río Cega, el caudal medio de octubre es más bajo que julio, lo que puede ser un resultado engañoso ya que es reflejo de valores atípicos encontrados en apenas algunos años de la serie.

El río Trabaque en Priego presenta una variabilidad altísima con un coeficiente de variación del caudal diario de $185,2 \%$. El valor máximo diario registrado fue de 36,1 $\mathrm{m}^{3} \mathrm{~s}^{-1}$ en el día 15/02/1986 y el mínimo fue muy próximo a cero en muchas fechas en el período estudiado.

Tabla 40. Estadística básica de los caudales medios del Río Trabaque en Priego para el período hidrológico de 1974 - 2004.

\begin{tabular}{|c|c|c|c|}
\hline \hline Período & $\begin{array}{c}\text { Caudal Medio } \\
\left(\mathbf{m}^{\mathbf{3}} \mathbf{s}^{-1}\right)\end{array}$ & $\begin{array}{c}\text { Mediana } \\
\left(\mathbf{m}^{\mathbf{3}} \mathbf{s}^{-1}\right)\end{array}$ & $\begin{array}{c}\text { Caudal } \\
\text { Relativo }\end{array}$ \\
\hline \hline ANUAL & 0,59 & 0,45 & 1,00 \\
\hline OCT & 0,28 & 0,16 & 0,48 \\
\hline NOV & 0,37 & 0,28 & 0,63 \\
\hline DIC & 0,51 & 0,34 & 0,86 \\
\hline ENE & 0,83 & 0,52 & 1,39 \\
\hline FEB & 1,08 & 0,61 & 1,81 \\
\hline MAR & 0,90 & 0,58 & 1,51 \\
\hline ABR & 0,85 & 0,81 & 1,42 \\
\hline MAY & 0,87 & 0,68 & 1,47 \\
\hline JUN & 0,68 & 0,47 & 1,14 \\
\hline JUL & 0,34 & 0,13 & 0,58 \\
\hline AGO & 0,21 & 0,11 & 0,36 \\
\hline SEP & 0,21 & 0,11 & 0,36 \\
\hline \hline
\end{tabular}

Los coeficientes Qx3, Qx5 y Qx10 han sido analizados también para el río Trabaque (Fig. 45). En este río aparecen 670 días que registran el triple del caudal medio, o sea un $6 \%$ de aguas bastante altas. Un total de 240 episodios registrados, o sea un $2 \%$, son superiores a cinco veces su caudal medio y solamente un $0,5 \%$ alcanzan diez veces este umbral. 


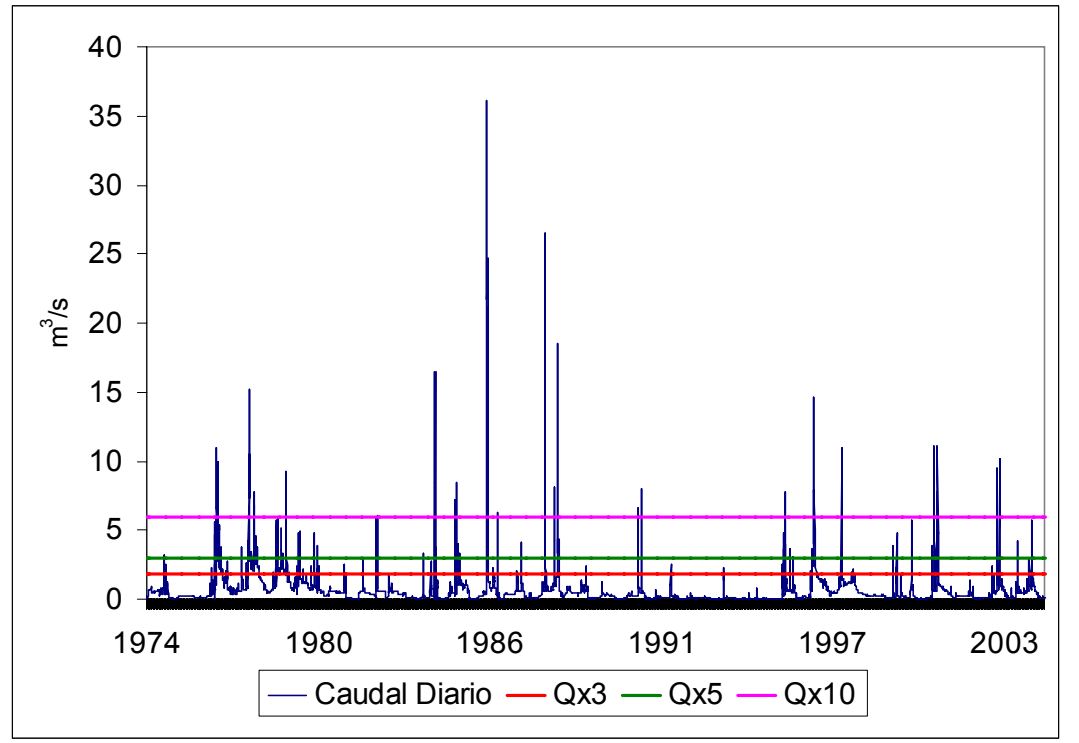

Figura 45 - Distribución de caudales diarios del río Trabaque en Priego y los correspondientes a $3(Q \times 3), 5(Q \times 5)$ y $10(Q \times 10)$ veces el caudal medio en el período hidrológico 1974-2004.

La figura 46 muestra la distribución de la frecuencia de los caudales diarios, estando el $99,8 \%$ de los valores entre 0 y $10 \mathrm{~m}^{3} \mathrm{~s}^{-1}$.

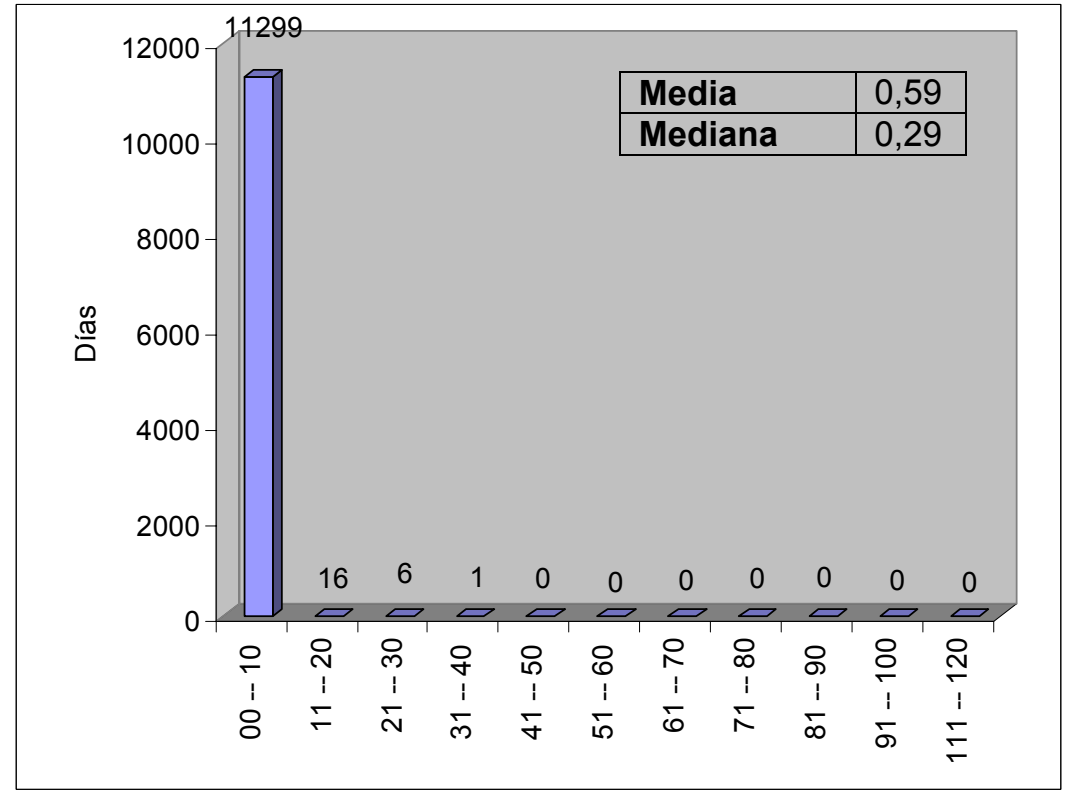

Figura 46 - Distribución de Frecuencias con indicación de la media y de la mediana.

La variabilidad interanual de los caudales es muy grande, con un coeficiente de variación anual del $80,8 \%$ (Tabla 41). Todos los meses presentan también una variabilidad alta (> 50\%) o muy alta, lo que también refleja las características mediterráneas del área de estudio. En la mayoría de los meses (octubre, enero, 
febrero, marzo, junio, julio, agosto y septiembre) este valor sobrepasa el $100 \%$. El mes de julio (Fig. 47) tiene el coeficiente de variación más alto, con 133,4\% y el mes de abril (Fig. 48) registra el más bajo, con $74,8 \%$. La gran variabilidad encontrada en el río Trabaque es un factor de primera magnitud a la hora de analizar todo lo relacionado con el comportamiento hidrológico de este río.

Tabla 41. Coeficiente de variación de los caudales medios mensuales y anuales del Río Trabaque en Priego para el período hidrológico de 1974 - 2004.

\begin{tabular}{|c|c|}
\hline Período & $\begin{array}{c}\text { Coeficiente de Variación } \\
\%\end{array}$ \\
\hline \hline ANUAL & 80,8 \\
\hline OCT & 110,5 \\
\hline NOV & 92,7 \\
\hline DIC & 79,1 \\
\hline ENE & 113,4 \\
\hline FEB & 124,6 \\
\hline MAR & 104,2 \\
\hline ABR & 74,8 \\
\hline MAY & 87,6 \\
\hline JUN & 111,9 \\
\hline JUL & 133,4 \\
\hline AGO & 122,9 \\
\hline SEP & 109,6 \\
\hline \hline
\end{tabular}

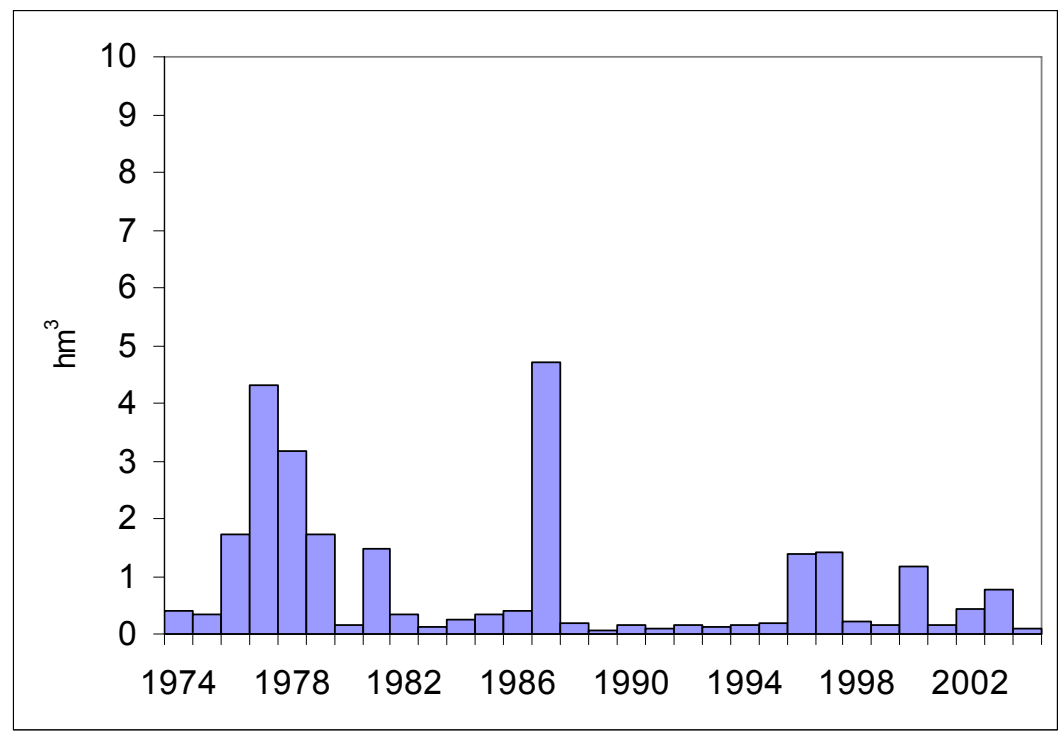

Figura 47 - Aportaciones del mes de julio en la Estación de Aforo 186, del río Trabaque en Priego. 


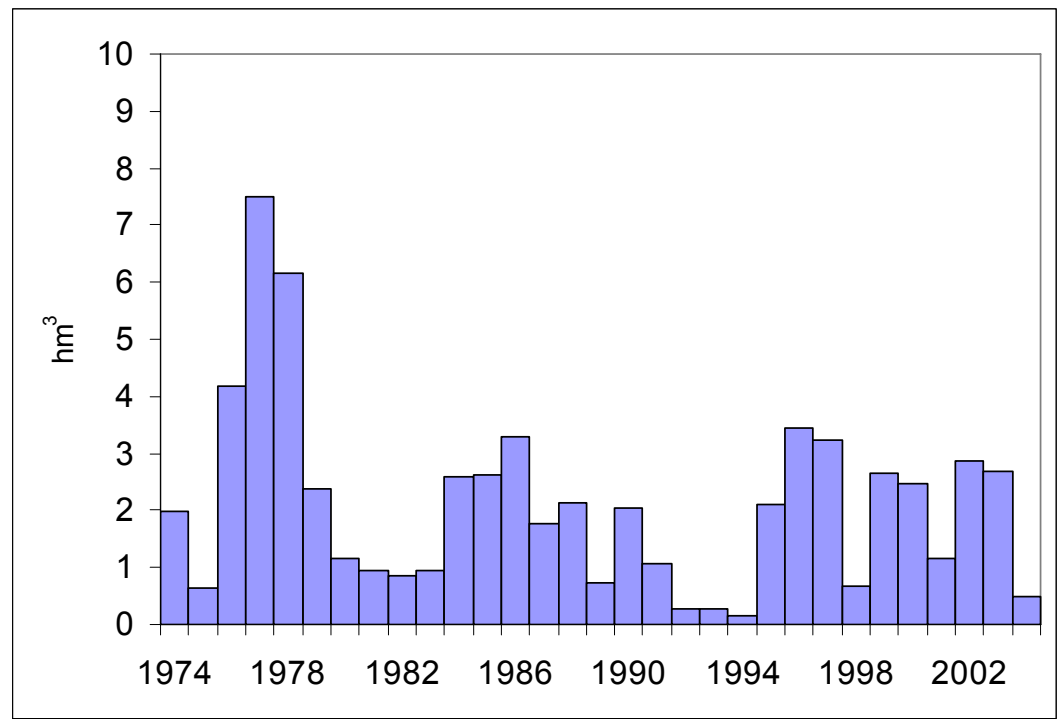

Figura 48 - Aportaciones del mes de abril en la Estación de Aforo 186, del río Trabaque en Priego.

De la observación de la figura 49, que representa la variabilidad interanual del caudal en la cuenca del río Trabaque, se puede percibir que hay un aumento, lo que significa que la variabilidad interanual está sufriendo una tendencia progresiva, aunque no fueron encontrados valores estadísticamente significativos.

Es bastante claro que los altos índices de variabilidad interanual encontrados y el hecho de que están presentando un ligero aumento, aunque no sea muy marcado, refleja un inconveniente de cara a planificar la gestión de los recursos hídricos de esta región, así como a la hora de cualquier tipo de análisis hidrológico de esta cuenca.

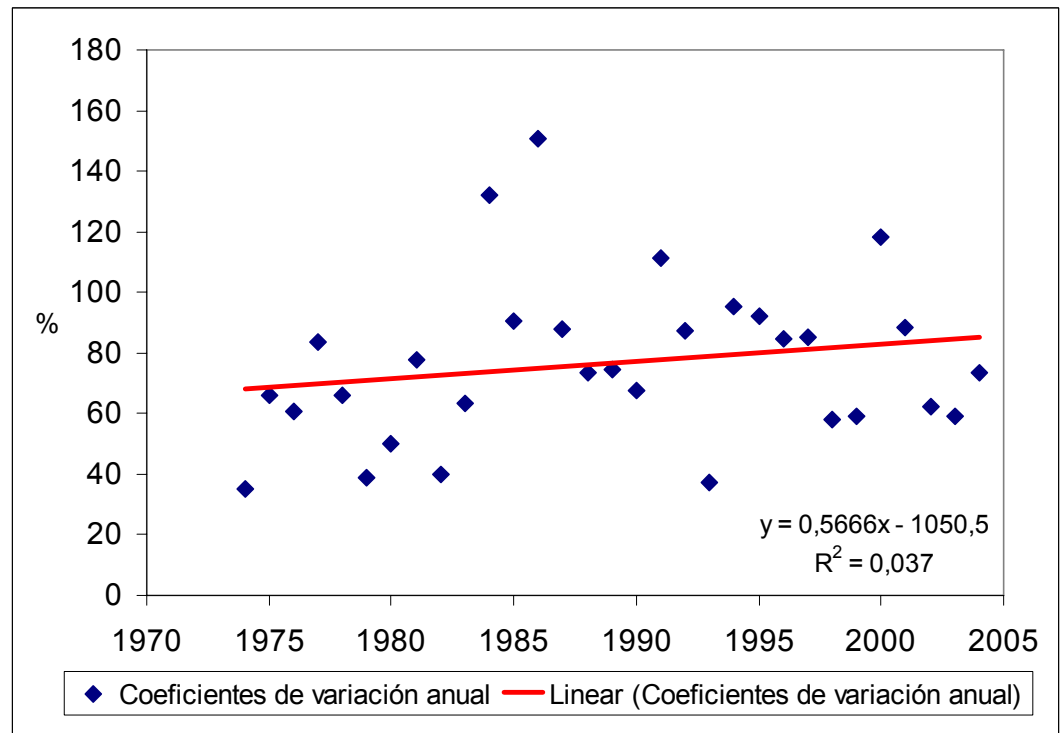

Figura 49 - Coeficientes de variación interanual del río Trabaque con indicación de su tendencia - Período 1974 - 2004. 
Tabla 42. Caudal específico del Río Trabaque en Priego para el período hidrológico de 1974 - 2004.

\begin{tabular}{|c|c|}
\hline \hline Período & $\begin{array}{c}\text { Caudal Específico } \\
\left(\mathbf{I s}^{-1} \mathbf{k m}^{-\mathbf{2}}\right)\end{array}$ \\
\hline ANUAL & 1,65 \\
\hline OCT & 0,79 \\
\hline NOV & 1,03 \\
\hline DIC & 1,41 \\
\hline ENE & 2,30 \\
\hline FEB & 2,98 \\
\hline MAR & 2,49 \\
\hline ABR & 2,35 \\
\hline MAY & 2,42 \\
\hline JUN & 1,88 \\
\hline JUL & 0,95 \\
\hline AGO & 0,59 \\
\hline SEP & 0,59 \\
\hline
\end{tabular}

El río Trabaque presenta un caudal específico anual de $1,65 \mathrm{Is}^{-1} \mathrm{~km}^{-2}$ (Tabla 42) que está muy por debajo de lo encontrado en las cuencas de los ríos Cega, Porma y Tajo. Los meses de enero, febrero, marzo, abril, mayo y junio son los que registran valores más altos para el caudal específico, siendo febrero el que tiene el mayor registro, con $2,98 \mathrm{Is}^{-1} \mathrm{~km}^{-2}$. Por otro lado, los meses de agosto y septiembre son los que tienen los registros más bajos, con $0,59 \mathrm{Is}^{-1} \mathrm{~km}^{-2}$ y $0,79 \mathrm{Is}^{-1} \mathrm{~km}^{-2}$, respectivamente.

Tabla 43. Estadística Básica de los aportes medios mensuales del río Trabaque en Priego para el período hidrológico de 1974 - 2004.

\begin{tabular}{|c|c|c|c|c|c|c|}
\hline Período & $\begin{array}{l}\text { Media } \\
\left(\mathrm{hm}^{3}\right)\end{array}$ & $\begin{array}{c}\text { Mediana } \\
\left(\mathrm{hm}^{3}\right)\end{array}$ & $\begin{array}{c}\text { Desviación } \\
\text { Típica } \\
\left(\mathrm{hm}^{3}\right)\end{array}$ & $\begin{array}{c}\text { Mínimo } \\
\left(\mathrm{hm}^{3}\right)\end{array}$ & $\begin{array}{c}\text { Máximo } \\
\left(\mathrm{hm}^{3}\right)\end{array}$ & $\begin{array}{c}\text { Coeficiente } \\
\text { de variación } \\
(\%)\end{array}$ \\
\hline OCT & 0,83 & 0,47 & 0,90 & 0,10 & 4,30 & 109,4 \\
\hline NOV & 1,10 & 0,75 & 1,14 & 0,14 & 4,95 & 103,6 \\
\hline DIC & 1,51 & 1,10 & 1,27 & 0,15 & 5,12 & 83,8 \\
\hline ENE & 2,39 & 1,46 & 2,62 & 0,17 & 12,90 & 109,8 \\
\hline FEB & 2,76 & 1,52 & 3,28 & 0,17 & 13,54 & 119,2 \\
\hline MAR & 2,57 & 1,55 & 2,64 & 0,15 & 11,32 & 102,5 \\
\hline ABR & 2,34 & 2,09 & 1,86 & 0,15 & 7,51 & 79,6 \\
\hline MAY & 2,25 & 1,81 & 2,00 & 0,14 & 8,95 & 88,8 \\
\hline JUN & 1,74 & 1,14 & 1,99 & 0,07 & 7,79 & 114,9 \\
\hline JUL & 0,94 & 0,34 & 1,23 & 0,05 & 4,71 & 130,4 \\
\hline AGO & 0,58 & 0,29 & 0,70 & 0,03 & 3,09 & 121,7 \\
\hline SEP & 0,54 & 0,25 & 0,60 & 0,05 & 2,48 & 111,5 \\
\hline
\end{tabular}


Tabla 44. Estadística Básica de los aportes medios anuales del Río Trabaque en Priego para el período hidrológico de 1974 - 2004.

\begin{tabular}{|l|c|}
\hline \multicolumn{2}{|c|}{ Río Trabaque - Estación de Aforos $\mathbf{1 8 6}$} \\
\hline \hline Media $\left(\mathrm{hm}^{3}\right)$ & 17,8 \\
\hline Mediana $\left(\mathrm{hm}^{3}\right)$ & 13,6 \\
\hline Desviación Típica $\left(\mathrm{hm}^{3}\right)$ & 14,7 \\
\hline Mínimo $\left(\mathrm{hm}^{3}\right)$ & 1,8 \\
\hline Máximo $\left(\mathrm{hm}^{3}\right)$ & 57,7 \\
\hline CV $(\%)$ & 82,8 \\
\hline
\end{tabular}

Con relación a la aportación (Tablas 43 y 44), se puede observar que el mínimo anual registrado fue de $1,8 \mathrm{hm}^{3}$ en el año de 1994 y el máximo de $57,7 \mathrm{hm}^{3}$ en el año de 1977. La aportación media anual fue de $17,8 \mathrm{hm}^{3}$. La gran variabilidad encontrada hasta ahora está plenamente corroborada por los datos encontrados para la aportación tanto mensual como anual.

\subsubsection{Tendencias a medio plazo}

Analizando la evolución de los aportes (Fig. 50), se pueden identificar tres ciclos que van, aproximadamente, de 1974 a 1983, de 1984 a 1994 y de 1995 a 2004. En el primer período se encuentra el año de 1977 donde hubo el registro más grande de aportación $\left(57,66 \mathrm{hm}^{3}\right)$. En el último ciclo es donde se nota el mayor descenso en los valores de aportaciones y también una mayor estabilización en estos valores, de hecho es el que tiene el menor coeficiente de variación, con un 66,0\%. En el primer y segundo ciclo es muy grande la variabilidad en los datos (coeficiente de variación de $80,5 \%$ y $86,7 \%$ respectivamente). El último año de este ciclo (1983) presenta un total de aportación de tan sólo $3,82 \mathrm{hm}^{3}$, lo que refleja muy bien la variabilidad en este período. El segundo ciclo se caracteriza principalmente por un período muy prolongado de aportaciones muy pequeñas. Este período va del año de 1989 hasta 1994 y es exactamente en este último donde se registra el menor valor de aportación $\left(1,82 \mathrm{hm}^{3}\right)$ en toda la serie histórica estudiada. Este puede ser considerado atípico ya que es un único período en todo el ciclo hidrológico analizado, donde hay un registro de varios años seguidos con valores muy bajos. El tercer período es donde se encuentra una cierta estabilización en los valores, y analizado en relación a los otros dos ciclos, se observa una cierta tendencia a la disminución en los valores totales. 
La pendiente de la recta de regresión refleja una clara evolución negativa en la aportación anual, paralela a la de la precipitación, sin embargo no se ha obtenido un resultado estadísticamente significativo a esta escala y con esté tipo de análisis.

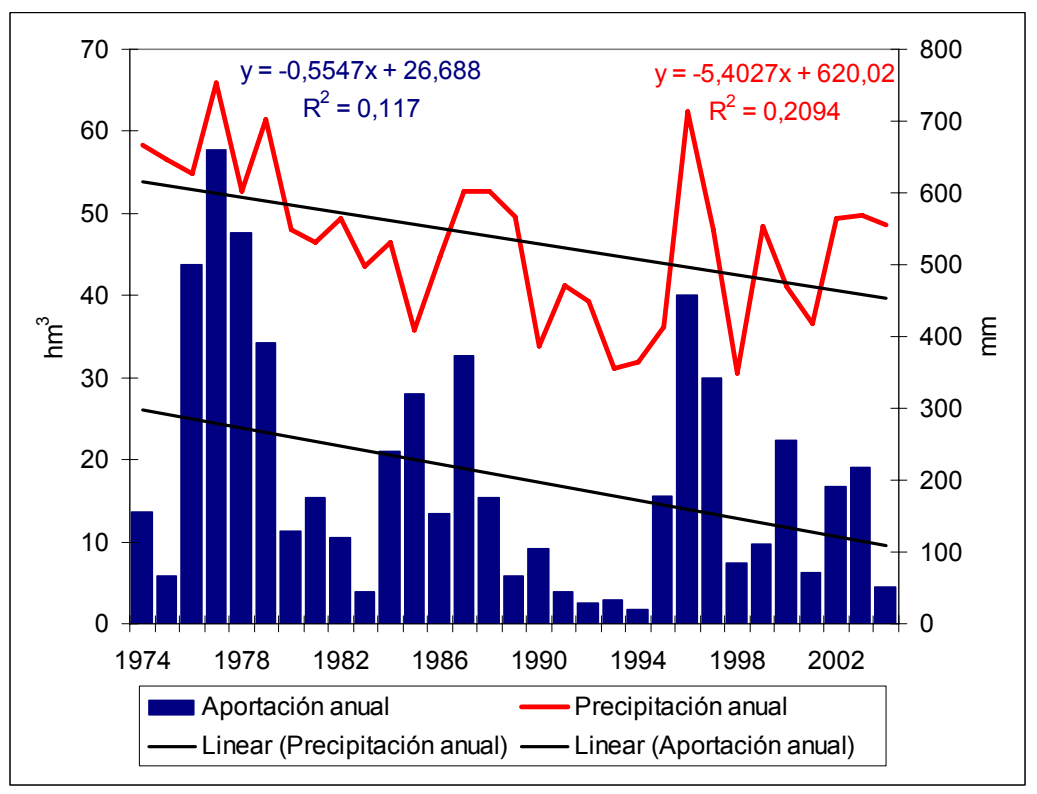

Figura 50 - Evolución de las aportaciones, línea de tendencia y precipitaciones anuales entre 1974 y 2004, con indicación de la tendencia del río Trabaque en Priego.

Las tablas 45 y 46 , presentan los coeficientes de correlación de los aportes anuales y mensuales en el tiempo y reflejan una tendencia regresiva en el período estudiado. El valor anual del $\mathrm{R}$ es de $-0,248$, confirmando un descenso claro y acentuado en la aportación en el río Trabaque en Priego, pero sin alcanzar la significación estadística. Este resultado puede estar enmascarado por la alta variabilidad detectada en esta cuenca.

Tabla 45. Coeficiente de correlación entre el aporte anual y el tiempo del río Trabaque en Priego para el período 1974 - 2004.

\begin{tabular}{|l|c|c|c|}
\hline \hline Estación de Aforo & $\mathbf{n}$ & $\begin{array}{c}\text { Signif. } \\
\text { Estad. }\end{array}$ & $\mathbf{R}$ \\
\hline Cuenca del río Trabaque & 31 & NS & $-0,248$ \\
\hline \hline
\end{tabular}

NS $=$ Valores no significativos 
Tabla 46. Coeficientes de correlación entre el aporte mensual y el tiempo del río Trabaque en Priego para el período de 1974 - 2004.

\begin{tabular}{|l|c|c|}
\hline \multicolumn{1}{|c|}{ Período } & $\begin{array}{l}\text { Signif. } \\
\text { Estad. }\end{array}$ & \multicolumn{1}{l|}{ R } \\
\hline \hline Octubre & NS & $-0,186$ \\
\hline Noviembre & $*$ & $-0,363$ \\
\hline Diciembre & ${ }^{*}$ & $-0,375$ \\
\hline Enero & NS & $-0,244$ \\
\hline Febrero & NS & $-0,300$ \\
\hline Marzo & NS & $-0,216$ \\
\hline Abril & NS & $-0,098$ \\
\hline Mayo & NS & $-0,216$ \\
\hline Junio & NS & $-0,353$ \\
\hline Julio & NS & $-0,334$ \\
\hline Agosto & NS & $-0,085$ \\
\hline Septiembre & NS & $-0,089$ \\
\hline
\end{tabular}

NS $=$ Valores no significativos

$*$ = Significativo al $95 \%$

Al hacer el análisis mensual, sólo presentan valores significativos al 95\% los meses de noviembre $(-0,363)$ y diciembre $(-0,375)$, siendo por lo tanto este último el mes con coeficiente de correlación más destacado. Todos los demás meses no presentan valores significativos, aunque los meses de junio y julio presentan valores muy cercanos a la significación estadística $(-0,353$ y $-0,334$, respectivamente). Por otro lado, los meses que presentan menores valores de correlación entre la aportación y el tiempo son agosto y septiembre.

Los resultados encontrados con el estadístico M-K (Tabla 47), demuestran que anualmente se puede afirmar la existencia de una tendencia regresiva significativa. Este resultado diverge ligeramente del encontrado con el análisis de correlación que reflejaba una tendencia negativa de los aportes en el tiempo, pero sin valores significativos. El análisis mensual de los resultados de $\mathrm{M}-\mathrm{K}$ revela una tendencia regresiva en todos los meses y solamente en agosto no se puede rechazar la hipótesis nula de no tendencia ( $S=-14$ y $Z=-0,95)$. En este mes fue encontrado también el valor de $\mathrm{R}$ menos significativo. En todos los demás meses los resultados superan los límites de confianza. Los valores más altos en las tendencias regresivas fueron encontrados en los meses de diciembre y noviembre. 
Tabla 47. Test estadístico Mann-Kendall para los aportes mensuales y anuales del río Trabaque en Priego.

\begin{tabular}{|l|c|c|c|c|}
\hline \hline \multicolumn{1}{|c|}{ Período } & $\begin{array}{c}\text { S de } \\
\text { Kendall }\end{array}$ & $\mathbf{Z}_{\mathbf{s}}$ & $\begin{array}{c}\text { Rechazo de hipótesis } \\
\text { nula para } \mathbf{p < 0 , 0 5}\end{array}$ & Valor $\boldsymbol{p}$ \\
\hline \hline Anual & -89 & $-7,71$ & $\mathrm{Si}$ & 0,0001 \\
\hline Octubre & -55 & $-4,76$ & $\mathrm{Si}$ & 0,0001 \\
\hline Noviembre & -119 & $-11,36$ & $\mathrm{Si}$ & 0,0001 \\
\hline Diciembre & -125 & $-13,19$ & $\mathrm{Si}$ & 0,0001 \\
\hline Enero & -99 & $-10,23$ & $\mathrm{Si}$ & 0,0001 \\
\hline Febrero & -110 & $-10,00$ & $\mathrm{Si}$ & 0,0001 \\
\hline Marzo & -79 & $-7,74$ & $\mathrm{Si}$ & 0,0001 \\
\hline Abril & -36 & $-3,18$ & $\mathrm{Si}$ & 0,0015 \\
\hline Mayo & -64 & $-5,32$ & $\mathrm{Si}$ & 0,0001 \\
\hline Junio & -101 & $-8,14$ & $\mathrm{Si}$ & 0,0001 \\
\hline Julio & -102 & $-9,09$ & $\mathrm{Si}$ & 0,0001 \\
\hline Agosto & -14 & $-0,95$ & $\mathrm{No}$ & 0,3421 \\
\hline Septiembre & -27 & $-2,06$ & $\mathrm{Si}$ & 0,0394 \\
\hline \hline
\end{tabular}

Zs $>(+/-) 1,96$ se rechaza la hipótesis nula de no tendencia Valor $p<0,05$ se rechaza la hipótesis nula de no tendencia

Para intentar localizar el año de inicio de las tendencias encontradas con los test estadísticos ha sido utilizado M-Ks (Fig. 51). Al analizar esta figura se puede ver la tendencia negativa de los aportes en el tiempo en el río Trabaque, sin embargo no es posible detectar el año de inicio pues hay muchas intersecciones entre las estadísticas $u(t) \mathrm{y}^{*}(\mathrm{t})$. Lo que se puede afirmar es que a partir del año de 1990 la tendencia regresiva es indudable, llegando a presentar valores estadísticamente significativos a partir del año de 1993.

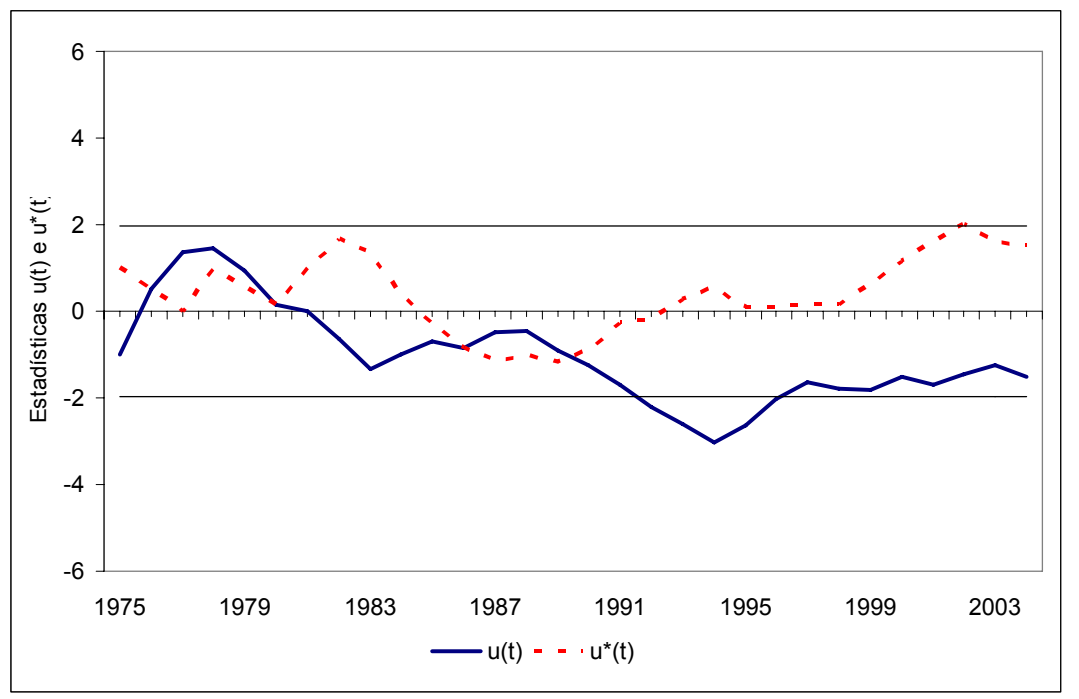

Figura 51 - Test Mann-Kendall secuencial para la aportación anual entre 1974 y 2004 del río Trabaque en Priego. 
Todos los resultados encontrados llevan a pensar en la existencia de una tendencia negativa de las aportaciones en el río Trabaque en Priego. En el caso de $\mathrm{R}$ se encontró una tendencia negativa pero sin valores estadísticamente significativos. Sin embargo, con los estadísticos M-K y M-Ks los resultados encontrados dejan clara la existencia de una tendencia negativa significativa. No hay duda de que la gran variabilidad registrada en esta cuenca genera dificultades a la hora de certificar la tendencia y el comportamiento del río.

La pérdida total de aportación encontrada en el río Trabaque en Priego en todo el período estudiado fue de $17,05 \mathrm{hm}^{3}$, que equivale a una pérdida media de $0,55 \mathrm{hm}^{3}$ al año. Este último valor supone un $3,1 \%$ del promedio de aportación anual, valor muy elevado, si se tiene en cuenta el periodo analizado y que es, incluso, superior al encontrado en las otras cuencas analizadas anteriormente. Al comparar la aportación media en la primera década estudiada $\left(24,4 \mathrm{hm}^{3}\right)$ con la última $\left(15,8 \mathrm{hm}^{3}\right)$ se aprecia una reducción de $35,5 \%$ en sus valores. 


\section{VARIABLES CLIMATOLÓGICAS}

El estudio de las precipitaciones y de la temperatura es de fundamental importancia para analizar el comportamiento de una cuenca hidrográfica y de sus recursos hídricos, sobre todo en el actual contexto de cambio climático. Según Yevjevich (1972), la tendencia en una serie temporal es un cambio sistemático y continuo en cualquier parámetro de una muestra, excluyéndose cambios periódicos o casi periódicos. Además de las tendencias, las variables climáticas pueden sufrir modificaciones que son definidas por Goossens y Berger (1986) y diferenciadas en fluctuación, oscilación y cambio abrupto. Según estos autores las fluctuaciones climáticas son cualquier forma de cambio sistemático regular o irregular, con excepción de la tendencia y de los cambios abruptos. Por otro lado, definen oscilación climática como la fluctuación en la cual la variable tiende a moverse gradualmente y de forma moderada entre sucesivos máximos y mínimos. Por fin, los cambios abruptos son modificaciones bruscas en el período de registro, de un valor medio a otro.

El principal objetivo del estudio de estas variables, en este trabajo de investigación, es analizar su evolución temporal y detectar si hay alguna tendencia. Para lograr este objetivo, los datos climatológicos fueron sometidos a las metodologías de análisis sugeridas por la OMM incluyendo el proceso previo de control de calidad de los datos con evaluación de la homogeneidad de las series, así como las correcciones que se consideraron necesarias. Las estaciones climatológicas utilizadas para todos los análisis están descritas en la tabla 48.

Las series históricas empleadas para análisis de la precipitación son distintas para cada estación, pues se buscó la mayor cantidad de datos para el estudio, teniendo así un análisis riguroso en lo que se refiere a algún tipo de tendencia.

En el caso de los análisis de temperatura fue utilizado el mismo período de tiempo para todas las estaciones (1969-2006) con el objetivo principal de obtener series comunes, lo más largas posibles y con datos de más calidad. De este modo, siguiendo las directrices de la OMM, el período de estudio en todas las estaciones utilizadas para análisis de la precipitación y de la temperatura en las cuencas tiene en cuenta como mínimo las últimas tres décadas del siglo XX (1971-2000). 
Tabla 48. Estaciones pluviométricas y termométricas utilizadas para análisis climatológicas de las cuencas de los ríos Cega, Porma, Tajo y Trabaque.

\begin{tabular}{|c|c|c|c|}
\hline Cuenca & Estaciones & Tipo & Altitud (m) \\
\hline \multirow[t]{6}{*}{ Cuenca del río Cega } & La Granja de San Ildefonso & Precipitación & 1191 \\
\hline & Matabuena & Precipitación & 1154 \\
\hline & Rascafria (El Paular) & Precipitación & 1159 \\
\hline & Rascafria (El Paular) & Temperatura & 1159 \\
\hline & Torreiglesias & Precipitación & 1053 \\
\hline & Turégano & Precipitación & 935 \\
\hline \multirow[t]{6}{*}{ Cuenca del río Porma } & Acebedo & Precipitación & 1181 \\
\hline & Crémenes & Precipitación & 997 \\
\hline & Maraña & Precipitación & 1253 \\
\hline & Pantano del Porma & Precipitación & 1040 \\
\hline & Pantano del Porma & Temperatura & 1040 \\
\hline & Puebla de Lillo & Precipitación & 1130 \\
\hline \multirow[t]{6}{*}{ Cuenca alta del Tajo } & Beteta & Precipitación & 1214 \\
\hline & Cañizares (Central Vadillo) & Precipitación & 940 \\
\hline & Cañizares (Central Vadillo) & Temperatura & 940 \\
\hline & Poyatos (Tejadillos) C. F. & Precipitación & 1150 \\
\hline & Santa María del Val & Precipitación & 1195 \\
\hline & Vega del Codorno & Precipitación & 1345 \\
\hline \multirow[t]{6}{*}{ Cuenca del río Trabaque } & Albalate de las Nogueras & Precipitación & 855 \\
\hline & Arrancacepas & Precipitación & 937 \\
\hline & Arrancacepas & Temperatura & 937 \\
\hline & Cañaveras & Precipitación & 819 \\
\hline & Torrecilla & Precipitación & 969 \\
\hline & Villar de Domingo García & Precipitación & 942 \\
\hline
\end{tabular}

El análisis de los factores climáticos puede revelar su evolución y si hay alguna tendencia y a partir de entonces se puede establecer una relación con el comportamiento de los caudales, y con los cambios efectuados en los usos del suelo en las cuencas. Por lo tanto, en este apartado se efectúa un análisis climatológico de las cuatro áreas estudiadas con el objetivo de detectar el comportamiento reciente de las series. 


\subsection{Evolución de la Precipitación en la Cuenca Del Río Cega}

\subsubsection{Caracterización de la precipitación}

En la cuenca del río Cega (Fig. 52) la precipitación media anual en el período estudiado es de $698 \mathrm{~mm}$ con un coeficiente de variación medio de 21,8\%. Los valores máximos de precipitación (Tabla 49) fueron de $1500 \mathrm{~mm}$ (un 114,9\% por encima de la media de la cuenca) en la estación Rascafria, en 1963, y 1140 mm en la estación La Granja de San Ildefonso en 1972. La precipitación mínima anual fue encontrada en la estación Turégano, en 1982, con solamente $323 \mathrm{~mm}$ lo que representa un 53,7\% por debajo de la media de la cuenca, seguido de $341 \mathrm{~mm}$ en la estación Torreiglesias en 1983. En este último año también fueron encontrados los valores mínimos de las estaciones La Granja de San Ildefonso (360 mm) y Rascafria (389 mm).

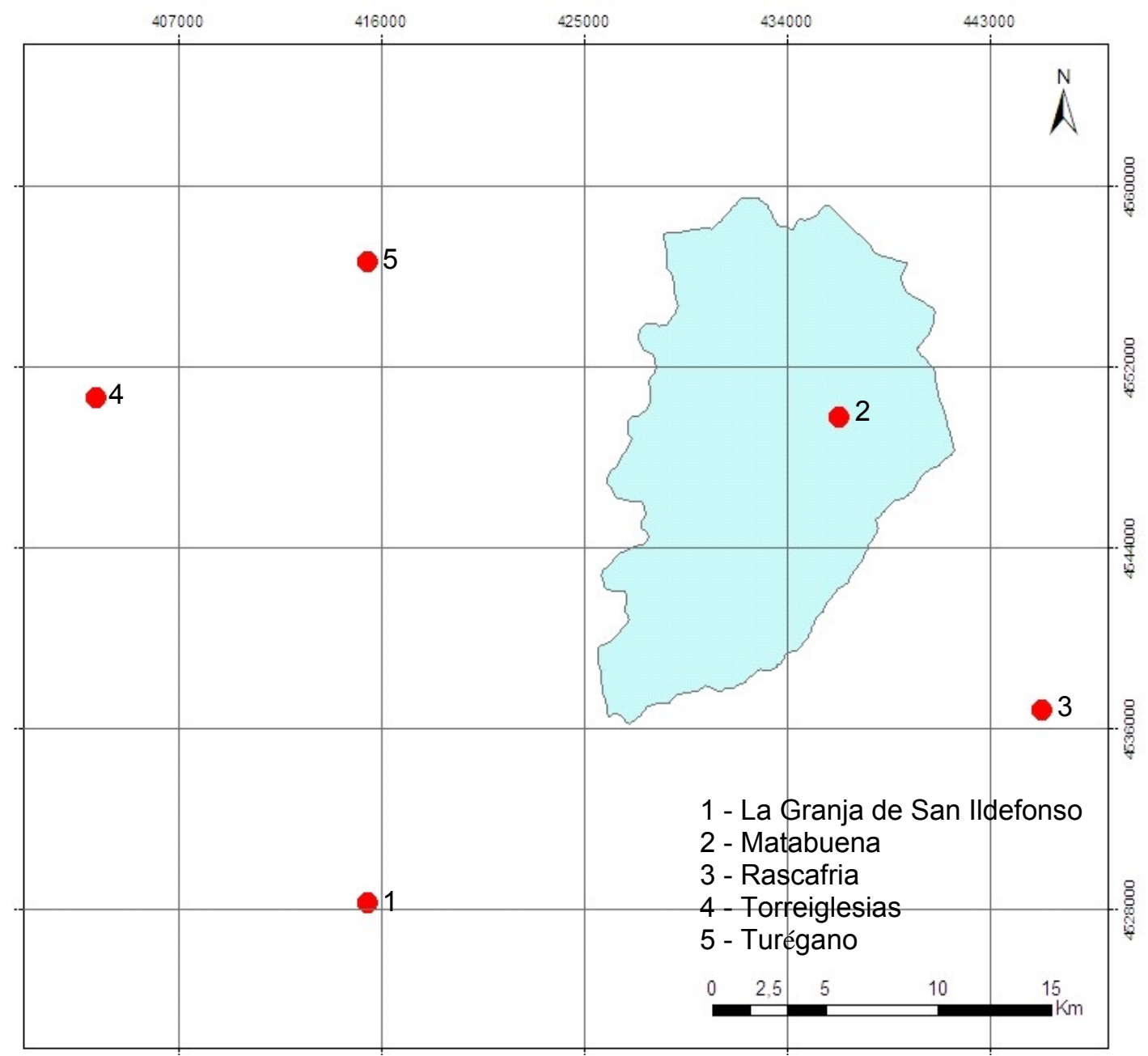

Figura 52 - Localización de las estaciones termométricas y pluviométricas (Cuenca del río Cega). 
Tabla 49. Precipitación media, mínima, máxima, coeficientes de variación y altitud para todas las estaciones utilizadas para análisis de la cuenca del río Cega.

\begin{tabular}{|l|c|c|c|c|c|}
\hline \hline \multicolumn{1}{|c|}{ Estación } & $\begin{array}{c}\text { Altitud } \\
\mathbf{( m )}\end{array}$ & $\begin{array}{c}\text { Media } \\
\mathbf{( m m )}\end{array}$ & $\begin{array}{c}\text { Mínima } \\
\mathbf{( m m )}\end{array}$ & $\begin{array}{c}\text { Máxima } \\
\mathbf{( m m}\end{array}$ & $\mathbf{C V}(\mathbf{m})$ \\
\hline \hline La Granja de San Ildefonso & 1191 & 699 & 360 & 1140 & 26,1 \\
\hline Matabuena & 1154 & 698 & 443 & 1012 & 20,6 \\
\hline Rascafria & 1159 & 865 & 389 & 1500 & 32,7 \\
\hline Torreiglesias & 1053 & 512 & 341 & 738 & 20,3 \\
\hline Turégano & 935 & 501 & 323 & 817 & 22,2 \\
\hline \hline
\end{tabular}

Los coeficientes de variación encontrados en todas las estaciones son considerados medios. En Torreiglesias se registró el más bajo con 20,3\%. Con un valor bastante parecido se encuentra la estación Matabuena, con 20,6\%, mientras el más alto fue encontrado en la estación de Rascafria, con $32,7 \%$.

La precipitación media mensual (Tabla 50 ) de la cuenca tuvo sus valores más altos en los meses de noviembre y diciembre, con 78,5 y $77,4 \mathrm{~mm}$ respectivamente. Por otro lado los meses de menor precipitación fueron agosto con $22,8 \mathrm{~mm}$ y julio con 23,3 $\mathrm{mm}$. Utilizando el método Thornthwaite se obtuvo los valores de evapotranspiración potencial (ETP) de la cuenca del río Cega. La ETP media anual detectada fue de $611,4 \mathrm{~mm}$. En los meses de verano la evapotranspiración es bastante alta llegando al máximo en julio con $110,6 \mathrm{~mm}$, seguido de los meses de agosto $(103,1 \mathrm{~mm})$ y junio $(92,5 \mathrm{~mm})$ (Tabla 50$)$.

Tabla 50. Precipitación y evapotranspiración media mensual de la cuenca del río Cega.

\begin{tabular}{|l|c|c|}
\hline \multicolumn{1}{|c|}{ Mes } & $\begin{array}{c}\text { Prec. Med. Menual } \\
(\mathbf{m m})\end{array}$ & $\begin{array}{c}\text { Evapotranspiración } \\
\text { Med. Mensual (mm) }\end{array}$ \\
\hline \hline Enero & 72,0 & 10,3 \\
\hline Febrero & 58,6 & 15,7 \\
\hline Marzo & 61,1 & 27,1 \\
\hline Abril & 67,8 & 41,2 \\
\hline Mayo & 71,8 & 63,5 \\
\hline Junio & 54,4 & 92,5 \\
\hline Julio & 23,3 & 110,6 \\
\hline Agosto & 22,8 & 103,1 \\
\hline Septiembre & 48,2 & 70,9 \\
\hline Octubre & 62,3 & 44,0 \\
\hline Noviembre & 78,5 & 22,5 \\
\hline Diciembre & 77,4 & 10,0 \\
\hline \hline
\end{tabular}


Al analizar la figura 53 se ve muy claramente el déficit hídrico en la cuenca que se extiende de junio hasta septiembre donde la ETP supera la precipitación media. A su vez en los meses de invierno los valores de evapotranspiración pueden llegar a aproximadamente un $10 \%$ del encontrado en verano.

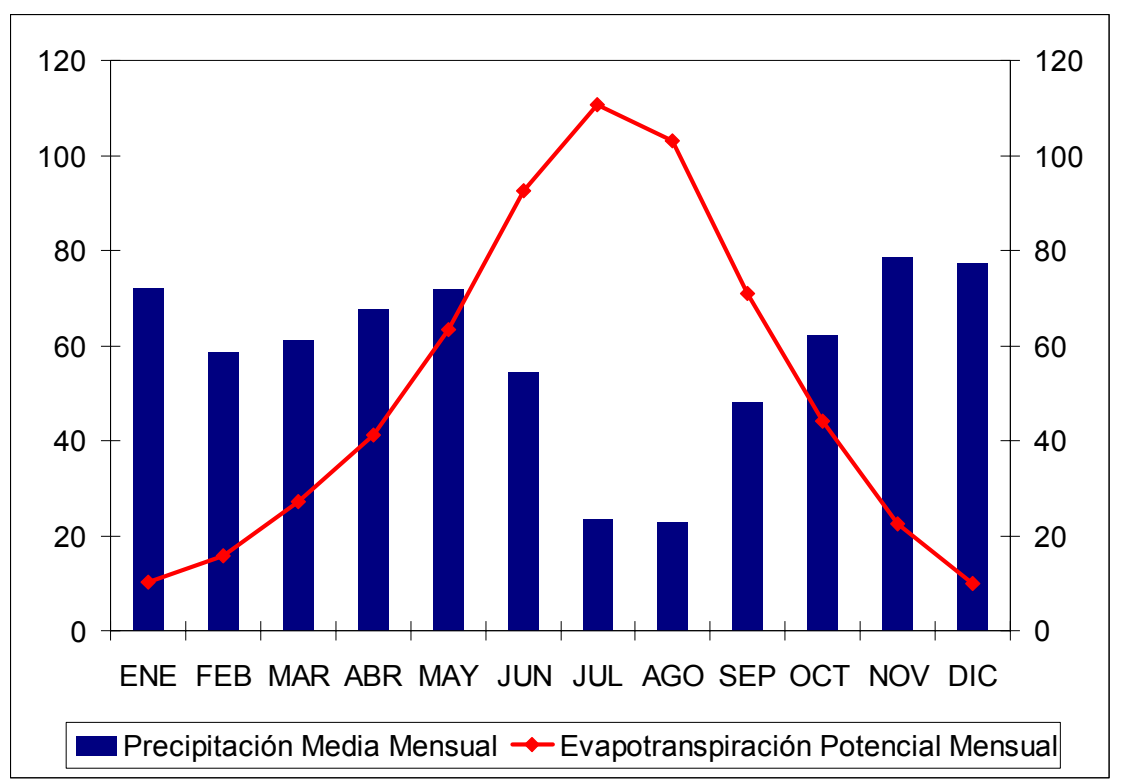

Figura 53 - Evapotranspiración potencial y precipitación mensual $(\mathrm{mm})$ de la cuenca del río Cega.

\subsubsection{Caracterización de cada estación}

\subsubsection{Estación La Granja de San Ildefonso}

La estación La Granja de San Ildefonso presenta una cierta regularidad en la precipitación, con un coeficiente de variación anual de $26,1 \%$. El período utilizado para el análisis de esta estación es del año de 1961 hasta 2007 (Fig. 54), lo que significa un total de 47 años.

La media de precipitación encontrada en el período estudiado fue de $699 \mathrm{~mm}$. El registro más bajo ocurrió en 1983, con $360 \mathrm{~mm}$ (un 48,5\% por debajo de su media). A su vez, el más alto ocurrió en 1972, con un valor de $1140 \mathrm{~mm}$, que está un $63,1 \%$ por encima de la media. En la década de 80 hubo un período seco bastante pronunciado dónde fueron encontrados los valores más bajos de precipitación de toda la serie. Los registros encontrados en este período seco fueron $407 \mathrm{~mm}$ en 1982, $360 \mathrm{~mm}$ en 1983 
(el más bajo de toda la serie), $398 \mathrm{~mm}$ en 1985 y $365 \mathrm{~mm}$ en el año de 1986. Este ultimo considerado el segundo más bajo de toda la serie.

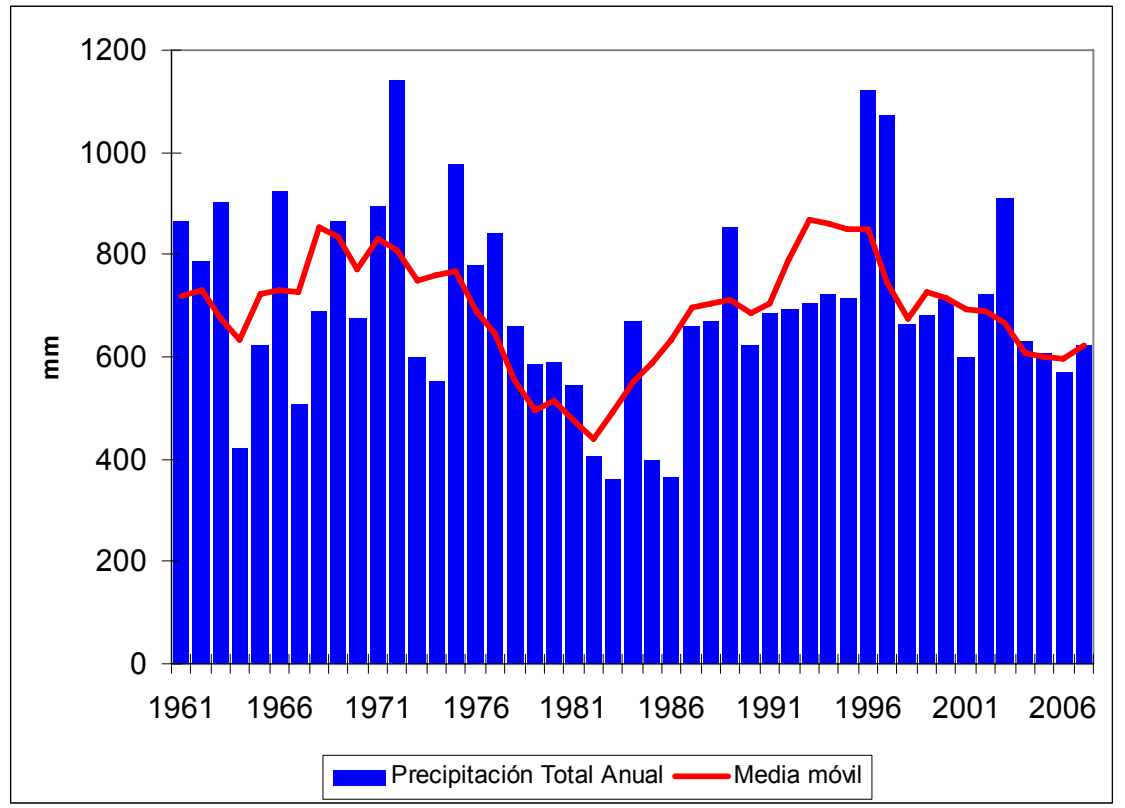

Figura 54 - Evolución de la precipitación total anual de la estación La Granja de San Ildefonso con representación de la media móvil de 5 años - Cuenca del río Cega.

El mes en que se encuentran los valores medios más altos (Fig. 55) es noviembre $(90,3 \mathrm{~mm})$ y los más bajos en julio $(20,5 \mathrm{~mm})$.

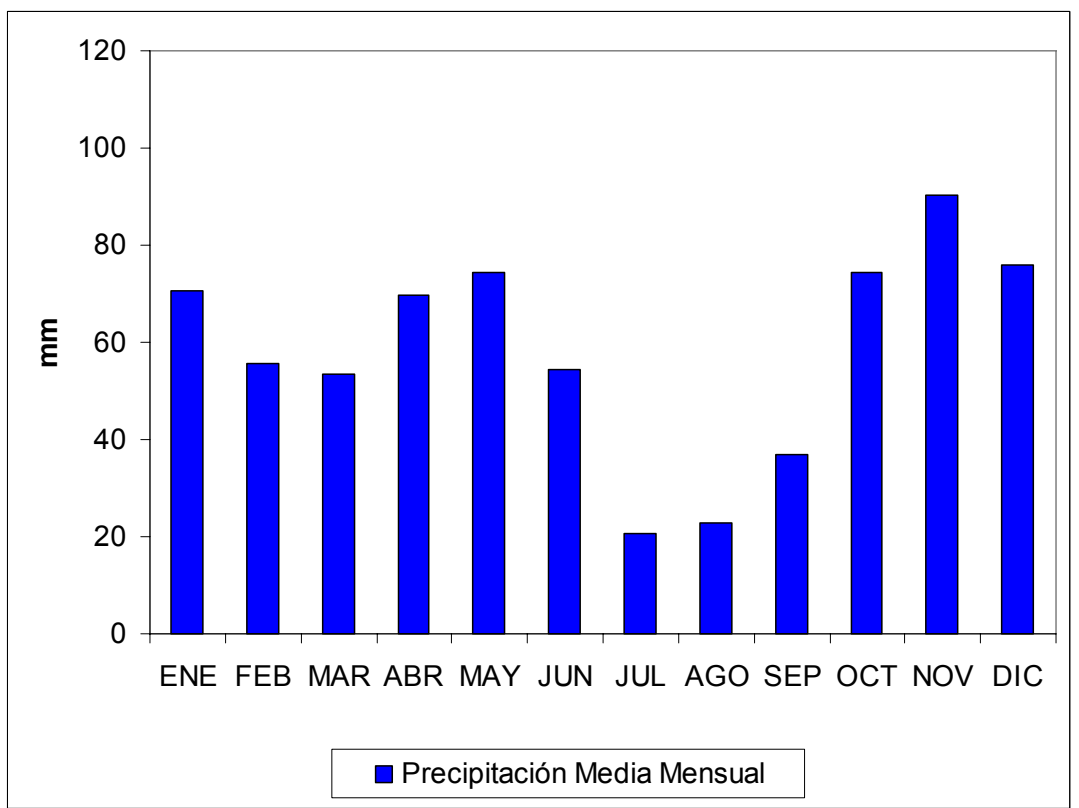

Figura 55 - Precipitación media mensual para el período estudiado - Estación La Granja de San Ildefonso, Cuenca del río Cega. 
Todos los meses presentan coeficientes de variación bastante altos (> 50\%), siendo el más alto el mes de julio con un $107,1 \%$ y el más bajo el mes de abril, con un $61,4 \%$ (Tabla 51). Estos datos revelan una gran variabilidad de los valores mensuales de la precipitación en la estación La Granja de San Ildefonso.

Tabla 51. Precipitación media mensual y coeficiente de variación de la estación La Granja de San Ildefonso - Cuenca del río Cega.

\begin{tabular}{|l|c|c|}
\hline \hline \multicolumn{1}{|c|}{ Mes } & Precipit. media (mm) & CV (\%) \\
\hline Enero & 70,8 & 85,9 \\
\hline Febrero & 55,5 & 73,6 \\
\hline Marzo & 53,5 & 65,7 \\
\hline Abril & 69,7 & 61,4 \\
\hline Mayo & 74,5 & 63,5 \\
\hline Junio & 54,5 & 65,9 \\
\hline Julio & 20,5 & 107,1 \\
\hline Agosto & 22,7 & 102,4 \\
\hline Septiembre & 37,0 & 85,4 \\
\hline Octubre & 74,3 & 74,1 \\
\hline Noviembre & 90,3 & 68,8 \\
\hline Diciembre & 75,9 & 60,0 \\
\hline \hline
\end{tabular}

\subsubsection{Estación Matabuena}

Los datos de precipitación de la estación Matabuena presentan bastante regularidad en todo el período estudiado, con un coeficiente de variación anual de $20,6 \%$. En la figura 56 se puede ver que no hay grandes variaciones interanuales en sus valores. Se ha hecho el estudio utilizando un período de 69 años (1939-2007).

La precipitación media registrada en la estación Matabuena en el período estudiado fue de 698 mm, muy similar a la media encontrada en la estación La Granja de San Ildefonso. El valor más bajo de precipitación total anual fue encontrado en 2001, con $443 \mathrm{~mm}$, que está un 36,5\% por debajo de la media encontrada en la estación. Como ocurre en la estación La Granja de San Ildefonso, el año de 1983 presenta uno de los valores más bajos de toda la serie con $458 \mathrm{~mm}$. El registro más alto fue encontrado en 1996, con $1012 \mathrm{~mm}$ (un 45,0\% por encima de la media de todo el período). 


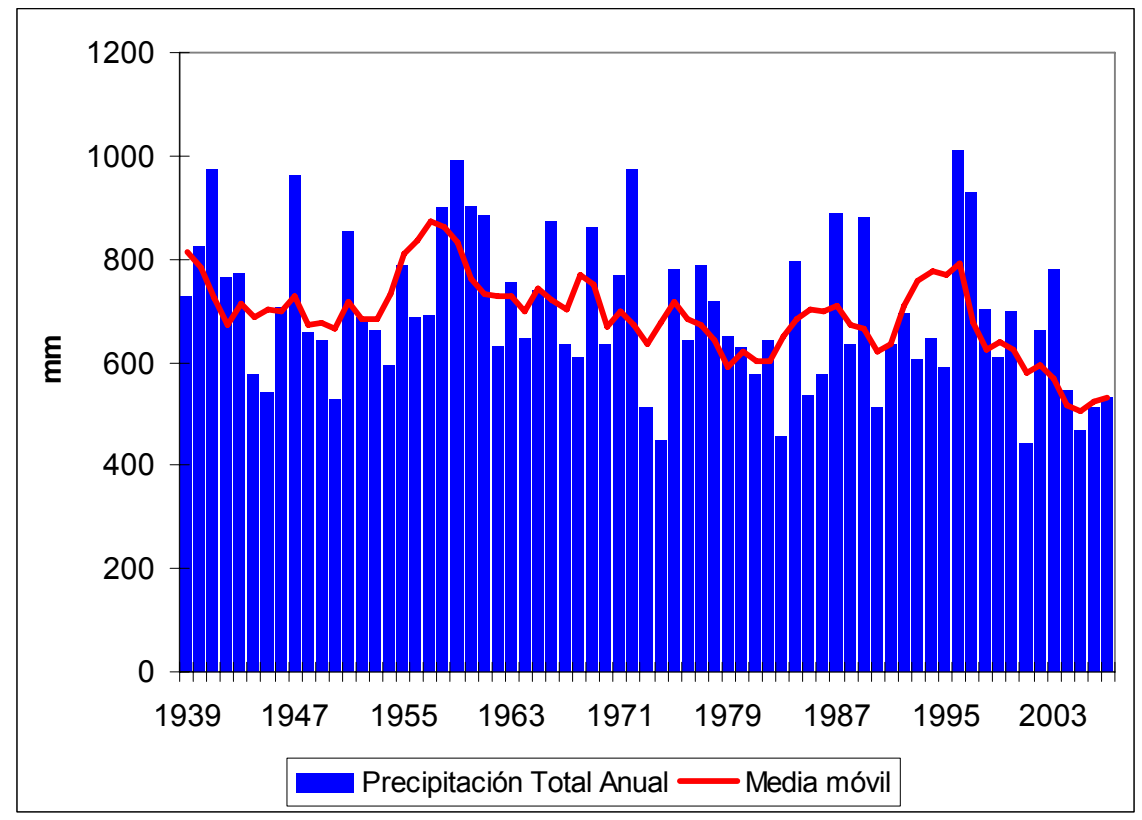

Figura 56 - Evolución de la precipitación total anual de la estación Matabuena con representación de la media móvil de 5 años - Cuenca del río Cega.

Las precipitaciones medias mensuales representadas en la figura 57 revelan que el valor medio mensual más alto se registra en noviembre con $78,4 \mathrm{~mm}$ y los más bajos en julio y agosto, con 23,4 y $22,8 \mathrm{~mm}$, respectivamente. Resultados semejantes fueron detectados también en la estación La Granja de San Ildefonso.

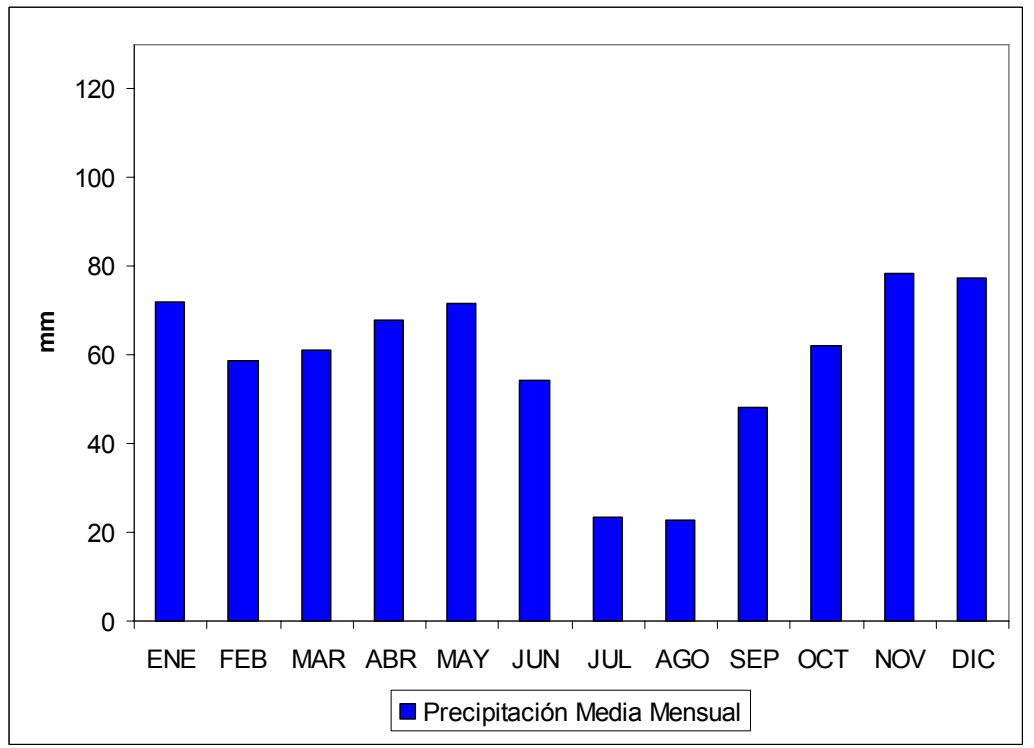

Figura 57 - Precipitación media mensual para el período estudiado - Estación Matabuena, Cuenca del río Cega.

Los coeficientes de variación de la precipitación mensual de la estación Matabuena también son altos (Tabla 52). El mes de julio, presenta el valor más alto con un 
$112,7 \%$. Por otro lado, el menor coeficiente de variación mensual fue detectado en el mes de mayo, con un 51,9\%. Los resultados descritos dejan claro una gran variabilidad en los valores de la precipitación mensual de esta estación.

Tabla 52. Precipitación media mensual y coeficiente de variación de la estación Matabuena - Cuenca del río Cega.

\begin{tabular}{|l|c|c|}
\hline \multicolumn{1}{|c|}{ Mes } & Precipit. media (mm) & CV (\%) \\
\hline \hline Enero & 72,0 & 77,9 \\
\hline Febrero & 58,6 & 78,6 \\
\hline Marzo & 61,2 & 62,9 \\
\hline Abril & 67,8 & 54,9 \\
\hline Mayo & 71,8 & 51,9 \\
\hline Junio & 54,4 & 66,1 \\
\hline Julio & 23,4 & 112,7 \\
\hline Agosto & 22,8 & 96,0 \\
\hline Septiembre & 48,4 & 71,7 \\
\hline Octubre & 62,1 & 68,2 \\
\hline Noviembre & 78,4 & 71,6 \\
\hline Diciembre & 77,4 & 57,9 \\
\hline
\end{tabular}

\subsubsection{Estación Rascafria}

Para el análisis de los datos de precipitación de la estación Rascafria fueron utilizados 47 años, de 1961 hasta 2007 (Fig. 58).

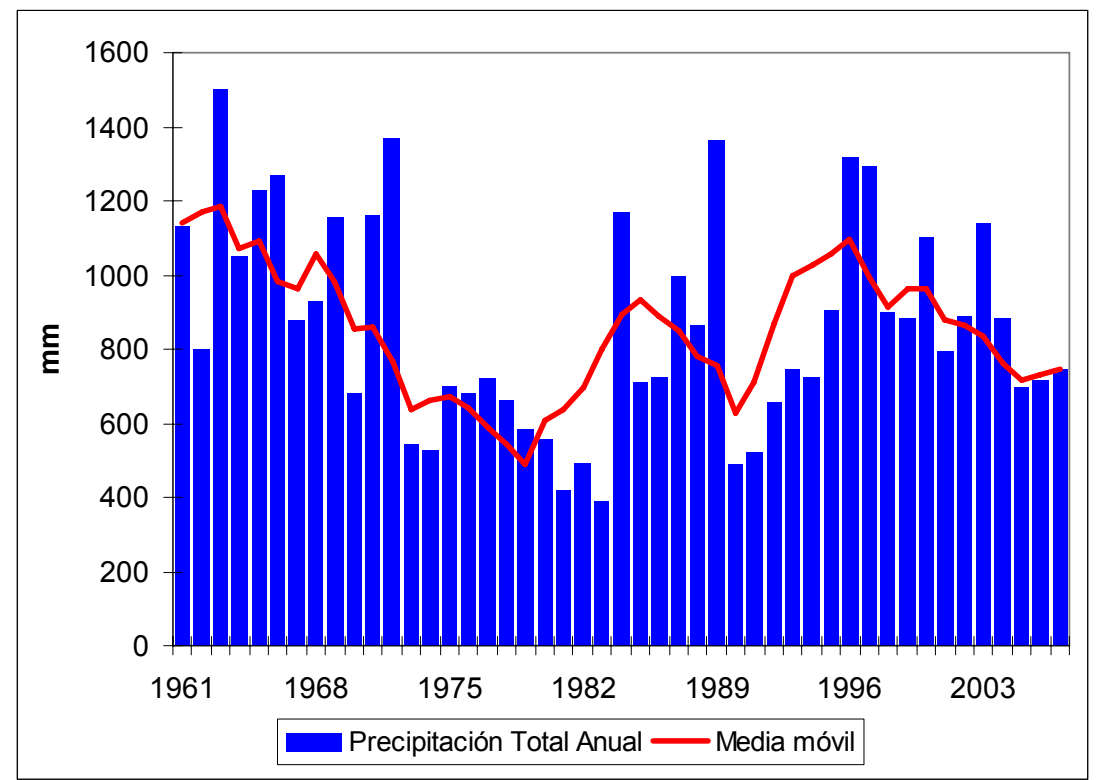

Figura 58 - Evolución de la precipitación total anual de la estación Rascafria con representación de la media móvil de 5 años - Cuenca del río Cega. 
La precipitación de esta estación presenta mucha irregularidad en sus dados interanuales en todo el período estudiado, con un coeficiente de variación anual de $32,7 \%$, el más alto encontrado entre las estaciones utilizadas para análisis de la cuenca del río Cega.

En la estación Rascafria la precipitación media registrada para toda la serie estudiada fue de $865 \mathrm{~mm}$. Como lo ocurrido con los datos de la estación La Granja de San Ildefonso, el valor más bajo fue encontrado en 1983, con $389 \mathrm{~mm}$, que está un 55\% por debajo de la media. El año que presenta el registro más alto es 1963, con 1500 mm (un $73,4 \%$ por encima de la media de todo el período).

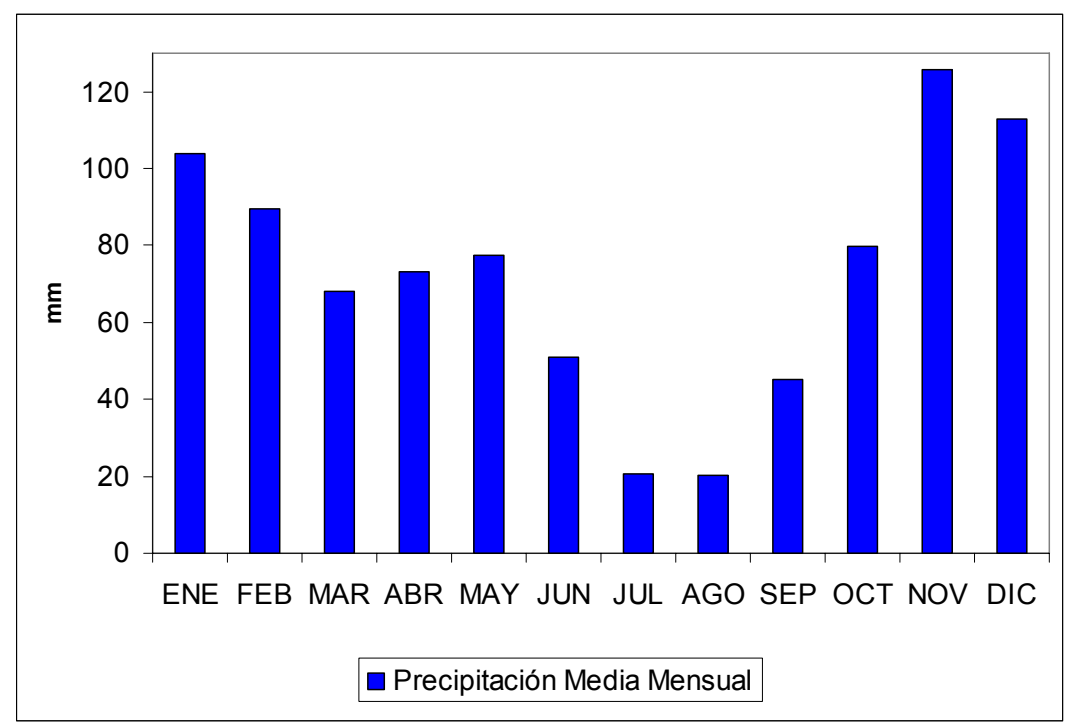

Figura 59 - Precipitación media mensual para el período estudiado - Estación Rascafria, Cuenca del río Cega.

El valor medio mensual más alto se da en el mes de noviembre (Fig. 59) con 125,7 $\mathrm{mm}$ y los más bajos fueron encontrados en los meses de agosto y julio, con 20,4 y $20,6 \mathrm{~mm}$, respectivamente. Las estaciones analizadas anteriormente también presentan resultados semejantes. Aún en conformidad con los resultados obtenidos para las otras estaciones, los coeficientes de variación de la precipitación mensual de la estación Rascafria son todos considerados bastante altos (Tabla 53). Los resultados muestran una gran variabilidad en los valores de la precipitación mensual de esta estación, habiendo sido detectada una diferencia de $385 \%$ entre el valor mínimo y el máximo registrados en todo el período estudiado. 
Tabla 53. Precipitación media mensual y coeficiente de variación de la estación Rascafria - Cuenca del río Cega.

\begin{tabular}{|l|c|c|}
\hline \hline \multicolumn{1}{|c|}{ Mes } & Precipit. media (mm) & CV (\%) \\
\hline \hline Enero & 104,0 & 77,9 \\
\hline Febrero & 89,6 & 76,9 \\
\hline Marzo & 68,0 & 71,7 \\
\hline Abril & 73,1 & 66,6 \\
\hline Mayo & 77,3 & 64,6 \\
\hline Junio & 51,2 & 74,8 \\
\hline Julio & 20,6 & 98,0 \\
\hline Agosto & 20,4 & 90,3 \\
\hline Septiembre & 45,1 & 75,8 \\
\hline Octubre & 79,9 & 75,9 \\
\hline Noviembre & 125,7 & 77,1 \\
\hline Diciembre & 113,0 & 65,5 \\
\hline \hline
\end{tabular}

\subsubsection{Estación Torreiglesias}

Para análisis de la precipitación de la estación Torreiglesias fueron utilizados un total de 38 años de datos (1970-2007). Analizando la figura 60 se puede detectar que la precipitación en esta estación presenta cierta regularidad en sus dados interanuales en el período estudiado, con un coeficiente de variación anual de $20,3 \%$. Este coeficiente es el más bajo encontrado entre las estaciones utilizadas para análisis de la cuenca del río Cega.

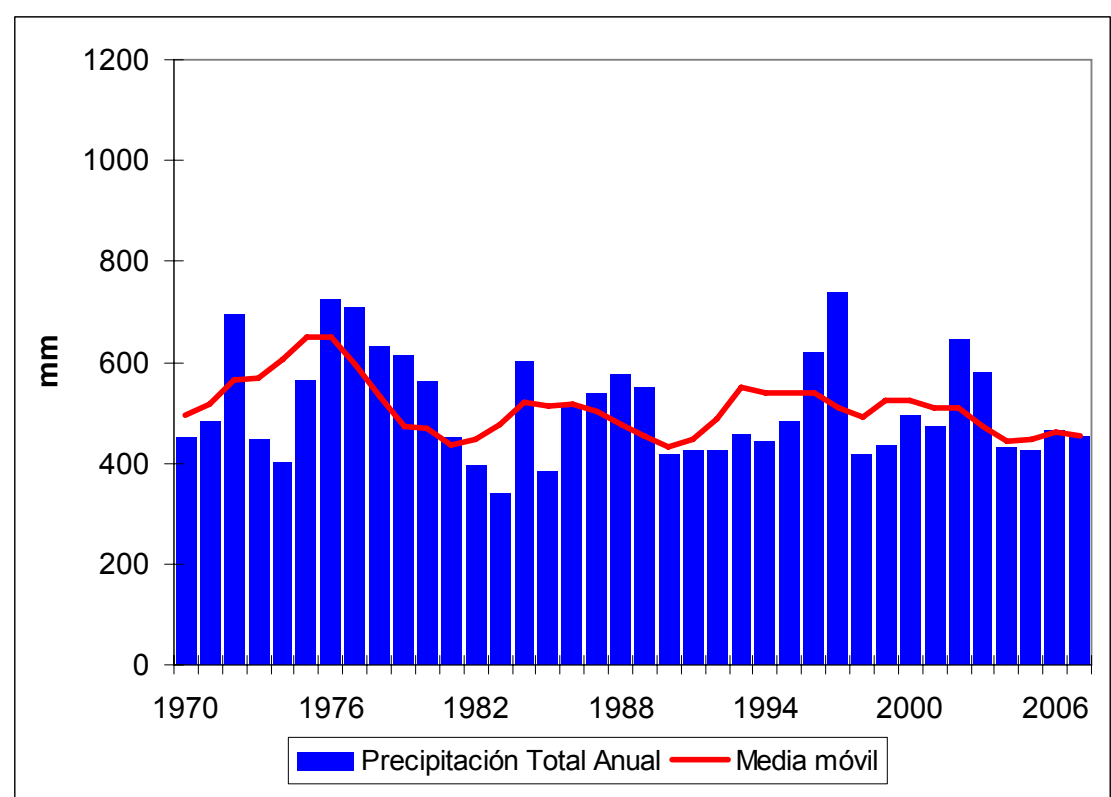

Figura 60 - Evolución de la precipitación total anual de la estación Torreiglesias con representación de la media móvil de 5 años - Cuenca del río Cega. 
La precipitación media registrada en la estación Torreiglesias para toda la serie fue de $512 \mathrm{~mm}$. El año que registra el valor más alto es 1997, con $738 \mathrm{~mm}$, un 44,1\% por encima de la media de todo el período. El valor más bajo fue encontrado en 1983, con $341 \mathrm{~mm}$, que está un 33,4\% por debajo de la media registrada. Lo mismo ocurrió en las estaciones La Granja de San Ildefonso y Rascafria, confirmando un fuerte período seco en este año en toda la cuenca. También de acuerdo con lo visto en la estación La Granja de San Ildefonso, en los años 80 se presentaron otros 2 años bastante secos, con $385 \mathrm{~mm}$ en 1985 (segundo valor más bajo de todo el período analizado) y $394 \mathrm{~mm}$ en 1982 (tercero valor más bajo de toda la serie).

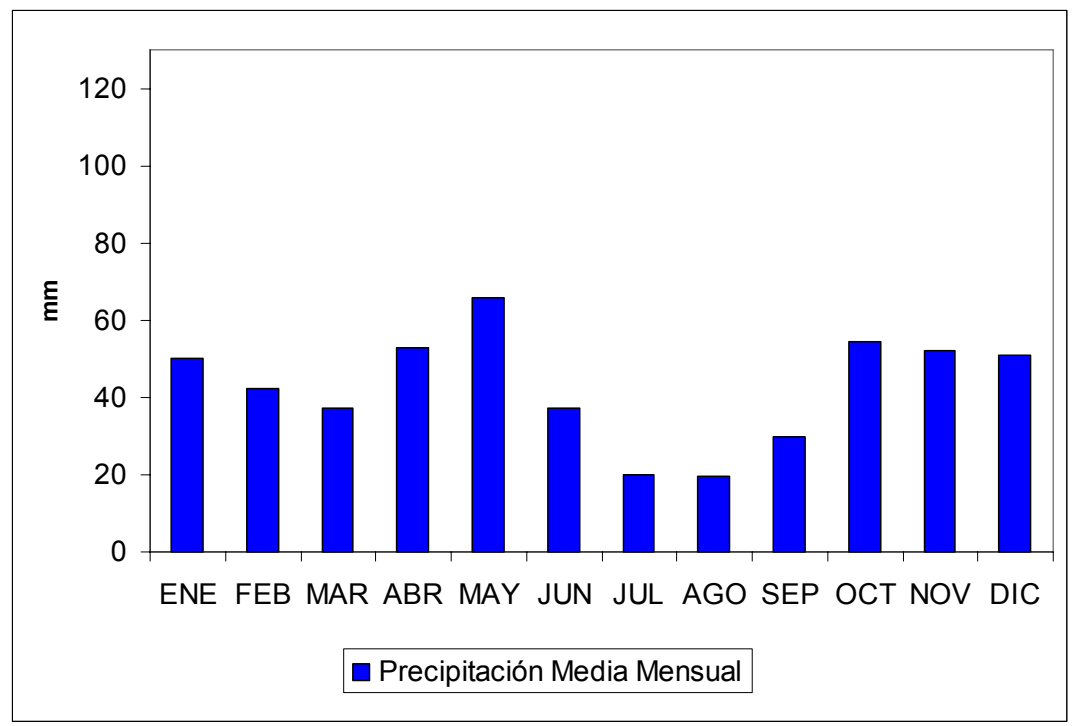

Figura 61 - Precipitación media mensual para el período estudiado - Estación Torreiglesias, Cuenca del río Cega.

Tabla 54. Precipitación media mensual y coeficiente de variación de la estación Torreiglesias - Cuenca del río Cega.

\begin{tabular}{|l|c|c|}
\hline \multicolumn{1}{|c|}{ Mes } & Precipit. media (mm) & CV (\%) \\
\hline \hline Enero & 50,2 & 76,8 \\
\hline Febrero & 42,1 & 76,5 \\
\hline Marzo & 37,3 & 62,6 \\
\hline Abril & 52,8 & 57,0 \\
\hline Mayo & 65,9 & 50,0 \\
\hline Junio & 37,0 & 87,3 \\
\hline Julio & 19,8 & 107,2 \\
\hline Agosto & 19,5 & 105,4 \\
\hline Septiembre & 29,8 & 70,1 \\
\hline Octubre & 54,6 & 71,6 \\
\hline Noviembre & 52,1 & 57,4 \\
\hline Diciembre & 50,8 & 68,6 \\
\hline \hline
\end{tabular}


A diferencia de lo encontrado en las estaciones La Granja de San Ildefonso, Matabuena y Rascafria, el valor medio mensual (Fig. 61) más alto se da en el mes de mayo con $65,9 \mathrm{~mm}$. Sin embargo, los valores más bajos coinciden con los de las otras estaciones, habiendo sido constatados en los meses de agosto y julio, con 19,5 y 19,8 $\mathrm{mm}$, respectivamente. En la tabla 54 se observa que los coeficientes de variación de la precipitación mensual son $\geq 50 \%$. El más alto fue visto en julio, con un $107,2 \%$, seguido de agosto con un $105,8 \%$ y el más bajo en mayo con un $50,0 \%$.

\subsubsection{Estación Turégano}

La figura 62 representa los datos de la precipitación total anual obtenidos en la estación Turégano y su media móvil de 5 años. Para el análisis de estos datos fueron utilizados 60 años, comprendidos entre 1948 y 2007. El coeficiente de variación encontrado fue de $22,2 \%$, demostrando una regularidad media en sus dados interanuales en el período estudiado.

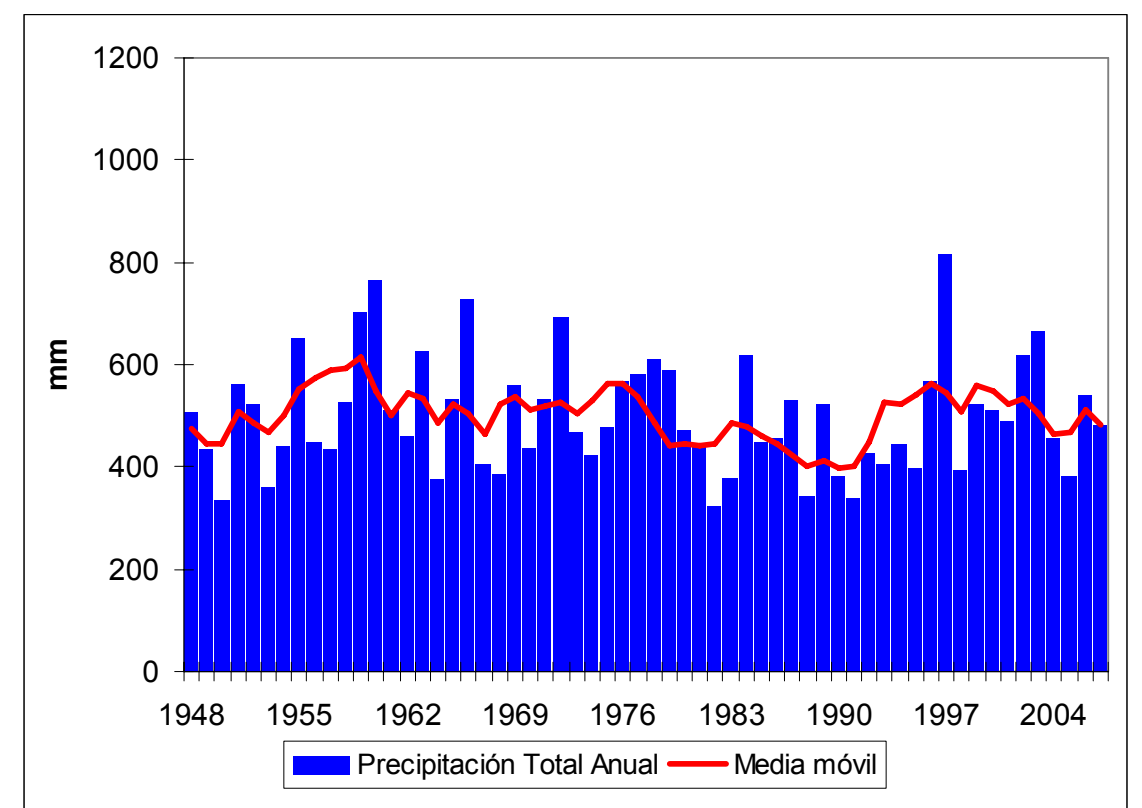

Figura 62 - Evolución de la precipitación total anual de la estación Turégano con representación de la media móvil de 5 años - Cuenca del río Cega.

Según los resultados del análisis de los datos, la media de todo el período fue de 501 $\mathrm{mm}$, el valor más bajo registrado entre las estaciones utilizadas para análisis de la cuenca del río Cega. De forma similar a lo encontrado en la estación Torreiglesias, el año que registra el valor más alto es 1997 , con $817 \mathrm{~mm}$ anuales, un $63,1 \%$ por encima de la media. El registro más bajo fue encontrado en el año de 1982, con $323 \mathrm{~mm}$, el 
más bajo encontrado entre las estaciones analizadas y que está $64,5 \%$ por debajo de la media registrada. Como se ha comentado previamente, en 1982 fue bastante seco en toda la cuenca. En los meses de mayo, con $55 \mathrm{~mm}$ y noviembre, con $54 \mathrm{~mm}$, se detectan los valores medios mensuales más altos (Fig. 63). Estos resultados están de acuerdo con los encontrados en las estaciones La Granja de San Ildefonso, Matabuena y Rascafria, en dónde noviembre presenta la precipitación media más alta y también con la estación Torreiglesias que tiene en el mes de mayo su dato más elevado. Como ocurrió en todas las estaciones analizadas, se constató que los meses de agosto, con 19,0 mm y julio, con $20,1 \mathrm{~mm}$ son los que presentan los menores valores medios mensuales.

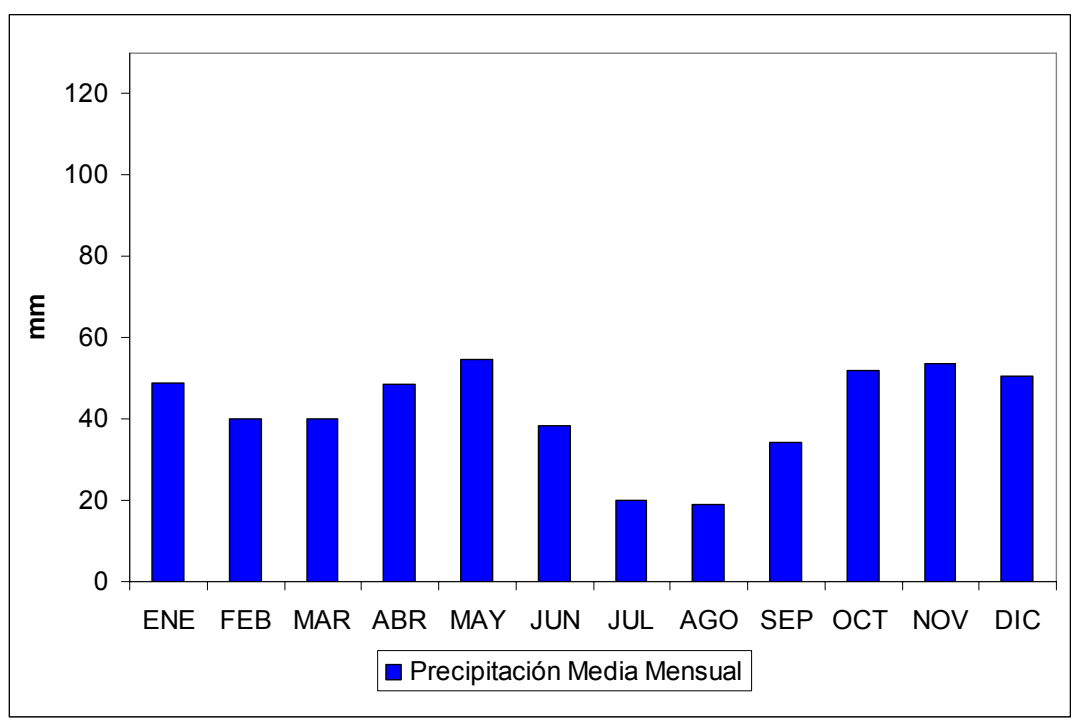

Figura 63 - Precipitación media mensual para el período estudiado - Estación Turégano, Cuenca del río Cega.

Siguiendo también el patrón de las otras estaciones, en ésta se detecta una alta variabilidad en sus valores mensuales (Tabla 55). El coeficiente de variación más alto es el de julio, con 132\%, seguido de agosto con 110,1\%. Resultados semejantes fueron encontrados en todas las estaciones mencionadas anteriormente, ya que en todas ellas los meses que presentan los coeficientes de variación más alto son julio y agosto. El valor más bajo fue el de mayo con 53,5\%. Se encontraron resultados semejantes también en las estaciones Matabuena, Rascafria y Torreiglesias. 
Tabla 55. Precipitación media mensual y coeficiente de variación de la estación Turégano - Cuenca del río Cega.

\begin{tabular}{|l|c|c|}
\hline \multicolumn{1}{|c|}{ Mes } & Precipit. media (mm) & CV (\%) \\
\hline \hline Enero & 48,9 & 86,4 \\
\hline Febrero & 40,2 & 77,1 \\
\hline Marzo & 40,2 & 66,2 \\
\hline Abril & 48,7 & 54,8 \\
\hline Mayo & 54,7 & 53,5 \\
\hline Junio & 38,3 & 62,9 \\
\hline Julio & 20,1 & 132,0 \\
\hline Agosto & 19,0 & 110,1 \\
\hline Septiembre & 34,5 & 73,3 \\
\hline Octubre & 52,1 & 77,8 \\
\hline Noviembre & 53,6 & 63,5 \\
\hline Diciembre & 50,5 & 66,8 \\
\hline \hline
\end{tabular}

\subsection{Evolución de la Precipitación en la Cuenca del Río Porma}

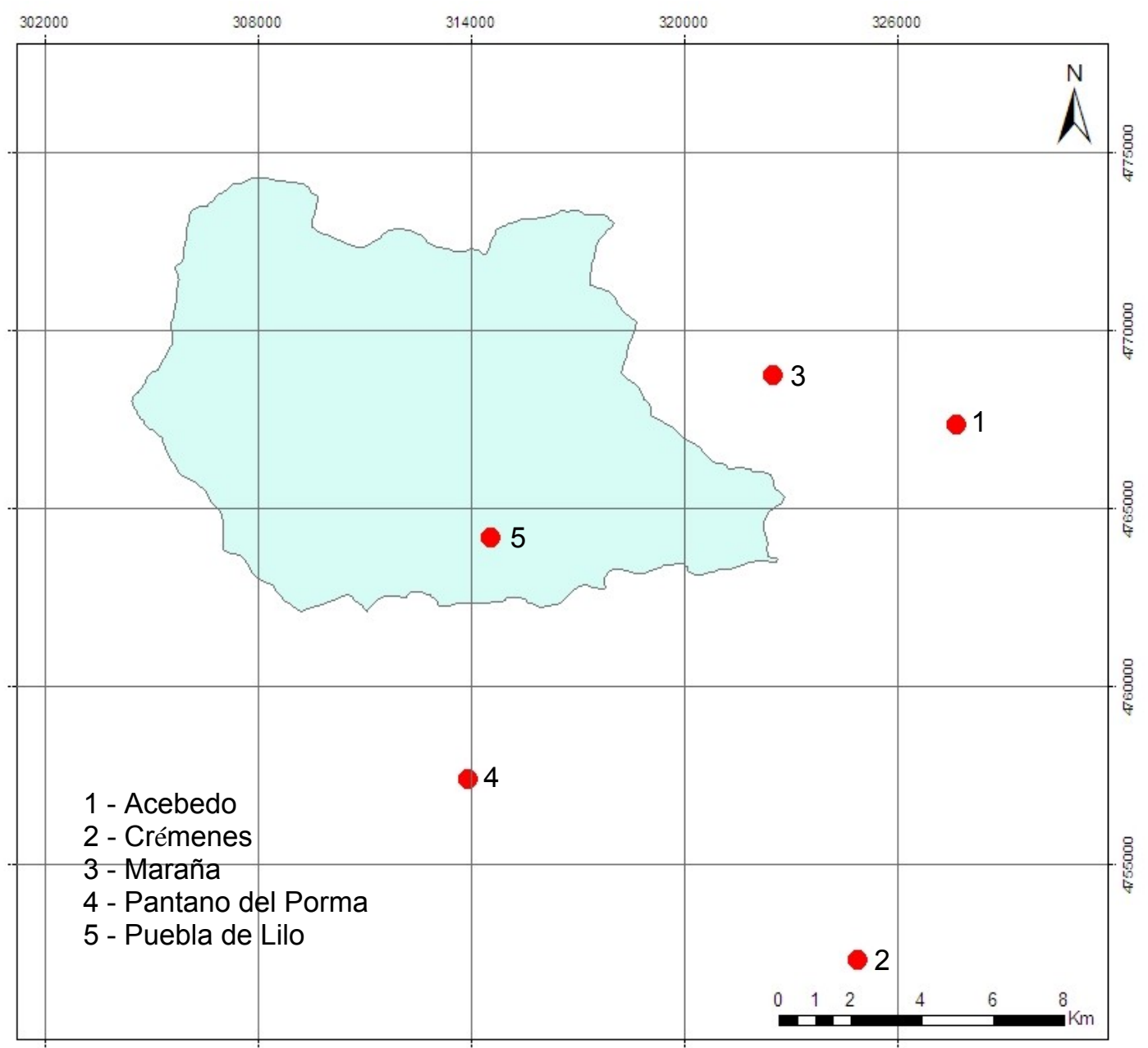

Figura 64 - Localización de las estaciones termométricas y pluviométricas (Cuenca del río Porma). 


\subsubsection{Caracterización de la precipitación}

La precipitación media anual en la cuenca del río Porma (Fig. 64) en el período estudiado fue de $1437 \mathrm{~mm}$, con un coeficiente de variación de $15,7 \%$, lo que demuestra bastante regularidad en la precipitación en este período. Los valores máximos de precipitación (Tabla 56) fueron de $2153 \mathrm{~mm}$, un 49,8\% por encima de la media de la cuenca, en la estación de Maraña, en 1978 y 2116 mm en la estación Puebla de Lillo en 1959. En 1978 también se registró el valor máximo de la estación Acebedo, con $1951 \mathrm{~mm}$ y el segundo más alto de la estación Crémenes, con 1640 $\mathrm{mm}$. Estos resultados revelan que 1978 fue un año bastante húmedo en toda la cuenca. La precipitación mínima anual se dio en la estación Crémenes con $630 \mathrm{~mm}$, en 2006, lo que representa un $56,2 \%$ por debajo de la media de precipitación de la cuenca.

Tabla 56. Precipitación media, mínima, máxima, coeficientes de variación y altitud para todas las estaciones utilizadas para análisis de la cuenca del río Porma.

\begin{tabular}{|l|c|c|c|c|c|}
\hline \hline \multicolumn{1}{|c|}{ Estación } & $\begin{array}{c}\text { Altitud } \\
\mathbf{( m )}\end{array}$ & $\begin{array}{c}\text { Media } \\
\mathbf{( m m )}\end{array}$ & $\begin{array}{c}\text { Mínima } \\
\mathbf{( m m )}\end{array}$ & $\begin{array}{c}\text { Máxima } \\
\mathbf{( m m}\end{array}$ & $\mathbf{C V} \mathbf{( \% )}$ \\
\hline \hline Acebedo & 1181 & 1415 & 1088 & 1951 & 15,6 \\
\hline Crémenes & 997 & 1184 & 630 & 1678 & 19,8 \\
\hline Maraña & 1253 & 1570 & 810 & 2153 & 18,3 \\
\hline Pantano del Porma & 1040 & 1259 & 814 & 1684 & 20,7 \\
\hline Puebla de Lillo & 1130 & 1413 & 893 & 2116 & 20,4 \\
\hline \hline
\end{tabular}

Los coeficientes de variación encontrados en todas las estaciones son considerados medios. El valor más alto se da en la estación Pantano del Porma, con $20,7 \%$ y el más bajo en la estación Acebedo, con 15,6\%. Estos resultados demuestran que la cuenca tiene bastante regularidad en cuanto a la precipitación.

La precipitación media mensual (Tabla 57) en la cuenca del río Porma tiene sus más altos valores en los meses de diciembre, enero y febrero, con valores muy semejantes. Los meses de menor precipitación media son julio, con $34,5 \mathrm{~mm}$ y agosto con 40,4 $\mathrm{mm}$. La ETP, como es lógico, presentó un comportamiento inverso y en los meses de verano es donde se encuentran sus más altos valores (Julio 107,7 mm, agosto 100,2 $\mathrm{mm}$ y junio 90,1). Los meses en que la precipitación es menor que la ETP son exactamente junio, julio y agosto (Fig. 65). La ETP potencial anual detectada fue 587,3 $\mathrm{mm}$. 
Tabla 57. Precipitación y evapotranspiración media mensual de la cuenca del río Porma.

\begin{tabular}{|l|c|c|}
\hline \hline \multicolumn{1}{|c|}{ Mes } & $\begin{array}{c}\text { Prec. Med. Menual } \\
(\mathbf{m m})\end{array}$ & $\begin{array}{c}\text { Evapotranspiración } \\
\text { Med. Mensual (mm) }\end{array}$ \\
\hline \hline Enero & 181,9 & 7,7 \\
\hline Febrero & 141,0 & 13,1 \\
\hline Marzo & 138,1 & 24,7 \\
\hline Abril & 121,1 & 38,9 \\
\hline Mayo & 119,2 & 61,3 \\
\hline Junio & 61,2 & 90,1 \\
\hline Julio & 34,5 & 107,7 \\
\hline Agosto & 40,4 & 100,2 \\
\hline Septiembre & 82,7 & 73,9 \\
\hline Octubre & 154,3 & 41,8 \\
\hline Noviembre & 183,1 & 20,4 \\
\hline Diciembre & 181,0 & 7,5 \\
\hline \hline
\end{tabular}

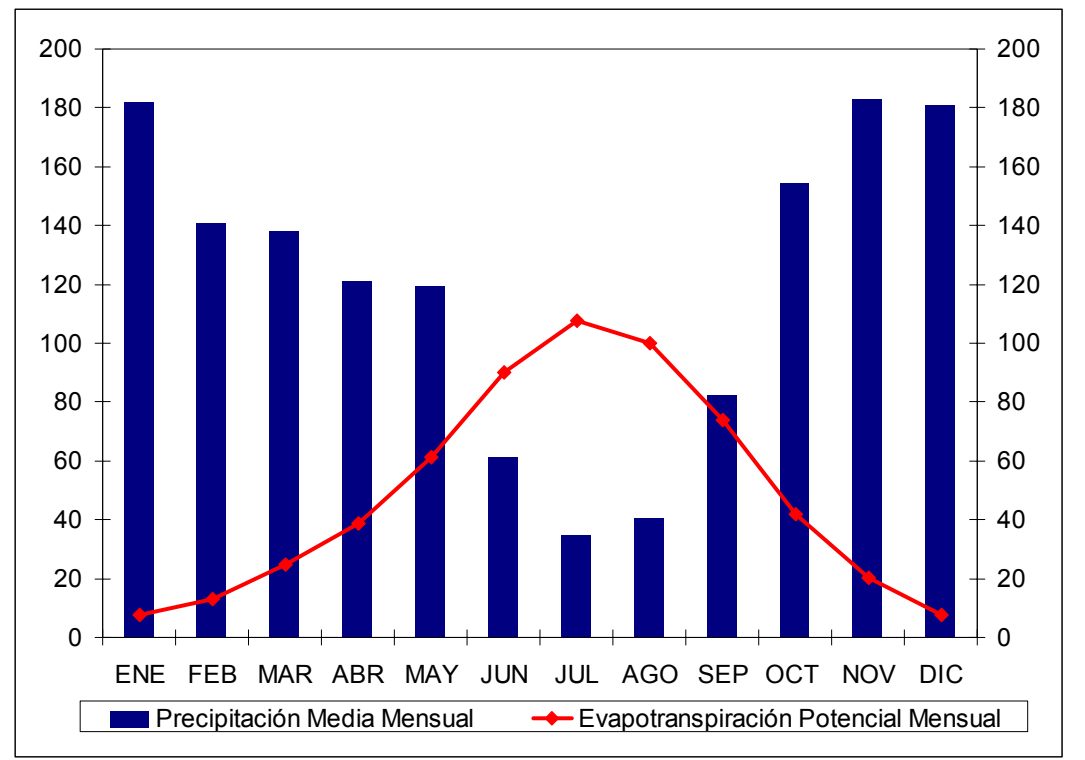

Figura 65 - Evapotranspiración potencial y precipitación mensual $(\mathrm{mm})$ de la cuenca del río Porma.

\subsubsection{Caracterización de cada estación}

\subsubsection{Estación Acebedo}

Fue utilizado un total de 36 años de datos para el análisis de esta estación, desde 1971 hasta 2006. Se puede percibir una gran regularidad en la evolución de la precipitación (Fig. 66), con un coeficiente de variación de solamente el 15,6\%. La media de precipitación en todo el período fue de $1415 \mathrm{~mm}$. En los años de 1986 y 
2005 ocurrieron los registros más bajos de precipitación, ambos con $1088 \mathrm{~mm}$ y en 1978, el registro más alto, con $1951 \mathrm{~mm}$.

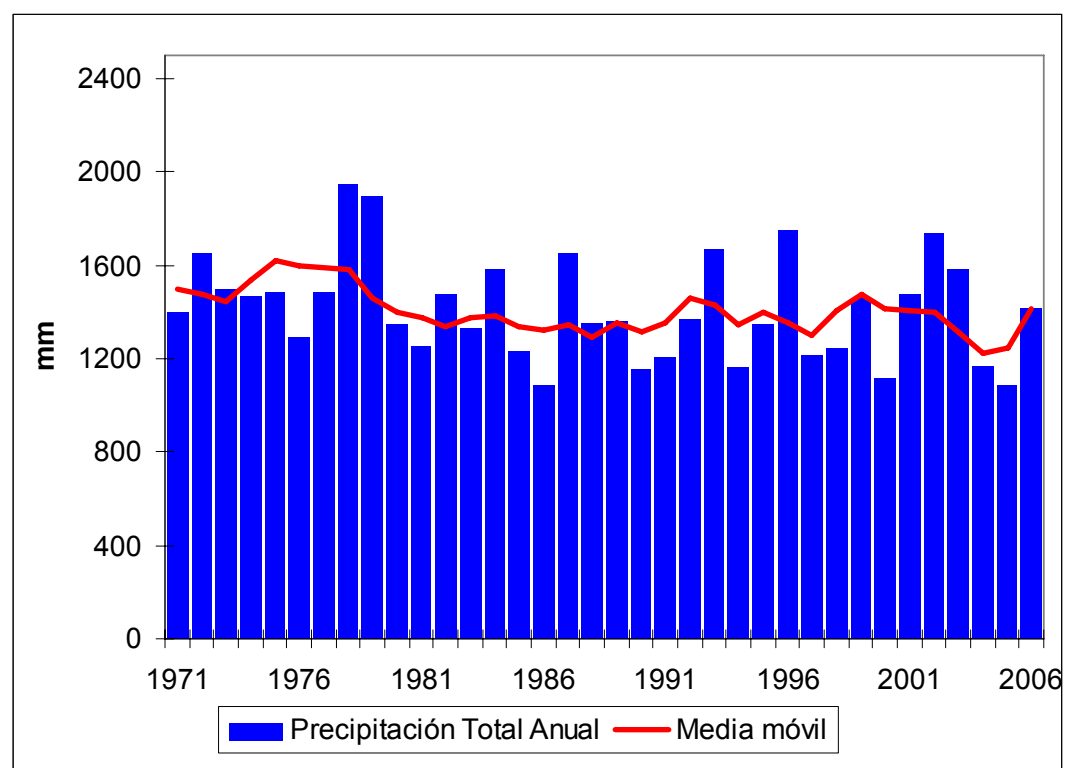

Figura 66 - Evolución de la precipitación total anual de la estación Acebedo con representación de la media móvil de 5 años - Cuenca del río Porma.

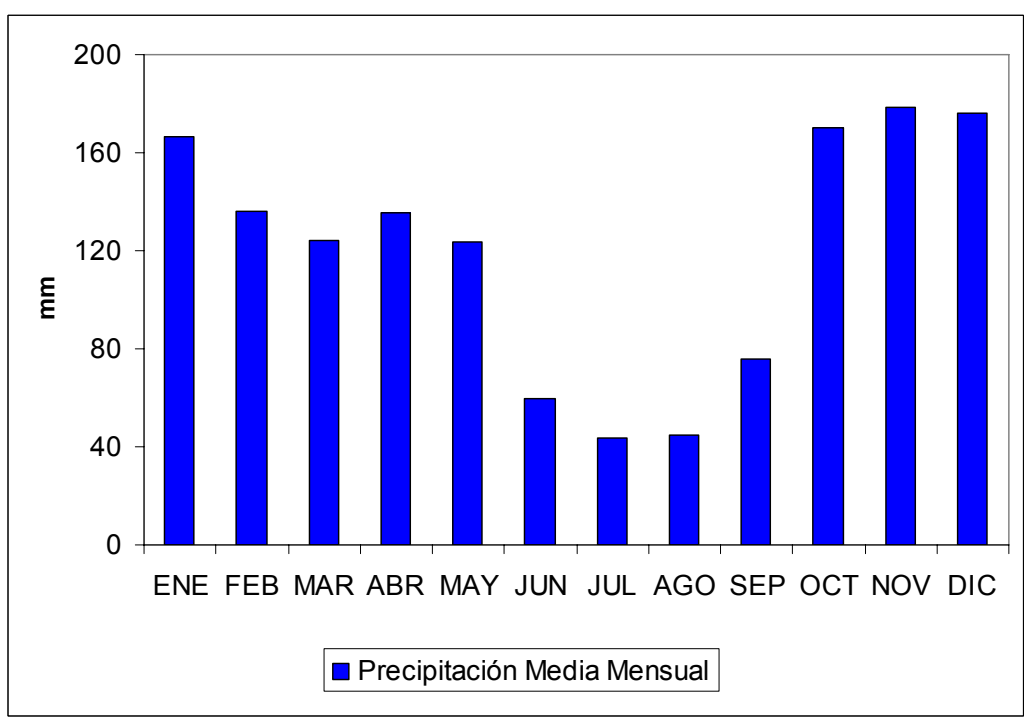

Figura 67 - Precipitación media mensual para el período estudiado - Estación Acebedo, Cuenca del río Porma.

El valor medio más alto se encuentra en noviembre (Fig. 67) con 178,7 mm, mientras los meses con los valores más bajos son julio, con 43,7 mm y agosto con 44,7 mm. Mensualmente se registra una variabilidad alta de los valores de precipitación (Tabla 58). Los resultados más bajos se encuentran en noviembre con un $50,7 \%$, seguido de 
mayo con un $51,7 \%$ y los más altos se encuentran en julio con un $81,1 \%$ y junio con un $76,2 \%$.

Tabla 58. Precipitación media mensual y coeficiente de variación de la estación Acebedo - Cuenca del río Porma.

\begin{tabular}{|l|c|c|}
\hline \multicolumn{1}{|c|}{ Mes } & Precipit. media (mm) & CV (\%) \\
\hline Enero & 166,8 & 53,5 \\
\hline Febrero & 136,0 & 65,1 \\
\hline Marzo & 124,3 & 63,3 \\
\hline Abril & 135,7 & 55,9 \\
\hline Mayo & 123,6 & 51,7 \\
\hline Junio & 59,5 & 76,2 \\
\hline Julio & 43,7 & 81,1 \\
\hline Agosto & 44,7 & 75,0 \\
\hline Septiembre & 76,0 & 66,4 \\
\hline Octubre & 170,4 & 52,8 \\
\hline Noviembre & 178,7 & 50,7 \\
\hline Diciembre & 176,3 & 58,0 \\
\hline \hline
\end{tabular}

\subsubsection{Estación Crémenes}

Para el análisis de la estación Crémenes fueron utilizados 40 años de datos, desde 1967 hasta 2006 (Fig. 68), habiendo sido detectada una regularidad media en el comportamiento de la precipitación con un coeficiente de variación de 19,8\%.

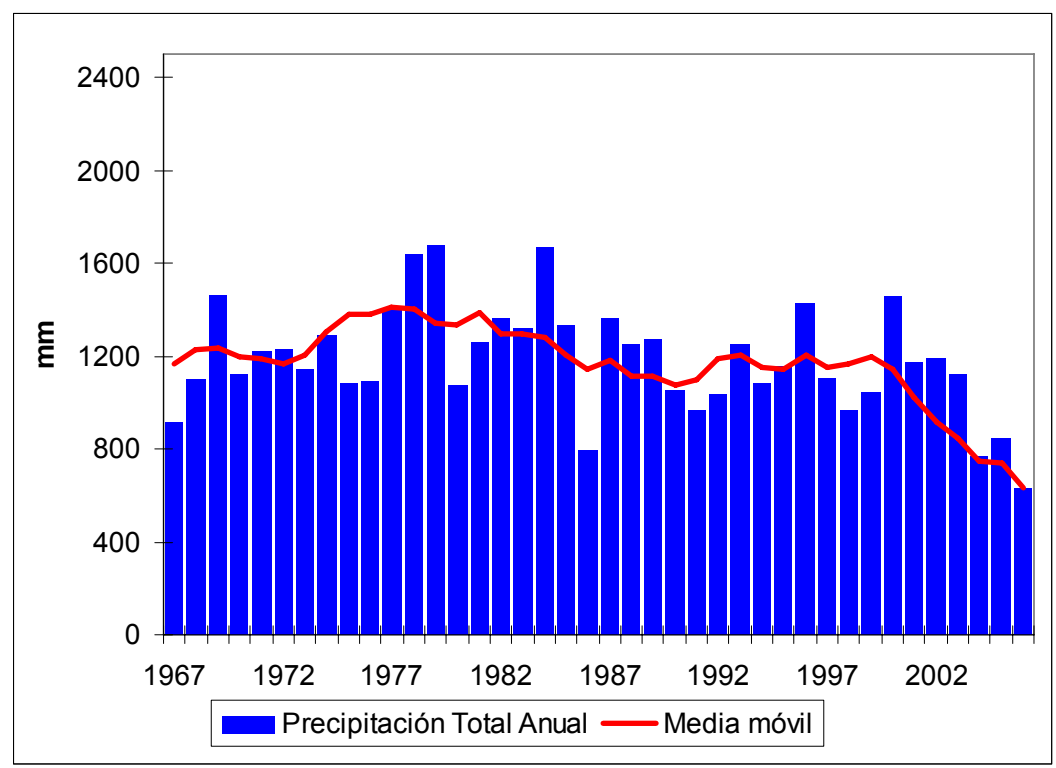

Figura 68 - Evolución de la precipitación total anual de la estación Crémenes con representación de la media móvil de 5 años - Cuenca del río Porma. 
La media de todo el período es de $1184 \mathrm{~mm}$, dándose en los últimos 5 años de la serie el registro de valores más bajos, con una media de solamente $775 \mathrm{~mm}$ (36,7\% por debajo de la media). Estos resultados están de acuerdo con los de la estación Puebla de Lillo que es la que presenta más fuerte correlación con la estación Crémenes ( $r=$ $0,87)$. En la estación Puebla de Lillo estos últimos años también registran un descenso en sus valores con un $18,9 \%$ por debajo de su media. El mínimo fue registrado en 2006, con tan sólo $630 \mathrm{~mm}$, casi un $50 \%$ menos que la media. Los años con valores más altos fueron 1979, con $1678 \mathrm{~mm}$ y 1978, con $1640 \mathrm{~mm}$, coincidiendo con los resultados obtenidos para las estaciones Maraña y Acebedo.

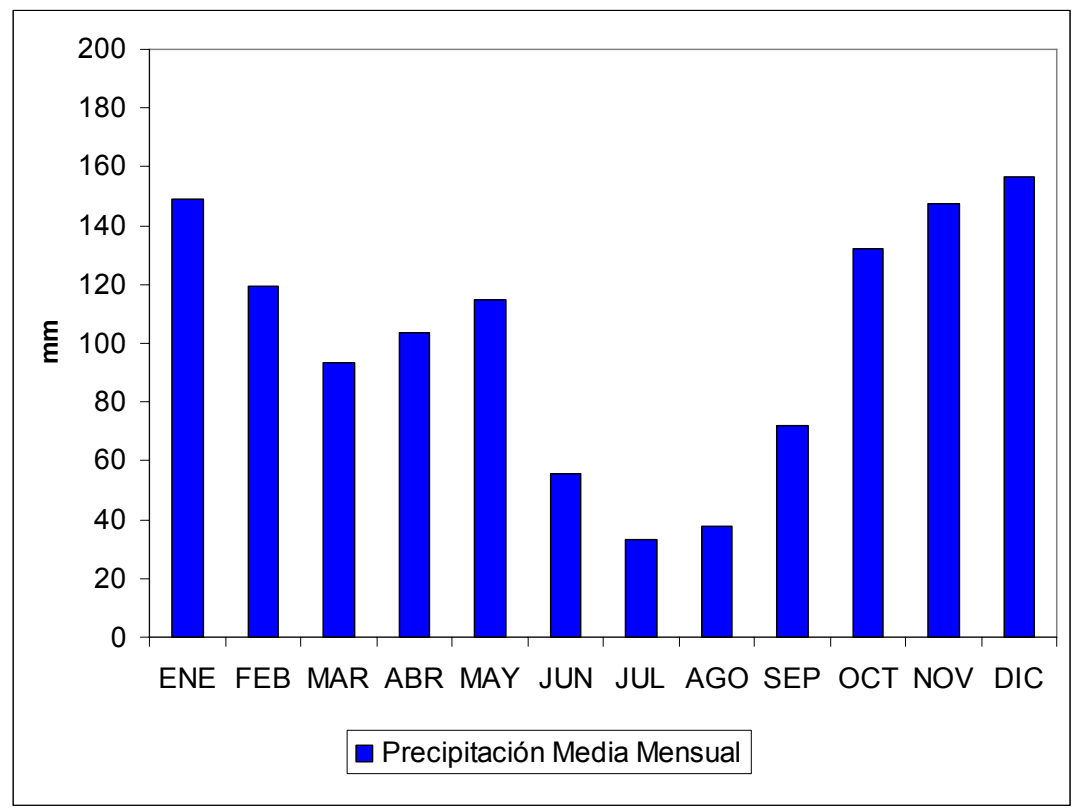

Figura 69 - Precipitación media mensual para el período estudiado - Estación Crémenes, Cuenca del río Porma.

Tabla 59. Precipitación media mensual y coeficiente de variación de la estación Crémenes - Cuenca del río Porma.

\begin{tabular}{|c|c|c|}
\hline Mes & Precipit. media (mm) & CV (\%) \\
\hline Enero & 148,7 & 64,0 \\
\hline Febrero & 119,4 & 61,9 \\
\hline Marzo & 93,4 & 69,9 \\
\hline Abril & 103,6 & 81,0 \\
\hline Mayo & 114,6 & 54,9 \\
\hline Junio & 55,7 & 86,2 \\
\hline Julio & 32,9 & 83,5 \\
\hline Agosto & 37,7 & 88,0 \\
\hline Septiembre & 71,9 & 90,2 \\
\hline Octubre & 132,1 & 62,1 \\
\hline Noviembre & 147,4 & 60,4 \\
\hline Diciembre & 156,5 & 69,3 \\
\hline
\end{tabular}


El valor medio mensual más alto de la estación Crémenes (Fig. 69) se encuentra en diciembre con $156,5 \mathrm{~mm}$, seguido del mes de enero con 148,7 mm, mientras los meses que presentan los valores más bajos son julio, con $32,9 \mathrm{~mm}$ y agosto, con 37,7 $\mathrm{mm}$. En todos los meses los coeficientes de variación (Tabla 59) son altos (> 50\%) y dejan claro una gran variabilidad mensual en el periodo estudiado. El valor más bajo fue detectado en mayo con $54,9 \%$ y el más alto en septiembre con $90,2 \%$.

\subsubsection{Estación Maraña}

La estación Maraña presenta una cierta regularidad en la precipitación, con un coeficiente de variación anual de 18,3\% (Fig. 70). Para el análisis de los datos de esta estación fueron utilizados 74 años, desde 1933 hasta 2006.

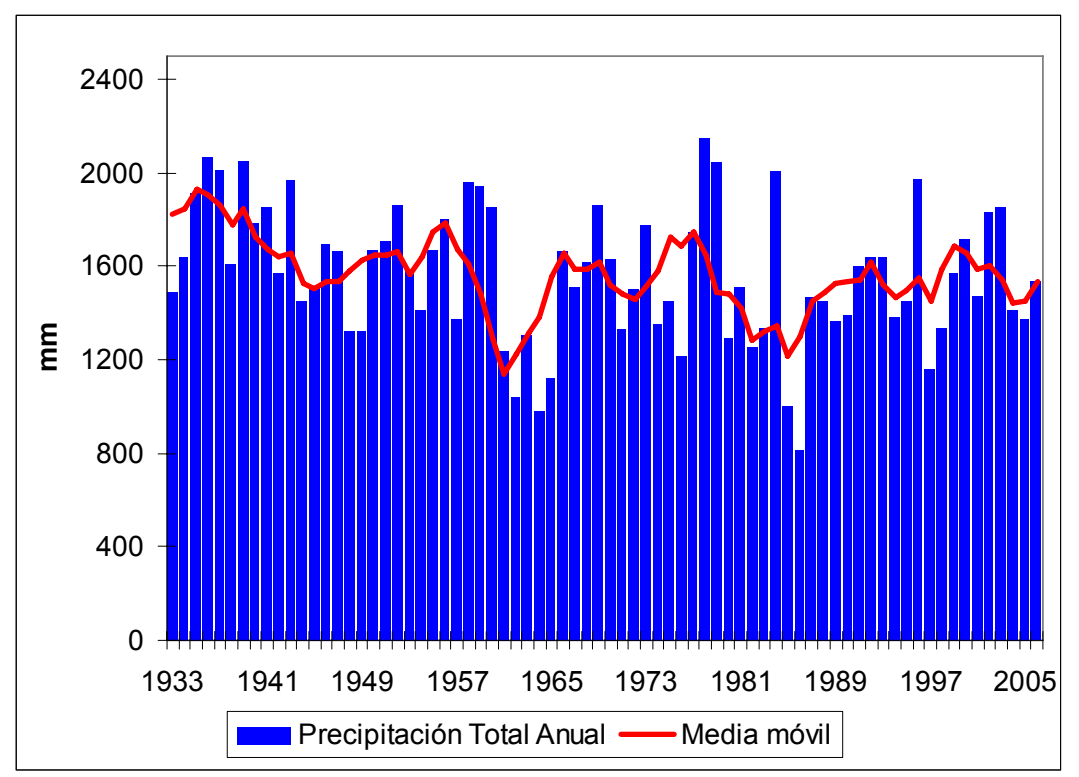

Figura 70 - Evolución de la precipitación total anual de la estación Maraña con representación de la media móvil de 5 años - Cuenca del río Porma.

La media de todo el período estudiado fue de $1570 \mathrm{~mm}$. El registro más bajo de precipitación ocurrió en 1986, con $810 \mathrm{~mm}$ (48,4\% por debajo de la media). Por otro lado, el más alto ocurrió en 1978, con un valor de $2153 \mathrm{~mm} \mathrm{(37,1 \%} \mathrm{por} \mathrm{encima} \mathrm{de} \mathrm{la}$ media). En el año de 1964 también hay un fuerte descenso en la precipitación, con $997 \mathrm{~mm}$. Otros dos años que también presentan valores considerablemente bajos con relación a los valores medios de la estación son 1985, con 1000 mm y 1962, con 1044 $\mathrm{mm}$. 


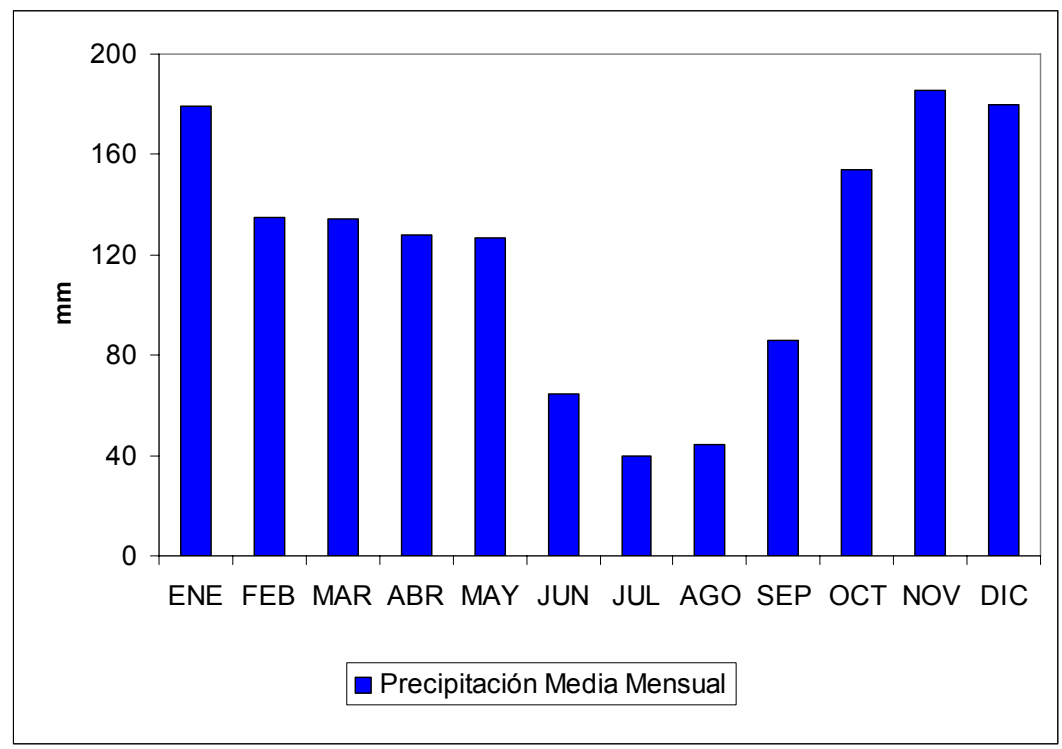

Figura 71 - Precipitación media mensual para el período estudiado - Estación Maraña, Cuenca del río Porma.

Noviembre es el mes con el valor medio más alto (Fig. 71 ) con $185,3 \mathrm{~mm}$, seguido de diciembre, con 179,6 mm y enero, con 179,1 mm. Por otro lado, los meses con los valores más bajos son julio, con $39,9 \mathrm{~mm}$ y agosto, con $44,1 \mathrm{~mm}$. Casi todos los meses presentan valores de coeficiente de variación (Tabla 60 ) altos (>50\%), demostrando una gran variabilidad mensual de la precipitación, exceptuando el mes de noviembre con el valor más bajo, con un $47,6 \%$. El más alto fue detectado en el mes de julio con un $86,3 \%$.

Tabla 60. Precipitación media mensual y coeficiente de variación de la estación Maraña Cuenca del río Porma.

\begin{tabular}{|l|c|c|}
\hline \multicolumn{1}{|c|}{ Mes } & Precipit. media (mm) & CV (\%) \\
\hline \hline Enero & 179,1 & 56,7 \\
\hline Febrero & 134,8 & 61,6 \\
\hline Marzo & 134,3 & 59,9 \\
\hline Abril & 128,2 & 57,6 \\
\hline Mayo & 126,9 & 54,8 \\
\hline Junio & 64,7 & 59,6 \\
\hline Julio & 39,9 & 86,3 \\
\hline Agosto & 44,1 & 74,6 \\
\hline Septiembre & 86,1 & 76,6 \\
\hline Octubre & 153,6 & 62,2 \\
\hline Noviembre & 185,3 & 47,6 \\
\hline Diciembre & 179,6 & 54,7 \\
\hline \hline
\end{tabular}




\subsubsection{Estación Pantano del Porma}

Para el estudio de la estación Pantano del Porma (Fig. 72) fueron utilizados un total de 44 años, de 1963 hasta 2006. Esta estación también tiene cierta regularidad en la precipitación, con un coeficiente de variación de $20,7 \%$, que es el más alto entre todas las estaciones utilizadas para análisis de la cuenca del río Porma.

Los datos revelan que desde 1967 hasta 1977 hubo un periodo bastante seco. La media registrada en estos diez años fue de $1037 \mathrm{~mm}$ y en todos se registraron valores por debajo de la media de toda la serie, que fue de $1259 \mathrm{~mm}$. A partir de 1978 hubo un aumento progresivo llegando al máximo en 1995, con un total de $1684 \mathrm{~mm}$. El registro más bajo se dio en 2005 con 814 mm, seguido del año de 1967, con 829 mm.

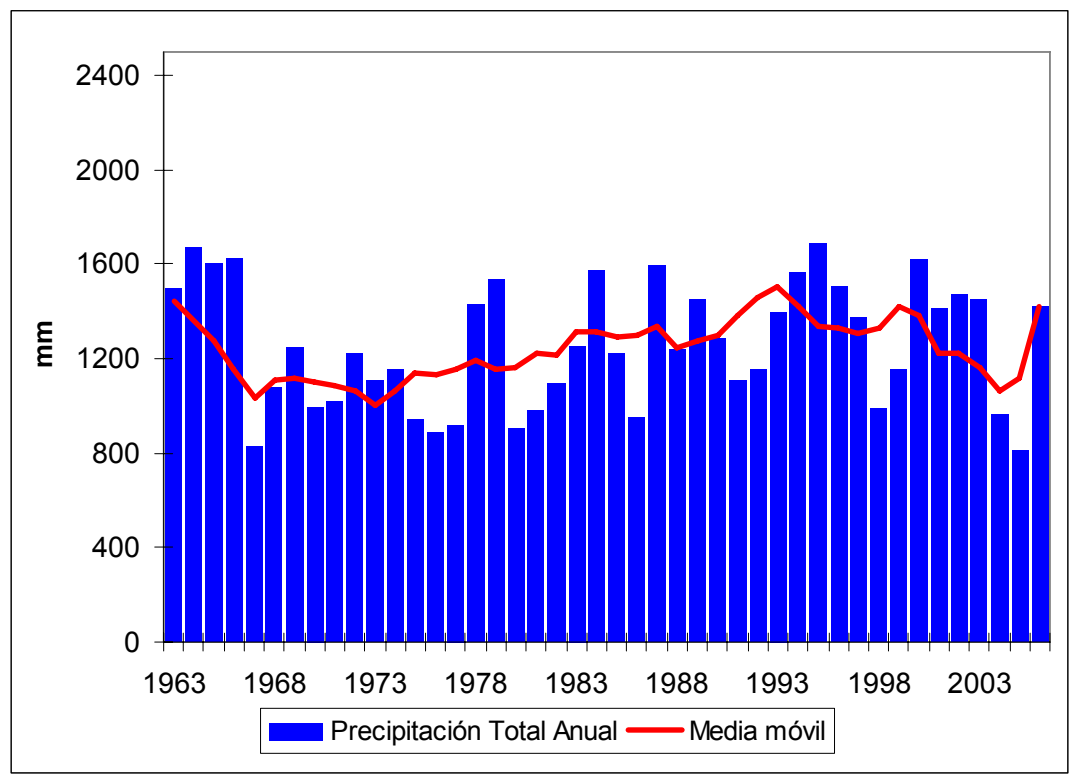

Figura 72 - Evolución de la precipitación total anual de la estación Pantano del Porma con representación de la media móvil de 5 años - Cuenca del río Porma.

La media mensual más alta se encuentra en noviembre (Fig. 73) con 156,3 mm, seguido de muy cerca por los meses de diciembre, octubre y enero, con 153,2, 151,6 y $151,0 \mathrm{~mm}$, respectivamente. A su vez, las más bajas se dan en los meses de julio, con $34,9 \mathrm{~mm}$ y agosto, con $38,0 \mathrm{~mm}$. De acuerdo con los datos expuestos en la tabla 61 , en todos los meses los coeficientes de variación son altos, evidenciándose una gran variabilidad en los valores mensuales. El mes que presenta el valor más bajo es mayo con un $64,9 \%$ y el más alto se detectó en julio con un $96,1 \%$. 


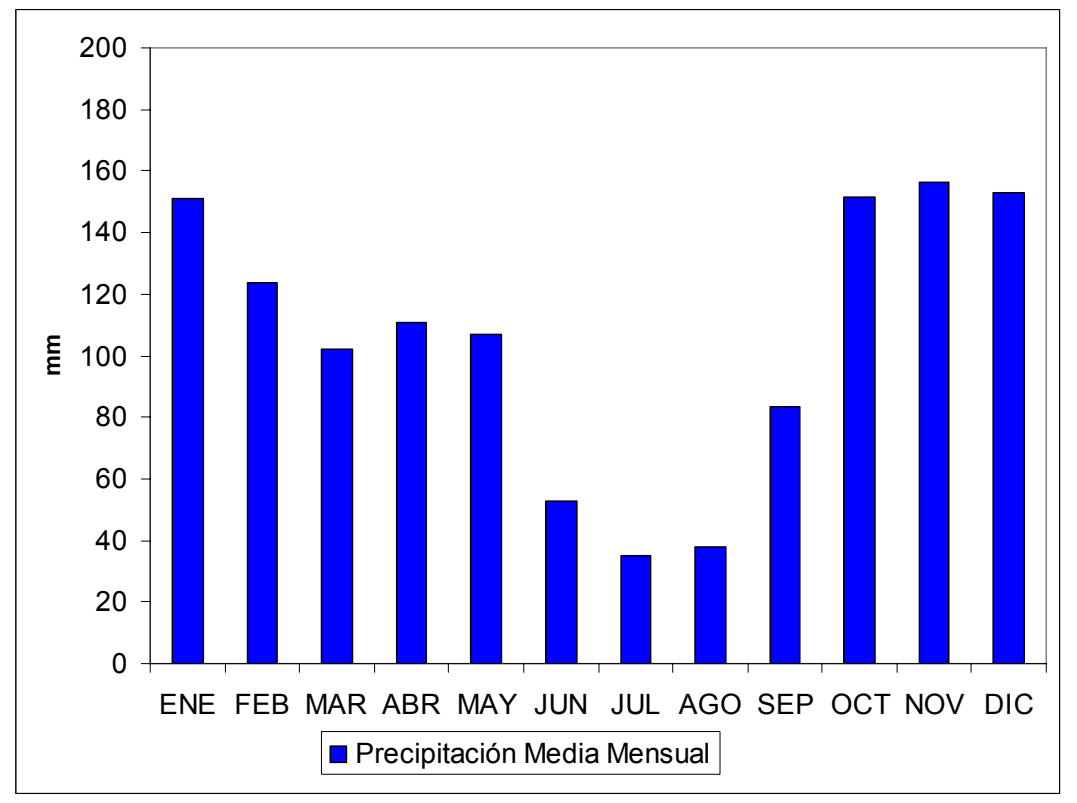

Figura 73 - Precipitación media mensual para el período estudiado - Estación Pantano del Porma, Cuenca del río Porma.

Tabla 61. Precipitación media mensual y coeficiente de variación de la estación Pantano del Porma - Cuenca del río Porma.

\begin{tabular}{|l|c|c|}
\hline \multicolumn{1}{|c|}{ Mes } & Precipit. media (mm) & CV (\%) \\
\hline Enero & 151,0 & 66,4 \\
\hline Febrero & 123,6 & 71,7 \\
\hline Marzo & 102,3 & 84,4 \\
\hline Abril & 110,7 & 73,3 \\
\hline Mayo & 106,8 & 64,9 \\
\hline Junio & 52,8 & 79,7 \\
\hline Julio & 34,9 & 96,1 \\
\hline Agosto & 38,0 & 86,4 \\
\hline Septiembre & 83,6 & 74,5 \\
\hline Octubre & 151,6 & 74,4 \\
\hline Noviembre & 156,3 & 67,6 \\
\hline Diciembre & 153,2 & 77,0 \\
\hline \hline
\end{tabular}

\subsubsection{Estación Puebla de Lillo}

Para el análisis de los datos de la estación Puebla de Lillo fueron utilizados 73 años (1934-2006). La evolución de la precipitación y la media móvil de 5 años están reflejadas en la figura 74 y el gráfico puede ser dividido en 6 ciclos (1934-1943, 19441954, 1955-1966, 1967-1977, 1978-1984, 1985-2006). No obstante, aunque haya diferencias entre ellos, se mantiene una cierta regularidad en la precipitación en la serie estudiada, comprobada por un coeficiente de variación de 20,4\%. La media de precipitación en todo el período es de $1413 \mathrm{~mm}$. 


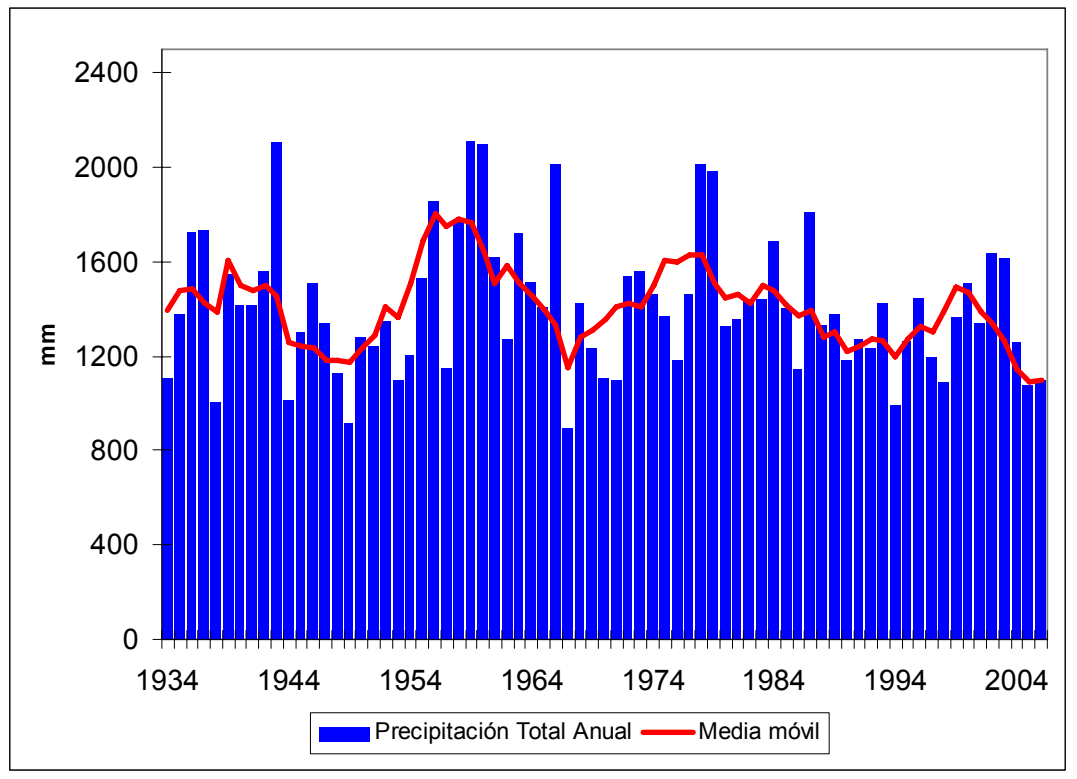

Figura 74 - Evolución de la precipitación total anual de la estación Puebla de Lillo con representación de la media móvil de 5 años - Cuenca del río Porma.

El primer ciclo analizado va desde el inicio de la serie (1934) hasta 1943 y presentó uno de los valores más altos de todo el período, con $2107 \mathrm{~mm}$ en 1943, así como el coeficiente de variación más alto, con 21,1\%. El segundo ciclo se extiende desde 1944 hasta 1954 y fue donde se registró una menor irregularidad, con un coeficiente de variación de tan sólo 13,8\%. La media encontrada en este período fue $1217 \mathrm{~mm}$ que está un 13,9\% por debajo de la media. El siguiente ciclo va de 1955 hasta 1966, siendo este el período que presenta la media más alta con $1674 \mathrm{~mm}$ que está un $18,5 \%$ por encima de la media y dónde se registra el valor más alto de toda la serie, en 1959, con 2116 mm. El siguiente ciclo se extiende de 1967 hasta 1977. En 1967 hubo una disminución muy grande registrando el valor más bajo de toda la serie, con solamente $893 \mathrm{~mm}$, manteniendo hasta 1977 una media de $1303 \mathrm{~mm}$ (7,8\% por debajo de la media). De 1978 hasta 1984, empieza un nuevo aumento progresivo y un nuevo ciclo, con una media de $1608 \mathrm{~mm}$ (13,8\% por encima de la media). A partir de entonces es el último ciclo que va hasta 2006 y en este período nuevamente se produjo un descenso en la precipitación con una media de $1323 \mathrm{~mm}, 6,4 \%$ por debajo de la media de todo el período.

El valor medio más alto se encuentra en noviembre (Fig. 75) con 182,7 mm, seguido de los meses de enero y diciembre, con 182,4 y 181,2 mm, mientras el mes con el valor más bajo es julio con $33,5 \mathrm{~mm}$. Los resultados más bajos del coeficiente de 
variación se encuentran en mayo con un $52,1 \%$ y los resultados más altos en julio con un $79,7 \%$ y septiembre con un $79,5 \%$ (Tabla 62 ). Como ocurre en todas las estaciones analizadas anteriormente, los resultados encontrados revelan gran variabilidad en los valores mensuales de la precipitación en la estación Puebla de Lillo.

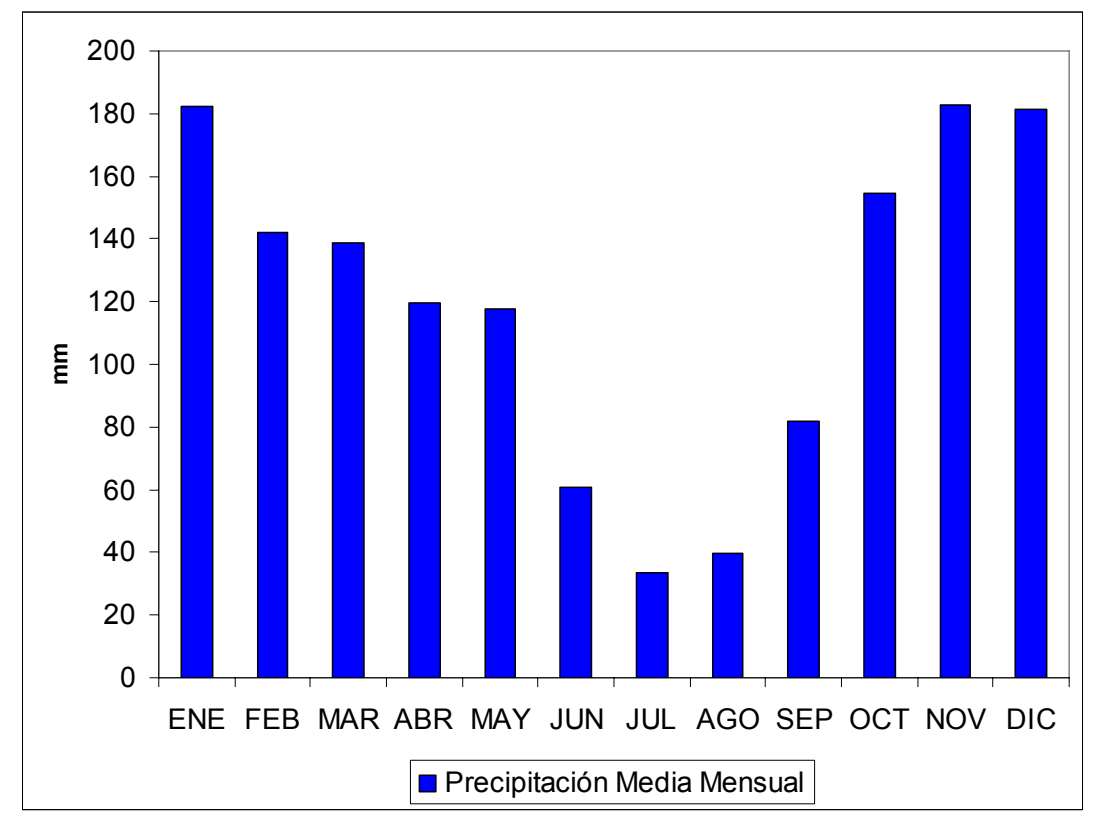

Figura 75 - Precipitación media mensual para el período estudiado - Estación Puebla de Lillo, Cuenca del río Porma.

Tabla 62. Precipitación media mensual y coeficiente de variación de la estación Puebla de Lillo - Cuenca del río Porma.

\begin{tabular}{|l|c|c|}
\hline \multicolumn{1}{|c|}{ Mes } & $\begin{array}{c}\text { Precipit. media } \\
\text { mensual (mm) }\end{array}$ & CV (\%) \\
\hline \hline Enero & 182,4 & 61,7 \\
\hline Febrero & 142,2 & 76,9 \\
\hline Marzo & 138,7 & 73,3 \\
\hline Abril & 119,9 & 59,5 \\
\hline Mayo & 117,8 & 52,1 \\
\hline Junio & 60,6 & 68,0 \\
\hline Julio & 33,5 & 79,7 \\
\hline Agosto & 39,7 & 77,8 \\
\hline Septiembre & 82,0 & 79,5 \\
\hline Octubre & 154,4 & 74,6 \\
\hline Noviembre & 182,7 & 54,6 \\
\hline Diciembre & 181,2 & 60,2 \\
\hline \hline
\end{tabular}




\subsection{Evolución de la Precipitación en la Cuenca Alta del Tajo}

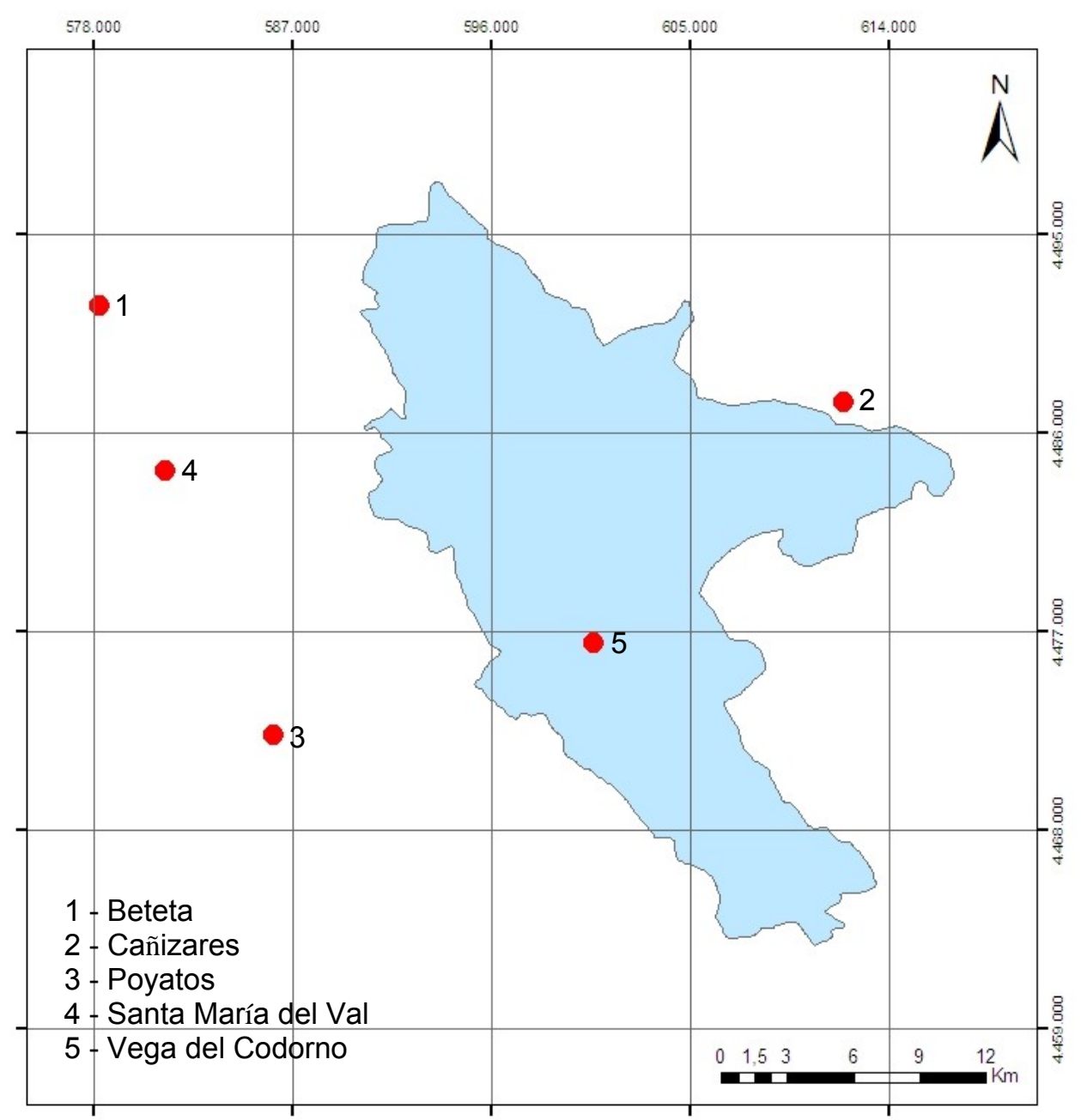

Figura 76 - Localización de las estaciones termométricas y pluviométricas (Cuenca alta del Tajo).

\subsubsection{Caracterización de la precipitación}

La precipitación media anual detectada en la cuenca alta del Tajo (Fig. 76) en el período estudiado es de $906 \mathrm{~mm}$ con un coeficiente de variación del 24,5\%. Los valores máximos encontrados fueron de $1691 \mathrm{~mm}$, un $86,6 \%$ por encima de la media de la cuenca, en la estación Vega del Codorno, en 1979 y 1661 mm en la estación Poyatos en 1960. En este último año también fue constatado el dato más alto en la estación Santa María del Val, con $1486 \mathrm{~mm}$. La precipitación mínima anual fue encontrada en la estación Santa María del Val, en 1994, con 439 mm (51,5\% por debajo de la media). Es importante resaltar que en el año de 2005 todas las otras 
estaciones presentaron sus valores mínimos, siendo, Beteta con $593 \mathrm{~mm}$, Cañizares con 480 mm, Poyatos con 492 mm y Vega del Codorno con 507 mm (Tabla 63).

Tabla 63. Precipitación media, mínima, máxima, coeficientes de variación y altitud para todas las estaciones.

\begin{tabular}{|l|c|c|c|c|c|}
\hline \hline \multicolumn{1}{|c|}{ Estación } & $\begin{array}{c}\text { Altitud } \\
\mathbf{( m )}\end{array}$ & $\begin{array}{c}\text { Media } \\
\mathbf{( m m )}\end{array}$ & $\begin{array}{c}\text { Mínima } \\
\mathbf{( m m})\end{array}$ & $\begin{array}{c}\text { Máxima } \\
\mathbf{( m m})\end{array}$ & $\mathbf{C V}(\mathbf{m})$ \\
\hline \hline Beteta & 1214 & 947 & 593 & 1581 & 25,2 \\
\hline Cañizares & 940 & 839 & 480 & 1625 & 29,5 \\
\hline Poyatos & 1150 & 917 & 492 & 1661 & 29,8 \\
\hline Santa María del Val & 1195 & 855 & 439 & 1486 & 29,0 \\
\hline Vega del Codorno & 1345 & 936 & 507 & 1691 & 26,9 \\
\hline \hline
\end{tabular}

Los coeficientes de variación encontrados en todas las estaciones son considerados medios, siendo el más alto en la estación Poyatos, con 29,8\% mientras el más bajo fue encontrado en la estación Beteta, con 25,2\%.

En la cuenca del río Tajo, como en todas las demás, la precipitación media mensual tiene una oscilación bastante grande pasando de tan sólo $22,4 \mathrm{~mm}$ en el mes de julio a aproximadamente $100 \mathrm{~mm}$ en los meses de noviembre y diciembre (Tabla 64). La ETP potencial anual registrada en la cuenca fue de $644,3 \mathrm{~mm}$, teniendo sus valores máximos en julio $(126,5 \mathrm{~mm})$ y agosto $(111,7)$ y los mínimos en noviembre y diciembre con cerca de $8 \mathrm{~mm}$. Desde junio hasta septiembre se observa un déficit hídrico se si compara la precipitación media y la evapotranspiración potencial (Fig. 77).

Tabla 64. Precipitación y evapotranspiración media mensual de la cuenca del río Tajo.

\begin{tabular}{|l|c|c|}
\hline \multicolumn{1}{|c|}{ Mes } & $\begin{array}{c}\text { Prec. Med. Menual } \\
(\mathbf{m m})\end{array}$ & $\begin{array}{c}\text { Evapotranspiración } \\
\text { Med. Mensual (mm) }\end{array}$ \\
\hline \hline Enero & 92,9 & 8,3 \\
\hline Febrero & 92,3 & 12,9 \\
\hline Marzo & 76,1 & 23,2 \\
\hline Abril & 86,6 & 41,6 \\
\hline Mayo & 89,4 & 70,1 \\
\hline Junio & 63,8 & 100,2 \\
\hline Julio & 22,4 & 126,5 \\
\hline Agosto & 25,8 & 111,7 \\
\hline Septiembre & 56,5 & 77,6 \\
\hline Octubre & 95,2 & 44,6 \\
\hline Noviembre & 99,0 & 19,5 \\
\hline Diciembre & 106,7 & 8,1 \\
\hline \hline
\end{tabular}




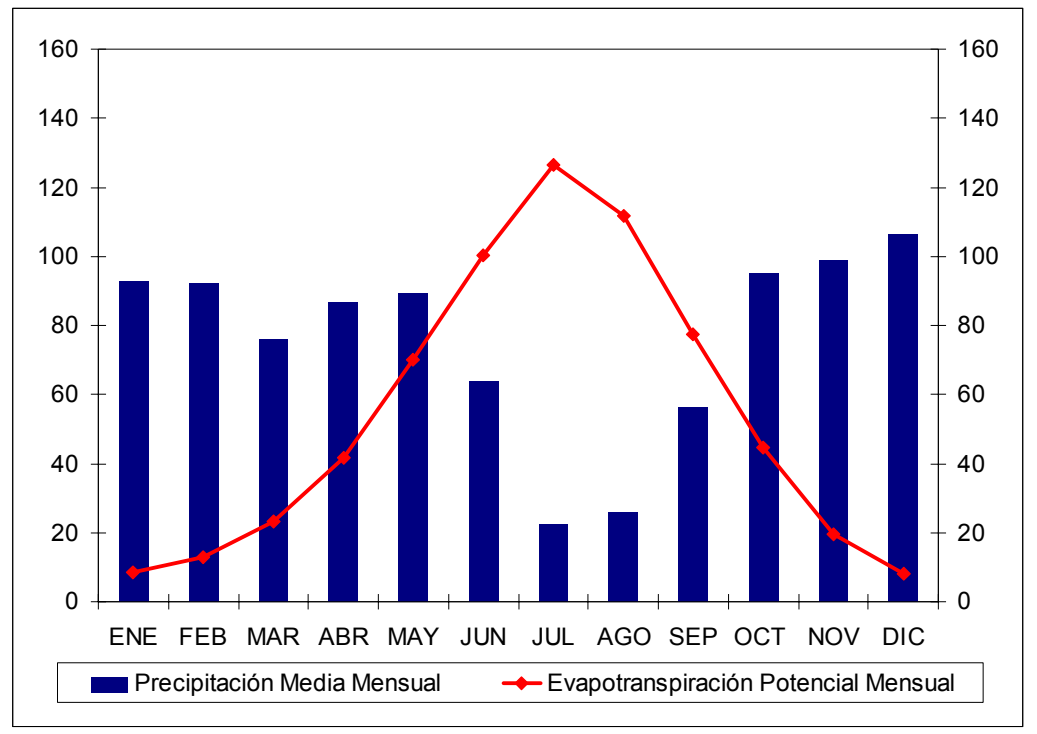

Figura 77 - Evapotranspiración potencial y precipitación mensual $(\mathrm{mm})$ de la cuenca del río Tajo.

\subsubsection{Caracterización de cada estación}

\subsubsection{Estación Beteta}

La estación Beteta presenta una cierta regularidad en la precipitación (Fig. 78), con un coeficiente de variación anual del $25,2 \%$. El período utilizado para el análisis de esta estación está comprendido entre 1960 y 2007 (48 años).

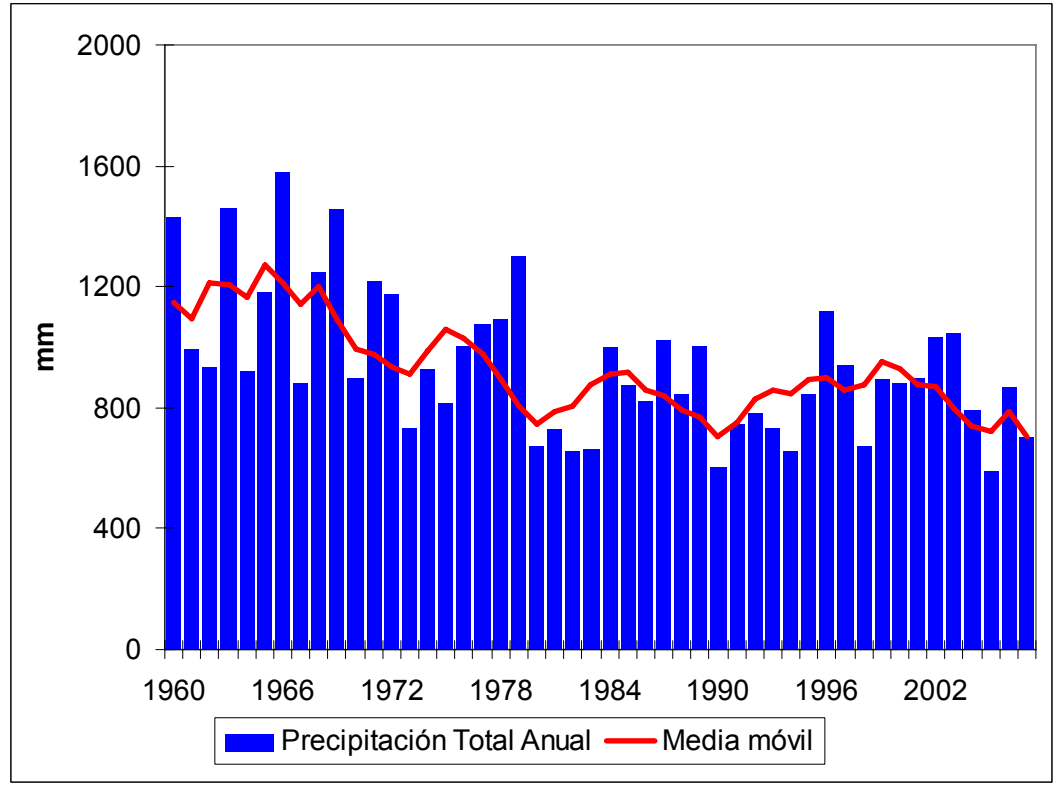

Figura 78 - Evolución de la precipitación total anual de la estación Beteta con representación de la media móvil de 5 años - Cuenca alta del Tajo. 
La media de precipitación encontrada en el período estudiado fue de $947 \mathrm{~mm}$. El registro más bajo de precipitación ocurrió en 2005, con $593 \mathrm{~mm}$, un 37,4\% por debajo de la media. A su vez el más alto ocurrió en 1966, con $1581 \mathrm{~mm}$, que está un $66,9 \%$ por encima de la media. Como ya se constató en la cuenca del río Cega, en la década de 80 hubo un período más seco, que se extiende de 1980 hasta 1983, con una media de $681 \mathrm{~mm}$. Los registros encontrados en este período son $673 \mathrm{~mm}$ en 1980, $729 \mathrm{~mm}$ en $1981,658 \mathrm{~mm}$ en 1982 y $664 \mathrm{~mm}$ en 1983.

El mes en que se encuentra el valor medio más alto es noviembre con 106,7 mm, seguido por octubre y diciembre, con 99,7 y $99,8 \mathrm{~mm}$, respectivamente y los más bajos en agosto, con $25,3 \mathrm{~mm}$ y julio con $26,0 \mathrm{~mm}$ (Fig. 79 ).

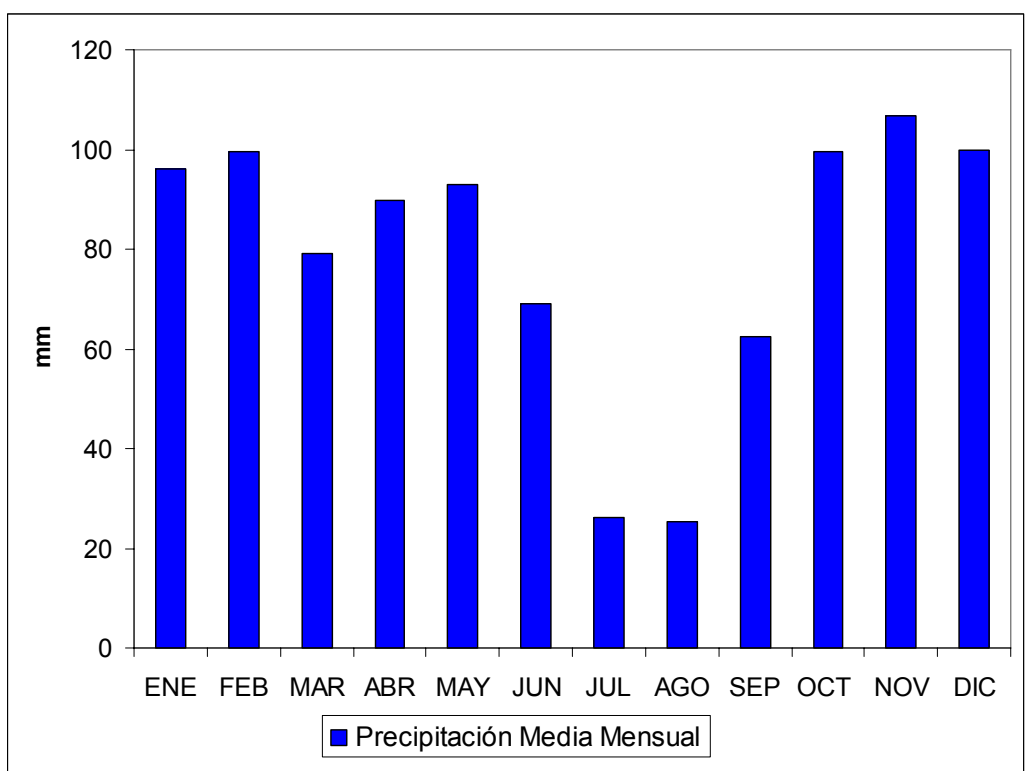

Figura 79 - Precipitación media mensual para el período estudiado - Estación Beteta, Cuenca alta del Tajo.

Los coeficientes de variación mensual (Tabla 65) son bastante altos (> 50\%), llegando al máximo en agosto con $115,4 \%$ mientras el más bajo es en mayo, con $51,7 \%$, revelando gran variabilidad de los valores mensuales. 
Tabla 65. Precipitación media mensual y coeficiente de variación de la estación Beteta Cuenca alta del Tajo.

\begin{tabular}{|l|c|c|}
\hline \hline \multicolumn{1}{|c|}{ Mes } & Precipit. media (mm) & CV (\%) \\
\hline \hline Enero & 96,1 & 82,8 \\
\hline Febrero & 99,5 & 86,4 \\
\hline Marzo & 79,3 & 77,3 \\
\hline Abril & 89,7 & 58,7 \\
\hline Mayo & 93,0 & 51,7 \\
\hline Junio & 69,1 & 65,3 \\
\hline Julio & 26,0 & 107,7 \\
\hline Agosto & 25,3 & 115,4 \\
\hline Septiembre & 62,5 & 69,9 \\
\hline Octubre & 99,7 & 79,9 \\
\hline Noviembre & 106,7 & 71,4 \\
\hline Diciembre & 99,8 & 76,4 \\
\hline \hline
\end{tabular}

\subsubsection{Estación Cañizares}

Los datos de precipitación de la estación Cañizares presentan un coeficiente de variación anual de $29,5 \%$, el segundo más alto entre las estaciones utilizadas para análisis de la cuenca alta del Tajo. Se ha hecho el estudio utilizando un período de 53 años, desde 1955 hasta 2007 (Fig. 80).

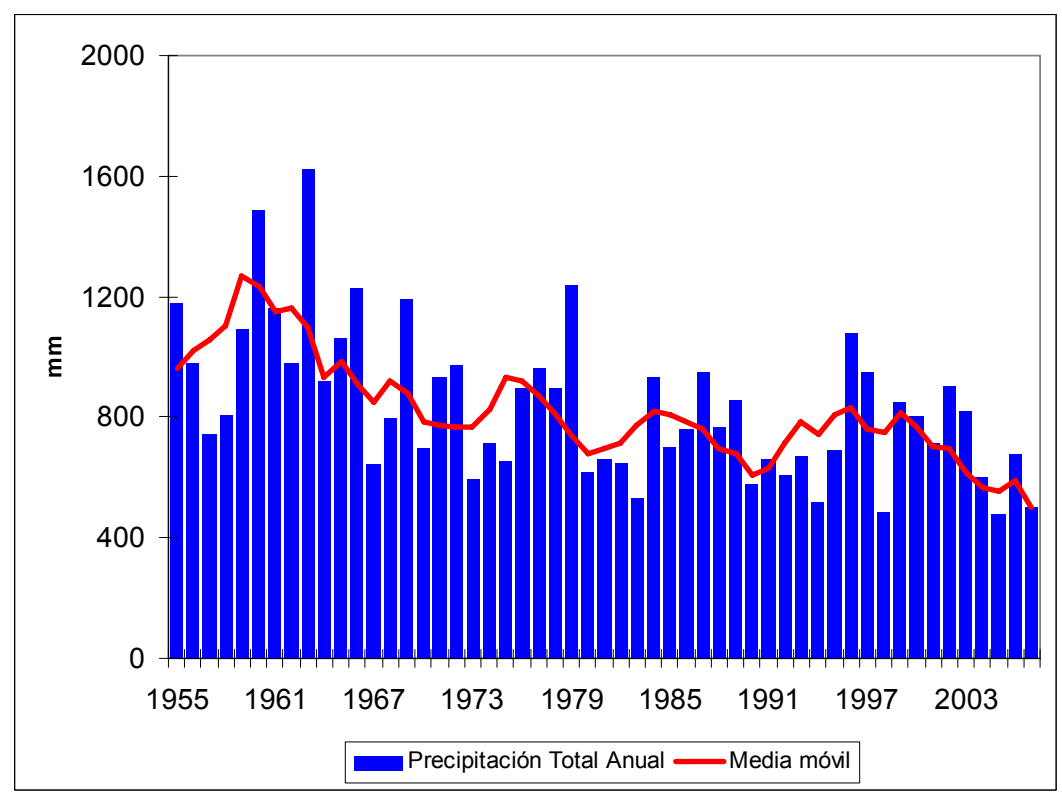

Figura 80 - Evolución de la precipitación total anual de la estación Cañizares con representación de la media móvil de 5 años - Cuenca alta del Tajo.

La precipitación media registrada en la estación Cañizares fue de $839 \mathrm{~mm}$. El valor más bajo de precipitación total anual fue encontrado en 2005 , con $480 \mathrm{~mm}$, un $42,8 \%$ 
por debajo de la media. El año de 2005 ha tenido también los registros más bajos en las estaciones Beteta, Poyatos y Vega del Codorno. El registro más alto fue encontrado en 1963, con $1625 \mathrm{~mm}$, un $93,7 \%$ por encima de la media de todo el período.

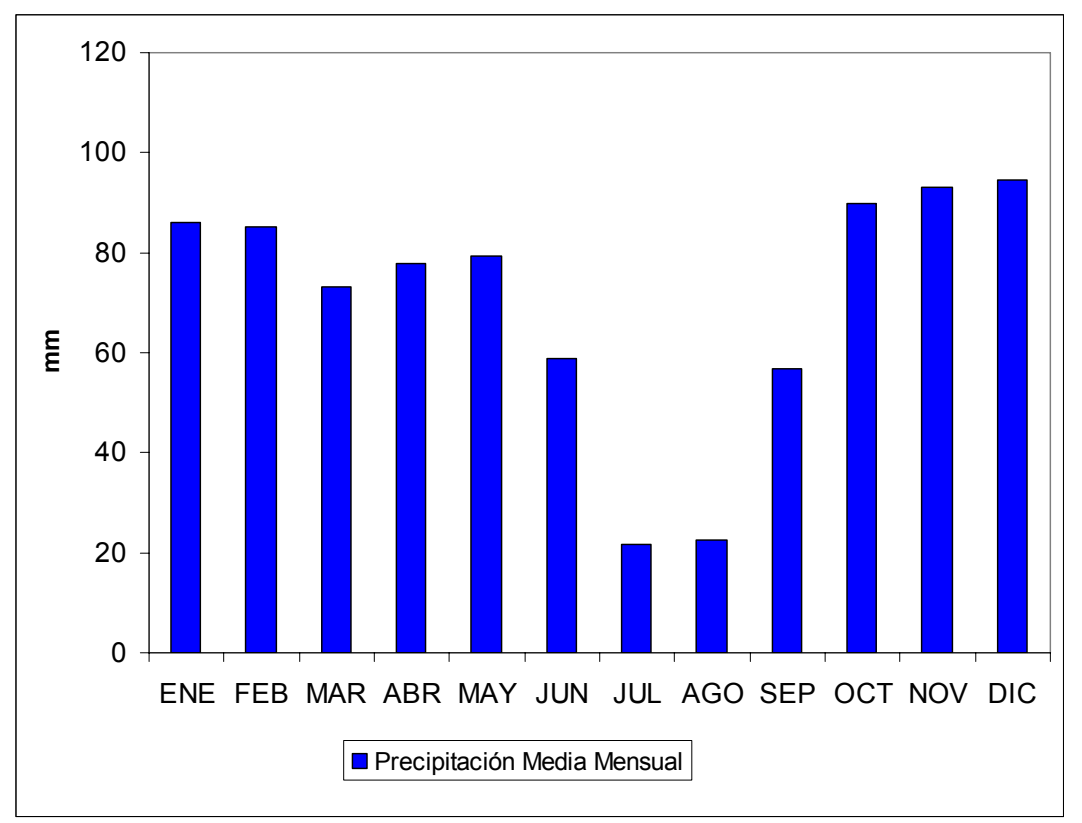

Figura 81 - Precipitación media mensual para el período estudiado - Estación Cañizares, Cuenca alta del Tajo.

Tabla 66. Precipitación media mensual y coeficiente de variación de la estación Cañizares - Cuenca alta del Tajo.

\begin{tabular}{|l|c|c|}
\hline \multicolumn{1}{|c|}{ Mes } & Precipit. media (mm) & CV (\%) \\
\hline Enero & 86,0 & 87,7 \\
\hline Febrero & 85,2 & 89,3 \\
\hline Marzo & 73,3 & 82,2 \\
\hline Abril & 77,9 & 59,7 \\
\hline Mayo & 79,4 & 54,6 \\
\hline Junio & 58,7 & 65,2 \\
\hline Julio & 21,6 & 113,3 \\
\hline Agosto & 22,5 & 102,4 \\
\hline Septiembre & 56,9 & 83,0 \\
\hline Octubre & 89,8 & 85,7 \\
\hline Noviembre & 93,2 & 81,2 \\
\hline Diciembre & 94,7 & 80,0 \\
\hline \hline
\end{tabular}

Las precipitaciones medias mensuales están representadas en la figura 81 y el valor más alto se da en noviembre con $93,2 \mathrm{~mm}$ y los más bajos en julio, con 21,6 mm y agosto con 22,5 mm. El mes de julio presenta el coeficiente de variación más alto con $113,3 \%$ (Tabla 66). A su vez el menor fue encontrado en mayo, con 54,6\%, 
comprobando así una gran variabilidad en los valores de la precipitación mensual en la estación Cañizares.

\subsubsection{Estación Poyatos}

Para el análisis de los datos de precipitación de la estación Poyatos fueron utilizados 55 años, de 1953 hasta 2007 (Fig. 82). La precipitación de esta estación presenta una irregularidad bastante considerable en sus dados interanuales en todo el período estudiado, con un coeficiente de variación anual de $29,8 \%$, el más alto encontrado entre las estaciones utilizadas para análisis de la cuenca del Tajo.

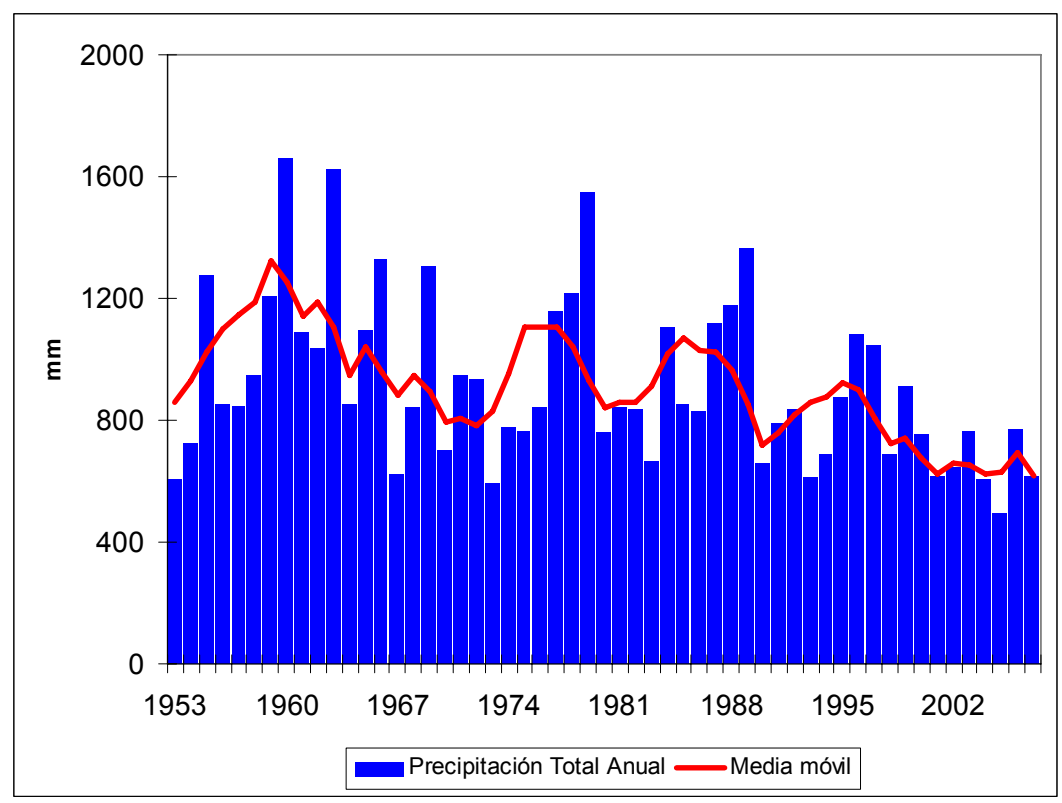

Figura 82 - Evolución de la precipitación total anual de la estación Poyatos con representación de la media móvil de 5 años - Cuenca alta del Tajo.

En la estación Poyatos la precipitación media registrada para toda la serie fue de 917 mm. Como ocurrió en las estaciones Beteta, Cañizares y Vega del Codorno, el valor más bajo de precipitación total anual fue encontrado en 2005, con $492 \mathrm{~mm}$, que es un $46,4 \%$ por debajo de la media. El año que presenta el registro más alto es 1960 , con $1661 \mathrm{~mm}$, lo que representa un 81,1\% por encima de la media. A partir de 1990, los valores de precipitación total anual tuvieron una reducción, llegando en este período a un valor medio de $748 \mathrm{~mm}$. 
El valor medio mensual más alto es el de diciembre (Fig. 83) con $111,5 \mathrm{~mm}$ y el más bajo julio con $22,5 \mathrm{~mm}$, seguido de agosto con $24,0 \mathrm{~mm}$. De acuerdo con los datos obtenidos para las otras estaciones, los coeficientes de variación de la precipitación mensual de la estación Poyatos son todos altos (tabla 67). El más elevado es el de julio con $106,6 \%$ y el más bajo mayo con $60,6 \%$.

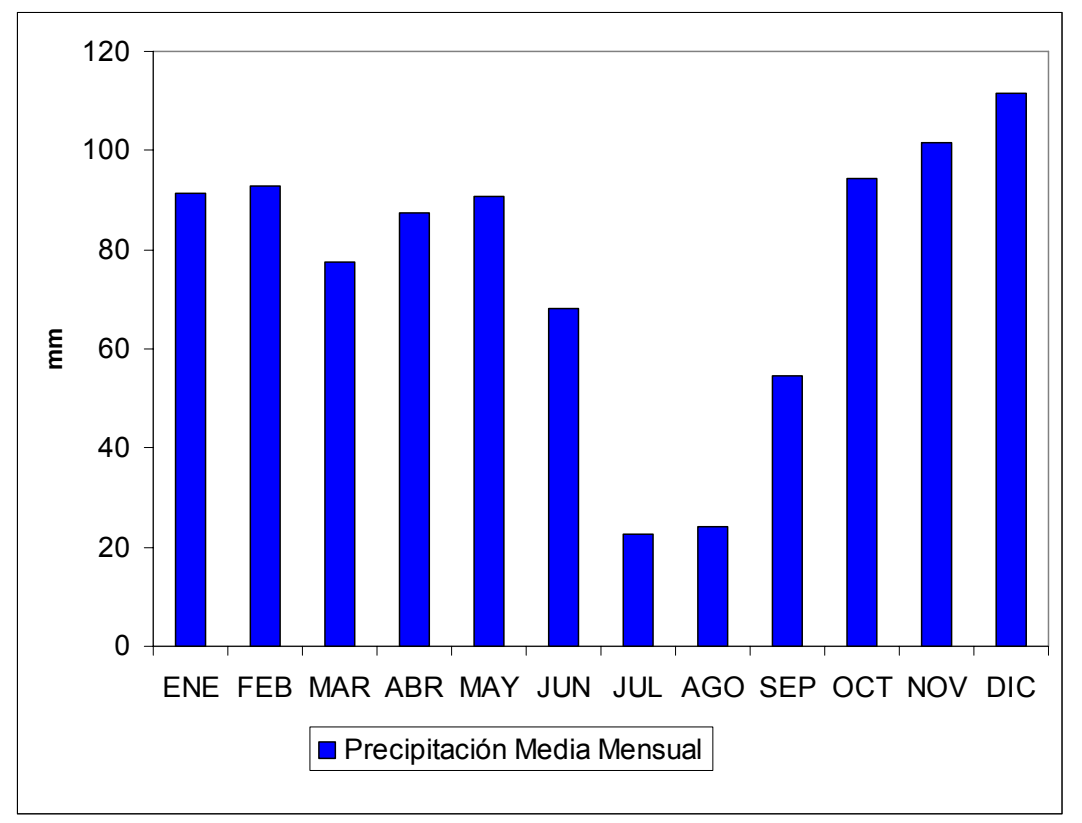

Figura 83 - Precipitación media mensual para el período estudiado - Estación Poyatos, Cuenca alta del Tajo.

Tabla 67. Precipitación media mensual y coeficiente de variación de la estación Poyatos - Cuenca alta del Tajo.

\begin{tabular}{|l|c|c|}
\hline \multicolumn{1}{|c|}{ Mes } & Precipit. media (mm) & CV (\%) \\
\hline Enero & 91,5 & 84,4 \\
\hline Febrero & 92,9 & 91,8 \\
\hline Marzo & 77,5 & 83,4 \\
\hline Abril & 87,5 & 64,4 \\
\hline Mayo & 90,6 & 60,6 \\
\hline Junio & 68,0 & 73,0 \\
\hline Julio & 22,5 & 106,6 \\
\hline Agosto & 24,0 & 98,9 \\
\hline Septiembre & 54,5 & 71,5 \\
\hline Octubre & 94,3 & 91,7 \\
\hline Noviembre & 101,7 & 82,0 \\
\hline Diciembre & 111,5 & 88,3 \\
\hline \hline
\end{tabular}




\subsubsection{Estación Santa María del Val}

Para el análisis de la precipitación de la estación Santa María del Val fueron utilizados 48 años de datos, de 1960 hasta 2007 (Fig. 84). A partir del análisis realizado, se puede detectar que la precipitación en esta estación presenta gran irregularidad en sus dados interanuales en el período estudiado, con un coeficiente de variación anual del $29 \%$. La precipitación media registrada en la estación Santa María del Val para toda la serie estudiada fue de $855 \mathrm{~mm}$. Al igual que en la estación Poyatos, el año que registra el valor más alto es 1960 , con $1486 \mathrm{~mm}$, un 73,8\% por encima de la media de todo el período. Por otro lado, el valor más bajo de precipitación total anual fue encontrado en 1994, con $439 \mathrm{~mm}$, un $48,7 \%$ por debajo de la media. También como en la estación Poyatos, a partir del año de 1990, se nota una reducción en los valores de precipitación. La media de 1990 hasta 2007 fue de $700 \mathrm{~mm}$, lo que representa un $18,1 \%$ por debajo de la media de todo el periodo.

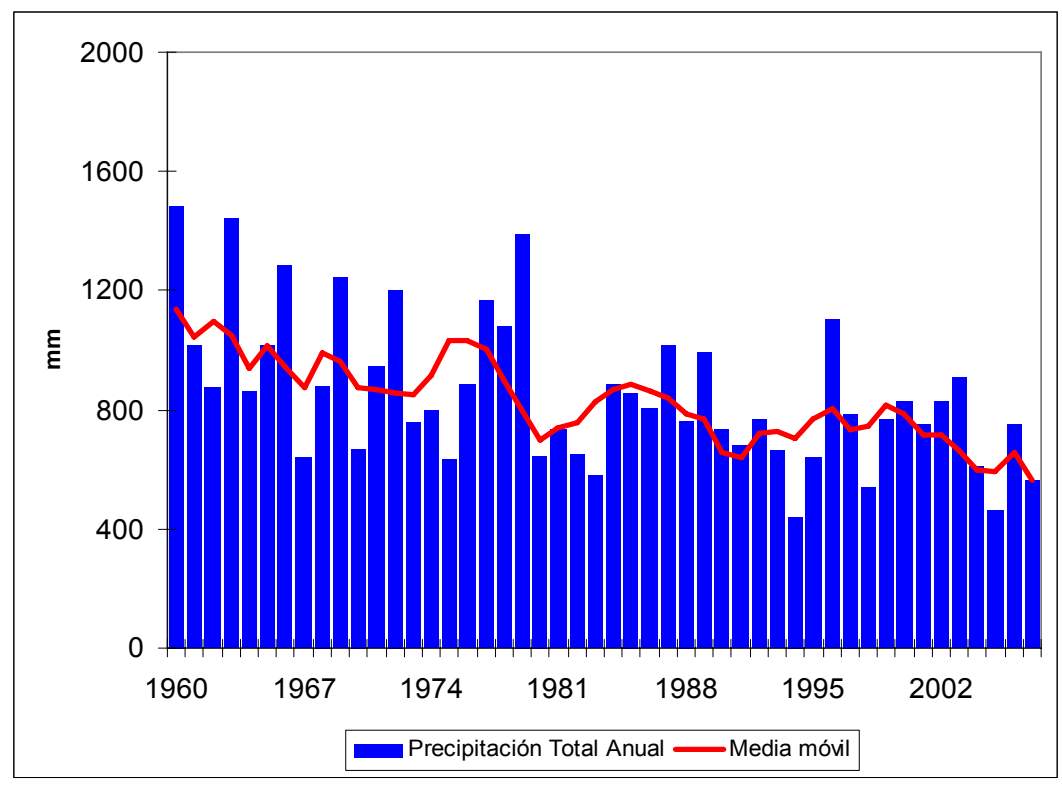

Figura 84 - Evolución de la precipitación total anual de la estación Santa María del Val con representación de la media móvil de 5 años - Cuenca alta del Tajo.

El valor medio mensual más alto se da en noviembre (Fig. 85) con 98,9 mm mientras el más bajo es en julio, con $23,1 \mathrm{~mm}$ y agosto, con $23,8 \mathrm{~mm}$. De acuerdo con los resultados encontrados hasta el momento en todas las estaciones analizadas, los coeficientes de variación (Tabla 68) de la precipitación mensual son todos altos. El valor más alto es el de agosto, con $118,5 \%$ y el más bajo mayo con $53,1 \%$. 


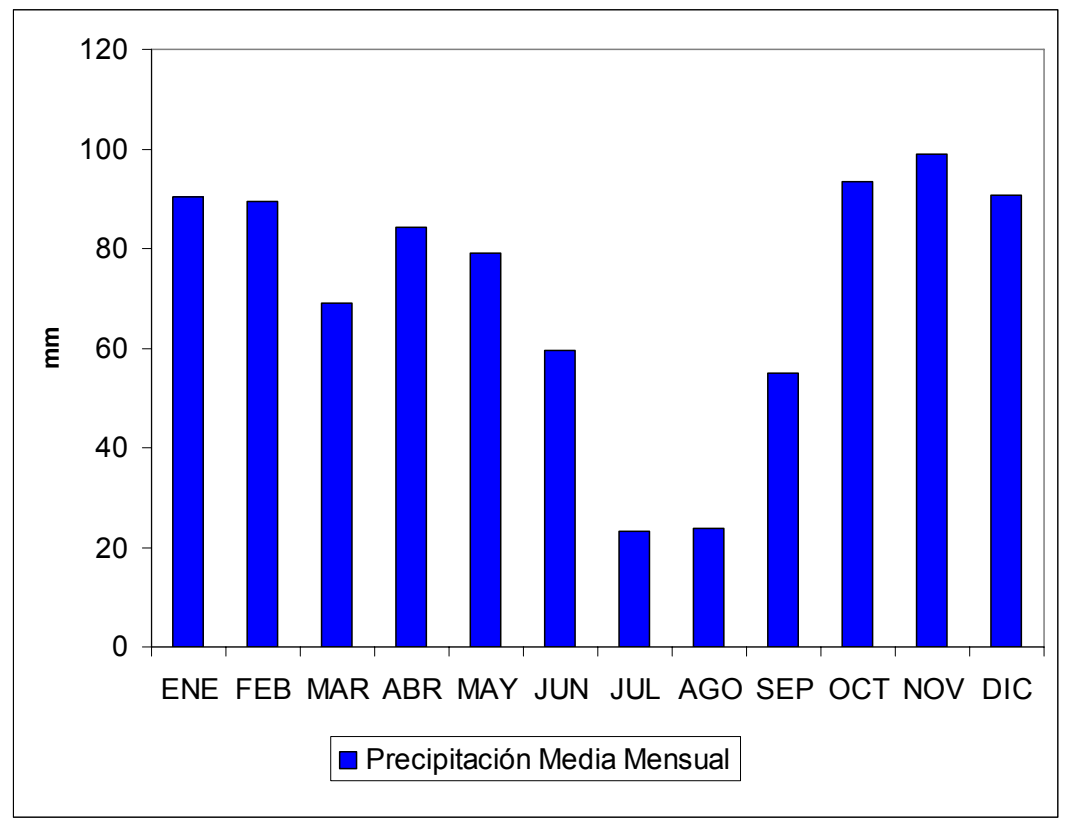

Figura 85 - Precipitación media mensual para el período estudiado - Estación Santa María del Val, Cuenca alta del Tajo.

Tabla 68. Precipitación media mensual y coeficiente de variación de la estación Santa María del Val - Cuenca alta del Tajo.

\begin{tabular}{|l|c|c|}
\hline \multicolumn{1}{|c|}{ Mes } & Precipit. media (mm) & CV (\%) \\
\hline \hline Enero & 90,3 & 84,8 \\
\hline Febrero & 89,5 & 89,0 \\
\hline Marzo & 68,9 & 78,5 \\
\hline Abril & 84,4 & 58,1 \\
\hline Mayo & 79,2 & 53,1 \\
\hline Junio & 59,5 & 70,1 \\
\hline Julio & 23,1 & 99,9 \\
\hline Agosto & 23,8 & 108,5 \\
\hline Septiembre & 55,1 & 76,2 \\
\hline Octubre & 93,4 & 89,1 \\
\hline Noviembre & 98,9 & 80,9 \\
\hline Diciembre & 90,6 & 85,1 \\
\hline
\end{tabular}

\subsubsection{Estación Vega del Codorno}

Para el estudio de la estación Vega del Codorno fueron utilizados 52 años, estando comprendidos entre 1956 y 2007 (Fig. 86). El coeficiente de variación de la precipitación encontrado fue del $26,9 \%$, evidenciando una regularidad media en los datos interanuales en dicho período. 


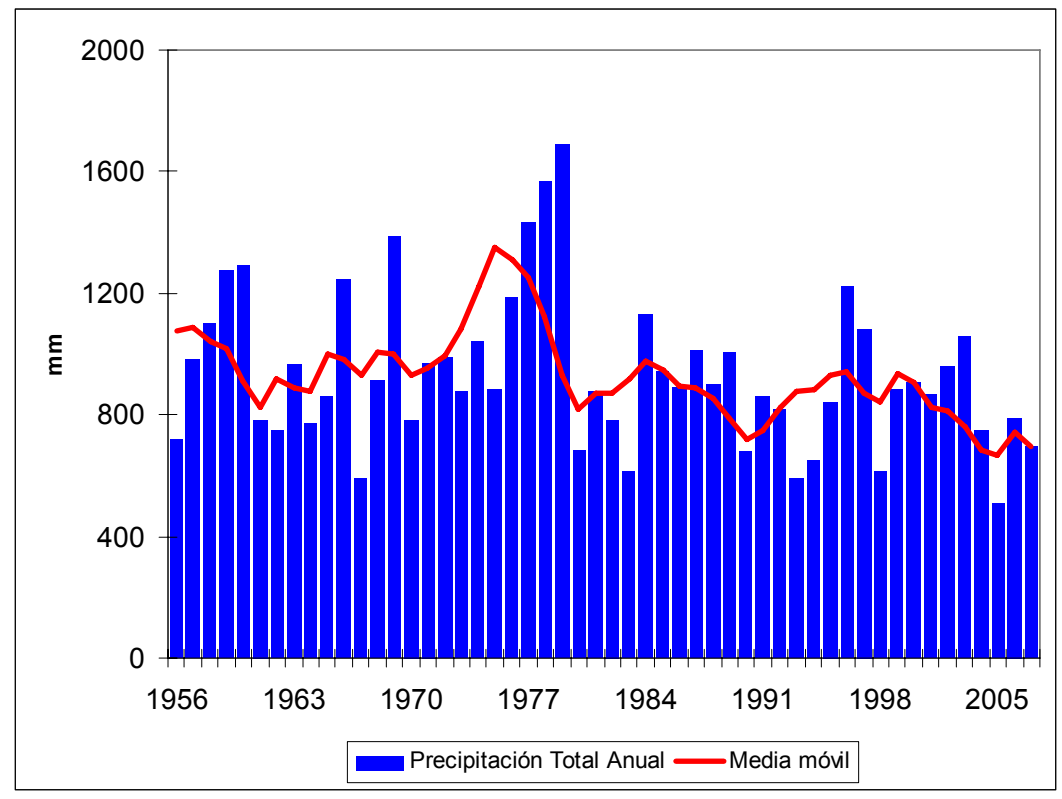

Figura 86 - Evolución de la precipitación total anual de la estación Vega del Codorno con representación de la media móvil de 5 años - Cuenca alta del Tajo.

Según los resultados del análisis de los datos de la precipitación registrada en la estación Vega del Codorno, la media de todo el período fue de $936 \mathrm{~mm}$. De manera similar a lo encontrado en las estaciones Beteta, Cañizares y Poyatos, el año que registra el valor más bajo es 2005 , con $507 \mathrm{~mm}$ anuales, un $45,8 \%$ por debajo de la media. El registro más alto fue encontrado en 1979, con $1691 \mathrm{~mm}$, un 80,6\% por encima de la media, siendo el registro más alto encontrado entre las estaciones utilizadas para análisis de esta cuenca. Cabe resaltar que en la década de 1970 hubo un período con valores bastante elevados. Desde el año de 1976 hasta el año de 1979 la media encontrada fue $1470 \mathrm{~mm}$, que está un $57,1 \%$ por encima de la media de la serie.

En el mes de diciembre (Fig. 87) con 113,1 mm, se da el valor medio mensual más alto. Por otro lado, el más bajo se observa en julio, con 22,5 mm. Como ocurrió en todas las estaciones analizadas hasta el momento, se aprecia una alta variabilidad en sus valores mensuales (Tabla 69). El coeficiente de variación más alto fue constatado en diciembre, con $98,7 \%$ y el más bajo en mayo con $54,9 \%$. 


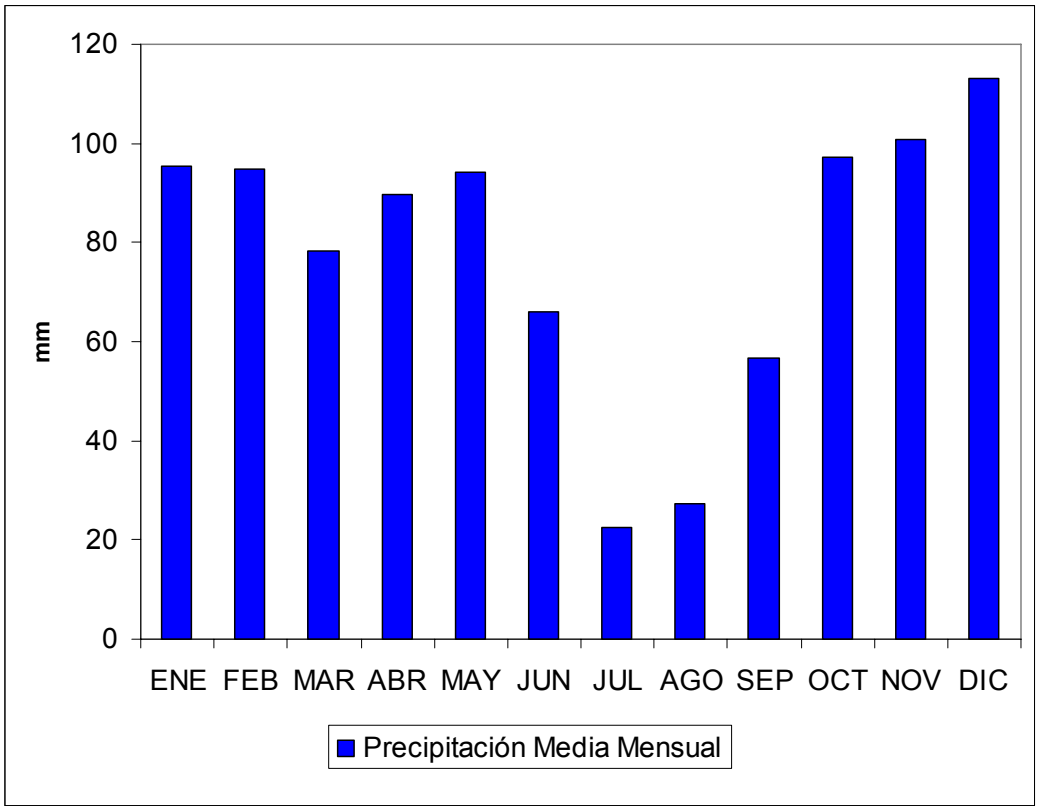

Figura 87 - Precipitación media mensual para el período estudiado - Estación Vega del Codorno, Cuenca alta del Tajo.

Tabla 69. Precipitación media mensual y coeficiente de variación de la estación Vega del Codorno - Cuenca alta del Tajo.

\begin{tabular}{|l|c|c|}
\hline \hline \multicolumn{1}{|c|}{ Mes } & Precipit. media (mm) & CV (\%) \\
\hline Enero & 95,4 & 88,5 \\
\hline Febrero & 94,9 & 90,3 \\
\hline Marzo & 78,2 & 78,3 \\
\hline Abril & 89,7 & 58,2 \\
\hline Mayo & 94,2 & 54,9 \\
\hline Junio & 66,1 & 67,3 \\
\hline Julio & 22,5 & 95,4 \\
\hline Agosto & 27,2 & 78,3 \\
\hline Septiembre & 56,7 & 73,4 \\
\hline Octubre & 97,2 & 84,8 \\
\hline Noviembre & 100,7 & 70,9 \\
\hline Diciembre & 113,1 & 98,7 \\
\hline
\end{tabular}




\subsection{Evolución de la Precipitación en la Cuenca Del Río Trabaque}

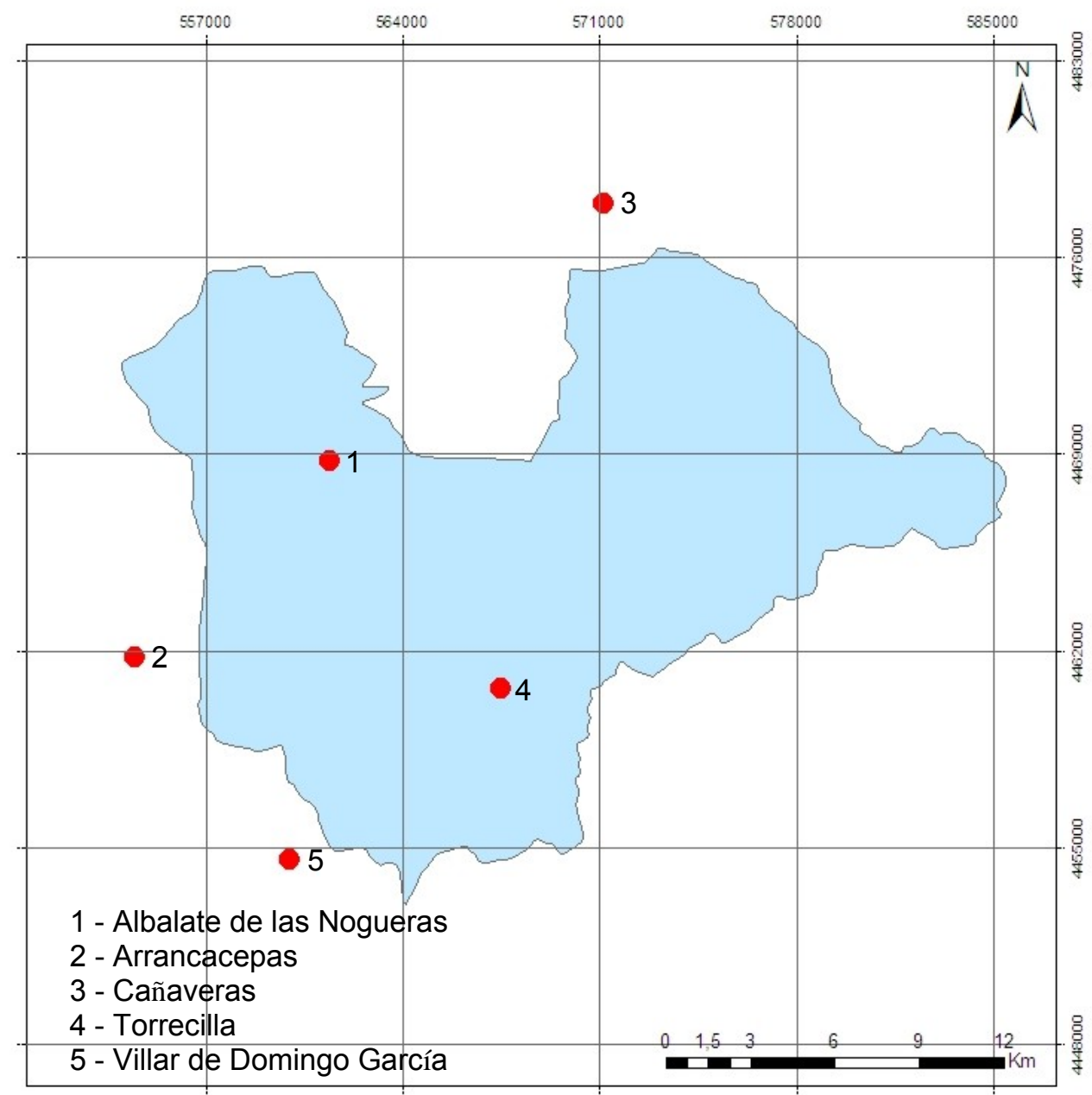

Figura 88 - Localización de las estaciones termométricas y pluviométricas (Cuenca del río Trabaque).

\subsubsection{Caracterización de la precipitación}

La precipitación media anual en la cuenca del río Trabaque (Fig. 88) en el período estudiado es de $558 \mathrm{~mm}$ con un coeficiente de variación del 21,4\%. El valor máximo de precipitación fue de $1306 \mathrm{~mm}$, un 134,1\% por encima de la media de la cuenca, en la estación de Torrecilla en 1960. En este año la estación Villar de Domingo García también presentó un valor bastante alto con $766 \mathrm{~mm}$, un $37,3 \%$ por encima de la media. La estación de Torrecilla registró también el segundo valor más alto que fue de 1125 mm en 1963 (101,6\% por encima de la media). En este año también fueron encontrados valores altos en las estaciones de Albalate de las Nogueras con $956 \mathrm{~mm}$ (71,3\% por encima de la media) y Villar de Domingo García con $698 \mathrm{~mm}$ (25,1\% por 
encima de la media). La precipitación mínima anual fue encontrada en la estación Cañaveras, en 1983, con solamente $241 \mathrm{~mm}$ (56,8\% por debajo de la media). También en 1983 fueron encontrados valores bajos en las estaciones de Cañaveras, también con $241 \mathrm{~mm}$, Villar de Domingo García con $301 \mathrm{~mm}$ (46,1\% por debajo de la media) y Arrancacepas con $357 \mathrm{~mm}$ (36,1\% por debajo de la media).

Los coeficientes de variación (Tabla 70) encontrados en todas las estaciones son considerados medios. El valor más alto fue registrado en la estación Torrecilla, con $30,3 \%$ y el más bajo en la estación Arrancacepas, con $23,7 \%$.

Tabla 70. Precipitación media, mínima, máxima, coeficientes de variación y altitud para todas las estaciones.

\begin{tabular}{|l|c|c|c|c|c|}
\hline \multicolumn{1}{|c|}{ Estación } & $\begin{array}{c}\text { Altitud } \\
\mathbf{( m )}\end{array}$ & $\begin{array}{c}\text { Media } \\
\mathbf{( m m )}\end{array}$ & $\begin{array}{c}\text { Mínima } \\
\mathbf{( m m )}\end{array}$ & $\begin{array}{c}\text { Máxima } \\
\mathbf{( m m )}\end{array}$ & $\mathbf{C V}(\mathbf{\%})$ \\
\hline Albalate de las Nogueras & 855 & 513 & 284 & 956 & 29,5 \\
\hline Arrancacepas & 937 & 523 & 336 & 797 & 23,7 \\
\hline Cañaveras & 819 & 429 & 241 & 727 & 26,3 \\
\hline Torrecilla & 969 & 645 & 321 & 1306 & 30,3 \\
\hline Villar de Domingo García & 942 & 520 & 244 & 834 & 25,5 \\
\hline \hline
\end{tabular}

La precipitación media mensual máxima se da en el mes de octubre con $64 \mathrm{~mm}$ y los menores valores se dan en agosto con $16,8 \mathrm{~mm}$ y julio con 14,6 mm (Tabla 71).

Tabla 71. Precipitación y evapotranspiración media mensual de la cuenca del río Trabaque.

\begin{tabular}{|l|c|c|}
\hline \hline \multicolumn{1}{|c|}{ Mes } & $\begin{array}{c}\text { Prec. Med. Menual } \\
(\mathbf{m m})\end{array}$ & $\begin{array}{c}\text { Evapotranspiración } \\
\text { Med. Mensual (mm) }\end{array}$ \\
\hline \hline Enero & 54,4 & 11,2 \\
\hline Febrero & 51,7 & 15,7 \\
\hline Marzo & 44,5 & 30,2 \\
\hline Abril & 57,7 & 44,3 \\
\hline Mayo & 60,5 & 74,9 \\
\hline Junio & 43,0 & 118,2 \\
\hline Julio & 14,6 & 151,9 \\
\hline Agosto & 16,8 & 141,9 \\
\hline Septiembre & 40,1 & 98,3 \\
\hline Octubre & 64,0 & 52,6 \\
\hline Noviembre & 60,7 & 21,5 \\
\hline Diciembre & 55,0 & 10,9 \\
\hline \hline
\end{tabular}


Se observa que entre las cuencas analizadas es esta donde están los menores valores de precipitación en general. Esta realidad está en contraste con los fuertes valores de ETP que causan grande déficit hídrico en la cuenca desde mayo hasta septiembre (Fig. 89). La ETP potencia anual registrada fue de $780,8 \mathrm{~mm}$, un valor extremadamente alto al comparar con los valores de precipitación.

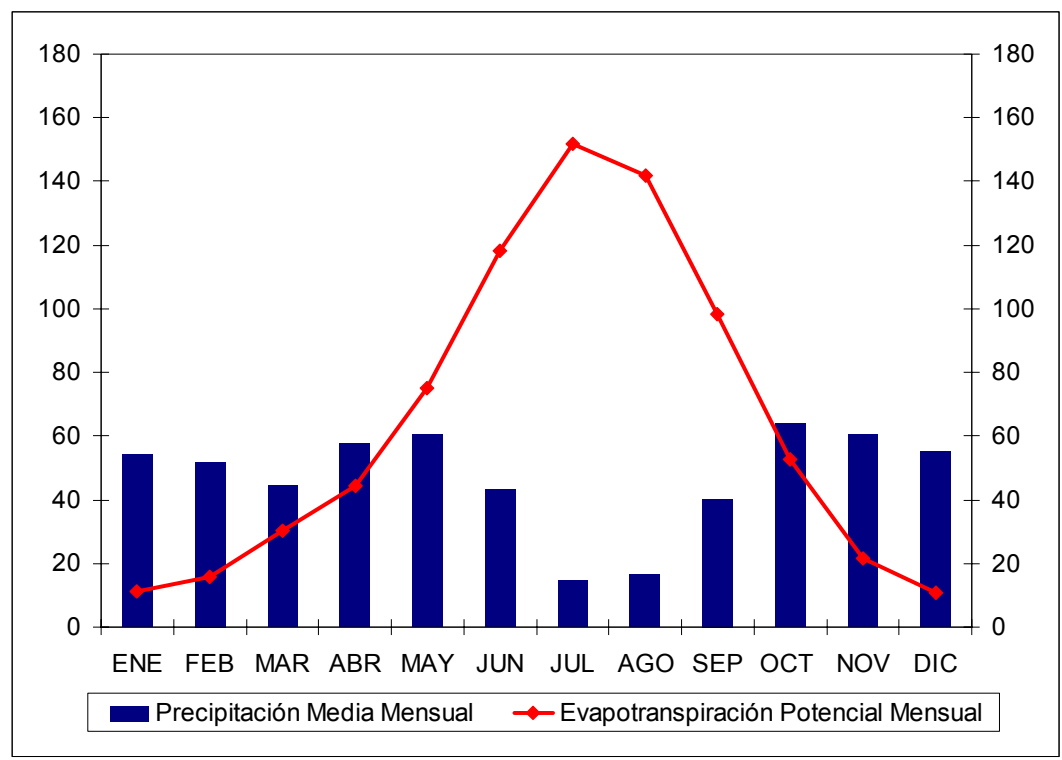

Figura 89 - Evapotranspiración potencial y precipitación mensual $(\mathrm{mm})$ de la cuenca del río Trabaque.

\subsubsection{Caracterización de cada estación}

\subsubsection{Estación Albalate de las Nogueras}

El estudio de la estación Albalate de las Nogueras fue realizado con un total de 44 años (Fig. 90) de datos, desde 1963 hasta 2006. La serie muestra una gran variabilidad interanual. El coeficiente de variación encontrado fue del 29,5\%.

La media de precipitación de la serie es de $513 \mathrm{~mm}$. El registro más bajo es del año de 2005, con tan sólo $284 \mathrm{~mm}$ y el más alto es de 1963, con $956 \mathrm{~mm}$, que es casi el doble de la media. En los años 1993, 1994 y 1995 hay un período bastante seco con un descenso acentuado en la precipitación, con una media de $311 \mathrm{~mm}$, que está un $39,4 \%$ por debajo de la media de la cuenca. 


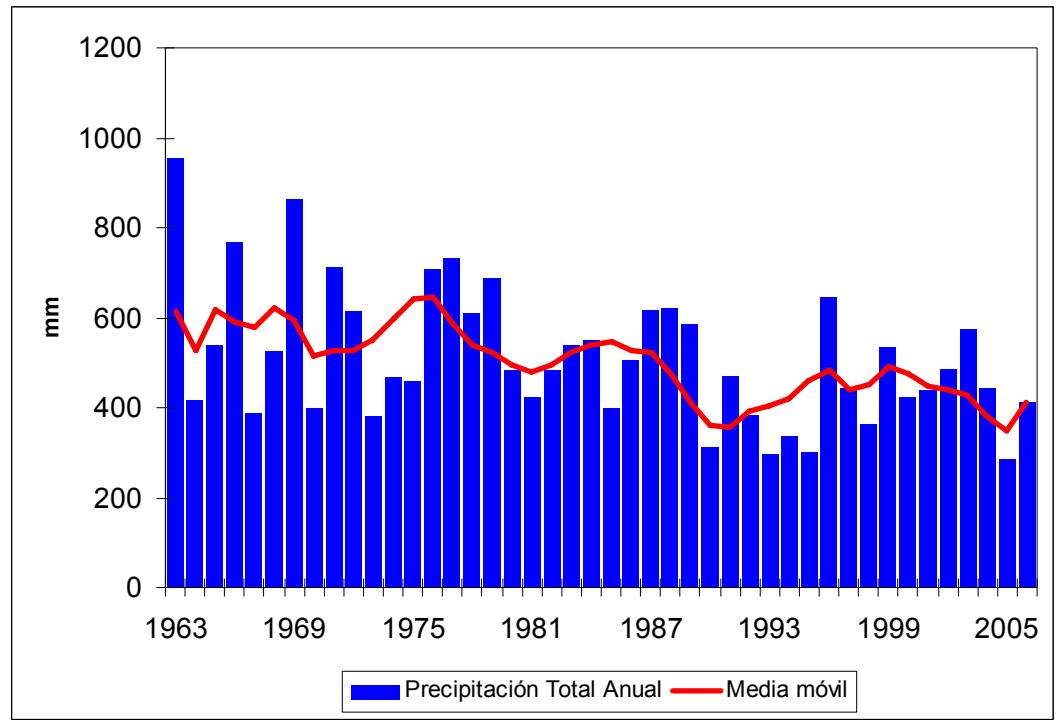

Figura 90 - Evolución de la precipitación total anual de la estación Albalate de las Nogueras con representación de la media móvil de 5 años - Cuenca del río Trabaque.

Los valores medios más altos se dan en los meses de octubre y abril (Fig. 91), con 60,5 y $59,1 \mathrm{~mm}$, respectivamente, mientras los meses con los valores más bajos son julio, con 11,5 mm y agosto con 12,0 mm. Los coeficientes de variación encontrados confirman una alta variabilidad en la precipitación mensual. El resultado más bajo se da en abril con $66,3 \%$, y los más altos son julio y agosto con $181,3 \%$ y $125,6 \%$, respectivamente (Tabla 72 ).

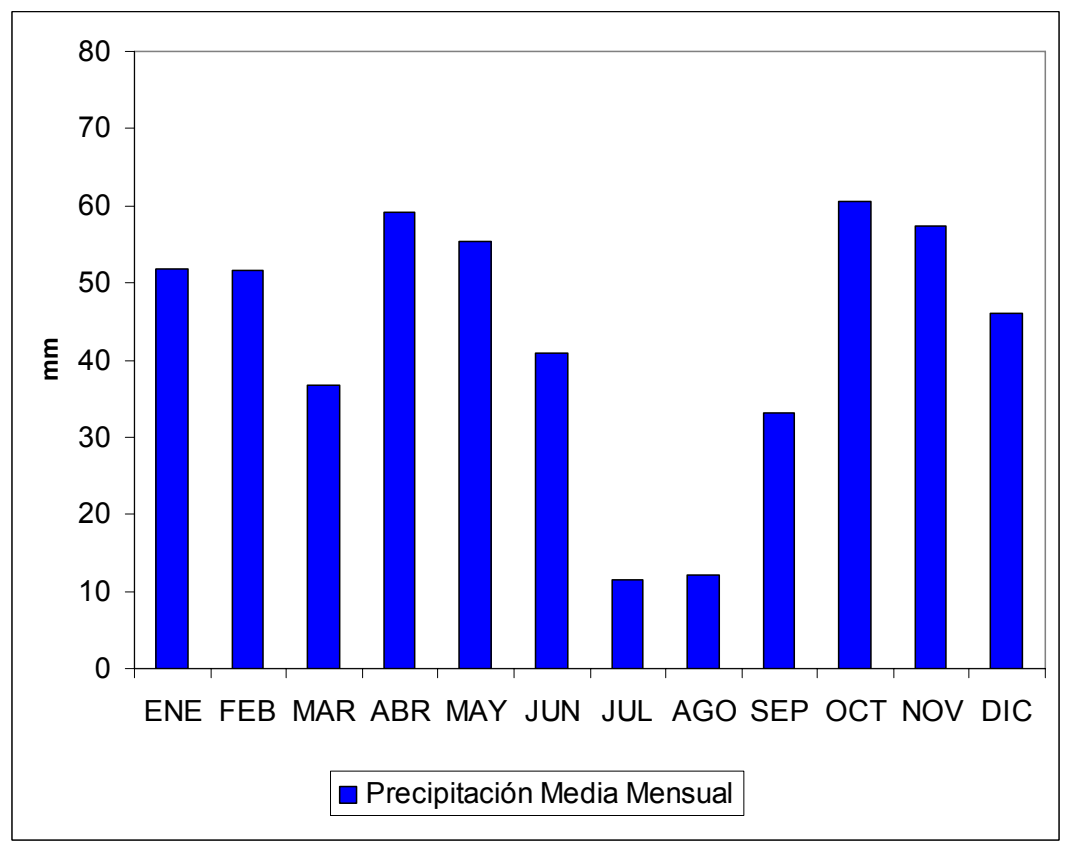

Figura 91 - Precipitación media mensual para el período estudiado - Estación Albalate de las Nogueras, Cuenca del río Trabaque. 
Tabla 72. Precipitación media mensual y coeficiente de variación de la estación Albalate de las Nogueras - Cuenca del río Trabaque.

\begin{tabular}{|l|c|c|}
\hline \hline \multicolumn{1}{|c|}{ Mes } & $\begin{array}{c}\text { Precipit. media } \\
\text { mensual (mm) }\end{array}$ & CV (\%) \\
\hline \hline Enero & 51,9 & 91,1 \\
\hline Febrero & 51,5 & 76,1 \\
\hline Marzo & 36,7 & 84,3 \\
\hline Abril & 59,1 & 66,3 \\
\hline Mayo & 55,4 & 74,1 \\
\hline Junio & 40,9 & 76,8 \\
\hline Julio & 11,5 & 181,3 \\
\hline Agosto & 12,0 & 125,6 \\
\hline Septiembre & 33,1 & 96,6 \\
\hline Octubre & 60,5 & 73,2 \\
\hline Noviembre & 57,4 & 70,2 \\
\hline Diciembre & 46,1 & 85,3 \\
\hline
\end{tabular}

\subsubsection{Estación Arrancacepas}

Para análisis de la estación Arrancacepas fueron utilizados 38 años (Fig. 92) de datos (1969-2006), habiendo sido detectada una regularidad media en el comportamiento de la precipitación con un coeficiente de variación de $23,7 \%$, el más bajo encontrado entre las estaciones estudiadas para análisis de la cuenca del río Trabaque.

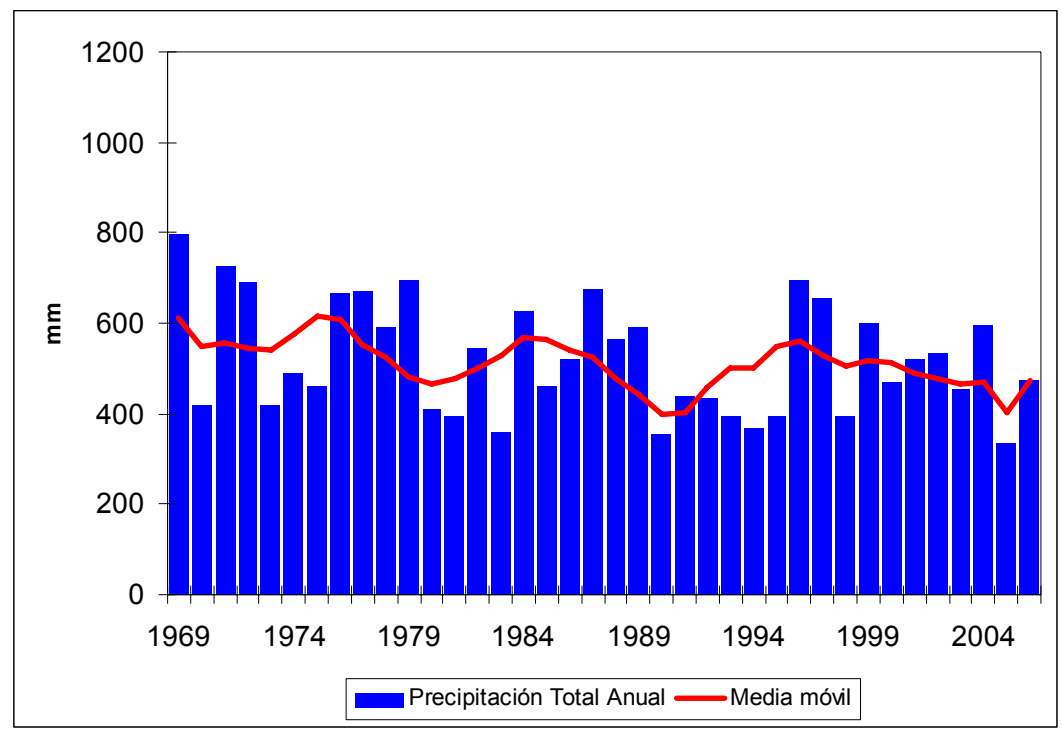

Figura 92 - Evolución de la precipitación total anual de la estación Arrancacepas con representación de la media móvil de 5 años - Cuenca del río Trabaque.

La media de todo el período analizado es de $523 \mathrm{~mm}$. Desde 1990 hasta 1995 hubo un período bastante seco con una media anual de tan sólo $396 \mathrm{~mm}$ (24,3\% por debajo de la media). El valor más bajo registrado para todo el período fue de $336 \mathrm{~mm}$ en 
2005, coincidiendo con los datos obtenidos para la estación Albalate de las Nogueras, anteriormente citada. El registro más alto fue en el año de 1969 con $797 \mathrm{~mm}$.

La media mensual (Fig. 93) más alta se da en mayo con $61,4 \mathrm{~mm}$, seguido de octubre y abril con 59,4 y $58,5 \mathrm{~mm}$, respectivamente, mientras los meses que presentan los valores más bajos son julio y agosto, ambos con 15,9 mm. En todos los meses los coeficientes de variación (Tabla 73) son altos y dejan clara la gran variabilidad de la precipitación en esta estación. El mes que presenta el valor más bajo es mayo con $57,2 \%$ y el más alto es julio con $123,2 \%$.

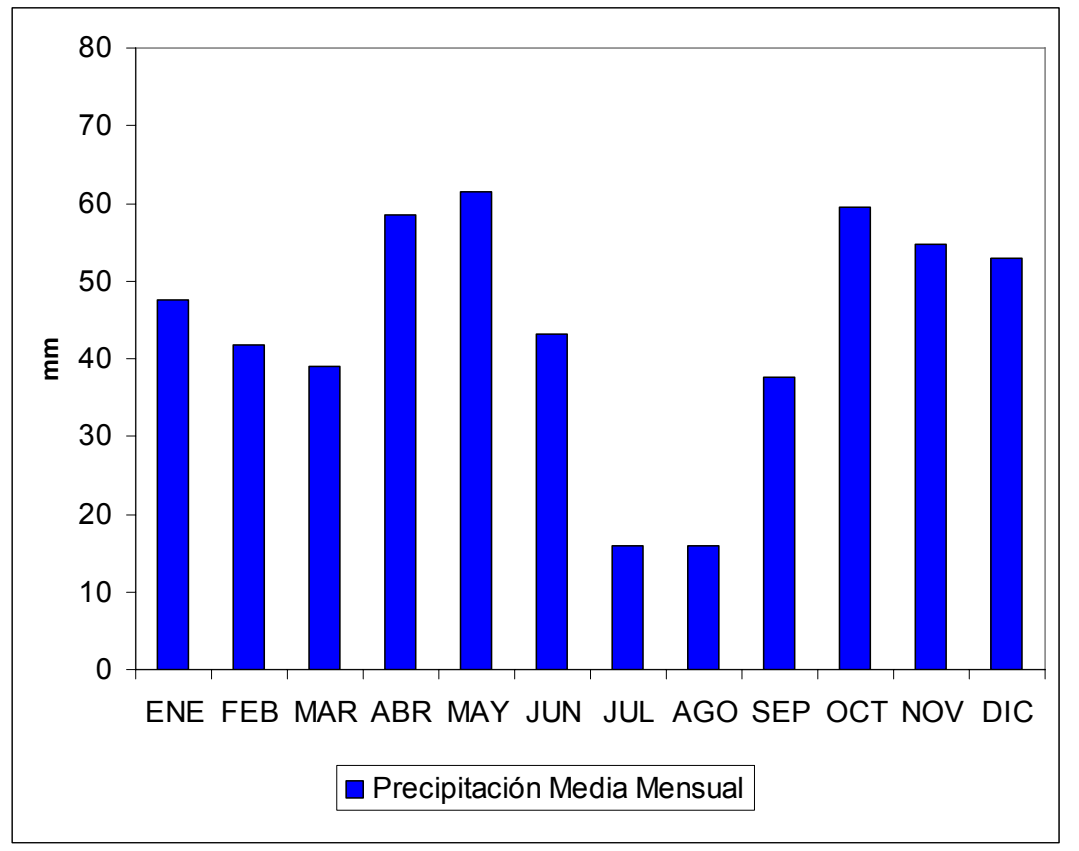

Figura 93 - Precipitación media mensual para el período estudiado - Estación Arrancacepas, Cuenca del río Trabaque.

Tabla 73. Precipitación media mensual y coeficiente de variación de la estación Arrancacepas - Cuenca del río Trabaque.

\begin{tabular}{|l|c|c|}
\hline \hline \multicolumn{1}{|c|}{ Mes } & Precipit. media (mm) & CV (\%) \\
\hline \hline Enero & 47,5 & 90,3 \\
\hline Febrero & 41,8 & 75,6 \\
\hline Marzo & 39,0 & 77,4 \\
\hline Abril & 58,5 & 61,9 \\
\hline Mayo & 61,4 & 57,2 \\
\hline Junio & 43,1 & 76,2 \\
\hline Julio & 15,9 & 123,2 \\
\hline Agosto & 15,9 & 89,4 \\
\hline Septiembre & 37,5 & 91,4 \\
\hline Octubre & 59,4 & 76,8 \\
\hline Noviembre & 54,7 & 70,5 \\
\hline Diciembre & 52,9 & 78,7 \\
\hline \hline
\end{tabular}




\subsubsection{Estación Cañaveras}

Para el análisis de los datos de la estación Cañaveras fueron utilizados 30 años, desde 1977 hasta 2006 (Fig. 94). En la serie se puede identificar un periodo seco que coincide con el mismo encontrado en la estación Arrancacepas. Este período se extiende desde 1990 hasta 1995 y la media de precipitación es de $341 \mathrm{~mm}$, un 20,51\% por debajo de la media anual de todo el período estudiado que es de $429 \mathrm{~mm}$.

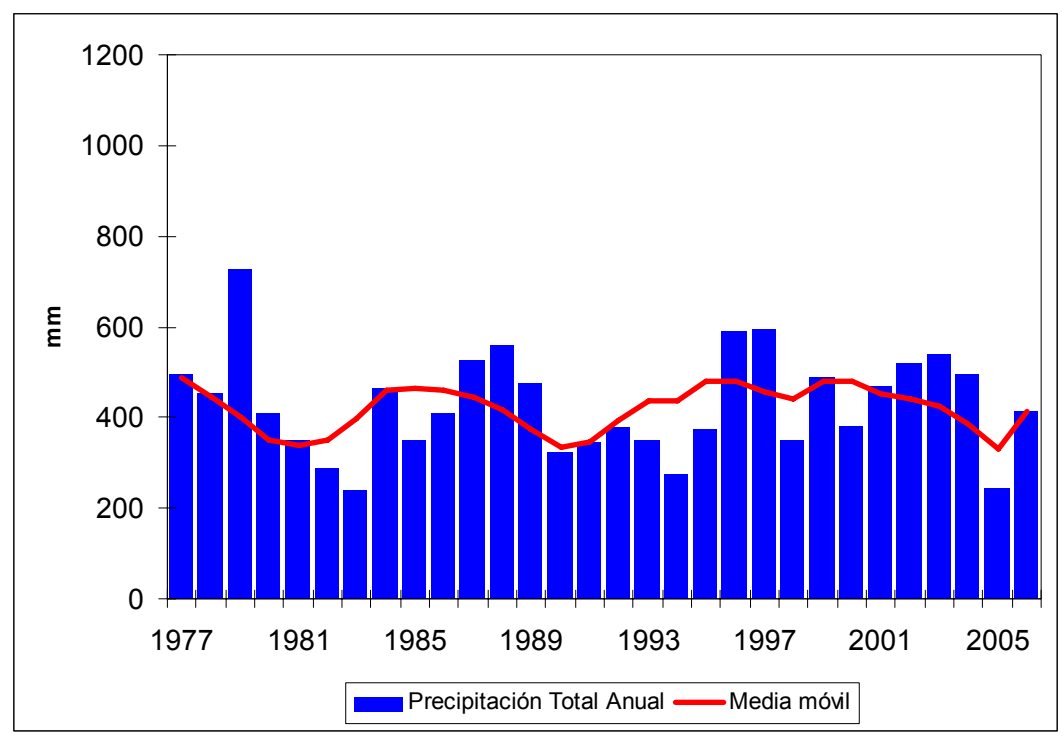

Figura 94 - Evolución de la precipitación total anual de la estación Cañaveras con representación de la media móvil de 5 años - Cuenca del río Trabaque.

Se puede destacar que entre las estaciones elegidas para análisis de la cuenca del río Trabaque, la estación Cañaveras es la que tiene el valor medio más bajo. Hay una variabilidad interanual considerable, con un coeficiente de variación de $26,3 \%$. El registro más alto es de 1979, con una precipitación total de $727 \mathrm{~mm}$ y los más bajos son de los años de 1983 con tan sólo $241 \mathrm{~mm}$ y de 2005 con $246 \mathrm{~mm}$. El valor registrado para el año de 2005 está en consonancia con los datos obtenidos en las estaciones Albalate de las Nogueras y Arrancacepas que registran el valor más bajo también en este año.

Mayo es el mes con el valor medio más alto con $58,5 \mathrm{~mm}$, seguido de octubre, con $54,4 \mathrm{~mm}$ (Fig. 95). Por otro lado, los meses en que se dan los valores más bajos son julio $(11,8 \mathrm{~mm})$ y agosto $(13,3 \mathrm{~mm})$. Los coeficientes de variación (Tabla 74$)$ presentan valores bastante altos, sobre todo en los meses de junio, julio y agosto, con 109\%, 
$147,1 \%$ y $130,4 \%$ respectivamente, confirmando una gran variabilidad en la precipitación mensual en esta estación. El valor más bajo de coeficiente de variación fue obtenido en abril con un 58,5\%.

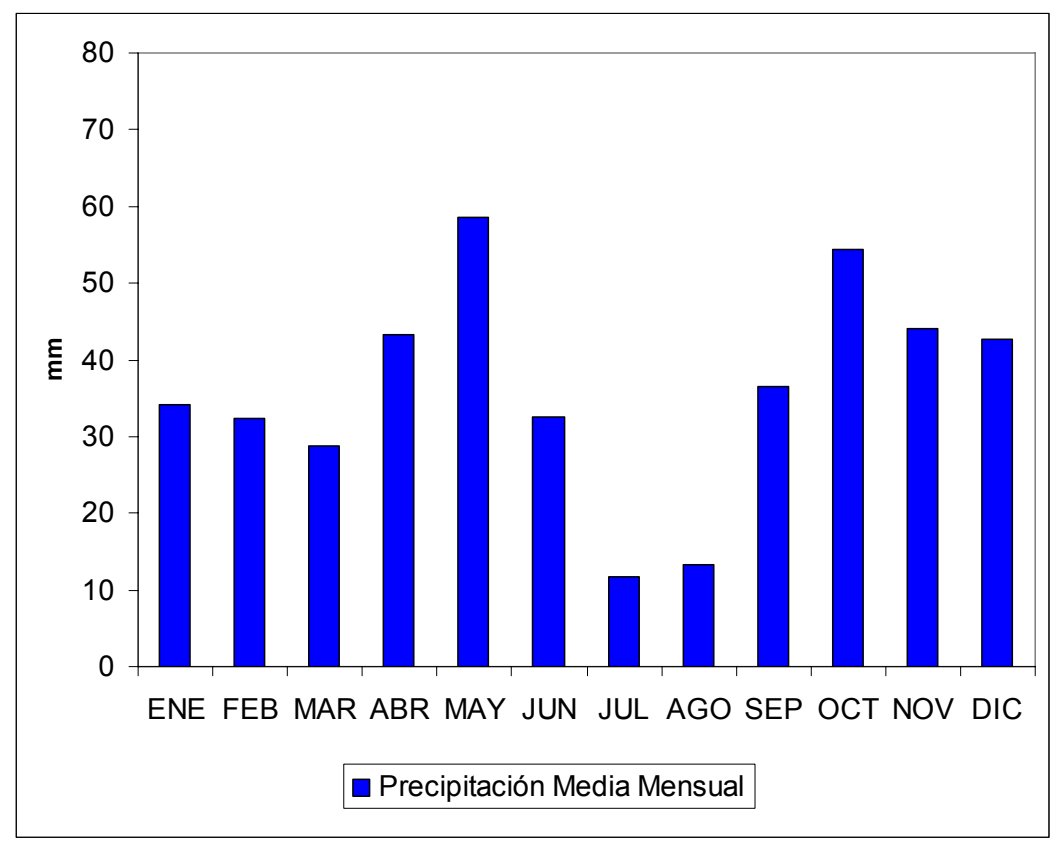

Figura 95 - Precipitación media mensual para el período estudiado - Estación Cañaveras, Cuenca del río Trabaque.

Tabla 74. Precipitación media mensual y coeficiente de variación de la estación Cañaveras - Cuenca del río Trabaque.

\begin{tabular}{|l|c|c|}
\hline \hline \multicolumn{1}{|c|}{ Mes } & Precipit. media (mm) & CV (\%) \\
\hline Enero & 34,2 & 99,3 \\
\hline Febrero & 32,4 & 72,5 \\
\hline Marzo & 28,9 & 74,0 \\
\hline Abril & 43,2 & 58,5 \\
\hline Mayo & 58,5 & 63,7 \\
\hline Junio & 32,6 & 109,0 \\
\hline Julio & 11,8 & 147,1 \\
\hline Agosto & 13,3 & 130,4 \\
\hline Septiembre & 36,6 & 77,3 \\
\hline Octubre & 54,4 & 73,5 \\
\hline Noviembre & 44,2 & 74,5 \\
\hline Diciembre & 42,6 & 89,2 \\
\hline \hline
\end{tabular}




\subsubsection{Estación Torrecilla}

En la figura 96 aparecen los datos de la estación Torrecilla (51 años, de 1956 hasta 2006). El análisis de la figura muestra claramente una gran variabilidad interanual. El coeficiente de variación encontrado fue del $30,3 \%$, el más alto entre todas las estaciones elegidas para el estudio de la cuenca del río Trabaque.

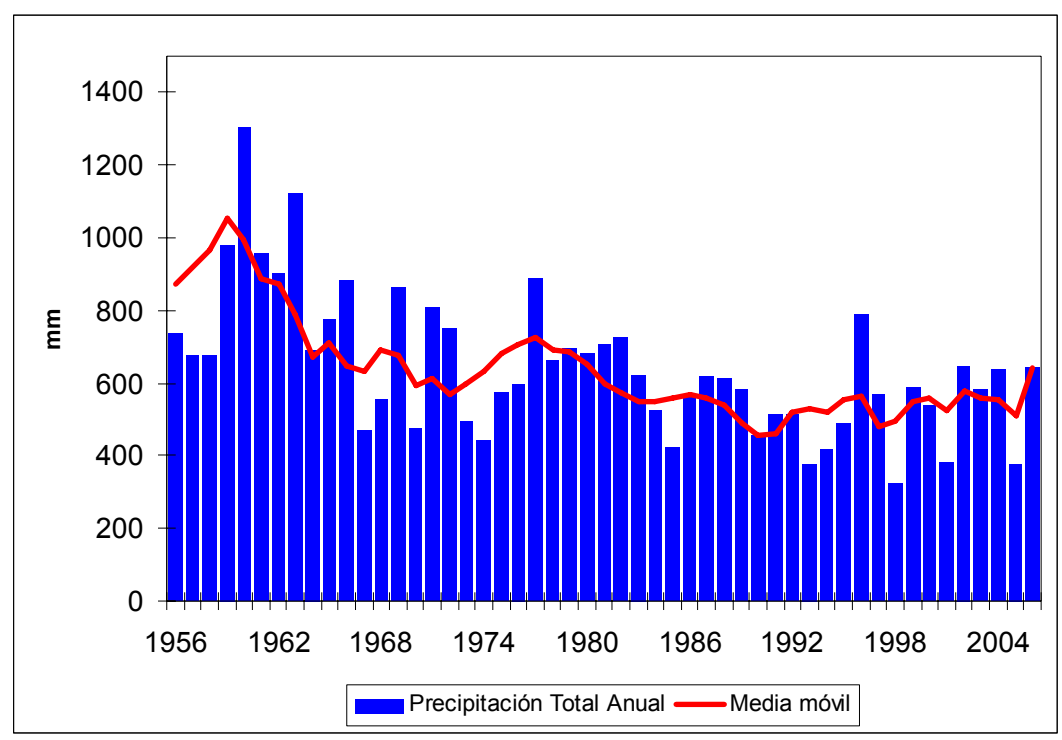

Figura 96 - Evolución de la precipitación total anual de la estación Torrecilla con representación de la media móvil de 5 años - Cuenca del río Trabaque.

La media de todo el período fue $645 \mathrm{~mm}$, siendo la estación de Torrecilla la que tiene los registros más altos de precipitación entre las estaciones analizadas en esta cuenca. El máximo registrado fue 1306 mm en 1960, seguido de 1125 mm en 1963. Por otro lado, el mínimo fue $321 \mathrm{~mm}$ en 1998. Se observa un claro descenso en la precipitación a partir de 1964 . Hasta 1963 la media de precipitación es de 919 mm, lo que está un 42,5\% por encima de la media. A partir de 1964 la media cae para 593 $\mathrm{mm}$, que es un valor muy similar a la media.

La media mensual más alta se da en octubre con $70,7 \mathrm{~mm}$ y noviembre con $69,9 \mathrm{~mm}$ y la más baja en julio, con 17,6 mm (Fig. 97). Los coeficientes de variación mensual (Tabla 75) muestran una gran variabilidad en los valores mensuales en el periodo estudiado. El mes que presenta el valor más bajo es abril, con $53,7 \%$ y el más alto se detectó en julio con 100,9\%. 


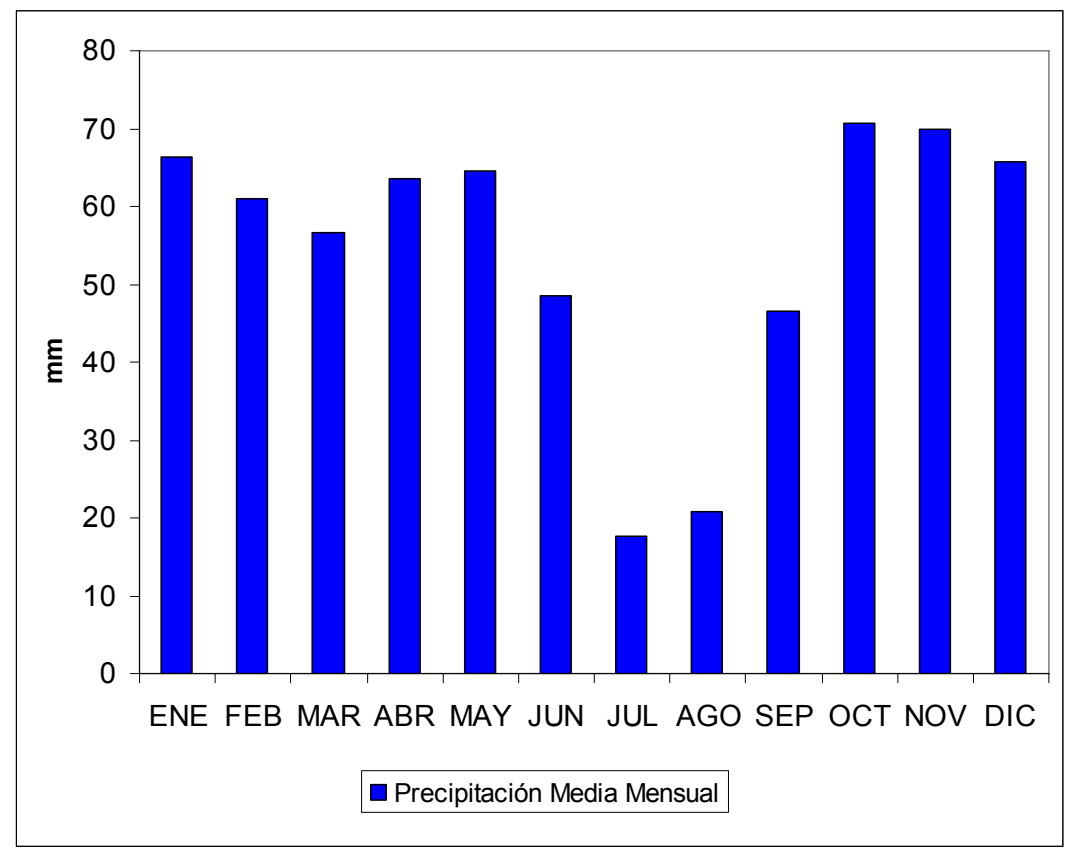

Figura 97 - Precipitación media mensual para el período estudiado - Estación Torrecilla, Cuenca del río Trabaque.

Tabla 75. Precipitación media mensual y coeficiente de variación de la estación Torrecilla - Cuenca del río Trabaque.

\begin{tabular}{|l|c|c|}
\hline \multicolumn{1}{|c|}{ Mes } & Precipit. media (mm) & CV (\%) \\
\hline \hline Enero & 66,3 & 78,5 \\
\hline Febrero & 61,1 & 75,0 \\
\hline Marzo & 56,7 & 76,3 \\
\hline Abril & 63,5 & 53,7 \\
\hline Mayo & 64,5 & 64,3 \\
\hline Junio & 48,6 & 74,0 \\
\hline Julio & 17,6 & 100,9 \\
\hline Agosto & 20,8 & 98,6 \\
\hline Septiembre & 46,6 & 91,3 \\
\hline Octubre & 70,7 & 86,8 \\
\hline Noviembre & 69,9 & 82,0 \\
\hline Diciembre & 65,8 & 78,4 \\
\hline \hline
\end{tabular}

\subsubsection{Estación Villar de Domingo García}

Para el análisis de los datos de la estación Villar de Domingo García fueron utilizados 51 años, desde el año de 1956 hasta 2006, coincidiendo con el período utilizado para análisis de la estación Torrecilla (Fig. 98). Se puede apreciar una cierta variabilidad en los valores registrados, con un coeficiente de variación de $25,5 \%$. El valor mínimo registrado fue $244 \mathrm{~mm}$ en 1973 seguido de $246 \mathrm{~mm}$ en 2005, lo que está de acuerdo con lo encontrado también para las estaciones Albalate de las Nogueras, 
Arrancacepas y Cañaveras, y el máximo fue $834 \mathrm{~mm}$ en 1996. La media de los registros en la estación para todo el período fue de $520 \mathrm{~mm}$.

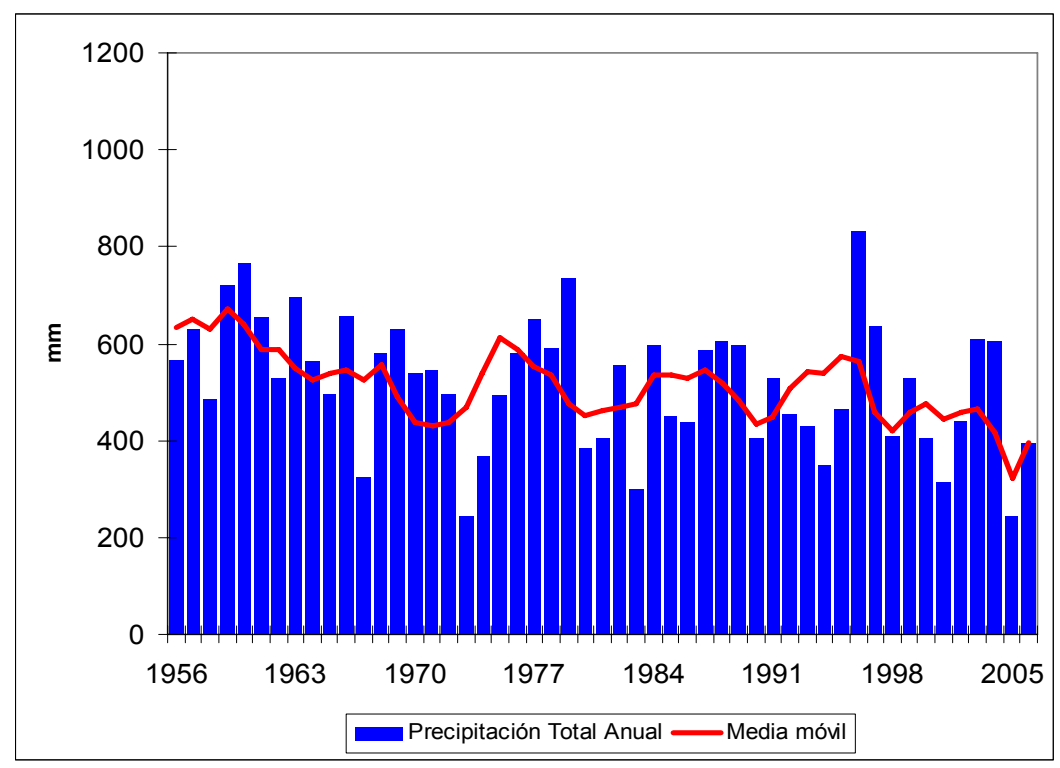

Figura 98 - Evolución de la precipitación total anual de la estación Villar de Domingo García con representación de la media móvil de 5 años - Cuenca del río Trabaque.

Los valores medios más altos se observan en los meses de octubre con 61,5 mm y noviembre con $60,6 \mathrm{~mm}$ (Fig. 99), mientras el mes con el valor más bajo es julio con tan sólo $13,7 \mathrm{~mm}$.

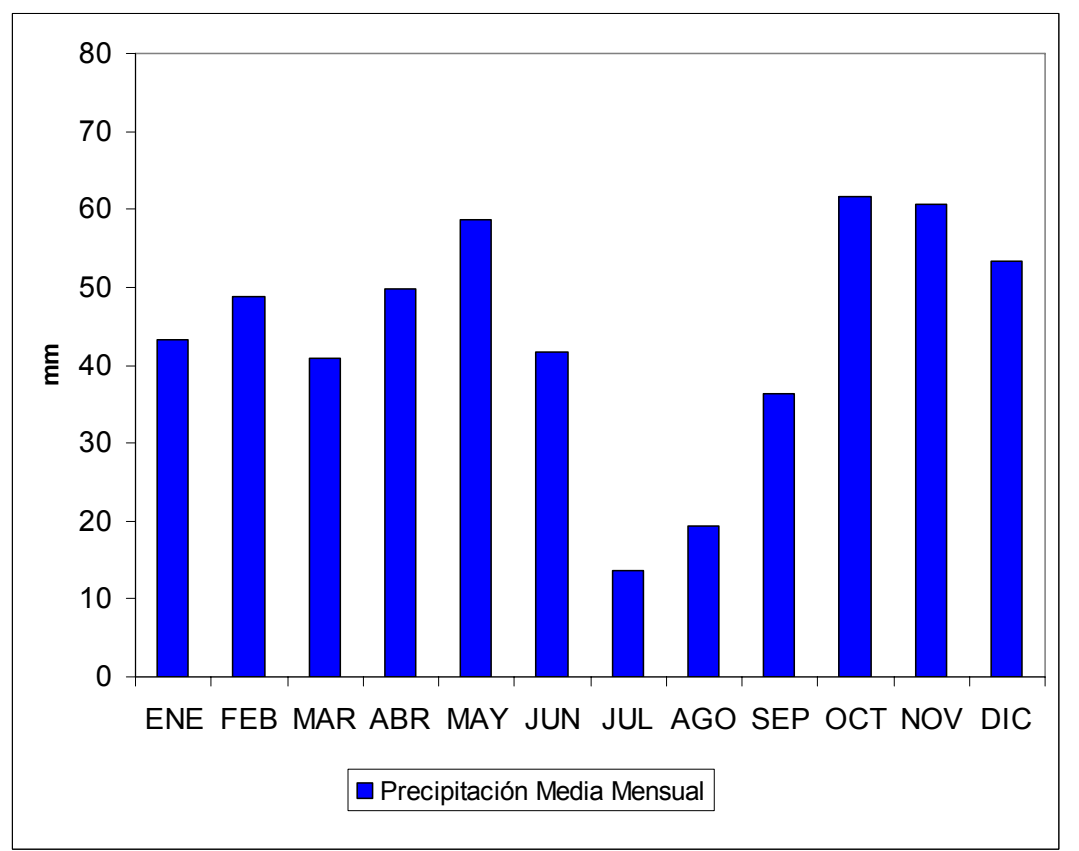

Figura 99 - Precipitación media mensual para el período estudiado - Estación Villar de Domingo García, Cuenca del río Trabaque. 
Los coeficientes de variación mensual (Tabla 76) son todos altos (> 50\%). El resultado más bajo se da en abril con un $56,1 \%$ y lo más alto en julio con un $130,4 \%$. Estos valores muestran la gran variabilidad en los valores mensuales de la precipitación en la estación Villar de Domingo García.

Tabla 76. Precipitación media mensual y coeficiente de variación de la estación Villar de Domingo García - Cuenca del río Trabaque.

\begin{tabular}{|l|c|c|}
\hline \multicolumn{1}{|c|}{ Mes } & Precipit. media (mm) & CV (\%) \\
\hline \hline Enero & 43,3 & 90,9 \\
\hline Febrero & 48,9 & 79,3 \\
\hline Marzo & 40,9 & 77,4 \\
\hline Abril & 49,9 & 56,5 \\
\hline Mayo & 58,6 & 66,8 \\
\hline Junio & 41,6 & 82,4 \\
\hline Julio & 13,7 & 130,4 \\
\hline Agosto & 19,5 & 93,1 \\
\hline Septiembre & 36,4 & 82,7 \\
\hline Octubre & 61,5 & 80,8 \\
\hline Noviembre & 60,6 & 72,3 \\
\hline Diciembre & 53,4 & 75,8 \\
\hline \hline
\end{tabular}

\subsection{Análisis de tendencias de las precipitaciones}

Para hacer el estudio de la evolución de la precipitación en las cuencas de los ríos Cega, Porma, Tajo y Trabaque, se realizó un análisis estadístico exhaustivo de cada una de las estaciones elegidas con el objetivo de verificar se hay algún tipo de tendencia. Para análisis de tendencias en las series históricas de precipitación se aplicaron los test estadísticos Rho de Spearman (R), Mann-Kendall (M-K) y MannKendall en su versión secuencial (M-Ks).

\subsubsection{Cuenca del río Cega}

Los coeficientes de correlación (Tabla 77) entre la precipitación y el tiempo en las diferentes estaciones pluviométricas utilizadas para análisis de la cuenca del río Cega son todos negativos. Este resultado sugiere un ligero descenso en la precipitación en todas las estaciones. No obstante, solamente la estación Matabuena presenta valores que pueden ser considerados estadísticamente significativos al nivel de $0,05(-0,307)$.

El R más próximo a cero fue encontrado en la estación Turégano con tan sólo -0,030. 
En este caso, con un valor tan próximo a cero, no puede se considerar ningún tipo de tendencia.

Tabla 77. Coeficientes de correlación (Rho de Spearman) entre la precipitación anual y el tiempo en las estaciones de la cuenca del río Cega.

\begin{tabular}{|l|c|c|c|}
\hline \hline \multicolumn{1}{|c|}{ Estación } & n & $\begin{array}{c}\text { Signif. } \\
\text { Estad. }\end{array}$ & $\begin{array}{c}\text { R } \\
\text { (Precipitación) }\end{array}$ \\
\hline \hline La Granja de San Ildefonso & 47 & NS & $-0,083$ \\
\hline Matabuena & 69 & $*$ & $-0,307$ \\
\hline Rascafria & 47 & NS & $-0,096$ \\
\hline Torreiglesias & 38 & NS & $-0,132$ \\
\hline Turégano & 60 & NS & $-0,030$ \\
\hline \hline
\end{tabular}

NS = Valores no significativos estadísticamente

* $=$ Correlación significativa al nivel de 0,05

Como en el caso de $\mathrm{R}$, todos los valores de $\mathrm{S}$ de $\mathrm{M}-\mathrm{K}$ y $\mathrm{Z}$ (Tabla 78) presentan valores negativos, lo que representa una disminución en la precipitación en todas las estaciones analizadas. Sin embargo, en este caso, solamente en la estación de Turégano $(S=-16$ y $Z=-0,72)$, no se puede rechazar la hipótesis nula de no tendencia, o sea, en todas las otras estaciones (La Granja de San Ildefonso, Matabuena, Rascafria y Torreiglesias) se acepta la existencia de una tendencia significativa $\left(Z_{s}>-1,96\right)$.

Tabla 78. Test estadístico Mann-Kendall para la precipitación total anual en las estaciones utilizadas para análisis de la cuenca del río Cega.

\begin{tabular}{|l|c|c|c|c|}
\hline \hline \multicolumn{1}{|c|}{ Estación } & $\begin{array}{c}\text { S de } \\
\text { Kendall }\end{array}$ & $\mathbf{Z}_{\mathbf{s}}$ & $\begin{array}{c}\text { Rechazo de hipótesis } \\
\text { nula para } \mathbf{p}<\mathbf{0 , 0 5}\end{array}$ & Valor $\boldsymbol{p}$ \\
\hline \hline La Granja de San Ildefonso & -52 & $-2,87$ & $\mathrm{Si}$ & 0,0041 \\
\hline Matabuena & -485 & $-22,94$ & $\mathrm{Si}$ & 0,0001 \\
\hline Rascafria & -57 & $-3,19$ & $\mathrm{Si}$ & 0,0014 \\
\hline Torreiglesias & -67 & $-4,49$ & $\mathrm{Si}$ & 0,0001 \\
\hline Turégano & -16 & $-0,72$ & $\mathrm{No}$ & 0,4715 \\
\hline
\end{tabular}

Zs $>(+/-) 1,96$ se rechaza la hipótesis nula de no tendencia Valor $p<0,05$ se rechaza la hipótesis nula de no tendencia

Corroborando también lo encontrado con $\mathrm{R}$, la estación que presenta la tendencia negativa más clara es Matabuena ( $S=-485$ y un $Z=-22,94)$. Un valor de $Z$ tan alto $\left(Z_{s}\right.$ $>-1,96)$ indica claramente una tendencia negativa en el tiempo. Las estaciones La Granja, Rascafria y Torreiglesias también presentan valores de $Z$ que nos permiten 
rechazar la hipótesis nula de no tendencia. Aunque estos valores no sean tan altos como los encontrados para la estación Matabuena, nos indican que hay una tendencia regresiva en los valores de precipitación en todas estas estaciones, incluso con valores de $\mathrm{S}$ y $\mathrm{Z}$ muy parecidos entre si (Tabla 78).

Para analizar el momento de cambio de tendencia en las series se calculó el estadístico no paramétrico test de Mann-Kendall en su versión secuencial (M-Ks). Este test es considerado una herramienta eficiente para localizar el año inicial de una tendencia (Back, 2001; Groppo et al. 2001; Piccinini Silveira et al. 2006; Ezber et al. 2007). En este estudio sólo han sido analizados aquellos casos en los que el cambio de tendencia se ha podido detectar claramente y además presentaba significación estadística. Las estaciones en las que eso no se ha podido detectar no se han analizado, a pesar de que M-K evidenciara la existencia de una clara tendencia.

En la gráfica de los resultados encontrados para la estación Matabuena (Fig. 100) se puede ver claramente que el año de 1943 es donde empieza la tendencia regresiva en la precipitación. Sin embargo, se observa que a pesar de que el cruce de curvas de 1943 es el indicador de la presencia de un cambio de tendencia sostenido en el tiempo, hasta 1967 las estadísticas $u(t)$ y $u^{*}(t)$ no se separan definitivamente, y hasta 1986 no se alcanza la significación estadística. Las líneas horizontales representan los valores críticos $( \pm 1,96)$ correspondiendo al nivel de significación de $95 \%$.

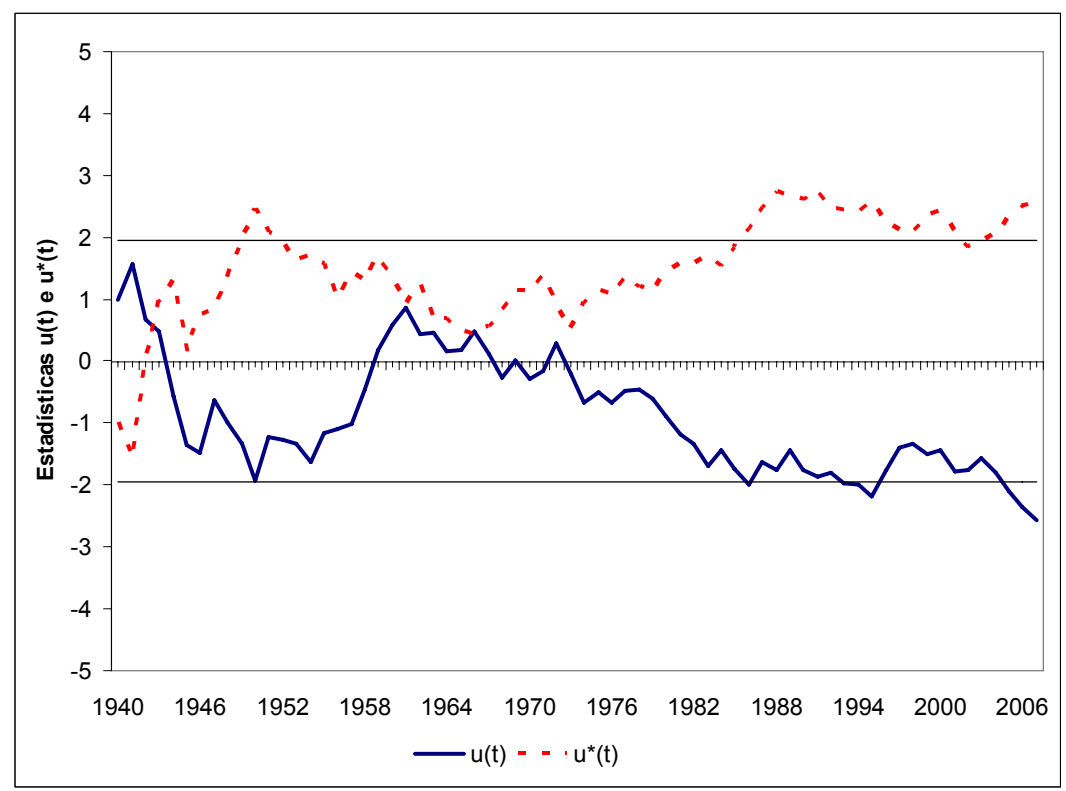

Figura 100 - Test Mann-Kendall secuencial para la precipitación total anual - Estación Matabuena, Cuenca del río Cega. 
Debido a los valores claros de tendencia encontrados en la estación Matabuena se ha hecho un estudio mensual (Tabla 79) para evaluar los meses en que esto se presenta con mayor intensidad.

Tabla 79. Test estadísticos Rho de Spearman y Mann-Kendall para la precipitación mensual de la Estación Matabuena - Cuenca del río Cega.

\begin{tabular}{|l|c|c|c|c|c|}
\hline \multicolumn{1}{|c|}{ Mes } & Rho & $\begin{array}{c}\text { S de } \\
\text { Kendall }\end{array}$ & $\mathbf{Z}_{\mathbf{s}}$ & $\begin{array}{c}\text { Rechazo de hipótesis } \\
\text { nula para } \mathbf{p}<\mathbf{0 , 0 5}\end{array}$ & Valor $\boldsymbol{p}$ \\
\hline Enero & $-0,167$ & -277 & $-12,12$ & $\mathrm{Si}$ & 0,0001 \\
\hline Febrero & $-0,026$ & -28 & $-1,18$ & $\mathrm{No}$ & 0,2380 \\
\hline Marzo & $-0,326\left(^{* *}\right)$ & -518 & $-22,08$ & $\mathrm{Si}$ & 0,0001 \\
\hline Abril & $-0,126$ & -198 & $-8,42$ & $\mathrm{Si}$ & 0,0001 \\
\hline Mayo & $-0,012$ & -53 & $-2,11$ & $\mathrm{Si}$ & 0,0349 \\
\hline Junio & $-0,279\left(^{*}\right)$ & -432 & $-20,26$ & $\mathrm{Si}$ & 0,0001 \\
\hline Julio & $-0,067$ & -72 & $-2,85$ & $\mathrm{Si}$ & 0,0044 \\
\hline Agosto & $-0,078$ & -121 & $-6,25$ & $\mathrm{Si}$ & 0,0001 \\
\hline Septiembre & $-0,251\left(^{*}\right)$ & -394 & $-14,86$ & $\mathrm{Si}$ & 0,0001 \\
\hline Octubre & 0,189 & 281 & 13,75 & $\mathrm{Si}$ & 0,0001 \\
\hline Noviembre & $-0,005$ & -30 & $-1,26$ & $\mathrm{No}$ & 0,2077 \\
\hline Diciembre & $-0,010$ & 1 & 0,05 & $\mathrm{No}$ & 0,9601 \\
\hline \hline
\end{tabular}

Zs $>(+/-) 1,96$ se rechaza la hipótesis nula de no tendencia Valor $p<0,05$ se rechaza la hipótesis nula de no tendencia

* = Correlación significativa al nivel de 0,05

** $=$ Correlación significativa al nivel de 0,01

Tanto los valores del $\mathrm{R}$ cuanto los de $\mathrm{M}-\mathrm{K}$ confirman que los meses en que hay una tendencia negativa bastante significativa son marzo, junio y septiembre. El mes de enero también presenta una fuerte tendencia regresiva aunque en el caso de $R$ no se puede considerar significativo. A su vez, octubre presenta fuerte tendencia positiva, aunque en el caso de $\mathrm{R}$, tampoco puede ser considerado significativo. Los valores encontrados con ambos test para los meses de febrero, noviembre y diciembre son despreciables y en estos casos no se puede considerar ningún tipo de tendencia. En los demás meses (abril, mayo, julio y agosto) se aprecia una ligera tendencia negativa en el tiempo.

Los análisis de regresión realizados permitieron determinar que la pérdida de precipitación en la estación Matabuena fue de aproximadamente 2,1 $\mathrm{mm}$ al año, lo que en todo el período equivale a $143,5 \mathrm{~mm}$. 


\subsubsection{Cuenca del río Porma}

En la cuenca del río Porma el coeficiente de correlación (Tabla 80) entre la precipitación y el tiempo no refleja para la estación Pantano del Porma ninguna tendencia clara $(0,082)$. Por otro lado, el valor de $\mathrm{R}$ de las estaciones Acebedo, Crémenes, Maraña y Puebla de Lillo muestra valores con tendencia negativa, sin embargo sólo la estación Maraña presenta valores significativos al nivel de 0,05 ($0,270)$.

Tabla 80. Coeficientes de correlación (Rho de Spearman) entre la precipitación anual y el tiempo de las estaciones de la cuenca del río Porma.

\begin{tabular}{|l|c|c|c|}
\hline \hline \multicolumn{1}{|c|}{ Estación } & $\mathbf{n}$ & $\begin{array}{c}\text { Signif. } \\
\text { Estad. }\end{array}$ & $\begin{array}{c}\text { R } \\
\text { (Precipitación) }\end{array}$ \\
\hline \hline Acebedo & 36 & NS & $-0,269$ \\
\hline Crémenes & 40 & NS & $-0,293$ \\
\hline Maraña & 74 & $\star$ & $-0,270$ \\
\hline Pantano del Porma & 44 & NS & 0,082 \\
\hline Puebla de Lillo & 73 & NS & $-0,106$ \\
\hline \hline
\end{tabular}

NS = Valores no significativos estadísticamente

* $=$ Correlación significativa al nivel de 0,05

Los resultados encontrados con M-K (Tabla 81) confirman todas las tendencias detectadas con $\mathrm{R}$.

Tabla 81. Test estadístico Mann-Kendall para la precipitación total anual en las estaciones utilizadas para análisis de la cuenca del río Porma.

\begin{tabular}{|l|c|c|c|c|}
\hline \multicolumn{1}{|c|}{ Estación } & $\begin{array}{c}\mathbf{S} \text { de } \\
\text { Kendall }\end{array}$ & $\mathbf{Z}_{\mathbf{s}}$ & $\begin{array}{c}\text { Rechazo de hipótesis } \\
\text { nula para } \mathbf{p}<\mathbf{0 , 0 5}\end{array}$ & Valor $\boldsymbol{p}$ \\
\hline Acebedo & -114 & $-10,76$ & $\mathrm{Si}$ & 0,0001 \\
\hline Crémenes & -156 & $-12,30$ & $\mathrm{Si}$ & 0,0001 \\
\hline Maraña & -467 & $-18,36$ & $\mathrm{Si}$ & 0,0001 \\
\hline Pantano del Porma & 76 & 4,43 & $\mathrm{Si}$ & 0,0001 \\
\hline Puebla de Lillo & -212 & $-7,89$ & $\mathrm{Si}$ & 0,0001 \\
\hline
\end{tabular}

Zs $>(+/-) 1,96$ se rechaza la hipótesis nula de no tendencia Valor $p<0,05$ se rechaza la hipótesis nula de no tendencia

La estación Pantano del Porma es la única en que se detecta una tendencia positiva y se puede rechazar la hipótesis nula de no tendencia $(S=76$ y $Z=4,43)$. A su vez, las estaciones Acebedo, Crémenes, Maraña y Puebla de Lillo presentan valores de $S$ y $Z$ negativos, lo que representa una disminución en la precipitación en todas ellas. Además en todas estas estaciones se rechaza la hipótesis nula de no tendencia $\left(Z_{s}>\right.$ - 
1,96). Los valores encontrados para $Z$ indican claramente una tendencia negativa en el tiempo en todas las estaciones analizadas.

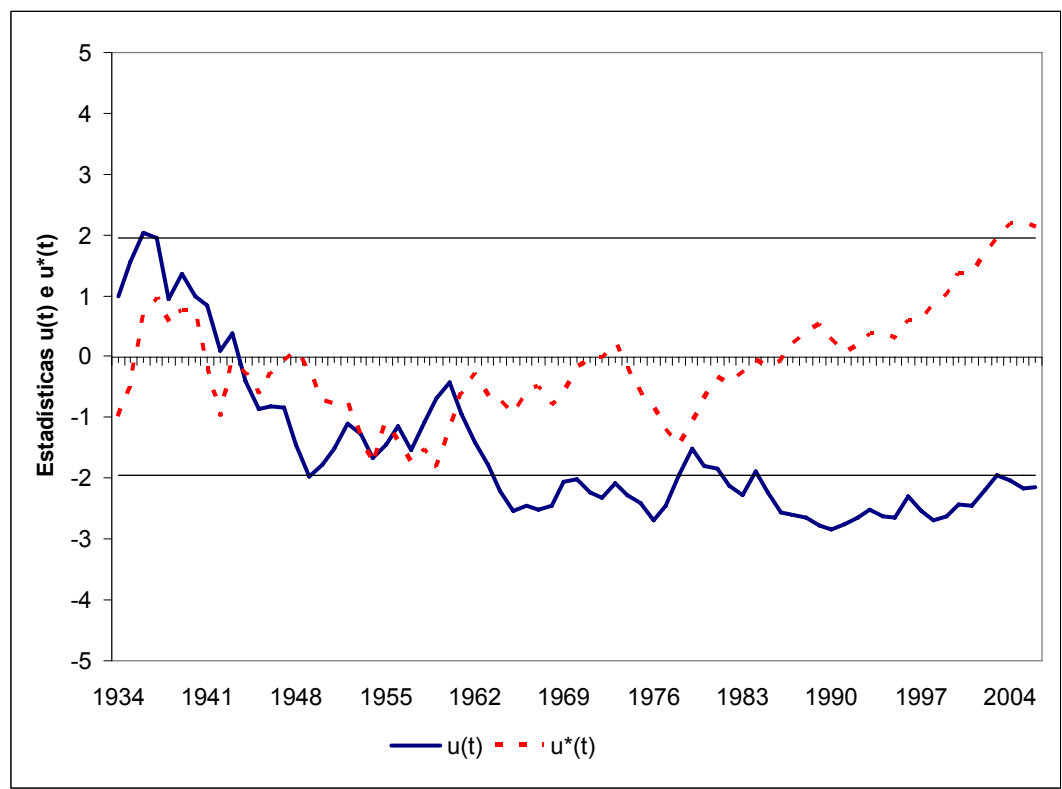

Figura 101 - Test Mann-Kendall secuencial para la precipitación total anual - Estación Maraña, Cuenca del río Porma.

Por los resultados obtenidos con M-Ks para la estación Maraña (Fig. 101), que es donde se encontró más significación, no se puede definir con exactitud el año de inicio de la tendencia debido a las diversas intersecciones encontradas. No obstante se puede ver claramente que a partir de 1961 la tendencia regresiva de la precipitación es muy marcada pasando a ser significativa a partir de 1964.

Los análisis mensuales no han aportado ninguna información definitiva sobre cuales son los meses responsables del descenso en la precipitación.

Se ha identificado en la estación Maraña una pérdida de aproximadamente 3,5 $\mathrm{mm}$ a cada año, lo que representa un total de $259 \mathrm{~mm}$ en todo el período analizado.

\subsubsection{Cuenca del Tajo}

En el caso de la cuenca del Tajo, en todas las estaciones estudiadas se observa un descenso muy acusado en la precipitación ya que todas presentan $\mathrm{R}$ negativos y en prácticamente todos los casos con resultados muy relevantes (Tabla 82). 
Tabla 82. Coeficientes de correlación (Rho de Spearman) entre la precipitación anual y el tiempo de las estaciones de la cuenca del Tajo.

\begin{tabular}{|l|c|c|c|}
\hline \hline \multicolumn{1}{c|}{ Estación } & $\mathbf{n}$ & $\begin{array}{c}\text { Signif. } \\
\text { Estad. }\end{array}$ & $\begin{array}{c}\text { R } \\
\text { (Precipitación) }\end{array}$ \\
\hline \hline Beteta & 48 & $* *$ & $-0,484$ \\
\hline Cañizares & 53 & ${ }^{* *}$ & $-0,529$ \\
\hline Poyatos & 55 & ${ }^{* *}$ & $-0,389$ \\
\hline Santa María del Val & 48 & ${ }^{* *}$ & $-0,502$ \\
\hline Vega del Codorno & 52 & NS & $-0,260$ \\
\hline \hline
\end{tabular}

NS = Valores no significativos estadísticamente

** $=$ Correlación significativa al nivel de 0,01

Solamente la estación Vega del Codorno no presenta valores significativos, aunque se puede considerar que el valor de $\mathrm{R}$ encontrado está muy cercano a la significación (0,260). En las demás estaciones fueron detectados valores significativos al nivel de 0,01 . Los resultados encontrados con el coeficiente de correlación llevan a suponer que en esta cuenca está ocurriendo una fuerte disminución de la precipitación. Entre todas las cuencas analizadas en este estudio, la cuenca del Tajo es dónde los valores de $\mathrm{R}$ presentan más significación estadística.

Los resultados del M-K (Tabla 83) confirman todas las tendencias detectadas por R y se puede ver claramente que todas las estaciones presentan valores regresivos muy claros.

Tabla 83. Test estadístico Mann-Kendall para la precipitación total anual en las estaciones utilizadas para análisis de la cuenca del Tajo.

\begin{tabular}{|l|c|c|c|c|}
\hline \multicolumn{1}{|c|}{ Estación } & $\begin{array}{c}\text { S de } \\
\text { Kendall }\end{array}$ & $\mathbf{Z}_{\mathbf{s}}$ & $\begin{array}{c}\text { Rechazo de hipótesis } \\
\text { nula para } \mathbf{p}<\mathbf{0 , 0 5}\end{array}$ & Valor $\boldsymbol{p}$ \\
\hline \hline Beteta & -365 & $-21,05$ & $\mathrm{Si}$ & 0,0001 \\
\hline Cañizares & -496 & $-27,46$ & $\mathrm{Si}$ & 0,0001 \\
\hline Poyatos & -407 & $-21,95$ & $\mathrm{Si}$ & 0,0001 \\
\hline Santa María del Val & -388 & $-22,57$ & $\mathrm{Si}$ & 0,0001 \\
\hline Vega del Codorno & -210 & $-12,08$ & $\mathrm{Si}$ & 0,0001 \\
\hline \hline
\end{tabular}

Zs $>(+/-) 1,96$ se rechaza la hipótesis nula de no tendencia Valor $p<0,05$ se rechaza la hipótesis nula de no tendencia

Se puede destacar que, incluso la estación Vega del Codorno, que con $\mathrm{R}$ presentaba una tendencia negativa menos clara, con $\mathrm{M}-\mathrm{K}$ muestra una tendencia negativa bastante significativa $(S=-210$ y $Z=-12,08)$. Esta es la estación con valores de $S$ y $Z$ más bajos. Por otro lado la estación Cañizares es la que presenta los más altos 
valores de significación estadística ( $S=-496$ y $Z=-27,46)$. En las demás estaciones los resultados de M-K son muy semejantes. En todas las estaciones utilizadas para el análisis de la cuenca del Tajo se rechaza la hipótesis nula de no tendencia $\left(Z_{s}>-1,96\right)$ y los valores encontrados para $Z$ indican claramente una tendencia negativa de la precipitación.

Debido a los resultados encontrados con los test aplicados anteriormente y a su alta significación estadística se han llevado a cabo los análisis con M-Ks para todas las estaciones con el objetivo de intentar localizar los años de inicio de las tendencias detectadas. En el caso de la estación Beteta (Fig. 102) no se puede definir el año a partir del cual empieza la tendencia regresiva ya que, como se observa en el gráfico, no hay ninguna intersección entre las estadísticas $u(t)$ y $u^{*}(t)$ durante el período estudiado. Sin embargo se aprecia un descenso bastante pronunciado en la precipitación llegando a ser considerado significativo a partir de 1982. Estos resultados demuestran que la tendencia negativa en la precipitación probablemente se ha iniciado antes del período utilizado para el análisis en este estudio.

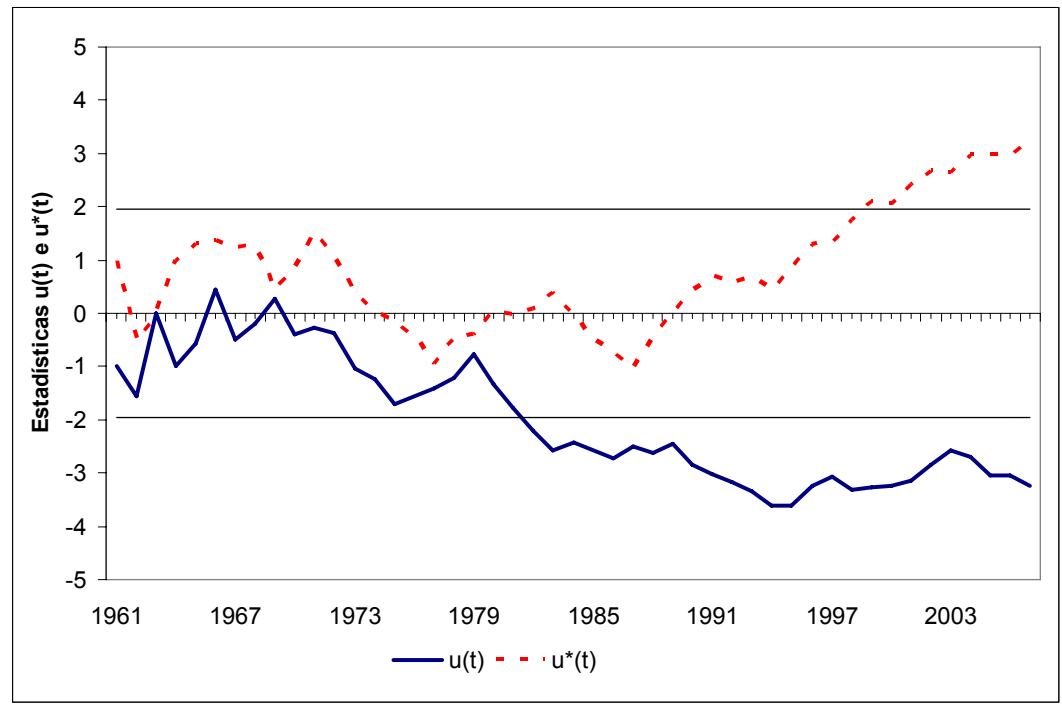

Figura 102 - Test Mann-Kendall secuencial para la precipitación total anual - Estación Beteta, Cuenca del Tajo.

Resultados semejantes fueron encontrados en la estación Cañizares (Fig. 103) ya que tampoco está claro a partir de que año se ve el inicio de la tendencia una vez que en el período estudiado no hay ninguna intersección de las estadística $u(t)$ y $u^{*}(t)$. No obstante, se puede ver claramente una tendencia regresiva en los valores de precipitación llegando a ser considerados significativos a partir del año de 1975. Por lo tanto se registra claramente una fuerte tendencia regresiva de la precipitación y en 
función de los datos de M-Ks no se puede detectar un año de inicio, pues esta situación perdura desde el comienzo de la serie. De esta manera es muy probable que esta tendencia haya empezado antes del periodo analizado en esta investigación.

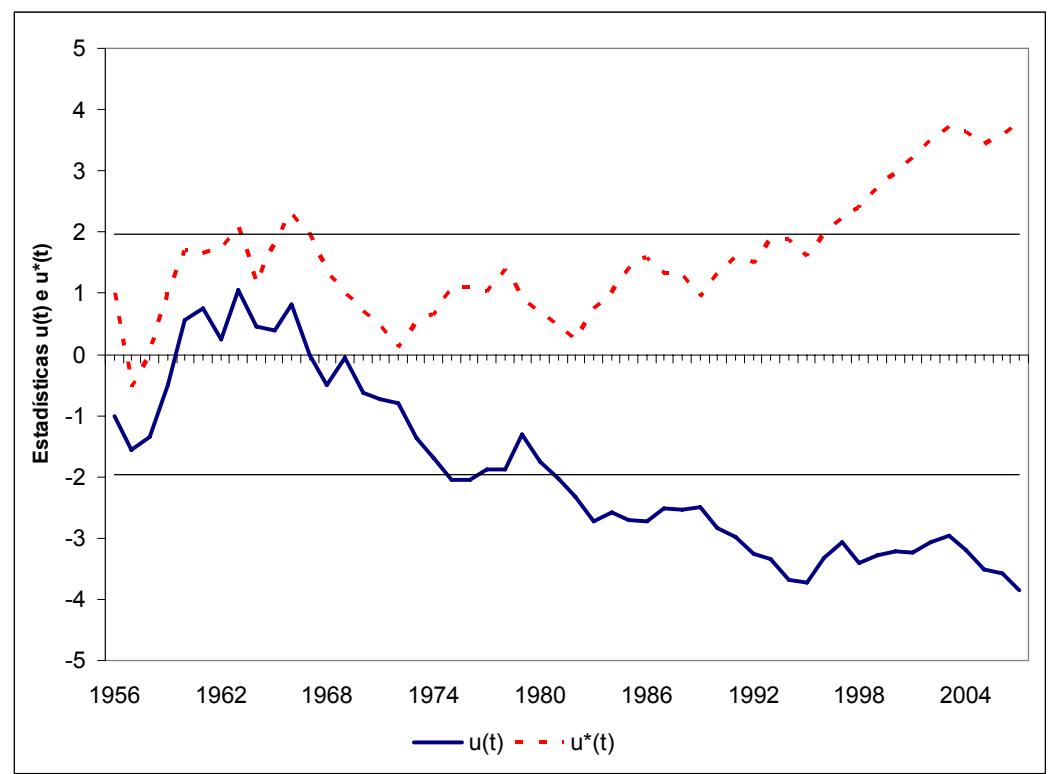

Figura 103 - Test Mann-Kendall secuencial para la precipitación total anual - Estación Cañizares, Cuenca del Tajo.

A partir del análisis de los resultados de M-Ks para la estación Poyatos (Fig. 104), se ve claramente la tendencia regresiva de la precipitación.

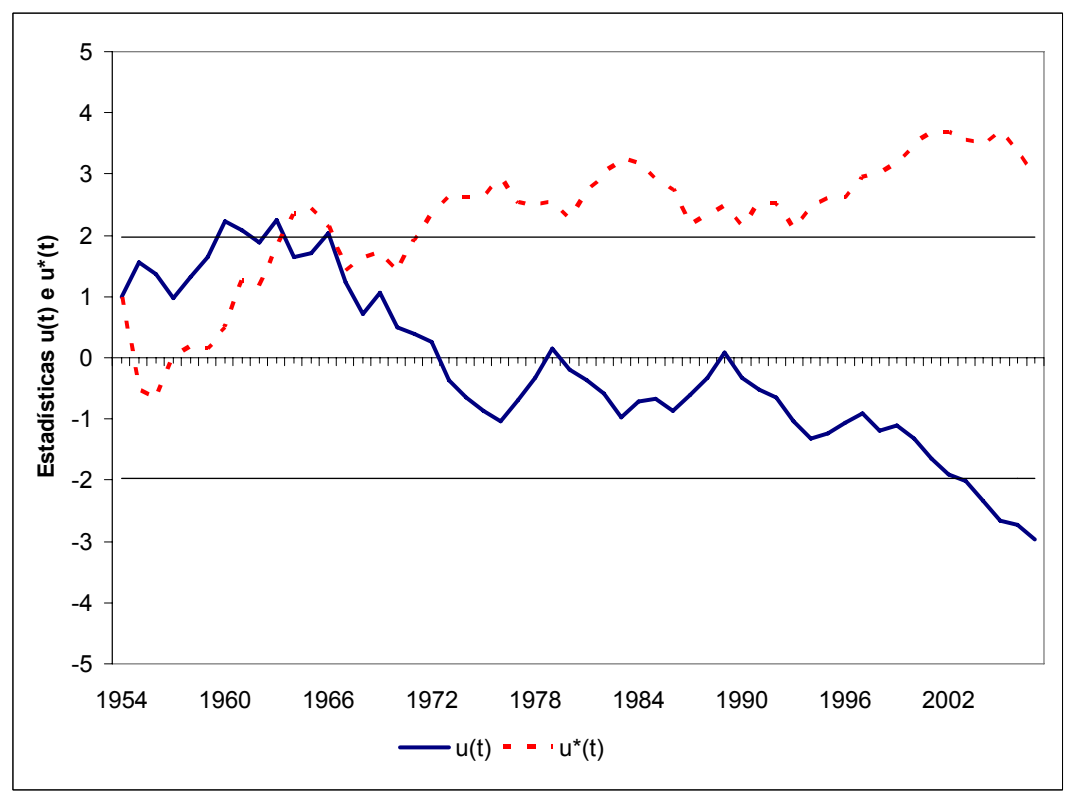

Figura 104 - Test Mann-Kendall secuencial para la precipitación total anual - Estación Poyatos, Cuenca del Tajo. 
Además se puede observar el año (1964) a partir del cual ha empezado esta tendencia, que está definido por la intersección de las estadísticas $u(t)$ y $u^{*}(t)$. No obstante, la significación estadística sólo fue alcanzada a partir de 2003.

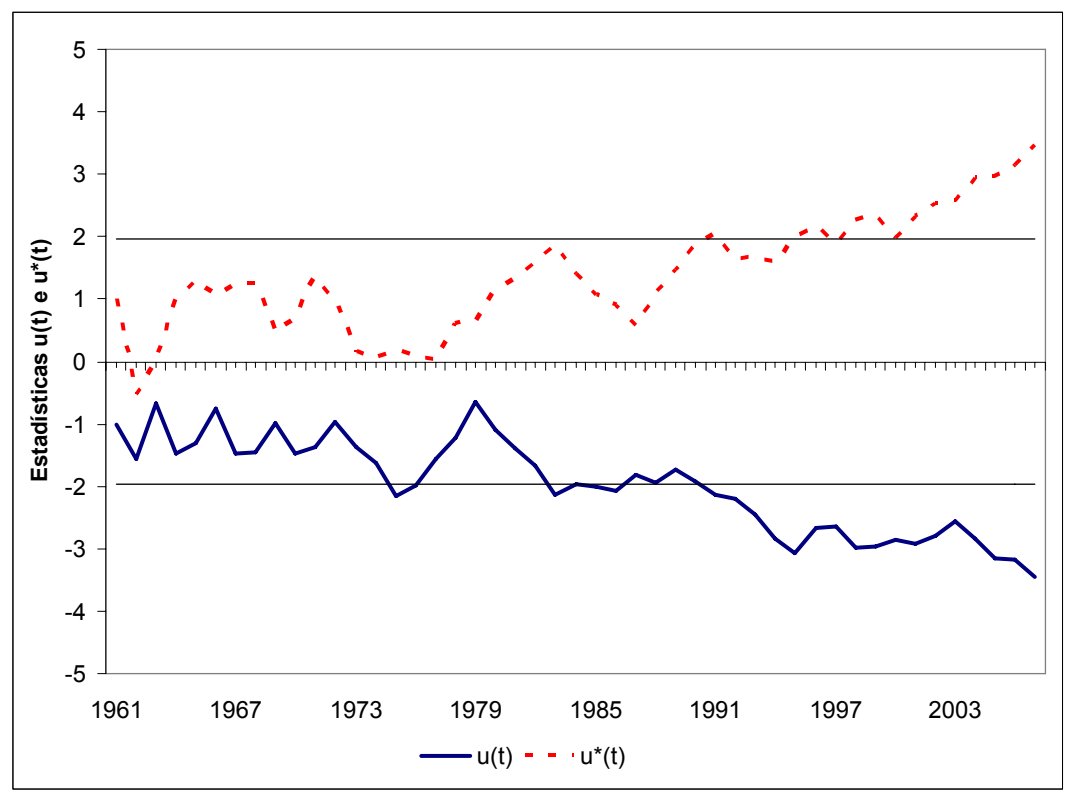

Figura 105 - Test Mann-Kendall secuencial para la precipitación total anual - Estación Santa María del Val, Cuenca del Tajo.

Como ocurre en las estaciones Beteta y Cañizares, los resultados de M-Ks para la estación Santa María del Val (Fig. 105) no permiten definir el año de inicio de la tendencia pues en el período estudiado no hay ninguna intersección de las estadísticas $u(t)$ y $u^{*}(t)$. Sin embargo, se aprecia una fuerte tendencia regresiva, llegando a ser significativa a partir del año 1983. Aunque haya un período con ligeras oscilaciones en los valores de la estadística $u(t)$, no hay duda de que también en la estación Santa María del Val la tendencia negativa de la precipitación es bastante clara.

La figura 106 refleja los resultados encontrados con M-Ks para la estación Vega del Codorno que fue dónde se dieron los valores más bajos de significación estadística con $\mathrm{R}$ y $\mathrm{M}-\mathrm{K}$. 


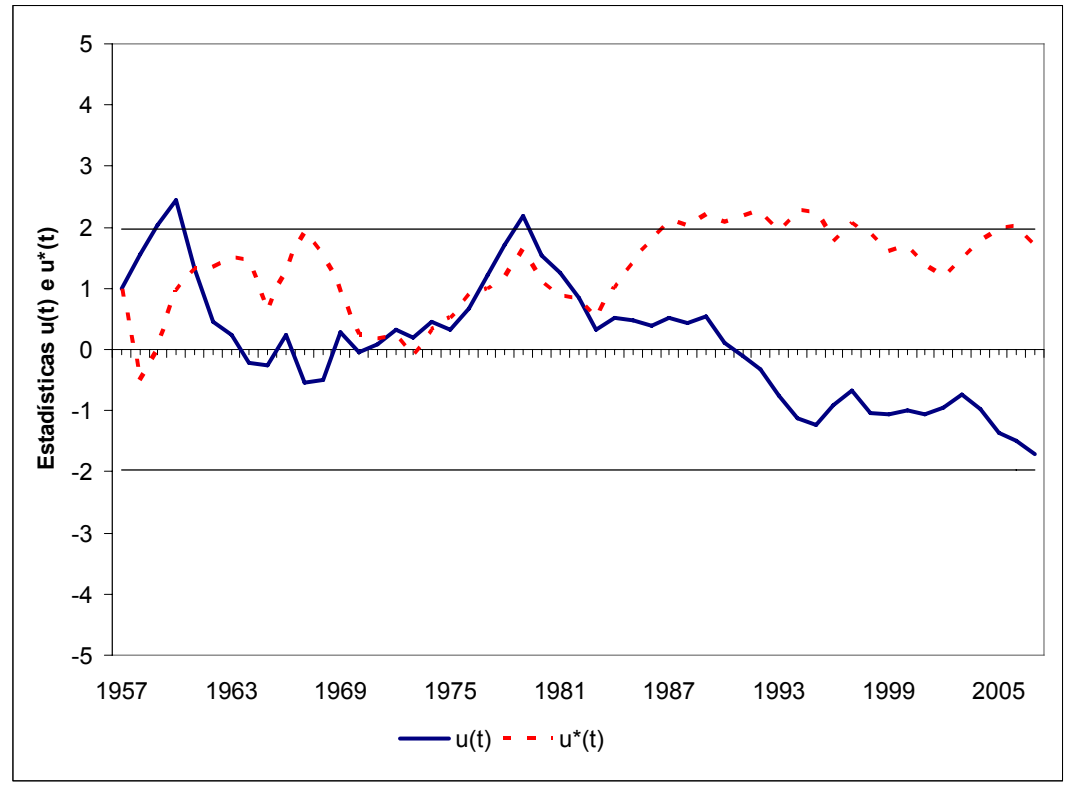

Figura 106 - Test Mann-Kendall secuencial para la precipitación total anual - Estación Vega del Codorno, Cuenca del Tajo.

Se puede ver una tendencia regresiva en el tiempo, aunque menos pronunciada que la encontrada para las otras estaciones utilizadas para análisis de la cuenca del Tajo. No se puede definir en qué año se ha iniciado esta tendencia debido a las muchas intersecciones que presenta. No obstante, se puede afirmar que hasta 1982 hay muchas oscilaciones entre valores positivos y negativos y que a partir de este año las curvas se separan definitivamente. Aunque esta tendencia no llega en ningún momento a sobrepasar los valores de los límites de confianza $( \pm 1,96)$.

Todos los análisis realizados hasta el momento no dejan dudas sobre la disminución de la precipitación en todas las estaciones utilizadas para estudio climatológico de la cuenca del río Tajo.

Fue observada una pérdida de precipitación bastante clara en todas ellas. En Beteta, Cañizares y Santa María del Val fue donde más se ha notado, con una disminución aproximada de $9 \mathrm{~mm}$ a cada año de estudio (Tabla 84).

En Poyatos se ha visto una reducción de 6,4 $\mathrm{mm}$ al año, que representa un total de $352 \mathrm{~mm}$ en todo el período estudiado y en Vega del Codorno, donde la disminución ha sido más relevante, $4,4 \mathrm{~mm}$ a cada año, que significa $228,8 \mathrm{~mm}$ en el período estudiado. 
Tabla 84. Pérdida de precipitación en las estaciones Beteta, Cañizares, Poyatos, Santa María del Val y Vega del Codorno.

\begin{tabular}{|l|c|c|c|}
\hline \hline \multicolumn{1}{|c|}{ Estación } & $\mathbf{n}$ & $\begin{array}{c}\text { Pérdida } \\
\text { anual }(\mathbf{m m})\end{array}$ & $\begin{array}{c}\text { Pérdida } \\
\text { total (mm) }\end{array}$ \\
\hline \hline Beteta & 48 & 9,0 & 432,0 \\
\hline Cañizares & 53 & 8,7 & 461,1 \\
\hline Poyatos & 55 & 6,4 & 352,0 \\
\hline Santa María del Val & 48 & 9,4 & 451,2 \\
\hline Vega del Codorno & 52 & 4,4 & 228,8 \\
\hline
\end{tabular}

Debido a los valores de tendencias detectados en todos los test estadísticos descritos anteriormente para todas las estaciones utilizadas para análisis de la evolución de la precipitación en la cuenca del Tajo, se realizaron análisis mensuales de todas ellas con el objetivo de evaluar los meses en que se ha notado mayores cambios en el período estudiado.

En la estación Beteta (Tabla 85 ) se puede ver que solamente octubre presenta una ligera tendencia positiva en ambos test estadísticos, aunque en el caso de $\mathrm{R}$ no se puede considerar como significativa. Sin embargo, con M-K se puede rechazar la hipótesis nula de no tendencia para este mes.

Tabla 85. Test estadísticos Rho de Spearman y Mann-Kendall para la precipitación mensual de la Estación Beteta - Cuenca del Tajo.

\begin{tabular}{|l|c|c|c|c|c|}
\hline \multicolumn{1}{|c|}{ Mes } & Rho & $\begin{array}{c}\text { S de } \\
\text { Kendall }\end{array}$ & $\mathbf{Z}_{\mathbf{s}}$ & $\begin{array}{c}\text { Rechazo de hipótesis } \\
\text { nula para } \mathbf{p}<\mathbf{0 , 0 5}\end{array}$ & Valor $\boldsymbol{p}$ \\
\hline Enero & $-0,278$ & -211 & $-13,53$ & $\mathrm{Si}$ & 0,0001 \\
\hline Febrero & $-0,332\left(^{*}\right)$ & -244 & $-13,29$ & $\mathrm{Si}$ & 0,0001 \\
\hline Marzo & $-0,283$ & -221 & $-11,84$ & $\mathrm{Si}$ & 0,0001 \\
\hline Abril & $-0,026$ & -9 & $-0,47$ & $\mathrm{No}$ & 0,6384 \\
\hline Mayo & $-0,109$ & -64 & $-3,93$ & $\mathrm{Si}$ & 0,0001 \\
\hline Junio & $-0,310\left(^{*}\right)$ & -227 & $-14,79$ & $\mathrm{Si}$ & 0,0001 \\
\hline Julio & $-0,250$ & -206 & $-12,40$ & $\mathrm{Si}$ & 0,0001 \\
\hline Agosto & $-0,085$ & -49 & $-3,09$ & $\mathrm{Si}$ & 0,0020 \\
\hline Septiembre & $-0,112$ & -63 & $-3,53$ & $\mathrm{Si}$ & 0,0004 \\
\hline Octubre & 0,104 & 60 & 4,06 & $\mathrm{Si}$ & 0,0001 \\
\hline Noviembre & $-0,260$ & -200 & $-11,91$ & $\mathrm{Si}$ & 0,0001 \\
\hline Diciembre & $-0,053$ & -38 & $-2,67$ & $\mathrm{Si}$ & 0,0076 \\
\hline \hline
\end{tabular}

Zs $>(+/-) 1,96$ se rechaza la hipótesis nula de no tendencia Valor $p<0,05$ se rechaza la hipótesis nula de no tendencia

* = Correlación significativa al nivel de 0,05 
Todos los demás meses presentan valores negativos, lo que confirma que en todos ellos hubo una disminución de la precipitación en el tiempo. En el caso de $\mathrm{R}$ solamente febrero $(-0,332)$ y junio $(-0,310)$ presentan valores significativos al nivel de 0,05 . Con $\mathrm{M}-\mathrm{K}$ solamente en abril no se puede rechazar la hipótesis nula de no tendencia. En todos los demás meses se puede ver que los valores de $S$ y $Z$ son negativos y significativos, o sea, en todos ellos se puede rechazar la hipótesis nula de no tendencia. En ambos test los meses que presentan valores de tendencia negativa más alto son febrero, marzo y junio.

En la estación Cañizares (Tabla 86), como ocurre en la estación Beteta, solamente octubre presenta valores positivos, indicando alguna tendencia progresiva en los datos de precipitación en este mes.

Tabla 86. Test estadísticos Rho de Spearman y Mann-Kendall para la precipitación mensual de la Estación Cañizares - Cuenca del Tajo.

\begin{tabular}{|l|c|c|c|c|c|}
\hline \hline \multicolumn{1}{|c|}{ Mes } & Rho & $\begin{array}{c}\text { S de } \\
\text { Kendall }\end{array}$ & $\mathbf{Z}_{\mathbf{s}}$ & $\begin{array}{c}\text { Rechazo de hipótesis } \\
\text { nula para } \mathbf{p}<\mathbf{0 , 0 5}\end{array}$ & Valor $\boldsymbol{p}$ \\
\hline \hline Enero & $-0,326\left(^{*}\right)$ & -295 & $-17,00$ & $\mathrm{Si}$ & 0,0001 \\
\hline Febrero & $-0,307\left(^{*}\right)$ & -284 & $-12,99$ & $\mathrm{Si}$ & 0,0001 \\
\hline Marzo & $-0,348\left(^{*}\right)$ & -319 & $-15,67$ & $\mathrm{Si}$ & 0,0001 \\
\hline Abril & $-0,056$ & -38 & $-2,08$ & $\mathrm{Si}$ & 0,0375 \\
\hline Mayo & $-0,059$ & -50 & $-2,48$ & $\mathrm{Si}$ & 0,0131 \\
\hline Junio & $-0,485\left(^{* *}\right)$ & -462 & $-25,91$ & $\mathrm{Si}$ & 0,0001 \\
\hline Julio & $-0,140$ & -126 & $-7,86$ & $\mathrm{Si}$ & 0,0001 \\
\hline Agosto & $-0,191$ & -171 & $-9,29$ & $\mathrm{Si}$ & 0,0001 \\
\hline Septiembre & $-0,125$ & -93 & $-5,32$ & $\mathrm{Si}$ & 0,0001 \\
\hline Octubre & 0,103 & 88 & 5,82 & $\mathrm{Si}$ & 0,0001 \\
\hline Noviembre & $-0,193$ & -166 & $-8,88$ & $\mathrm{Si}$ & 0,0001 \\
\hline Diciembre & $-0,247$ & -234 & $-14,34$ & $\mathrm{Si}$ & 0,0001 \\
\hline \hline
\end{tabular}

Zs $>(+/-) 1,96$ se rechaza la hipótesis nula de no tendencia

Valor $p<0,05$ se rechaza la hipótesis nula de no tendencia

* = Correlación significativa al nivel de 0,05

** = Correlación significativa al nivel de 0,01

Confirmando también lo encontrado anteriormente, $\mathrm{R}$ para este mes no presenta valores significativos, y con $\mathrm{M}-\mathrm{K}$ se puede rechazar la hipótesis nula de no tendencia, aunque no sea una tendencia tan marcada. En los demás meses y con ambos estadísticos es posible ver que todos los valores encontrados son negativos y demuestran alguna tendencia negativa. Al aplicar el test $\mathrm{R}$ los meses de enero (- 
$0,326)$, febrero $(-0,307)$ y marzo $(-0,348)$ presentan valores significativos al nivel de 0,05 y junio $(-0,485)$ presenta valor significativo al nivel de 0,01 . Sin embargo, con $M-$ $\mathrm{K}$, en todos los meses se puede rechazar la hipótesis nula de no tendencia aunque, como ocurrió con $\mathrm{R}$, los meses que presentan valores de tendencia más altos son enero, febrero, marzo y junio.

Los resultados encontrados en el análisis mensual de la estación Poyatos (Tabla 87) muestran que abril y octubre presentan una ligera tendencia positiva. Con $\mathrm{R}$ no han sido encontrados valores significativos en ninguno de ellos. Sin embargo al utilizar M-K se puede rechazar la hipótesis nula de no tendencia en ambos meses, aunque en ninguno de los dos casos esta tendencia es muy marcada. Los menores valores de significación estadística se encuentran en mayo. Con $R=-0,004, S=-14$ y $Z=-0,64$ nos permite concluir que en este mes los valores negativos encontrados son absolutamente despreciables y no se puede hablar en ningún tipo tendencia. Los demás meses presentan tendencias regresivas. El valor de $\mathrm{R}$ encontrado para marzo $(-0,297)$ y de junio $(-0,296)$ es significativo al nivel de 0,05 , pero los demás meses no presentan significación estadística con este estadístico. Al utilizar M-K, los meses en que los valores de tendencia son más altos son marzo y junio, seguidos de febrero y enero.

Tabla 87. Test estadísticos Rho de Spearman y Mann-Kendall para la precipitación mensual de la Estación Poyatos - Cuenca del Tajo.

\begin{tabular}{|l|c|c|c|c|c|}
\hline \hline \multicolumn{1}{|c|}{ Mes } & Rho & $\begin{array}{c}\text { S de } \\
\text { Kendall }\end{array}$ & $\mathbf{Z}_{\mathbf{s}}$ & $\begin{array}{c}\text { Rechazo de hipótesis } \\
\text { nula para } \mathbf{p}<\mathbf{0 , 0 5}\end{array}$ & Valor $\boldsymbol{p}$ \\
\hline \hline Enero & $-0,232$ & -237 & $-13,08$ & $\mathrm{Si}$ & 0,0001 \\
\hline Febrero & $-0,242$ & -252 & $-12,82$ & $\mathrm{Si}$ & 0,0001 \\
\hline Marzo & $-0,297\left(^{*}\right)$ & -294 & $-14,03$ & $\mathrm{Si}$ & 0,0001 \\
\hline Abril & 0,101 & 128 & 7,12 & $\mathrm{Si}$ & 0,0001 \\
\hline Mayo & $-0,004$ & -14 & $-0,64$ & $\mathrm{No}$ & 0,5222 \\
\hline Junio & $-0,296\left(^{*}\right)$ & -268 & $-15,13$ & $\mathrm{Si}$ & 0,0001 \\
\hline Julio & $-0,166$ & -132 & $-8,08$ & $\mathrm{Si}$ & 0,0001 \\
\hline Agosto & $-0,158$ & -158 & $-8,35$ & $\mathrm{Si}$ & 0,0001 \\
\hline Septiembre & $-0,106$ & -93 & $-4,36$ & $\mathrm{Si}$ & 0,0001 \\
\hline Octubre & 0,086 & 65 & 3,48 & $\mathrm{Si}$ & 0,0005 \\
\hline Noviembre & $-0,109$ & -113 & $-5,65$ & $\mathrm{Si}$ & 0,0001 \\
\hline Diciembre & $-0,162$ & -152 & $-8,90$ & $\mathrm{Si}$ & 0,0001 \\
\hline
\end{tabular}

Zs $>(+/-)$ 1,96 se rechaza la hipótesis nula de no tendencia Valor $p<0,05$ se rechaza la hipótesis nula de no tendencia

* = Correlación significativa al nivel de 0,05 
Con el análisis mensual de los datos de precipitación de la estación Santa María del Val (Tabla 88) se observa en los meses agosto y octubre una ligera tendencia positiva.

Tabla 88. Test estadísticos Rho de Spearman y Mann-Kendall para la precipitación mensual de la Estación Santa María del Val - Cuenca del Tajo.

\begin{tabular}{|l|c|c|c|c|c|}
\hline \multicolumn{1}{|c|}{ Mes } & Rho & $\begin{array}{c}\text { S de } \\
\text { Kendall }\end{array}$ & $\mathbf{Z}_{\mathbf{s}}$ & $\begin{array}{c}\text { Rechazo de hipótesis } \\
\text { nula para } \mathbf{p}<\mathbf{0 , 0 5}\end{array}$ & Valor $\boldsymbol{p}$ \\
\hline \hline Enero & $-0,296\left(^{*}\right)$ & -249 & $-16,45$ & $\mathrm{Si}$ & 0,0001 \\
\hline Febrero & $-0,333\left(^{*}\right)$ & -264 & $-14,34$ & $\mathrm{Si}$ & 0,0001 \\
\hline Marzo & $-0,261$ & -203 & $-10,93$ & $\mathrm{Si}$ & 0,0001 \\
\hline Abril & $-0,055$ & -33 & $-1,83$ & $\mathrm{No}$ & 0,0673 \\
\hline Mayo & $-0,065$ & -47 & $-2,71$ & $\mathrm{Si}$ & 0,0067 \\
\hline Junio & $-0,347\left(^{*}\right)$ & -267 & $-14,82$ & $\mathrm{Si}$ & 0,0001 \\
\hline Julio & $-0,129$ & -90 & $-5,54$ & $\mathrm{Si}$ & 0,0001 \\
\hline Agosto & 0,039 & 43 & 2,99 & $\mathrm{Si}$ & 0,0028 \\
\hline Septiembre & $-0,172$ & -129 & $-7,31$ & $\mathrm{Si}$ & 0,0001 \\
\hline Octubre & 0,052 & 23 & 1,57 & $\mathrm{No}$ & 0,1164 \\
\hline Noviembre & $-0,295\left(^{*}\right)$ & -220 & $-13,03$ & $\mathrm{Si}$ & 0,0001 \\
\hline Diciembre & $-0,140$ & -125 & $-9,45$ & $\mathrm{Si}$ & 0,0001 \\
\hline \hline
\end{tabular}

Zs $>(+/-) 1,96$ se rechaza la hipótesis nula de no tendencia Valor $p<0,05$ se rechaza la hipótesis nula de no tendencia * = Correlación significativa al nivel de 0,05

No obstante se aprecia que el valor de $\mathrm{R}$ es casi despreciable en ambos meses. Sin embargo, con M-K solamente en octubre no se puede rechazar la hipótesis de no tendencia. Todos los demás meses presentan valores negativos, lo que refleja una tendencia regresiva. Los resultados de $\mathrm{R}$ tienen significación al nivel de 0,05 en enero, febrero, junio y noviembre. El único mes en que no se puede rechazar la hipótesis nula de no tendencia con el test M-K es abril. Confirmando los valores encontrados con el coeficiente de correlación, los meses en que S y Z son más altos son enero, febrero, junio y noviembre.

Para la estación Vega del Codorno, los resultados de R y M-K (Tabla 89) muestran también que el único mes que presenta una pequeña tendencia progresiva es octubre. En este caso, con el coeficiente de correlación no se puede ver ningún resultado significativo, sin embargo, con $\mathrm{M}-\mathrm{K}$ se puede rechazar la hipótesis nula de no tendencia. En los demás meses se aprecian valores negativos, lo que sugiere una tendencia regresiva en todos ellos. Los resultados de $\mathrm{R}$ indican que solamente junio presenta valores significativos estadísticamente al nivel de 0,05 (-0,342). Con M-K 
solamente en abril no se puede rechazar la hipótesis nula de no tendencia. Los meses con valores de $S$ y $Z$ más altos son junio y marzo.

Tabla 89. Test estadísticos Rho de Spearman y Mann-Kendall para la precipitación mensual de la Estación Vega del Codorno - Cuenca del Tajo.

\begin{tabular}{|l|c|c|c|c|c|}
\hline \multicolumn{1}{|c|}{ Mes } & Rho & $\begin{array}{c}\text { S de } \\
\text { Kendall }\end{array}$ & $\mathbf{Z}_{\mathbf{s}}$ & $\begin{array}{c}\text { Rechazo de hipótesis } \\
\text { nula para } \mathbf{p}<\mathbf{0 , 0 5}\end{array}$ & Valor $\boldsymbol{p}$ \\
\hline Enero & $-0,149$ & -102 & $-7,07$ & $\mathrm{Si}$ & 0,0001 \\
\hline Febrero & $-0,169$ & -127 & $-7,23$ & $\mathrm{Si}$ & 0,0001 \\
\hline Marzo & $-0,234$ & -189 & $-10,32$ & $\mathrm{Si}$ & 0,0001 \\
\hline Abril & $-0,020$ & -4 & $-0,17$ & $\mathrm{No}$ & 0,8650 \\
\hline Mayo & $-0,110$ & -92 & $-4,55$ & $\mathrm{Si}$ & 0,0001 \\
\hline Junio & $-0,342\left(^{*}\right)$ & -298 & $-16,76$ & $\mathrm{Si}$ & 0,0001 \\
\hline Julio & $-0,099$ & -78 & $-4,41$ & $\mathrm{Si}$ & 0,0001 \\
\hline Agosto & $-0,127$ & -98 & $-6,52$ & $\mathrm{Si}$ & 0,0001 \\
\hline Septiembre & $-0,062$ & -41 & $-2,11$ & $\mathrm{Si}$ & 0,0349 \\
\hline Octubre & 0,147 & 124 & 7,84 & $\mathrm{Si}$ & 0,0001 \\
\hline Noviembre & $-0,117$ & -107 & $-5,74$ & $\mathrm{Si}$ & 0,0001 \\
\hline Diciembre & $-0,081$ & -82 & $-4,78$ & $\mathrm{Si}$ & 0,0001 \\
\hline \hline
\end{tabular}

Zs $>(+/-) 1,96$ se rechaza la hipótesis nula de no tendencia Valor $p<0,05$ se rechaza la hipótesis nula de no tendencia

* $=$ Correlación significativa al nivel de 0,05

El comportamiento mensual de la precipitación para todas las estaciones analizadas confirma los resultados encontrados anteriormente a escala anual. Ha quedado ampliamente demostrado que en todas las estaciones utilizadas para análisis de la cuenca del Tajo hubo considerables tendencias negativas en los valores de precipitación en la mayoría de los meses.

\subsubsection{Cuenca del río Trabaque}

Los coeficientes de correlación entre la precipitación y el tiempo en las diferentes estaciones pluviométricas analizadas para la cuenca del río Trabaque están representados en la tabla 90 . El valor de $\mathrm{R}$ encontrado para la estación Cañaveras fue el único con un valor positivo, aunque este valor, por ser tan irrelevante, no significa ningún tipo de tendencia. En las demás estaciones $\mathrm{R}$ es negativo lo que refleja una tendencia regresiva en todas ellas. A excepción de Arrancacepas, las demás estaciones (Albalate de las Nogueras, Torrecilla y Villar de Domingo García) reflejan valores significativos. Los valores registrados para la estación Villar de Domingo García son significativos al nivel de 0,05 y para las estaciones Albalate de las 
Nogueras y Torrecilla $R$ es significativo al nivel de 0,01 . Estos resultados dejan claro que hay una tendencia a disminución de la precipitación en estas estaciones.

Tabla 90. Coeficientes de correlación (Rho de Spearman) entre la precipitación anual y el tiempo de las estaciones de la cuenca del río Trabaque.

\begin{tabular}{|l|c|c|c|}
\hline \hline \multicolumn{1}{|c|}{ Estación } & n & $\begin{array}{c}\text { Signif. } \\
\text { Estad. }\end{array}$ & $\begin{array}{c}\text { R } \\
\text { (Precipitación) }\end{array}$ \\
\hline Albalate de las Nogueras & 44 & $* *$ & $-0,388$ \\
\hline Arrancacepas & 38 & NS & $-0,272$ \\
\hline Cañaveras & 30 & NS & 0,08 \\
\hline Torrecilla & 51 & $* *$ & $-0,564$ \\
\hline Villar de Domingo García & 51 & $*$ & $-0,334$ \\
\hline \hline
\end{tabular}

NS = Valores no significativos estadísticamente

* = Correlación significativa al nivel de 0,05

** $=$ Correlación significativa al nivel de 0,01

Los valores resultantes del estadístico M-K (Tabla 91) para todas las estaciones confirman las tendencias detectadas por el coeficiente de correlación. La estación Cañaveras es la única que presenta valores positivos en el tiempo y se puede rechazar la hipótesis nula de no tendencia, aunque con valores de $S(29)$ y $Z(2,63)$ poco relevantes. Los resultados de M-K para todas las demás estaciones demuestran una tendencia negativa de los valores de la precipitación bastante considerable y en todas ellas se rechaza la hipótesis nula de no tendencia.

Tabla 91. Test estadístico Mann-Kendall para la precipitación total anual en las estaciones utilizadas para análisis de la cuenca del río Trabaque.

\begin{tabular}{|l|c|c|c|c|}
\hline \multicolumn{1}{|c|}{ Estación } & $\begin{array}{c}\text { S de } \\
\text { Kendall }\end{array}$ & $\mathbf{Z}_{\mathbf{s}}$ & $\begin{array}{c}\text { Rechazo de hipótesis } \\
\text { nula para } \mathbf{p < 0 , 0 5}\end{array}$ & Valor $\boldsymbol{p}$ \\
\hline \hline Albalate de las Nogueras & -257 & $-15,74$ & $\mathrm{Si}$ & 0,0001 \\
\hline Arrancacepas & -137 & $-9,45$ & $\mathrm{Si}$ & 0,0001 \\
\hline Cañaveras & 29 & 2,63 & $\mathrm{Si}$ & 0,0085 \\
\hline Torrecilla & -497 & $-26,61$ & $\mathrm{Si}$ & 0,0001 \\
\hline Villar de Domingo García & -285 & $-16,67$ & $\mathrm{Si}$ & 0,0001 \\
\hline \hline
\end{tabular}

Zs $>$ (+/-) 1,96 se rechaza la hipótesis nula de no tendencia Valor $p<0,05$ se rechaza la hipótesis nula de no tendencia

El estadístico M-Ks fue analizado solamente para las estaciones que presentan valores más claros. En el caso de la estación Albalate de las Nogueras (Fig. 107) los resultados encontrados no dejan claro a partir de que año se observa el inicio de la tendencia registrada anteriormente, ya que en el período estudiado hay más de una intersección de las estadísticas $u(t)$ y $u^{*}(t)$. Sin embargo, se puede ver que a partir de 
1980 esta tendencia regresiva es más clara, llegando a ser considerada significativa a partir de 1994, cuando pasa a estar fuera de los límites de confianza $( \pm 1,96)$.

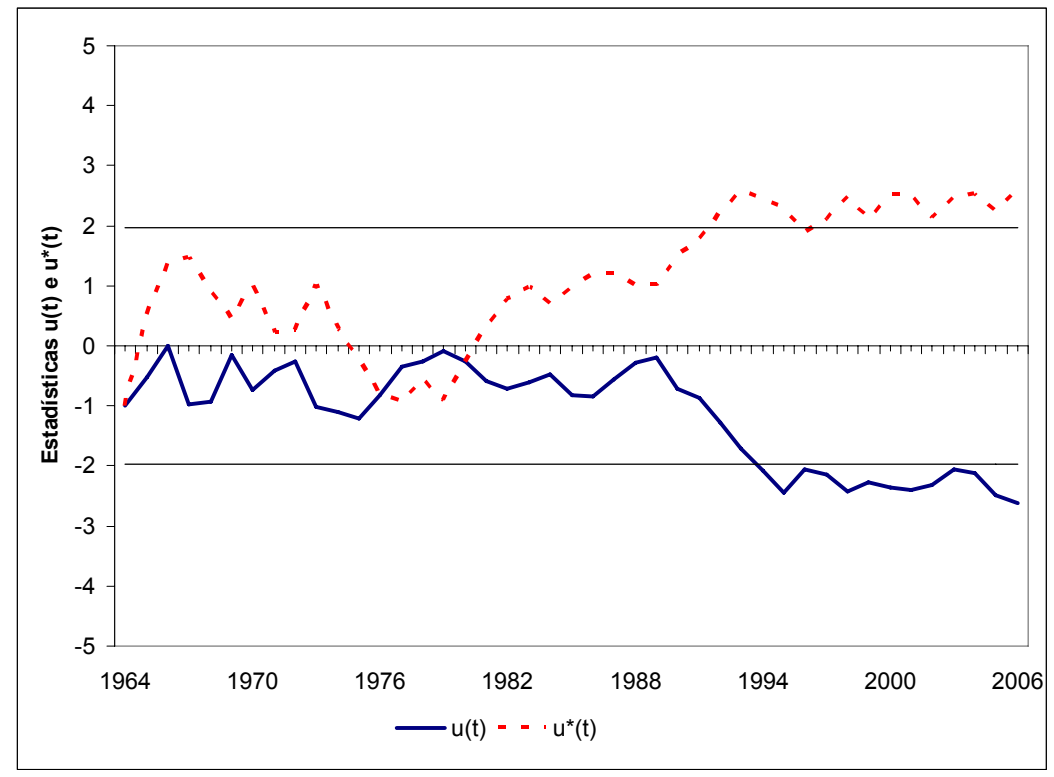

Figura 107 - Test Mann-Kendall secuencial para la precipitación total anual - Estación Albalate de las Nogueras, Cuenca del río Trabaque.

En el análisis de los resultados encontrados para la estación Arrancacepas (Fig. 108) no se puede definir a partir de que año ha empezado la tendencia regresiva encontrada por $\mathrm{R}$ y $\mathrm{M}-\mathrm{K}$, pues no hay ninguna intersección entre las estadísticas $u(t)$ y $u^{*}(t)$ en el período estudiado. Por lo tanto, es muy probable que el año de inicio de esta tendencia sea anterior al período estudiado.

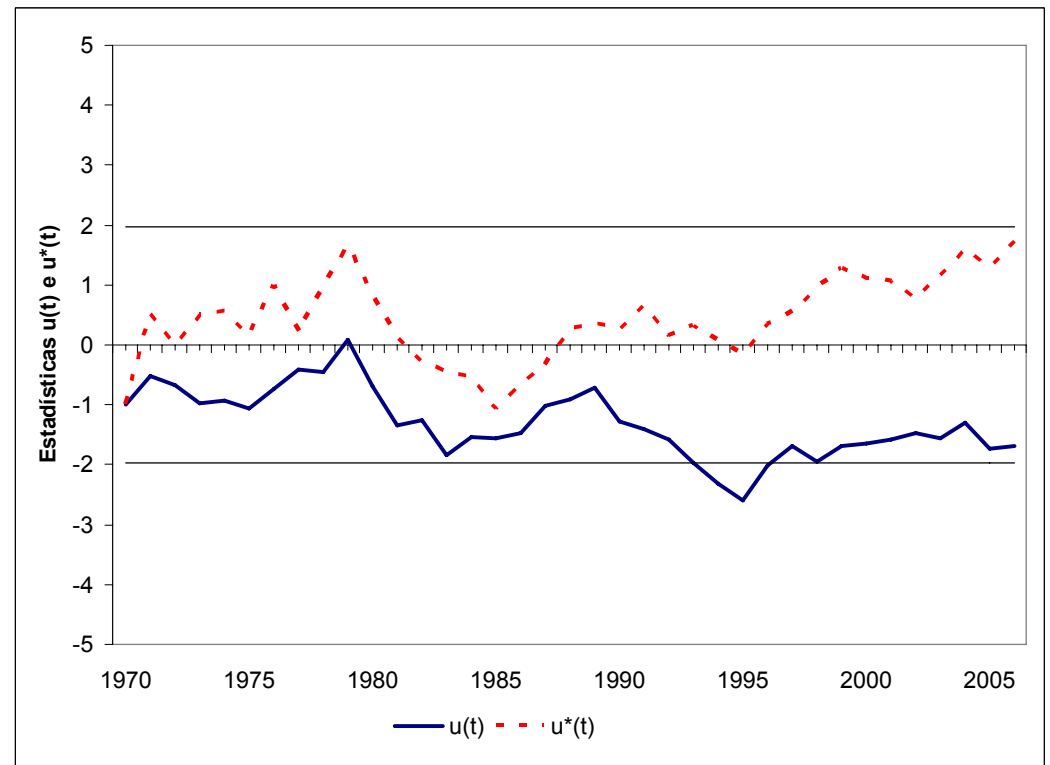

Figura 108 - Test Mann-Kendall secuencial para la precipitación total anual - Estación Arrancacepas, Cuenca del río Trabaque. 
Los resultados del M-Ks para la estación Torrecilla (Fig. 109) revelan claramente una tendencia regresiva muy marcada.

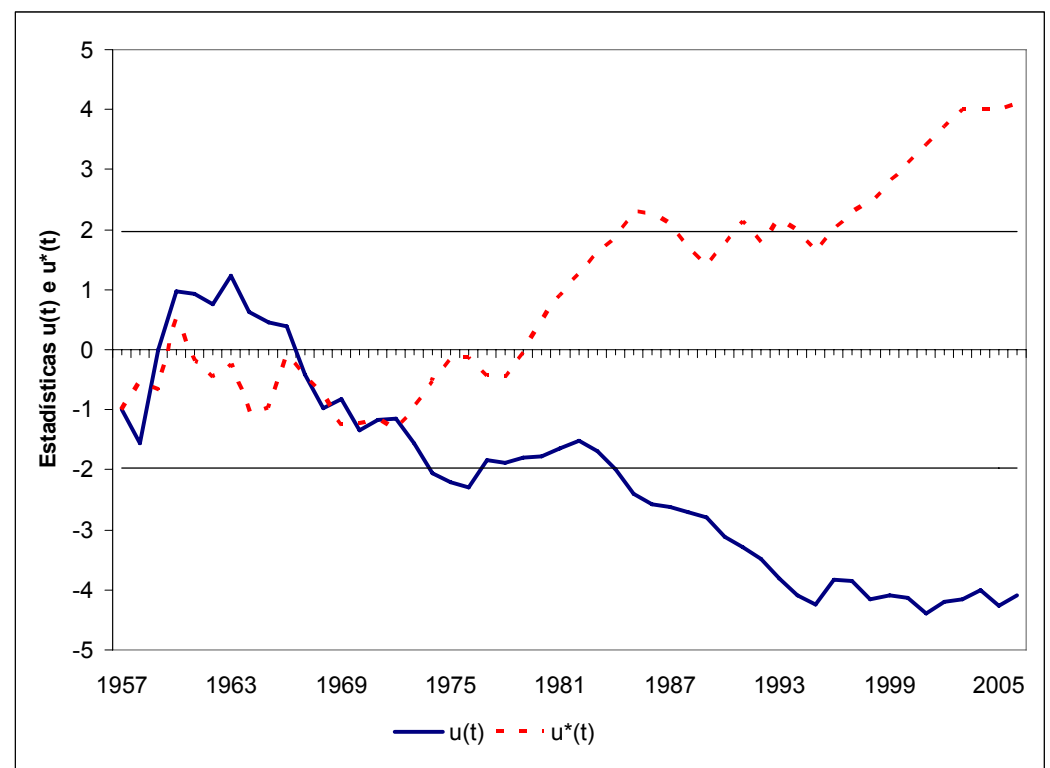

Figura 109 - Test Mann-Kendall secuencial para la precipitación total anual - Estación Torrecilla, Cuenca del río Trabaque

No es posible determinar el año exacto en que empezó debido a las muchas intersecciones encontradas, sin embargo, es claro que a partir de 1972 las curvas se separan definitivamente. Esta tendencia llega a ser significativa a partir de 1974 donde los valores sobrepasan los límites de confianza

En el caso de la estación Villar de Domingo García (Fig. 110), como sucedió en las estaciones Torrecilla y Albalate de las Nogueras, no se puede definir claramente a partir de que año empezó la tendencia negativa debido a las diversas intersecciones. No obstante se puede afirmar que a partir de 1964 esta tendencia negativa es más pronunciada, llegando a la significación estadística a partir de 1973. 


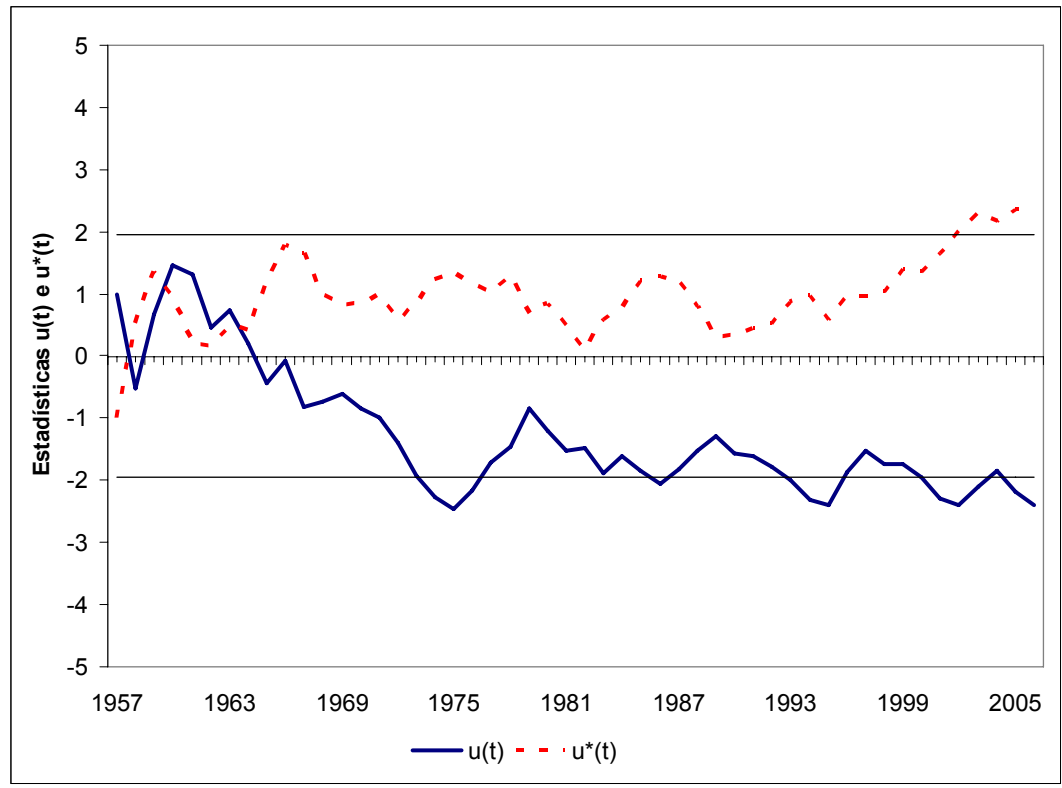

Figura 110 - Test Mann-Kendall secuencial para la precipitación total anual - Estación Villar de Domingo García, Cuenca del río Trabaque.

Las pérdidas de precipitación, sobre todo en las estaciones Torrecilla y Albalate de las Nogueras son bastante significativas, 7,6 y $5,5 \mathrm{~mm}$ a cada año (Tabla 92), que equivale a aproximadamente 397,6 y 242 mm durante todo el período. En la estación Arrancacepas ha sido detectada una disminución de $3,5 \mathrm{~mm}$ al año (133 $\mathrm{mm}$ total) y en Villar de Domingo García 2,9 mm al año (147,9 mm total).

Tabla 92. Pérdida de precipitación en las estaciones Albalate de las Nogueras, Arrancacepas, Cañaveras, Torrecilla y Villar de Domingo García.

\begin{tabular}{|l|c|c|c|}
\hline \multicolumn{1}{|c|}{ Estación } & $\mathbf{n}$ & $\begin{array}{c}\text { Pérdida } \\
\text { anual } \mathbf{( m m )}\end{array}$ & $\begin{array}{c}\text { Pérdida } \\
\text { total }(\mathbf{m m})\end{array}$ \\
\hline \hline Albalate de las Nogueras & 44 & 5,5 & 242,0 \\
\hline Arrancacepas & 38 & 3,5 & 133,0 \\
\hline Torrecilla & 51 & 7,6 & 397,6 \\
\hline Villar de Domingo García & 51 & 2,9 & 147,9 \\
\hline \hline
\end{tabular}

Debido a que la tendencia encontrada no dejaba lugar a dudas, se llevaron a cabo análisis mensuales de las estaciones Albalate de las Nogueras, Arrancacepas, Torrecilla y Villar de Domingo García con el objetivo de evaluar los meses en que se han visto cambios más relevantes. Los resultados de $\mathrm{R}$ y $\mathrm{M}-\mathrm{K}$ mensuales para la estación Albalate de las Nogueras (Tabla 93) revelan que solamente mayo y octubre presentan una ligera tendencia positiva en ambos test, aunque con $R$ no se 
encuentran valores significativos. Sin embargo, con $M-K$ se puede rechazar la hipótesis nula de no tendencia. Todos los demás meses presentan valores negativos, demostrando una fuerte tendencia regresiva en la mayoría de ellos.

Tabla 93. Test estadísticos Rho de Spearman y Mann-Kendall para la precipitación mensual de la Estación Albalate de las Nogueras - Cuenca del río Trabaque.

\begin{tabular}{|l|c|c|c|c|c|}
\hline \hline \multicolumn{1}{|c|}{ Mes } & Rho & $\begin{array}{c}\text { S de } \\
\text { Kendall }\end{array}$ & $\mathbf{Z}_{\mathbf{s}}$ & $\begin{array}{c}\text { Rechazo de hipótesis } \\
\text { nula para } \mathbf{p}<\mathbf{0 , 0 5}\end{array}$ & Valor $\boldsymbol{p}$ \\
\hline \hline Enero & $-0,301\left(^{*}\right)$ & -194 & $-12,70$ & $\mathrm{Si}$ & 0,0001 \\
\hline Febrero & $-0,468\left(^{* *}\right)$ & -294 & $-18,42$ & $\mathrm{Si}$ & 0,0001 \\
\hline Marzo & $-0,158$ & -110 & $-6,79$ & $\mathrm{Si}$ & 0,0001 \\
\hline Abril & $-0,220$ & -115 & $-9,31$ & $\mathrm{Si}$ & 0,0001 \\
\hline Mayo & 0,067 & 51 & 3,16 & $\mathrm{Si}$ & 0,0016 \\
\hline Junio & $-0,364\left(^{*}\right)$ & -244 & $-16,18$ & $\mathrm{Si}$ & 0,0001 \\
\hline Julio & $-0,281$ & -160 & $-11,60$ & $\mathrm{Si}$ & 0,0001 \\
\hline Agosto & $-0,121$ & -93 & $-7,44$ & $\mathrm{Si}$ & 0,0001 \\
\hline Septiembre & $-0,070$ & -43 & $-2,56$ & $\mathrm{Si}$ & 0,0105 \\
\hline Octubre & 0,220 & 130 & 9,05 & $\mathrm{Si}$ & 0,0001 \\
\hline Noviembre & $-0,128$ & -69 & $-4,29$ & $\mathrm{Si}$ & 0,0001 \\
\hline Diciembre & $-0,071$ & -40 & $-2,52$ & $\mathrm{Si}$ & 0,0117 \\
\hline \hline
\end{tabular}

Zs $>$ (+/-) 1,96 se rechaza la hipótesis nula de no tendencia

Valor $p<0,05$ se rechaza la hipótesis nula de no tendencia

* = Correlación significativa al nivel de 0,05

** = Correlación significativa al nivel de 0,01

Con $\mathrm{R}$ los meses de enero y junio presentan valores significativos al nivel de 0,05 y febrero es significativo al nivel de 0,01. Con M-K en todos los meses se puede ver que los valores de $S$ y $Z$ son significativos, o sea, en todos ellos se puede rechazar la hipótesis nula de no tendencia. Al igual que con el coeficiente de correlación, los meses que presentan valores de tendencia negativa más alto son febrero, junio y enero.

En el caso de la estación Arrancacepas (Tabla 94) el comportamiento de la precipitación difiere un poco de la Albalate de las Nogueras, analizada anteriormente, sobre todo con relación a los meses en que se observan tendencias positivas. En mayo, con $\mathrm{R}$ y $\mathrm{M}-\mathrm{K}$ se observan valores casi imperceptibles. Por lo tanto en este mes no se puede decir que haya ningún tipo de tendencia. Además de esto, en los meses de septiembre, octubre y noviembre los valores son positivos. Con $\mathrm{R}$ no se han encontrados valores significativos en ninguno de estos meses, aunque en octubre se aprecia un valor de $\mathrm{R}$ muy cerca de la significación estadística $(0,292)$. A su vez con 
M-K en los meses de septiembre y octubre se puede rechazar la hipótesis nula de no tendencia y solamente en noviembre los valores de $S$ y $Z$ no son significativos. En los meses de enero, febrero, marzo, abril, junio, julio, agosto y diciembre los estadísticos indican alguna tendencia regresiva de la precipitación. El mes de junio $R$ es significativo al nivel de 0,01 y en julio al nivel de 0,05. Estos dos meses son también los que presentan valores de $S$ y $Z$ más significativos. De los meses en que se detectaron tendencias negativas, solamente en abril y diciembre no se puede rechazar la hipótesis nula de no tendencia.

Tabla 94. Test estadísticos Rho de Spearman y Mann-Kendall para la precipitación mensual de la Estación Arrancacepas - Cuenca del río Trabaque.

\begin{tabular}{|l|c|c|c|c|c|}
\hline \hline \multicolumn{1}{|c|}{ Mes } & Rho & $\begin{array}{c}\text { S de } \\
\text { Kendall }\end{array}$ & $\mathbf{Z}_{\mathbf{s}}$ & $\begin{array}{c}\text { Rechazo de hipótesis } \\
\text { nula para } \mathbf{p}<\mathbf{0 , 0 5}\end{array}$ & Valor $\boldsymbol{p}$ \\
\hline Enero & $-0,259$ & -124 & $-10,24$ & $\mathrm{Si}$ & 0,0001 \\
\hline Febrero & $-0,246$ & -119 & $-8,77$ & $\mathrm{Si}$ & 0,0001 \\
\hline Marzo & $-0,113$ & -74 & $-5,91$ & $\mathrm{Si}$ & 0,0001 \\
\hline Abril & $-0,031$ & -24 & $-1,48$ & $\mathrm{No}$ & 0,1389 \\
\hline Mayo & $-0,013$ & 2 & 0,08 & $\mathrm{No}$ & 0,9362 \\
\hline Junio & $-0,418\left(^{* *}\right)$ & -186 & $-14,93$ & $\mathrm{Si}$ & 0,0001 \\
\hline Julio & $-0,330\left(^{*}\right)$ & -164 & $-12,12$ & $\mathrm{Si}$ & 0,0001 \\
\hline Agosto & $-0,077$ & -33 & $-2,87$ & $\mathrm{Si}$ & 0,0041 \\
\hline Septiembre & 0,080 & 55 & 3,85 & $\mathrm{Si}$ & 0,0001 \\
\hline Octubre & 0,292 & 149 & 11,67 & $\mathrm{Si}$ & 0,0001 \\
\hline Noviembre & 0,049 & 17 & 1,25 & $\mathrm{No}$ & 0,2113 \\
\hline Diciembre & $-0,082$ & -18 & $-1,41$ & $\mathrm{No}$ & 0,1585 \\
\hline
\end{tabular}

Zs $>(+/-) 1,96$ se rechaza la hipótesis nula de no tendencia

Valor $p<0,05$ se rechaza la hipótesis nula de no tendencia

* $=$ Correlación significativa al nivel de 0,05

** $=$ Correlación significativa al nivel de 0,01

El comportamiento mensual de la estación Torrecilla (Tabla 95) tiene bastante semejanza con la estación Albalate de las Nogueras. Con $\mathrm{R}$ y $\mathrm{M}-\mathrm{K}$ el único mes que presenta valores positivos es octubre, aunque solamente con $\mathrm{M}-\mathrm{K}$ es posible rechazar la hipótesis nula de no tendencia. En los demás meses se presentan valores negativos lo que sugiere una tendencia regresiva de la precipitación en todos ellos. Los coeficientes de correlación de febrero, marzo, junio y julio son significativos al nivel de 0,05 y con M-K se puede rechazar la hipótesis nula de no tendencia en todos los meses. Igual que ocurría con $\mathrm{R}$, los meses que presentan valores más altos del $\mathrm{S}$ y $\mathrm{Z}$ son febrero, marzo, junio y julio y el mes en que estos valores son más bajos es abril. 
Tabla 95. Test estadísticos Rho de Spearman y Mann-Kendall para la precipitación mensual de la Estación Torrecilla - Cuenca del río Trabaque.

\begin{tabular}{|l|c|c|c|c|c|}
\hline \hline \multicolumn{1}{|c|}{ Mes } & Rho & $\begin{array}{c}\text { S de } \\
\text { Kendall }\end{array}$ & $\mathbf{Z}_{\mathbf{s}}$ & $\begin{array}{c}\text { Rechazo de hipótesis } \\
\text { nula para } \mathbf{p}<\mathbf{0 , 0 5}\end{array}$ & Valor $\boldsymbol{p}$ \\
\hline \hline Enero & $-0,242$ & -199 & $-11,95$ & $\mathrm{Si}$ & 0,0001 \\
\hline Febrero & $-0,308\left(^{*}\right)$ & -246 & $-12,57$ & $\mathrm{Si}$ & 0,0001 \\
\hline Marzo & $-0,320\left(^{*}\right)$ & -283 & $-14,71$ & $\mathrm{Si}$ & 0,0001 \\
\hline Abril & $-0,017$ & -45 & $-2,35$ & $\mathrm{Si}$ & 0,0188 \\
\hline Mayo & $-0,173$ & -134 & $-7,52$ & $\mathrm{Si}$ & 0,0001 \\
\hline Junio & $-0,341\left(^{*}\right)$ & -304 & $-17,41$ & $\mathrm{Si}$ & 0,0001 \\
\hline Julio & $-0,299\left(^{*}\right)$ & -255 & $-13,88$ & $\mathrm{Si}$ & 0,0001 \\
\hline Agosto & $-0,083$ & -105 & $-6,43$ & $\mathrm{Si}$ & 0,0001 \\
\hline Septiembre & $-0,128$ & -79 & $-4,08$ & $\mathrm{Si}$ & 0,0001 \\
\hline Octubre & 0,050 & 44 & 2,72 & $\mathrm{Si}$ & 0,0065 \\
\hline Noviembre & $-0,087$ & -75 & $-3,69$ & $\mathrm{Si}$ & 0,0001 \\
\hline Diciembre & $-0,236$ & -207 & $-11,21$ & $\mathrm{Si}$ & 0,0001 \\
\hline \hline
\end{tabular}

Zs $>(+/-) 1,96$ se rechaza la hipótesis nula de no tendencia

Valor $p<0,05$ se rechaza la hipótesis nula de no tendencia

* $=$ Correlación significativa al nivel de 0,05

La tabla 96 refleja los datos mensuales de precipitación de la estación Villar de Domingo García y es posible ver que solamente los meses de agosto y octubre presentan valores de R positivos, aunque muy próximos a cero. Sin embargo, con M-K en ambos meses se puede rechazar la hipótesis nula de no tendencia.

Tabla 96. Test estadísticos Rho de Spearman y Mann-Kendall para la precipitación mensual de la Estación Villar de Domingo García - Cuenca del río Trabaque.

\begin{tabular}{|l|c|c|c|c|c|}
\hline \hline \multicolumn{1}{|c|}{ Mes } & Rho & $\begin{array}{c}\text { S de } \\
\text { Kendall }\end{array}$ & $\mathbf{Z}_{\mathbf{s}}$ & $\begin{array}{c}\text { Rechazo de hipótesis } \\
\text { nula para } \mathbf{p}<\mathbf{0 , 0 5}\end{array}$ & Valor $\boldsymbol{p}$ \\
\hline \hline Enero & $-0,201$ & -170 & $-10,99$ & $\mathrm{Si}$ & 0,0001 \\
\hline Febrero & $-0,252$ & -247 & $-13,15$ & $\mathrm{Si}$ & 0,0001 \\
\hline Marzo & $-0,241$ & -196 & $-9,88$ & $\mathrm{Si}$ & 0,0001 \\
\hline Abril & $-0,015$ & -6 & $-0,29$ & $\mathrm{No}$ & 0,7718 \\
\hline Mayo & $-0,072$ & -49 & $-2,75$ & $\mathrm{Si}$ & 0,0060 \\
\hline Junio & $-0,341\left(^{*}\right)$ & -283 & $-16,41$ & $\mathrm{Si}$ & 0,0001 \\
\hline Julio & $-0,204$ & -161 & $-9,63$ & $\mathrm{Si}$ & 0,0001 \\
\hline Agosto & 0,072 & 63 & 3,33 & $\mathrm{Si}$ & 0,0009 \\
\hline Septiembre & $-0,108$ & -75 & $-4,31$ & $\mathrm{Si}$ & 0,0001 \\
\hline Octubre & 0,092 & 88 & 5,22 & $\mathrm{Si}$ & 0,0001 \\
\hline Noviembre & $-0,115$ & -88 & $-5,05$ & $\mathrm{Si}$ & 0,0001 \\
\hline Diciembre & $-0,176$ & -98 & $-6,46$ & $\mathrm{Si}$ & 0,0001 \\
\hline \hline
\end{tabular}

Zs $>$ (+/-) 1,96 se rechaza la hipótesis nula de no tendencia

Valor $p<0,05$ se rechaza la hipótesis nula de no tendencia

* = Correlación significativa al nivel de 0,05 
En todos los demás meses se encuentran valores negativos de los estadísticos $\mathrm{R}$ y $\mathrm{M}$ K. Valores de R significativos al nivel de 0,05 , fueron localizados solamente para el mes de junio. El mes de abril presenta un $R$ negativo muy próximo a cero $(-0,015)$, confirmado por los valores del M-K y es el único mes en que no se puede rechazar la hipótesis nula de no tendencia. Debido a los valores observados, no se puede considerar que haya ninguna tendencia en este mes. En todos los demás meses, con $\mathrm{M}-\mathrm{K}$, se puede rechazar la hipótesis nula de no tendencia y los valores más altos de $\mathrm{S}$ y $Z$ fueron detectados en los meses de junio, de febrero y marzo.

De acuerdo con el comportamiento mensual de la precipitación encontrado para todas las estaciones analizadas, se puede ver que en la mayoría de los meses hay fuertes tendencias regresivas, como ocurría también con los datos anuales.

\subsection{Evolución de la Temperatura en las Cuencas de los Ríos Cega, Porma, Tajo y Trabaque}

Para el análisis de las temperaturas de las cuencas de los ríos Cega, Porma, Tajo y Trabaque se hizo un estudio detallado a escala anual y mensual a partir de la caracterización de la temperatura en cada una de ellas y de los análisis estadísticos que tienen como objetivo principal evaluar la evolución de la temperatura y detectar si hay alguna tendencia. Todos los análisis fueron hechos por el período de 38 años comprendido entre 1969 y 2006. Como ya se comentó en el apartado Material y Métodos, este es el período común para todas las cuencas y fue seleccionado para posibilitar comparaciones entre ellas.

\subsubsection{Evolución de la Temperatura en la Cuenca Del Río Cega}

\subsubsection{Caracterización de la temperatura}

La temperatura media anual encontrada para todo el período analizado en la cuenca del río Cega es de $9,6^{\circ} \mathrm{C}$, con un coeficiente de variación de $7,9 \%$, lo que indica que en esta cuenca hay bastante regularidad en la temperatura en la serie estudiada (Fig. 111). La temperatura mínima absoluta encontrada fue $-19,0^{\circ} \mathrm{C}$ en dos fechas distintas, 26 de diciembre de 1970 y 01 de marzo de 2005 y la media de las temperaturas mínimas fue $3,4^{\circ} \mathrm{C}$. Por otro lado, la temperatura máxima absoluta registrada fue 37,5 
${ }^{\circ} \mathrm{C}$ el día 24 de julio de 1995 y la media de las temperaturas máximas fue $15,9{ }^{\circ} \mathrm{C}$. La temperatura media anual registró en 1972 su valor mínimo, que fue de $8,4^{\circ} \mathrm{C}$, y su valor máximo se registró en 1995 con $11,1^{\circ} \mathrm{C}$.

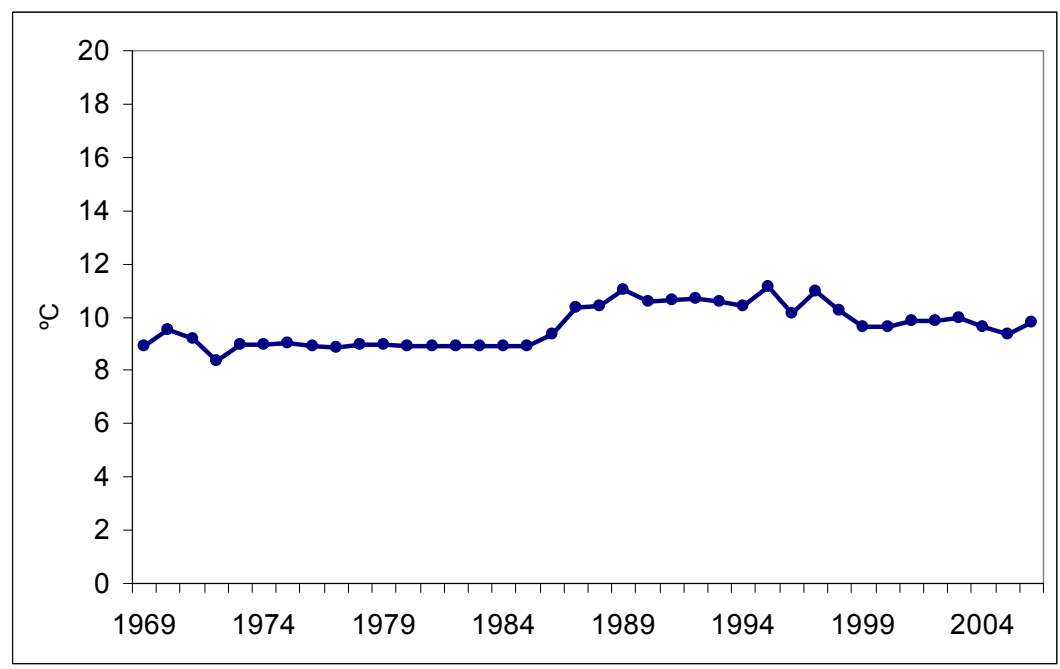

Figura 111 - Evolución de la temperatura media anual en la estación Rascafria - Cuenca del Río Cega.

Existe una gran oscilación entre los valores del coeficiente de variación mensual (Tabla 97). El mes que presenta más variabilidad es febrero, con un $44,4 \%$, seguido de enero con un $44,1 \%$ y diciembre con un $42,2 \%$. Los meses con más alta variabilidad coinciden con los de invierno y los meses con coeficientes de variación más bajo son los del verano. Agosto es el mes que tiene menos variabilidad, seguido de julio y junio.

Tabla 97. Estadística básica de la temperatura media mensual y anual de la cuenca del río Cega - Estación Rascafria.

\begin{tabular}{|c|c|c|c|c|c|}
\hline \hline Período & $\begin{array}{c}\text { Media } \\
{ }^{\circ} \mathbf{C}\end{array}$ & $\begin{array}{c}\text { Desviación Típica } \\
{ }^{\circ} \mathbf{C}\end{array}$ & $\begin{array}{c}\text { Mínimo } \\
{ }^{\circ} \mathbf{C}\end{array}$ & $\begin{array}{c}\text { Máximo } \\
{ }^{\circ} \mathbf{C}\end{array}$ & $\begin{array}{c}\text { Coeficiente de Variación } \\
\%\end{array}$ \\
\hline ANUAL & 9,6 & 0,8 & 8,4 & 11,1 & 7,9 \\
\hline ENE & 2,7 & 1,2 & 0,0 & 5,1 & 44,1 \\
\hline FEB & 3,6 & 1,6 & $-0,2$ & 7,1 & 44,4 \\
\hline MAR & 5,5 & 1,9 & 2,0 & 9,4 & 34,2 \\
\hline ABR & 7,7 & 1,2 & 4,2 & 10,9 & 15,5 \\
\hline MAY & 11,1 & 1,1 & 8,8 & 13,6 & 9,8 \\
\hline JUN & 15,2 & 1,4 & 13,2 & 18,5 & 8,9 \\
\hline JUL & 18,3 & 1,1 & 12,5 & 20,3 & 6,3 \\
\hline AGO & 18,0 & 1,0 & 16,2 & 20,2 & 5,3 \\
\hline SEP & 14,4 & 1,2 & 11,6 & 17,5 & 8,1 \\
\hline OCT & 10,3 & 1,1 & 6,9 & 12,7 & 10,6 \\
\hline NOV & 5,9 & 1,1 & 3,2 & 8,2 & 19,2 \\
\hline DIC & 3,1 & 1,3 & 0,3 & 6,1 & 42,2 \\
\hline \hline
\end{tabular}




\subsubsection{Análisis de tendencias}

Para evaluar las tendencias en los valores de la temperatura se hizo un estudio de las mínimas, de las máximas y de la temperatura media. Los métodos estadísticos utilizados fueron, como en el caso de las precipitaciones, el coeficiente de correlación Rho de Spearman, Mann Kendall y Mann Kendall en su versión secuencial.

En la estación Rascafria (Tabla 98) todos los valores de $\mathrm{R}$ son positivos reflejando una tendencia progresiva de la temperatura. Aunque en el caso de las mínimas anuales no se puede hablar en tendencia ya que el coeficiente de correlación es muy próximo a cero $(R=0,019)$. Sin embargo, tanto en la temperatura máxima anual $(0,761)$, como en la media anual $(0,616)$, $R$ presenta valores bastante altos y significativos al nivel de 0,01 . Estos valores encontrados con $R$ muestran de forma evidente que está habiendo un fuerte aumento en las temperaturas, sobre todo en la máxima anual.

Tabla 98. Coeficiente de correlación (Rho de Spearman) entre las temperaturas mínima, máxima y media anual y el tiempo en la cuenca del río Cega - Estación Rascafria.

\begin{tabular}{|l|c|c|c|}
\hline \hline $\begin{array}{c}\text { Estación Termométrica } \\
\text { Rascafria }\end{array}$ & N & $\begin{array}{c}\text { Signif. } \\
\text { Estad. }\end{array}$ & R \\
\hline \hline Temperatura Mínima Anual & 38 & NS & 0,019 \\
\hline Temperatura Máxima Anual & 38 & ${ }^{* *}$ & 0,761 \\
\hline Temperatura Media Anual & 38 & ${ }^{* *}$ & 0,616 \\
\hline \hline
\end{tabular}

NS = Valores no significativos estadísticamente

** $=$ Correlación significativa al nivel de 0,01

Según lo encontrado con M-K (Tabla 99) hay una pequeña diferencia para la temperatura mínima con relación al detectado con $\mathrm{R}$, ya que con $\mathrm{M}-\mathrm{K}$ se aprecia una ligera tendencia negativa. Sin embargo, los valores de $S$ y $Z$ son también muy bajos, lo que hace creer que las temperaturas mínimas no vienen sufriendo ningún tipo de tendencia. Más bien pueden ser oscilaciones consideradas normales en el tiempo. Por otro lado, las máximas y las medias, presentan una clara tendencia positiva ya detectada anteriormente con $\mathrm{R}$ y confirmada con M-K. En ambas de puede rechazar la hipótesis nula de no tendencia y con valores bastante significativos. 
Tabla 99. Test estadístico Mann-Kendall para las temperaturas mínima, máxima y media anual en la estación Rascafria - Cuenca del río Cega.

\begin{tabular}{|l|c|c|c|c|}
\hline \hline \multicolumn{1}{|c|}{ Estación Rascafria } & $\begin{array}{c}\mathbf{S} \text { de } \\
\text { Kendall }\end{array}$ & $\mathbf{Z}_{\mathbf{s}}$ & $\begin{array}{c}\text { Rechazo de hipótesis } \\
\text { nula para } \mathbf{p}<\mathbf{0 , 0 5}\end{array}$ & Valor $\boldsymbol{p}$ \\
\hline \hline Temperatura Mínima Anual & -31 & $-2,95$ & $\mathrm{Si}$ & 0,0032 \\
\hline Temperatura Máxima Anual & 371 & 29,02 & $\mathrm{Si}$ & 0,0001 \\
\hline Temperatura Media Anual & 241 & 17,61 & $\mathrm{Si}$ & 0,0001 \\
\hline \hline
\end{tabular}

Zs $>(+/-) 1,96$ se rechaza la hipótesis nula de no tendencia Valor $p<0,05$ se rechaza la hipótesis nula de no tendencia

El estadístico M-K en su versión secuencial fue utilizado para intentar localizar el año de inicio de las tendencias detectadas anteriormente, por lo tanto sólo se analizó para las temperaturas máximas y medias. En el caso de las máximas anuales (Fig. 112), no se puede definir con seguridad en qué año ha empezado la tendencia positiva detectada anteriormente pues hay más de una intersección entre las estadísticas $u(t)$ y $\mathrm{u}^{*}(\mathrm{t})$. No obstante se afirma que a partir de 1987 se aprecia claramente la fuerte tendencia positiva detectada anteriormente, que llega a ser considerada significativa a partir de 1990.

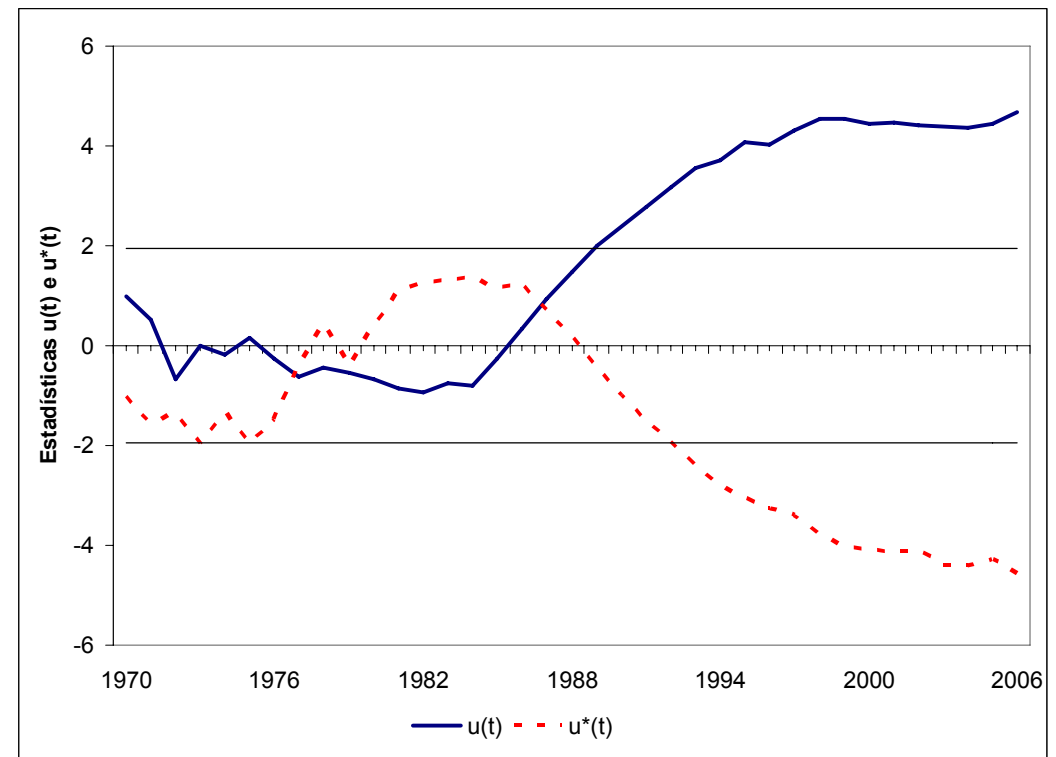

Figura 112 - Test Mann-Kendall secuencial para la temperatura máxima anual - Estación Rascafria, Cuenca del río Cega. 
Todos estos resultados están en consonancia con el fuerte aumento de la temperatura a partir de la década de los 90 del siglo pasado, observado en innumerables regiones (Hanssen-Bauer et al. 2000; Brunetti et al. 2004; Del Río et al. 2005; Brunet et al. 2005; Hanssen-Bauer, 2005).

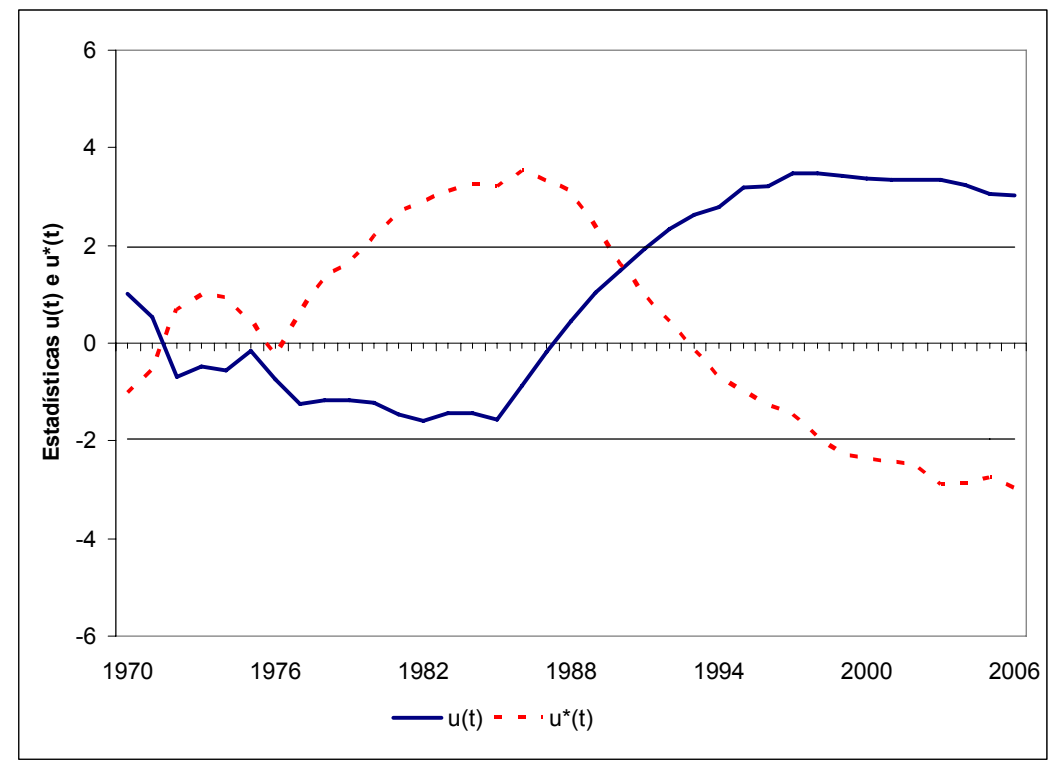

Figura 113 - Test Mann-Kendall secuencial para la temperatura media anual - Estación Rascafria, Cuenca del río Cega.

Los resultados encontrados con M-Ks para la temperatura media anual (Fig. 113) no permiten detectar con seguridad en qué año ha empezado la tendencia positiva demostrada anteriormente por haber más de una intersección entre las estadísticas $u$ (t) $\mathrm{y} \mathrm{u}^{*}(\mathrm{t})$. Sin embargo, no hay dudas de que a partir de 1990 hay una tendencia progresiva bastante fuerte, llegando a ser considerada significativa a partir de 1992.

El análisis de regresión ha permitido determinar que la temperatura en la cuenca del río Cega tuvo un aumento de $0,04^{\circ} \mathrm{C}$ a cada año, representando una progresión de $1,52^{\circ} \mathrm{C}$ en todo el período estudiado (38 años).

Debido a los fuertes valores de las tendencias encontrados a escala anual para las temperaturas máximas y medias se ha hecho un análisis mensual para intentar localizar los meses que tienen más influencia en este comportamiento.

Los análisis mensuales realizados para las temperaturas máximas (Tabla 100) ratifican claramente las fuertes tendencias positivas encontradas a escala anual. 
Tabla 100. Test estadísticos Rho de Spearman y Mann-Kendall para la temperatura máxima mensual de la Estación Rascafria - Cuenca del río Cega.

\begin{tabular}{|l|c|c|c|c|c|}
\hline \hline \multicolumn{1}{|c|}{ Mes } & Rho & $\begin{array}{c}\text { S de } \\
\text { Kendall }\end{array}$ & $\mathbf{Z}_{\mathbf{s}}$ & $\begin{array}{c}\text { Rechazo de hipótesis } \\
\text { nula para } \mathbf{p}<\mathbf{0 , 0 5}\end{array}$ & Valor $\boldsymbol{p}$ \\
\hline \hline Enero & 0,227 & 115 & 10,28 & $\mathrm{Si}$ & 0,0001 \\
\hline Febrero & $0,435\left(^{* *}\right)$ & 229 & 20,44 & $\mathrm{Si}$ & 0,0001 \\
\hline Marzo & $0,68\left(^{* *}\right)$ & 317 & 23,14 & $\mathrm{Si}$ & 0,0001 \\
\hline Abril & $\left.0,492^{* *}\right)$ & 217 & 22,62 & $\mathrm{Si}$ & 0,0001 \\
\hline Mayo & $0,699\left(^{* *}\right)$ & 343 & 27,07 & $\mathrm{Si}$ & 0,0001 \\
\hline Junio & $0,81\left(^{* *}\right)$ & 439 & 45,95 & $\mathrm{Si}$ & 0,0001 \\
\hline Julio & $0,487\left(^{* *}\right)$ & 253 & 22,23 & $\mathrm{Si}$ & 0,0001 \\
\hline Agosto & $0,640\left(^{* *}\right)$ & 333 & 21,44 & $\mathrm{Si}$ & 0,0001 \\
\hline Septiembre & $0,476\left(^{* *}\right)$ & 240 & 16,56 & $\mathrm{Si}$ & 0,0001 \\
\hline Octubre & $-0,052$ & -37 & $-3,66$ & $\mathrm{Si}$ & 0,0003 \\
\hline Noviembre & 0,155 & 121 & 8,75 & $\mathrm{Si}$ & 0,0001 \\
\hline Diciembre & $0,588\left(^{* *}\right)$ & 297 & 20,45 & $\mathrm{Si}$ & 0,0001 \\
\hline
\end{tabular}

Zs $>(+/-) 1,96$ se rechaza la hipótesis nula de no tendencia Valor $p<0,05$ se rechaza la hipótesis nula de no tendencia ** $=$ Correlación significativa al nivel de 0,01

Solamente el mes de octubre presenta una ligera tendencia negativa, pues con M-K se puede rechazar la hipótesis nula de no tendencia, aunque con valores bajos y de poca significación. Todos los demás meses presentan resultados positivos. Los meses de noviembre y enero son los únicos que no presentan coeficientes de correlación significativos. No obstante, en todos ellos con M-K se puede rechazar la hipótesis nula de no tendencia. En los meses de junio y julio es donde se encuentran los valores más fuertes de significación estadística. Pero no hay dudas de que en la mayoría de los meses se aprecia en los últimos años un aumento considerable de las temperaturas máximas.

Los resultados de los estadísticos $\mathrm{R}$ y $\mathrm{M}-\mathrm{K}$ para la temperatura media mensual (Tabla 101) verifican los encontrados a escala anual y están en consonancia con lo encontrado para la temperatura máxima mensual.

También en este caso, solamente el mes de octubre presenta una ligera tendencia regresiva $(R=-0,117, S=-32$ y $Z=-2.98)$. En los demás meses se observa una tendencia positiva que con $\mathrm{R}$ es considerada significativa al nivel de 0,05 en febrero, abril, agosto, septiembre y diciembre. A su vez los meses de marzo, mayo y junio presentan $R$ significativos al nivel de 0,01 . Por otro lado, con $M-K$, en todos los meses se puede rechazar la hipótesis nula de no tendencia. Junio, marzo y mayo son los que 
presentan mayor significación estadística. La primavera y el verano son las estaciones donde más se aprecia la subida de las temperaturas medias mensuales.

Tabla 101. Test estadísticos Rho de Spearman y Mann-Kendall para la temperatura media mensual de la Estación Rascafria - Cuenca del río Cega.

\begin{tabular}{|l|c|c|c|c|c|}
\hline \multicolumn{1}{|c|}{ Mes } & Rho & $\begin{array}{c}\text { S de } \\
\text { Kendall }\end{array}$ & $\mathbf{Z}_{\mathbf{s}}$ & $\begin{array}{c}\text { Rechazo de hipótesis } \\
\text { nula para } \mathbf{p}<\mathbf{0 , 0 5}\end{array}$ & Valor $\boldsymbol{p}$ \\
\hline Enero & 0,086 & 53 & 4,22 & $\mathrm{Si}$ & 0,0001 \\
\hline Febrero & $0,334\left(^{*}\right)$ & 183 & 16,22 & $\mathrm{Si}$ & 0,0001 \\
\hline Marzo & $0,672\left(^{* *}\right)$ & 323 & 22,06 & $\mathrm{Si}$ & 0,0001 \\
\hline Abril & $0,344\left(^{*}\right)$ & 131 & 12,72 & $\mathrm{Si}$ & 0,0001 \\
\hline Mayo & $0,575\left(^{* *}\right)$ & 273 & 23,94 & $\mathrm{Si}$ & 0,0001 \\
\hline Junio & $0,806\left(^{* *}\right)$ & 426 & 40,39 & $\mathrm{Si}$ & 0,0001 \\
\hline Julio & 0,266 & 123 & 11,07 & $\mathrm{Si}$ & 0,0001 \\
\hline Agosto & $0,404\left(^{*}\right)$ & 208 & 14,47 & $\mathrm{Si}$ & 0,0001 \\
\hline Septiembre & $0,391\left(^{*}\right)$ & 207 & 13,77 & $\mathrm{Si}$ & 0,0001 \\
\hline Octubre & $-0,117$ & -32 & $-2,98$ & $\mathrm{Si}$ & 0,0029 \\
\hline Noviembre & 0,178 & 98 & 7,77 & $\mathrm{Si}$ & 0,0001 \\
\hline Diciembre & $0,378\left(^{*}\right)$ & 201 & 13,75 & $\mathrm{Si}$ & 0,0001 \\
\hline \hline
\end{tabular}

Zs $>(+/-) 1,96$ se rechaza la hipótesis nula de no tendencia

Valor $p<0,05$ se rechaza la hipótesis nula de no tendencia

* = Correlación significativa al nivel de 0,05

** = Correlación significativa al nivel de 0,01

Todos los análisis estadísticos hechos para la temperatura en la estación Rascafria (Cuenca del río Cega) dejan claro una fuerte tendencia progresiva en las temperaturas máximas y medias anuales.

\subsubsection{Evolución de la Temperatura en la Cuenca Del Río Porma}

\subsubsection{Caracterización de la temperatura}

En la cuenca del río Porma la temperatura media anual en el período estudiado es de $8,7^{\circ} \mathrm{C}$, con un coeficiente de variación de $6,8 \%$, reflejando una variabilidad baja y una gran regularidad en la temperatura (Fig. 114).

El valor mínimo absoluto de temperatura encontrado en la serie fue de $-20,0{ }^{\circ} \mathrm{C}$ en el día 09/02/1986 y la media de las mínimas fue $2,2^{\circ}{ }^{\circ} \mathrm{C}$. La máxima absoluta diaria fue de $35,8{ }^{\circ} \mathrm{C}$ en el día 19/07/1969 y la media de las máximas fue $15,2{ }^{\circ} \mathrm{C}$. La temperatura media anual registró en el año de 1993 su valor mínimo que fue de $7,4^{\circ} \mathrm{C}$ y la media anual tuvo su valor máximo en el año de 1983 con $9,9^{\circ} \mathrm{C}$. 


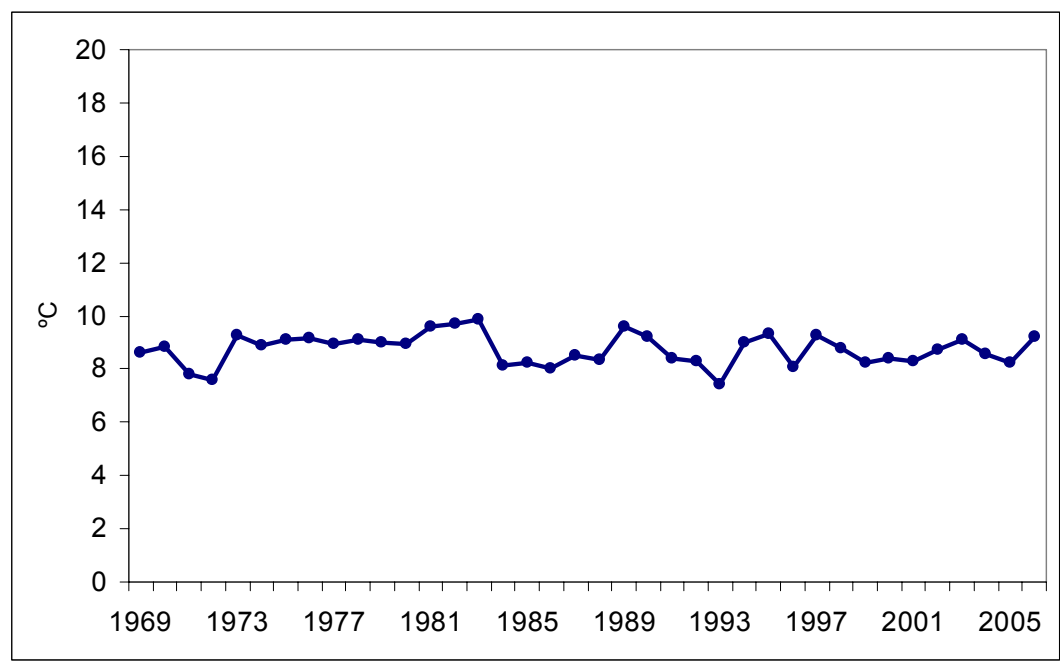

Figura 114 - Evolución de la temperatura media anual en la estación Pantano del Porma - Cuenca del Río Porma.

Como ocurría en la cuenca del río Cega, en la estación Pantano del Porma (Tabla 102), hay grandes oscilaciones entre los valores del coeficiente de variación mensual, lo que demuestra la gran variabilidad entre los valores de la temperatura en los distintos meses.

Tabla 102. Estadística básica de la temperatura media mensual y anual de la cuenca del río Porma - Estación Pantano del Porma.

\begin{tabular}{|c|c|c|c|c|c|}
\hline \hline Período & $\begin{array}{c}\text { Media } \\
{ }^{\circ} \mathbf{C}\end{array}$ & $\begin{array}{c}\text { Desviación Típica } \\
{ }^{\circ} \mathbf{C}\end{array}$ & $\begin{array}{c}\text { Mínimo } \\
{ }^{\circ} \mathbf{C}\end{array}$ & $\begin{array}{c}\text { Máximo } \\
{ }^{\circ} \mathbf{C}\end{array}$ & $\begin{array}{c}\text { Coeficiente de Variación } \\
\%\end{array}$ \\
\hline \hline ANUAL & 8,7 & 0,6 & 7,4 & 9,9 & 6,8 \\
\hline ENE & 1,7 & 1,4 & $-1,7$ & 4,2 & 84,7 \\
\hline FEB & 2,8 & 1,5 & $-0,4$ & 6,3 & 54,9 \\
\hline MAR & 5,0 & 1,4 & 2,1 & 8,2 & 28,6 \\
\hline ABR & 6,7 & 1,3 & 2,8 & 9,6 & 19,4 \\
\hline MAY & 10,1 & 1,3 & 6,1 & 13,1 & 13,1 \\
\hline JUN & 14,3 & 1,4 & 10,9 & 16,7 & 9,6 \\
\hline JUL & 16,8 & 1,1 & 14,7 & 19,0 & 6,9 \\
\hline AGO & 16,5 & 1,3 & 14,2 & 19,1 & 7,9 \\
\hline SEP & 13,7 & 1,8 & 10,0 & 16,9 & 12,9 \\
\hline OCT & 9,4 & 1,3 & 6,3 & 11,4 & 13,3 \\
\hline NOV & 5,2 & 1,5 & 2,0 & 9,6 & 29,1 \\
\hline DIC & 2,4 & 1,5 & $-0,9$ & 6,1 & 62,1 \\
\hline \hline
\end{tabular}

El mes que presenta más alta variabilidad es enero $(84,7 \%)$ seguido de diciembre $(62,1 \%)$ y febrero $(54,9 \%)$, todos con un coeficiente de variación por encima de $50 \%$ y todos meses invernales. Los meses de verano son los que presentan menor coeficiente de variación, inferior al 10\%. 


\subsubsection{Análisis de tendencias}

El coeficiente de correlación entre la temperatura y el tiempo (Tabla 103) demuestra que al contrario de lo ocurrido con la cuenca del río Cega, se ha detectado una ligera tendencia regresiva en las temperaturas mínima, máxima y media. En todos los casos se aprecian valores de $\mathrm{R}$ negativos, aunque en ninguno ha habido resultados significativos estadísticamente. Sobre todo en el caso de la temperatura mínima, debido a los valores de $\mathrm{R}$ próximos a cero, no se puede hablar en ninguna tendencia utilizando solamente este estadístico.

Tabla 103. Coeficiente de correlación (Rho de Spearman) entre las temperaturas mínima, máxima y media anual y el tiempo en la cuenca del río Porma - Estación Pantano del Porma.

\begin{tabular}{|l|c|c|c|}
\hline \hline $\begin{array}{c}\text { Estación Termométrica } \\
\text { Pantano del Porma }\end{array}$ & N & $\begin{array}{c}\text { Signif. } \\
\text { Estad. }\end{array}$ & R \\
\hline \hline Temperatura Mínima Anual & 38 & NS & $-0,087$ \\
\hline Temperatura Máxima Anual & 38 & NS & $-0,184$ \\
\hline Temperatura Media Anual & 38 & NS & $-0,111$ \\
\hline \hline
\end{tabular}

NS = Valores no significativos estadísticamente

Con M-K (Tabla 104) también se registra una ligera tendencia negativa en la temperatura. En el caso de la mínima anual no se puede rechazar la hipótesis nula de no tendencia. Estos resultados confirman lo visto anteriormente con R. Por lo tanto, no queda clara la tendencia de las temperaturas mínimas anuales. Sin embargo, en el caso de las máximas y medias, se puede rechazar la hipótesis nula de no tendencia, aunque los valores no son muy altos. Así, se observa una ligera tendencia regresiva de las temperaturas máximas y medias en la cuenca del río Porma.

Tabla 104. Test estadístico Mann-Kendall para las temperaturas mínima, máxima y media anual en la estación Pantano del Porma - Cuenca del río Porma

\begin{tabular}{|l|c|c|c|c|}
\hline \hline \multicolumn{1}{|c|}{ Estación Rascafria } & $\begin{array}{c}\mathbf{S} \text { de } \\
\text { Kendall }\end{array}$ & $\mathbf{Z}_{\mathbf{s}}$ & $\begin{array}{c}\text { Rechazo de hipótesis } \\
\text { nula para } \mathbf{p}<\mathbf{0 , 0 5}\end{array}$ & Valor $\boldsymbol{p}$ \\
\hline \hline Temperatura Mínima Anual & -25 & $-1,71$ & $\mathrm{No}$ & 0,0873 \\
\hline Temperatura Máxima Anual & -65 & $-4,86$ & $\mathrm{Si}$ & 0,0001 \\
\hline Temperatura Media Anual & -43 & $-3,18$ & $\mathrm{Si}$ & 0,0015 \\
\hline \hline
\end{tabular}

Zs $>$ (+/-) 1,96 se rechaza la hipótesis nula de no tendencia

Valor $p<0,05$ se rechaza la hipótesis nula de no tendencia 
Los resultados encontrados con el estadístico M-Ks, así como los análisis mensuales, no aportan ninguna información sustancial y por lo tanto no han sido incluidos en el caso de la cuenca del río Porma.

Por todo expuesto no queda claro ninguna tendencia en los valores de la temperatura, más bien hacen creer que lo que ocurre son oscilaciones normales en el tiempo.

\subsubsection{Evolución de la Temperatura en la Cuenca Del Tajo}

\subsubsection{Caracterización de la temperatura}

La temperatura media anual encontrada en la estación Cañizares (Fig. 115) fue de $11,3^{\circ} \mathrm{C}$, con un coeficiente de variación de $7,4 \%$, que demuestra bastante regularidad en la evolución de la temperatura en la serie analizada.

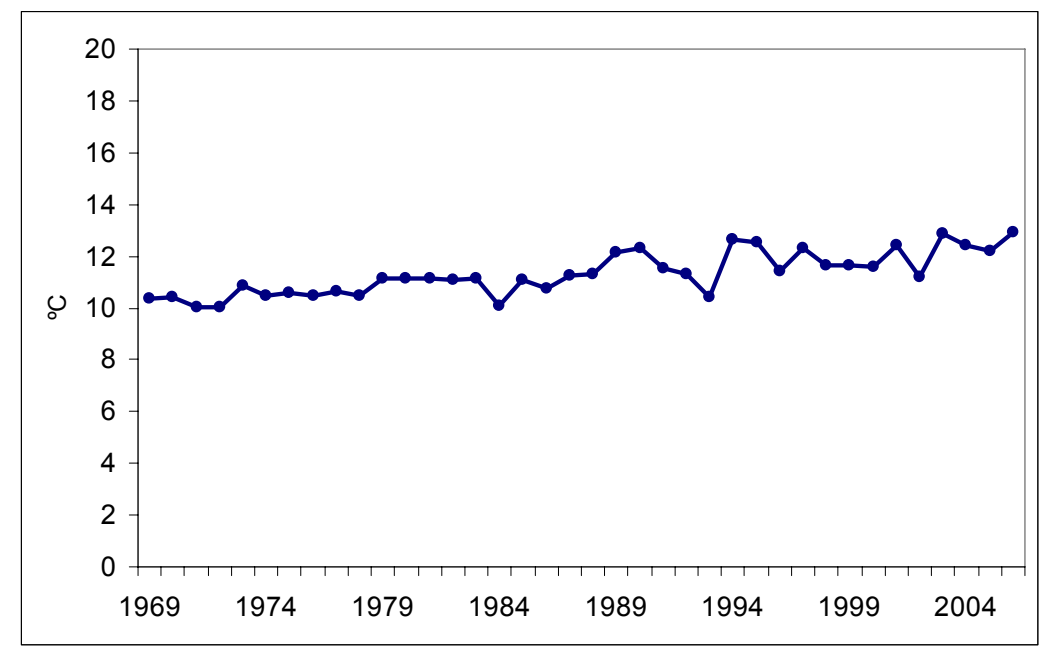

Figura 115 - Evolución de la temperatura media anual en la estación Cañizares - Cuenca del río Tajo.

El día 3 de enero de 1971 registró la temperatura mínima absoluta más baja, con -21,0 ${ }^{\circ} \mathrm{C}$. La media de las mínimas fue $2,7^{\circ} \mathrm{C}$. A su vez, la temperatura máxima absoluta más alta fue $40^{\circ} \mathrm{C}$ en los días 21, 23, 24 y 26 de julio de 1995. La media de las máximas fue $18,6^{\circ} \mathrm{C}$. En 1972 se registró la temperatura media anual mínima, que fue de $16,1^{\circ} \mathrm{C}$ y la media anual máxima fue $21,1^{\circ} \mathrm{C}$ en 1994 .

En la tabla 105 se puede ver que hay diferencias considerables entre los coeficientes de variación mensual. En los meses de invierno se dan los valores más altos. Sin 
embargo, los meses de junio, julio y agosto presentan los valores más bajos, siempre por debajo del $10 \%$.

Tabla 105. Estadística Básica de la temperatura media mensual y anual de la cuenca del río Tajo - Estación Cañizares.

\begin{tabular}{|c|c|c|c|c|c|}
\hline \hline Período & $\begin{array}{c}\text { Media } \\
{ }^{\circ} \mathbf{C}\end{array}$ & $\begin{array}{c}\text { Desviación Típica } \\
{ }^{\circ} \mathbf{C}\end{array}$ & $\begin{array}{c}\text { Mínimo } \\
{ }^{\circ} \mathbf{C}\end{array}$ & $\begin{array}{c}\text { Máximo } \\
{ }^{\circ} \mathbf{C}\end{array}$ & $\begin{array}{c}\text { Coeficiente de Variación } \\
\%\end{array}$ \\
\hline ANUAL & 11,3 & 0,8 & 10,0 & 12,9 & 7,4 \\
\hline ENE & 2,6 & 1,4 & $-1,0$ & 5,1 & 56,2 \\
\hline FEB & 3,8 & 1,7 & 1,1 & 7,5 & 44,8 \\
\hline MAR & 6,4 & 1,8 & 2,0 & 10,1 & 28,6 \\
\hline ABR & 8,5 & 1,5 & 4,8 & 11,6 & 17,1 \\
\hline MAY & 12,7 & 2,0 & 7,7 & 18,3 & 15,7 \\
\hline JUN & 17,4 & 1,6 & 14,4 & 20,6 & 9,2 \\
\hline JUL & 20,5 & 1,3 & 17,3 & 24,0 & 6,2 \\
\hline AGO & 20,0 & 1,5 & 15,9 & 23,4 & 7,3 \\
\hline SEP & 15,7 & 1,7 & 9,7 & 18,5 & 10,9 \\
\hline OCT & 10,8 & 1,8 & 6,3 & 13,8 & 16,3 \\
\hline NOV & 6,0 & 1,5 & 2,8 & 9,4 & 25,3 \\
\hline DIC & 3,4 & 1,3 & 0,4 & 6,5 & 39,4 \\
\hline \hline
\end{tabular}

\subsubsection{Análisis de tendencias}

La tabla 106 muestra los coeficientes de correlación entre los valores de temperatura y el tiempo para la estación Cañizares, y los resultados dejan claro una tendencia positiva bastante marcada.

La temperatura mínima tiene $\mathrm{R}$ significativo al nivel de 0,05 , y las temperaturas máximas al nivel de 0,01 . Los valores encontrados con el coeficiente de correlación dejan bastante claro que existe una tendencia progresiva de la temperatura.

Tabla 106. Coeficiente de correlación entre las temperaturas mínima, máxima y media anual y el tiempo en la cuenca del río Tajo - Estación Cañizares.

\begin{tabular}{|l|c|c|c|}
\hline \multicolumn{1}{|c|}{$\begin{array}{c}\text { Estación Termométrica } \\
\text { Cañizares }\end{array}$} & $\mathbf{n}$ & $\begin{array}{c}\text { Signif. } \\
\text { Estad. }\end{array}$ & R \\
\hline \hline Temperatura Mínima Anual & 38 & ${ }^{*}$ & 0,374 \\
\hline Temperatura Máxima Anual & 38 & ${ }^{* *}$ & 0,810 \\
\hline Temperatura Media Anual & 38 & ${ }^{* *}$ & 0,839 \\
\hline \hline
\end{tabular}

* = Correlación significativa al nivel de 0,05

** $=$ Correlación significativa al nivel de 0,01 
Los resultados encontrados con el estadístico M-K (Tabla 107) para las temperaturas mínimas, máximas y medias corroboran los valores encontrados con $\mathrm{R}$ y muestran una fuerte tendencia progresiva de esta variable en el tiempo. Como ocurrió con $\mathrm{R}$, la temperatura mínima es la que tiene valores más bajos de $S$ y $Z(189$ y 17,14), aún así es un valor bastante alto. En todos los casos se puede rechazar la hipótesis nula de no tendencia y los valores tan altos detectados dejan muy clara la tendencia positiva detectada anteriormente por el coeficiente de correlación.

Tabla 107. Test estadístico Mann-Kendall para las temperaturas mínima, máxima y media anual en la estación Cañizares - Cuenca del río Tajo.

\begin{tabular}{|l|c|c|c|c|}
\hline \hline \multicolumn{1}{|c|}{ Estación Cañizares } & $\begin{array}{c}\text { S de } \\
\text { Kendall }\end{array}$ & $\mathbf{Z}_{\mathbf{s}}$ & $\begin{array}{c}\text { Rechazo de hipótesis } \\
\text { nula para } \mathbf{p}<\mathbf{0 , 0 5}\end{array}$ & Valor $\boldsymbol{p}$ \\
\hline \hline Temperatura Mínima Anual & 189 & 17,14 & $\mathrm{Si}$ & 0,0001 \\
\hline Temperatura Máxima Anual & 443 & 34,14 & $\mathrm{Si}$ & 0,0001 \\
\hline Temperatura Media Anual & 457 & 39,85 & $\mathrm{Si}$ & 0,0001 \\
\hline
\end{tabular}

Zs $>(+/-) 1,96$ se rechaza la hipótesis nula de no tendencia Valor $p<0,05$ se rechaza la hipótesis nula de no tendencia

Con el objetivo de localizar el año de inicio de las tendencias detectadas anteriormente fue utilizado M-Ks. La figura 116 representa los resultados encontrados para la temperatura mínima anual y en este caso no se puede definir exactamente a partir de que año empezó la tendencia positiva de la temperatura, pues no hay ninguna intersección entre las estadísticas $u(t)$ y $u^{*}(t)$.

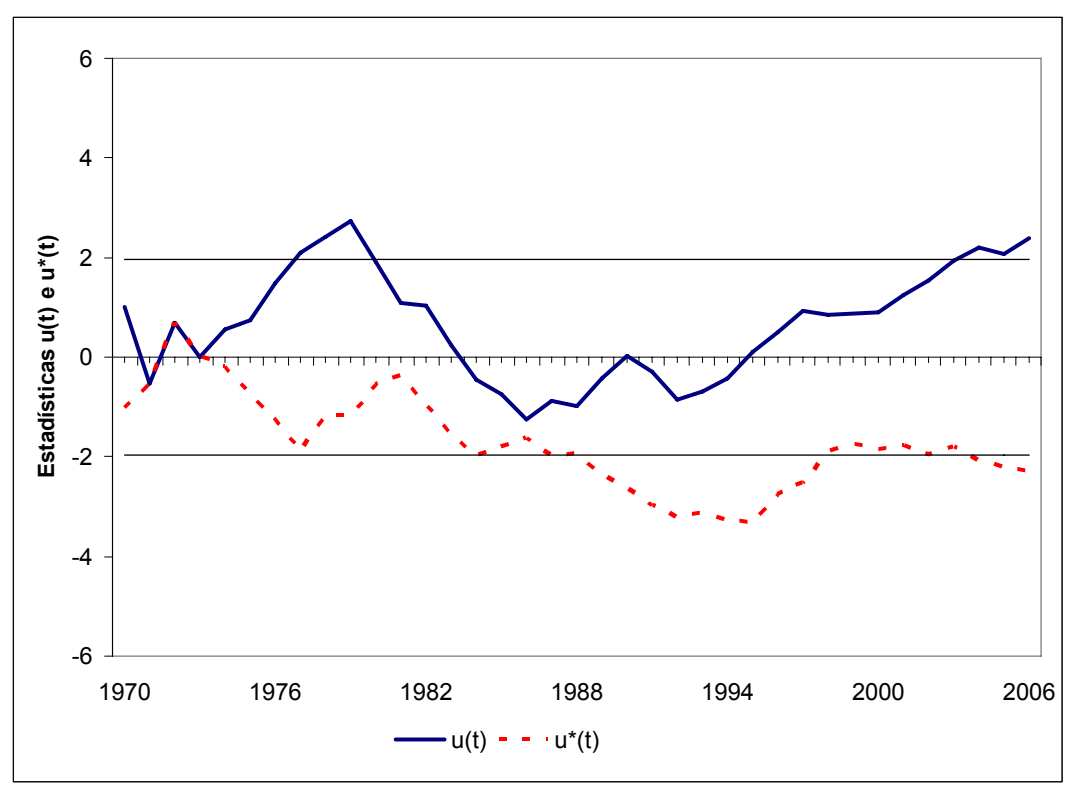

Figura 116 - Test Mann-Kendall secuencial para la temperatura mínima anual - Estación Cañizares, Cuenca del río Tajo. 
Lo que se observa es un período en que hay una coincidencia en los valores de estas estadísticas que va desde 1971 hasta 1973. A partir de este último año hay un período de oscilaciones hasta 1986 que es dónde empieza a notarse más claramente al aumento de las temperaturas que llegan a ser significativo a partir de 2004. Es bastante clara la tendencia positiva en el tiempo en los valores de la temperatura mínima en los últimos años, aunque no se pueda definir a partir de cuando ha empezado.

La tendencia positiva en la temperatura máxima en la estación Cañizares está muy claramente representada en la figura 117. Se puede ver claramente que hay una tendencia progresiva en los valores de la temperatura máxima en el tiempo y que esta tendencia empezó a partir de 1972, Ilegando a la significación estadística a partir de 1981. El análisis de la figura corrobora todos los valores encontrados anteriormente con $\mathrm{R}$ y $\mathrm{M}-\mathrm{K}$.

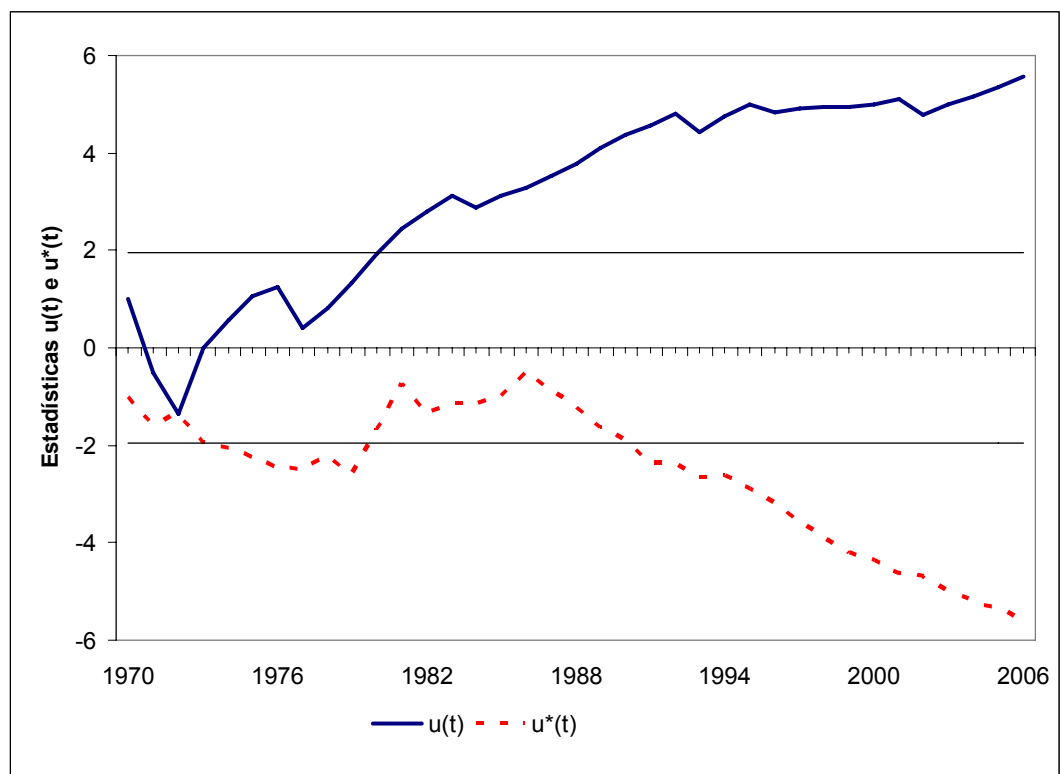

Figura 117 - Test Mann-Kendall secuencial para la temperatura máxima anual - Estación Cañizares, Cuenca del río Tajo

El comportamiento de la temperatura media anual (Fig. 118) según M-Ks se asemeja mucho al de las máximas. No se puede definir exactamente el año en que empezó la tendencia pues hay más de una intersección entre las curvas $u(t) y u^{*}(t)$. Sin embargo se observa claramente la tendencia positiva a partir de 1973 y ésta pasa a tener significación estadística desde 1980. 


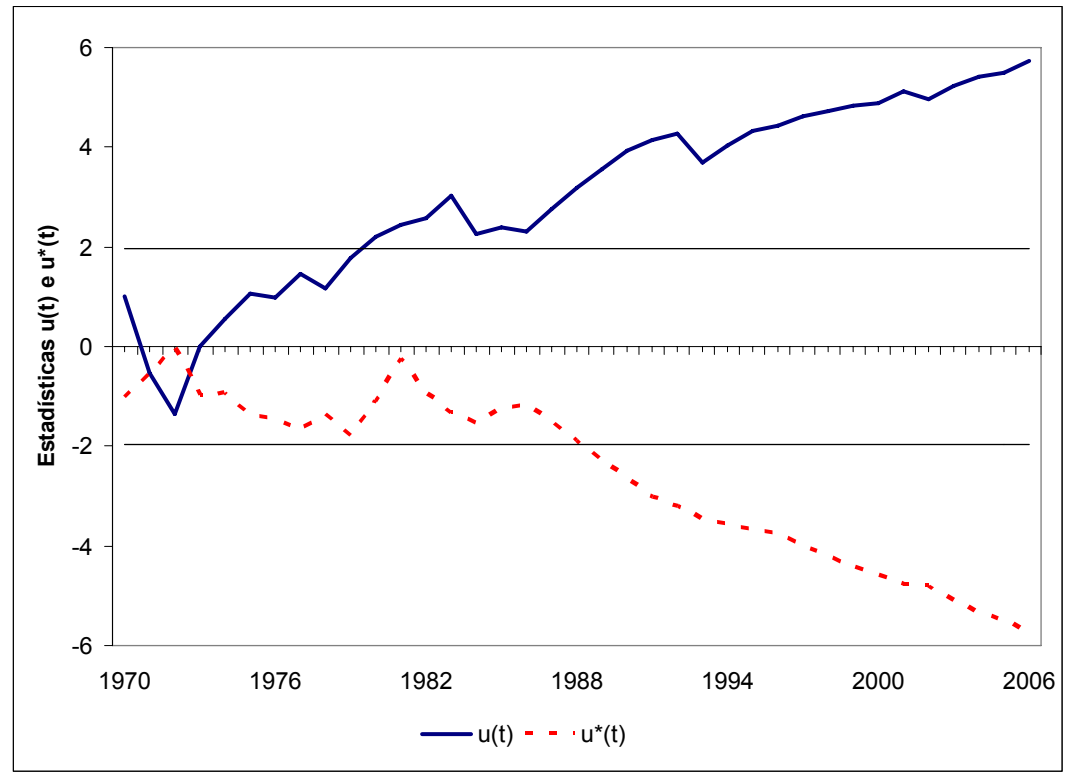

Figura 118 - Test Mann-Kendall secuencial para la temperatura media anual - Estación Cañizares, Cuenca del río Tajo

El resultado de los análisis de regresión demuestra un aumento de $0,06{ }^{\circ} \mathrm{C}$ en la temperatura media anual a cada año, lo que representa un total de $2,28{ }^{\circ} \mathrm{C}$ durante todo el período estudiado.

Los fuertes valores de tendencia encontrados a escala anual para las temperaturas mínimas, máximas y medias han llevado a un análisis de sus datos mensuales con la intención de ver los meses en que este aumento ha sido más pronunciado.

Para las temperaturas mínimas mensuales (Tabla 108) se puede ver que solamente los meses de febrero $(-0,128)$ y diciembre $(-0,160)$ presentan $R$ negativos, aunque sin valores estadísticamente significativos. Sin embargo, con $\mathrm{M}-\mathrm{K}$ se puede rechazar la hipótesis nula de no tendencia, aunque con valores no muy relevantes. Los demás meses reflejan resultados positivos, lo que sugiere una tendencia positiva en todos ellos. No obstante, sólo se constata significación estadística con $R$ en marzo (significativo al nivel de 0,05) y octubre (significativo al nivel de 0,01). Al considerar los resultados de $\mathrm{M}-\mathrm{K}$, en los meses con tendencia positiva, solamente en enero y junio no se puede rechazar la hipótesis nula de no tendencia. Los meses con más altos valores de $S$ y $Z$ son los otoñales (octubre y noviembre) y los primaverales (marzo y mayo). 
Tabla 108. Test estadísticos Rho de Spearman y Mann-Kendall para la temperatura mínima mensual de la Estación Cañizares - Cuenca del río Tajo

\begin{tabular}{|l|c|c|c|c|c|}
\hline \hline Mes & Rho & $\begin{array}{c}\text { S de } \\
\text { Kendall }\end{array}$ & $\mathbf{Z}_{\mathbf{s}}$ & $\begin{array}{c}\text { Rechazo de hipótesis } \\
\text { nula para } \mathbf{p}<\mathbf{0 , 0 5}\end{array}$ & Valor $\boldsymbol{p}$ \\
\hline \hline Enero & 0,047 & 21 & 1,78 & $\mathrm{No}$ & 0,0751 \\
\hline Febrero & $-0,128$ & -67 & $-4,79$ & $\mathrm{Si}$ & 0,0001 \\
\hline Marzo & $0,331\left(^{*}\right)$ & 176 & 13,18 & $\mathrm{Si}$ & 0,0001 \\
\hline Abril & 0,203 & 104 & 8,41 & $\mathrm{Si}$ & 0,0001 \\
\hline Mayo & 0,312 & 141 & 12,80 & $\mathrm{Si}$ & 0,0001 \\
\hline Junio & 0,067 & 19 & 1,61 & $\mathrm{No}$ & 0,1074 \\
\hline Julio & 0,183 & 90 & 7,58 & $\mathrm{Si}$ & 0,0001 \\
\hline Agosto & 0,121 & 50 & 3,87 & $\mathrm{Si}$ & 0,0001 \\
\hline Septiembre & 0,199 & 93 & 8,14 & $\mathrm{Si}$ & 0,0001 \\
\hline Octubre & $0,441\left(^{* *}\right)$ & 215 & 19,52 & $\mathrm{Si}$ & 0,0001 \\
\hline Noviembre & 0,299 & 139 & 10,46 & $\mathrm{Si}$ & 0,0001 \\
\hline Diciembre & $-0,160$ & -85 & $-7,06$ & $\mathrm{Si}$ & 0,0001 \\
\hline \hline
\end{tabular}

Zs $>(+/-) 1,96$ se rechaza la hipótesis nula de no tendencia

Valor $p<0,05$ se rechaza la hipótesis nula de no tendencia

* = Correlación significativa al nivel de 0,05

** $=$ Correlación significativa al nivel de 0,01

Corroborando los resultados encontrados anteriormente, la temperatura máxima mensual (Tabla 109) presenta valores positivos y fuertemente significativos en casi todos los meses.

Tabla 109. Test estadísticos Rho de Spearman y Mann-Kendall para la temperatura máxima mensual de la Estación Cañizares - Cuenca del río Tajo

\begin{tabular}{|l|c|c|c|c|c|}
\hline \hline \multicolumn{1}{|c|}{ Mes } & Rho & $\begin{array}{c}\text { S de } \\
\text { Kendall }\end{array}$ & $\mathbf{Z}_{\mathbf{s}}$ & $\begin{array}{c}\text { Rechazo de hipótesis } \\
\text { nula para } \mathbf{p}<\mathbf{0 , 0 5}\end{array}$ & Valor $\boldsymbol{p}$ \\
\hline \hline Enero & $0,479\left(^{* *}\right)$ & 237 & 17,51 & $\mathrm{Si}$ & 0,0001 \\
\hline Febrero & $0,505\left(^{* *}\right)$ & 233 & 19,39 & $\mathrm{Si}$ & 0,0001 \\
\hline Marzo & $0,687\left(^{* *}\right)$ & 348 & 25,65 & $\mathrm{Si}$ & 0,0001 \\
\hline Abril & $0,495\left(^{* *}\right)$ & 246 & 24,97 & $\mathrm{Si}$ & 0,0001 \\
\hline Mayo & $0,509\left(^{* *}\right)$ & 238 & 20,53 & $\mathrm{Si}$ & 0,0001 \\
\hline Junio & $0,557\left(^{* *}\right)$ & 284 & 26,02 & $\mathrm{Si}$ & 0,0001 \\
\hline Julio & 0,269 & 146 & 12,15 & $\mathrm{Si}$ & 0,0001 \\
\hline Agosto & $0,443\left(^{* *}\right)$ & 211 & 17,64 & $\mathrm{Si}$ & 0,0001 \\
\hline Septiembre & 0,248 & 123 & 9,33 & $\mathrm{Si}$ & 0,0001 \\
\hline Octubre & $0,372\left(^{*}\right)$ & 185 & 16,76 & $\mathrm{Si}$ & 0,0001 \\
\hline Noviembre & $0,356\left(^{*}\right)$ & 161 & 11,99 & $\mathrm{Si}$ & 0,0001 \\
\hline Diciembre & $0,599\left(^{* *}\right)$ & 280 & 19,47 & $\mathrm{Si}$ & 0,0001 \\
\hline \hline
\end{tabular}

Zs $>(+/-) 1,96$ se rechaza la hipótesis nula de no tendencia

Valor $p<0,05$ se rechaza la hipótesis nula de no tendencia

* = Correlación significativa al nivel de 0,05

** = Correlación significativa al nivel de 0,01 
Con $\mathrm{R}$, únicamente en julio y septiembre no se detecta significación estadística. Octubre y noviembre son significativos al nivel de 0,05 y todos los demás meses al nivel de 0,01 . Con $M-K$ se observa que en todos los meses se puede rechazar la hipótesis nula de no tendencia y además con valores bastantes relevantes, que no dejan dudas sobre la tendencia progresiva de la temperatura máxima.

En el caso de la temperatura media mensual (Tabla 110) se observa un comportamiento muy semejante al descrito anteriormente para las máximas. En todos los meses se dan valores positivos y en su mayoría con resultados bastante significativos. Con R, los meses febrero, julio, septiembre y diciembre no reflejan significación estadística. Enero, agosto y noviembre son significativos al nivel de 0,05 y los demás meses significativos al nivel de 0,01 . No obstante con M-K en todos ellos se puede rechazar la hipótesis nula de no tendencia y con valores muy significativos estadísticamente, sobre todo en marzo $(S=377$ y $Z=28,68)$ y octubre $(S=275$ y $Z=$ 24,96).

Tabla 110. Test estadísticos Rho de Spearman y Mann-Kendall para la temperatura media mensual de la Estación Cañizares - Cuenca del río Tajo

\begin{tabular}{|l|c|c|c|c|c|}
\hline \hline \multicolumn{1}{|c|}{ Mes } & Rho & $\begin{array}{c}\text { S de } \\
\text { Kendall }\end{array}$ & $\mathbf{Z}_{\mathbf{s}}$ & $\begin{array}{c}\text { Rechazo de hipótesis } \\
\text { nula para } \mathbf{p}<\mathbf{0 , 0 5}\end{array}$ & Valor $\boldsymbol{p}$ \\
\hline \hline Enero & $0,367\left(^{*}\right)$ & 180 & 14,80 & $\mathrm{Si}$ & 0,0001 \\
\hline Febrero & 0,299 & 131 & 12,32 & $\mathrm{Si}$ & 0,0001 \\
\hline Marzo & $0,738\left(^{* *}\right)$ & 377 & 28,68 & $\mathrm{Si}$ & 0,0001 \\
\hline Abril & $0,442\left(^{* *}\right)$ & 210 & 20,50 & $\mathrm{Si}$ & 0,0001 \\
\hline Mayo & $0,507\left(^{* *}\right)$ & 234 & 23,29 & $\mathrm{Si}$ & 0,0001 \\
\hline Junio & $0,474\left(^{* *}\right)$ & 236 & 22,65 & $\mathrm{Si}$ & 0,0001 \\
\hline Julio & 0,317 & 174 & 15,39 & $\mathrm{Si}$ & 0,0001 \\
\hline Agosto & $0,396\left(^{*}\right)$ & 188 & 14,86 & $\mathrm{Si}$ & 0,0001 \\
\hline Septiembre & 0,292 & 137 & 10,71 & $\mathrm{Si}$ & 0,0001 \\
\hline Octubre & $0,515\left(^{* *}\right)$ & 275 & 24,96 & $\mathrm{Si}$ & 0,0001 \\
\hline Noviembre & $0,402\left(^{*}\right)$ & 190 & 14,45 & $\mathrm{Si}$ & 0,0001 \\
\hline Diciembre & 0,215 & 77 & 5,76 & $\mathrm{Si}$ & 0,0001 \\
\hline \hline
\end{tabular}

Zs $>$ (+/-) 1,96 se rechaza la hipótesis nula de no tendencia

Valor $p<0,05$ se rechaza la hipótesis nula de no tendencia

* = Correlación significativa al nivel de 0,05

** $=$ Correlación significativa al nivel de 0,01

Todos los análisis de las temperaturas mínima, máxima y media, sea a escala anual o mensual, de la estación Cañizares, utilizada para estudio de la cuenca del Tajo no 
dejan dudas de que en las últimas décadas está habiendo un aumento bastante pronunciado de la temperatura.

\subsubsection{Evolución de la Temperatura en la Cuenca Del Río Trabaque}

\subsubsection{Caracterización de la temperatura}

En la cuenca del río Trabaque la temperatura media anual en el período estudiado es de $14,5^{\circ} \mathrm{C}$. Se puede destacar que es la temperatura media más alta encontrada entre las cuencas utilizadas para esta investigación. A su vez presentó un coeficiente de variación de 6,8\%, demostrando gran regularidad en la temperatura (Fig. 119).

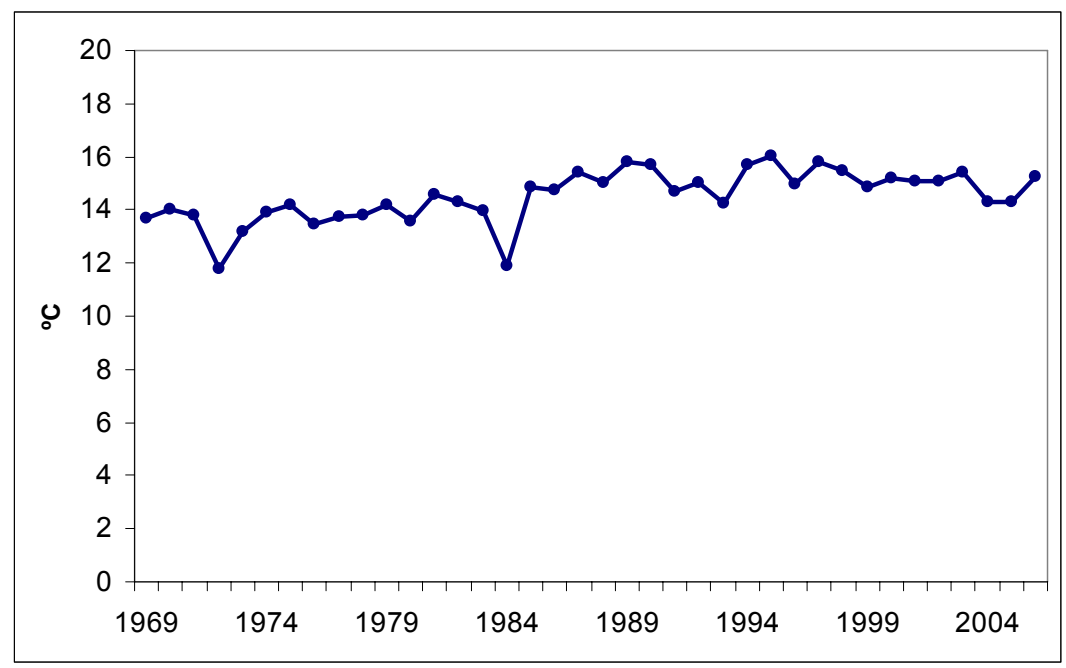

Figura 119 - Evolución de la temperatura media anual en la estación Arrancacepas Cuenca del Río Trabaque

El valor mínimo absoluto encontrado en toda la serie fue $-12,0{ }^{\circ} \mathrm{C}$ en el día 06 de marzo de 1971. La media de las mínimas registrada fue $7,6^{\circ} \mathrm{C}$. La máxima absoluta diaria fue $48{ }^{\circ} \mathrm{C}$ en el día 11 de agosto de 1969. La media de las máximas fue $21,5^{\circ} \mathrm{C}$. La temperatura media anual registró en 1972 su valor mínimo que fue de $11,8{ }^{\circ} \mathrm{C}$, mientras que la media anual tuvo su máximo en 1995 con $16,1^{\circ} \mathrm{C}$.

Como ocurriera en las otras cuencas, hay una gran oscilación entre los valores del coeficiente de variación mensual (Tabla 111). 
Tabla 111. Estadística básica de la temperatura media mensual y anual de la cuenca del río Trabaque - Estación Arrancacepas

\begin{tabular}{|c|c|c|c|c|c|}
\hline \hline Período & $\begin{array}{c}\text { Media } \\
{ }^{\circ} \mathbf{C}\end{array}$ & $\begin{array}{c}\text { Desviación Típica } \\
{ }^{\circ} \mathbf{C}\end{array}$ & $\begin{array}{c}\text { Mínimo } \\
{ }^{\circ} \mathbf{C}\end{array}$ & $\begin{array}{c}\text { Máximo } \\
{ }^{\circ} \mathbf{C}\end{array}$ & $\begin{array}{c}\text { Coeficiente de Variación } \\
\%\end{array}$ \\
\hline \hline ANUAL & 14,5 & 1,0 & 11,8 & 16,1 & 6,8 \\
\hline ENE & 5,9 & 1,3 & 3,2 & 7,7 & 21,6 \\
\hline FEB & 6,9 & 2,1 & 3,5 & 11,7 & 30,0 \\
\hline MAR & 9,9 & 2,4 & 3,5 & 14,8 & 24,6 \\
\hline ABR & 11,8 & 1,8 & 8,7 & 16,0 & 14,9 \\
\hline MAY & 16,0 & 2,2 & 8,7 & 19,2 & 14,0 \\
\hline JUN & 21,4 & 2,0 & 16,9 & 24,7 & 9,1 \\
\hline JUL & 25,5 & 1,6 & 21,4 & 28,6 & 6,2 \\
\hline AGO & 25,4 & 1,6 & 21,2 & 28,4 & 6,3 \\
\hline SEP & 21,0 & 1,9 & 15,6 & 24,4 & 9,0 \\
\hline OCT & 14,7 & 1,9 & 11,4 & 18,5 & 13,0 \\
\hline NOV & 9,3 & 1,4 & 6,8 & 12,2 & 15,4 \\
\hline DIC & 6,2 & 1,7 & 1,8 & 9,6 & 26,8 \\
\hline
\end{tabular}

Los meses con coeficiente más altos son febrero y diciembre, con $30 \%$ y $26,8 \%$, respectivamente. Por otro lado, los meses con coeficiente de variación más bajo son julio y agosto, por debajo del $10 \%$. Todas las cuencas tienen un comportamiento muy semejante en lo que se refiere a la variabilidad mensual en los valores de la temperatura.

\subsubsection{Análisis de tendencias}

Los resultados de $\mathrm{R}$ para las temperaturas mínimas, máximas y medias anuales (Tabla 112) son todos positivos y reflejan una fuerte tendencia progresiva.

Tabla 112. Coeficiente de correlación (Rho de Spearman) entre las temperaturas mínima, máxima y media anual y el tiempo en la cuenca del río Trabaque

\begin{tabular}{|l|c|c|c|}
\hline \hline \multicolumn{1}{|c|}{$\begin{array}{c}\text { Estación Termométrica } \\
\text { Rascafria }\end{array}$} & $\mathbf{n}$ & $\begin{array}{c}\text { Signif. } \\
\text { Estad. }\end{array}$ & $\mathbf{R}$ \\
\hline \hline Temperatura Mínima Anual & 38 & ${ }^{* *}$ & 0,816 \\
\hline Temperatura Máxima Anual & 38 & $\mathrm{NS}$ & 0,107 \\
\hline Temperatura Media Anual & 38 & ${ }^{* *}$ & 0,720 \\
\hline \hline
\end{tabular}

NS = Valores no significativos estadísticamente

** $=$ Correlación significativa al nivel de 0,01 
La principal diferencia entre la estación Arrancacepas, utilizada para análisis de la cuenca del río Trabaque y las estaciones utilizadas para análisis de las cuencas de los ríos Cega y Tajo, es que el principal aumento en los valores de la temperatura se ha visto en las mínimas. En todas las otras cuencas este aumento fue más pronunciado en las temperaturas máximas o medias. En la estación Arrancacepas, en el caso de la mínima anual esta tendencia es considerada significativa al nivel de 0,01 (0,816). A su vez, en la máxima anual $\mathrm{R}$ no presenta valores significativos. La temperatura media anual también presenta valores positivos y significativos al nivel de $0,01(0,720)$. Estos valores encontrados con $\mathrm{R}$ dejan bastante evidente que está habiendo un fuerte aumento en las temperaturas, sobre todo en la mínima anual.

A partir del análisis de M-K (Tabla 113), para las temperaturas mínimas, máximas y medias es posible rechazar la hipótesis nula de no tendencia, además se ha comprobado que es una tendencia positiva y bastante pronunciada. Como ocurrió con $\mathrm{R}$, la mínima anual presentó la tendencia progresiva más alta y la máxima anual presentó los valores más bajos. Los resultados encontrados con M-K corroboran los encontrados con $\mathrm{R}$ y confirman una fuerte tendencia progresiva de la temperatura.

Tabla 113. Test estadístico Mann-Kendall para las temperaturas mínima, máxima y media anual en la estación Arrancacepas - Cuenca del río Trabaque

\begin{tabular}{|l|c|c|c|c|}
\hline \multicolumn{1}{|c|}{ Estación Rascafria } & $\begin{array}{c}\mathbf{S} \text { de } \\
\text { Kendall }\end{array}$ & $\mathbf{Z}_{\mathbf{s}}$ & $\begin{array}{c}\text { Rechazo de hipótesis } \\
\text { nula para } \mathbf{p}<\mathbf{0 , 0 5}\end{array}$ & Valor $\boldsymbol{p}$ \\
\hline \hline Temperatura Mínima Anual & 435 & 32,88 & $\mathrm{Si}$ & 0,0001 \\
\hline Temperatura Máxima Anual & 57 & 4,37 & $\mathrm{Si}$ & 0,0001 \\
\hline Temperatura Media Anual & 357 & 26,11 & $\mathrm{Si}$ & 0,0001 \\
\hline \hline
\end{tabular}

Zs $>(+/-) 1,96$ se rechaza la hipótesis nula de no tendencia Valor $p<0,05$ se rechaza la hipótesis nula de no tendencia

Al igual que en las otras estaciones, M-Ks fue utilizado para intentar localizar el año de inicio de las tendencias detectadas anteriormente en los casos en que esta tendencia fue más significativa. La figura 120 es la representación gráfica de los resultados encontrados para la temperatura mínima anual y no se puede detectar el año de inicio de las tendencias una vez que se aprecia en esta figura diversas intersecciones entre las estadísticas $u(t)$ y $u^{*}(t)$. No obstante se observa claramente que a partir de 1982 la tendencia positiva es evidente y continuada hasta el final de la serie. Esta tendencia pasa a ser significativa a partir de 1983. 


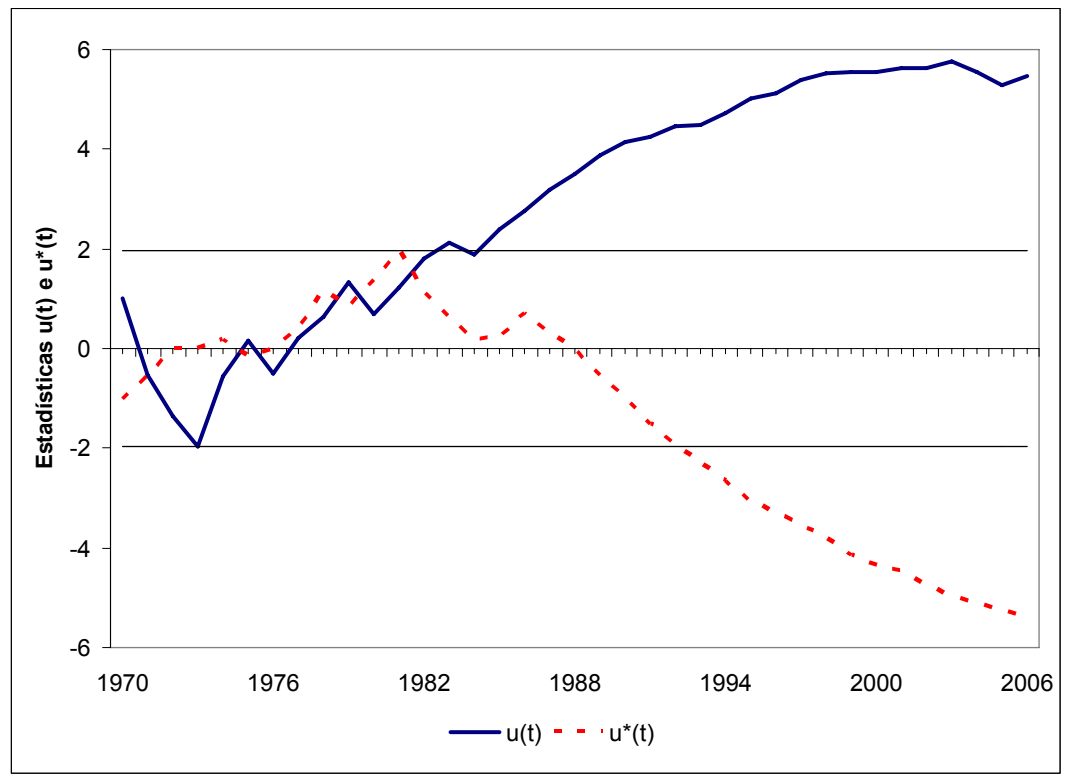

Figura 120 - Test Mann-Kendall secuencial para la temperatura mínima anual - Estación Arrancacepas, Cuenca del río Trabaque

Con los resultados encontrados con M-Ks para la temperatura media anual (Fig. 121), no se puede detectar exactamente el año en que ha empezado la tendencia positiva detectada anteriormente también por las intersecciones encontradas en la figura. No obstante a partir de 1984 se observa un aumento muy claro en los valores de la temperatura que pasa a ser significativo a partir de 1987.

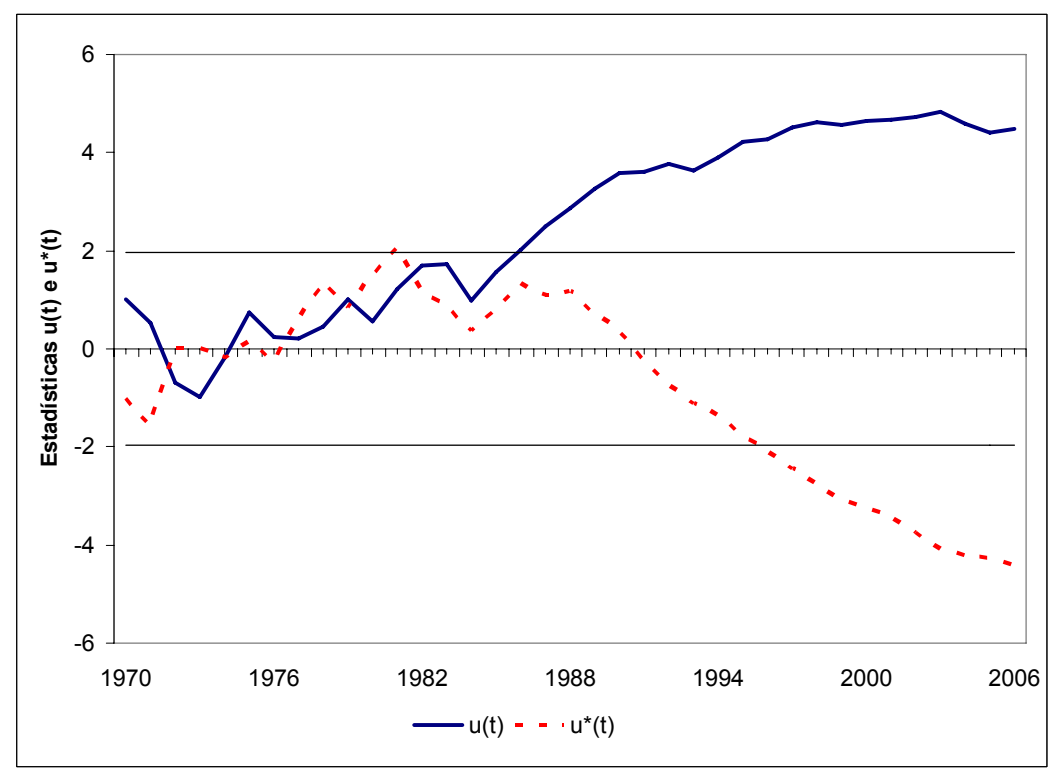

Figura 121 - Test Mann-Kendall secuencial para la temperatura media anual - Estación Arrancacepas, Cuenca del río Trabaque 
El análisis de regresión reveló un aumento de la temperatura en la cuenca del río Trabaque de $0,06{ }^{\circ} \mathrm{C}$, que al igual que en la cuenca del Tajo, significa un aumento de $2,28^{\circ} \mathrm{C}$ en todo el periodo investigado. Por la proximidad entre las dos zonas es perfectamente normal la semejanza encontrada en sus resultados.

Siguiendo la metodología aplicada para las demás cuencas analizadas, se hizo un estudio de los datos mensuales de las temperaturas mínimas y medias (donde fue encontrada más significación estadística). Los resultados para la temperatura mínima mensual (Tabla 114) no dejan duda sobre las fuertes tendencias positivas. Con R, únicamente el mes de enero no refleja un valor significativo y diciembre presenta significación al nivel de 0,05. En todos los demás meses se observan valores de $R$ significativos al nivel de 0,01 y con valores bastante altos. Con el estadístico M-K, en todos los meses se puede rechazar la hipótesis nula de no tendencia y en todos ellos los valores de $S$ y $Z$ son bastante significativos. En ambos test los meses en los que se encuentra una tendencia más clara son los de verano, otoño y primavera.

Tabla 114. Test estadísticos Rho de Spearman y Mann-Kendall para la temperatura media mensual de la Estación Arrancacepas - Cuenca del río Trabaque

\begin{tabular}{|l|c|c|c|c|c|}
\hline \hline \multicolumn{1}{|c|}{ Mes } & Rho & $\begin{array}{c}\text { S de } \\
\text { Kendall }\end{array}$ & $\mathbf{Z}_{\mathbf{s}}$ & $\begin{array}{c}\text { Rechazo de hipótesis } \\
\text { nula para } \mathbf{p}<\mathbf{0 , 0 5}\end{array}$ & Valor $\boldsymbol{p}$ \\
\hline \hline Enero & 0,212 & 113 & 8,82 & $\mathrm{Si}$ & 0,0001 \\
\hline Febrero & $0,415\left(^{* *}\right)$ & 202 & 14,05 & $\mathrm{Si}$ & 0,0001 \\
\hline Marzo & $0,751\left(^{* *}\right)$ & 375 & 28,98 & $\mathrm{Si}$ & 0,0001 \\
\hline Abril & $0,665\left(^{* *}\right)$ & 322 & 24,64 & $\mathrm{Si}$ & 0,0001 \\
\hline Mayo & $0,598\left(^{* *}\right)$ & 284 & 25,26 & $\mathrm{Si}$ & 0,0001 \\
\hline Junio & $0,834\left(^{* *}\right)$ & 450 & 40,99 & $\mathrm{Si}$ & 0,0001 \\
\hline Julio & $0,698\left(^{* *}\right)$ & 320 & 25,89 & $\mathrm{Si}$ & 0,0001 \\
\hline Agosto & $0,657\left(^{* *}\right)$ & 303 & 24,20 & $\mathrm{Si}$ & 0,0001 \\
\hline Septiembre & $0,500\left(^{* *}\right)$ & 212 & 15,90 & $\mathrm{Si}$ & 0,0001 \\
\hline Octubre & $0,753\left(^{* *}\right)$ & 398 & 34,10 & $\mathrm{Si}$ & 0,0001 \\
\hline Noviembre & $0,415\left(^{* *}\right)$ & 206 & 14,14 & $\mathrm{Si}$ & 0,0001 \\
\hline Diciembre & $0,325\left(^{*}\right)$ & 160 & 10,87 & $\mathrm{Si}$ & 0,0001 \\
\hline
\end{tabular}

Zs $>(+/-) 1,96$ se rechaza la hipótesis nula de no tendencia

Valor $\mathrm{p}<0,05$ se rechaza la hipótesis nula de no tendencia

* = Correlación significativa al nivel de 0,05

** $=$ Correlación significativa al nivel de 0,01

En el caso de las temperaturas medias mensuales (Tabla 115) se aprecia menos significación estadística que la detectada anteriormente para las mínimas. Sin 
embargo, es bastante claro que en la mayoría de los meses se obtienen valores significativos de la tendencia positiva. Mediante el análisis de $\mathrm{R}$ se observa que septiembre no presenta ningún tipo de tendencia. Con $\mathrm{M}-\mathrm{K}$ es posible rechazar la hipótesis nula de no tendencia, pero también con valores no muy elevados. Los demás meses reflejan tendencias positivas. Con $\mathrm{R}$, los meses de enero, julio, agosto, noviembre y diciembre no reflejan valores significativos. Por otro lado, abril y octubre son significativos al nivel de 0,05 y febrero, marzo, mayo y junio son significativos al nivel de 0,01. Los meses donde se detecta una tendencia progresiva más clara son marzo y junio.

Tabla 115. Test estadísticos Rho de Spearman y Mann-Kendall para la temperatura media mensual de la Estación Arrancacepas - Cuenca del río Trabaque

\begin{tabular}{|l|c|c|c|c|c|}
\hline \multicolumn{1}{|c|}{ Mes } & Rho & $\begin{array}{c}\text { S de } \\
\text { Kendall }\end{array}$ & $\mathbf{Z}_{\mathbf{s}}$ & $\begin{array}{c}\text { Rechazo de hipótesis } \\
\text { nula para } \mathbf{p}<\mathbf{0 , 0 5}\end{array}$ & Valor $\boldsymbol{p}$ \\
\hline \hline Enero & 0,253 & 123 & 9,41 & $\mathrm{Si}$ & 0,0001 \\
\hline Febrero & $0,476\left(^{* *}\right)$ & 235 & 17,95 & $\mathrm{Si}$ & 0,0001 \\
\hline Marzo & $0,649\left(^{* *}\right)$ & 317 & 23,57 & $\mathrm{Si}$ & 0,0001 \\
\hline Abril & $0,397\left(^{*}\right)$ & 185 & 14,68 & $\mathrm{Si}$ & 0,0001 \\
\hline Mayo & $0,439\left(^{* *}\right)$ & 209 & 17,92 & $\mathrm{Si}$ & 0,0001 \\
\hline Junio & $0,621\left(^{* *}\right)$ & 315 & 28,44 & $\mathrm{Si}$ & 0,0001 \\
\hline Julio & 0,101 & 73 & 4,50 & $\mathrm{Si}$ & 0,0001 \\
\hline Agosto & 0,177 & 74 & 5,03 & $\mathrm{Si}$ & 0,0001 \\
\hline Septiembre & $-0,096$ & -48 & $-3,19$ & $\mathrm{Si}$ & 0,0014 \\
\hline Octubre & $0,346\left(^{*}\right)$ & 157 & 11,09 & $\mathrm{Si}$ & 0,0001 \\
\hline Noviembre & 0,113 & 47 & 3,42 & $\mathrm{Si}$ & 0,0006 \\
\hline Diciembre & 0,269 & 137 & 8,43 & $\mathrm{Si}$ & 0,0001 \\
\hline \hline
\end{tabular}

Zs $>$ (+/-) 1,96 se rechaza la hipótesis nula de no tendencia

Valor $p<0,05$ se rechaza la hipótesis nula de no tendencia

* $=$ Correlación significativa al nivel de 0,05

** = Correlación significativa al nivel de 0,01

Los análisis estadísticos utilizados para la temperatura en la estación Arrancacepas, no dejan muy claro una tendencia positiva en el caso de la temperatura máxima anual, ya que hay muchas contradicciones entre los estadísticos utilizados. Estas contradicciones llevan a creer que hay oscilaciones normales en los valores de la temperatura. No obstante hay una notable tendencia positiva de los valores de las temperaturas mínimas y medias. Además de todo esto, la principal diferencia entre la cuenca del río Trabaque y las cuencas del río Tajo y Cega es que el principal aumento en los valores de temperaturas fue encontrado en las mínimas. 
Hay que tener en consideración fue utilizada solamente una estación para análisis de las temperaturas y que aunque hayan sido encontradas fuertes tendencias progresivas de la temperatura en las cuencas de los ríos Cega, Tajo y Trabaque el hecho de ser solamente una estación puede no generar resultados totalmente conclusivos. 


\section{ANÁLISIS DE LA EVOLUCIÓN DE LOS USOS Y DE LA COBERTURA DEL SUELO}

\subsection{Los cambios de población}

Desde principios del siglo $\mathrm{XX}$ los espacios rurales en España han sufrido una fuerte evolución regresiva de la población. El proceso de migración en España tiene tres periodos fundamentales. De 1887 hasta 1939, el avance de la industria provoca un movimiento de migración hacia las tres principales áreas de desarrollo industrial, Madrid, Barcelona y el País Vasco. En el periodo 1939-1975, la política de estabilización de la Dictadura produce un significativo éxodo rural hacia las ciudades. Las áreas rurales se despueblan a favor de las áreas urbanas. En la España de hoy se pueden todavía encontrar las huellas de este proceso. El papel que desempeña la agricultura en el total de la economía disminuye a finales de los años setenta debido a la crisis económica de estos años. Desde 1975 hasta hoy se produce un menor crecimiento urbano. Este crecimiento se produce tanto en las antiguas áreas de desarrollo industrial, como en las áreas urbanas de las provincias en la periferia, por la política de descentralización del gobierno español. Además, se produce una tendencia de suburbanización desde los núcleos industriales, como muestran los saldos migratorios positivos en algunas provincias limítrofes de estas áreas urbanas (Jan Slomp, 2004).

Este éxodo rural fue demográficamente muy selectivo. En los momentos de mayor intensidad los emigrantes son población activa y joven. Así, el medio rural no sólo pierde población, sino que principalmente pierde a una generación. Los protagonistas del éxodo rural fueron jóvenes de veinte a veinte cinco años en los años 60, quienes se corresponden con los nacidos entre 1935-1940, es decir, durante la Guerra Civil (Camarero Rioja, 1991). Incluso se observa en el país una importante disminución del número de municipios, que pasa de 9.256 en el censo de 1981 a 8.108 en el censo de 2001 , es decir, disminuye un $12,5 \%$. Durante esta etapa se produce una paulatina desaparición de municipios deshabitados o muy escasamente poblados mediante decisiones políticas tomadas entre 1960 y 1981 que eliminan casi 1.100 municipios, según la Ley 48/1966 (Arroyo Pérez et al. 2003). Los cambios en la estructura demográfica tuvieron repercusión en toda España y fueron descritos por diversos autores (Camarero Rioja, 1991; Lasanta et al. 2000; García Ruiz et al. 2001; Pascual Aguilar, 2002; Sancho Comíns et al. 2003; Bustos Gisbert, 2005; Lasanta et al. 2006; Lasanta et al. 2007; Arnáez et al. 2008). Es en las provincias del interior, en general, y 
principalmente en las áreas de montaña de ambas Castillas y Aragón donde se constatan los mayores problemas de despoblamiento (Sancho Comíns et al. 2003). En el caso de las zonas de estudio utilizadas en esta investigación, se ha detectado igualmente este cambio y abandono del espacio rural, con grandes pérdidas de habitantes desde 1900 hasta 2001 (Tabla 116).

Tabla 116. Cuencas de los ríos Cega, Porma, Tajo y Trabaque y pérdidas de la población.

\begin{tabular}{|l|c|c|c|}
\hline \multicolumn{1}{|c|}{ Cuenca } & Habitantes en 1900 & Habitantes en 2001 & Pérdida Total (\%) \\
\hline \hline Cega & 6422 & 1867 & 70,9 \\
\hline Porma & 1590 & 725 & 54,4 \\
\hline Tajo & 728 & 173 & 76,2 \\
\hline Trabaque & 3602 & 1286 & 64,3 \\
\hline \hline
\end{tabular}

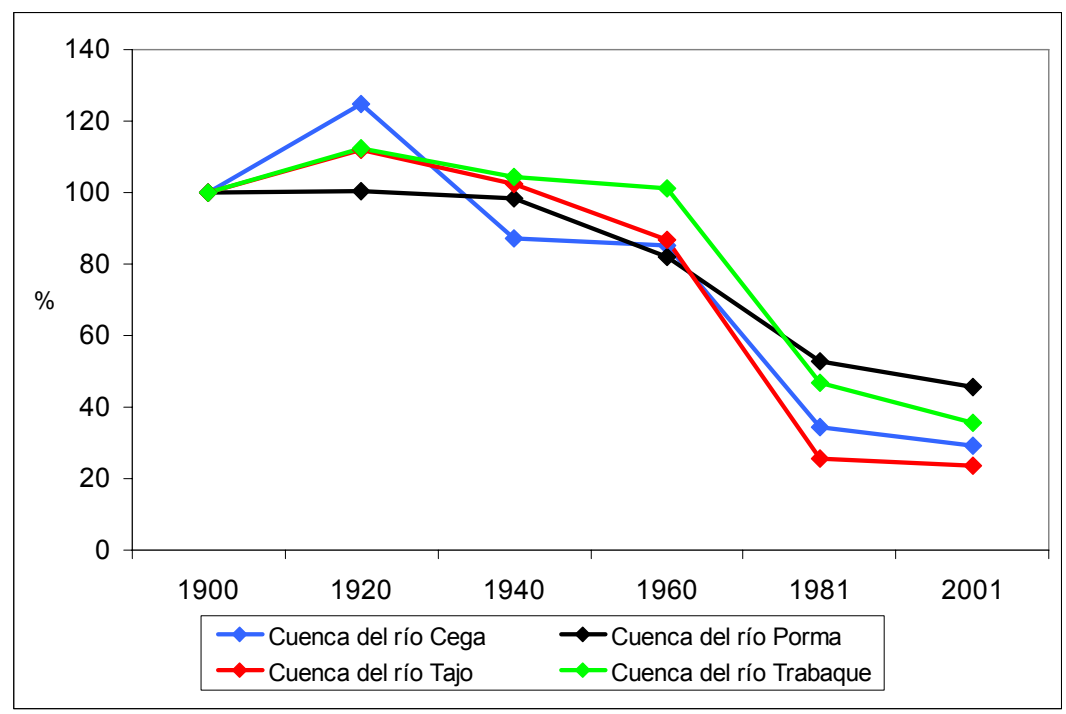

Figura 122 - Evolución de la población en las cuencas de los ríos Cega, Porma, Tajo y Trabaque.

La cuenca del río Cega perdió a lo largo del siglo XX un 70,9\% de su población, la del Porma perdió $54,4 \%$, la cuenca alta del Tajo $76,2 \%$ y en la del Trabaque se ha registrado una pérdida de $64,3 \%$ (Fig. 122).

En las zonas de estudio, al igual que en la mayoría de España, ocurrieron fuertes cambios en la organización social y en los usos del suelo como consecuencia de todas las alteraciones demográficas descritas. De acuerdo con Bustos Gisbert (2005), los espacios rurales pasan a caracterizarse por su escaso número de habitantes y por su alto índice de envejecimiento, condicionando su propia supervivencia así como sus posibilidades de desarrollo y adaptación a la realidad socioeconómica actual. Esta nueva realidad trae una profunda crisis de los sistemas agrarios tradicionales. 
Consecuentemente se aprecia un retroceso en la ganadería, el abandono de cultivos y la subexplotación de los productos forestales, con la disminución de la extracción de madera por la sustitución de leña por otros combustibles. Como reflejo de esta nueva realidad se observan también cambios en los usos y coberturas de suelo, especialmente un proceso de recuperación espontánea de herbáceas, matorrales y del bosque (Lasanta et al. 2000; García Ruiz et al. 2001; Pascual Aguilar, 2002; Lasanta et al. 2006; Lasanta et al. 2007; Arnáez et al. 2008). Según Arnáez et al. (2008) este proceso puede sintetizarse en el incremento de la densidad de las áreas que ya eran bosque y aumento de la superficie forestal, tanto por la sucesión natural como por repoblaciones efectuadas por el hombre. Otra serie de procesos como, por ejemplo, las repercusiones de la Política Agraria Comunitaria, la incentivación del abandono de tierras agrícolas y de su transformación en tierras forestales, o las repoblaciones, han contribuido también, junto a la evolución demográfica, a ese cambio profundo del paisaje vegetal español.

\subsection{Aumento de las masas forestales}

Para el análisis general de la evolución de las masas forestales en las zonas de estudio han sido empleados los datos del Inventario Forestal Nacional (IFN). Este, según el Ministerio de Medio Ambiente y Medio Rural y Medio Marino, es un "proyecto encaminado a obtener el máximo de información posible sobre la situación, régimen de propiedad y protección, naturaleza, estado legal, probable evolución y capacidad productora de todo tipo de bienes de los montes españoles". La unidad básica de trabajo es la provincia $y$, al ser un inventario continuo, se repiten las mismas mediciones cada 10 años, recorriéndose todo el territorio nacional en cada ciclo decenal. Las provincias donde están localizadas las cuencas hidrográficas objeto de este estudio demuestran un aumento bastante significativo de la superficie arbolada desde el primer inventario que ha sido realizado entre los años 1966-1975 hasta el último (1997-2007). Según los datos de los Inventarios Forestales Nacionales 1, 2 y 3 , en la provincia de Segovia se ha observado un aumento de $36,3 \%$ de la superficie arbolada, en León un aumento de $65,6 \%$, en Guadalajara, $83,7 \%$ y finalmente en la provincia de Cuenca se ha apreciado un aumento $70,1 \%$ (Fig. 123). 


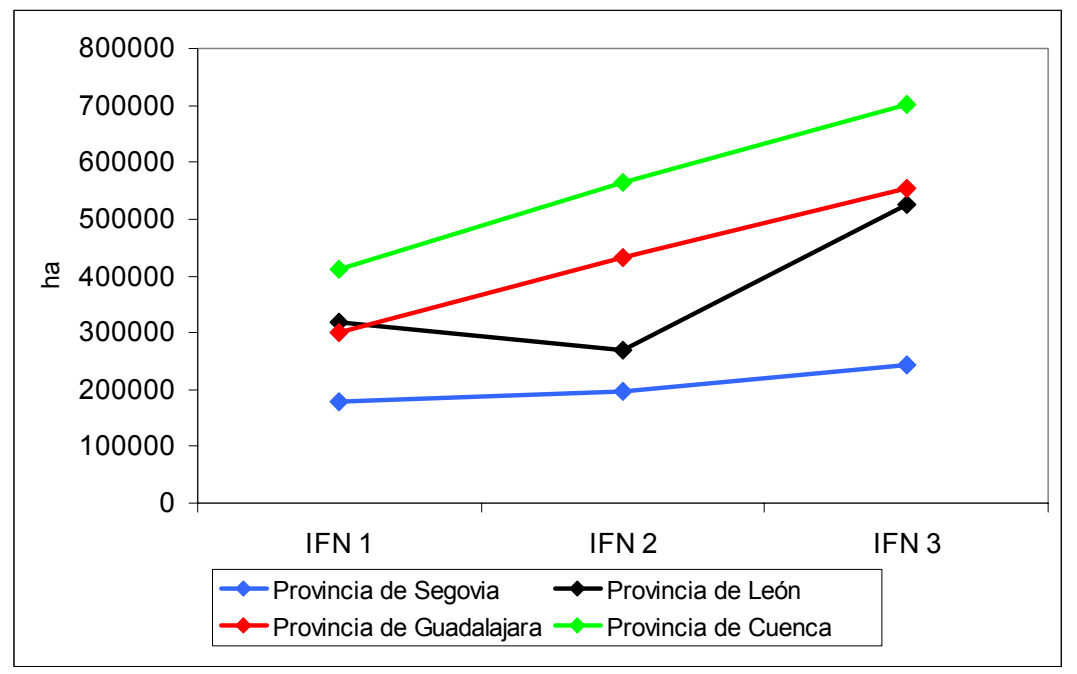

Figura 123 - Evolución de la superficie arbolada en las provincias de Segovia, León, Guadalajara y Cuenca según los datos del IFN.

A toda esta nueva realidad, fruto principalmente de los cambios de población, se añade los planes de reforestación del gobierno español y de organismos privados (Ley de 24 de junio de 1908 de Conservación de Montes y Repoblación Forestal, creación de las Confederaciones Hidrográficas en 1926, elaboración del Plan Nacional de Repoblaciones de los Montes en 1926, Ley de 9 de octubre de 1935 creando el Patrimonio Forestal del Estado y elaboración en 1939 del Plan Nacional para la Repoblación Forestal de España). En el período de 1940-1980, tres millones de hectáreas fueron reforestadas (Tabla 117).

Tabla 117. Superficie reforestada por especie en España, entre 1940 y 1980.

\begin{tabular}{|l|c|c|}
\hline \multicolumn{1}{|c|}{ Especie } & Superficie (ha) & Superficie (\%) \\
\hline \hline Pinus sylvestris & 516.974 & $15,90 \%$ \\
\hline Pinus nigra & 358.501 & $11,00 \%$ \\
\hline Pinus pinaster & 723.274 & $22,20 \%$ \\
\hline Pinus pinea & 239.713 & $7,40 \%$ \\
\hline Pinus halepensis & 495.349 & $15,20 \%$ \\
\hline Pinus canariensis & 23.413 & $0,70 \%$ \\
\hline Pinus radiata & 190.646 & $5,90 \%$ \\
\hline Populus sp. & 71.775 & $2,20 \%$ \\
\hline Eucalyptus sp. & 347.604 & $10,70 \%$ \\
\hline Otras especies & 286.702 & $8,80 \%$ \\
\hline TOTAL & $\mathbf{3 . 2 5 3 . 9 5 1}$ & $\mathbf{1 0 0 , 0 0 \%}$ \\
\hline \hline
\end{tabular}

Fuente: Dirección General de Conservación de la Naturaleza (DGCN). Ministerio de Medio Ambiente y Medio Rural y Medio Marino.

Probablemente el gran problema relacionado con las áreas reforestadas es que en la mayoría de estos proyectos no hubo una gestión adecuada. Según el Ministerio de 
Medio Ambiente y Medio Rural y Medio Marino, buena parte de esta superficie no ha sido objeto de ningún tipo de gestión desde su implantación, presentando una densidad excesiva, una estructura inadecuada y una composición específica poco equilibrada. Además hay que añadir la ingente acumulación de biomasa. Todos estos factores incrementan, incluso, el riesgo en relación con la propagación de plagas e incendios forestales.

Es innegable que estos cambios en los usos y en la cobertura del suelo tienen consecuencias directas en los caudales de los ríos sobre todo en las zonas de cabecera (Poyatos et al. 2003).

\subsection{Evolución reciente de los usos y cobertura del suelo}

El análisis de la dinámica de la cubierta vegetal y de los usos del suelo es de fundamental importancia para el entendimiento del funcionamiento de una cuenca hidrográfica. Además de permitir la evaluación de las alteraciones ocurridas por las manos del hombre o por la propia naturaleza, proporciona informaciones esenciales para el manejo adecuado de los recursos naturales de la zona estudiada. Es importante que la información sobre toda esta dinámica esté actualizada, para el manejo eficiente de los recursos agrícolas y forestales y para que sus tendencias puedan ser analizadas. Márquez González (2008) afirma que la importancia de los estudios sobre el tipo de vegetación y los usos del suelo radica sobre todo en que, a escala global, regional y local, los cambios en el uso y el la cobertura del suelo están ocurriendo a un paso bastante acelerado.

Briceño (2003) ha mencionado que el análisis del uso de la tierra y los cambios que en ésta tienen lugar, son de interés para numerosas ramas del conocimiento, ya que generan información básica para la formulación de planes, programas y proyectos en los organismos de planificación responsables de la ordenación y organización del territorio y el manejo de los recursos naturales. Según Angnes Teresa (2005), han sido emprendidas iniciativas de investigación sobre el tema bajo distintos enfoques metodológicos y técnicas, automatizadas o no, a partir de análisis y evaluación del comportamiento de variables con diversos grados de complejidad y número. Estas variables han sido seleccionadas con base en criterios ecológicos, económicos, sociales o geográficos, para múltiples fines y a diversas escalas. Es posible encontrar diversas investigaciones que tienen como objetivo evaluar los cambios en la cubierta vegetal (Lasanta et al. 2000; Ruescas Orient, 2001; Gonzalez Gonzalez, 2004; 
Almeida Matos et al. 2005; Kleinpaul et al. 2005; Silva Brito et al. 2005; Dupuy Rada et al. 2006; Lasanta et al. 2006, 2007; Sousa Silva et al. 2007; Arnáez et al. 2008) o en los usos del suelo (Foley et al. 2005; Silva Brito et al. 2005; Dupuy Rada et al. 2006; Rounsevell et al. 2006; Muschong, 2007). Además, hay muchos estudios que relacionan estas variables con el desarrollo turístico (Briceño, 2003; Márquez González, 2008), con el riesgo de desertificación (Monteiro de Carvalho et al. 2007) y de deforestación (François Mas, 2003; Boletta et al. 2006), con la elaboración de cartografías (Ruescas Orient, 1999; Angnes Teresa, 2005), con el análisis del paisaje (Gómez et al. 2000; Carreño Fructuoso et al. 2007) y con la escorrentía superficial (Henríquez et al. 2006; López-Moreno et al. 2006; Pizarro et al. 2006; Oudin et al. 2008).

Lo primero a hacer, por lo tanto, es definir exactamente los conceptos de usos y coberturas del suelo. De acuerdo con la FAO (Organización para la Alimentación y la Agricultura - Naciones Unidas) la definición de cobertura del suelo es fundamental porque en muchas de las clasificaciones y leyendas esta se confunde el término uso del suelo. La cobertura es la cubierta biofísica que se observa sobre la superficie terrestre. Incluye la vegetación y elementos antrópicos, así como la roca, los suelo desnudos y los cuerpos de agua. A su vez, los usos del suelo son actividades que el hombre emprende en un cierto tipo de cobertura de la tierra para producir, cambiarla o mantenerla. Establece una relación directa entre la cobertura de la tierra y las acciones del hombre en su medio ambiente. En esta investigación se ha tratado de utilizar una leyenda híbrida entre las coberturas y usos de suelo, con el objetivo de caracterizar la repercusión de los mismos sobre los recursos hídricos de las zonas estudiadas.

Con el análisis multitemporal realizado en esta investigación y la utilización de técnicas de procesamiento digital de imágenes, se ha llevado a cabo la detección y cuantificación de los cambios ocurridos en los usos y en la cobertura del suelo en las cuencas de los ríos Cega, Porma, Tajo y Trabaque, con el objetivo de intentar hacer una evaluación de su evolución en las últimas décadas.

\subsubsection{Cuenca del río Cega}

Han sido identificados los cambios sufridos en cuatro momentos (1956, 1976, 1989 y 2002). Como resultado del procesamiento de las imágenes se obtuvieron los mapas correspondientes a estos momentos (Fig. 124, 125, 126 y 127) que muestran la 
evolución de los cambios sufridos por los usos y la cobertura del suelo. Tanto los mapas generados como los gráficos han servido de base para el análisis comparativo de la evolución de estas variables en el tiempo.

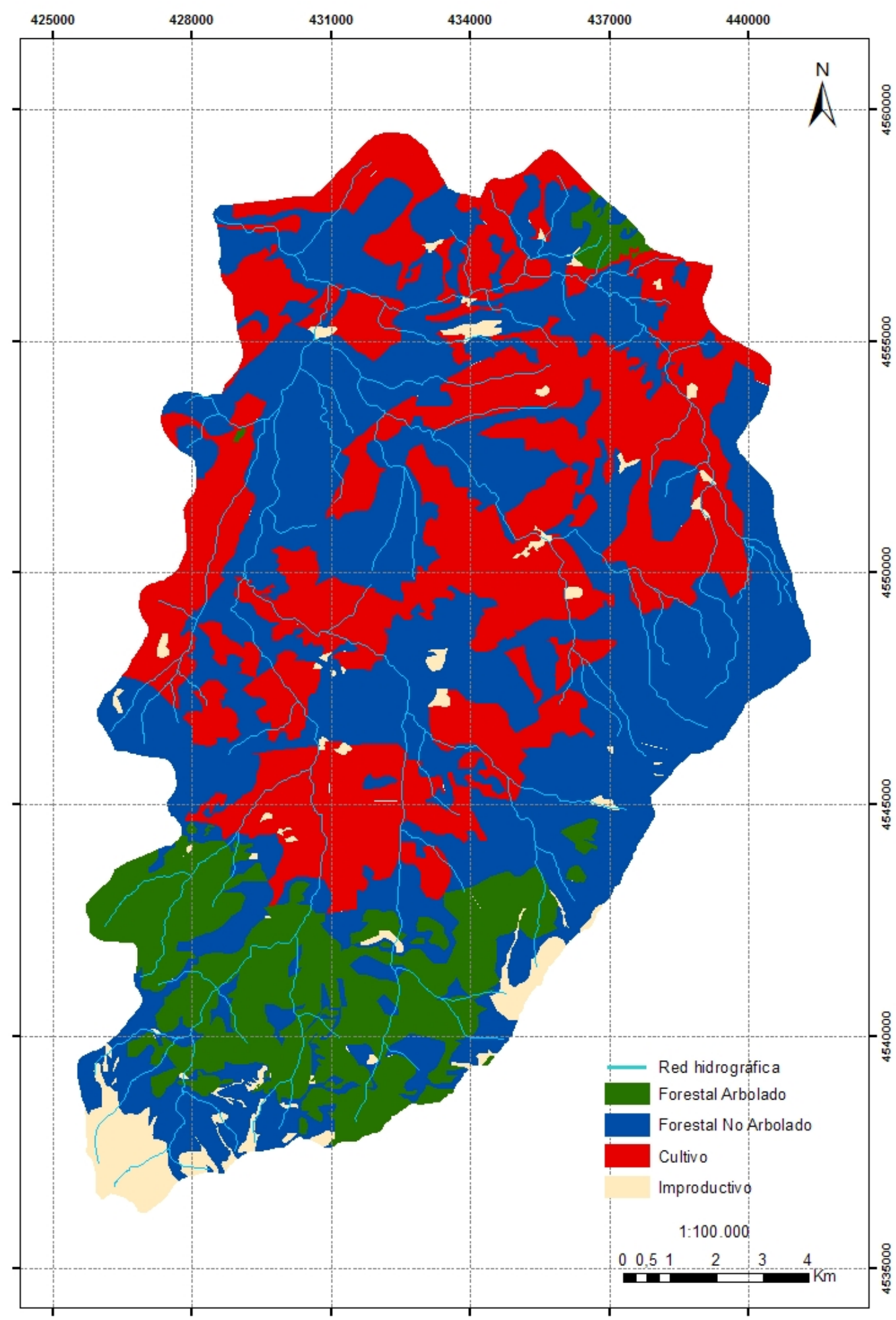

Figura 124 - Usos y cobertura del suelo en la cuenca del río Cega en 1956. 


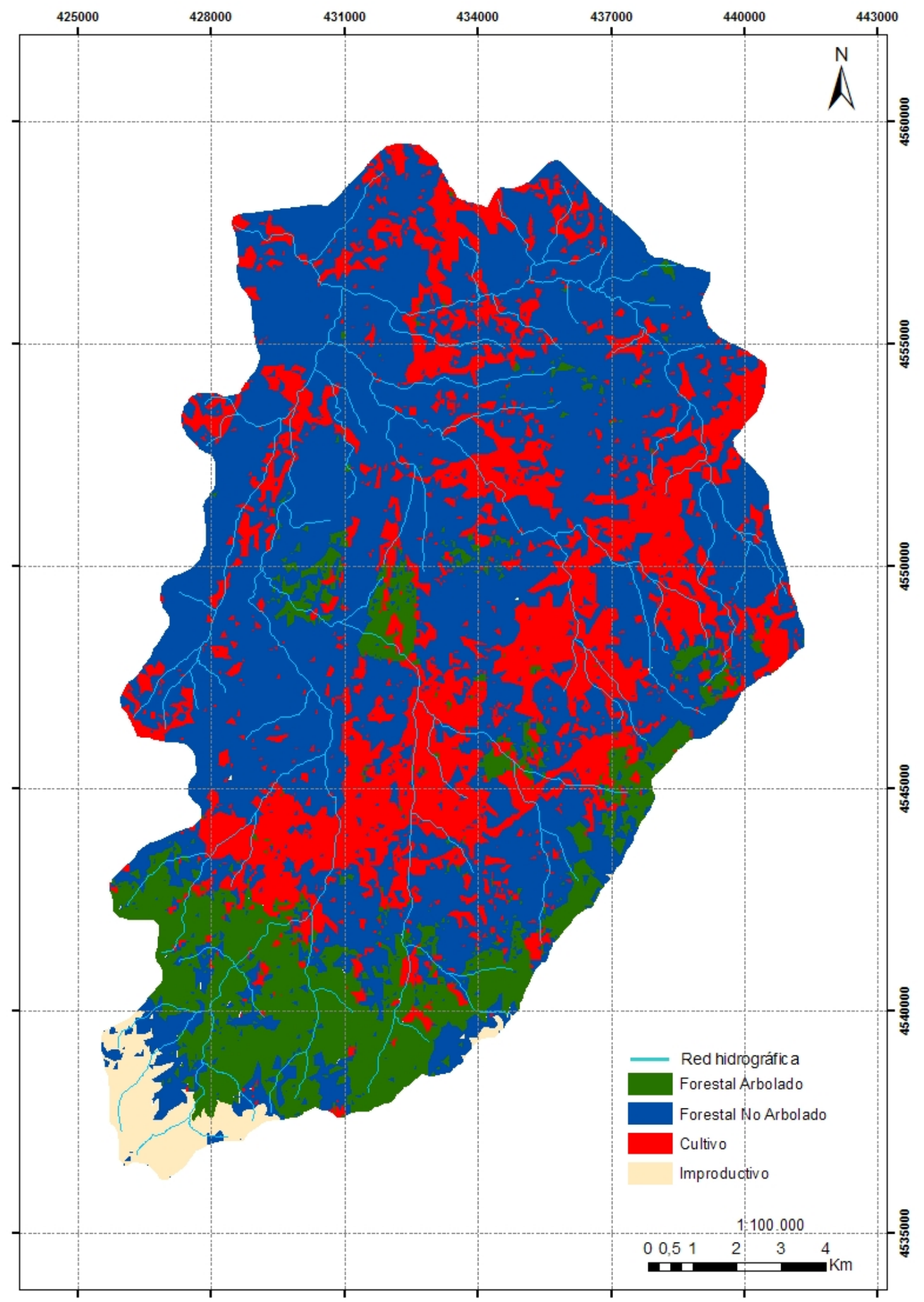

Figura 125 - Usos y cobertura del suelo en la cuenca del río Cega en 1976.

La dinámica de los usos y de la cobertura del suelo en la cuenca del río Cega en el período estudiado viene determinada principalmente por la disminución de los campos de cultivo y por la forestación espontánea de estas áreas abandonadas, resultando 
finalmente en un aumento considerable de las áreas consideradas como forestal arbolado.

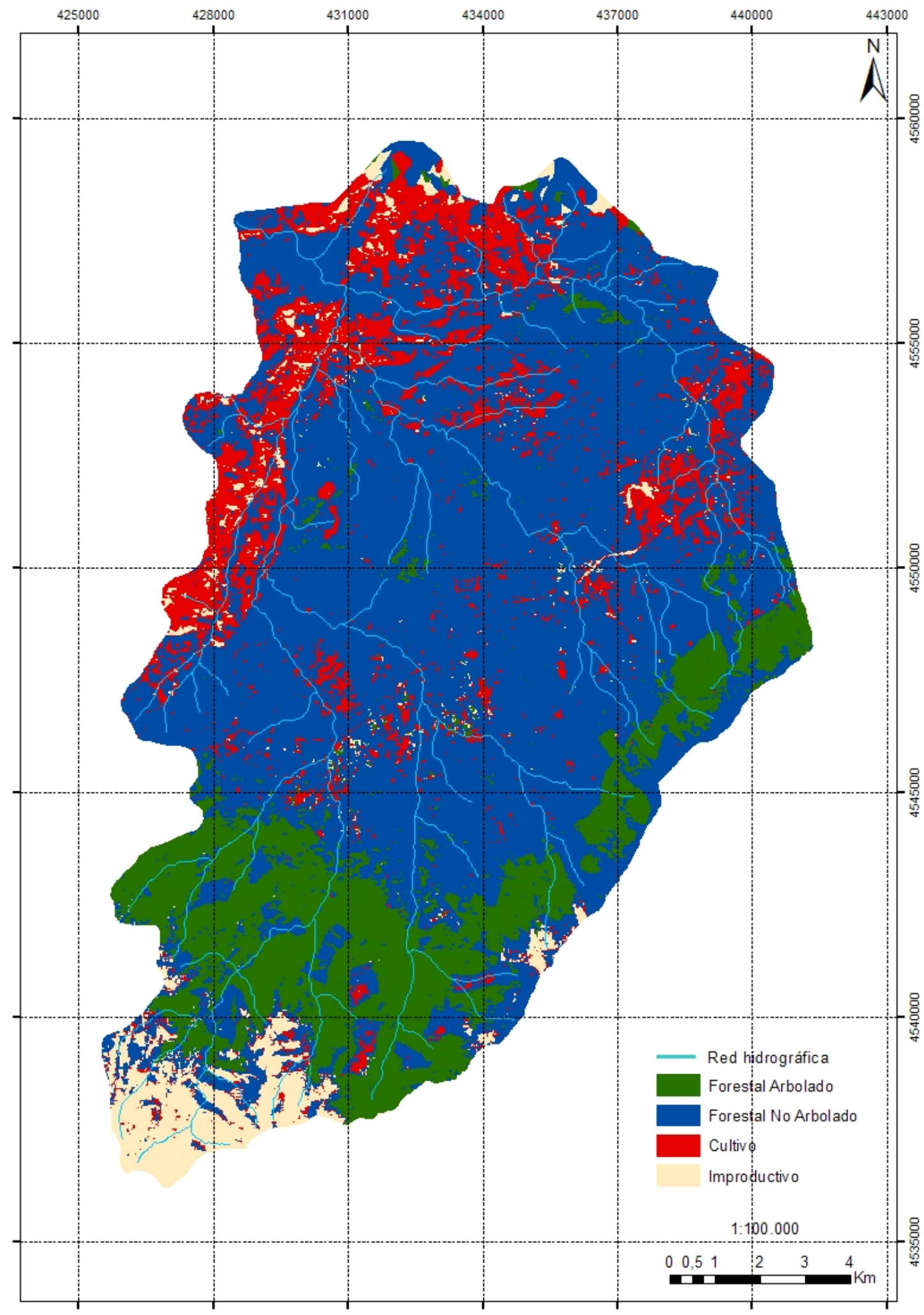

Figura 126 - Usos y cobertura del suelo en la cuenca del río Cega en 1989. 


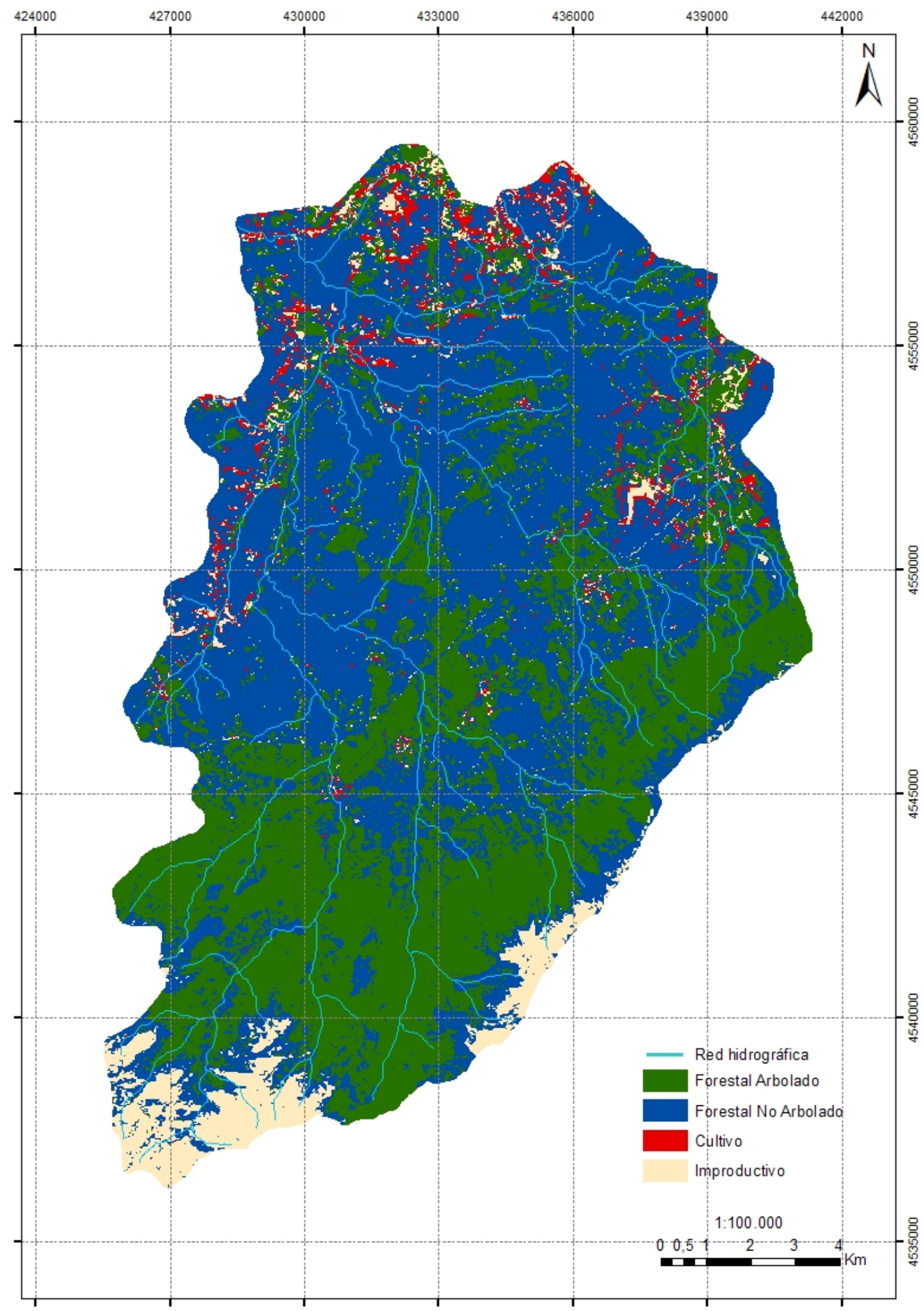

Figura 127 - Usos y cobertura del suelo en la cuenca del río Cega en 2002.

Los campos de cultivo son los que han sufrido la más fuerte transformación. Se ha detectado una reducción del $80 \%$ de las áreas cultivadas (Tabla 118 y Fig. 128) desde 1956 hasta 2002 , siendo casi el $100 \%$ de esa disminución a partir de 1976 . Por otro 
lado las áreas definidas como forestal arbolado sufrieron un aumento nada menos que del $214 \%$ de 1956 hasta 2002. La nueva superficie de bosque se extiende sobre 8260 ha.

Tabla 118. Evolución de los usos y de la cobertura del suelo en la cuenca del río Cega.

\begin{tabular}{|l|c|c|c|c|c|c|c|c|}
\hline \multirow{2}{*}{ Categoría } & \multicolumn{2}{|c|}{1956} & \multicolumn{2}{c|}{1976} & \multicolumn{2}{c|}{1989} & \multicolumn{2}{c|}{2002} \\
\cline { 2 - 9 } & $\mathbf{( \% )}$ & $\mathbf{( h a )}$ & $\mathbf{( \% )}$ & $\mathbf{( h a )}$ & $\mathbf{( \% )}$ & (ha) & (\%) & (ha) \\
\hline Forestal Arbolado & 13,8 & 3864 & 14,2 & 3976 & 24,3 & 6804 & 43,3 & 12124 \\
\hline Forestal No Arbolado & 45,2 & 12656 & 46,4 & 12992 & 51,7 & 14476 & 43,8 & 12264 \\
\hline Cultivo & 37,6 & 10528 & 36,5 & 10220 & 19,9 & 5572 & 7,6 & 2128 \\
\hline Improductivo & 3,4 & 952 & 2,9 & 812 & 4,1 & 1148 & 5,3 & 1484 \\
\hline \hline
\end{tabular}

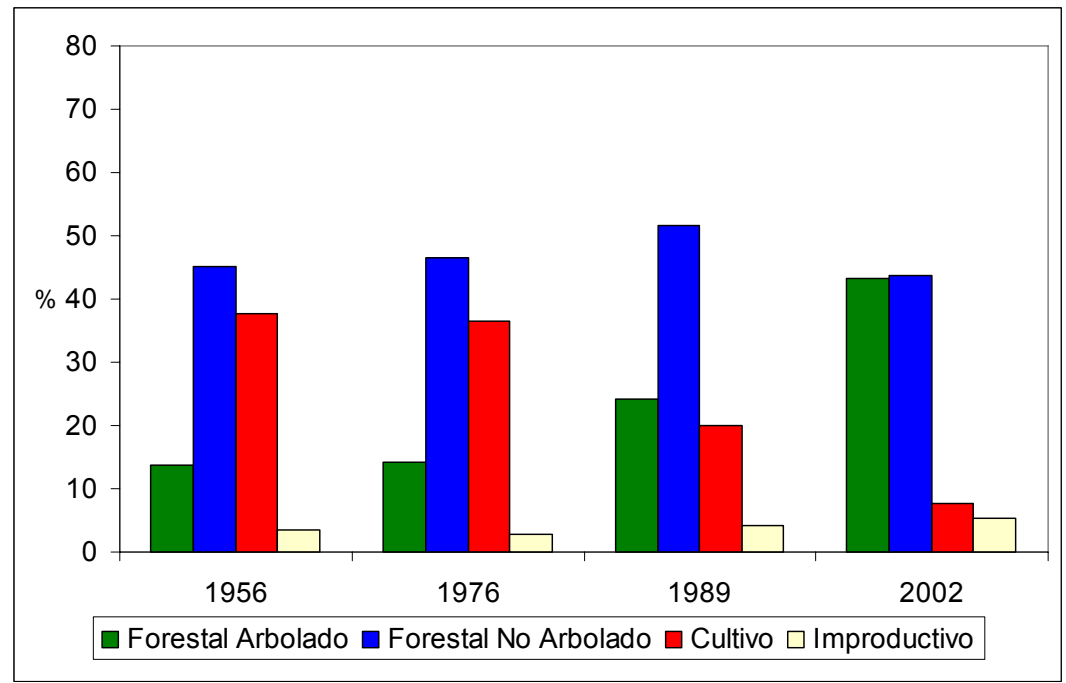

Figura 128 - Evolución de los usos y coberturas del suelo en la cuenca del río Cega (\%).

En este mismo período ha sido observada una relativa estabilización en las áreas de forestal no arbolado y de improductivo. En el caso del no arbolado ha sido detectado un aumento un poco más significativo solamente de 1976 hasta 1989 (11,4\%). Este equilibrio puede estar explicado sobre todo por el proceso natural de reforestación, ya que en las áreas de cultivos abandonadas inicialmente ocurre un aumento de los matorrales y de las herbáceas, que en algunos años se convierte en un aumento de las áreas de forestal arbolado. En este mismo período se ha observado una reducción de $66 \%$ de la población en la cuenca del río Cega, lo que confirma el abandono a las prácticas agrícolas y de ganadería. 


\subsubsection{Cuenca del río Porma}

Como se hizo anteriormente para la cuenca del río Cega, de los mapas generados mediante fotointerpretación y la digitalización de las imágenes de satélite se extrajeron tablas y gráficos para los análisis. Se hicieron mapas de usos y coberturas del suelo de los años de 1957, 1977, 1991 y 2001 (Fig. 129, 130, 131 y 132).

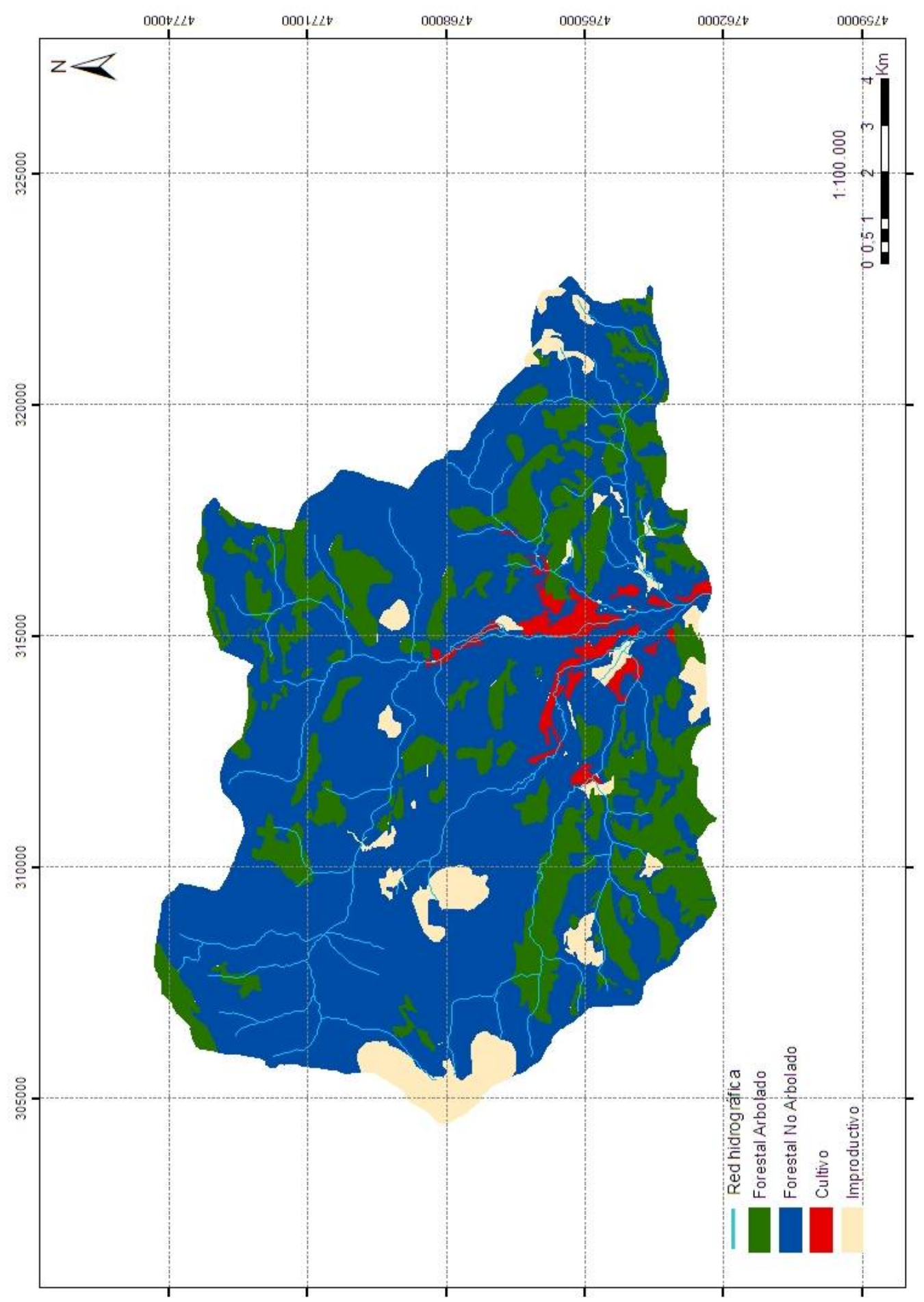

Figura 129 - Usos y cobertura del suelo en la cuenca del río Porma en 1957. 


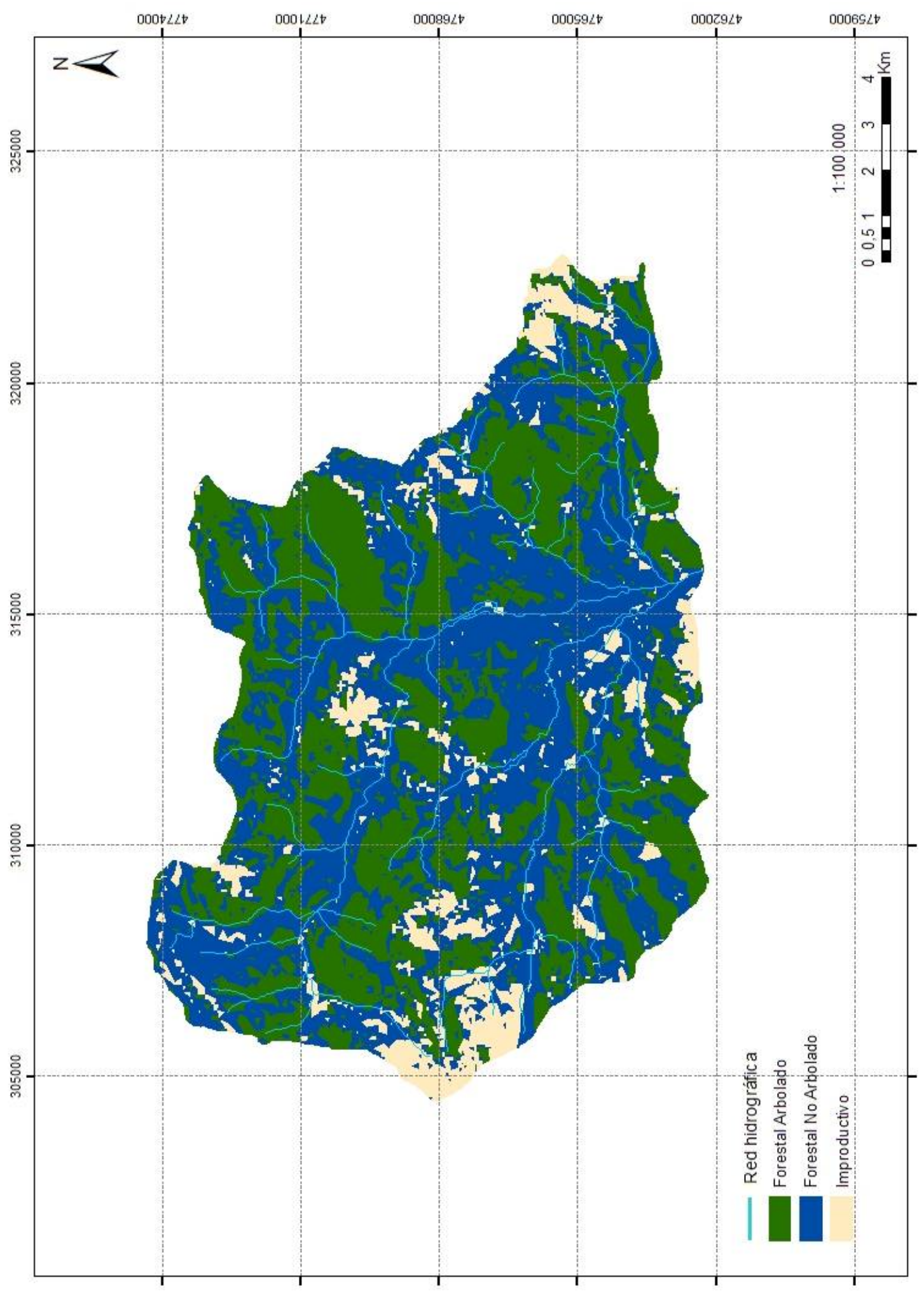

Figura 130 - Usos y cobertura del suelo en la cuenca del río Porma en 1977. 


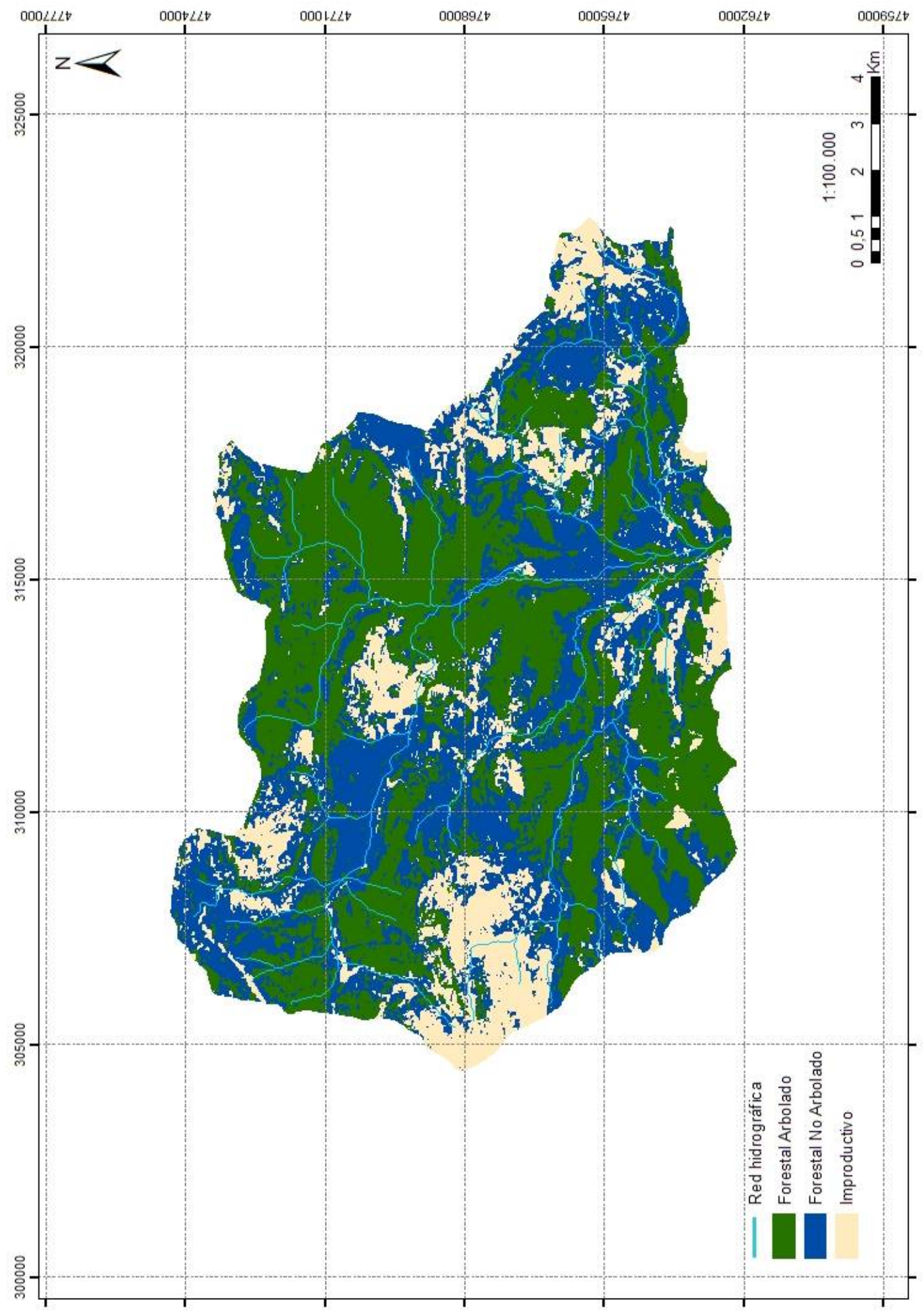

Figura 131 - Usos y cobertura del suelo en la cuenca del río Porma en 1991. 


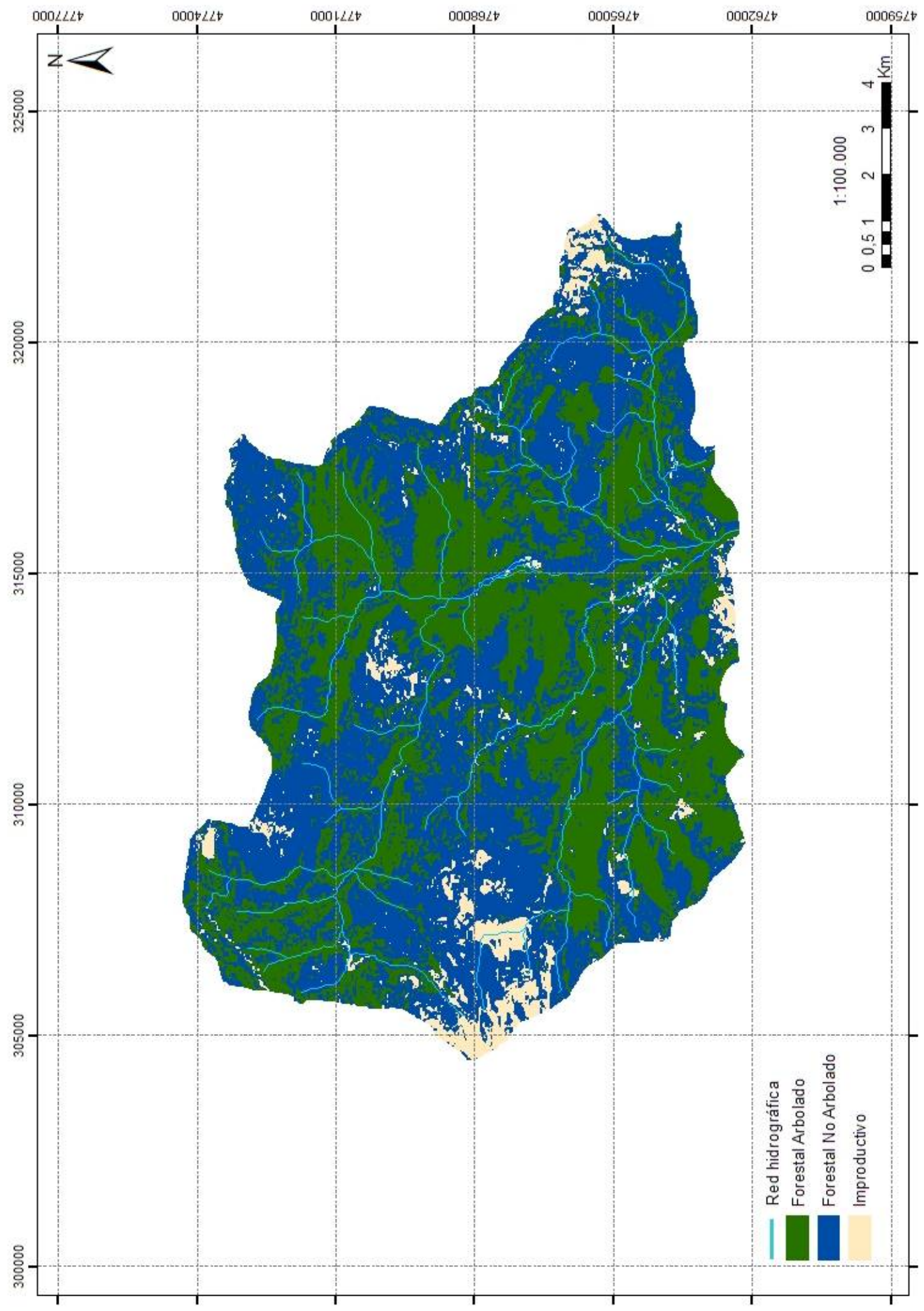

Figura 132 - Usos y cobertura del suelo en la cuenca del río Porma en 2001. 
Se aprecia en los resultados de los análisis principalmente un aumento de las zonas de forestal arbolado, pasando del 21,8\% del territorio en 1956 al 44,8\% en 2001 (Tabla 119 y Fig. 133).

Durante ese periodo se ha producido un aumento del 105\%, lo que representa 3542 ha. Este aumento ha ocurrido paulatinamente, de manera continua y proporcional en todos los intervalos analizados. A su vez, se observa una reducción bastante significativa de las zonas de forestal no arbolado pasando del 69,9\% (10.766 ha) en 1956 al 48,4\% (7454 ha) en 2001. Toda esta disminución está claramente asociada al aumento de las áreas de forestal arbolado.

Tabla 119. Evolución de los usos y de la cobertura del suelo en la cuenca del río Porma.

\begin{tabular}{|l|c|c|c|c|c|c|c|c|}
\hline \multirow{2}{*}{ Categoría } & \multicolumn{2}{|c|}{1956} & \multicolumn{2}{c|}{1977} & \multicolumn{2}{c|}{1991} & \multicolumn{2}{c|}{2001} \\
\cline { 2 - 9 } & $\mathbf{( \% )}$ & (ha) & $\mathbf{( \% )}$ & (ha) & $\mathbf{( \% )}$ & (ha) & (\%) & (ha) \\
\hline \hline Forestal Arbolado & 21,8 & 3360 & 30,7 & 4728 & 35,6 & 5482 & 44,8 & 6899 \\
\hline Forestal No Arbolado & 69,9 & 10766 & 51,5 & 7931 & 44,8 & 6899 & 48,4 & 7454 \\
\hline Cultivo & 2,4 & 367 & 0 & 0 & 0 & 0 & 0 & 0 \\
\hline Improductivo & 5,9 & 907 & 17,8 & 2741 & 19,6 & 3018 & 6,8 & 1047 \\
\hline \hline
\end{tabular}

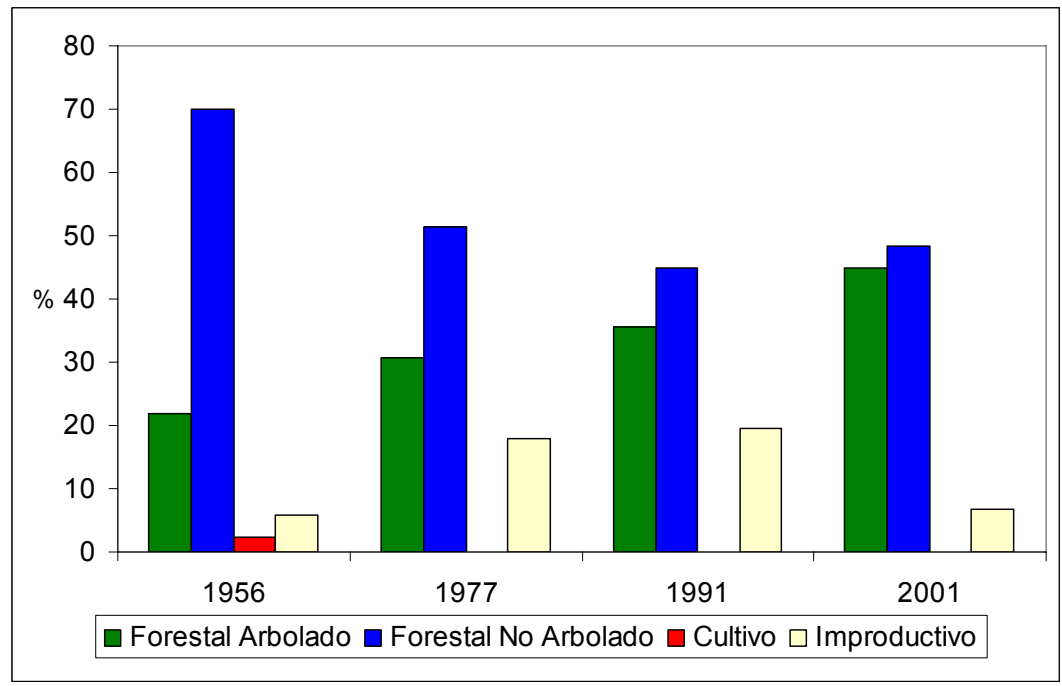

Figura 133 - Evolución de los usos y coberturas del suelo en la cuenca del río Porma (\%).

En la cabecera del río Porma ha tenido bastante repercusión el abandono de la ganadería y de los campos cultivados, incluso se observa que esta categoría de uso 
sólo aparece en 1956, con solamente el 2,4\% de la superficie. A partir de 1977 ya no se observan zonas cultivadas en la cabecera del río Porma.

Estos resultados están corroborados por el análisis de la población en la zona en la misma época que sufrió una reducción de 44\%, pasando de 1305 habitantes en 1960 a 725 en 2001.

Las zonas consideradas improductivas presentan un ligero aumento de 1956 hasta 2001, pasando del 5,9\% al 6,8\%. Sin embargo, se aprecian en 1977 y 1991 un pequeño aumento de éstas, presentando incluso valores semejantes en estos dos períodos. Es muy probable que en estas dos fechas estas áreas hayan sufrido más el abandono del pastoreo y por las imágenes se identifiquen como improductivas. Posteriormente, lo natural es que haya ocurrido una sustitución de estas áreas por las zonas de forestal no arbolado y de ésta a forestal arbolado.

\subsubsection{Cuenca del río Tajo}

Para análisis de la cuenca del Tajo, la más grande entre las utilizadas en esta investigación (41000 ha), los períodos analizados fueron 1956-57, 1976, 1987 y 2001 (Fig. 134, 135, 136 y 137).

Los mapas generados después de los trabajos de fotointerpretación y digitalización de las imágenes demuestran un comportamiento muy semejante al encontrado para la cuenca del río Porma. 


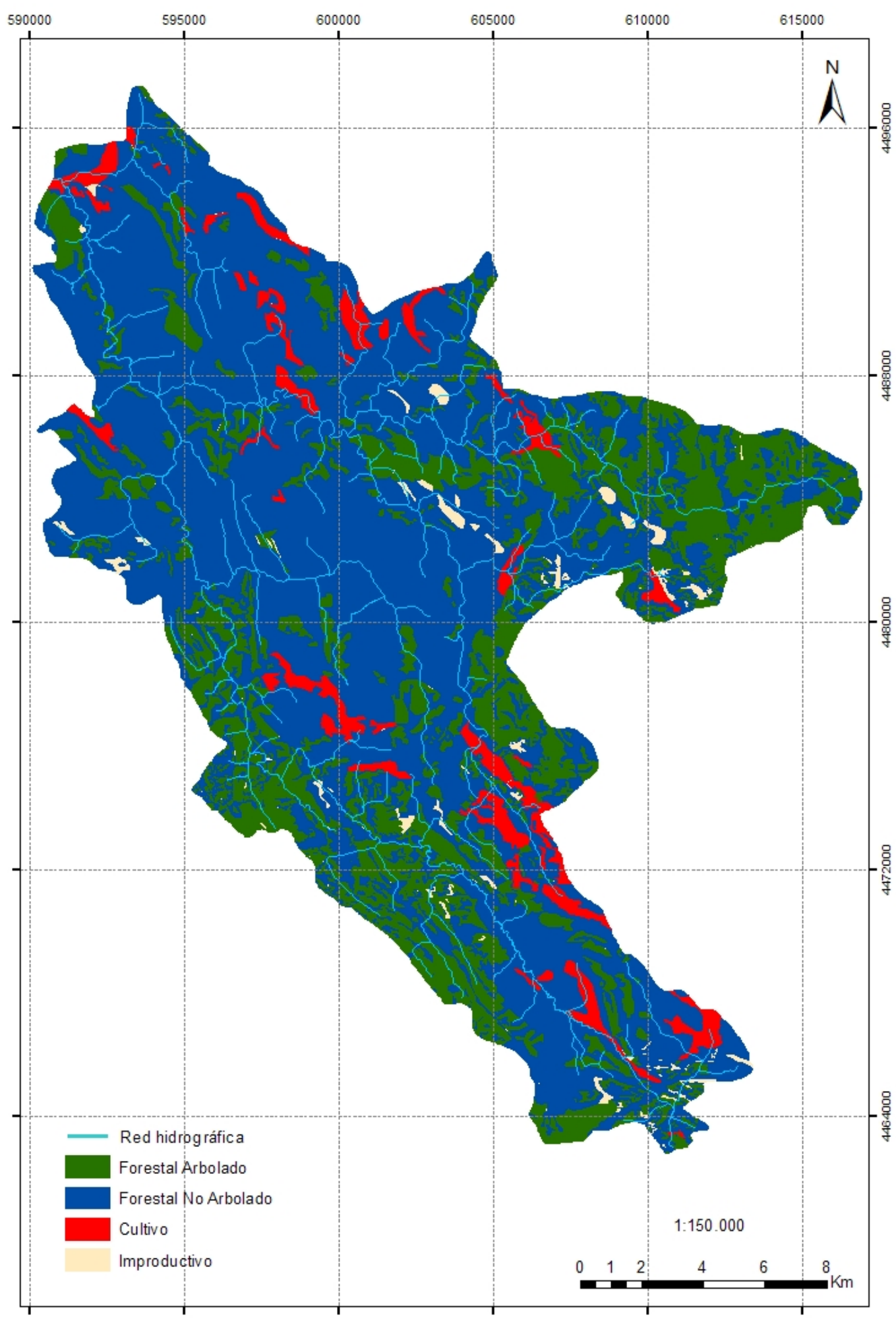

Figura 134 - Usos y coberturas del suelo en la cuenca del río Tajo en 1956-57. 


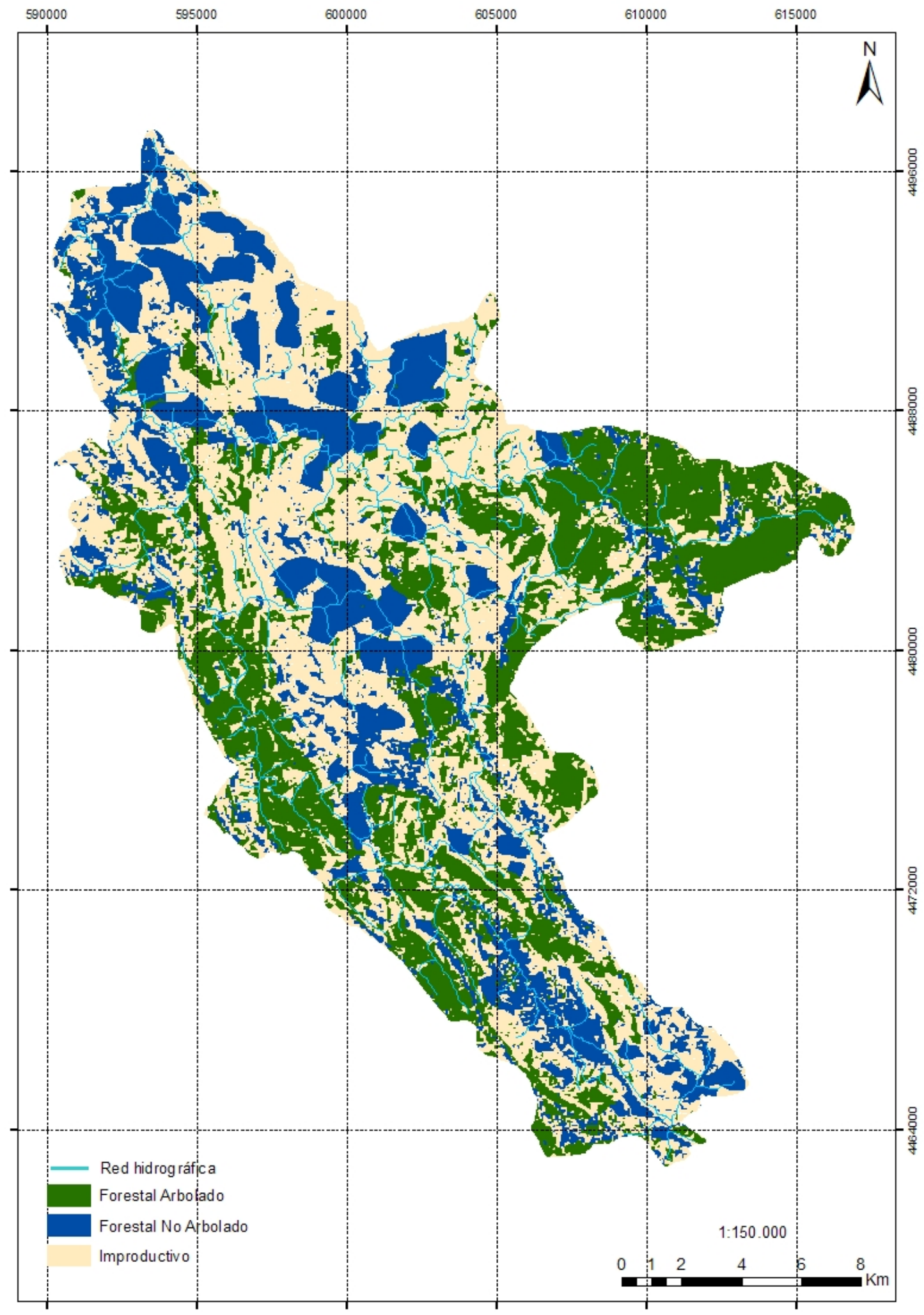

Figura 135 - Usos y coberturas del suelo en la cuenca del río Tajo en 1976. 


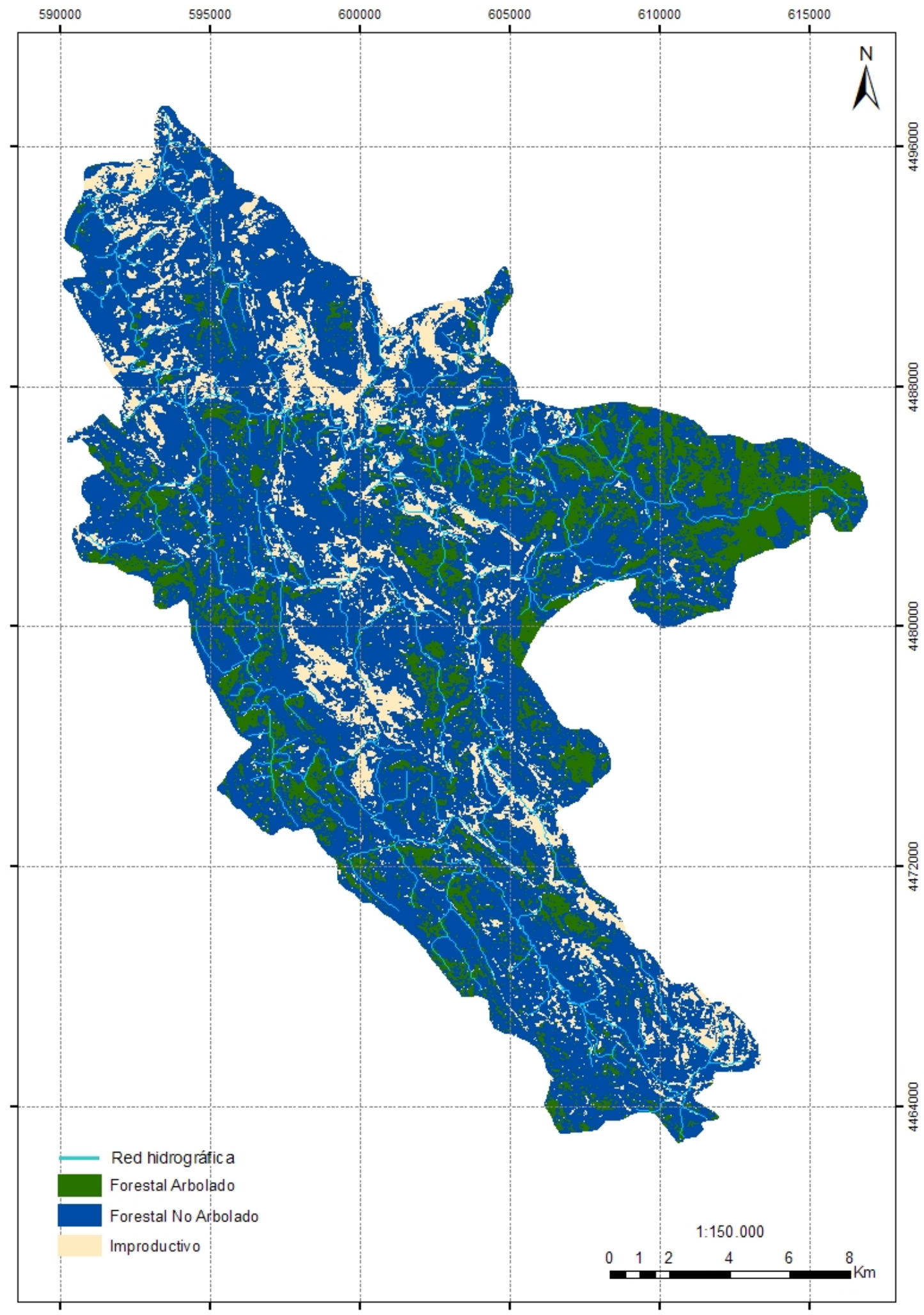

Figura 136 - Usos y coberturas del suelo en la cuenca del río Tajo en 1987. 


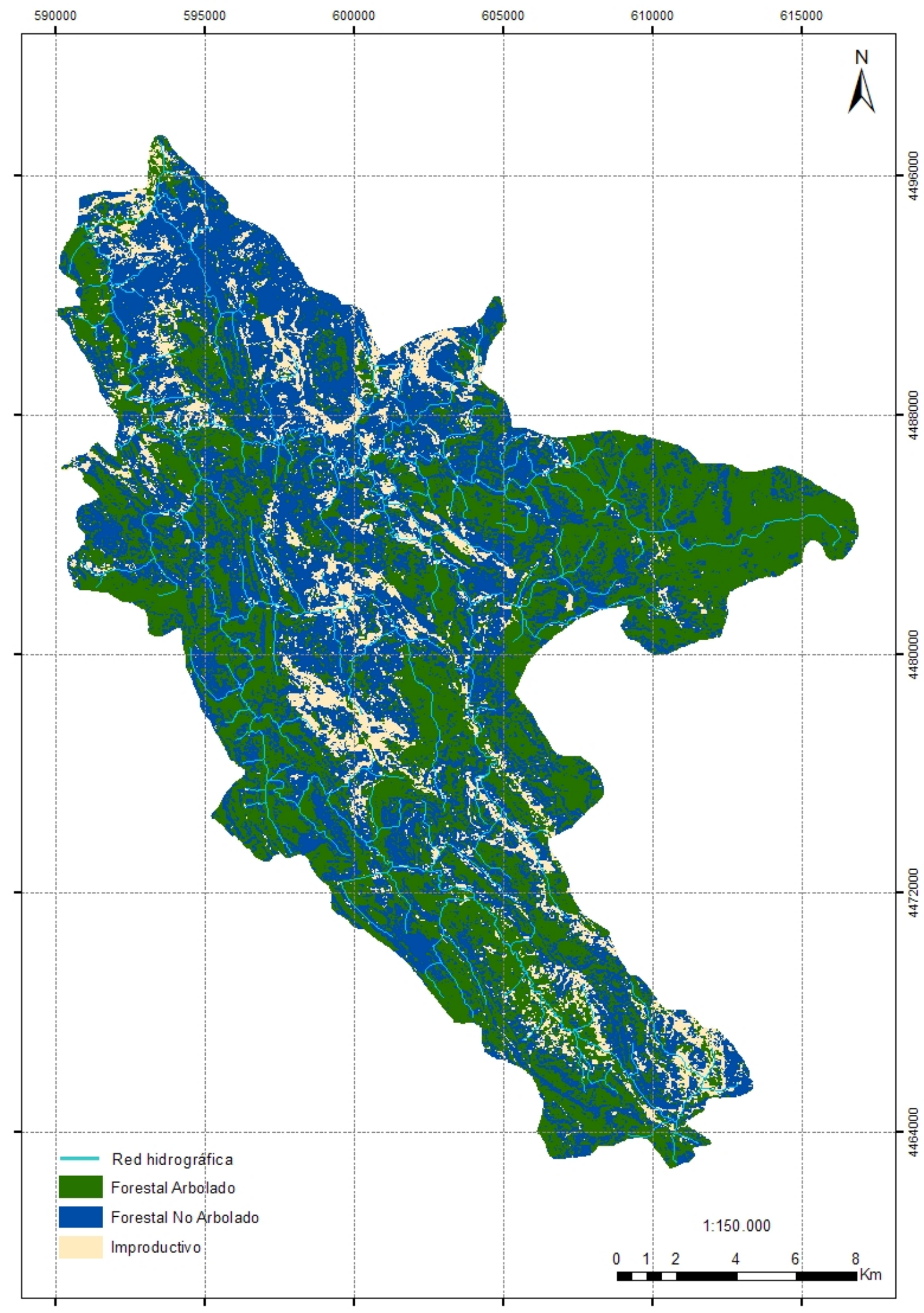

Figura 137 - Usos y coberturas del suelo en la cuenca del río Tajo en 2001. 
La categoría forestal arbolado tuvo un aumento bastante considerable, pasando del $26,7 \%$ del territorio en $1956-57$ al $51,4 \%$ en 2001 (Tabla 120 y Fig. 138), que representa un aumento (92\%) de 10127 ha de superficie ocupada por bosques en el período estudiado. Al mismo tiempo ha ocurrido una reducción de la superficie ocupada por la categoría forestal no arbolado que ha disminuido del 66,8\% (27401 ha) en 1956-57, al 40,2\% (16482 ha) en 2001. La relación entre ambos cambios es fácilmente explicada ya que, sobre todo, tras la disminución de la presión antrópica, que coincide con el período estudiado, ocurre un proceso natural de sucesión vegetal hasta estadios de mayor madurez. La población en la zona se redujo de 631 a 173 habitantes de 1960 a 2001, es decir, se registró una reducción de 73\%.

Tabla 120. Evolución de los usos y de la cobertura del suelo en la cuenca del río Tajo.

\begin{tabular}{|l|c|c|c|c|c|c|c|c|}
\hline \multirow{2}{*}{ Categoría } & \multicolumn{2}{|c|}{$\mathbf{1 9 5 6 - 5 7}$} & \multicolumn{2}{c|}{$\mathbf{1 9 7 6}$} & \multicolumn{2}{c|}{$\mathbf{1 9 8 7}$} & \multicolumn{2}{c|}{2001} \\
\cline { 2 - 9 } & $\mathbf{( \% )}$ & $\mathbf{( h )}$ & $\mathbf{( \% )}$ & $\mathbf{( h a )}$ & $\mathbf{( \% )}$ & $\mathbf{( h a )}$ & $\mathbf{( \% )}$ & (ha) \\
\hline \hline Forestal Arbolado & 26,7 & 10962 & 32,3 & 13243 & 34,1 & 13981 & 51,4 & 21074 \\
\hline Forestal No Arbolado & 66,8 & 27401 & 42,9 & 17589 & 53,7 & 22017 & 40,2 & 16482 \\
\hline Cultivo & 5,2 & 2149 & 0 & 0 & 0 & 0 & 0 & 0 \\
\hline Improductivo & 1,2 & 487 & 24,8 & 10168 & 12,2 & 5002 & 8,4 & 3444 \\
\hline \hline
\end{tabular}

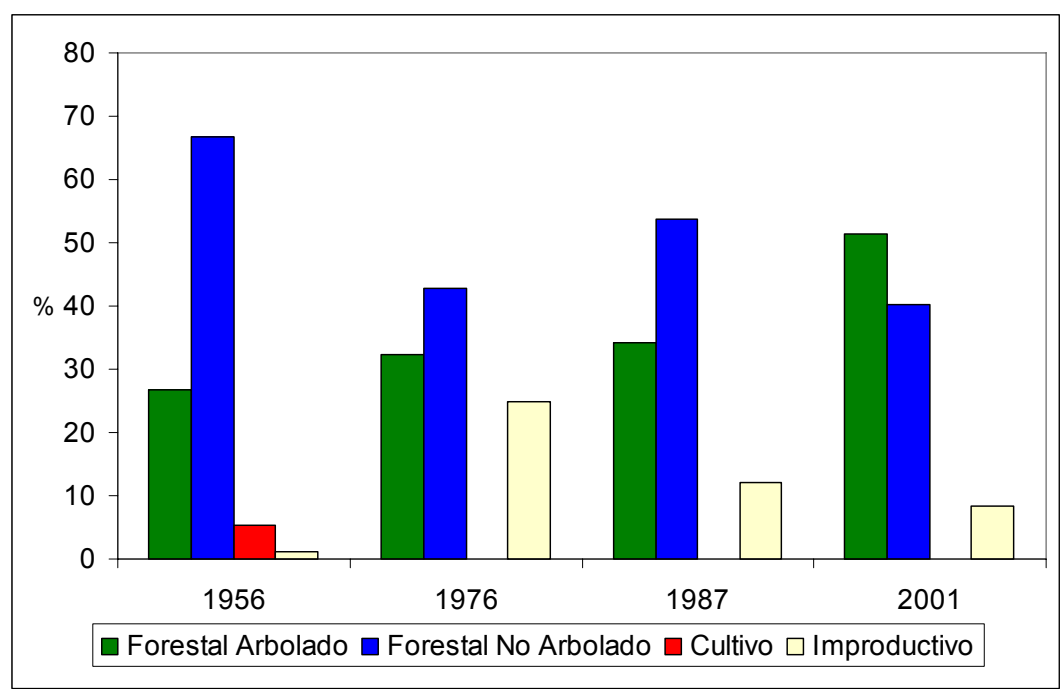

Figura 138 - Evolución de los usos y coberturas del suelo en la cuenca del río Tajo (\%). 
Como ocurrió en la cuenca del río Porma, los campos de cultivos sólo aparecen en la primera fecha (1956-1957), con solamente el 5,2\%, es decir, 2149 ha. En las demás fechas la agricultura ha sido completamente abandonada en la cuenca del Tajo y no se encuentran más trazos de estas actividades.

También con un comportamiento parecido al de la cuenca del Porma, las áreas consideradas improductivas tuvieron un aumento de 1956-57 a 2001. Sin embargo en 1976 y 1987 esta categoría presentó valores más altos, sobre todo de 1956 a 1976 donde fue detectado un aumento 9676 ha. Este valor es muy alto y no parece muy lógico ya que hay un reemplazo de las áreas de forestal no arbolado a improductivo. Es posible que en la imagen Landsat utilizada para esta fecha haya problemas de calidad y resolución que hayan producido resultados que enmascaren la realidad a la hora de la clasificación. Es evidente que parte de este cambio se dio debido a que en esta época se ha sentido más el abandono de los cultivos agrícolas y de la presión ganadera. A partir de 1987, cuando disminuyen considerablemente los valores de las áreas consideradas improductivas, se nota el reflejo de los procesos naturales de revegetación.

\subsubsection{Cuenca del río Trabaque}

Las imágenes de satélite utilizadas para análisis de la cuenca del río Trabaque son las mismas empleadas para la cuenca del Tajo pues están localizadas en zonas cercanas incluidas en las mismas escenas. Por lo tanto, fue posible utilizar las mismas fechas para estudio de ambas áreas, que fueron, 1956-57, 1976, 1987 y 2001 (Fig. 139, 140, $141,142)$. 


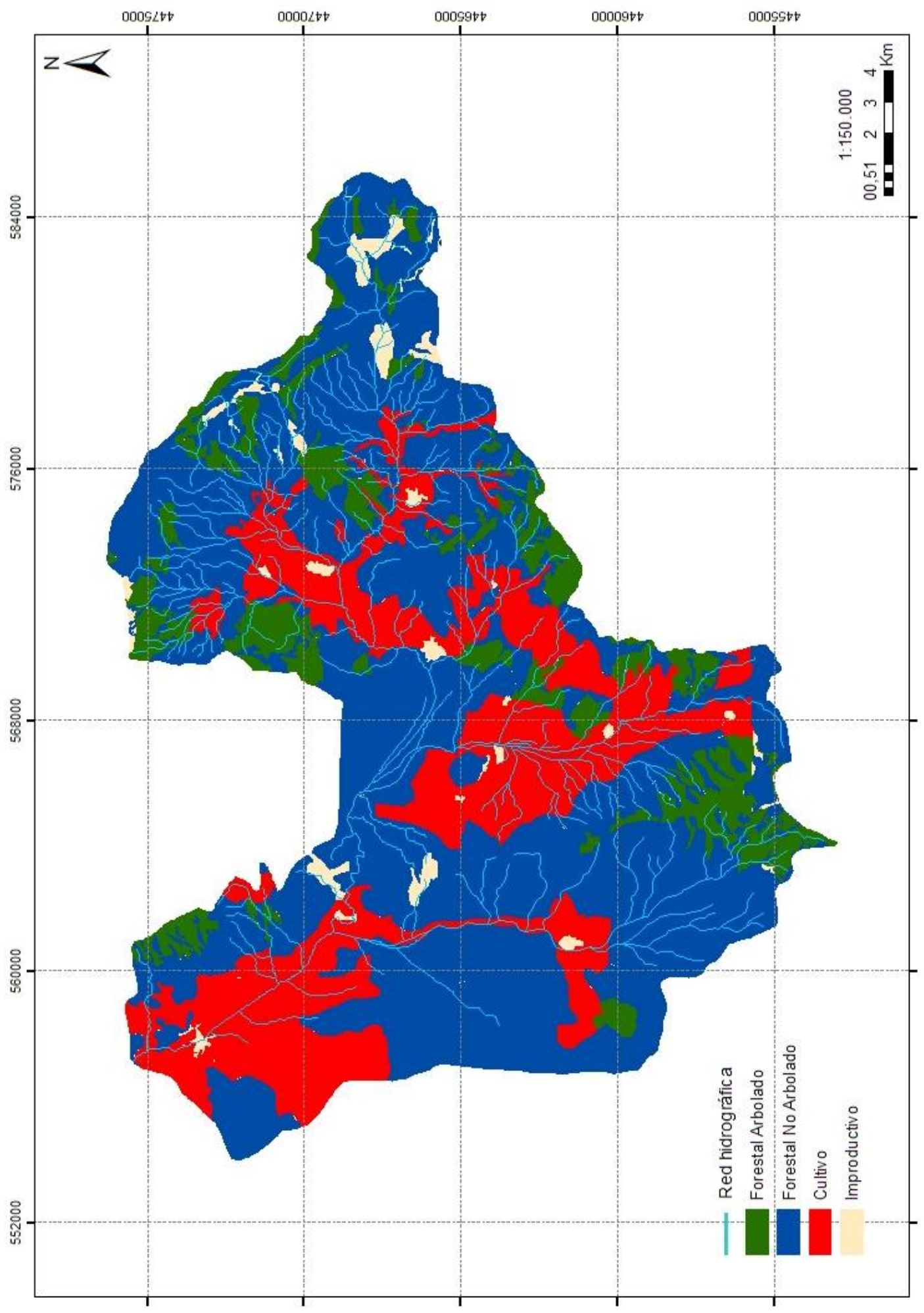

Figura 139 - Usos y coberturas del suelo en la cuenca del río Trabaque en 1956-57. 


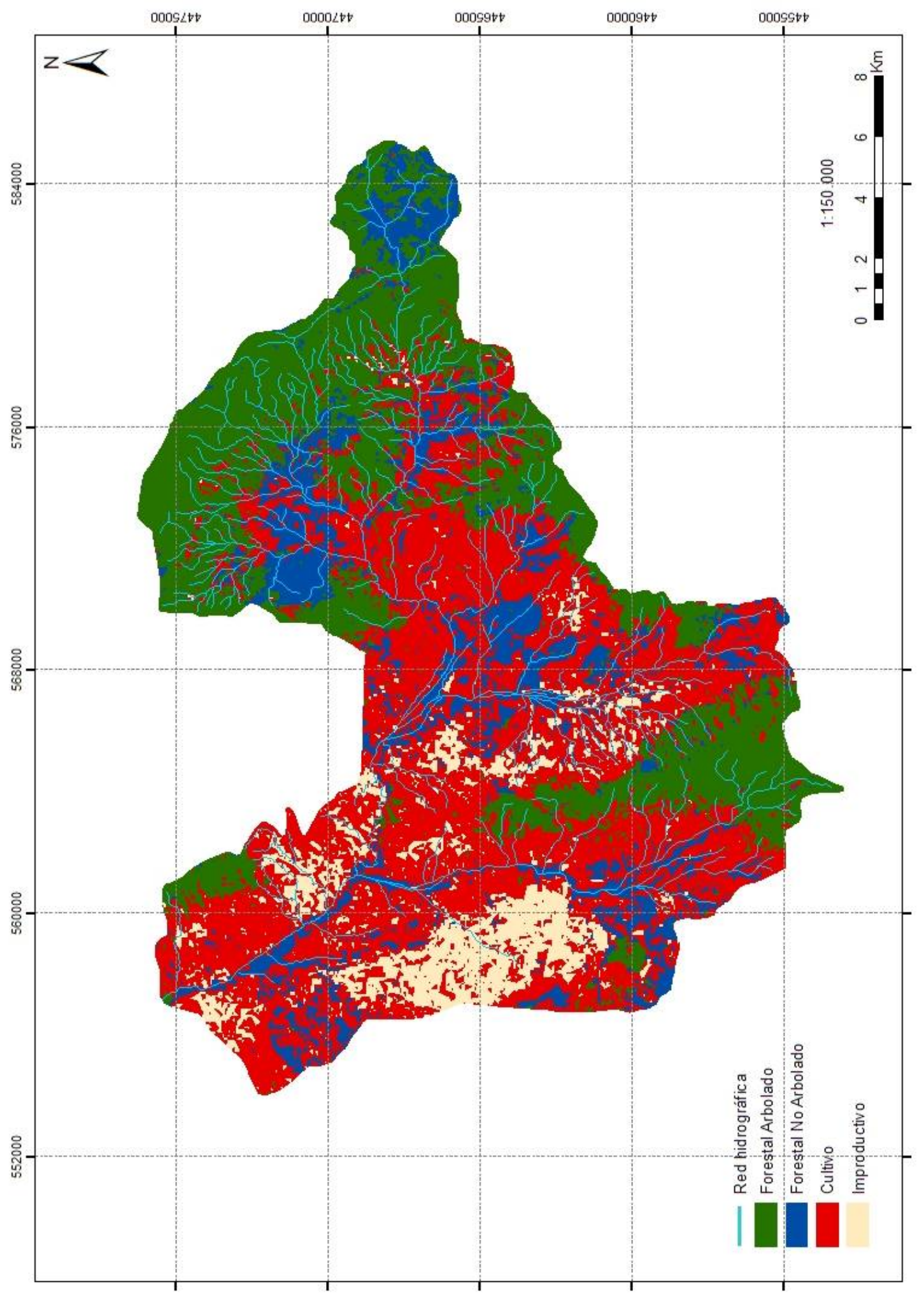

Figura 140 - Usos y coberturas del suelo en la cuenca del río Trabaque en 1976. 


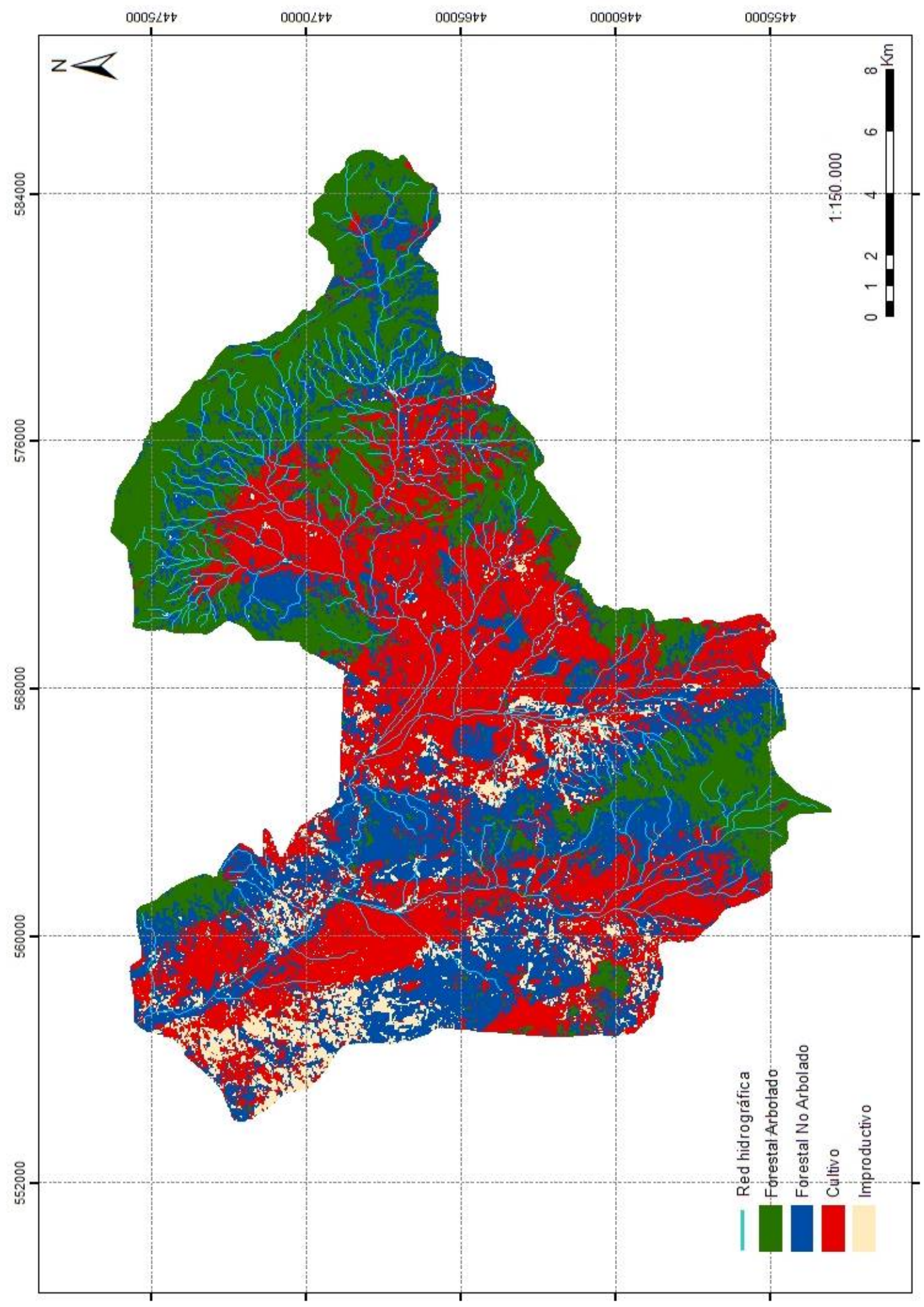

Figura 141 - Usos y coberturas del suelo en la cuenca del río Trabaque en 1987. 


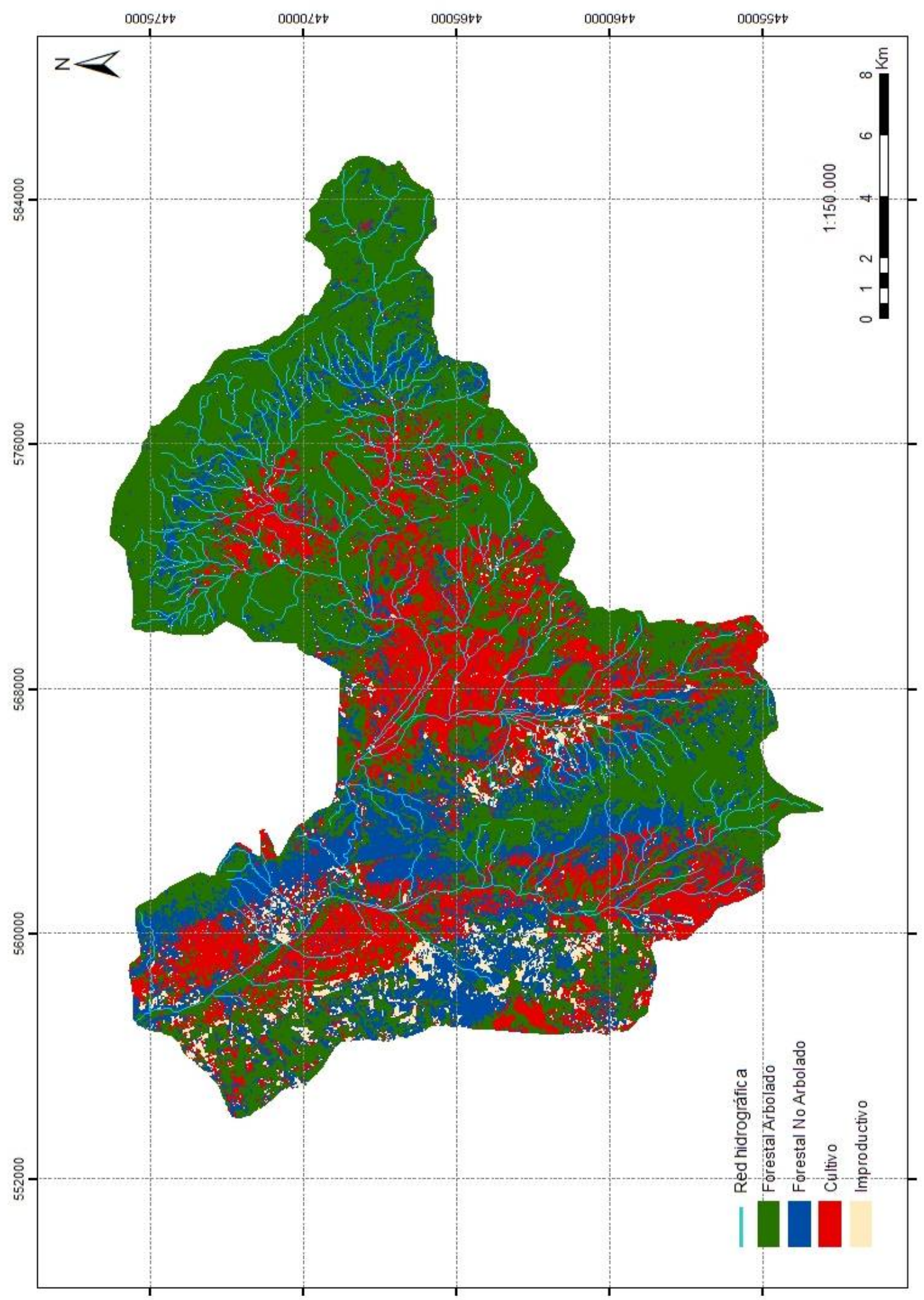

Figura 142 - Usos y coberturas del suelo en la cuenca del río Trabaque en 2001.

En el caso de la cuenca del río Trabaque los análisis llevan a dos panoramas principales. Lo primero es que, como ocurre en las demás cuencas utilizadas en este 
estudio, hubo un aumento considerable de la categoría considerada como forestal arbolado. Además, se observa un aumento en las fechas intermedias de los cultivos y al final valores muy semejantes a los encontrados en la primera fecha utilizada (19561957).

Las zonas consideradas como forestal arbolado aumentaron del $12,2 \%$ en $1956-57$ a 41,5\% en 2001 (Tabla 121 y Fig. 143), lo que representa un incremento extraordinario del $240 \%$, que equivale a $10.577,3$ ha. Al mismo tiempo se ha observado una reducción de las zonas de forestal no arbolado. Esta disminución ha sido del 52\%.

No obstante, es con relación a los campos cultivados donde más difiere esta cuenca con relación a las otras analizadas. A priori, al analizar solamente las fechas iniciales y finales, se aprecian valores prácticamente idénticos, con 25,8 y 25,7\%, respectivamente. Sin embargo al observarse los resultados de las dos fechas intermedias se identifica un aumento bastante significativo de los cultivos sobre todo en los mapas de 1976. Los campos cultivados han pasado de 9330 ha en 1956-57 a 17797 ha en 1976. A la vez se observa una disminución muy significativa de la categoría forestal no arbolado que pasa de $59,7 \%$ a $15,8 \%$ del territorio.

La cuenca del río Trabaque es la que presenta menores valores altitudinales, lo que puede explicar la menor influencia del éxodo rural en su comportamiento. No obstante no se puede menospreciar la reducción de la población en esta zona de 1960 a 2001 que fue de un 65\%. De 1976 hasta 1987 se aprecia una reducción significativa de los cultivos que pasan del $49,3 \%$ al $33,3 \%$. Esta tendencia regresiva de los campos cultivados sigue siendo observada hasta 2001 , año en que los valores bajan al $25,7 \%$ (muy semejante al encontrado en la primera fecha analizada).

Tabla 121. Evolución de los usos y de la cobertura del suelo en la cuenca del río Trabaque.

\begin{tabular}{|l|c|c|c|c|c|c|c|c|}
\hline \multirow{2}{*}{ Categoría } & \multicolumn{2}{|c|}{$\mathbf{1 9 5 6 - 5 7}$} & \multicolumn{2}{c|}{$\mathbf{1 9 7 6}$} & \multicolumn{2}{c|}{$\mathbf{1 9 8 7}$} & \multicolumn{2}{c|}{$\mathbf{2 0 0 1}$} \\
\cline { 2 - 9 } & $\mathbf{( \% )}$ & $\mathbf{( h a )}$ & $\mathbf{( \% )}$ & $\mathbf{( h a )}$ & $\mathbf{( \% )}$ & $\mathbf{( h a )}$ & $\mathbf{( \% )}$ & (ha) \\
\hline Forestal Arbolado & 12,2 & 4388 & 22,6 & 8159 & 27,3 & 9855 & 41,5 & 14982 \\
\hline Forestal No Arbolado & 59,7 & 21563 & 15,8 & 5704 & 32,1 & 11588 & 28,5 & 10289 \\
\hline Cultivo & 25,8 & 9330 & 49,3 & 17797 & 33,3 & 12021 & 25,7 & 9278 \\
\hline Improductivo & 2,3 & 819 & 12,3 & 4440 & 7,3 & 2635 & 4,3 & 1552 \\
\hline \hline
\end{tabular}




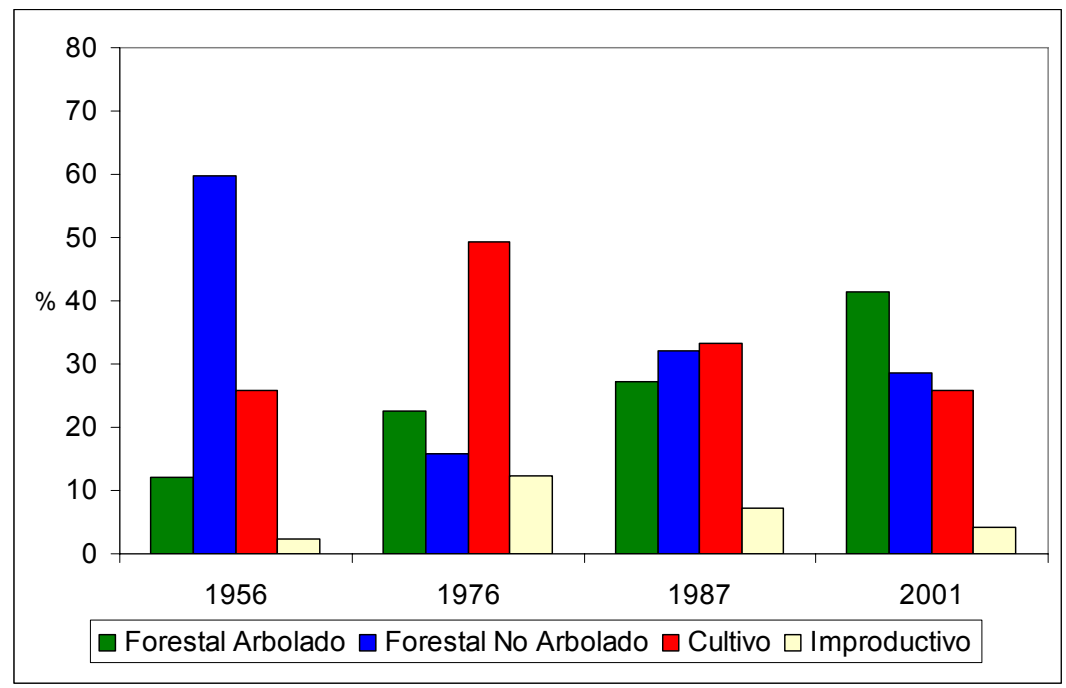

Figura 143 - Evolución de los usos y coberturas del suelo en la cuenca del río Trabaque (\%).

Las áreas consideradas improductivas también presentan cierta estabilidad con un ligero aumento si consideramos la fecha inicial (1956-57) y la final (2001). No obstante, se observa en 1976 un aumento más significativo, pasando de 819 ha en 1956-57 a 4440 ha en 1976. En 1987 se redujo nuevamente este valor, llegando a 2635 ha. Estas oscilaciones están claramente relacionadas con las encontradas al analizar las zonas cultivadas.

\subsection{Discusión de los resultados encontrados}

De acuerdo con lo explicado en el apartado Material y Métodos, no es posible cuantificar los errores que puedan haber en las clasificaciones de las fotografías aéreas y de las imágenes de satélites. Esto puede hacer pensar que algunos de los resultados encontrados puedan estar enmascarando la realidad de las zonas de estudio. Sin embargo, no hay duda de que las cuatro cuencas utilizadas para el análisis en esta investigación están inmersas en un proceso de intensos cambios en los usos y en la cobertura del suelo, en donde la principal característica, común a todas ellas, es un incremento notable de las zonas de forestal arbolado. Dichos cambios están ocurriendo en fuertes proporciones y no resulta arriesgado pensar que tengan influencia en los procesos hidrológicos de las cuencas. Está también bastante claro que esta nueva realidad es consecuencia directa de la dinámica de la sociedad, ya que los medios rurales fueron abandonados muy significativamente en la segunda mitad del siglo XX. Además, en estos territorios no hubo políticas de gestión que estuviesen destinadas a coordinar estos espacios evitando las posibles consecuencias 
sobre todo ambientales y paisajísticas. Ha sido detectado en las cuatro zonas estudiadas un incremento de las áreas de forestal arbolado bastante considerable. En donde más se ha notado ha sido en la cuenca del río Trabaque, con un $241 \%$, seguido de la cuenca del Cega con un $214 \%$. A su vez en las cuencas de los ríos Porma y Tajo este aumento fue un algo menor pero muy considerable también, con $105 \%$ y $92 \%$ respectivamente.

Resultados muy semejantes están siendo observados en muchas partes del mundo y en España no es diferente. Lasanta et al. (2000, 2006, 2007), afirman que los Pirineos vienen sufriendo un proceso de revegetación muy importante, con avances significativos de los matorrales de sucesión y de los bosques de pinos y robles, fundamentalmente. También en los Pirineos, García-Ruiz et al. (2001) concluyen que se observa una lenta recuperación del bosque hacia sectores más elevados, debido probablemente al descenso de la presión ganadera en las últimas décadas. Por esta misma razón, amplias extensiones de pastos subalpinos muestran evidencias de infrautilización o incluso abandono. En los Cameros, en el Sistema Ibérico Occidental, Arnáez et al. (2008), también relatan que como consecuencia del abandono de tierras y del descenso de la presión ganadera, se asiste, desde mediados del siglo XX, a un intenso proceso de revegetación. En Valencia, en la Rambla del Poyo y en el Barranc de Carraixet, los estudios de Pascual Aguilar (2002), revelan también que el relativo aumento de las clases de monte en ambos espacios debe considerarse consecuencia de la crisis de los cultivos tradicionales de secano, al ser recolonizados por la vegetación natural tras el abandono de zonas marginales. Poyatos et al. (2003), en la cuenca Cal Rodo, en el Prepirineo catalán, al igual que los anteriores también encontró un incremento de la densidad de bosques ya presentes en 1957 y la forestación espontánea de campos abandonados y áreas vegetadas de manera dispersa. Además afirma que el área afectada por estos procesos representa más del $43 \%$ de toda la cuenca. En otros países también se encuentran resultados semejantes. Henríquez et al. (2006), en Chile, ha visto que en la región estudiada por ellos, los usos de suelo que más han disminuido han sido el matorral, los cultivos y pastizales, y humedales, en ese orden, mientras que el uso forestal ha aumentado. Además, concluyen que todas estas alteraciones tienen importante repercusión en el comportamiento del coeficiente de escorrentía. En el sur de Brasil, en la cuenca de Arroyo Grande, Kleinpaul et al. (2005), identificó un aumento de la cobertura forestal del 10,24\%, también consecuencia del abandono rural en esta región. 
Muchas son las consecuencias del aumento del bosque en cuestiones ambientales, sobre todo en la generación de escorrentía. Según García Ruiz et al. (2001) la producción de escorrentía es muy alta mientras las laderas permanecen cultivadas y, una vez abandonada, se reduce a medida que la colonización vegetal se hace más y más densa. Una tendencia similar se observa en la producción de sedimento. También, según los estudios realizados por García Ruiz et al. (2001), es difícil cuantificar, en términos de cantidad de agua, lo que representan estos cambios de cubierta vegetal. Pero es evidente que la sustitución de antiguos campos de cultivo por repoblaciones forestales y por matorrales densos ha de tener una influencia directa sobre el caudal, como asimismo la tendencia al abandono de algunos pastos supraforestales. No hay dudas de que las principales influencias de la cubierta vegetal en la producción de escorrentía son el aumento de la interceptación de la precipitación por la vegetación y el propio papel de esta como consumidora de agua.

Una adecuada planificación de los usos y de la cobertura del suelo es de extrema necesidad para mitigar y reducir los impactos ambientales asociados a problemas en la generación de escorrentía producto de los acelerados cambios sufridos en las últimas décadas relacionados con estas variables.

Es evidente que el estudio de los cambios en los usos y en la cobertura del suelo representa una herramienta indispensable para gestores y legisladores, pues conociendo la utilización del suelo en una determinada área, se puede elaborar una mejor política de usos del suelo para desarrollo de dicha región. Además, es muy importante que estos estudios sean realizados de forma multitemporal pues la conformación del paisaje expresa muy fielmente las relaciones seculares de los hombres con el medio $\mathrm{y}$, como se ha demostrado en esta investigación, las transformaciones en los usos y en la cubierta vegetal están directamente relacionadas con la dinámica de la población y consecuentemente con las políticas de gestión territorial. Investigaciones como esta son solamente un paso inicial que sirve para plantear cambios a grandes rasgos, y para una gestión eficaz son indispensable estudios más detallados y con más resolución temporal y espacial. 


\section{ANÁLISIS GLOBAL DE LAS VARIABLES ESTUDIADAS}

\subsection{Evolución de la Escorrentía}

La comparación de la evolución de los aportes en las cuencas de los ríos Cega, Porma, Tajo y Trabaque es posible una vez que son cuencas de cabecera en zonas de media montaña y en un contexto geográfico mediterráneo. Entretanto, las condiciones bioclimáticas específicas de ellas son distintas, lo que se puede comprobar con el análisis de los resultados climáticos y hidrológicos encontrados. La diferencia en la producción de escorrentía entre las cuatro cuencas queda reflejada en los resultados de los caudales específicos (Fig. 144).

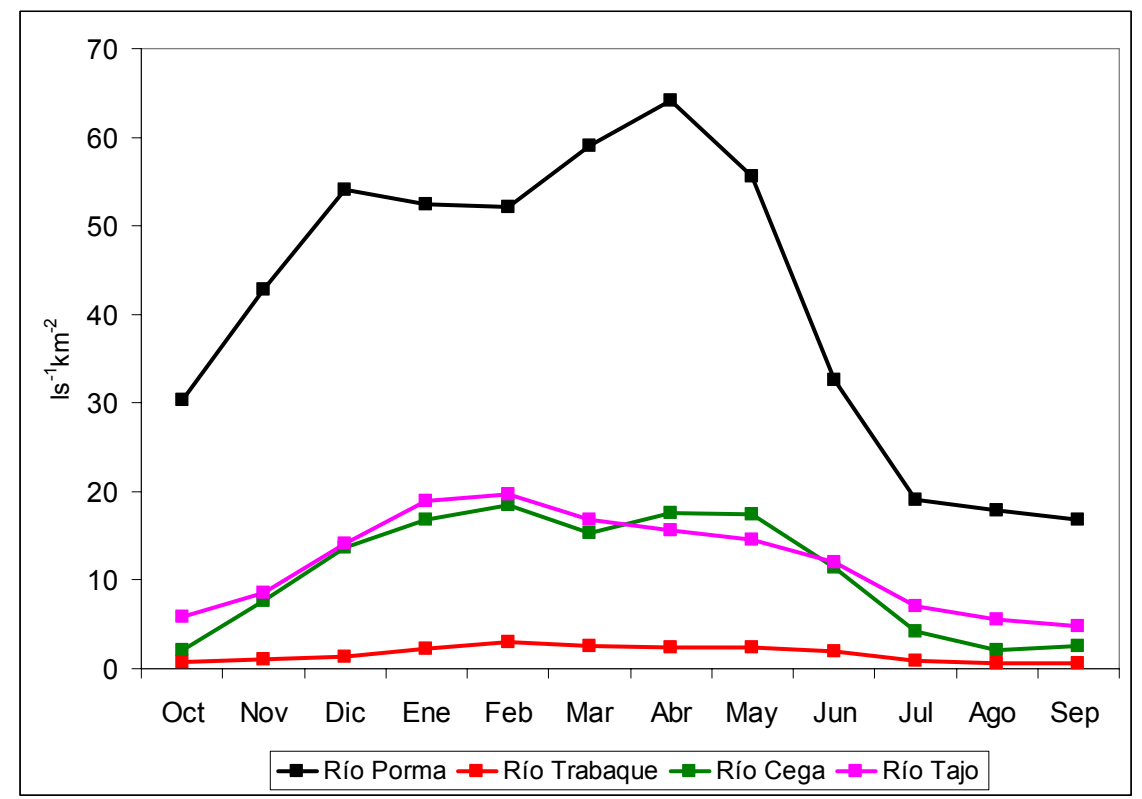

Figura 144 - Caudal específico de las cuencas de los ríos Cega, Porma, Tajo y Trabaque.

Se observa claramente la diferencia entre la cantidad de escorrentía producida en cada una de las áreas analizadas. En las cuencas de los ríos Cega y Tajo en el $60 \%$ del tiempo el caudal específico está entre 10 y $20 \mathrm{Is}^{-1} \mathrm{~km}^{-2}$. Por otro lado está el río Porma, en donde en el $75 \%$ de los meses se observa un caudal específico entre $30 \mathrm{y}$ $70 \mathrm{ls}^{-1} \mathrm{~km}^{-2}$, el valor más alto entre las cuencas analizadas. A su vez, la menor producción de escorrentía se da en la cuenca del río Trabaque, en donde en todos los meses el caudal específico está por debajo de $10 \mathrm{Is}^{-1} \mathrm{~km}^{-2}$, y su valor medio es de tan solo $1,6 \mathrm{ls}^{-1} \mathrm{~km}^{-2}$, un valor muy bajo tratándose de una cuenca de cabecera. 
La figura 145 refleja el comportamiento hidrológico de las cuatro cuencas a través del uso del caudal relativo. Los resultados varían de cero a dos, independientemente de las características de la cuenca, lo que permite comparar espacial y temporalmente los caudales.

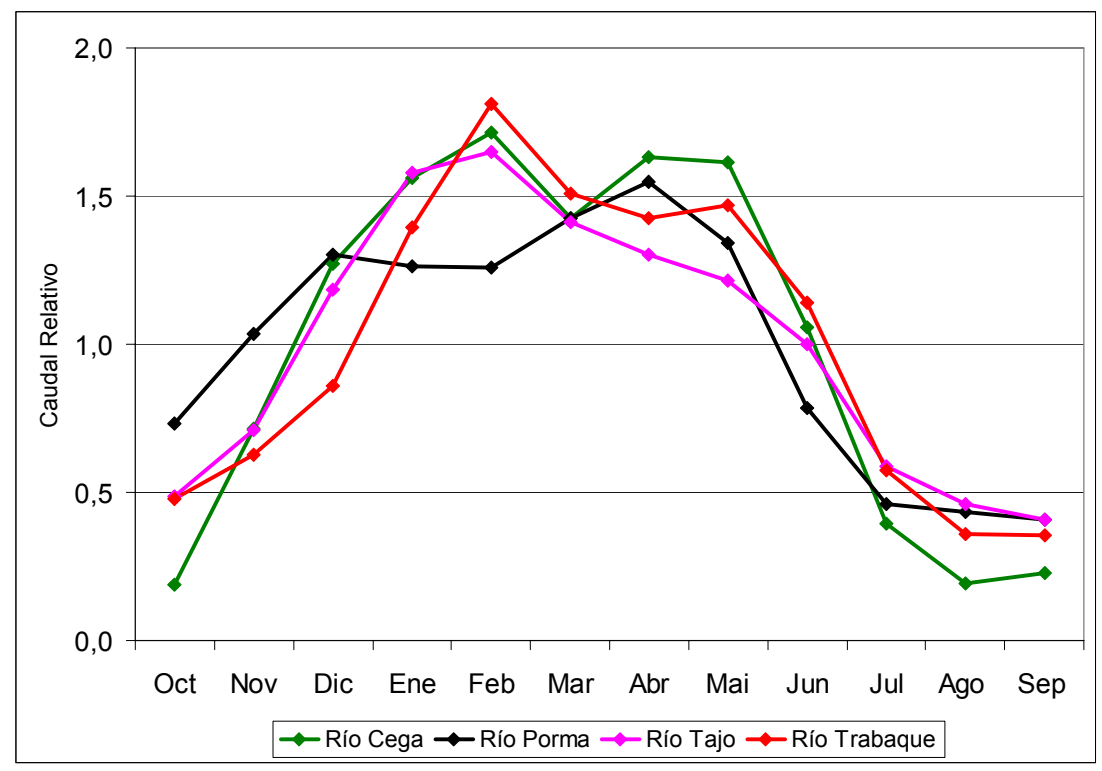

Figura 145 - Caudal relativo (adimensional) de las cuencas de los ríos Cega, Porma, Tajo y Trabaque.

Es bastante evidente la similitud entre las cuencas del Cega, Porma, Tajo y Trabaque en cuanto al comportamiento de sus ríos. Aunque haya una diferencia marcada en las cantidades de los recursos hídricos en ellas, es muy claro que los ríos se comportan de manera muy similar con relación a sus períodos de aguas altas y bajas. Se trata, por tanto, de ríos mediterráneos con regímenes fluviales muy similares, y se pone de manifiesto la premisa de partida del estudio, en relación con la selección de cuencas pertenecientes a un mismo contexto hidrológico. Se pueden explicar esas semejanzas por las características comunes de todas ellas: cuencas de cabecera, de media montaña y que están bajo clima mediterráneo. De la misma manera, las características bioclimáticas específicas de cada una definen sus diferencias. En todas las cuencas (Fig. 145) los meses de verano (julio, agosto y septiembre) son los que poseen registros más bajos de aportación, y se puede percibir que el estiaje es muy fuerte, ya que en todas ellas el caudal es menos de la mitad de la media anual. En todos los casos los valores por debajo de la media se prolongan hasta el mes de octubre. En los 
ríos Cega, Tajo y Trabaque coinciden los picos máximos de caudal en invierno. El único matiz diferenciador se observa en el Porma, con un máximo claramente primaveral, reflejo de la contribución de la fusión nival en la Cordillera Cantábrica al total de caudales circulantes. La nieve no tiene una importancia muy destacada en el resto de cuencas, sin embargo, las lluvias otoñales son muy relevantes en todas ellas, pues marcan el comienzo del aumento en la aportación. Buena parte de estas primeras lluvias se destina a la recarga de los acuíferos y a la recuperación de la humedad del suelo después del fuerte estiaje que las cuencas han sufrido.

En la tabla 122 están reflejados los coeficientes de correlación entre la aportación anual y el tiempo encontrados. Las cuencas de los ríos Porma, Tajo y Trabaque presentan una tendencia marcadamente negativa en su escorrentía. Sin embargo solamente en el Porma y en el Tajo esta tendencia es estadísticamente significativa con R. Probablemente la elevadísima variabilidad del caudal en el Trabaque, como ya ha quedado demostrado, esté enmascarando una tendencia regresiva, igualmente significativa. Los valores de $\mathrm{R}$ encontrados en la cuenca del río Cega no presentan ningún tipo de tendencia y, aunque sea un valor negativo, es casi despreciable.

Tabla 122. Coeficientes de correlación entre aporte anual y tiempo de los ríos Porma y Trabaque para el periodo 1974 - 2004.

\begin{tabular}{|l|l|c|c|c|}
\hline \hline \multicolumn{1}{|c|}{ Cuencas } & \multicolumn{1}{|c|}{ Estación de Aforo } & n & $\begin{array}{c}\text { Signif. } \\
\text { Estad. }\end{array}$ & R \\
\hline \hline Cega & 016 - Pajares de Pedraza & 31 & NS & $-0,069$ \\
\hline Porma & 078 - Camposolillo & 31 & $*$ & $-0,467$ \\
\hline Tajo & $001-$ Peralejos de las Truchas & 31 & $*$ & $-0,355$ \\
\hline Trabaque & 186 - Priego & 31 & NS & $-0,248$ \\
\hline \hline
\end{tabular}

NS = Valores no significativos estadísticamente

* = Significativo estadísticamente al $95 \%$

Los resultados del test $\mathrm{M}-\mathrm{K}$ corroboran lo encontrado con $\mathrm{R}$ y demuestran que el río Trabaque también presenta valores de aportación negativos estadísticamente significativos (Tabla 123). Aunque el río Cega presente valores de $S$ de Kendall y $Z$ negativos no se puede deducir con este estadístico que realmente haya ningún tipo de tendencia en los aportes. 
Tabla 123. Resultados del test Mann-Kendall para el aporte anual para el periodo 1974 2004.

\begin{tabular}{|l|l|c|c|c|}
\hline \hline \multicolumn{1}{|c|}{ Cuencas } & \multicolumn{1}{c|}{ Estación de Aforo } & S & $\mathbf{Z}_{\mathbf{s}}$ & $\mathbf{P}$ \\
\hline \hline Cega & 016 - Pajares de Pedraza & -16 & $-1,44$ & 0,07 \\
\hline Porma & 078 - Camposolillo & -150 & $-14,24$ & 0,0001 \\
\hline Tajo & 001 - Peralejos de las Truchas & -129 & $-13,62$ & 0,0001 \\
\hline Trabaque & 186 - Priego & -89 & $-7,71$ & 0,0001 \\
\hline \hline
\end{tabular}

Zs $>(+/-) 1,96$ se rechaza la hipótesis nula de no tendencia Valor $p<0,05$ se rechaza la hipótesis nula de no tendencia

Por tanto, solamente en la cuenca del río Cega no se aprecia una pérdida de aportación significativa. La pérdida total de la aportación en los 31 años analizados en las cuencas de los ríos Porma, Tajo y Trabaque es considerable y muy parecida, $33,5 \%, 28,8 \%$ y $35,3 \%$, respectivamente. Valores semejantes de pérdida de aportación fueron encontradas por García Ruiz et al. (2001) y por Begueria et al. (2003) en algunos ríos del Pirineo aragonés que tuvieron una disminución media en torno al $30 \%$ en un período de 30 años. Estos valores de reducción de los caudales circulantes, en torno a un tercio, suponen una cantidad muy notable, máxime teniendo en consideración que se trata de un contexto hidrológico de carácter mediterráneo, en el que se parte siempre de condiciones de escasez en la disponibilidad de agua. Es lógico pensar, por tanto, que esta merma de aportación tiene que haber tenido consecuencias en la cantidad de recursos hídricos disponibles en el resto de sus respectivas cuencas aguas abajo.

Esta tendencia al decrecimiento en los valores de aportación están siendo apuntadas en diversos estudios que han sido llevados a cabo en diversas zonas de España (García Ruiz et al. 2001; López Moreno et al. 2002; Begueria et al. 2003; Machin et al. 2005; López Moreno, 2006).

\subsection{Evolución de la Precipitación}

El comportamiento de las precipitaciones observado en todas las cuencas revela diferencias significativas entre ellas, sobre todo con relación a la cantidad (Fig. 146). En las cuencas de los ríos Cega y Tajo se dan unos valores intermedios de precipitación próximos entre si, con una media de 698 y $906 \mathrm{~mm}$, respectivamente. La cuenca del río Trabaque es la que presenta valores más bajos, con una media anual 
de $558 \mathrm{~mm}$, y en el otro extremo se encuentra la cuenca del Porma con una media de $1436 \mathrm{~mm}$ anuales.

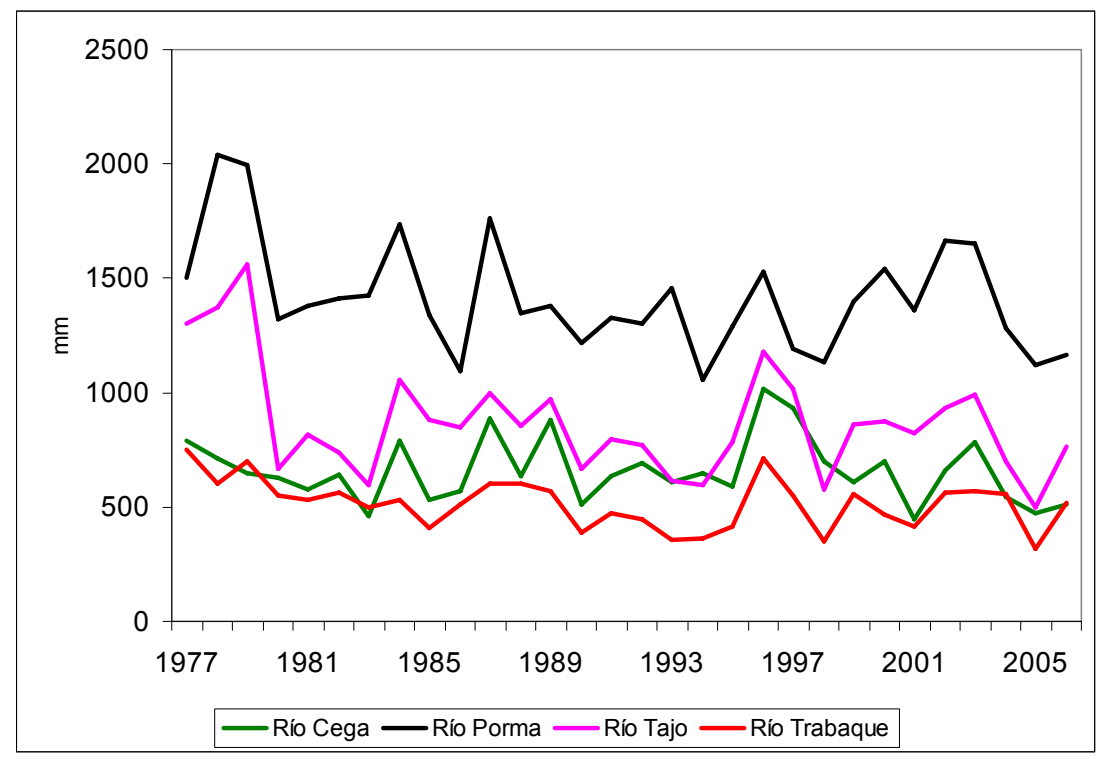

Figura 146 - Evolución de la precipitación total anual en las cuencas de los ríos Cega, Porma, Tajo y Trabaque.

Los valores normalizados basados en el uso de la media y de la desviación típica, revelan el comportamiento de las cuatro zonas y facilita su comparación (Fig. 147). Es innegable la similitud en todas ellas. En la cuenca del río Trabaque, en un $43 \%$ de los años los valores de precipitación están por debajo de la media. En las demás zonas estudiadas la precipitación ha estado por debajo de la media en un $60 \%$ del período estudiado. 


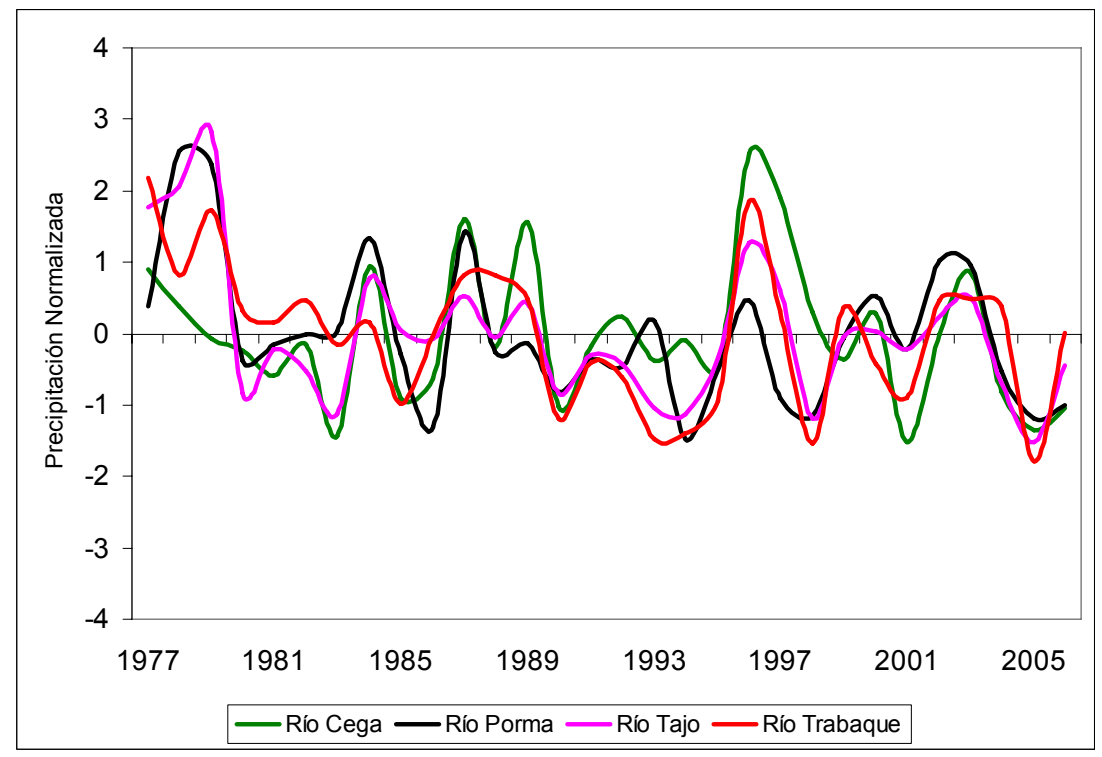

Figura 147 - Valores normalizados de la precipitación total anual en las cuencas de los ríos Cega, Porma, Tajo y Trabaque.

En las cuencas de los ríos Cega y Porma, ambos afluentes del río Duero, solamente en una estación en cada cuenca se ha encontrado una tendencia negativa estadísticamente significativa (Tabla 124). A su vez, en las cuencas de los ríos Tajo y Trabaque, en casi todas las estaciones se han detectado valores claramente negativos. Estos resultados muestran que en estas dos zonas se está produciendo una reducción de la precipitación. Por otro lado, en las cuencas de los ríos Cega y Porma es muy probable que estén ocurriendo solamente oscilaciones normales y características del clima mediterráneo.

Tabla 124. Resultados de los estadísticos Rho de Sperman y Mann-Kendall para la precipitación de las estaciones con tendencia negativa significativa, en el periodo 1977 2006.

\begin{tabular}{|l|l|c|c|c|c|}
\hline \hline Cuencas & \multicolumn{1}{|c|}{ Estaciones } & $\mathbf{R}$ & $\mathbf{S}$ & $\mathbf{Z}_{\mathbf{s}}$ & $\mathbf{P}$ \\
\hline \hline Cega & Matabuena & $-0,307\left(^{*}\right)$ & -485 & $-22,94$ & 0,0001 \\
\hline Porma & Maraña & $-0,270\left(^{*}\right)$ & -467 & $-18,36$ & 0,0001 \\
\hline \multirow{3}{*}{ Tajo } & Beteta & $-0,484\left(^{* *}\right)$ & -365 & $-21,05$ & 0,0001 \\
\cline { 2 - 6 } & Cañizares & $-0,529\left(^{* *}\right)$ & -496 & $-27,46$ & 0,0001 \\
\cline { 2 - 6 } & Poyatos & $-0,389\left(^{* *}\right)$ & -407 & $-21,95$ & 0,0001 \\
\cline { 2 - 6 } & Santa María del Val & $-0,502\left(^{* *}\right)$ & -388 & $-22,57$ & 0,0001 \\
\hline \multirow{2}{*}{ Trabaque } & Albalate de las Nogueras & $-0,388\left(^{* *}\right)$ & -257 & $-15,74$ & 0,0001 \\
\cline { 2 - 6 } & Torrecilla & $-0,564\left(^{* *}\right)$ & -497 & $-26,61$ & 0,0001 \\
\cline { 2 - 6 } & Villar de Domingo García & $-0,334\left(^{*}\right)$ & -285 & $-16,67$ & 0,0001 \\
\hline \hline
\end{tabular}

Zs $>(+/-)$ 1,96 se rechaza la hipótesis nula de no tendencia Valor $p<0,05$ se rechaza la hipótesis nula de no tendencia $\mathrm{NS}=$ Valores no significativos estadísticamente

* = Correlación significativa al nivel de 0,05

${ }^{* *}=$ Correlación significativa al nivel de 0,01 
Muchos son los estudios realizados en los últimos años en relación con la evolución de la precipitación en España. Diversos autores no han detectado tendencias estadísticamente significativas en la precipitación, y simplemente fluctuaciones que únicamente deben ser consideradas como normales (Labajo y Piorno, 2001; Abaurrea et al. 2002; Chazarra Bernabé et al. 2002; López Moreno et al. 2002; Andreo et al. 2006; López Moreno, 2006; Norrant et al. 2006). Las conclusiones de estos estudios concuerdan con los resultados encontrados en este trabajo. En un artículo sobre la Depresión del Ebro, Saladié et al. (2002) encontraron un descenso no significativo en los meses de primavera, verano y otoño, mientras en el invierno se registró una tendencia ligeramente positiva. Por otro lado Brunetti et al. (2004) detectaron en Italia en el último siglo que no hubo decrecimiento en las precipitaciones, pero que hubo un aumento considerable en la intensidad de los eventos. Esteban-Parra et al. (1998), en su estudio en España, para el período 1880-1992 encontraron un descenso estadísticamente significativo en la precipitación. Estos resultados tienen otra significación por tratarse de una serie muy larga de datos. Resultados similares también fueron encontrados por Piervitali et al. (1998) en el centro-oeste mediterráneo con una serie de 45 años.

\subsection{Evolución de la Temperatura}

La temperatura es una variable que está indirectamente relacionada con la evolución de los recursos hídricos ya que controla procesos tan importantes como la evapotranspiración y distribución y duración del manto nival. La diferencia en los valores de temperatura en las cuatro cuencas está reflejada en la figura 148. Esta diferencia es confirmada por el valor de la media de cada una que es de $9,6^{\circ} \mathrm{C}$ para la cuenca del río Cega, $8,7^{\circ} \mathrm{C}$ para la del Porma, $11,3^{\circ}$ para la cuenca del Tajo y $14,5^{\circ} \mathrm{C}$ para la del río Trabaque. Se aprecia que se mantiene una cierta regularidad en la temperatura aunque a partir de los años 80 hay oscilaciones más considerables en todas ellas. 


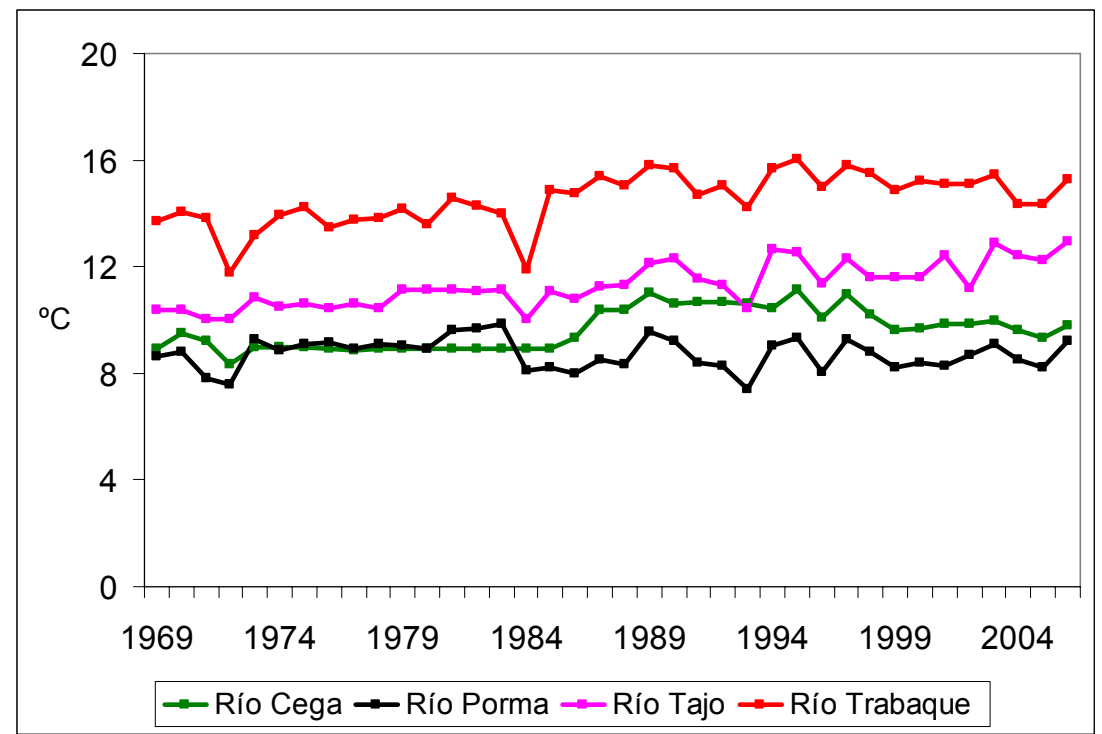

Figura 148 - Evolución de la temperatura anual en las cuencas de los ríos Cega, Porma, Tajo y Trabaque.

Solamente la cuenca del río Porma presenta una cierta reducción en los valores de la temperatura en el tiempo, aunque no es significativa al utilizar el estadístico $\mathrm{R}$ y sí lo es, aunque reducida, con M-K. Estos resultados probablemente reflejen la existencia simplemente de fluctuaciones normales en el tiempo. Sin embargo, en todas las demás cuencas se observa una tendencia estadísticamente significativa al aumento de la temperatura en los últimos años al utilizar los estadísticos $R$ y M-K (Tabla 125). Además, esta tendencia es muy marcada.

Tabla 125. Resultados de los estadísticos Rho de Sperman y Mann-Kendall para la temperatura media anual en el periodo $1969-2006$.

\begin{tabular}{|l|l|c|c|c|c|}
\hline \hline Cuencas & \multicolumn{1}{|c|}{ Estaciones } & $\mathbf{R}$ & $\mathbf{S}$ & $\mathbf{Z}_{\mathbf{s}}$ & $\mathbf{P}$ \\
\hline \hline Cega & Rascafria & $0,616\left(^{* *}\right)$ & 241 & 17,61 & 0,0001 \\
\hline Porma & Pantano del Porma & $-0,111(\mathrm{NS})$ & -43 & $-3,18$ & 0,0015 \\
\hline Tajo & Cañizares & $0,839\left(^{* *}\right)$ & 457 & 39,85 & 0,0001 \\
\hline Trabaque & Arrancacepas & $0,720\left({ }^{* *}\right)$ & 357 & 26,11 & 0,0001 \\
\hline \hline
\end{tabular}

Zs $>$ (+/-) 1,96 se rechaza la hipótesis nula de no tendencia Valor $p<0,05$ se rechaza la hipótesis nula de no tendencia $\mathrm{NS}=$ Valores no significativos estadísticamente

** $=$ Correlación significativa al nivel de 0,01 
Como ha quedado demostrado, las cuatro cuencas poseen una realidad distinta desde el punto de vista de la temperatura. Con los valores normalizados (Fig. 149) es posible observar mejor el comportamiento de esta variable en las zonas analizadas.

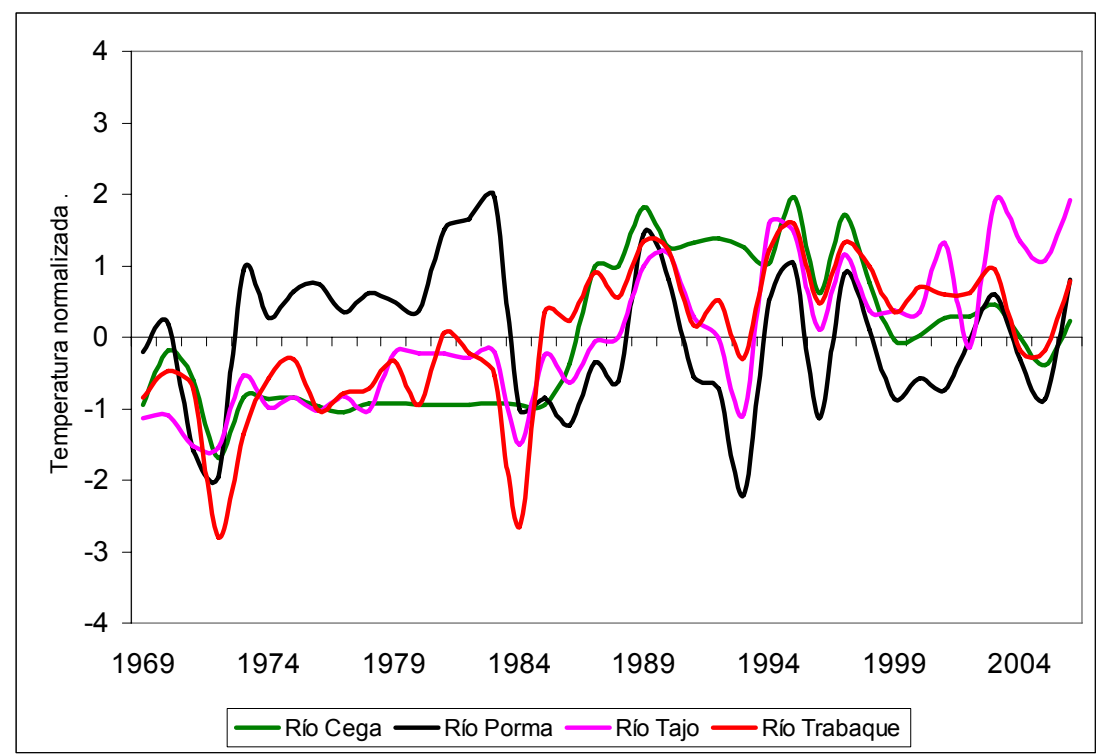

Figura 149 - Valores normalizados de la temperatura media anual en las cuencas de los ríos Cega, Porma, Tajo y Trabaque.

En todas las cuencas hay una cierta regularidad con relación a la cantidad de años en que se presentaron valores por debajo o por en cima de la media. No obstante, lo que cambia es que en la cuenca del río Porma durante toda la serie se encuentran estos valores muy bien distribuidos, lo que no ocurre en las otras zonas. En la cuenca del río Cega casi todos los valores que están por debajo de la media fueron detectados antes del año de 1986. A partir de este año la mayoría está por en cima de la media (86\%). Las cuencas de los ríos Tajo y Trabaque también reflejan un comportamiento muy parecido. En ambas los valores que están por encima de la media se detectan básicamente a partir del año de 1987. Estos resultados corroboran los encontrados con los estadísticos $\mathrm{R}$ y $\mathrm{M}-\mathrm{K}$.

Un aumento significativo en la temperatura en las últimas décadas, que es el caso del resultado encontrado en las cuencas de los ríos Cega, Tajo y Trabaque, fue encontrado también por Brunetti et al. (2004), Brunet et al. (2005) y Del Río et al. (2005). Resultados semejantes al obtenido para la cuenca del río Porma, fueron detectados por Andreo et al. (2006) que no hallaron tendencias estadísticamente significativas en la temperatura. Los resultados encontrados en esta investigación 
pueden ser considerados como la prueba evidente de un cambio significativo en las condiciones térmicas de las áreas estudiadas. El aumento de la temperatura, principal indicador del cambio climático, ha de tenerse muy en cuenta por la gran influencia que ejerce esta variable en la configuración bioclimática de un territorio y en la dinámica del ciclo hidrológico.

\subsection{Evolución de los Cambios en los Usos y en la Cobertura Del Suelo}

Con relación a los cambios en los usos y en la cobertura del suelo lo principal a destacar ha sido el aumento, en todas las zonas analizadas, de la categoría de forestal arbolado, es decir, del bosque (Fig. 150).

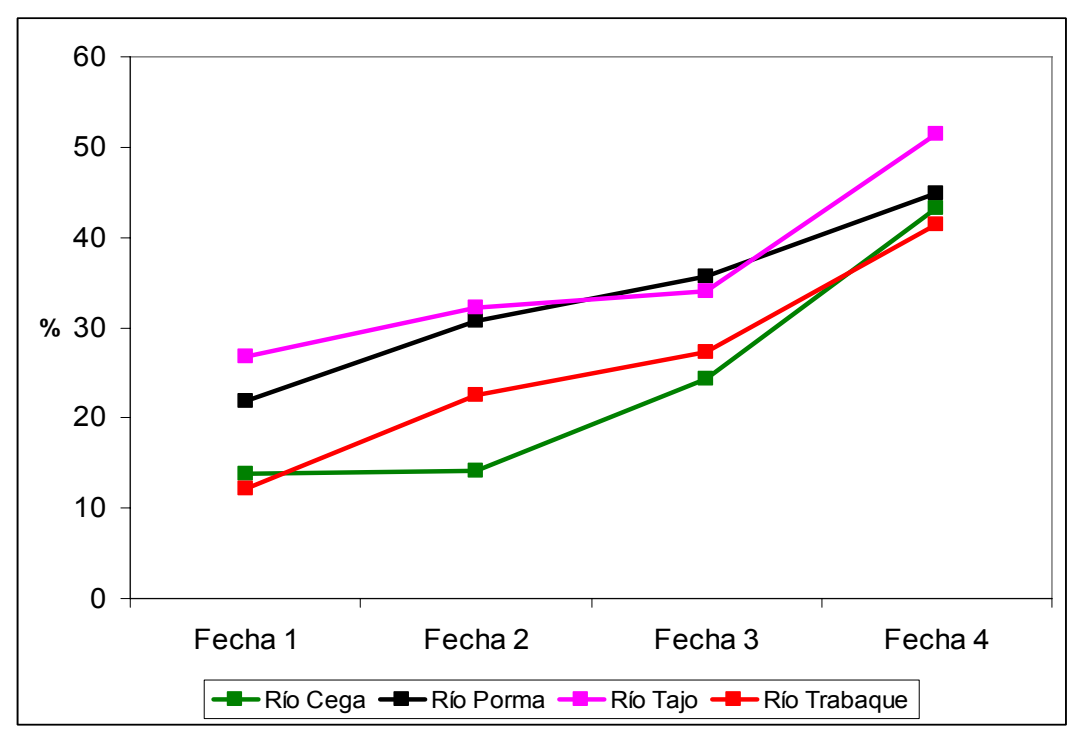

Figura 150 - Evolución de la categoría Forestal Arbolado en las cuencas de los ríos Cega, Porma, Tajo y Trabaque.

Todas las tasas de aumento son muy altas y reflejan una realidad que posiblemente tiene bastante influencia en la dinámica y evolución de los recursos hídricos de estas zonas. En la cuenca del río Cega hubo un aumento de las áreas de forestal arbolado de un $214 \%$, en la del Porma un 105\%, en la del Tajo un aumento del $92 \%$ y en la cuenca del río Trabaque nada menos que un $241 \%$. Como ha quedado demostrado en la mayoría de estas zonas, todas de cabeceras de estos ríos, hubo una reducción bastante considerable de las actividades agrícolas y de la ganadería y un especial abandono del medio rural. Como consecuencia de todo este proceso es bastante 
evidente una natural sucesión vegetal, caracterizada inicialmente por la invasión de herbáceas y matorrales y más tarde por árboles de gran porte.

Los resultados obtenidos en esta investigación pueden posiblemente explicar parte de la reducción en la aportación una vez que la cubierta vegetal tiene un papel directo en la producción de escorrentía. Bosch \& Hewlett (1982) demostraron ampliamente que la introducción de cambios en la cubierta vegetal aumenta o disminuye la interceptación o el consumo de agua y consecuentemente influye en la variabilidad espacio-temporal de la producción de escorrentía. Además, es innegable que las zonas de cabeceras son especialmente sensibles a estos cambios. Resultados semejantes a los encontrados en este estudio están siendo encontrados en varias partes de España (Poyatos et al. 2003; Gallart et al. 2004; Boix-Fayos et al. 2007; Lasanta et al. 2007; Arnáez el al. 2008). En todos estos estudios se evidencia un aumento inicial de los matorrales y un aumento posterior de las masas boscosas. Está claro que para determinar concretamente la influencia de los cambios en los usos y en la cobertura del suelo en la aportación de una cuenca se hace necesario ampliar la investigación sobre todo con respecto al tipo específico de cobertura y a los tipos de suelos. De esta manera sería posible identificar la importancia de la humedad del suelo, de la interceptación de la cubierta vegetal y de los caudales de bases de las cuencas para conocer mejor la respuesta hidrológica al clima y a los cambios en los usos y coberturas del suelo.

\subsection{Relación entre Aportación y Precipitación}

Es necesario hacer un análisis conjunto de la aportación y de la precipitación para que se puedan verificar las relaciones existentes entre ambas variables. En el caso de las cuencas de los ríos Cega y Porma (Fig. 151 y 152) es posible ver que la correlación entre estas variables no es muy alta. De hecho en el análisis de regresión de la precipitación y las aportaciones con el tiempo, se apreciaba que el valor de la pendiente de la recta era mucho más acusado en el caso de la aportación en el Porma, indicando esta circunstancia un cierto desacople entre las dos variables. No se puede deducir, por tanto, una relación bien definida entre las oscilaciones que ocurren en ambas. En algunos años las fluctuaciones en estas dos variables son coincidentes y parte de las reducciones o aumentos en la aportación es explicada por las oscilaciones de la precipitación. Por tanto, como se puede observar por los gráficos, y 
también por todo lo que se expuso hasta ahora, la precipitación no puede ser considerada la única responsable de las variaciones en los valores de la aportación.

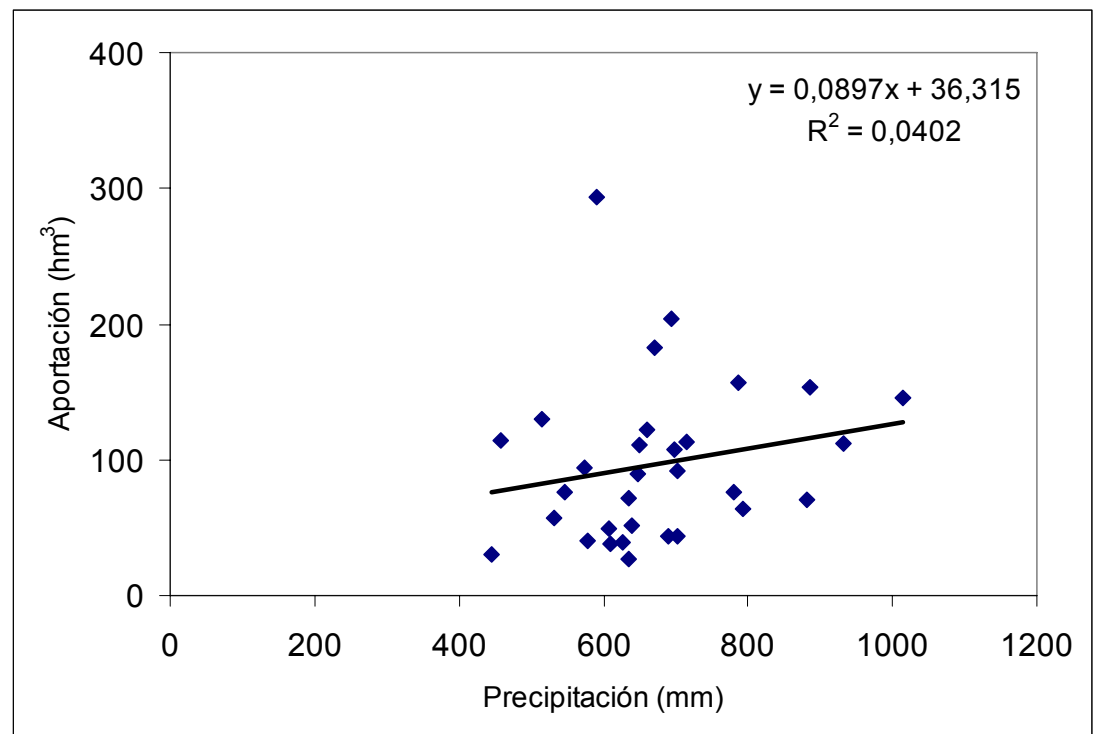

Figura 151 - Relación entre precipitación y aportación - Río Cega.

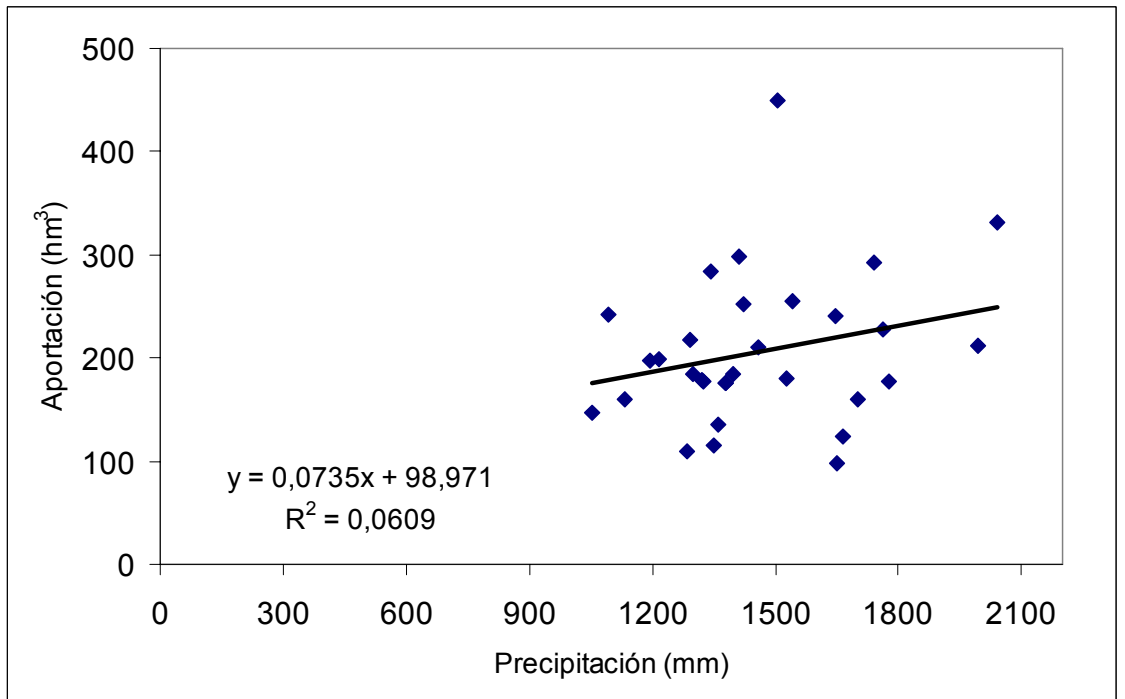

Figura 152 - Relación entre precipitación y aportación - Río Porma.

En el caso de las cuencas de los ríos Tajo y Trabaque (Fig. 153 y 154) se puede percibir que existe una relación más estrecha entre estas dos variables. Por lo tanto, las oscilaciones en la precipitación pueden explicar de manera directa buena parte de las fluctuaciones en el caudal medio anual en estas cuencas, aunque tampoco se puede considerar ésta la única responsable del descenso en las aportaciones. 


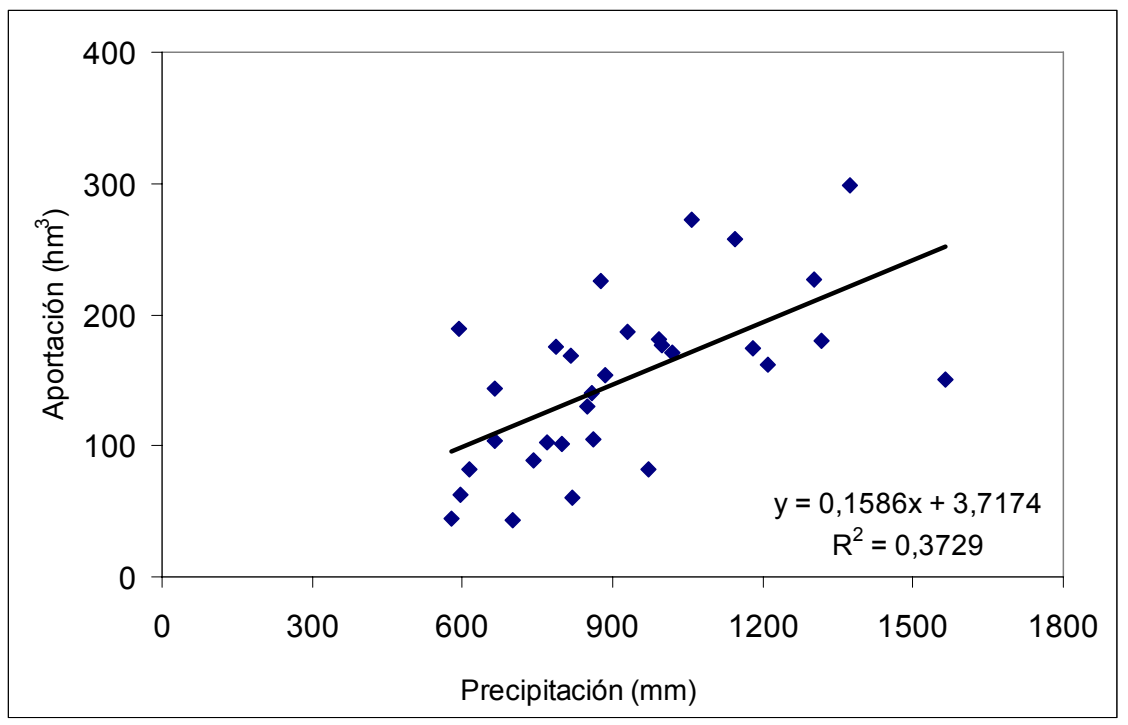

Figura 153 - Relación entre precipitación y aportación - Río Tajo.

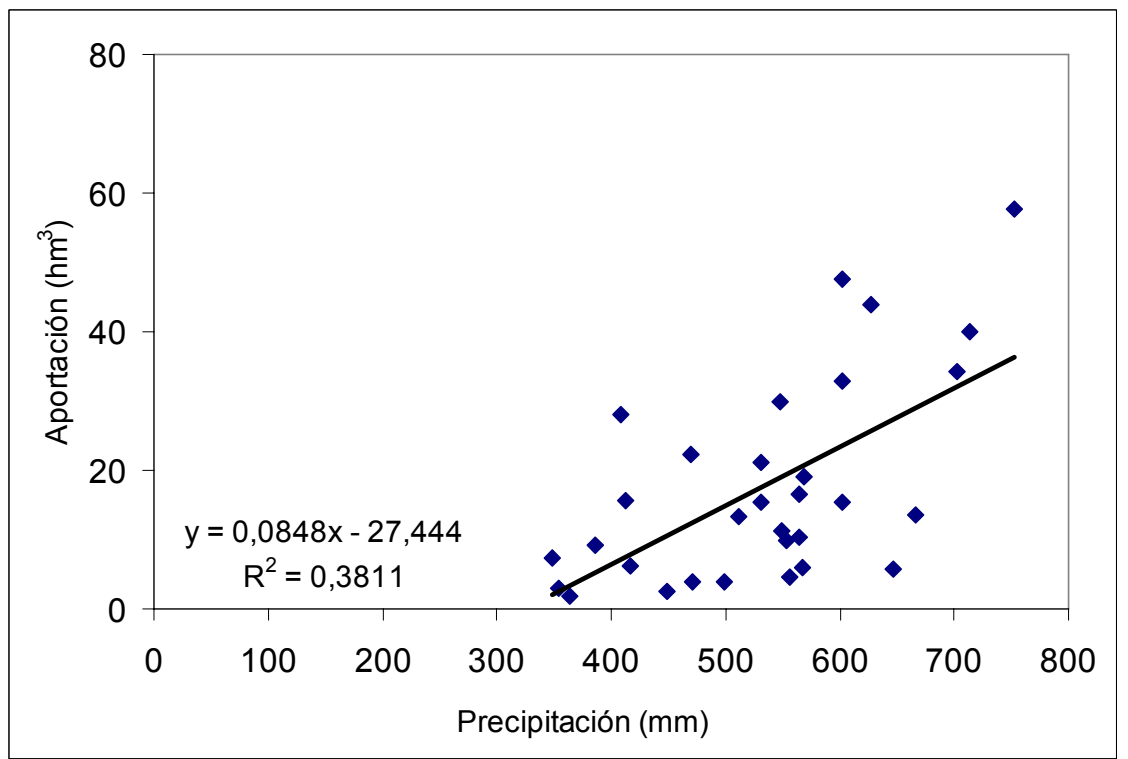

Figura 154 - Relación entre precipitación y aportación - Río Trabaque.

El distinto comportamiento de la aportación con relación a la precipitación observada en las cuencas analizadas se debe, en buena parte, a las diferencias bioclimáticas de las dos áreas. Los usos y coberturas del suelo son un factor que puede determinar estas diferencias ya que están directamente relacionados con la infiltración y con la interceptación del agua, que son partes fundamentales en la formación de la escorrentía superficial. La nieve es otro factor a se tener en cuenta a la hora de analizar la diferencia entre el comportamiento de las cuencas, ya que la retención nival va a determinar buena parte de la escorrentía en el invierno y primavera. En la cuenca del río Porma este factor es más destacado produciendo un efecto diferido en el 
tiempo y un condicionante mayor en relación con la infiltración y el drenaje en profundidad.

\subsection{Análisis de las Relaciones entre las Variables Estudiadas}

Cabe en este punto mencionar que las variables analizadas en este estudio son de una importancia relevante en el comportamiento hidrológico de una cuenca y que, por lo tanto, cambios sufridos por éstas se pueden reflejar en la producción de escorrentía. Es innegable y ha quedado ampliamente demostrado que todas estas variables están sufriendo significativas variaciones de un modo simultáneo. Por lo tanto, además de las relaciones existentes entre la aportación y la precipitación, es igualmente importante analizar la relación de éstas con las otras variables estudiadas. Según García Ruiz et al. (2001), estas variables son básicamente los factores que explican la redución en los caudales y pueden ser justificados por: i) las precipitaciones, que influyen directamente en las entradas de agua en la cuenca, uno de los factores fundamentales del ciclo hidrológico; ii) las temperaturas, que influyen en la evaporación del agua en el suelo y en los procesos de transpiración por parte de la vegetación, y por lo tanto perturban el funcionamento interno del ciclo del agua; y iii) la cubierta vegetal y los usos del suelo, que provocan perturbaciones muy variadas, esencialmente sobre la interceptación de las precipitaciones por parte de la vegetación, sobre la tasa de infiltración del agua en el suelo y sobre el consumo de agua por parte de las plantas.

Ha quedado demostrado que en las cuencas de los ríos Porma, Tajo y Trabaque la reducción en el caudal ha sido más fuerte que la disminución de las precipitaciones, y que especialmente en el Porma la correlación existente entre estas dos variables no es muy alta. Estos resultados hacen creer que hay otros factores contribuyendo a esta reducción en los caudales. Sobre todo en el caso de los usos y cobertura del suelo, se observa que la acción antrópica está provocando cambios rápidos y que seguramente tendrán influencia en la producción de escorrentía principalmente en cuencas de cabecera.

Los importantes cambios en los usos y en la cobertura del suelo sufridos en las últimas décadas coinciden con la reducción en los caudales. En las cuencas analizadas en este trabajo de investigación, el principal rasgo de estos cambios es la reducción de los cultivos y el aumento de las masas forestales. Esta realidad está siendo 
encontrada también en otros estudios realizados en España (Joffre y Rambal, 1993; Gallart et al. 2001; Beguería et al. 2003; Llorens et al. 2005).

La cuenca del río Cega fue la única en donde no se ha detectado un cambio considerable en los valores de aportación en el tiempo. Tampoco se ha observado una tendencia clara en la precipitación una vez que solamente en una estación climática se encontraron valores negativos significativos. Se observó un claro paralelismo en el comportamiento de estas dos variables. Lo más destacable fueron las muy significativas variaciones sufridas por la temperatura y por los usos y la cobertura del suelo en esta zona. Sobre todo hubo una reducción considerable en el cultivo y un aumento progresivo muy claro de las áreas de forestal arbolado, así como un fuerte aumento de la temperatura media. Sin embargo, se ha observado que en esta cuenca estas dos últimas variables no han ejercido una gran influencia sobre la aportación una vez que los cambios ocurridos en ellas no afectaron sensiblemente a la escorrentía.

En la cuenca del río Porma, en donde la correlación entre la precipitación y la aportación no es muy alta, queda un vacío en la explicación de la gran reducción observada en la escorrentía. La temperatura tampoco puede ser utilizada con este objetivo pues no se ha encontrado ningun tipo de tendencia en esta variable. En esta cuenca los cambios observados en los usos y en la cobertura del suelo podrían haber tenido bastante importancia en todo este proceso. Se ha detectado un aumento de la superficie de forestal arbolado bastante considerable y han desaparecido en las últimas décadas los cultivos. Estas dos categorias tienen influencia directa en la producción de escorrentía y en esta cuenca estos cambios podrían explicar una buena parte de la fuerte reducción en los aportes.

Un resultado muy similar ha sido observado en las cuencas de los ríos Tajo y Trabaque. La diferencia es que en estas dos la mayor correlación existente entre la aportación y la precipitación explica buena parte de la reducción sufrida por la escorrentía. En ambas ha sido observada una disminución considerable de la precipitación y, basada en la correlación encontrada, esta reducción refleja en los resultados observados en los aportes. El aumento de las temperaturas también ha sido muy evidente en ambas, aunque la influencia de este factor es más difícil de correlacionar. Los cambios en los usos y en la cobertura del suelo también parecen tener un papel más secundario en estos casos, auque su papel es innegable en el comportamiento hidrológico de las cuencas. Lo que es posible deducir es que el 
aumento detectado en la superfície de forestal arbolado en ellas es la clave que falta para justificar los cambios en la aportación por su influencia directa en esta variable.

Los resultados detectados en la mayoría de las cuencas analizadas en esta investigación reflejan una fuerte relación entre la aportación, las precipitaciones, la temperatura y los usos y cobertura de los suelos. En España parece muy claro que, en diversas partes y estudios realizados, las conclusiones son muy semejantes a las encontradas en este estudio. García Ruiz et al. (2001) concluye que la evolución de las precipitaciones y de la temperatura, así como las transformaciones en los usos del suelo, explican las tendencias que se observan en los caudales anuales, mensuales y en eventos individuales. Beguería et al. (2003), que también analizaron cuencas pirenaicas, observaron que cambios en el uso y en la cobertura del suelo produjeron una reducción de la producción de agua de cerca de 30\% entre 1945 y 1995. Finalmente la publicación del IPCC "Climate Change and Water" que sintetiza los resultados de los estudios que relacionan el cambio climático con el agua en el mundo deja claro que es de fundamental importancia para la gestión adecuada de los recursos hídricos conocer los factores que tienen influencian sobre ellos. Además explican que las variables estudiadas en esta investigación están directa o indirectamente relacionadas con el comportamento de los recursos hídricos en todos los tipos de ecosistemas, justificando de esta manera la importancia de su conocimiento y de estudiar sus relaciones. 


\section{CONCLUSIONES}

El escenario de Cambio Global en el que nos encontramos, en el que los cambios ambientales y socioeconómicos se producen a un ritmo desconocido hasta ahora, hace patente la necesidad de investigar sobre la respuesta del medio a dichos procesos de transformación. En el trabajo que aquí se ha presentado, se ha pretendido abordar el estudio de la respuesta de diversos sistemas hidrológicos a esa dinámica evolutiva. El ámbito de los recursos hídricos es especialmente sensible al cúmulo de modificaciones que los sistemas naturales están sufriendo, bien sea como consecuencia de cambios en los procesos físicos o como resultado de la coyuntura social o económica. Se ha realizado un estudio sobre las tendencias recientes de la escorrentía y de diversos factores bio-climáticos, vinculados con la generación de caudales, en cuatro sub-cuencas en régimen natural de los ríos Tajo y Duero, todas ellas bajo condiciones mediterráneas, pero situadas en ambientes bio-climáticos diferentes. Las cuencas estudiadas son las de los ríos Cega, Porma, cabecera del Tajo y Trabaque, y las variables analizadas son, además de la escorrentía, la temperatura, la precipitación y los cambios de uso del suelo y cobertura vegetal a lo largo de las últimas décadas.

Con relación a la aportación, la cuenca del río Cega ha sido la única en la que no se ha observado ninguna tendencia en el período estudiado. En las demás se ha encontrado una tendencia regresiva muy clara. Se ha producido a lo largo de las tres décadas analizadas una reducción muy importante en los caudales circulantes. En el caso de los ríos Porma y Tajo, la disminución se ha cifrado en el 33,5\% y el $28 \%$, respectivamente. En el caso del río Trabaque la disminución de la escorrentía ha sido todavía mayor $(35,3 \%)$, si bien la significación estadística de la tendencia estuvo ligeramente enmascarada por la elevada variabilidad de los datos, característica esta común a los sistemas fluviales mediterráneos. La disminución de alrededor de un tercio del agua que circula por los cauces representa un hecho altamente significativo que, sin duda, estará teniendo consecuencias en el funcionamiento de los procesos naturales de las cuencas estudiadas, pero, sobre todo, en la dinámica hidrológica y ecológica aguas abajo, así como en la disponibilidad de recursos hídricos en esos territorios.

Al analizar el comportamiento de la precipitación no se ha encontrado un patrón común en los resultados, aunque se han visto ciertas similitudes, sobre todo con relación a las tendencias. En el caso del río Cega se han detectado valores 
ligeramente negativos en todas las estaciones climáticas, aunque solo en una se obtuvieron valores estadísticamente significativos para los tests utilizados. La precipitación en la cuenca del Porma presenta valores de tendencia positivos en una de las estaciones, pero no alcanzó la significación estadística. Las demás reflejan valores negativos aunque solamente en una de ellas los valores de $\mathrm{R}$ y $\mathrm{M}-\mathrm{K}$ son significativos, con una pérdida media de $3,5 \mathrm{~mm}$ al año. En la cuenca del Tajo, en todas las estaciones se observa un descenso muy acusado en la precipitación, con una pérdida media de $7,6 \mathrm{~mm}$ al año. Finalmente en la cuenca del río Trabaque, todas las estaciones menos una presentan una clara tendencia negativa de la precipitación a escala anual en las últimas décadas, con una reducción promedio en la lluvia registrada de 4,9 $\mathrm{mm}$ al año. Aunque parece observarse en el conjunto de las zonas estudiadas una tendencia a la disminución de la precipitación, no se da una pauta común y la diversidad de situaciones es evidente. Dentro de una misma cuenca, no todas las estaciones climáticas reflejan un mismo comportamiento $\mathrm{y}$, en ocasiones, la tendencia, del signo que sea, tiene un carácter puntual. En definitiva, parece apuntarse una tendencia a la disminución en la lluvia registrada pero con cierto grado de incertidumbre.

Con respecto a la temperatura únicamente en la cuenca del río Porma no queda clara la existencia de tendencia de un signo u otro. En las demás zonas estudiadas se encontró una tendencia progresiva bien marcada de la temperatura media en las últimas décadas, con un aumento anual promedio de $0,04^{\circ} \mathrm{C}$ en el Cega y $0,06{ }^{\circ} \mathrm{C}$ en los ríos Tajo y Trabaque. Por tanto, a excepción de la cuenca más septentrional, en el resto de los casos, se ha observado un incremento muy significativo de la temperatura que parece tener continuidad conforme pasan los años. Este patrón de aumento de la temperatura ha sido observado en numerosos estudios en diferentes regiones españolas. Esta variable, principal indicador del cambio climático, tiene una enorme trascendencia en relación con la dinámica de los procesos hidrológicos y, particularmente, con la escorrentía. La temperatura influye directamente en variables como la evaporación, la transpiración vegetal, la duración del ciclo vegetativo, etc, por todo ello debe tenerse muy en cuenta.

La dinámica de los usos y de la cobertura del suelo en las cuencas analizadas viene dada, sobre todo, por un proceso de intensos cambios. La característica común a todas las zonas de estudio es un aumento de más del 100\%, y en algún caso de más del $200 \%$, de la superficie forestal arbolada. Por otro lado, se ha observado una destacada reducción de las superficies de cultivo, siendo solamente la cuenca del río 
Trabaque la que ha mantenido dichos usos sin cambios significativos. Es evidente que el abandono de la agricultura, la ganadería y las actividades extractivas del monte han posibilitado una intensa regeneración espontánea del bosque. Si a todo ello se le añaden las repoblaciones forestales llevadas a cabo en los años 60 y 70 del siglo pasado, el resultado no puede ser otro que un paisaje vegetal completamente distinto al que existía en la España de la posguerra en las zonas rurales y de montaña. Es indudable que un cambio de semejante magnitud tiene que tener una fuerte influencia en la producción de escorrentia de las cuencas analizadas. El aumento de la interceptación y el papel de la vegetación como consumidora de agua tienen un papel insoslayable en el balance de agua. Sin embargo, resulta complicado atribuir a esta variable el peso que tiene en la deriva de la escorrentía. Esta dificultad proviene, sobre todo, de la complejidad metodológica y analítica inherente al estudio de la evolución de los cambios de uso del suelo, y de la comparación de procesos (escorrentía y cambios en la cubierta vegetal) que operan a escalas espacio/temporales diferentes.

Teniendo en cuenta los resultados obtenidos en este estudio y toda la evolución ambiental experimentada, especialmente en los últimos años, se concluye que la notable reducción en los aportes sufrida en muchas cuencas de cabecera en España no puede ser explicada por la influencia ejercida por un solo factor. Queda claro que es consecuencia de las variaciones sufridas por diversos factores que, como es el caso del aumento temperatura y de la superficie de bosque y la disminución de la precipitación, actúan conjuntamente y con mayor o menor peso según el caso analizado. Baste como ejemplo de esto lo encontrado en la cuenca del Porma, la más septentrional y la que podría considerarse menos mediterránea de las cuatro. En este caso la disminución de la escorrentía es indudable y de una magnitud superior al $30 \%$. Si embargo, no queda clara la existencia de una tendencia similar en la precipitación ni de la temperatura en ningún sentido. Por tanto, no se ha detectado un paralelismo entre procesos hidrológicos y climáticos, como, a priori, cabría esperar. Sin embargo, la transformación del paisaje vegetal, evidenciada con un aumento de la superficie de bosque del $105 \%$, ha sido muy intensa y coetánea a la evolución de la escorrentía.

Queda de manifiesto, por tanto, que es imprescindible tener en cuenta que las cuencas de cabecera constituyen las principales áreas suministradoras de agua y que son muy sensibles a cualquier cambio. Por ello, el estudio de su evolución y de las tendencias de las variables que están involucradas en la generación de escorrentía, son fundamentales para la planificación y gestión adecuadas de los recursos hídricos. 
Ha quedado muy claro que en los últimos años los cambios sufridos por las variables analizadas en este estudio están alcanzando una proporción muy elevada, y que la velocidad con que están ocurriendo hace imprescindible que se profundice en investigaciones de este tipo. Los resultados de estos trabajos son una herramienta fundamental, y casi imprescindible, para los responsables de la gestión de los recursos hídricos. 


\section{REFERENCIAS BIBLIOGRÁFICAS}

AAVIKSOO, K., MURU, K. (2008). A methodology of the satellite mapping and monitoring of protected landscapes in Estonia. Estonian Journal of Ecology, 57, 3: $159-184$.

ABAURREA, J., ASÍN, J., CENTELlES, A. (2002). Caracterización espaciotemporal de la evolución de la precipitación anual en la Cuenca del Ebro. En (J.A. Guijarro, M. Laita, S. Alonso, Eds.) El Agua y el clima. Publicación de la Asociación Española de Climatología, Série A, $N^{\circ} 3$, Palma de Mallorca.

AGUILO ALONSO, M. (coordinador) (2007). Guía para la elaboración de estudios del medio físico. Ed. Ministerio de Medio Ambiente y Medio Rural y Marino, 916 pp., Madrid.

ALEXANDERSSON, H., MOBERG, A. (1997). Homogenization of Swedish temperature data. Part 1: Homogeneity test for linear trends. International Journal of Climatology, 17: 25-34.

ALMEIDA MATOS, F. D., EMÍDIO DA SILVA, K. (2005). Detecção de mudanças na cobertura vegetal na cidade de Manaus e seu entorno. En: Anais do XII Simpósio Brasileiro de Sensoriamento Remoto, pp. 609-616, Brasil.

ANDERSON, J. R., HARDY, E. E., ROACH, J. T., WITMER, R. E. (1976). A land use and land cover clasification system for use with remote sensor data. U. S. Geological Survey Profesional Paper, 964, 28 pp.

ANDRÉASSIAN, V. (2004). Waters and forests: from historical controversy to scientific debate. Journal of Hidrology, 291: 01-27.

ANDREO, B., JIMÉNEZ, P., DURÁN, J.J., CARRASCO, F., VADILLO, I., MANGIN, A. (2006). Climatic and hydrological variations during the last 117-166 years in the south of the Iberian Peninsula, from spectral and correlation analices and continuous wavelet analyses. Journal of Hydrology, 324: 24-39. 
ANGNES TERESA, A. D. (2005). Cartografía de los cambios en las cubiertas artificiales de la comunidad de Madrid-España (1987-1997). Revista Forestal Latinoamericana, 20(1), 37: 59-86.

ANGueIRA, C., LÓPEZ, J., BARRAZA, G., PRIETO, S., ANGELlA, G., PRIETO, D. (2008). Estimación de cultivos mediante teledetección y SIG en el área de riego del río dulce, santiago del estero, Argentina. En: Taller Internacional Red Riegos - CYTED (Programa Iberoamericano Ciencia y Tecnología para el desarrollo). Poster.

APARECIDO GONÇALVES, D., SOUZA SANTOS, N., ALVES MOREIRA, R., ARAÚJO AGUIAR, A., OLIVEIRA DOURADO, H. S., RAMOS NETO, M. B. (2005). Fotografias aéreas de pequeno formato aplicadas na identificação, quantificação e planejamento de recuperação de áreas de preservação permanente. En: Anais XII Simpósio Brasileiro de Sensoriamento Remoto, 21852190, Brasil.

ARANEDA MILLA, F., EMANUELLI, P. (1999). Análisis de la fotointerpretación en bosques del tipo forestal siempre verde. Aplicación a la reserva nacional de Valdivia. En: Catastro y evaluación de recursos vegetacionales nativos de Chile. Informe nacional con variables ambientales. Coorporación Nacional Forestal, 90 pp., Chile.

ARNÁEZ, J., OSERIN, M., ORTIGOSA, L., LASANTA, T. (2008). Cambios en la cubierta vegetal y usos del suelo en el Sistema Ibérico Noroccidental entre 1956 y 2001: Los Cameros (La Rioja, España). Boletín de la Asociación de Geógrafos Españoles, 47: 195-211.

ARORA, V. K. (2002). The use of the aridity index to assess climate change effect on annual runoff. Journal of Hidrology, 265: 164-177.

ARQUERO, A., GONZALO, C., MARTíNEZ, E., FERRERAS, A. M. (1998). Utilización de scattergrams de ER mapper para la elección de áreas de entrenamiento en la clasificación temática de imágenes Landsat. Revista Internacional de Ciencias de la Tierra, ISSN: 1.131-9.100. 
ARROYO PÉREZ, A., ZOIDO NARANJO, F. (2003). La población de España. Tendencias demográficas durante el siglo XX en España. Instituto Nacional de Estadística, V. 1, pp. 17-55, Madrid.

AUPÍ, V. (2004). Guía del Clima de España - Con datos de más de 200 observatorios, 68 tablas y 150 fotografías, imágenes de satélite y mapas meteorológicos en color. $1^{\text {a }}$ ed. Ediciones Omega, S.A., 336 pp., Barcelona.

BACK, A. J. (2001). Aplicação de análise estatística para identificação de tendências climáticas. Pesquisa Agropecuária Brasileira, 36 (05): 717-726.

BAEZA SANZ, D., GARCÍA DE JALÓN, D. (1999). Cálculo de caudales de mantenimiento en ríos de la cuenca del Tajo a partir de variables climáticas y de sus cuencas. Limnetica, 16: 69-84.

BATISTA, M. H., HAERTEL, V. (2007). Classificação hierárquica orientada a objeto em imagens de alta resolução espacial empregando atributos espaciais e espectrais. Anais XIII Simpósio Brasileiro de Sensoriamento Remoto, pp. 489-497, Brasil.

BATES, B. C., KUNDZEWICZ, Z. W., WU, S., PALUTIKOF, J.P. (2008). Climate change and water. IPCC Technical Paper VI. Ed. IPCC Secretariat, 210 pp., Geneva.

BEDNORZ, E., KOSSOWSKI, T. (2004). Long-term changes in snow cover depth in eastern Europe. Climate Research, 27: 231-236.

BEGUERÍA, S., LÓPEZ-MORENO, J., LORENTE, A., SEEGER, M., GARCÍA-RUÍZ, J. M. (2003). Assessing the effect of climate oscillations and land-use changes on streamflow in the Central Spanish Pyrenees. En: Ambio, 32 (4): 283-286.

BEGUERÍA, S., LÓPEZ-MORENO, J., GÓMEZ-VILLAR, A., RUBIO, V., LANARENAULT, N., GARCÍA-RUÍZ, J. M. (2006). Fluvial Adjustments to soil erosion and plant cover changes in the central Spanish Pyrenees. En: Journal Compilation Swedish Society for Anthropology and Geography, 177-186. 
BEKTAS, F., GÖKSEL, C. (2005). Remote sensing and GIS integration for land cover analysis, a case study: Bozcaada Island. Water Science and Technology, 51 (11): 239-244.

BERLANGA ROBLES, C. A., RUIZ LUNA, A. (2007). Análisis de las tendencias de cambio del bosque de mangle del sistema lagunar Teacapán-Agua Brava, México. Una aproximación con el uso de imágenes de Satélite Landsat. Universidad y Ciencia, 23 (1): 29-46.

BEST, S., LEON, L. (2005). Use of precision agriculture tools for profitability optimization in pomaceas orchard. En: Anais do $3^{\circ}$ Simpósio Internacional de Agricultura de Precisão. Sete Lagoas, Brasil.

BHATTACHARYYA, A. (1943). On a measure of divergence between two statistical populations defined by their probability distributions. Bulletin of the Calcutta Mathematical Society, 35: 99-109.

BOCCO, G., Mendoza, M., Masera, O. R. (2001). La dinámica del cambio del uso del suelo en Michoacán. Una propuesta metodológica para el estudio de los procesos de deforestación. Investigaciones Geográficas, Boletín del Instituto de Geografía, UNAM, 44: 18-38.

BOIX-FAYOS, C., BARBERÁ, G.G., LÓPEZ-BERMÚDEZ, F., CASTILLO, V.M. (2007). Effects of check dams, reforestation and land-use changes on river channel morphology: Case study of the Rogativa catchment (Murcia, Spain). Geomorphology, 91: 103-123.

Boletta, P. E., RaVelo, A. C., Planchuelo, A. M., GRILli, M. (2006). Assessing deforestation in the Argentine Chaco. Forest Ecology and Management, 228: 108-114.

BORGES, M. H., PFEIFER, R. M.., DEMATTÊ, J. A. M. (1993). Evolução e mapeamento do uso da terra, através de imagens aerofotogramétricas e orbitais em Santa Bárbara D'Oeste (SP). Scientia Agricola, 50 (3) 365-371. 
$\mathrm{BOSCH}$, J., HEWLETT, JD. (1982). A review of catchment experiments to determine the effect of vegetation changes on water yield and evapotranspiration. Journal of Hydrology, 55: 3-23.

BOUZA DEAÑO, R., TERNERO RODRÍGUEZ, M., FERNÁNDEZ ESPINOSA, A. J. (2006). Metodologías para la evaluación de tendencias de la calidad de aguas en el contexto de la Directiva Marco de Aguas. Aplicación al estudio del río Ebro (España). VI Simposio sobre el agua en Andalucía. Instituto Geológico y Minero de España, 1247-1254, Madrid.

BRICEÑO, F. (2003). Cambios de cobertura de la tierra en el Valle del río Momboy, Estado Trujillo. Geoenseñanza, 8 (1): 91-100.

BRUNET, M., SIGRÓ, J., SALADIÉ, O., AGUILAR, E., JONES, P. D., MOBERG, A., WALTHER, A., LÓPEZ, D. (2005). Spatial patterns of long-term spanish temperatura change. Geophysical Research, V. 7. European Geosciences Union.

BRUNETTI, M., BUFFONI, L., MANGIANTI, F., MAUGERI, M., NANNI, T. (2004). Temperature, precipitation and extreme events during the last century in Italy. Global and Planetary Change, 40: 141-149.

BUSTOS GISBERT, M. L. (2005). Envejecimiento y despoblación. Dos problemas básicos para la revitalización de la Sierra de Francia (Salamanca). Boletín de la Asociación de Geógrafos Españoles, 40: 135-151.

CABERO DIÉGUEZ, V., JABLONSKI GARCÍA, J., SANTOS FRANCÉS, F. (2008). Bases para la ordenación, el uso y la gestión del espacio natural de la Sierra de Guadarrama (Segovia y Ávila) - Tomo I - Introducción Medio Natural: Clima, Geología, Geomorfología, Suelos, Hidrología, 105 pp., Junta de Castilla y León.

CAMARERO RIOJA, L. A. (1991). Tendencias recientes y evolución de la población rural en España. Política y Sociedad, Madrid, 8: 13-24.

CAPEL MOLINA, J. J. (1981). Los climas de España. 1ª ed. Oikos-tau S. A., 429 pp., Barcelona. 
CARREÑo FRUCtUOSO, M. F., CALVO, J. F., ESTEVE, M. A., MARTíneZ, J., MIÑANO, J., PALAZÓN, J. A., PARDO, M. T., ROBLEDANO, F., RODRÍGUEZ, S. (2007). Análisis del paisaje a partir de la cartografía de usos del suelo en el campo de Cartagena. En: Actas del III Congreso de la naturaleza de la región de Murcia.

CHAZARRA BERNABÉ, A., ALMARZA MATA, C. (2002). Reconstrucción desde 1864 de la serie de precipitación útil de las cuencas del Sureste y Levante. En: (J.A. Guijarro, M. Grimalt, M. Laita, S. Alonso, Eds) El agua y el clima. Publicación de la Asociación Española de Climatología. Palma de Mallorca. Serie A, no. 3.

CHUVIECO, E. (1996). Fundamentos de teledetección espacial. $3^{\text {a }}$ ed. Ediciones Rialp S.A., 568 pp., Madrid.

COLOTTI, E., RODRÍGUEZ, J., BLANCO, A. E. (2001). Propuesta metodológica para el análisis de la consistencia de los datos climáticos. IV Simposio Internacional de Desarrollo Sustentable en los Andes, 23-49.

COSANDEY, C., ANDRÉASSIAN, V., MARTIN, C., DIDON-LESCOT, J. F., LAVABRE, J., FOLTON, N.., MATHYS, N., RICHARD, D. (2005). The hydrological impact of the mediterranean forest: a review of French research. Journal of Hidrology, 301: 235-249.

CRISCUOLO, A., BERRY, V., DOUZERY, E. J. P., GASCUEL, O. (2006). SDM: A fast distance-based approach for (super) tree building in phylogenomics. System Biology Research, 55: 740-755.

CUADRAT PRATS, J. M., VICENTE-SERRANO, S. M. (2004). Comportamiento de las sequías en la península ibérica: análisis mediante el Standardized Precipitation Index. En: García Codron, J.C.; Diego Liaño, C.; Fdez. de Arróyabe Hernáez, P.; Garmendia Pedraja, C. y Rasilla Álvarez, D. (Eds.) (2004). El Clima entre el Mar y la Montaña. Asociación Española de Climatología y Universidad de Cantabria, Serie A, $n^{\circ} 4$, Santander.

CUNHA, A. M., LANI, J. L., AMARAL, E. F., REZENDE, S. B., RIBEIRO, L. S. (2006). Mosaico digital de aerofotos não-convencionais na avaliação de 
recursos naturais: estudo de caso. Revista Brasileira de Engenharia Agrícola e Ambiental, 10 (1) 182-187.

DAI, A., FUNG, I. Y., DEL GENIO, A. D. (1997). Surface Observed Global Land Precipitation Variations during 1900-88. Journal of Climate, 10: 2943-2962.

DARÍO MALDONADO, F., SANTOS, J. R. (2005). Metodología de detección de cambios utilizando técnicas de rotación radiométrica. En: Anais XII Simpósio Brasileiro de Sensoriamento Remoto, pp. 601-608, Goiânia, Brasil.

DE JUANA, E., GARCÍA, A. M. (2005). Fluctuaciones relacionadas con la precipitación en la riqueza y abundancia de aves de medios esteparios mediterráneos. Ardeola, 52 (1): 53-66.

DE LA PEÑA, A. (1995). Los Peces terciarios de las cuencas continentales ibéricas: Marco histórico y registro fósil conocido. Coloquios de Paleontología de Madrid, 47: 25-46.

DEL OLMO, F. Díaz, Del Río, V. Díaz, GOY, J. L., GUTIERREZ ELORZA, M., MARTíN SERRANO, A., MARTíNEZ PISÓN, E., PEDRAZA, J., PEÑA MONNÉ, J. L., PÉReZ gonzÁlez, A., MÉndeZ, C. Pol, QUIRANTES, F., ROdRíGUEZ VIDAL, J., SALA, M., SOMOZA, L., UGARTE, F. M., ZAZO, C. (1994). Geomorfología de España. Edición coordinada: Mateo Gutiérrez Elorza. Editorial Rueda, $1^{\text {a }}$ ed., 636 pp., Madrid.

DEL RÍO, S., PENAS, Á., FRAILE, R. (2005). Analysis of recent climatic variations in Castile and Leon (Spain). Atmospheric Research, 73: 69-85.

DÍEZ, A. Y MARTÍN-DUQUE, J.F. (2006). Las raíces del paisaje. Condicionantes geológicos del territorio de Segovia. En: ABELLA MARDONES, J.A. et al. (Coords.), Colección Hombre y Naturaleza, VII. Ed. Junta de Castilla y León, 464 pp. ISBN 84-9718-326-6; D.L.: S. 1.752-2005.

DI GREGORIO, A. (2005). Land Cover Classification System Classification concepts and user manual Software version (2). $1^{\mathrm{a}}$ ed. Food and Agriculture Organization of the United Nations, 208 pp., Rome. 
DRAPER, N. R., SMITH, H. (1998). Applied Regression Analysis. $3^{a}$ ed. Wiley Interscience, J. Wiley \& Sons, 709 pp., New York.

DUDA, R.O. and HART, P. E. (1973). Pattern Classification and Scene Analysis. John Wiley and Sons Publications, 482 pp., New York.

DUNJÓ, G., PARDINI, G., GISPERT, M. (2004). The role of land-use cover on runoff generation and sediment yield at a microplot scale, in a small Mediterranean catchment. Journal of Arid Environments, 57: 99-116.

DUPUY RADA, J. M., CONZÁLEZ ITURBE, J. A., IRIARTE VIVAR, S., CALVO IRABIEN, L. M., ESPADAS MANRIQUE, C., TUN DZUL, F., DORANTES EUÁN, A. (2006). Cambios de cobertura y uso del suelo (1979-2000) en dos comunidades rurales en el noroeste de Quintana Roo. Investigaciones Geográficas, Boletín del Instituto de Geografía, UNAM, 62: 104-124.

EASTERLING, D. R., PETERSON, T. C. (1995). The effect of artificial discontinuities on recent trends in minimum and maximum temperatures. Atmospheric Research, 37: 19-26.

ESTEBAN-PARRA, M.J., RODRIGO, F.S., CASTRO-DIEZ, Y. (1998). Spatial and temporal patterns of precipitation in Spain for the period 1880-1992. International Journal of Climatology, 18: 1557-1574.

ESA/ESRIN-GAEL (2003). Landsat TM/ETM+ ESA Products. CEOS Format Specification, European Space Agency.

EZBER, Y., SEN, O. L., KINDAP, T., KARACA, M. (2007). Climatic effects of urbanization in Istanbul: a statistical and modeling analysis. International Journal of Climatology, 27: 667-679.

EZZAT ELSHAMY, A., WHEATER, Howard S., GEDNEY, Nicola, HUNTINGFORD, Chris (2006). Evaluation of the rainfall component of a weather generator for climate impact studies. Journal of Hydrology, 326: 1-24. 
FAJARDO DE LA FUENTE, A. (2008). Osuna y su territorio a través de las fotografías del vuelo americano: (1956-57). Cuadernos de los Amigos de los Museos de Osuna, 10: 26-29.

FELIX, A., NEVES, J. (2006). Proposta metodológica aplicada para a confecção de mosaico aerofotogramétrico semicontrolado digital: estudo de caso na

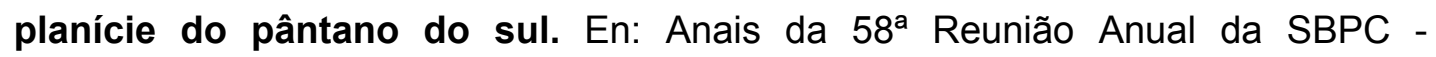
Florianópolis, Brasil.

FERNÁNDEZ GARCIA, F. (2000). Introducción a la fotointerpretación. Ed. Ariel Geografía, 256 pp., Barcelona.

FERREIRA, E., PEREIRA SANTOS, J., BARRETO, A. C., AGUILAR DANTAS, A. A. (2005). Identificação de fragmentos de floresta nativa, por diferentes intérpretes, com a utilização de imagens Landsat e Cbers em lavras, MG. Ciência e Agrotecnologia, 29: 3-8.

FERRER JULIA, M., RUIZ VERDÚ, A., DIMAS SUÁREZ, M., ESTRELA MONREAL, T. (1998). Aportación de la teledetección para la determinación del parámetro hidrológico del número de curva. Ingeniería del Agua, 5 (1): 35-46.

FLORES MONTOYA, F. J., LIÉBANA, G. (2002). La cuenca del Tajo en cifras. Confederación Hidrográfica del Tajo, $2^{\mathrm{a}}$ ed., 152 pp., Madrid.

FLORES MONTOYA, F. J., DÍAZ GUERRA, C., DÍAZ SÁNCHEZ, P., FLORES VARELA, C. J., DEL POZO, G. L., MOLINA IBÁÑEZ, M., MORALES SEGURA, M., ORTíZ, J. A., PÉREZ VELASCO, E., SEGURA GRAIÑO, C., SEGURA NOTARIO, N., SOTELO NAVALPOTRO, J. A., DEL VILLAR JUEZ, D. (2004). 50 Años de la Confederación Hidrográfica del Tajo. Ministerio del Medio Ambiente, $1^{\text {a }}$ ed., Madrid.

FOLEY, J. A., DE FRIES, R., ASNER, G. P., BARFORD, C., BONAN, G., CARPENTER, S. R., STUART CHAPIN, F., COE, M.T., DAILY, G. C., GIBBS, H. K., HELKOWSKI, J. H., HOLLOWAY, T., HOWARD, E. A., KUCHARIK, C. J., MONFREDA, C., PATZ, J. A., PRENTICE, I. C., RAMANKUTTY, N., SNYDER, P. K. (2005). Global consequences of land use. Science, 309 (5734): 570-574. 
FONSECA CONCEIÇÃO, M. A. (2003). Estimativa da evapotranspiração de referência com base na temperatura do ar para as condições do Baixo Rio Grande, SP. Revista Brasileira de Agrometeorologia, 11 (2): 229-236.

FOODY, G.M. (2002). Status of land cover classification accuracy assessment. Remote Sensing of Environment, 80: 185-201.

FORTEZA, J., LORENZO, L. F., NAJAC, N., et al., (1987). Mapa de Suelos de Castilla y León. Memoria y Mapa 1:500.000. 98 pp., Junta de Castilla y León, Valladolid.

FRANCO-MÚGICA, F., GARCÍA-ANTÓN, M., MALDONADO-RUIZ, J., MORLAJUARISTI, C., SAINZ-OLLERO, H. (2005). Ancient pine forest on inland dunes in the Spanish northern meseta. Quaternary Research, 63:1-14.

FRANÇOIS MAS, J., PUIG, H., LUIS PALACIO, J., SOSA, A. (2003). Un modelo espacial del riesgo de deforestación. Anais XI SBSR, Belo Horizonte, 13571363.

FRITSCH, D., ENGLICH, M., SESTER, M. (1998). Multitemporal effects in regional planning over a part of semi-arid region of Paraiba, Brazil. International Society for Photogrammetry and Remote Sensing, 621-624.

GALLART, F., LLORENS, P. (2004). Observations on land cover changes and water resources in the headwaters of the Ebro catchment, Iberian Peninsula. Journal of Hidrology, 29: 769-773.

GARCÍA-BARRÓN, L., PITA, M. F. (2001). Propuesta metodológica para la determinación de inhomogeneidades relativas en las series de observacíones. En: El tiempo del clima, Publicaciones de la Asociación Española de Climatología, Serie A, 02: 87-95.

GARCÍA CODRON, J.C., DIEGO LIAÑO, C., ARRÓYABE HERNÁEZ, P. F., GARMENDIA PEDRAJA, C., RASILLA ÁLVAREZ, D. (2004). El estiaje del Ebro durante el verano de 2002. Causas climáticas y consecuencias sobre la calidad del agua en el tramo Zaragoza - Escatrón. El Clima entre el Mar y la 
Montaña. Asociación Española de Climatología y Universidad de Cantabria, Serie A, 4: 725-734.

GARCÍA DE CELIS, A., GARCÍA LOPEZ, D., DURANY CASTRILLO, M. P., GONZÁLEZ GONZÁLEZ, M. J., BREL CACHÓN, P., LUENGO UGIDOS, M. (1988). Análisis del Medio Físico de León - Delimitación de Unidades y Estructura Territorial. Simancas Ediciones S.A. - Junta de Castilla y León, Valladolid.

GARCÍA FERNÁNDEZ, J., ÁLVAREZ DURANGO, E. (2000). Expansión altitudinal del avión zapador Riparia riparia en la Cordillera Cantábrica. Ardeola, 47 (2): 247-250.

GARCÍA RUIZ, J. M., BEgueRÍA PORTUGUÊS, S., LÓPEZ MORENO, J. I., LORENTE GRIMA, A., SEEGER, M. (2001). Los recursos hídricos superficiales del Pirineo aragonés y su evolución reciente. Geoforma Ediciones, $1^{a}$ ed., 192 pp., Logroño.

GARCÍA RUIZ, J. M., LANA-RENAULT, N., BEGUERÍA, S., VALERO-GARCÉS, B., LASANTA, T., ARNÁEZ, J., LÓPEZ MORENO, J. I., REGÜÉZ, D., MARTÍ-BONO, C. (2004). Temporal and spatial interactions of slope and catchment processes in the Central Spanish Pyrenees. IAHS Publ. 288: 21-28.

GIL OLCINA, A., GÓMEZ MENDOZA, J. (2001). Geografía de España. Editorial Ariel S.A., $1^{\text {a }}$ ed., 675 pp., Barcelona.

GILBERT, R.O. (1987). Statistical methods for environmental pollution monitoring. Van Nostrand Reinhold Company, 336 pp., New York.

GOETZ, S. J., VARLYGUIN, D., SMITH, A. J., WRIGHT, R. K., PRINCE, S. D., MAZZACATO, M. E., TRINGE, J., JANTZ, C., MELCHOIR, B. (2004). Application of multitemporal Landsat data to map and monitor land cover and land use change in the Chesapeake Bay watershed. En: P.C. Smits and L. Bruzzone, Editors, Proceedings of the second international workshop on the analysis of multitemporal remote sensing images, World Scientific Publishing Co., Singapore, 223232. 
GÓMEZ, H., LINARES DE GÓMEZ, R., BRADSHAW, R. (2000). El paisaje fronterizo: una visión satelital. Caso San Antonio del Táchira (Venezuela) Cúcuta (Colombia). Aldea Mundo, 4 (8): 5-12.

GOMIG, K., ANRAIN LINDNER, E., KOBIYAMA, M. (2007). Áreas de influência das estações pluviométricas na bacia rio do Peixe/SC pelo método de polígonos de Thiessen utilizando imagem de satélite e SIG. En: Anais XII Simpósio Brasileiro de Sensoriamento Remoto, Florianópolis, 3373-3380.

GONZÁLEZ GONZÁLEZ, H. A. (2004). Detección de los cambios de la cobertura de bosques y matorrales utilizando la percepción remota y los sistemas de información geográfica. Instituto de Geografía Tropical, Revista Internacional de Ciencias de la Tierra, Cuba, ISSN: 1.131-9.100.

GONZÁLEZ GONZÁLEZ, M. J., GONZÁLEZ POLLEDO, L. A., REDONDO VEGA, J. M. (1987). La Provincia de León y sus Comarcas. Valles del Curueño y Porma. 14 pp., León.

GONZÁLEZ HIDALGO, J. C., DE LUÍS, M., STEPÁNEK, P., RAVENTÓS, J., MARÍA CUADRAT, J. (2002). Reconstrucción, estabilidad y proceso de homogeneizado de series de precipitación en ambientes de elevada variabilidad pluvial. En: VII Reunión Nacional de Climatología - Grupo de Clima de la Asociación de Geógrafos Españoles, 47-57.

GONZÁLEZ-ROUCO J. F., JIMÉNEZ J. L., QUESADA V., VALERO F. (2001). Quality control and homogeneity of precipitation data in the southwest of Europe. Journal of Climate, 14: 964-978.

GOOSSENS, C., BERGER, A. (1986). Annual and seasonal climatic variations over the northern hemisphere and Europe during the last century. Annales Geophysicae, Berlin, 4 (B4): 385-400.

GRACIANI, S. D., MORANES NOVO, E. M. L. (2003). Determinação da cobertura de macrófitas aquáticas em reservatórios tropicais. En: Anais XI SBSR, Belo Horizonte, 2509-2516. 
GRAHAM, R., READ, R. (1993). Manual de fotografía aérea. Ediciones Omega, $1^{a}$ ed., Barcelona, 359 pp.

GRÁNDEZ, E., NAVARRO, P. (2006). Detección de áreas de alteración hidrotermal a partir de datos aster en el distrito minero de San Genaro - Huancavelica. XIII Congreso Peruano de Geología, 494-497, Peru.

GROPPO, J. D., EDUARDO MILDE, L. C., GUAMERO, M. E., DE MORAES, J. M., MARTINELLI, L.A. (2001). Análise de séries temporais de vazão e de precipitação na Bacia do Rio Piracicaba. Revista de Ciencia \& Tecnologia, 8 (18) 109-117.

GRUNFELD, F. V. (1988). Wild Spain. A traveller's and naturalist's handbook. Sheldrake Publishing Ltda, 222 pp., London.

GUERRA VELASCO, J. C., GARCíA DE CELIS, A. J., ARROYO PÉREZ, P. (2006). Estructura y dinámica de una población de Betula alba L. en las Ilanuras sedimentarias de la cuenca del Duero (tramo medio del río Cega - Cuéllar Segovia). Serie Geográfica - Biogeografía: Distribuciones, Dinámicas y Diversidad, 13: $65-79$.

GUIJARRO, J. A. (2004). Tendencias de la precipitación en el litoral mediterráneo español. Instituto Nacional de Meteorología.

GUILFORD, J. P., FRUCHTER, B. (1984). Métodos y problemas especiales de correlación. En: Estadística aplicada a la psicología y la educación. Editorial MacGraw-Hill, pp. 265-333.

GÜLER, M., YOMRALIOĞLU, T., REIS, S. (2006). Using Landsat data to determine land use/land cover changes in Samsun, Turkey. Environmental Monitoring and Assessment, 127, 1-3: 155-167.

HAMED, K. H. (2008). Trend detection in hydrologic data: The mann-kendall trend test under the scaling hypothesis. Journal of Hydrology, 349: 350-363. 
HANSSEN-BAUER, I., FORLAND, E. (2000). Temperature and precipitation variations in Norway 1900-1994 and their links to atmospheric circulation. International Journal of Climatology, 20: 1693-1708.

HANSSEN-BAUER, I. (2005). Regional temperature and precipitation series for Norway: analyses of time-series updated to 2004. Norwegian Meteorological Institute, $\mathrm{N}^{\circ} 15$.

HARRIS, P. M., VENTURA, S. J. (1995). The integration of geographic data with remotely sensed imagery to improve classification in an urban area. Photogrammetric Engineering and Remote Sensing, 61 (8) 993-998.

HENKE DE OLIVEIRA, C. (2009). Análisis de padrones y procesos en el uso del suelo, vegetación, crecimiento y adensamiento urbano. Estudio de caso: Município de Luiz Antônio (São Paulo, Brasil). Tesis Doutoral, Universidade Federal de São Carlos, 462 pp., São Carlos.

HENRÍQUEZ, C., AZÓCAR, G., AGUAYO, M. (2006). Cambio de uso del suelo y escorrentía superficial: aplicación de un modelo de simulación espacial en Los Ángeles, VIII Región del Biobío, Chile. Revista de Geografía Norte Grande, 36: 61-74.

HERNÁNDEZ HERNÁNDEZ, E. (1987). Mapa de las series de vegetación de la cuenca alta del río Porma (NE de León, España). Lazaroa, 7: 383-390.

HERRERA CASADO, A. (2005). Monasterios y conventos de Castilla-La-Mancha. AAECHE Ediciones, 267 pp., Guadalajara.

IPCC - Intergovernmental Panel on Climate Change (2001). Climate Change 2001: Synthesis Report. Watson, R.T. and the Core Writing Team (Eds.) Contains the Synthesis Report itself, the Summaries for Policymakers and Technical Summaries of the three Working Group volumes, and supporting Annexes. Cambridge University Press, UK. 398 pp., England.

JAN SLOMP, H. (2004). La despoblación del medio rural español. Un estudio sobre las causas, las consecuencias y la política con respecto a un proceso de éxodo. Diversificación rural en Matarraña, Teruel: ¿nuevas oportunidades 
para el campo en transformación? Tesis Doctoral. Universidad de Groningen, 307 pp., Países Bajos.

JOFFRE, R. y RAMBAL, S. (1993). How tree cover influences the water balance of Mediterranean rangelands. Ecology, 74: 570-582.

JOHNSON, A., TRUAX, D. D., O'HARA, C. G. (2002). Remote sensing, GIS and land use and land cover mapping along the I-10 corridor. En: Mid-Term Symposium in conjunction with Pecora 15 / Land Satellite Information IV Conference, Denver, Colorado, USA.

KLEINPAUL, J. J., SOARES PEREIRA, R., RABUSKE HENDGES, E., PAIM BENEDETTI, A. C., ZORZI, C., FERRARI, R. (2005). Análise Multitemporal da Cobertura Florestal da Microbacia do Arroio Grande, Santa María, RS. Boletim de Pesquisa Florestal, Colombo, 51: 171-184.

LABAJO, J. L., PIORNO, A. (2001). Regionalisation of precipitation in Castilla and Leon (Spain). Analysis of its temporal behaviour. En BRUNET, M y LÓPEZ, D. (Eds.): Detecting and Modelling Regional Climate Change, Springer, pp. 163-173, Berlín.

LANG, R., SHAO, G., PIJANOWSKI, B. C., FARNSWORTH, R. L. (2008). Optimizing unsupervised classifications of remotely sensed imagery with a data-assisted labeling approach. Computers \& Geosciences, 34 (12): 1877-1885.

LASANTA, T., VICENTE SERRANO, S. M., CUADRAT PRATS, J. M. (2000). Marginación productiva y recuperación de la cubierta vegetal en el Pirineo: un caso de estudio en el Valle de Borau. Boletín de la Asociación de Geógrafos Españoles, 29: 5-28.

LASANTA, T., BEGUERIA, S., GARCÍA-RUIZ, J. M. (2006). Geomorphic and hydrological effects of traditional shifting agriculture in a mediterranean mountain area, Central Spanish Pyrenees. Mountain Reserach and Development, 26 (2): 146-152.

LASANTA, T., VICENTE SERRANO, S.M. (2007). Cambios en la cubierta vegetal en el Pirineo Aragonés en los últimos 50 años. Pirineos, 162: 125-154. 
LI, L-J., ZHANG, L., WANG, H., WANG, J., YANG, J-W., JIANG, D-J, LI, J-Y, QIN, D-Y (2007). Assessing the impact of climate variability and human activities on streamflow from the Wuding River basin in China. Hydrological Processes, 21 : 3485-3491.

LIBISELLER, C. (2002). A program for the computation of multivariate and partial Mann-Kendall test. Manual University of. Linköping, Sweden

LILLESAND, T. M., KIEFER, R. W. (1999). Remote sensing and image interpretation. Publisher John Wiley \& Sons Inc, $4^{\text {a }}$ ed., 736 pp., New York.

LLORENS, P., POYATOS, R., RUBIO, C., LATRON, J. Y GALLART, F. (2005). EI papel del bosque en los procesos hidrológicos. Ejemplos en las cuencas de investigación de Vallcebre (Prepirineo Catalán). Cuadernos de Investigación Geográfica, 31: 27-44.

LÓPEZ GONZÁLEZ, F. J., CRECENTE MASEDA, R., ÁlVAREZ LÓPEZ, C. J. (2002). Los usos del suelo analizados mediante S.I.G.. En: XIV Congreso Internacional de Ingeniería Gráfica. Santander, España

LÓPEZ GONZÁLEZ, G. (2001). Los árboles y arbustos de la Península lbérica e Islas Baleares - Tomo I e II. Ediciones Mundi-Prensa, 1731 pp., Madrid.

LÓPEZ MORENO, J. L.., BERGUERÍA PORTUGUÉS, S., GARCÍA RUIZ, J. M. (2002). El régimen del Río Ésera, Pirineo Aragonés, y su tendencia reciente. Boletín Glaciológico Aragonés, 3: 131-162.

LÓPEZ-MORENO, J. I., GARCÍA-RUIZ, J. M. (2004). Influence of snow accumulation and snowmelt on streamflow in the Central Spanish Pyrenees. Hydrological Sciences, 49 (5): 787-802.

LÓPEZ MORENO, J. I. (2006). Cambio ambiental y gestión de los embalses en el Pirineo Central Español. Publicaciones del Consejo de Protección de la

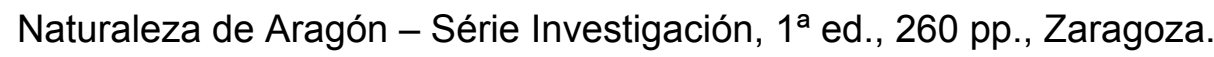


LÓPEZ MORENO, J. I., GOYETTE, S., BENISTON, M. (2007). Climate change prediction over complex areas: spatial variability of uncertainties and predictions over the Pyrenees from a set of regional climate models. International Journal of Climatology, Published on line 6 December in Wiley InterScience.

LÓPEZ MORENO, J. I., BENISTON, M., GARCÍA RUIZ, J. M. (2008). Environmental change and water management in the Pyrenees: Facts and future perspectives for mediterranean mountains. Global and Planetary Change, 61: 300-312.

LOZANO RIVERA, P., SIERRA-CORREA, P. C. (2005). Propuesta metodológica para delimitación de bosques de manglar a partir de datos satelitales utilizando SPRING v 4.1, en la reserva de biósfera Ciénaga Grande de Santa Marta, Caribe Colombiano. Anais XII Simpósio Brasileiro de Sensoriamento Remoto, Goiânia, 4285-4293, Brasil.

LUCÍA, A., VICENTE, F., MARTÍN-MORENO, C., MARTÍN-DUQUE, J. F., SANZ, M. A., DE ANDRÉS, C., BODOQUE, J. M. (2008). Procesos geomorfológicos activos en cárcavas del borde del piedemonte norte de la Sierra de Guadarrama (Provincia de Segovia, España). Boletín de la Real Sociedad Española de Historia Natural, Sección Geología, 102 1-4:47-69.

LUENGO UGIDOS, M. Á. (2002). El Clima de la Provincia de León. En XVII Jornadas de Geografía Física. Editorial Universidad de León - Secretariado de Publicaciones y Medios Audiovisuales, $1^{\text {a }}$ ed., 177 pp., León.

LUO, Y., LIU, S., FU, S., LIU, J., WANG, G., ZHOU, G (In press). Trends of precipitation in Beijiang River Basin, Guangdong Province, China. Hydrological Processes.

MACHADO, D., PUCHE, M., VILORIA, J., PARRA, M., PRIMERA, M. (2007). Geoespacialización de información climática mediante la utilización de sistemas de información geográfica. Caso cuenca alta del Río Guárico. II Jornadas Nacionales de Geomática. Caracas, Venezuela. 
MCBEAN, E., MOTIEE, H. (2008). Assessment of impact of climate change on water resources: a long term analysis of the Great Lakes of North America. Hydrology and Earth System Sciences, 12: 239-255.

MCCABE JR, G. J., WOLOCK, D. M. (1997). Climate change and the detection of trends in annual runoff. Climate Research, 8: 129-134.

MACHIN, J., NAVAS, A., DOMENECH, S., VICENTE, M. L. (2005). EI Río Arlanza en cabecera: evolución reciente y tendencias en condiciones de cambio global. En: Cuadernos de Investigación Geográfica. Universidad de La Rioja, pp. 77-95, Zaragoza.

MARINI, M. F., VERGARA, M. F., KRÜGER, H. (2007). Determinación del uso de la tierra en el partido de Guamini (Argentina) mediante un estudio multitemporal con imágenes Landsat. Revista de Teledetección, 27: 80-88.

MÁRQUEZ GONZÁLEZ, A. R. (2008). Cambio de uso de suelo y el desarrollo turístico en Bahía de Banderas, Nayarit. Ciencia UANL, 11, (2): 161-167.

MARTIN-VIDE, J., CALBO, J., SANCHEZ-LORENZO, A. (2006). Tendencias recientes de la insolación en la España peninsular y Baleares (1971-2000). En: $5^{\text {a }}$ Asamblea hispano-portuguesa de geodesia y geofísica, Sevilla.

MARTÍNEZ FERNÁNDEZ, J., BARBANCHO, A. CEBALLOS, SANTANA, V. HERNÁNDEZ, LEDESMA, S. CASADO, TEJEDA, C. MORÁN (2005). Procesos Hidrológicos en una Cuenca Forestal del Sistema Central: Cuenca Experimental de Rinconada. En: Cuadernos de Investigación Geográfica. Universidad de La Rioja, 31: 07-25.

MARTÍNEZ FERNANDEZ, J. (2006). Cambios en la cubierta vegetal y recursos hídricos: un análisis de la interceptación en la Cuenca del Duero. En: Congreso homenaje al Douro/Duero y sus ríos: Memoria, Cultura y Porvenir.

MENNIS, J. (2006). Socioeconomic-Vegetation Relationships in Urban, Residential Land: The Case of Denver, Colorado. Photogrammetric Engineering \& Remote Sensing, 72 (8): 911-921. 
MERINO POYO, M. J., CALVO BONACHO, M. (2008). "DEHESA COMÚN DE SOLANILLOS": Un proyecto de recuperación ambiental, económica y social. Comunicación Técnica en $9^{\circ}$ Congreso Nacional del Medio Ambiente - CONAMA, Madrid.

MIRÓN PÉREZ, I. J., MONTERO RUBIO, J. C., CRIADO-ÁLVAREZ, J.J., GUTIERREZ ÁVILA, G., PAREdes BEATO, D., MAYORAL ARENAS, S., LINARES GIL, C. (2006). Tratamiento y estudio de series de temperatura para su aplicación en salud pública. El caso de Castilla-La-Mancha. Revista Española de Salud Pública, 80: 113-124.

MOLINIER, M., LOUP GUYOT, J., OLIVEIRA, E., GUIMARÃES, V., CHAVES, A. (1995). Hidrologia da bacia do rio Amazonas. Revista Ciência e Tecnologia, 3136.

MONTEIRO DE CARVALHO, C., ALMEIDA-FILHO, R. (2007). Uso de imágens Landsat-TM para avaliar a extensão da desertificação na região de Gilbués, sul do estado do Piauí. En: Anais do XIII Simpósio Brasileiro de Sensoriamento Remoto, 4365-4372, Brasil.

M.O.P.T., Ministério de Obras Públicas y Transporte. (1992). Guía para la elaboración de estudios del medio físico. Ed. Secretaría general técnica y centro de publicaciones del M.O.P.T., 809 pp., Madrid.

MORAES, J. M., PEllegrino, G. Q., BAllester, M. V., MARTINELLI, L. A., VICTORIA, R. L., KRUSCHE, A. V. (1998). Trends in hydrological parameters of a southern brazilian watershed and its relation to human induced changes. Water Resources Management, 12: 295-311.

MORENO, F. (1989). Zonas kársticas en la vertiente $\mathbf{N}$ de la Sierra de Guadarrama. Tesis Doctoral, Universidad Complutense de Madrid, 773 pp. Madrid.

MORENO SOTO, F., CABEZAS CORCHERO, J. (2006). Un ejemplo de cómo la enseñanza puede acercar a los alumnos a la investigación y descubrimiento de una posible aplicación de la estadística descriptiva a la economía. En: XIV Jornadas de la Asociación Española de Profesores Universitarios de Matemáticas 
para la Economía y la Empresa (ASEPUMA) y el II Encuentro Internacional, Badajoz.

MOSSMANN, V., CASTRO, A., SÁNCHEZ, J. L. (2004). Análisis de la tendencia de las precipitaciones en los meses de febrero, marzo y abril en el territorio peninsular de España. XXVIII Jornadas Científicas Universidad de Extremadura en Badajoz - $5^{\circ}$ Encuentro Hispano-Luso de Meteorología.

MUSCHONG, D. (2007). Cambios en el uso del suelo en dos cuencas de la ecoregión Andino-Patagónica (Neuquén, Argentina). En Actas del II Encuentro de Becarios, La Plata, Argentina.

NAKAJIMA, N. Y., YOSHIDA, S., IMANAGA, M., CHYO, M. (1996). A Tentative for Vegetation Classification Using Landsat-5 Thematic Mapper-Imagery Covering an Area around Manaus City-Amazon. Memoirs of the Faculty of Agriculture, Kagoshima University, 32: 59-66.

NGATCHA BENJAMIN, N., JACQUES, M., REYNAULD JEAN, S. (2007). Groundwater recharge from rainfall in the southern border of lake chad in Cameroon. World Applied Sciences Journal, 2 (2): 125-131.

NORRANT, C., DOUGUÉDROIT, A. (2006). Monthly and daily precipitation trends in the Mediterranean (1950-2000). Theoretical an applied climatology, 83: 89-106.

O'HARA, C. G., KING, J. S., CARTWRIGHT , J. H., KING, R. L. (2003). Multitemporal land use and land cover classification of urbanized areas within sensitive coastal environments. IEEE Transactions on geoscience and remote sensing, 41 (9): 2005-2114.

OLIVEIRA MORAES, D. A. (2005). Extração de feições em dados imagem com alta dimensão por otimização da distância de Bhattacharyya em um classificador de decisão em árvore. Tesis de Mestrado da Universidade Federal do Rio Grande do Sul, 99 pp., Brasil.

OLIVEIRA MORAES, D. A., HAERTEL, V. (2006). Extração de feições em dados de imagens hiperespectrais por otimização da distância de Bhattacharyya em 
um classificador árvore de decisão. Boletim de Ciencias Geodésicas, 12 (2): 261-274.

OLIVEIRA PINTO, M. S. F. B., SOUZA FILHO, E. E. (2002). Estudo da erosão marginal no rio Paraná por meio de mosaicos de fotografias aéreas. XI Encontro Anual de Iniciação Científica, Universidade Estadual de Maringá.

OPAZO, S., CHUVIECO, E. (2007). Utilización de produtos MODIS para la cartografía de áreas quemadas. Revista de Teledetección, 27: 27-42.

ORMEÑO, S. (1993). Teledetección Fundamental. UPM. EUIT Topográfica, Madrid.

OUDIN, L., ANDRÉASSIAN, V., LERAT, J., MICHEL, C. (2008). Has land cover a significant impact on mean annual streamflow? An international assessment using 1508 catchments. Journal of Hydrology, 357: 303-316.

PAES DE CAMARGO, A., PAES DE CAMARGO, M. B. (2000). Uma revisão analítica da evapotranspiração potencial. Bragantia, 59 (2): 125-137.

PALMER, W. C., VAUGHN HAVENS, A. (1958). A graphical technique for determining evapotranspiration by the Thornthwaite Method. Monthly Weather Review, 123-128.

PARTAL, T., KAHYA, E. (2006). Trend analysis in Turkish precipitation data. Hydrological Processes, 20: 2011-2026.

PASCUAL AGUILAR, J. A. (2002). Cambios del suelo y régimen hídrico en la Rambla de Poyo y el Barranc de Carraixet. Tesis Doctoral de la Universitat de Valencia, 307 pp., Valencia.

PASQUINI, A. I., LECOMTE, K. L., PIOVANO, E. L., DEPETRIS, P. J. (2006). Recent rainfall and runoff variability in central Argentina. Quaternary International, 158: $127-139$.

PEMÁN GARCÍA, J. (1996). Dos ejemplos de utilización de los S.I.G. en la gestión forestal y un sistema de información territorial aplicado a la misma. Revista Internacional de Ciencias de la Tierra, ISSN: 1.131-9.100. 
PEÑA LLOPIS, J., POVEDA MARTíNEZ, R. M., BONET JORNET, A., BELLOT ABAD, J. F., ESCARRÉ ESTEVE, A. (2005). Cartografía de las coberturas y usos del suelo de la Marina Baixa (Alicante) para 1956, 1978 y 2000. Investigaciones Geográficas, 37: 93-107.

PEREIRA, A. R., VILLA NOVA, N. A., SEDIYAMA, G. C. (1997). Evapo(transpi)ração. Piracicaba: FEALQ, 183 p.

PETERSON, T. C., EASTERLING, D. R., KARL, T. R., GROISMAN, P., NICHOLLS, N., PlUMMER, N., TOROK, S., AUER, I., BOEHM, R., GULLETT, D., VINCENT, L., HEINO, R. TUOMENVIRTA, H., MESTRE, O., SZENTIMREY, T., SALINGER, J., FORLAND, E. J., HANSSEN-BAUER, I., ALEXANDERSSON, H., JONES, P., and PARKER, D. (1998). Homogeneity adjustments of in situ atmospheric climate data: a review. International Journal of Climatology, 18: 1493-1517.

PICCARRETA, M., CAPOlONGO, D., BOENZI, F., BENTIVENGA, M. (2006). Implications of decadal changes in precipitation and land use policy to soil erosion in Basilicata, Italy. Catena, 65: 138-151.

PICCININI SILVEIRA, V., ALONSO GAN, M. A. (2006). Estudo de tendência das temperaturas mínimas na região sul do Brasil. En: XIV Congresso Brasileiro de Meteorologia.

PIERVITALI, E., COLACINO, M., CONTE, M. (1998). Rainfall over the CentralWestern Mediterranean basin in the period 1951-1995. Part I: Precipitation Trends. II Nuovo Cimento, $21 \mathrm{C}, \mathrm{N}^{\circ} 3$.

PINILLA, C. (1995). Elementos de Teledetección. $1^{\text {a }}$ ed. Ra-Ma, 313 pp., Madrid.

PIZARRO, T. R., RAMIREZ, B. C., FLORES, J. B. V. (2003). Análisis comparativo de cinco métodos para la estimación de precipitaciones areales anuales en períodos extremos. Bosque, 24 (3): 31-38.

PIZARRO T., R., BENITEZ G., A., FARIAS D., C., JORDAN D., C., SANTIBAÑEZ Q., F., SANGÜESA P., C., Flores V., J., P., MARTíneZ A., E., ROMAN A., L. 
(2005). Influencia de las masas boscosas en el régimen hídrico de una cuenca semiárida, Chile. Bosque, 26 (1): 77-91.

PIZARRO, R., ARAYA, S., JORDÁN, C., FARÍAS, C., FLORES, J. P., BRO, P. B. (2006). The effects of changes in vegetative cover on river flows in the Purapel river basin of central Chile. Journal of Hydrology, 327: 249-257.

POZO RÍOS, M. M., SÁNCHEZ SÁNCHEZ, R., PINILLA RUIZ, C. (1998). Actualización cartográfica mediante integración de fotografías aéreas e imágenes de satélite. Mapping, ISSN 1131-9100, 50: 90-96.

POYATOS, R., LATRON, J., LLORENS, P. (2003). Land-use and land-cover change after agricultural abandonment. The case of a mediterranean mountain area (Catalan Pre-Pyrenees). Mountain Research and Development, 23 (4): 52-58.

PUTTY, M.R.Y., PRASAD, R. (2000). Understanding runoff processes using a watershed model - a case study in the Western Ghats in South India. Journal of Hydrology, 228: 215-227.

QUIRÓS LINARES, F., Fernández García, F. (1997). El vuelo fotográfico de la "Serie A". Ería: Revista Cuatrimestral de Geografía, 43: 190-198.

REDONDO VEGA, J. M., GÓMEZ VILLAR, A., GONZÁLEZ GUTIÉRREZ, R. B., CARRERA GÓMEZ, P. (2002). La Montaña Cantábrica Central Leonesa: Valles del Torío y Curueño. En XVII Jornadas de Geografía Física. Editorial Universidad de León - Secretariado de Publicaciones y Medios Audiovisuales, $1^{\text {a }}$ ed., 177 pp., León.

REGINALDO TENÓRIO, R. M., MOREIRA ALVES, M. (1993). Seleção de Bandas do Landsat/TM para identificação e mapeamento de áreas agrícolas no municipio de Juranda - PR. En Anais do VII Simpósio Brasileiro de Sensoriamento Remoto, 438-444, Brasil.

REIS DE ANDRADE, N. L., VIEIRA XAVIER, F., FREITAS ALVES, E. C. R., SILVEIRA, A., SANCHES, L., LIMA CUNHA, K., RONDON LIMA, E. B. N. (2008). Avaliação da precipitação média pelo método de Thiessen e da vazão líquida 
na bacia do Rio Manso - MT. En: XXXI Congreso Interamericano Aidis. Santiago, Chile.

RIUS DÍAZ, F., BARÓN LOPEZ, F. J., SÁNCHEZ FONT, E., PARRAS GUIJOSA, L. (1999) Bioestadística: Métodos y Aplicaciones. Manual de la Universidad de Málaga. ISBN: 847496-653-1.

ROBREDO, J. C., MINTEGUI, J. A. (1994). Diseño de un modelo distribuido elemental para el análisis del comportamiento hidrológico de una cuenca vertiente. Ingeniería del Agua, 1 (4): 79-100.

RODRÍGUEZ COHARD, J. C. (2002). De artesanos rurales a comerciantes globales - La adaptación estratégica del sistema productivo local de Los Villares. Boletín Económico De ICE, 2744: 31-37.

RODRÍGUEZ, R., LLASAT, M.C., WHEELER, D. (1999). Analysis of the Barcelona precipitation series 1850-1991. International Journal of Climatology, 19: 787-801.

ROSE, S. (2009). Rainfall-runoff trends in the south-eastern USA: 1938-2005. Hydrological Processes, 23: 1105-1118.

ROUNSEVELL, M. D. A., REgINSTER, I., ARAÚJO, M. B., CARTER, T. R., DENDONCKER, N., EWERT, F., HOUSE, J. L., KANKAAMPÄÄ, S., LEEMANS, R., METZGER, M. J., SCHMIT, C., SMITH, P., TUCK, G. (2006). A coherent set of future land use change scenarios for Europe. Agriculture, Ecosystems and Environment, 114: 57-68.

RUESCAS ORIENT, A. B. (1999). Cartografía de usos del suelo por teledetección: la cuenca del Carraixet. Cuadernos de Geografía, 65-66: 103-122.

RUESCAS ORIENT, A. B. (2001). Análisis de la dinámica espacio-temporal de los usos del suelo mediante sistemas de información geográfica: la cabecera de la cuenca de Cányoles. Cuadernos de Investigación Geográfica, 69-70: 215-230.

SABINS, F. F. (1996). Remote Sensing. Worth Publishers Incorporated, $3^{\mathrm{a}}$ ed., 432 pp., Nueva York. 
SALADIÉ, O., BRUNET, M., AGUILAR, E., SIGRÓ, J., LÓPEZ, D. (2002). Evolución de la precipitación en el sector suroriental de la depresión del Ebro durante la segunda mitad del siglo XX. En: (J.A. Guijarro, M. Grimalt, M. Laita, S. Alonso, Eds) El agua y el clima. Pub. de la Asociación Española de Climatología. Palma de Mallorca. Serie A, №. 3.

SALAS GUILLERMO, J. D. (1985). A comparative analysis of techniques for spatial interpolation of precipitation. Journal of the American Water Resources Association, 21 (3):365-380.

SALINAS, M. (2007). Modelos de regresión y correlación IV: Correlación de Spearman. Ciencia y Trabajo, 9 (25):143-145.

SAlMI, T., MÄÄTtÄ, A., ANTIllA, P., RUOHO-AIROBA, T., AMNELL, T. (2002). Detecting trends of annual values of atmospheric pollutants by the MannKendall test and Sen's slope estimates - The excel template application makesens. Published by Finnish Meteorological Institute, 35 p.

SAMANI, Z. (2000). Estimating solar radiation and evapotranspiration using minimum climatological data. Journal of Irrigation and Drainage Engineering, Reston, V. 126, 4: 265-267.

SANCHO COMÍNS, J., REINOSO MORENO, D. (2003). Población y poblamiento rural de España: un primer análisis a la luz del censo 2001. Serie Geográfica, 11: 163-176.

SANTANA, L. M., SALAS, J. (2007). Análisis de cambios en la ocupación del suelo ocurridos en sabanas de Colombia entre 1987 y 2001, usando imágenes Landsat. GeoFocus, 7: 281-313.

SERRANO MUELA, M.P., REGÜÉS, D., LATRÓN, J., MARTí BONO, C., LANARENAULT, N., NADAL ROMERO, E. (2005). Respuesta hidrológica de una cuenca forestal en la montaña media pirenaica: el caso de San Salvador. Cuadernos de Investigación Geográfica, 31: 59-76. 
SILVA BRITO, J. L., DINIZ PRUDENTE, T. (2005). Análise temporal do uso do solo e cobertura vegetal do município de Uberlândia-MG, utilizando imagens ETM+/LANDSAT 7. Sociedade \& Natureza, 17 (32): 37-46.

SMADI, M. M., ZGHOUL, A. (2006). A sudden change in rainfall characteristics in Amman, Jordan during the mid 1950s. American Journal of Environmental Sciences, 2 (3): 84-91.

SNEYERS, R. (1975). Sur l'analyse statisque des séries d'observations. Organisation Météorologique Mundial, 192 pp., Genève.

SOUSA SILVA, W., CALDAS BRITO, V. (2007). Evolução multitemporal do uso e cobertura do solo no município de Uruçui - PI. Anais do II Congresso de Pesquisa e Inovação da Rede Norte Nordeste de Educação Tecnológica. En prensa.

STAUDT, M., ESTEBAN-PARRA, M. J., CASTRO-DÍEZ, Y. (2007). Homogenization of long-term montly Spanish temperature data. International Journal of Climatology, 27: 1809-1823.

STEPANEK, P. (2003). AnClim - Software for time series analysis. Departament of Geography, Facultad of Natural Sciences, MU, Brno. 1.47 MB.

STEPANEK, P. (2003). Homogeneización de las series de temperatura del aire en la República Checa durante el período instrumental. Geographicalia, 43: 5-24.

STEPANEK, P. (2004). Homogenization of air temperature series in the Czech Republic during a period of instrumental measurements. Theoretical and Applied Climatology, 88: 247-258.

STONE, L. F., SILVEIRA, P. M. da (1995). Determinação da evapotranspiração para fins de irrigação. EMBRAPA-CNPAF, 49 pp., Goiânia. 
TENG, W. L. (1997). Fundamentals of photographic interpretation. In: Manual of photographic interpretation American Society for photogrammetry and remote sensing. $2^{\mathrm{a}}$ ed., $689 \mathrm{pp}$., Maryland, USA.

THORNTHWAITE, C. W. (1948). An approach toward a rational classification of climate. Geographic Review, 38 (1): 55-94.

TORRES, T., ORTIZ, J.E., GARCÍA DE LA MORENA, M.A., LLAMAS, F.J., GOODFRIEND, G. (2005). Ostracode-based aminostratigraphy and aminochronology of a tufa system in central Spain. Quaternary International, 135: 21-33.

TUCCI, C. E. M. (2000). Coeficiente de escoamento e vazão máxima de bacias urbanas. Revista Brasileira de Recursos Hídricos, 5 (1): 61-68.

UNESCO-WWAP. (2003). Water for people, water for life - Executive Summary of the UN World Water Development Report. First published by the Unite Nations Educational, Scientific and Cultural. Organization UNESCO, Paris, France.

UNITED NATIONS ENVIRONMENT PROGRAMME (2002). The World's Water Cycle and Estimated Residence Times of the World's Water Resources. Unesco, Paris, France.

VICENTE RODADO, M. F., VELA, A. L., SANZ, M. A., MARTÍN MORENO, C., MARTÍN DUQUE, J. F. (2008). Origen, evolución y dinámica actual de cárcavas del piedemonte norte del Guadarrama. Métodos de estudio y criterios para su gestión con bases ecológicas. Comunicación Técnica en $9^{\circ}$ Congreso Nacional del Medio Ambiente - CONAMA, Madrid.

VICENTE-SERRANO, S.M., CUADRAT-PRATS, J.M. (2007). Trends in drought intensity and variability in the middle Ebro valley (NE of the Iberian peninsula) during the second half of the twentieth century. Theoretical and Applied Climatology, 88: 247-258.

WARRICK, A. W. (1998). Spatial Variability. En: HILEL, D. Environmental Soil Physics. Academic Press, 771 pp., San Diego. 
WHISTLER, J. L., JAKUBAUSKAS, M. E., EGBERT, S. L., MARTINKO, E. A., BAUMGARTNER, D. W., LEE, R. (1995). The Kansas State land cover mapping project: regional scale land use / land cover mapping using Landsat Thematic Mapper data. ACSM/ASPRS - Annual Convention and Exposition Technical Papers, 3: 773-785.

WOLF, P. R. (1983). Elements of photogrammetry. McGraw-Gril, 628 pp., New York.

WORLD BANK (2001). World Development Indicators. V. 1, № 1, 396 pp., Publisher World Bank.

YEVJEVICH, V. (1972). Probability and statistics in hydrology. Fort Collins: Water Resources Publication, $276 \mathrm{p}$.

YUE, S., PILON, P., CAVADIAS, G. (2002). Power of the Mann-Kendall and Spearman's rho tests for detecting monotonic trends in hydrological series. Journal of Hydrology, 259: 254-271. 


\section{Lista de páginas web consultadas}

http://ceer.isa.utl.pt/cyted/brasil2008

http://glcf.umiacs.umd.edu

http://hdl.handle.net

http://reddeparquesnacionales.mma.es

http://www.bdtd.ufscar.br

http://www.bioestadistica.uma.es/libro

http://www.castillalamancha.es

http://www.chduero.es

http://www.chtajo.es

http://www.cuenca.org

http://www.dipuleon.es

http://www.eea.europa.eu

http://www.floraiberica.org

http://www.ign.es

http://www.inm.es

http://www.interscience.wiley.com

http://www.ipcc.ch

http://www.landsat.gsfc.nasa.gov

http://www.mai.liu.se

http://www.mapa.es/es/agricultura

http://www.mapa.es/es/sig/pags/sigpac

http://www.mappinginteractivo.com

http://www.marm.es

http://www.nayacu.com

http://www.noaa.gov

http://www.pornguadarrama.es

http://www.spot.com

http://www.unep.org

http://www.unesco.org

http://www.worldbank.org 


\section{Lista de Figuras}

Figura 01 - El Ciclo Hidrológico con el balance hídrico general (Unep, 2002). 19

Figura 02 - (a) Foto aérea $n^{\circ} 43051$ del vuelo americano de 1956-57 y (b) Escena de satélite Landsat $n^{\circ} 218-030$. 32

Figura 03 - Secuencia del trabajo desarrollado en el análisis hidrológico. 36

Figura 04 - Secuencia del trabajo desarrollado en el análisis climatológico. 43

Figura 05 - Esquema clásico de los Polígonos de Thiessen. 46

Figura 06 - Polígonos de Thiessen - Cuenca del río Cega..................................... 47

Figura 07 - Polígonos de Thiessen - Cuenca del río Porma. ................................... 47

Figura 08 - Polígonos de Thiessen - Cuenca del río Tajo..................................... 48

Figura 09 - Polígonos de Thiessen - Cuenca del río Trabaque. ............................... 48

Figura 10 - Fotografía aérea $n^{\circ} 6592$ (a) e imagen de la misma zona recortada de la escena Landsat 201/031 de 15/07/89

Figura 11 - Secuencia del trabajo desarrollado con las fotografías aéreas. 59

Figura 12 - Mosaico digital de la cuenca del río Porma. 60

Figura 13 - Recorte del mosaico - Cuenca del río Porma. 62

Figura 14 - Secuencia del trabajo desarrollado con las escenas Landsat. 64

Figura 15 - a) Escena Landsat 200032 y b) Recorte preliminar de la escena Landsat -

Cuenca del río Tajo 65

Figura 16 - Cuenca del río Porma...... 69

Figura 17 - Localización de la cuenca del río Cega.............................................. 71

Figura 18 - Localización de la cuenca del río Porma.............................................75

Figura 19 - Localización de la cuenca del río Tajo. .............................................. 80

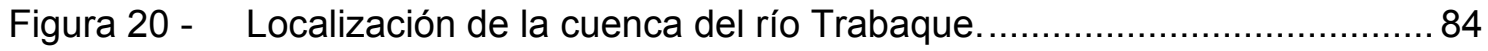

Figura 21 - Cabecera del río Cega y localización de la estación de aforo 016 en Pajares de Pedraza. 90 
Figura 22 - Caudal relativo (adimensional) y precipitación media mensual en la cuenca del río Cega en la estación 016 en Pajares de Pedraza......

Figura 23 - Distribución de caudales diarios del río Cega en Pajares de Pedraza y los correspondientes a $3(\mathrm{Q} \times 3), 5(\mathrm{Q} \times 5)$ y $10(\mathrm{Q} \times 10)$ veces el caudal medio en el período hidrológico 1974-2004.

Figura 24 - Distribución de frecuencias de los caudales diarios del río Cega con indicación de la media y de la mediana.

Figura 25 - Coeficientes de variación interanual del río Cega con indicación de su tendencia - Período $1974-2004$.

Figura 26 - Aportaciones del mes de septiembre en la estación de aforo 016, del río Cega en Pajares de Pedraza.

Figura 27 - Aportaciones del mes de mayo en la estación de aforo 016, del río Cega en Pajares de Pedraza. 96

Figura 28 - Evolución de las aportaciones, línea de tendencia y precipitaciones anuales entre 1974 y 2004, con indicación de la tendencia del río Cega en Pajares de Pedraza.

Figura 29 - Cabecera del río Porma y localización de la estación de aforo 078 en Camposolillo. 101

Figura 30 - Caudal relativo (adimensional) y precipitación media mensual en la cuenca del río Porma en la estación 078 en Camposolillo....... 102

Figura 31 - Distribución de caudales diarios del río Porma en Camposolillo y los correspondientes a $3(\mathrm{Q} \times 3), 5(\mathrm{Q} \times 5)$ y $10(\mathrm{Q} \times 10)$ veces el caudal medio en el período hidrológico 1974-2004.

Figura 32 - Distribución de frecuencias de los caudales diarios del río Porma con indicación de la media y de la mediana.

Figura 33 - Coeficientes de variación interanual del río Porma con indicación de su tendencia - Período $1974-2004$. 105 
Figura 34 - Evolución de las aportaciones, línea de tendencia y precipitaciones anuales entre 1974 y 2004, con indicación de la tendencia del río Porma en Camposolillo. 107

Figura 35 - Test Mann-Kendall secuencial para la aportación anual entre 1974 y 2004 del río Porma en Camposolillo. 110

Figura 36 - Cabecera del río Tajo y localización de la estación de aforo 001 en Peralejos de las Truchas. 112

Figura 37 - Caudal relativo (adimensional) y precipitación media mensual de la cuenca alta del Tajo en la estación 001 en Peralejos de las Truchas.

Figura 38 - Distribución de caudales diarios del río Tajo en Peralejos de las Truchas y los correspondientes a $3(\mathrm{Q} \times 3), 5(\mathrm{Q} \times 5)$ y $10(\mathrm{Qx10})$ veces el caudal medio en el período hidrológico 1974-2004. 114

Figura 39 - Distribución de frecuencias de los caudales diarios del río Tajo con indicación de la media y de la mediana.

Figura 40 - Coeficientes de variación interanual del río Tajo con indicación de su tendencia - Período $1974-2004$.

Figura 41 - Evolución de las aportaciones, línea de tendencia y precipitaciones anuales entre 1974 y 2004, con indicación de la tendencia del río Tajo en Peralejos de las Truchas. 119

Figura 42 - Test Mann-Kendall secuencial para la aportación anual entre 1974 y 2004 del río Tajo en Peralejos de las Truchas. 122

Figura 43 - Cabecera del río Trabaque y localización de la estación de aforo 186 en Priego. 123

Figura 44 - Caudal relativo (adimensional) y precipitación media mensual de la cuenca del río Trabaque en la estación 186 en Priego. 124

Figura 45 - Distribución de caudales diarios del río Trabaque en Priego y los correspondientes a $3(\mathrm{Q} \times 3), 5(\mathrm{Q} \times 5)$ y $10(\mathrm{Q} \times 10)$ veces el caudal medio en el período hidrológico 1974-2004. 
Figura 46 - Distribución de Frecuencias con indicación de la media y de la mediana.

Figura 47 - Aportaciones del mes de julio en la Estación de Aforo 186, del río

Trabaque en Priego.

Figura 48 - Aportaciones del mes de abril en la Estación de Aforo 186, del río

Trabaque en Priego.

Figura 49 - Coeficientes de variación interanual del río Trabaque con indicación de su

tendencia - Período 1974 - 2004. 128

Figura 50 - Evolución de las aportaciones, línea de tendencia y precipitaciones

anuales entre 1974 y 2004, con indicación de la tendencia del río Trabaque en

Priego.

Figura 51 - Test Mann-Kendall secuencial para la aportación anual entre 1974 y 2004

del río Trabaque en Priego.

Figura 52 - Localización de las estaciones termométricas y pluviométricas (Cuenca del río Cega).

Figura 53 - Evapotranspiración potencial y precipitación mensual $(\mathrm{mm})$ de la cuenca del río Cega.

Figura 54 - Evolución de la precipitación total anual de la estación La Granja de San

Ildefonso con representación de la media móvil de 5 años - Cuenca del río Cega.

Figura 55 - Precipitación media mensual para el período estudiado - Estación La

Granja de San Ildefonso, Cuenca del río Cega.

Figura 56 - Evolución de la precipitación total anual de la estación Matabuena con

representación de la media móvil de 5 años - Cuenca del río Cega.

Figura 57 - Precipitación media mensual para el período estudiado - Estación

Matabuena, Cuenca del río Cega.

Figura 58 - Evolución de la precipitación total anual de la estación Rascafria con

representación de la media móvil de 5 años - Cuenca del río Cega. 
Figura 59 - Precipitación media mensual para el período estudiado - Estación

Rascafria, Cuenca del río Cega.

Figura 60 - Evolución de la precipitación total anual de la estación Torreiglesias con

representación de la media móvil de 5 años - Cuenca del río Cega. 145

Figura 61 - Precipitación media mensual para el período estudiado - Estación

Torreiglesias, Cuenca del río Cega.

Figura 62 - Evolución de la precipitación total anual de la estación Turégano con

representación de la media móvil de 5 años - Cuenca del río Cega.

Figura 63 - Precipitación media mensual para el período estudiado - Estación

Turégano, Cuenca del río Cega.

Figura 64 - Localización de las estaciones termométricas y pluviométricas (Cuenca del río Porma). 149

Figura 65 - Evapotranspiración potencial y precipitación mensual $(\mathrm{mm})$ de la cuenca del río Porma. 151

Figura 66 - Evolución de la precipitación total anual de la estación Acebedo con

representación de la media móvil de 5 años - Cuenca del río Porma.

Figura 67 - Precipitación media mensual para el período estudiado - Estación

Acebedo, Cuenca del río Porma.

Figura 68 - Evolución de la precipitación total anual de la estación Crémenes con

representación de la media móvil de 5 años - Cuenca del río Porma.

Figura 69 - Precipitación media mensual para el período estudiado - Estación

Crémenes, Cuenca del río Porma.

Figura 70 - Evolución de la precipitación total anual de la estación Maraña con

representación de la media móvil de 5 años - Cuenca del río Porma. 155

Figura 71 - Precipitación media mensual para el período estudiado - Estación Maraña,

Cuenca del río Porma. 156

Figura 72 - Evolución de la precipitación total anual de la estación Pantano del Porma con representación de la media móvil de 5 años - Cuenca del río Porma...... 157 
Figura 73 - Precipitación media mensual para el período estudiado - Estación Pantano del Porma, Cuenca del río Porma. 158

Figura 74 - Evolución de la precipitación total anual de la estación Puebla de Lillo con representación de la media móvil de 5 años - Cuenca del río Porma. 159

Figura 75 - Precipitación media mensual para el período estudiado - Estación Puebla de Lillo, Cuenca del río Porma 160

Figura 76 - Localización de las estaciones termométricas y pluviométricas (Cuenca alta del Tajo).

Figura 77 - Evapotranspiración potencial y precipitación mensual $(\mathrm{mm})$ de la cuenca del río Tajo.

Figura 78 - Evolución de la precipitación total anual de la estación Beteta con representación de la media móvil de 5 años - Cuenca alta del Tajo. 163

Figura 79 - Precipitación media mensual para el período estudiado - Estación Beteta,

Cuenca alta del Tajo. 164

Figura 80 - Evolución de la precipitación total anual de la estación Cañizares con representación de la media móvil de 5 años - Cuenca alta del Tajo.

Figura 81 - Precipitación media mensual para el período estudiado - Estación

Cañizares, Cuenca alta del Tajo. 166

Figura 82 - Evolución de la precipitación total anual de la estación Poyatos con representación de la media móvil de 5 años - Cuenca alta del Tajo.

Figura 83 - Precipitación media mensual para el período estudiado - Estación Poyatos,

Cuenca alta del Tajo. 168

Figura 84 - Evolución de la precipitación total anual de la estación Santa María del Val con representación de la media móvil de 5 años - Cuenca alta del Tajo. 169

Figura 85 - Precipitación media mensual para el período estudiado - Estación Santa

María del Val, Cuenca alta del Tajo. 170

Figura 86 - Evolución de la precipitación total anual de la estación Vega del Codorno con representación de la media móvil de 5 años - Cuenca alta del Tajo. 
Figura 87 - Precipitación media mensual para el período estudiado - Estación Vega del Codorno, Cuenca alta del Tajo.

Figura 88 - Localización de las estaciones termométricas y pluviométricas (Cuenca del río Trabaque).

Figura 89 - Evapotranspiración potencial y precipitación mensual $(\mathrm{mm})$ de la cuenca del río Trabaque. 175

Figura 90 - Evolución de la precipitación total anual de la estación Albalate de las Nogueras con representación de la media móvil de 5 años - Cuenca del río Trabaque. 176

Figura 91 - Precipitación media mensual para el período estudiado - Estación Albalate de las Nogueras, Cuenca del río Trabaque. 176

Figura 92 - Evolución de la precipitación total anual de la estación Arrancacepas con representación de la media móvil de 5 años - Cuenca del río Trabaque. 177

Figura 93 - Precipitación media mensual para el período estudiado - Estación

Arrancacepas, Cuenca del río Trabaque.

Figura 94 - Evolución de la precipitación total anual de la estación Cañaveras con representación de la media móvil de 5 años - Cuenca del río Trabaque. 179

Figura 95 - Precipitación media mensual para el período estudiado - Estación

Cañaveras, Cuenca del río Trabaque. 180

Figura 96 - Evolución de la precipitación total anual de la estación Torrecilla con

representación de la media móvil de 5 años - Cuenca del río Trabaque.

Figura 97 - Precipitación media mensual para el período estudiado - Estación

Torrecilla, Cuenca del río Trabaque.

Figura 98 - Evolución de la precipitación total anual de la estación Villar de Domingo

García con representación de la media móvil de 5 años - Cuenca del río

Trabaque. 183

Figura 99 - Precipitación media mensual para el período estudiado - Estación Villar de Domingo García, Cuenca del río Trabaque. 183 
Figura 100 - Test Mann-Kendall secuencial para la precipitación total anual - Estación

Matabuena, Cuenca del río Cega. 186

Figura 101 - Test Mann-Kendall secuencial para la precipitación total anual - Estación Maraña, Cuenca del río Porma. 189

Figura 102 - Test Mann-Kendall secuencial para la precipitación total anual - Estación

Beteta, Cuenca del Tajo. 191

Figura 103 - Test Mann-Kendall secuencial para la precipitación total anual - Estación

Cañizares, Cuenca del Tajo...... 192

Figura 104 - Test Mann-Kendall secuencial para la precipitación total anual - Estación

Poyatos, Cuenca del Tajo 192

Figura 105 - Test Mann-Kendall secuencial para la precipitación total anual - Estación

Santa María del Val, Cuenca del Tajo. 193

Figura 106 - Test Mann-Kendall secuencial para la precipitación total anual - Estación

Vega del Codorno, Cuenca del Tajo. 194

Figura 107 - Test Mann-Kendall secuencial para la precipitación total anual - Estación

Albalate de las Nogueras, Cuenca del río Trabaque. 201

Figura 108 - Test Mann-Kendall secuencial para la precipitación total anual - Estación

Arrancacepas, Cuenca del río Trabaque. 201

Figura 109 - Test Mann-Kendall secuencial para la precipitación total anual - Estación

Torrecilla, Cuenca del río Trabaque 202

Figura 110 - Test Mann-Kendall secuencial para la precipitación total anual - Estación

Villar de Domingo García, Cuenca del río Trabaque. 203

Figura 111 - Evolución de la temperatura media anual en la estación Rascafria -

Cuenca del Río Cega. 208

Figura 112 - Test Mann-Kendall secuencial para la temperatura máxima anual -

Estación Rascafria, Cuenca del río Cega. 210

Figura 113 - Test Mann-Kendall secuencial para la temperatura media anual -

Estación Rascafria, Cuenca del río Cega. 
Figura 114 - Evolución de la temperatura media anual en la estación Pantano del

Porma - Cuenca del Río Porma.

Figura 115 - Evolución de la temperatura media anual en la estación Cañizares -

Cuenca del río Tajo 216

Figura 116 - Test Mann-Kendall secuencial para la temperatura mínima anual -

Estación Cañizares, Cuenca del río Tajo.

Figura 117 - Test Mann-Kendall secuencial para la temperatura máxima anual -

Estación Cañizares, Cuenca del río Tajo.

Figura 118 - Test Mann-Kendall secuencial para la temperatura media anual -

Estación Cañizares, Cuenca del río Tajo.

Figura 119 - Evolución de la temperatura media anual en la estación Arrancacepas -

Cuenca del Río Trabaque 223

Figura 120 - Test Mann-Kendall secuencial para la temperatura mínima anual -

Estación Arrancacepas, Cuenca del río Trabaque..... 226

Figura 121 - Test Mann-Kendall secuencial para la temperatura media anual -

Estación Arrancacepas, Cuenca del río Trabaque 226

Figura 122 - Evolución de la población en las cuencas de los ríos Cega, Porma, Tajo y

Trabaque.

Figura 123 - Evolución de la superficie arbolada en las provincias de Segovia, León,

Guadalajara y Cuenca según los datos del IFN. 233

Figura 124 - Usos y cobertura del suelo en la cuenca del río Cega en $1956 \ldots \ldots \ldots \ldots . . .236$

Figura 125 - Usos y cobertura del suelo en la cuenca del río Cega en 1976 ........... 237

Figura 126 - Usos y cobertura del suelo en la cuenca del río Cega en 1989............ 238

Figura 127 - Usos y cobertura del suelo en la cuenca del río Cega en 2002 ............ 239

Figura 128 - Evolución de los usos y coberturas del suelo en la cuenca del río Cega

(\%). 240

Figura 129 - Usos y cobertura del suelo en la cuenca del río Porma en 1957. 241

Figura 130 - Usos y cobertura del suelo en la cuenca del río Porma en 1977. 242 
Figura 131 - Usos y cobertura del suelo en la cuenca del río Porma en 1991.

Figura 132 - Usos y cobertura del suelo en la cuenca del río Porma en 2001.

Figura 133 - Evolución de los usos y coberturas del suelo en la cuenca del río Porma 245

Figura 134 - Usos y coberturas del suelo en la cuenca del río Tajo en 1956-57 .......247

Figura 135 - Usos y coberturas del suelo en la cuenca del río Tajo en 1976. 248

Figura 136 - Usos y coberturas del suelo en la cuenca del río Tajo en 1987. 249

Figura 137 - Usos y coberturas del suelo en la cuenca del río Tajo en 2001. 250

Figura 138 - Evolución de los usos y coberturas del suelo en la cuenca del río Tajo $(\%)$ 251

Figura 139 - Usos y coberturas del suelo en la cuenca del río Trabaque en 1956-57.

Figura 140 - Usos y coberturas del suelo en la cuenca del río Trabaque en 1976...254

Figura 141 - Usos y coberturas del suelo en la cuenca del río Trabaque en 1987 .. 255

Figura 142 - Usos y coberturas del suelo en la cuenca del río Trabaque en 2001. .. 256

Figura 143 - Evolución de los usos y coberturas del suelo en la cuenca del río

Trabaque (\%). 258

Figura 144 - Caudal específico de las cuencas de los ríos Cega, Porma, Tajo y

Trabaque. 261

Figura 145 - Caudal relativo (adimensional) de las cuencas de los ríos Cega, Porma,

Tajo y Trabaque. 262

Figura 146 - Evolución de la precipitación total anual en las cuencas de los ríos Cega, Porma, Tajo y Trabaque. 265

Figura 147 - Valores normalizados de la precipitación total anual en las cuencas de los ríos Cega, Porma, Tajo y Trabaque. 266

Figura 148 - Evolución de la temperatura anual en las cuencas de los ríos Cega,

Porma, Tajo y Trabaque. 268 
Figura 149 - Valores normalizados de la temperatura media anual en las cuencas de los ríos Cega, Porma, Tajo y Trabaque. 269

Figura 150 - Evolución de la categoría Forestal Arbolado en las cuencas de los ríos

Cega, Porma, Tajo y Trabaque... 270

Figura 151 - Relación entre precipitación y aportación - Río Cega. 272

Figura 152 - Relación entre precipitación y aportación - Río Porma. 272

Figura 153 - Relación entre precipitación y aportación - Río Tajo. 273

Figura 154 - Relación entre precipitación y aportación - Río Trabaque 273 


\section{Lista de Tablas}

Tabla 01. Países con más y menos agua per cápita en el mundo................................ 18

Tabla 02. Indicadores meteorológicos y probables cambios...................................... 20

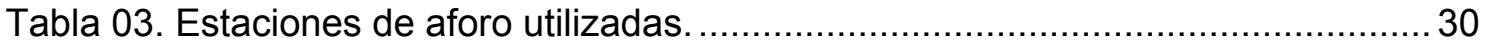

Tabla 04. Mapas topográficos utilizados para delimitación de las cuencas. .................30

Tabla 05. Estaciones pluviométricas y termométricas utilizadas en este estudio. ........ 31

Tabla 06. Fotografías aéreas utilizadas para análisis de las cuencas de los ríos Cega, Porma, Tajo y Trabaque y su correspondencia en el Mapa Topográfico Nacional

(MTN). 33

Tabla 07. Imágenes de satélite utilizadas para análisis de las cuencas de los ríos

Cega, Porma, Tajo y Trabaque..... 34

Tabla 08. Características generales de los programas Landsat, SPOT y NOAA-

AVHRR. 52

Tabla 09. Fuentes de información utilizadas. Ventajas y limitaciones. 53

Tabla 10. Comparación de las fotografías aéreas y escenas Landsat utilizadas en este estudio. .53

Tabla 11. Fuentes de datos utilizadas para análisis de las cuencas de los ríos Cega,

Porma, Tajo y Trabaque. .56

Tabla 12. Niveles de clasificación propuesto por Anderson et al., 1976. 57

Tabla 13. Combinaciones de bandas de imágenes Landsat más utilizadas. 65

Tabla 14. Coeficientes Kappa y clasificación global de precisión para todas las imágenes utilizadas en este estudio.

Tabla 15. Datos de localización de las estaciones de aforo utilizadas. 88

Tabla 16. Estadística básica de los caudales medios del Río Cega en Pajares de Pedraza para el período hidrológico de $1974-2004$. 
Tabla 17. Coeficiente de variación de los caudales medios mensuales y anuales del Río Cega en Pajares de Pedraza para el período hidrológico de 1974 - 2004.... 94

Tabla 18. Caudal específico del Río Cega en Pajares de Pedraza para el período hidrológico de $1974-2004$. .96

Tabla 19. Estadística básica de los aportes medios mensuales del río Cega en Pajares de Pedraza para el período hidrológico de $1974-2004$. 97

Tabla 20. Estadística Básica de los aportes anuales del Río Cega en Pajares de Pedraza para el período hidrológico de 1974 - 2004. 97

Tabla 21. Coeficiente de correlación entre el aporte anual y el tiempo del río Cega en Pajares de Pedraza para el período 1974 - 2004. 98

Tabla 22. Coeficientes de correlación entre el aporte mensual y el tiempo del río Cega en Pajares de Pedraza para el período de $1974-2004$. 99

Tabla 23. Test estadístico Mann-Kendall para los aportes mensuales y anuales del río Cega en Pajares de Pedraza...... 100

Tabla 24. Estadística básica de los caudales medios del Río Porma en Camposolillo para el período hidrológico de 1974 - 2004. 103

Tabla 25. Coeficiente de variación de los caudales medios mensuales y anuales del Río Porma en Camposolillo para el período hidrológico de 1974 - 2004. 104

Tabla 26. Caudal específico del Río Porma en Camposolillo para el período hidrológico de $1974-2004$. 106

Tabla 27. Estadística Básica de los aportes medios mensuales del río Porma en

Camposolillo para el período hidrológico de $1974-2004$ 106

Tabla 28. Estadística Básica de los aportes medios anuales del Río Porma en Camposolillo para el período hidrológico de $1974-2004$. 107

Tabla 29. Coeficiente de correlación entre el aporte anual y el tiempo del río Porma en Camposolillo para el período $1974-2004$. 108

Tabla 30. Coeficientes de correlación entre el aporte mensual y el tiempo del río

Porma en Camposolillo para el período de 1974 - 2004. 108 
Tabla 31. Test estadístico Mann-Kendall para los aportes mensuales y anuales del río Porma en Camposolillo. 109

Tabla 32. Estadística básica de los caudales medios del Río Tajo en Peralejos de las Truchas para el período hidrológico de 1974 - 2004. 114

Tabla 33. Coeficiente de variación de los caudales medios mensuales y anuales del Río Tajo en Peralejos de las Truchas para el período hidrológico de 1974 - 2004.

Tabla 34. Caudal específico del Río Tajo en Peralejos de las Truchas para el período hidrológico de $1974-2004$.

Tabla 35. Estadística básica de los aportes medios mensuales del río Tajo en

Peralejos de las Truchas para el período hidrológico de 1974 - 2004. 118

Tabla 36. Estadística Básica de los aportes anuales del Río Tajo en Peralejos de las

Truchas para el período hidrológico de $1974-2004$. 118

Tabla 37. Coeficiente de correlación entre el aporte anual y el tiempo del río Tajo en

Peralejos de las Truchas para el período $1974-2004$.

Tabla 38. Coeficientes de correlación entre el aporte mensual y el tiempo del río Tajo

en Peralejos de las Truchas para el período de $1974-2004$. 120

Tabla 39. Test estadístico Mann-Kendall para los aportes mensuales y anuales del río

Tajo en Peralejos de las Truchas. 121

Tabla 40. Estadística básica de los caudales medios del Río Trabaque en Priego para el período hidrológico de $1974-2004$. 125

Tabla 41. Coeficiente de variación de los caudales medios mensuales y anuales del

Río Trabaque en Priego para el período hidrológico de 1974 - 2004. 127

Tabla 42. Caudal específico del Río Trabaque en Priego para el período hidrológico de $1974-2004$ 129

Tabla 43. Estadística Básica de los aportes medios mensuales del río Trabaque en

Priego para el período hidrológico de $1974-2004$. 129 
Tabla 44. Estadística Básica de los aportes medios anuales del Río Trabaque en

Priego para el período hidrológico de 1974 - 2004. 130

Tabla 45. Coeficiente de correlación entre el aporte anual y el tiempo del río Trabaque en Priego para el período $1974-2004$. 131

Tabla 46. Coeficientes de correlación entre el aporte mensual y el tiempo del río Trabaque en Priego para el período de 1974 - 2004. 132

Tabla 47. Test estadístico Mann-Kendall para los aportes mensuales y anuales del río Trabaque en Priego. 133

Tabla 48. Estaciones pluviométricas y termométricas utilizadas para análisis climatológicas de las cuencas de los ríos Cega, Porma, Tajo y Trabaque. 136

Tabla 49. Precipitación media, mínima, máxima, coeficientes de variación y altitud para todas las estaciones utilizadas para análisis de la cuenca del río Cega. 138

Tabla 50. Precipitación y evapotranspiración media mensual de la cuenca del río

Cega. 138

Tabla 51. Precipitación media mensual y coeficiente de variación de la estación La

Granja de San Ildefonso - Cuenca del río Cega.

Tabla 52. Precipitación media mensual y coeficiente de variación de la estación

Matabuena - Cuenca del río Cega.

Tabla 53. Precipitación media mensual y coeficiente de variación de la estación

Rascafria - Cuenca del río Cega.

Tabla 54. Precipitación media mensual y coeficiente de variación de la estación

Torreiglesias - Cuenca del río Cega.

Tabla 55. Precipitación media mensual y coeficiente de variación de la estación

Turégano - Cuenca del río Cega.

Tabla 56. Precipitación media, mínima, máxima, coeficientes de variación y altitud para todas las estaciones utilizadas para análisis de la cuenca del río Porma. 150

Tabla 57. Precipitación y evapotranspiración media mensual de la cuenca del río

Porma 151 
Tabla 58. Precipitación media mensual y coeficiente de variación de la estación

Acebedo - Cuenca del río Porma.

Tabla 59. Precipitación media mensual y coeficiente de variación de la estación

Crémenes - Cuenca del río Porma.

Tabla 60. Precipitación media mensual y coeficiente de variación de la estación

Maraña - Cuenca del río Porma. 156

Tabla 61. Precipitación media mensual y coeficiente de variación de la estación

Pantano del Porma - Cuenca del río Porma. 158

Tabla 62. Precipitación media mensual y coeficiente de variación de la estación Puebla de Lillo - Cuenca del río Porma. 160

Tabla 63. Precipitación media, mínima, máxima, coeficientes de variación y altitud para todas las estaciones. 162

Tabla 64. Precipitación y evapotranspiración media mensual de la cuenca del río Tajo.

Tabla 65. Precipitación media mensual y coeficiente de variación de la estación Beteta

- Cuenca alta del Tajo. 165

Tabla 66. Precipitación media mensual y coeficiente de variación de la estación

Cañizares - Cuenca alta del Tajo. 166

Tabla 67. Precipitación media mensual y coeficiente de variación de la estación

Poyatos - Cuenca alta del Tajo. 168

Tabla 68. Precipitación media mensual y coeficiente de variación de la estación Santa

María del Val - Cuenca alta del Tajo.

Tabla 69. Precipitación media mensual y coeficiente de variación de la estación Vega del Codorno - Cuenca alta del Tajo. 172

Tabla 70. Precipitación media, mínima, máxima, coeficientes de variación y altitud para todas las estaciones. 174

Tabla 71. Precipitación y evapotranspiración media mensual de la cuenca del río

Trabaque. 
Tabla 72. Precipitación media mensual y coeficiente de variación de la estación

Albalate de las Nogueras - Cuenca del río Trabaque.

Tabla 73. Precipitación media mensual y coeficiente de variación de la estación

Arrancacepas - Cuenca del río Trabaque.

Tabla 74. Precipitación media mensual y coeficiente de variación de la estación

Cañaveras - Cuenca del río Trabaque.

Tabla 75. Precipitación media mensual y coeficiente de variación de la estación

Torrecilla - Cuenca del río Trabaque.

Tabla 76. Precipitación media mensual y coeficiente de variación de la estación Villar de Domingo García - Cuenca del río Trabaque. 184

Tabla 77. Coeficientes de correlación (Rho de Spearman) entre la precipitación anual y el tiempo en las estaciones de la cuenca del río Cega. 185

Tabla 78. Test estadístico Mann-Kendall para la precipitación total anual en las estaciones utilizadas para análisis de la cuenca del río Cega.

Tabla 79. Test estadísticos Rho de Spearman y Mann-Kendall para la precipitación mensual de la Estación Matabuena - Cuenca del río Cega.

Tabla 80. Coeficientes de correlación (Rho de Spearman) entre la precipitación anual y el tiempo de las estaciones de la cuenca del río Porma. 188

Tabla 81. Test estadístico Mann-Kendall para la precipitación total anual en las estaciones utilizadas para análisis de la cuenca del río Porma. 188

Tabla 82. Coeficientes de correlación (Rho de Spearman) entre la precipitación anual y el tiempo de las estaciones de la cuenca del Tajo. 190

Tabla 83. Test estadístico Mann-Kendall para la precipitación total anual en las estaciones utilizadas para análisis de la cuenca del Tajo. 190

Tabla 84. Pérdida de precipitación en las estaciones Beteta, Cañizares, Poyatos, Santa María del Val y Vega del Codorno. 195

Tabla 85. Test estadísticos Rho de Spearman y Mann-Kendall para la precipitación mensual de la Estación Beteta - Cuenca del Tajo. 
Tabla 86. Test estadísticos Rho de Spearman y Mann-Kendall para la precipitación mensual de la Estación Cañizares - Cuenca del Tajo.

Tabla 87. Test estadísticos Rho de Spearman y Mann-Kendall para la precipitación mensual de la Estación Poyatos - Cuenca del Tajo.

Tabla 88. Test estadísticos Rho de Spearman y Mann-Kendall para la precipitación mensual de la Estación Santa María del Val - Cuenca del Tajo. 198

Tabla 89. Test estadísticos Rho de Spearman y Mann-Kendall para la precipitación mensual de la Estación Vega del Codorno - Cuenca del Tajo. 199

Tabla 90. Coeficientes de correlación (Rho de Spearman) entre la precipitación anual y el tiempo de las estaciones de la cuenca del río Trabaque.

Tabla 91. Test estadístico Mann-Kendall para la precipitación total anual en las estaciones utilizadas para análisis de la cuenca del río Trabaque. 200

Tabla 92. Pérdida de precipitación en las estaciones Albalate de las Nogueras,

Arrancacepas, Cañaveras, Torrecilla y Villar de Domingo García.....

Tabla 93. Test estadísticos Rho de Spearman y Mann-Kendall para la precipitación mensual de la Estación Albalate de las Nogueras - Cuenca del río Trabaque... 204

Tabla 94. Test estadísticos Rho de Spearman y Mann-Kendall para la precipitación mensual de la Estación Arrancacepas - Cuenca del río Trabaque. 205

Tabla 95. Test estadísticos Rho de Spearman y Mann-Kendall para la precipitación mensual de la Estación Torrecilla - Cuenca del río Trabaque. 206

Tabla 96. Test estadísticos Rho de Spearman y Mann-Kendall para la precipitación mensual de la Estación Villar de Domingo García - Cuenca del río Trabaque... 206

Tabla 97. Estadística básica de la temperatura media mensual y anual de la cuenca del río Cega - Estación Rascafria. 208

Tabla 98. Coeficiente de correlación (Rho de Spearman) entre las temperaturas mínima, máxima y media anual y el tiempo en la cuenca del río Cega - Estación Rascafria 209 
Tabla 99. Test estadístico Mann-Kendall para las temperaturas mínima, máxima y media anual en la estación Rascafria - Cuenca del río Cega.

Tabla 100. Test estadísticos Rho de Spearman y Mann-Kendall para la temperatura máxima mensual de la Estación Rascafria - Cuenca del río Cega.

Tabla 101. Test estadísticos Rho de Spearman y Mann-Kendall para la temperatura media mensual de la Estación Rascafria - Cuenca del río Cega.

Tabla 102. Estadística básica de la temperatura media mensual y anual de la cuenca del río Porma - Estación Pantano del Porma. 214

Tabla 103. Coeficiente de correlación (Rho de Spearman) entre las temperaturas mínima, máxima y media anual y el tiempo en la cuenca del río Porma - Estación Pantano del Porma.

Tabla 104. Test estadístico Mann-Kendall para las temperaturas mínima, máxima y media anual en la estación Pantano del Porma - Cuenca del río Porma 215

Tabla 105. Estadística Básica de la temperatura media mensual y anual de la cuenca del río Tajo - Estación Cañizares.

Tabla 106. Coeficiente de correlación entre las temperaturas mínima, máxima y media anual y el tiempo en la cuenca del río Tajo - Estación Cañizares.

Tabla 107. Test estadístico Mann-Kendall para las temperaturas mínima, máxima y media anual en la estación Cañizares - Cuenca del río Tajo.

Tabla 108. Test estadísticos Rho de Spearman y Mann-Kendall para la temperatura mínima mensual de la Estación Cañizares - Cuenca del río Tajo

Tabla 109. Test estadísticos Rho de Spearman y Mann-Kendall para la temperatura máxima mensual de la Estación Cañizares - Cuenca del río Tajo

Tabla 110. Test estadísticos Rho de Spearman y Mann-Kendall para la temperatura media mensual de la Estación Cañizares - Cuenca del río Tajo 222

Tabla 111. Estadística básica de la temperatura media mensual y anual de la cuenca del río Trabaque - Estación Arrancacepas. .224 
Tabla 112. Coeficiente de correlación (Rho de Spearman) entre las temperaturas mínima, máxima y media anual y el tiempo en la cuenca del río Trabaque ........224

Tabla 113. Test estadístico Mann-Kendall para las temperaturas mínima, máxima y media anual en la estación Arrancacepas - Cuenca del río Trabaque

Tabla 114. Test estadísticos Rho de Spearman y Mann-Kendall para la temperatura media mensual de la Estación Arrancacepas - Cuenca del río Trabaque

Tabla 115. Test estadísticos Rho de Spearman y Mann-Kendall para la temperatura media mensual de la Estación Arrancacepas - Cuenca del río Trabaque. 228

Tabla 116. Cuencas de los ríos Cega, Porma, Tajo y Trabaque y pérdidas de la población.

Tabla 117. Superficie reforestada por especie en España, entre 1940 y 1980.

Tabla 118. Evolución de los usos y de la cobertura del suelo en la cuenca del río Cega.

Tabla 119. Evolución de los usos y de la cobertura del suelo en la cuenca del río

Porma.

Tabla 120. Evolución de los usos y de la cobertura del suelo en la cuenca del río Tajo.

Tabla 121. Evolución de los usos y de la cobertura del suelo en la cuenca del río

Trabaque.

Tabla 122. Coeficientes de correlación entre aporte anual y tiempo de los ríos Porma y

Trabaque para el periodo $1974-2004$

Tabla 123. Resultados del test Mann-Kendall para el aporte anual para el periodo 1974

$-2004$

Tabla 124. Resultados de los estadísticos Rho de Sperman y Mann-Kendall para la precipitación de las estaciones con tendencia negativa significativa, en el periodo $1977-2006$. 266

Tabla 125. Resultados de los estadísticos Rho de Sperman y Mann-Kendall para la temperatura media anual en el periodo $1969-2006$. 268 


\section{Lista de Fotos}

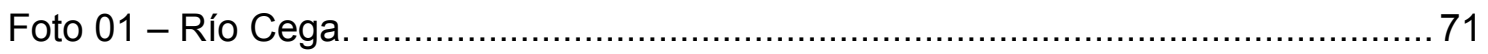

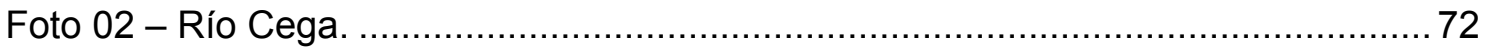

Foto 03 - Vista parcial de la cuenca del Río Porma (Puebla de Lillo).......................... 76

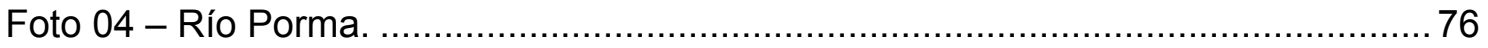

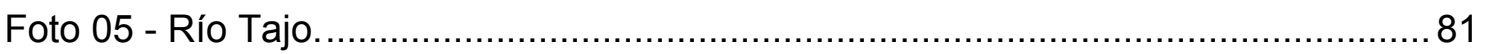

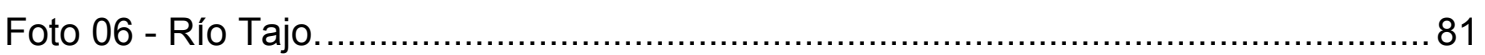

Foto 07 - Vista parcial de la cuenca del río Trabaque. ............................................... 85

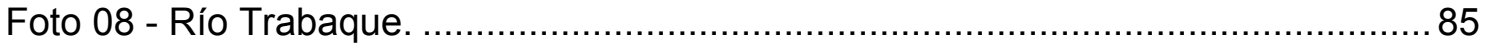

Foto 09 - Estación de aforo 016 en Pajares de Pedraza - Río Cega........................... 89

Foto 10 - Estación de aforo 078 en Camposolillo - Río Porma................................. 101

Foto 11 - Estación de aforo 001 en Peralejos de las Truchas - Río Tajo. ................. 112

Foto 12 - Estación de aforo 186 en Priego - Río Trabaque. .................................... 123 


\section{Acrónimos}

IPCC Intergovernmental Panel on Climate Change

AEMET Agencia Estatal de Meteorología

CECAF Centro Cartográfico y Fotográfico

AMS Army Map Service

GLCF Global Land Cover Facility

NASA National Aeronautics and Space Administration

UTM Universal Transversal Mercator

WGS84 World Geodetic System 1984

R Rho de Spearman

M-K Mann-Kendall

M-KS Mann-Kendall en su Versión Secuencial

OMM Organización Meteorológica Mundial

ETP Evapotranspiración Potencial

SPOT Système Probatoire pour l'Observation de la Terre

LANDSAT Land Remote Sensing Satellite

CNES Centre National d'Etudes Spatiales

NOAA National Oceanic and Atmospheric Administration

NESDIS National Environmental Satellite Data and Information Service

IGN Instituto Geográfico Nacional

SIGPAC Sistema de Información Geográfica de Parcelas Agrícolas

SIG Sistema de Información Geográfica

LIC Lugar de Interés Comunitario

ZEPA Zona de Especial Protección para las Aves

IFN Inventario Forestal Nacional

DGCN Dirección General de Conservación de la Naturaleza

FAO Organización para la Alimentación y la Agricultura - Naciones Unidas 